\title{
SYSTÈMES AGRAIRES ET CHANGEMENT CLIMATIQUE AU SUD
}

\section{Les chemins de l'adaptation}

Hubert Cochet, Olivier Ducourtieux, Nadège Garambois, coord.
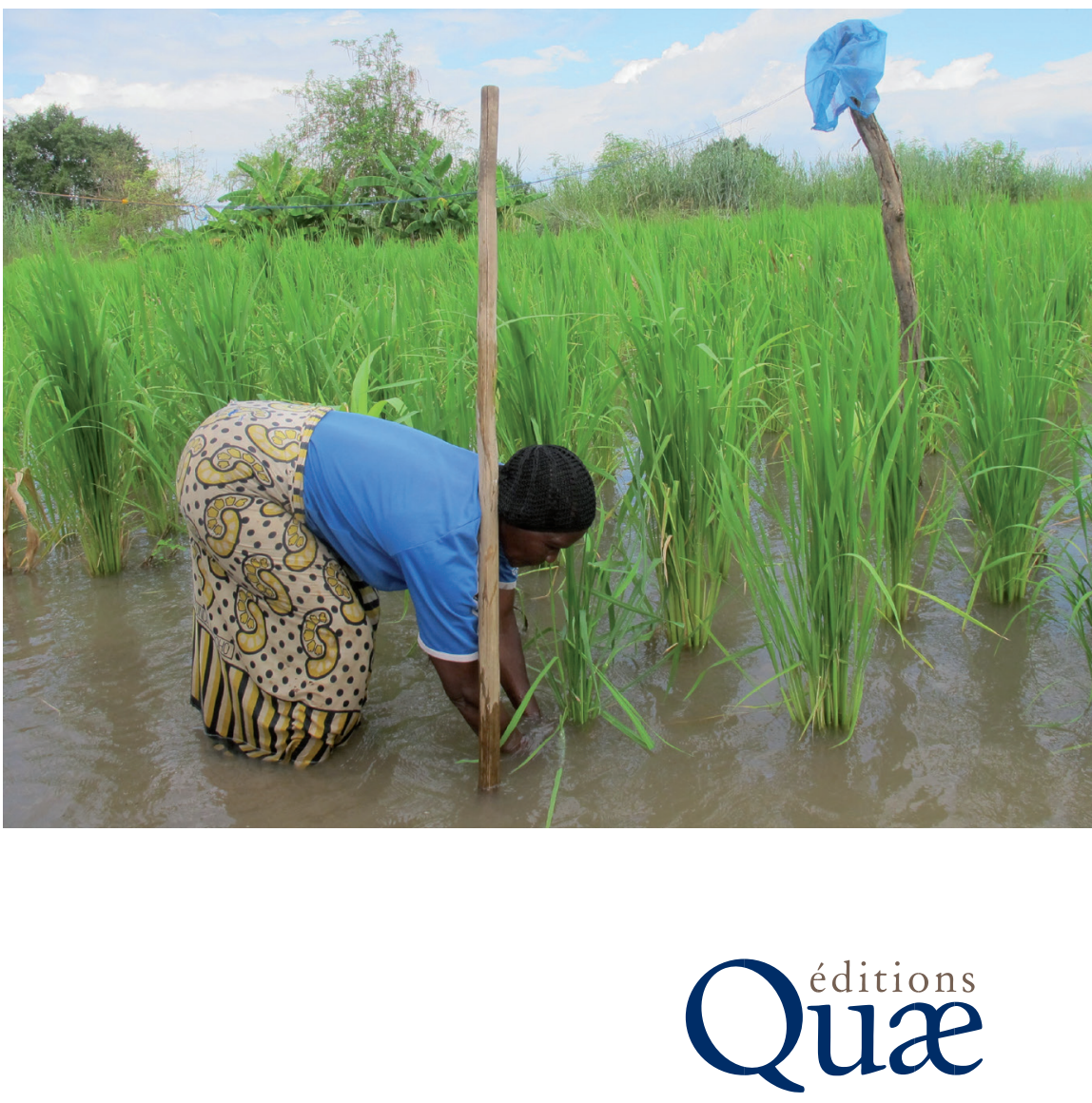



\section{Systèmes agraires et changement climatique au Sud Les chemins de l'adaptation}

Hubert Cochet, Olivier Ducourtieux et Nadège Garambois, coord. 


\section{Collection Update Sciences \& Technologies}

Stratégies des filières fromagères

sous AOP en Europe

Modes de régulation et

performance économique

P. Jeanneaux

2018

Services écosystémiques

et protection des sols

Analyses juridiques et

éclairages agronomiques

C. Hermon, coord.

2018

Paroles de chercheurs

Environnement et interdisciplinarité

E. Brun, J.-F. Ponge, J.-C. Lefeuvre 2017, 124 p.

Démanteler les barrages pour

restaurer les cours d'eau

Controverses et représentations

R. Barraud, M.-A. Germaine, coord. 2017, 260 p.

Construire des politiques

alimentaires urbaines

Concepts et démarches

C. Brand, N. Bricas, D. Conaré,

B. Daviron, J. Debru, L. Michel,

C.-T. Soulard, coord.

2017, $160 \mathrm{p}$.
Systèmes agroalimentaires en transition P. Lubello, A. Falque, L. Temri, coord. 2016, 184 p.

Campagnes contemporaines

Enjeux économiques et sociaux des espaces ruraux français

S. Blancard, C. Détang-

Dessendre, N. Renahy, coord.

2016, 162 p.

Les territoires de l'eau potable Chronique d'une transformation silencieuse (1970-2015)

R. Barbier, A. Roussary, coord. 2016, 144 p.

Valeurs de la biodiversité et services écosystémiques

Perspectives interdisciplinaires

P. Roche, I. Geijzendorffer, H. Levrel, V. Maris, coord. 2016, 220 p.

Éditions Quæ

RD 10, 78026 Versailles Cedex

(ㄷ) Éditions Quæ, 2018

ISBN (imprimé) : 978-2-7592-2919-2

ISBN (Pdf) : 978-2-7592-2920-8

ISBN (ePub) : 978-2-7592-2921-5

ISSN : 1773-7923

Le code de la propriété intellectuelle interdit la photocopie à usage collectif des ayants droit. Le non-respect de cette disposition met en danger l'édition, notamment scientifique, et est sanctionné pénalement. Toute reproduction même partielle du présent ouvrage est interdite sans autorisation du Centre français d'exploitation du droit de copie (CFC), 20 rue des Grands-Augustins, Paris 6e. 


\section{Table des matières}

Introduction. Enjeux et cadre d'analyse.

Hubert Cochet, Olivier Ducourtieux et Nadège Garambois

\section{PARTIE I}

\section{Agricultures PluViales SUb-SAHARIENNES}

Chapitre 1. Sécheresse et ajustement structurel, une double adaptation :

bassin arachidier sénégalais

Nadège Garambois, Ulysse Le Goff et Lucie Thibaudeau

Chapitre 2. Agriculture pluviale et petite irrigation :

plateaux d'Afrique orientale et australe

Hubert Cochet, Louis Thomazo, Esther Laske et Niel Verhoog

\section{PARTIE II \\ RiZICULTURE EN ZONE INONDABLE FACE À L'ALÉA}

Chapitre 3. Agriculture en zones inondables, aléas de la crue et absence d'aménagement : sud de la Tanzanie.

Hubert Cochet, Jean-Luc Paul, Céline Tewa et Philippe Le Clerc

Chapitre 4. Aléas de la crue, aménagements et politiques :

le Mékong du Cambodge au Vietnam

Olivier Ducourtieux, Elsa Champeaux, Charlotte Verger-Lécuyer et Florie-Anne Wiel

Chapitre 5. Sécheresse, grande hydraulique et modèles de développement :

delta du fleuve Senégal.

Nadège Garambois, Samir El Ouaamari, Mathilde Fert, Léa Radzik et Thibault Labetoulle

\section{PARTIE III \\ AdAPTATION ET RÉSILIENCE EN RÉGION DE MONTAGNE}

Chapitre 6. Étagement altitudinal, diversité et irrigation : les monts Uluguru, Tanzanie....183 Hubert Cochet et Thérèse Hartog 
Systèmes agraires et changement climatique au Sud

\section{PARTIE IV \\ PRATIQUES ET POLITIQUES POUR L'ADAPTATION AU CHANGEMENT CLIMATIQUE}

Chapitre 7. Résilience et adaptation, du changement climatique

aux changements globaux

Nadège Garambois, Hubert Cochet et Olivier Ducourtieux

Chapitre 8. Quelles politiques pour l'adaptation?

Leçons du passé et possibilités à venir

Hubert Cochet, Olivier Ducourtieux et Nadège Garambois

Conclusion générale

Hubert Cochet, Olivier Ducourtieux et Nadège Garambois

Liste des auteurs. .269 


\section{Introduction \\ Enjeux et cadre d'analyse

\author{
Hubert Cochet, Olivier Ducourtieux \\ et NADÈGE GARAMBoIS
}

Les études et publications sur les risques associés au changement climatique pour l'agriculture sont extrêmement nombreuses. Une rapide revue de cette abondante littérature permet d'identifier les aléas et les risques naturels liés au changement climatique qui affectent le plus - en fréquence et en intensité - les pratiques et les productions des agriculteurs dans le monde :

- la sécheresse, aléa ponctuel, et l'aridification, péjoration par la répétition de plus en plus fréquente de l'aléa jusqu'à ce qu'il devienne permanent;

- l'inondation, aléa ponctuel, et la submersion, notamment par la transgression marine;

- la hausse des températures qui affecte le calendrier des cultures et des élevages, voire leur répartition géographique en latitude (IPCC, 2014c), ainsi que les rendements (IPCC, 2014b), les modalités de conservations des récoltes et les équilibres biologiques.

Par ailleurs, les effets du changement climatique se manifestent à des échelles spatiales multiples : de la région à la cellule, en passant par la plante (ou l'animal), la parcelle, l'écosystème et le territoire. Ils affectent également les échanges économiques, la santé (Springmann et al., 2016) et les rapports sociaux. Le changement climatique, avec la diversité des phénomènes qu'il entraîne et ses dimensions multiscalaire et diachronique, a des effets systémiques sur l'agriculture (Altieri, 2016; IPCC, 2014b et 2014c). 
Les experts du Giec (ou International panel on climate change, IPCC) soulignent aussi, notamment dans le chapitre Food security and food production systems, la capacité d'adaptation des agriculteurs, notamment dans les pays en développement, et leur expérience en matière de prise en compte des changements climatiques dans leurs pratiques culturales, ainsi que la nécessaire prise en compte des savoirs locaux dans la recherche de solutions adaptatives. Ils insistent sur la dimension socioéconomique de la vulnérabilité et le nécessaire dépassement d'approches purement technologiques de l'adaptation au profit d'approches en termes de «construction de la résilience» (IPCC, 2014b). Pour un même changement «global» dont l'impact est perceptible à l'échelle d'une région ou d'un pays, les conséquences de ce changement, la vulnérabilité ou la résilience des systèmes productifs, ainsi que la capacité d'adaptation des acteurs diffèrent selon les conditions techniques, sociales et économiques dans lesquelles ils se trouvent. Elles dépendent en grande partie des conditions d'accès des agriculteurs aux ressources (terre et eau), aux moyens de production, à la connaissance et aux marchés. Ces conséquences dépendent aussi des modalités de combinaison des facteurs de production à l'échelle de l'exploitation agricole et à celle, plus vaste, de l'agroécosystème. Il en résulte alors des trajectoires d'impact et d'adaptation elles-mêmes différentes.

C'est à l'articulation entre changement global, et impacts et adaptation à l'échelon local que cet ouvrage est consacré, en combinant l'approche systémique et l'articulation des échelles d'analyse. Nous tenterons de dénouer les liens complexes existants entre les scenarii élaborés à des échelles d'analyse très vastes (mondiale, continentale, régionale, etc.) et l'expérience concrète des agriculteurs, expérience vécue à l'échelle du territoire. À ce grand écart en matière d'échelles d'analyse et de compréhension des processus, s'ajoute la nécessité de mettre en relation l'échelle pluri-générationnelle des évolutions possibles du climat et l'échelle des pratiques agricoles déroulées le temps d'une saison agricole.

Étudier les conséquences possibles du changement climatique sur les systèmes agraires, ainsi que les modalités et conditions d'adaptation des agriculteurs requière aussi une approche résolument transdisciplinaire. À ce propos, Charlotte Da Cunha et Jean-Paul Vanderlinden (2014, p. 279) soulignent la nécessité de reconnaître la complexité des systèmes socio-écologiques (Social-ecological systems, SES) pour aborder l'adaptation aux changements globaux. Ils pointent l'intérêt de la transdisciplinarité pour aborder cette question :

«Il devient ainsi nécessaire de construire un espace d'intégration des sciences naturelles, des sciences sociales et des sciences humaines dans l'analyse des dynamiques d'adaptation aux changements globaux».

En mobilisant des outils et concepts issus à la fois des sciences de la vie (écologie, agronomie et zootechnie) et des sciences sociales (géographie, économie, anthropologie et histoire) autour d'un objet - les transformations des agricultures en lien avec les changements globaux - , nous tenterons de mettre notre démarche d'agriculture comparée au service de la compréhension des dynamiques d'adaptation des agriculteurs au changement climatique.

Cet ouvrage n'a pas, bien sûr, pour ambition de faire le tour d'une question aussi complexe. Par son approche méthodologique au plus près «du terrain» et en 
s'appuyant sur l'étude détaillée des dynamiques agraires passées et en cours dans quelques régions du monde, il sera en mesure, nous l'espérons, de contribuer aux débats en cours sur la question de l'adaptation des agriculteurs des pays du Sud au changement climatique.

\section{Vulnérabilité, résilience et adaptation}

\section{Vulnérabilité, un concept des sciences sociales}

Le concept de vulnérabilité a émergé dans les sciences sociales et est encore aujourd'hui «restreint» à ce (vaste) champ. Les définitions sont multiples selon les disciplines, de la sociologie à la political ecology, en passant par l'histoire et la géographie (Buchheit et al., 2016; Becerra, 2012). La vulnérabilité apparaît d'abord comme la propension à souffrir des changements. Mais elle peut être aussi définie comme le déficit des droits d'accès aux ressources et l'incapacité à les mobiliser pour éviter de souffrir des effets délétères de l'aléa (Agder et al., 2003; Becerra et al., 2009; Brown, 2016; Buchheit et al., 2016; Janin, 2006). La vulnérabilité peut alors se définir (se mesurer?) comme le produit du degré d'exposition aux risques par la sensibilité à ces risques et la capacité à y faire face — aussi appelée réactivité — (Becerra et al., 2009).

En ce qui concerne le changement climatique, de nombreuses études et recherches se concentrent surtout sur la dimension physique de l'aléa abusivement appelé «risque naturel» (IPCC, 2014b et 2014c). Létude de la vulnérabilité permet de mettre en perspective ces approches technico-scientifiques centrées sur les facteurs causals de l'aléa, pour prendre en compte les constructions sociales qui font que les individus et les sociétés sont plus ou moins exposés à l'aléa et s'accommodent ou préviennent les risques (Barnes, 2013; Becerra, 2012). Cela implique de s'intéresser certes à la réactivité des individus, mais aussi aux rapports sociaux qui conditionnent les accès aux ressources et à la capacité de réaction des différents groupes sociaux (Lallau et al., 2009). Le «risque naturel» est certes un aléa physique, mais son ampleur procède de la robustesse de la société et donc de l'histoire des rapports sociaux qui l'ont façonnée (Becerra et al., 2009; Bonneuil et al., 2016).

La vulnérabilité de tel ou tel groupe n'est pas une donnée en soi. Il est plutôt le résultat des processus de différenciation, des trajectoires de paupérisation dont il faut comprendre le mécanisme et les causes profondes. Car, le changement climatique est aussi une sorte de révélateur des inégalités de développement dans une société donnée. Ainsi, nous verrons, à partir des études de cas approfondies présentées dans cet ouvrage, que le changement climatique n'est pas en soi responsable de la pauvreté. Étudier sa contribution à la fragilisation des sociétés ou de certains groupes au sein de ces sociétés impose d'avoir une approche holiste. Cette approche doit s'efforcer d'intégrer conjointement les différents changements globaux, leurs impacts, la plus ou moins grande vulnérabilité des différents groupes sociaux et les capacités d'adaptation. Chercher à isoler l'un des facteurs de changement (le changement climatique) n'est donc guère envisageable, car les raisonnements trop cloisonnés, et qui ne feraient varier qu'un élément isolément des autres facteurs («toutes choses égales par ailleurs») introduisent trop de simplifications abusives. 
Comme nous le verrons au chapitre 8, ce type de simplifications abusives inspire pourtant nombre de politiques publiques en matière d'adaptation.

\section{Résilience : des matériaux aux sociétés, en passant par les écosystèmes}

Lutilisation scientifique du terme de résilience est ancienne, initialement en ingénierie et en science des matériaux pour qualifier la résistance aux chocs. Le terme a vite dépassé le cadre de la physique pour être employé en thermodynamique, en psychologie, en informatique et en art. En écologie, il qualifie la robustesse d'un écosystème, c'est-à-dire sa capacité à retrouver plus ou moins rapidement et plus ou moins complètement son état antérieur après une perturbation. À ce titre, le concept de résilience est au cœur des approches développées dans l'Évaluation des écosystèmes pour le millénaire (Millenium ecosystem assessment) de l'ONU. De l'écologie, le terme de résilience est ensuite utilisé en science des risques (ou cindynique) et, toujours par analogie, en sciences sociales : sciences politiques (dont la political ecology), économie, sociologie et géographie (Mathevet et al., 2014; Brown, 2016; Buchheit et al., 2016; Reghezza-Zitt et al., 2015). On voit que plus encore que la vulnérabilité, la résilience est un terme polysémique et polyconceptuel. Cette richesse explique son succès, à la condition cependant d'éviter la confusion.

La résilience peut décrire une propriété, qualité intrinsèque d'un système qui se manifeste au moment du choc, un processus, succession des réponses consécutives à l'événement perturbateur, ou un résultat : le système a été capable de rebondir et a fait face à la menace (Reghezza-Zitt et al., 2015). La résilience est donc une caractéristique systémique à différentes échelles : écosystème, société, groupe social, foyer et individu (Altieri, 2016; Brown, 2016). Lanalogie avec l'élasticité d'un matériau sert aussi à définir les limites de la résilience d'un système écologique ou social, quand l'aléa dépasse la capacité d'absorption du point faible du système (Lallau et al., 2009). Une digue protège efficacement de l'inondation, à la condition que la hauteur d'eau ne dépasse pas celle de son point le plus bas.

Dépendantes étroitement de l'accès aux ressources et de la différenciation sociale, la résilience et la vulnérabilité au changement climatique dans une société ne peuvent être étudiées, comprises et évaluées qu'en prenant en compte très finement la diversité à l'échelle locale (IPCC, 2014c; Tasser et al., 2017) tant environnementale (écosystèmes et étages de ces écosystèmes; Locatelli, 2016) que socio-économique (Boit et al., 2016; Brémond et al., 2009; Hiwasaki et al., 2014). Considérée dans le temps long, la résilience dépasse la seule élasticité au choc et le retour à un état antérieur à l'aléa (Bidou et al., 2009; Chew et al., 2016; Brown, 2016; Lallau et al., 2009). Il s'agit des transformations dans la durée, voire irréversibles, qui mettent en évidence l'adaptation à la péjoration climatique (Mullenite, 2017).

\section{De la résilience à l'adaptation}

Ladaptation au changement climatique est l'expression de la capacité des individus et des groupes sociaux - les agriculteurs en ce qui nous concerne - à modifier leurs pratiques dans un environnement changeant pour maintenir (ou accroître) 
leur niveau de vie et leur sécurité, malgré des risques croissants (IPCC, 2014c; Mullenite, 2017). Ces changements prennent du temps (Chew et al., 2016) et ne visent pas seulement à maintenir un état métastable : dans le temps long, l'adaptation diffère de la résilience et de la vulnérabilité. Les capacités d'adaptation ne sont pas intrinsèquement identiques aux conditions de la résilience.

Dans cet ouvrage, nous nous intéressons aux effets du changement climatique sur les agriculteurs, leurs conditions de production et d'existence. En matière «d'adaptation», il s'agira d'éviter les raccourcis et les personnifications abusives de l'expression. Les agents économiques - agriculteurs notamment - cherchent à s'adapter au changement climatique pour en éviter les effets délétères sur leurs conditions de vie, en modifiant leurs pratiques et leur environnement dans la mesure de leurs moyens et capacités. En revanche, un écosystème ou un territoire ne s'adapte pas. Ce sont les différents groupes sociaux y interagissant qui ont, ou pas, une capacité active d'adaptation.

Ladaptation est un processus incrémental et multiscalaire (Cash et al., 2006; Chew et al., 2016), du changement de variété ou de dates de semis à la révolution agricole dans un système agraire : l'adaptation est un changement systémique (Altieri, 2016; Brown, 2016; Buchheit et al., 2016; Chew et al., 2016). Par ailleurs, l'adaptation des agriculteurs au changement climatique dépend également de l'action publique, notamment des politiques visant à réduire leur vulnérabilité et à accroître leurs capacités (Dupuis, 2015; Huang et al., 2016; La Branche, 2011). Comme la vulnérabilité et la résilience, l'adaptation repose largement sur des rapports sociaux pour lesquels l'autonomisation des acteurs et les modes de gouvernance - notamment la gestion communautaire des ressources — sont essentiels (Cash et al., 2006; Poteete et al., 2010).

Dans le cadre des recherches portant sur la vulnérabilité, de nombreux travaux avaient montré comment et pourquoi les groupes sociaux les plus pauvres étaient les plus vulnérables aux changements climatiques. Cependant, peu de choses ont été faites sur les modalités d'adaptation de ces groupes sociaux et les facteurs et mécanismes en jeu permettant d'accroître leur résilience (Leichenko et al., 2014).

En effet, ce type de recherches semble être le parent pauvre en matière d'adaptation. Les priorités sont manifestement ailleurs, comme en témoigne le rapport de Rhodes et ses collègues (2014, p. 40) traitant des principaux défis et lacunes de la recherche et des politiques en matière d'adaptation au changement climatique dans le secteur de l'agriculture en Afrique de l'Ouest. Loin d'accorder la moindre importance aux savoirs locaux, Rhodes et ses collègues écrivent par exemple que «les connaissances de la population sont limitées ou inappropriées». Plus justement sans doute, ils poursuivent : «il n’y a que peu ou pas de méthodes fiables pour prédire le début de la saison des pluies et la variabilité intra-saisonnière, et pas davantage de méthode pour conférer une utilité maximale aux prévisions météorologiques pour les petits exploitants». En matière de «priorités» de la recherche, ce rapport ne fait pas la moindre allusion aux autres pans de la recherche, notamment en sciences sociales et portant sur les processus de différenciation, les inégalités et la vulnérabilité. 


\section{" Du questionnement global aux enseignements d'une approche locale et contextualisée}

\section{Privilégier une approche locale}

Les documents de politique publique abordant la question de l'impact du changement climatique et l'adaptation font souvent référence, implicitement, à des résultats scientifiques qui, basés sur le traitement de vastes bases de données (climatiques et statistiques), tentent d'établir, avec plus ou moins de bonheur, des corrélations entre changement climatique et évolution des rendements, taux de pauvreté ou points du produit intérieur brut (PIB). En ce qui nous concerne, plutôt que de s'appuyer sur des statistiques reposant sur des unités administratives trop vastes pour rendre compte de la diversité du réel et dont les données peuvent être soumises à caution, nous avons choisi de travailler à l'échelle locale. Cette échelle s'intéresse à la petite région agricole, seule échelle permettant une immersion en profondeur et une étude minutieuse des pratiques d'agriculture et d'élevage, ainsi que des individus et groupes sociaux qui les développent. Observation du paysage et des pratiques, et dialogues construits avec celles et ceux qui les mettent en ouvre ont ainsi inspiré tous les travaux de terrains dont les résultats sont présentés dans cet ouvrage.

\section{De l'emboîtement d'échelles et de l'approche systémique}

Lobservation attentive des pratiques se réalise au champ, au corral, sur les espaces pâturés, dans l'eau des rizières ou dans l'intimité de la cour de ferme. Leur compréhension nécessite de longues discussions avec ceux qui les mettent en pratiques, parfois des démonstrations ou des reconstitutions lorsque l'observation directe n'est pas envisageable. Quant à l'interprétation des observations et des discussions, elle appelle d'avoir recours aux deux concepts de système de culture et de système d'élevage. Le premier est pertinent à l'échelle de la parcelle, le second à celle du troupeau d'animaux domestiques. Nous verrons par exemple comment, dans certains cas, les stratégies d'atténuation du risque climatique ne peuvent pas être appréciées sans une connaissance fine des micro-hétérogénéités intra-parcellaires et des pratiques mises en œuvre, à cette échelle-là, pour en tirer profit.

Lanalyse d'un espace cultivé (en termes de système de culture) ou celle d'un troupeau d'animaux domestiques (en termes de système d'élevage) intègre de nombreux éléments rencontrés à l'échelle de l'unité de production : l'outillage et la force de travail par exemple. C'est pourquoi l'analyse fine des pratiques ne peut pas être conduite sans référence à un niveau d'analyse supérieur et englobant, celui du système de production. C'est d'ailleurs à cette échelle d'analyse - celle du système de production — qu'il est possible de comprendre comment l'accès à différents écosystèmes et la combinaison de différents systèmes de culture et, le cas échéant, de différents systèmes d'élevage, permet de «ne pas mettre tous les œufs dans le même panier», et de profiter le plus largement possible des complémentarités offertes par l'éventail d'activités accessibles aux agriculteurs. C'est un atout considérable, comme nous le verrons, en matière de résilience et de capacité d'adaptation. Lorsque d'autres activités sont accessibles à l'agriculteur ou à l'un ou 
l'autre des membres de sa famille, elles peuvent également contribuer à renforcer l'économie domestique; pour peu qu'elles soient compatibles avec le maintien de l'activité agricole. Dans ce cas, nous mobiliserons le concept de système d'activités pour en rendre compte, étant entendu que ce concept se réfère à la même échelle d'analyse que celui de système de production : celle de l'unité domestique (Cochet et Devienne, 2006; Cochet, 2011a).

Ces deux échelles d'analyse - celle du système de culture/système d'élevage et celle du système de production/système d'activités — se révèlent cependant insuffisantes. Les unités de production sont en effet parties prenantes d'un territoire; leurs travailleurs ont façonné les paysages ruraux. Ces travailleurs sont eux-mêmes insérés dans des relations sociales complexes en ce qui concerne notamment l'accès aux ressources, aux moyens de production, à l'information et aux marchés.

\section{Étudier les pratiques et leur enchâssement dans les rapports sociaux}

Contrairement à ce qui ressort de la lecture de certains documents officiels traitant des conséquences du changement climatique sur les agricultures, l'adaptation n'est pas uniquement une affaire de changement de pratiques ou d'adoption de nouvelles techniques. Nous formulons en effet l'hypothèse que les conditions d'accès aux ressources productives par les agriculteurs (le foncier agricole, l'eau d'irrigation, les moyens de production et la force de travail) et les conditions d'accès au marché et à l'information contribuent de façon significative à éclairer les choix des agriculteurs et donc à expliquer certains aspects de la combinaison productive mise en ouvre. Or, ces conditions d'accès dépendent des rapports sociaux qui régissent la disponibilité et la répartition des ressources productives à l'échelle du village parfois, plus sûrement à l'échelle de la petite région. C'est pour cela que c'est à une échelle plus large que celle de l'exploitation agricole et des choix individuels de l'agriculteur que s'appréhendent ces processus : à l'échelle du système agraire (Cochet, 2011b).

C'est à cette échelle du système agraire que l'on peut identifier les différentes catégories d'agriculteurs qui vivent et travaillent dans les mêmes conditions de milieu. Alors, on peut comprendre pourquoi toutes les catégories d'agriculteurs ne sont pas armées de la même façon face aux aléas climatiques. La différenciation des systèmes de production au sein d'une même région, et donc les inégalités de développement qu'elle révèle, explique pourquoi ils n'ont ni la même résilience, ni la même capacité de réaction et d'adaptation à l'éventuelle péjoration des conditions du milieu.

Dans cet ouvrage, la plus grande attention sera donc portée aux processus de différenciation des systèmes de production et à l'approche typologique. Chaque catégorie d'agriculteurs (ou de groupes domestiques) se trouvant aujourd'hui dans une situation comparable - au regard de l'accès aux ressources, aux moyens de production et au marché - met souvent en ouvre une combinaison semblable de systèmes de culture et d'élevage, fruit de la trajectoire passée qu'elle a suivie. Elle se trouve donc dans une situation comparable en termes de vulnérabilité et d'adaptation. Ce sont ces trajectoires que nous essaierons de faire ressortir dans chacune des régions étudiées, en particulier les trajectoires qui expliquent les processus de paupérisa- 
tion et d'accroissement de la vulnérabilité, mais aussi celles qui sont porteuses au contraire de dynamiques limitant l'ampleur des risques encourus.

Enfin, les agriculteurs d'une région donnée sont aussi impactés par les choix politiques faits au niveau national et par les conditions d'insertion aux échanges marchands nationaux et internationaux. Ces impacts se font au travers des prix de vente de leurs productions et des prix des intrants et des équipements qu'ils doivent se procurer, mais aussi parfois du prix de la nourriture qu'ils doivent acheter. C'est pourquoi l'analyse des politiques agricoles passées et actuelles retiendra aussi toute notre attention.

\section{L'expérience passée des agriculteurs}

Le changement climatique n'est pas une nouveauté, les agriculteurs âgés du Sahel et des régions sahélo-soudaniennes en savent quelque chose. Tous se souviennent du début des années 1970 quand une sécheresse prolongée en plongea le plus grand nombre dans la détresse. Loin de constituer un épisode limité dans le temps, cette baisse drastique des précipitations (- $30 \%)$, dans un contexte climatique déjà tendu en temps «normal», a fait basculer toute cette bande géoclimatique dans une péjoration durable du climat. Autant dire que les agriculteurs de ces régions n'en sont pas à leur premier combat; ils ont une expérience approfondie du changement climatique et des moyens à mettre en ouvre pour y faire face.

C'est pour cela qu'il nous a semblé particulièrement intéressant d'accorder une place de choix aux témoignages de ces agriculteurs et à en restituer toute la richesse. Comment furent vécues ces difficultés? Quels furent les agriculteurs qui réussirent à en limiter l'impact et à s'adapter à ces conditions nouvelles? Quels furent au contraire les groupes les plus vulnérables? Et quels furent les effets des politiques agricoles mises en œuvre dans les pays sahéliens? Comment faire la part des choses entre l'impact de cette péjoration du climat et l'impact des politiques publiques?

Le recul que nous pouvons avoir sur certains changements opérés jadis par les agriculteurs eux-mêmes et leurs conséquences à long terme nous permettra d'entrevoir les effets possibles des changements actuels réalisés par les agriculteurs, les conditions de leur mise en place et les conséquences à venir prévisibles.

Lintérêt porté aux expériences passées des agriculteurs nous permettra aussi de distinguer, avec davantage de recul, deux notions développées dans la littérature actuelle traitant de l'adaptation :

- les adaptations «incrémentales» (dénommées aussi autonomous adaptations) et leurs effets, seulement perceptibles sur le temps long ${ }^{1}$;

- les adaptations «planifiées» (planned adaptations) à plus grande échelle, en général par des acteurs extérieurs au monde rural (pouvoirs, publics, projets, entrepreneurs agricoles) et susceptibles, d'après leurs promoteurs, de provoquer un véritable changement de système dans le sens d'une plus grande adaptation.

1. Dans le dernier rapport du Giec, les rédacteurs les définissent comme suit : Autonomous adaptations are incremental changes in the existing system including through the ongoing implementation of extant knowledge and technology in response to the changes in climate experienced. They include coping responses and are reactive in nature (IPCC, 2014b). 
Cette analyse nous permettra aussi de mieux évaluer l'impact que pourraient avoir certains projets ou programmes d'adaptation plus «volontaires » s'ils étaient mis en place (Crane et al., 2011).

\section{" Méthode d'enquête et corpus de données}

Ne pouvant pas, à l'échelle d'analyse choisie (la petite région agricole), compter sur un corpus de données statistiquement fiables, les études de systèmes agraires sur lesquelles notre analyse s'est appuyée ont reposé sur la collecte d'informations par voie d'enquêtes approfondies auprès des ruraux : agriculteurs et agricultrices en activité, personnes âgées, personnels techniques et commerçants. Des entretiens et visites d'exploitations suffisamment approfondis et répétés ont permis de collecter des informations de première main fiables, d'accéder à une compréhension fine du fonctionnement des différents systèmes de production identifiés, tant du point de vue technique que du point de vue économique et social. Il s'agissait aussi d'apporter autant de soin que possible à la compréhension des rapports sociaux existants et à leur évolution, notamment en ce qui concerne l'accès aux ressources (terre, eau, capital et marché), ainsi qu'à l'identification des impacts, sur les dynamiques agraires locales, des mesures de politique nationale et des projets de développement, de la croissance démographique, de l'évolution des marchés et bien sûr d'éventuels changements climatiques.

Dans chaque région étudiée, le travail de terrain a été réalisé par de jeunes chercheurs $^{2}$. La période passée sur chaque «terrain», au plus près des agriculteurs, a été de six mois. Par ailleurs, tous ces jeunes chercheurs étaient appuyés sur place par au moins une mission d'encadrement réalisée par nos soins à mi-parcours du travail de terrain. Tous les entretiens ont donc été conduits individuellement ou en équipe restreinte, sans faire appel à des enquêteurs tiers. Le plus grand soin a été apporté au choix des questions posées et à leur enchaînement, ainsi qu'à l'observation simultanée (et parfois participante) des gens, des outils et des machines, des gestes et de leur enchaînement.

En matière d'enquête en milieu rural, notre méthode de travail se rapproche donc de l'enquête de type ethnographique en ce qu'elle implique d'observations et d'écoutes, d'immersion dans le milieu, de prises de notes quotidiennes, d'absence de questionnaire fermé. Elle est aussi de type ethnographique par sa durée, la nécessaire contextualisation de l'enquête et sa non-délégation. En revanche, elle s'en éloigne par l'exigence d'échantillonnage raisonné et par son souci de quantification (Cochet, 2011a). Par quantification, on comprendra l'obtention in fine de résultats quantifiés et comparables (productions, coûts, quantité de travail, valeur ajoutée et revenus), et non pas le recours aux méthodes quantitatives de traitement des données.

Dans chaque région étudiée, nous avons procédé à un échantillonnage raisonné des unités de production à étudier, échantillonnage basé sur l'identification préalable

2. Tous les jeunes chercheurs sont des étudiants inscrits en dominante d'approfondissement Développement agricole ou Master 2 «Dynamique des pays émergents et en développement (DynPED)» dans l'UFR Agriculture comparée et Développement agricole d'AgroParisTech, sous notre supervision. 
- grâce à l'analyse du paysage et à la reconstitution des trajectoires des unités de production - des principaux «types» d'unités de production en présence. Cet échantillonnage avait pour objectif de refléter la diversité des systèmes de production agricole, de modéliser leur fonctionnement technique et leurs résultats technicoéconomiques, et d'en favoriser la comparaison. Il s'agissait d'un échantillon de taille limité, chaque unité de production sélectionnée donnant lieu à une étude de cas détaillée. C'est ainsi qu'une cinquantaine d'unités de production ${ }^{3}$ a été passée à la loupe sur chaque terrain. À cet échantillon, il convient d'ajouter les entretiens historiques conduits auprès des personnes âgées et, le cas échéant, auprès d'autres acteurs du monde rural.

En ce qui concerne l'étude des périodes plus anciennes, notamment celles où les agriculteurs furent déjà confrontés à des épisodes de péjoration climatique et dont la mémoire reste vive, nous avons procédé par entretien direct auprès des personnes âgées ${ }^{4}$. Cependant, parler «de la pluie et du beau temps» appelle souvent trop de réponses stéréotypées immédiatement servies à l'enquêteur. Le «changement climatique» est sur toutes les lèvres, même lorsque l'on ne sait pas de quel changement il est question ou s'il est avéré. La simple évocation du «changement climatique» ouvre souvent la voie à toutes sortes de considérations dont il est bien difficile de faire le tri entre les observations réelles, le «ressenti» et les discours entendus ici et là. C'est pour cela que nous avons fait le choix «d'étudier le changement climatique sans en parler $»^{5}$, ou plutôt à rentrer dans l'analyse du changement par les pratiques plutôt que par le climat. Interroger les personnes âgées sur leurs pratiques passées, en prenant soin de bien situer le sujet dans le temps et dans l'espace, permet en effet d'aborder - mais dans un deuxième temps seulement — la question du changement climatique. Si changement il y a et si les agriculteurs ont ressenti d'une façon ou d'une autre les effets des modifications du climat, alors ils en parlent d'eux-mêmes sans qu'il ne soit nécessaire de leur poser la question. Dès lors, les associations éventuelles d'idées entre évolution des pratiques et climat deviennent beaucoup plus

3. Les problèmes posés par l'identification des contours de «l'unité de production» dans les situations, nombreuses en Afrique sub-saharienne, où unité de production, unité de consommation, unité de résidence et unité d'accumulation ne coïncident pas, ont été abordés au cas par cas dans les études régionales (Gastellu, 1979).

4. La consultation de la bibliographie a permis de réaliser certains recoupements. Par exemple, l'évolution sur le long terme des pluies dans les régions sahéliennes et sahélo-soudaniennes est bien renseignée; la sécheresse des années 1970 ayant contribué à attirer l'attention des pouvoirs publics et des bailleurs de fonds sur ces questions et à l'établissement d'institutions spécialisées (notamment le centre régional Agrhymet, une institution spécialisée du Comité permanent inter-États de lutte contre la sécheresse dans le Sahel, CILSS). Cependant, il n'est pas facile de se procurer en tout lieu des séries climatiques de longue durée suffisamment fiables et permettant d'identifier d'éventuelles périodes anciennes de changement climatique. Bien que des données déjà traitées à l'échelle régionale soient souvent accessibles sur Internet, notamment sur le site de la Banque mondiale, il est indispensable de revenir aux données climatiques collectées au plus près des régions étudiées. En effet, les écarts constatés par rapport aux schémas régionaux sont souvent importants. Nécessairement, on se heurte alors aux difficultés d'accès aux données existantes, aux données parfois payantes, aux séries incomplètes et aux doutes sur la fiabilité des mesures réalisées.

5. Nous faisons référence aux travaux de Smadja et al. (2015), confrontés aux mêmes craintes que nous quant à l'orientation possible des réponses des agriculteurs interrogés à la simple évocation du changement climatique. 
signifiantes et riches d'enseignements. Elles reflètent beaucoup moins les effets de mode ou le désir de fournir à l'enquêteur les réponses qu'il a envie d'entendre.

\section{W Choix des terrains étudiés et plan de l'ouvrage}

Quelques situations contrastées ont été choisies pour leur caractère illustratif ou démonstratif des questions posées par les conséquences du changement climatique sur les systèmes agraires et les processus d'adaptation qui en résultent. Elles n'épuisent pas - et de loin - la diversité. De nombreuses autres études de cas auraient pu - auraient dû - compléter notre analyse. Par ailleurs, le choix des douze régions étudiées a aussi été réalisé en tenant compte des possibilités concrètes de réalisation du travail de terrain : contacts institutionnels et accueil possible des jeunes chercheurs sur le terrain et conditions de sécurité requises ${ }^{6}$. La majorité des régions étudiées (dix terrains) sont situées (figure I.1) en Afrique sub-saharienne dont quatre en zone sahélo-soudanienne (Sénégal) et six en Afrique australe (Zambie et Tanzanie). Deux autres régions sont situées en Asie du Sud-Est (Cambodge et Vietnam). Ce choix permet d'accroître la diversité des cas étudiés tout en renforçant le caractère comparatif de notre approche.

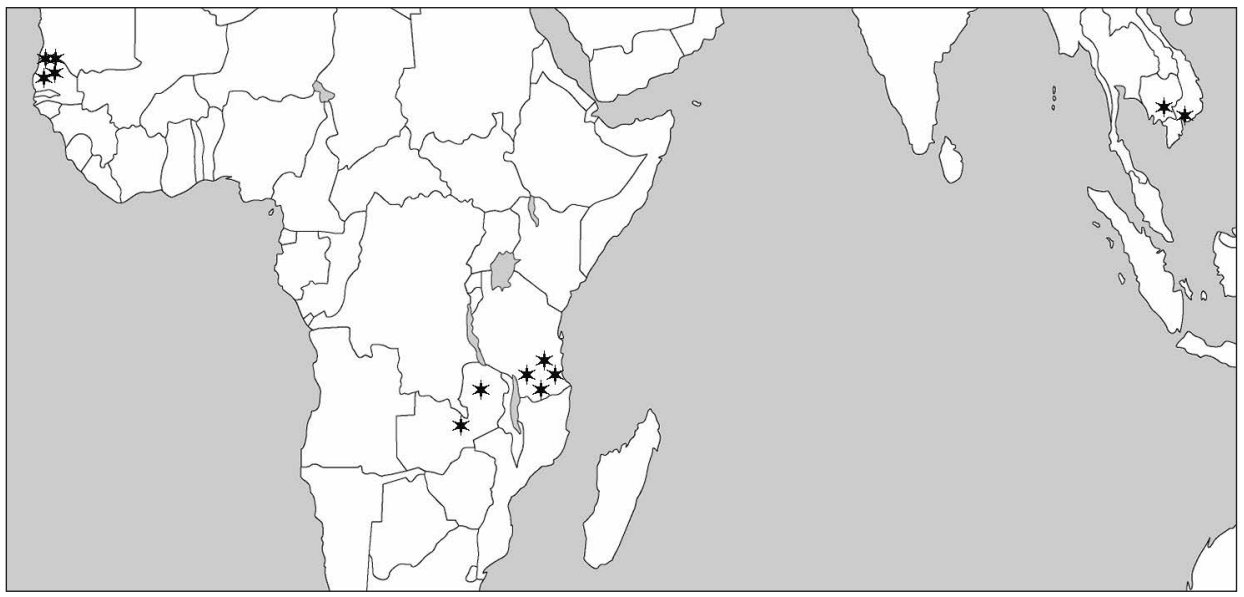

Figure I.1. Localisation des 12 régions étudiées.

La première partie de l'ouvrage abordera le cas des agricultures pluviales subsahariennes. Le chapitre 1 traitera de la situation des paysanneries de la bande sahélo-soudanienne, en s'appuyant sur deux études de cas au Centre et au NordSénégal. Il s'agit de la région de Bambey située dans la partie nord du bassin arachidier, et de la région de Louga retenue pour sa position encore plus septentrionale (Cayor). Ces terrains offrent l'opportunité de se pencher sur les épisodes anciens de péjoration climatique (années 1970 et 1980) — particulièrement graves

6. En effet, l'insécurité rend de nombreux pays de la zone sahélienne et sahélo-soudanienne inaccessibles aux chercheurs de terrain. 
dans cette région du monde - et sur les leçons à en tirer en matière de vulnérabilité et d'adaptation. Nous verrons que certaines régions ou groupes sociaux, dépourvus de toute possibilité de développement de l'irrigation, ont pourtant surmonté ces difficultés, au moins en partie, en adaptant leurs pratiques et systèmes d'activités aux nouvelles contraintes. Dans le chapitre 2, il sera question des systèmes agraires des hauts plateaux de l'Afrique de l'Est et australe. Nous nous appuierons sur l'étude de deux petites régions dans le nord de la Zambie : celle de Katongo Kapala dans le district de Mpika et celle de Miloso dans le district de Mkushi (figure 1.1). Nous étudierons aussi un cas dans la région d'Iringa, sur les hauts plateaux du Sud tanzanien. Ces trois régions sont caractérisées par une agriculture pluviale dans laquelle le maïs (en culture pure ou en culture associée) occupe une place de choix, autant comme culture vivrière que comme culture de rente. Cette hégémonie du maïs contribue, comme nous le verrons, à rendre ces systèmes agraires fort vulnérables au regard de l'évolution possible du régime des pluies. Une petite irrigation permet aux familles qui y ont accès de diversifier leur système de production et de s'affranchir partiellement de l'aléa des pluies. Létude détaillée de ces trois régions permettra donc d'aborder à la fois la question de la vulnérabilité de l'agriculture pluviale de cette région du monde et celle de l'irrigation à petite échelle. Ce type d'irrigation peut être considéré comme une voie possible pour développer cette agriculture et pour la rendre moins sujette aux aléas, tout en permettant d'anticiper l'éventuelle péjoration climatique annoncée sur le long terme.

La deuxième partie sera consacrée aux régions inondables où la riziculture occupe une place de choix dans les systèmes de production. Dans le chapitre 3 , il s'agira de deux régions du Sud-Tanzanie caractérisées par une inondation non maîtrisée en l'absence totale d'aménagement :

- la basse vallée du fleuve Rufiji, caractérisée par un écosystème complexe et des modes de mise en valeur à la fois très tributaires du régime du fleuve (lits majeurs et zones d'épandage des crues) et très dépendants du régime pluvial sur les versants; - la région d'Ifakara sur le Kilombero, affluent du fleuve Rufiji.

Ici, les agriculteurs sont confrontés à deux types d'aléas, tous deux liés au climat. Il s'agit, en premier lieu, du volume et de la répartition des pluies (date de la première pluie significative et répartition des suivantes) et en deuxième lieu, du volume et du calendrier de la crue (positionnement et durée), dont dépendent à la fois les surfaces semées, les surfaces récoltées et l'efficacité de la fertilisation (dépôts par la crue), ainsi que les rendements obtenus.

Par ailleurs, ces régions font partie du «corridor» de développement prôné par la Saggot (Southern agricultural growth corridor of Tanzania) où se côtoient différents modèles d'agriculture (agriculture familiale et grands projets d'investissement comprenant des aménagements, notamment pour la riziculture).

Dans le chapitre 4, deux situations contrastées seront comparées :

- en premier lieu, celle de la région de Kampong Thom sur les berges du Tonlé Sap, au Cambodge, où les riziculteurs jouent sur la hauteur de crue du Tonlé Sap et sur le décalage temporel des apports hydriques par les précipitations locales et par la crue pour développer un calendrier de riziculture complexe de deux cycles culturaux de saison des pluies, un cycle de décrue et deux cycles (irrigués) en saison sèche; 
- en deuxième lieu, la situation du delta du Mékong (au Vietnam). Cette région pourrait pâtir d'un probable accroissement important des précipitations sur son bassin versant, de crues plus violentes et d'une fréquence plus élevée des inondations. Nous montrerons comment, à l'échelle villageoise, les différents groupes socioéconomiques ont cependant réussi à accroître leur niveau de vie, notamment grâce à un large accès à l'équipement et aux aménagements hydrauliques, bien que le delta reste soumis au risque majeur d'élévation du niveau de la mer et de l'augmentation possible de l'ampleur des crues.

Le chapitre 5 sera consacré au delta du fleuve Sénégal où deux autres petites régions ont été étudiées. De faibles totaux pluviométriques et les variations interannuelles de la crue du fleuve expliquent l'adaptation ancienne des agriculteurs et éleveurs de cette région à des conditions climatiques et hydrographiques particulièrement contraignantes et aléatoires. Durement frappée par la sécheresse des années 1970-1980, cette région a parallèlement connu de profonds bouleversements sous l'influence d'aménagements hydro-agricoles de grande ampleur. Elle nous donnera ainsi l'occasion d'étudier le rôle joué par ces aménagements dans l'adaptation de l'agriculture du haut et du bas delta au bouleversement climatique à l'œuvre, ainsi que les modèles de développement dont ils ont été porteurs.

Dans la troisième partie (chapitre 6), nous nous intéresserons à l'adaptation en région de montagne, là où les agriculteurs doivent composer avec l'altitude, la pente et les phénomènes érosifs qu'elle facilite, l'étagement et parfois les difficultés de communication. Versants raides et entièrement cultivés par une population agricole très dense (250 à 350 habitants $\left./ \mathrm{km}^{2}\right)$, aménagements systématiques des versants, irrigation généralisée et diversité des productions : les monts Uluguru (Tanzanie) — seul exemple de région de montagnes traité dans cet ouvrage — nous offriront un exemple riche d'enseignements.

Enfin, dans la quatrième partie, nous tenterons de faire la synthèse des enseignements à retenir de ces quelques études de cas contrastées. Dans le chapitre 7, nous présenterons les éléments qui semblent les plus déterminants dans la capacité des agriculteurs à faire face aux aléas et à renforcer leur capacité d'adaptation. Nous insisterons sur les inégalités de développement qui caractérisent ces agricultures, leur différenciation socio-économique interne et ses conséquences en termes d'adaptation. Le dernier chapitre (chapitre 8) abordera la question des politiques à promouvoir en matière d'adaptation des agricultures des pays du Sud au changement climatique. Un aperçu des politiques généralement promues - ou en voie de l'être - sera présenté sur la base d'une analyse de quelques textes de référence émanant d'institutions internationales ou nationales. Puis, nous soulignerons les points de vigilance qui, à notre avis, devraient sous-tendre l'élaboration des politiques adaptées en la matière.

\section{Méférences}

Adger W.N., Huq S., Brown K., Conway D., Hulme M., 2003. Adaptation to climate change in the developing world. Progress in development studies 3(3), 179-195.

Altieri M.A., 2016. Developing and promoting agroecological innovations within country program strategies to address agroecosystem resilience in production landscapes: a guide. New York: Global environment facility/UNDP, $25 \mathrm{p}$. 
Barnes J., Dove M., Lahsen M., Mathews A., McElwee P., McIntosh R., Moore F., O'Reilly J., Orlove B., Puri R., Weiss H., Yager K., 2013. Contribution of anthropology to the study of climate change. Nature climate change 3(6), 541-544.

Becerra S., 2012. Vulnérabilité, risques et environnement : l'itinéraire chaotique d'un paradigme sociologique contemporain. VertigO, 12(1).

Becerra S., Peltier A. (eds), 2009. Risques et environnement : recherches interdisciplinaires sur la vulnérabilité des sociétés. Paris : L’Harmattan, 575 p.

Bidou J.E., Droy I., 2009. Décrire la construction temporelle des vulnérabilités : observatoires ruraux et analyse historique des moyens d'existence dans le Sud malgache. In : Risques et environnement : recherches interdisciplinaires sur la vulnérabilité des sociétés (Becerra S., Peltier A., eds). Paris : LHarmattan, 155-170.

Boit A., Sakschewski B., Boysen L., Cano-Crespo A., Clement J., Garcia-Alaniz N., Kok K., Kolb M., Langerwisch F., Rammig A., Sachse R., van Eupen M., von Bloh W., Clara Zemp D., Thonicke K., 2016. Large-scale impact of climate change vs. land-use change on future biome shifts in Latin America. Global change biology 22(11), 3689-3701.

Bonneuil C., Fressoz J.B., 2016. The shock of the anthropocene: the earth, history and us. London: Verso, $320 \mathrm{p}$.

Brémond P., Grelot F., Bauduceau N., 2009. De la vulnérabilité de la parcelle à celle de l'exploitation agricole : un changement d'échelle nécessaire pour l'évaluation économique des projets de gestion des inondations. In : Risques et environnement : recherches interdisciplinaires sur la vulnérabilité des sociétés (Becerra S., Peltier A., eds). Paris : L'Harmattan, 231-244.

Brown K., 2016. Resilience, development and global change. London: Routledge, 212 p.

Buchheit P., d'Aquino P., Ducourtieux O., 2016. Cadres théoriques mobilisant les concepts de résilience et de vulnérabilité. VertigO 16(1).

Cash D.W., Adger W.N., Berkes F., Garden P., Lebel L., Olsson P., Pritchard L., Young O.R., 2006. Scale and cross-scale dynamics: Governance and information in a multilevel world. Ecology and society 11(2).

Chew S., Sarabia D., 2016. Nature-culture relations: early globalization, climate changes, and system Crisis. Sustainability 8(1), 78-106.

Cochet H., 2011a. L'agriculture comparée. Paris : Quae/NSS-Dialogues, 159 p.

Cochet H., 2011b. Origine et actualité du «système agraire»: retour sur un concept. Revue TiersMonde 207, 97-114.

Cochet H., Devienne S., 2006. Fonctionnement et performances économiques des systèmes de production agricole : une démarche à l'échelle régionale. Cahiers agricultures 15(6), 578-583.

Crane T.A., Roncoli C., Hoogenboom G., 2011. Adaptation to climate change and climate variability : the importance of understanding agriculture as performance. NJAS - Wageningen journal of life sciences 57, 179-185.

Da Cunha C., Vanderlinden J.P., 2014. Adaptation aux changements globaux : quel apport de la transdisciplinarité? Revue française de socio-économie 204/1(13), 277-282.

Dupuis J., 2015. S'adapter au changement climatique : analyse critique des nouvelles politiques de gestion de l'environnement. Neufchâtel : Alphil Éditions, 392 p.

Gastellu J.M., 1979. Mais où sont donc ces unités économiques que nos amis cherchent tant en Afrique? In : Note de travail, Série : enquêtes et outils statistiques, vol. 1, «Le choix de l'unité», Amira, 1979, 99-122.

Hiwasaki L., Luna E., Syamsidik, Marçal J.A., 2014. Local and indigenous knowledge on climaterelated hazards of coastal and small island communities in Southeast Asia. Climatic change 128(1-2), $35-56$.

Huang W.C., Lee Y.Y., 2016. Strategic planning for land use under extreme climate changes: a case study in Taiwan. Sustainability 8(1), 53-69. 
IPCC, 2014a. Climate change 2014: synthesis report. contribution of working groups I, II and III to the Fifth assessment report of the intergovernmental panel on climate change. [Pachauri R.K., Meyer L.A. (eds.)]. Cambridge: Cambridge University Press, 151 p.

IPCC, 2014b. Climate change 2014: impacts, adaptation, and vulnerability. Part A: Global and sectoral aspects. contribution of working group II to the Fifth assessment report of the intergovernmental panel on climate change. [Field C.B., Barros V.R., Dokken D.J., Mach K.J., Mastrandrea M.D., Bilir T.E., Chatterjee M., Ebi K.L., Estrada Y.O., Genova R.C., Girma B., Kissel E.S., Levy A.N., MacCracken S., Mastrandrea P.R., White L.L. (eds)]. Cambridge: Cambridge University Press, 1132 p.

IPCC, 2014c. Climate change 2014: impacts, adaptation, and vulnerability. part b: regional aspects. contribution of working group II to the Fifth assessment report of the intergovernmental panel on climate change. [Barros V.R., Field C.B., Dokken D.J., Mastrandrea M.D., Mach K.J., Bilir T.E., Chatterjee M., Ebi K.L., Estrada Y.O., Genova R.C., Girma B., Kissel E.S., Levy A.N., MacCracken S., Mastrandrea P.R., White L.L. (eds)]. Cambridge: Cambridge University Press, 688 p.

IPCC, 2014d. climate change 2014: mitigation of climate change. contribution of working group III to the fifth assessment report of the intergovernmental panel on climate change. [Edenhofer O., PichsMadruga R., Sokona Y., Farahani E., Kadner S., Seyboth K., Adler A., Baum I., Brunner S., Eickemeier P., Kriemann B., Savolainen J., Schlömer S., von Stechow C., Zwickel T., Minx J.C. (eds)]. Cambridge: Cambridge University Press, 1454 p.

Janin P., 2006. La vulnérabilité alimentaire des sahéliens : concepts, échelles et enseignements d'une recherche de terrain. L'espace géographique 35(4), 355-366.

La Branche S. (ed.), 2011. Le changement climatique, du méta-risque à la méta-gouvernance. Paris : Lavoisier, $220 \mathrm{p}$.

Lallau B., Rousseau S., 2009. De la vulnérabilité à la résilience : une approche par les capabilités de la gestion des risques. In : Risques et environnement : recherches interdisciplinaires sur la vulnérabilité des sociétés (Becerra S., Peltier A., eds). Paris : LHarmattan, 171-183.

Lallau B., Thibaut E., 2009. La résilience en débat : quel devenir pour les agriculteurs en difficulté? Revue d'études en agriculture et environnement 90(1), 79-102.

Leichenko R., Silva J.A., 2014. Climate change and poverty: vulnerability, impacts, and alleviation strategies. WIREs clim change 5, 539-556.

Locatelli B., 2016. Ecosystem services and climate change. In: Routledge handbook of ecosystem services (Potschin M. et al., eds). London: Routledge, 481-490.

Mathevet R., Bousquet F., 2014. Résilience et environnement : penser les changements socio-écologiques. Paris : Buchet-Chastel, $176 \mathrm{p}$.

Mullenite J., 2017. Can climate change adaptation be a desirable goal? Human geography 10(2), 87-94.

Poteete A.R., Janssen M.A., Ostrom E., 2010. Working together: collective action, the commons, and multiple methods in practice. Princeton: Princeton University Press, $370 \mathrm{p}$.

Reghezza-Zitt M., Rufat S. (eds), 2015. Résiliences : sociétés et territoires face à l'incertitude, aux risques et aux catastrophes. Londres : Iste, $227 \mathrm{p}$.

Rhodes E.R., Jalloh A., Diouf A., 2014. Revue de la recherche et des politiques en matière d'adaptation au changement climatique dans le secteur de l'agriculture en Afrique de l'Ouest. Document de travail 090, Future Agricultures, IDRC/CRDI, 56 p.

Smadja J., Aubriot O., Puschiasis O., Duplan T., Grimaldi J., Hugonnet M., Buchheit P., 2015. Changement climatique et ressource en eau en Himalaya. Enquêtes auprès de villageois dans quatre unités géographiques du bassin de 1 Koshi, Népal. Journal de géographie alpine 103(2), 23 p. Springmann M., Mason-D’Croz D., Robinson S., Garnett T., Godfray H.C.J., Gollin D., Rayner M., Ballon P., Scarborough P., 2016. Global and regional health effects of future food production under climate change: a modelling study. Lancet 387(10031), 1937-1946.

Tasser E., Leitinger G., Tappeiner U., 2017. Climate change versus land-use change: What affects the mountain landscapes more? Land use policy 60, 60-72. 



\section{Partie I \\ Agricultures pluviales sub-sahariennes}





\title{
Chapitre 1 \\ Sécheresse et ajustement structurel, une double adaptation : bassin arachidier sénégalais
}

\author{
Nadège Garambois, Ulysse Le Goff et Lucie Thibaudeau
}

Si le Sahel avait déjà connu des épisodes de sécheresse sévère dans son histoire (1880, 1912-1914, 1940-1944; Jouve, 1991), celle qui a sévi à partir de la fin des années 1960 constitue un phénomène exceptionnel par sa persistance, son intensité et son déploiement à l'échelle de l'ensemble de l'Afrique au sud du Sahara. De 1968 à 1984, l'isohyète $100 \mathrm{~mm}$ est ainsi descendu de 250 à $300 \mathrm{~km}$ au sud et l'isohyète $500 \mathrm{~mm}$ de $150 \mathrm{~km}$ (Le Borgne, 1988). Le nord et le centre du Sénégal ont été particulièrement touchés avec des déficits pluviométriques de plus de 50\% en 1968-1973 et 1977-1984. À partir de l'étude du centre et du nord du bassin arachidier sénégalais, il s'agit ici tout à la fois d'analyser comment les agriculteurs se sont efforcés, de longue date, de limiter leur vulnérabilité dans des conditions pluviométriques difficiles et aléatoires, d'analyser l'impact de cette longue période de sécheresse sur les ménages agricoles et d'étudier comment ceux-ci se sont adaptés.

Deux terrains d'étude ont été retenus dans les régions historiques du Cayor et du Baol (figure 1.1) :

- la région de Louga (Le Goff, 2016) dans le nord du bassin arachidier, déjà sous climat sahélien (au sens de la limite de l'isohyète de $500 \mathrm{~mm}$ de précipitations annuelles) avant la sécheresse majeure des années 1970-1980 et passée sous la barre des $300 \mathrm{~mm}$ de pluie par an durant cette période;

- la région de Bambey (Thibaudeau, 2015) dans le centre du bassin arachidier, sous climat soudanien dans la première moitié du $\mathrm{xx}^{\mathrm{e}}$ siècle, qui a basculé en climat sahélien depuis les années 1970. 


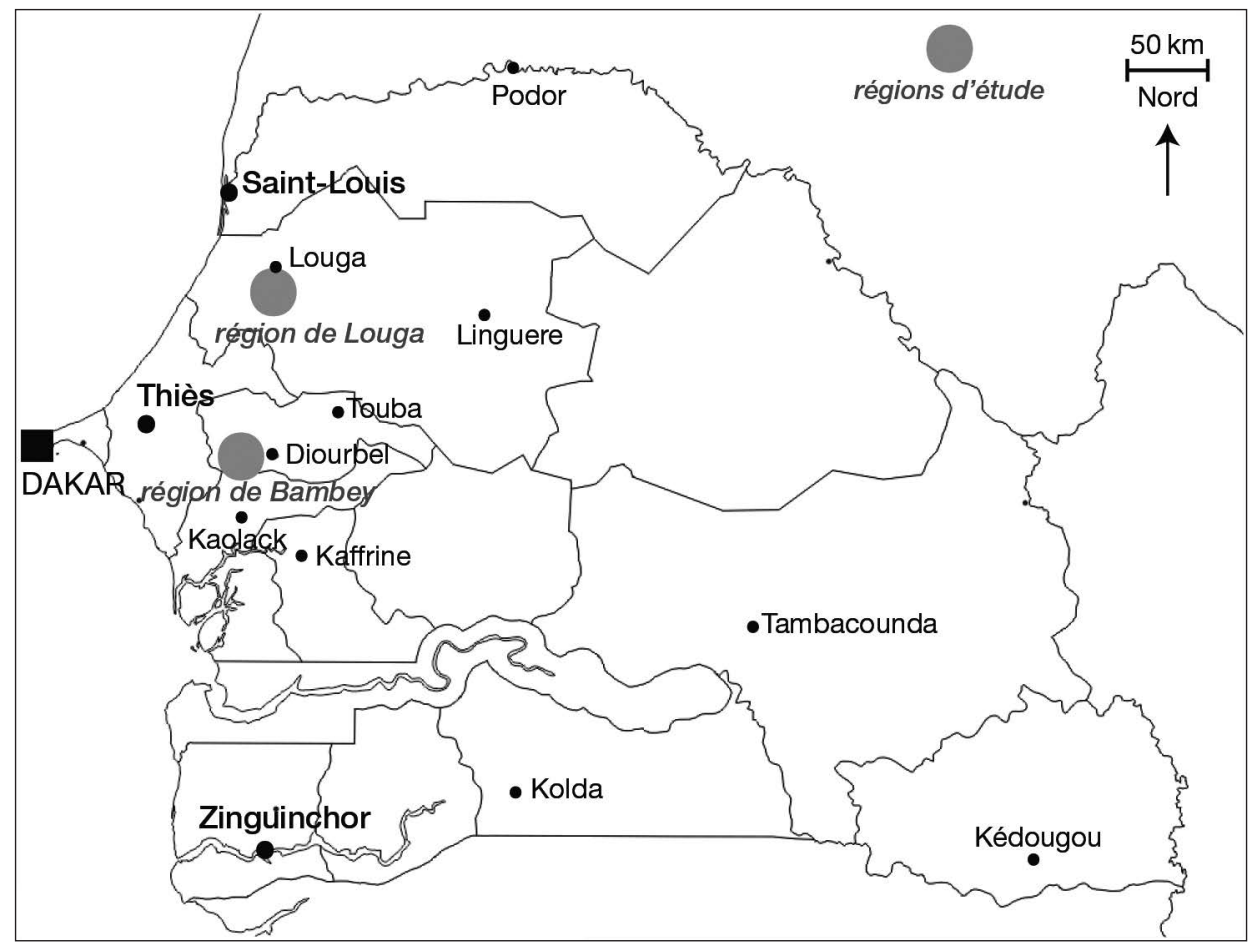

Figure 1.1. Localisation des régions de Bambey et de Louga au Sénégal.

En l'absence d'eaux de surface, le peuplement progressif de ces deux régions a reposé sur le creusement de puits artisanaux de plusieurs dizaines de mètres de profondeur pour l'abreuvement des hommes et des animaux. Aujourd'hui, ces puits sont secondés par des forages bien plus profonds puisant dans la nappe salée du Maastrichtien, dont l'eau est réservée aux usages domestiques non-alimentaires et non-agricoles. La péjoration brutale et pérenne des conditions climatiques dans les années 1970 s'est doublée, tout particulièrement à partir des années 1980, d'une profonde refonte de la politique agricole au Sénégal, qui a touché de plein fouet tout le bassin arachidier et imposé aux agriculteurs de s'adapter en parallèle à un profond bouleversement économique.

\section{Une agriculture pluviale sahélienne adaptée de longue date aux aléas}

\section{L’agriculture du bassin arachidier sahélien dans les années 1950}

Déjà sous climat sahélien dans les années 1950, le nord du bassin arachidier abrite à l'époque une agriculture pluviale centrée sur les cultures de mil et d'arachide conduites en assolement réglé sous parc arboré. Trois années de cultures sont suivies d'une friche de trois à dix ans pâturée par des ruminants. Dans la première moitié du $\mathrm{XX}^{\mathrm{e}}$ siècle, la pluviométrie moyenne de la région de Louga est inférieure à $500 \mathrm{~mm}$ de 
pluie par an, la saison des pluies dure en moyenne moins de 90 jours. Ces conditions climatiques n'autorisent qu'un cycle de culture pluviale. Les agriculteurs utilisent des variétés hâtives au regard des régions plus méridionales et plus arrosées du Sénégal : mil souna, niébé et pastèque de 70 jours; mil sanio, arachide et sorgho de 90 jours (Portères, 1950; Chevalier, 1947). Compte tenu de la très courte durée de l'hivernage et du caractère alors strictement manuel de cette agriculture, la plupart des semis sont réalisés en sec (mils, sorgho et niébé), sans attendre les premières pluies. Le but est de limiter la pointe de travail à l'arrivée des pluies et de permettre à l'ensemble de ces cultures de profiter de l'intégralité des pluies. Si les premières pluies sont particulièrement tardives ou que la seconde pluie est trop retardée (risque de pourrissement des semences), le faible poids de semences à l'hectare pour le mil et le sorgho permet de procéder, si nécessaire, à de nouveaux semis à moindre coût, de préférence avec les variétés les plus hâtives. Seule l'arachide, dont le stock de semences est beaucoup plus réduit (grosses graines et plus onéreuses) est semée après la première pluie. Si le sol est suffisamment meuble, le travail du sol à l'iler, particulièrement superficiel (3 à $5 \mathrm{~cm}$ de profondeur), voire le simple semis direct en poquet à l'aide d'un outil appelé larmet, contribuent à limiter l'évaporation et à accélérer l'étape de préparation du sol et de semis.

Une partie des productions agricoles est vendue (arachide pour l'huilerie coloniale, produits de l'élevage), mais les surplus sont souvent limités et l'agriculture de la région de Louga est, à cette époque, centrée sur l'autoconsommation. La robustesse que confère aux familles cette autonomie alimentaire rend la plupart d'entre elles, en l'absence de sources notables de revenus extra-agricoles, d'autant plus dépendantes de leurs productions agricoles. Or les conditions pluviométriques et, avec elles, les rendements des cultures sont déjà décrits comme très aléatoires d'une année sur l'autre à l'époque (Portères, 1950; Chevalier, 1947). Dans ce contexte, l'étalement du calendrier des récoltes contribue tout particulièrement à réduire la vulnérabilité alimentaire des familles en limitant la durée de la période de soudure. Le mil souna, le niébé et la pastèque (cycles de 70 jours) sont consommés dès leur récolte en septembre. Le mil sanio, le sorgho et l'arachide sont, quant à eux, récoltés après la fin de la saison des pluies (fin octobre-novembre) : mil et sorgho sont stockés et consommés durant la saison sèche. La culture de manioc joue un rôle prépondérant. Implanté sur les parcelles de topographie basse, dans des sols plus argileux et à plus forte réserve utile, le manioc est la seule culture qui s'apparente à une culture de contre-saison. Son enracinement profond (jusqu'à un mètre de profondeur) permet à cette culture d'explorer des horizons plus profonds, tandis que la plus grande proximité de la nappe phréatique permise par la topographie facilite les remontées par capillarité. Récolté dès le mois d'avril et de façon étalée grâce à sa bonne conservation dans le sol, le manioc est un précieux recours en cas de faibles récoltes de mil et de sorgho. Les jardins vergers installés à proximité des habitations complètent les ressources alimentaires, baobabs et manguiers étant particulièrement utiles (pour ne pas dire vitaux) les années où la période de soudure est plus difficile.

Le maintien de la fertilité des sols repose sur la construction progressive et l'entretien d'un parc arboré qui domine tous les espaces cultivés. Il se compose de Faidherbia albida (kad), d'Acacia raddiana, de Balanites aegyptia (sump) et de 
Neocarya macrophylla (pommier du Cayor), et inclut donc des légumineuses et des espèces utiles pour la cueillette. Faidherbia albida joue un rôle majeur par l'apport d'éléments minéraux basé sur des transferts verticaux :

- depuis les horizons plus profonds du sol grâce aux produits de l'altération du substrat puisés par son système racinaire;

- depuis l'atmosphère grâce à l'azote fixé par les bactéries symbiotiques installées dans des nodosités sur son appareil racinaire.

Inversé au regard des cultures annuelles, le rythme végétatif de Faidherbia albida permet le plein développement de son feuillage en saison sèche en puisant l'eau en profondeur, à une période où la réserve utile dans l'horizon superficiel des sols ne permet pas la croissance de cultures annuelles pluviales. Son ombrage limite alors l'évaporation des sols. En fin de saison sèche, la chute des feuilles et des gousses enrichit considérablement le sol en minéraux et en carbone, tout en ne faisant pas ombrage aux cultures annuelles en saison des pluies. Par ailleurs, en consommant les gousses, le bétail facilite la germination de ses graines rejetées dans les déjections.

Restitutions et transferts de fertilité reposent également sur l'articulation étroite entre cultures et élevages. En effet, les friches herbacées qui suivent les années de culture sont pâturées, dans le cadre d'un assolement réglé, durant la saison des pluies. Lensemble des terres cultivées est ensuite dédié à la vaine pâture en saison sèche (à l'exception des parcelles de sorgho, protégées par des haies) avec parcage des animaux la nuit sur les parcelles qui seront cultivées l'année suivante, permettant de concentrer la fertilité. Hormis les troupeaux des agriculteurs sédentaires, la région est le lieu de transhumance d'éleveurs en provenance du Ferlo et de leurs troupeaux en saison sèche. Cette mobilité à grande échelle — de leurs animaux et de ceux que leur confient les agriculteurs - est un facteur d'adaptation centrale des élevages à une ressource fourragère variable dans le temps et dans l'espace. Les trocs de céréales et de lait accompagnent la cohabitation durant plusieurs mois de polyculteurs-éleveurs et d'éleveurs transhumants et renforcent la robustesse alimentaire de ce système agraire soumis à des conditions pluviométriques difficiles et aléatoires.

Plus au sud, le système agraire de la région de Bambey, dans le centre du bassin arachidier, repose sur les mêmes productions et sur une semblable organisation, mais il bénéficie à l'époque d'un climat soudanien et d'une pluviométrie nettement supérieure. Les agriculteurs emploient aussi des variétés hâtives de mil souna (dont le cycle atteint 90 jours) pour des questions de soudures alimentaires, mais peuvent ici cultiver aussi des variétés semi-tardives (120 jours) de mil sanio, d'arachide et de sorgho. Dans les années 1950, ces variétés étaient semées dès les premières pluies et non en sec comme à Louga. À l'époque, les rendements enregistrés sur les cultures et les fourrages disponibles sur les friches et parcours sont nettement supérieurs à ceux de la région de Louga.

\section{Les effets de la révolution agricole soutenue par l'État dans les années 1960-1970}

Lindépendance du Sénégal en 1960 et l'accession au pouvoir de Léopold Sédar Senghor s'accompagnent d'une planification agricole au travers du Programme agricole 
(1960-1980). Celui-ci vise à accroître la production agricole, notamment l'arachide, principale source de devises pour le pays, en ayant recours aux engrais et semences sélectionnées et en accélérant l'équipement des agriculteurs sénégalais. À l'échelle du Sénégal, 226000 semoirs, 294000 cultivateurs et 71000 «souleveuses» pour déterrer les arachides sont distribuées en 20 ans. La promotion de ce matériel s'accompagne d'une politique de crédit aux engrais subventionnés et d'une multiplication par dix de la consommation d'engrais sur cette période (Freud et al., 1997).

Créé à l'aube de l'Indépendance, l'Office de commercialisation agricole (OCA) est, en charge de l'achat des récoltes, de la livraison et de la distribution des semences dès 1960, tandis que des Centres régionaux d'assistance au développement (Crad), créés en 1964, encouragent et accompagnent la formation de coopératives où les agriculteurs acquièrent des équipements et intrants, et commercialisent leur production. La création de l'Office national de coopération et d'assistance pour le développement (Oncad) en 1966, qui cumule les fonctions de l'OCA et du Crad, acte le monopole de l'État sur le commerce de l'arachide et des engrais (Dieng et al., 2005).

La politique de prix garantis pour l'arachide s'inscrit dans la continuité de la fin de la période coloniale. Depuis 1933, l'arachide sénégalaise bénéficie d'un tarif préférentiel, grâce à l'instauration d'un droit de douane sur l'arachide exportée vers la France. La recette est affectée préférentiellement à la subvention du prix d'achat de l'arachide aux producteurs. Le renforcement du Programme agricole en 1954 contribue à accroître sensiblement la production sénégalaise. En 1960, la subvention représentait encore $30 \%$ du prix FOB (Free on board, franco à bord) (Freud et al., 1997).

Dans les régions étudiées du nord et du centre du bassin arachidier, le Programme agricole se traduit par deux campagnes de distribution d'équipements (semoir, cultivateur et charrette) dans les villages où se sont structurées des coopératives. Peuvent en théorie y accéder, tous les agriculteurs moyennant un versement de $35 \mathrm{~kg}$ d'arachide décortiquée par an pendant cinq années. Cependant, le matériel mis à disposition ne permet pas de satisfaire toute la demande, ni d'équiper toutes les familles. Dans l'ensemble, les attributions favorisent les agriculteurs et les villages impliqués dans les coopératives et ceux qui produisent assez d'arachide pour pouvoir s'engager sur cinq ans et régler leurs dettes à la coopérative.

Certaines familles disposent ainsi, dès le milieu des années 1960, de tout l'équipement de traction attelée (semoir, cultivateur et charrette). D'autres familles ont pu acquérir un ou deux de ces trois outils et procèdent à des échanges de matériel pour accéder aux équipements manquants, tandis que les familles les plus pauvres sont totalement tributaires de l'emprunt de ce matériel. Face à la demande, les forgerons prennent néanmoins le relais en fabriquant non seulement des outils manuels, mais aussi des équipements de traction attelée inspirés des outils distribués dans le cadre du Programme agricole. Si ces outils de facture artisanale sont plus légers et moins résistants, ils sont aussi financièrement plus accessibles et permettent aux familles ne disposant ni de la trésorerie suffisante, ni des accointances requises avec les responsables des coopératives, d'être équipées à leur tour au début des années 1970. La diffusion de ces équipements de traction attelée va de pair avec celle de semences d'arachide sélectionnées à port dressé (et non plus de variété rampante) afin de mécaniser plus largement les sarclages. 
Dans l'ordre de priorité et selon leurs moyens, les agriculteurs choisissent de s'équiper d'un cultivateur qui permet de lever la pointe de travail majeure que représentent les binages manuels, puis dans un second temps et si leur capacité d'investissement le permet, d'un semoir, voire d'une charrette. Pour la culture de l'arachide, les pointes de travail correspondent aux périodes de sarclage et de récolte, beaucoup moins avec celle de préparation du sol ou de semis. Ainsi, pour l'arachide, 45 hommejours $(\mathrm{HJ})$ de travail manuel par hectare suffisent pour la préparation et l'entretien de la culture jusqu'à la récolte. En revanche, l'équivalent de plus de 80 jours de travail pour les femmes et les enfants sont requis pour la délicate tâche de l'enlèvement des gousses (Chevalier, 1929; enquêtes). Dès les années 1970, la fabrication par les forgerons de «souleveuses» attelées permettant de déterrer rapidement les arachides contribue à accroître la surface qu'une famille peut récolter. Les engrais mis en vente et le matériel distribué concernent avant tout la culture de l'arachide, mais des gains de productivité sont aussi enregistrés pour les cultures céréalières : le mil, cultivé dans des rotations avec l'arachide, bénéficie de l'arrière-effet.

Grâce aux gains de productivité du travail enregistrés, les familles équipées au moins d'un cultivateur (la «houe» tractée) ou qui peuvent l'emprunter sont en mesure d'accroître leur surface emblavée. La diffusion de la traction attelée (photo 1.1, planche 1) conduit ainsi à une large extension des terres semées au détriment des friches — trois années de cultures suivies désormais d'une friche n'excédant pas trois ans à Louga, culture continue à Bambey — et de l'ager au détriment du saltus. Ce dernier ne permet plus de nourrir les troupeaux sur place durant la saison des pluies. Dès lors, les troupeaux sont conduits en transhumance dans le Ferlo durant la saison des pluies. Mais à leur retour, ils disposent d'abondants résidus de culture laissés au champ et consommés en vaine pâture durant toute la saison sèche. Seules les fanes d'arachide sont plus souvent récoltées afin de nourrir les chevaux et les ânes, car ces animaux sont désormais sollicités non seulement comme animaux de bât, mais aussi pour la traction.

Dans les régions étudiées, la différenciation sociale entre les familles s'exprimait surtout, en agriculture manuelle, par la taille de la famille et la taille des troupeaux qui commandaient respectivement la surface pouvant être travaillée et fumée. Elle s'illustre désormais par les écarts enregistrés dans les niveaux d'équipement :

- d'un côté, des familles disposant de l'ensemble de la palette des équipements et outils attelés (et d'une trésorerie permettant le large recours aux engrais et semences d'arachide sélectionnées);

- de l'autre, des familles cultivant toujours avec un strict outillage manuel.

Laccroissement de la productivité du travail (rendement et surface cultivée par actif) et les rapports de prix favorables ont contribué à une véritable révolution agricole dans le bassin arachidier sénégalais dans les années 1960. Cette période est décrite comme un âge d'or par les agriculteurs qui ont vécu ces transformations. Cette révolution n'a néanmoins été possible qu'au prix du renoncement fréquent au remboursement des crédits d'équipement; l'accroissement de la production et les prix garantis et soutenus de l'arachide n'étant, pour nombre de producteurs, pas suffisants pour leur permettre, en une dizaine d'années, l'accumulation de capital nécessaire. Ces transformations et la spécialisation renforcée dans la production d'arachide traduisent aussi la dépendance de ces évolutions techniques et du revenu des producteurs aux soutiens publics et à cette culture d'exportation. 


\section{" Le double choc des années 1970-1980, sécheresse aiguë et bouleversements du cadre de politique agricole}

\section{Manifestations climatiques et hydriques de la sécheresse}

Le nord et le centre du bassin arachidier connaissent un profond bouleversement de la pluviométrie à partir de la fin des années 1960 et ce, jusqu'à la fin des années 1980, voire des années 1990. Différents paramètres liés à la pluviométrie conditionnent de manière particulièrement centrale les pratiques agricoles dans la zone sahélienne : la durée de la saison des pluies, la date des premières pluies, le nombre de jours de pluies sur l'ensemble de la saison, leur répartition et la fréquence des différents épisodes secs et humides pendant l'hivernage. À Louga, déjà sous climat sahélien dans la première moitié du $\mathrm{xx}^{\mathrm{e}}$ siècle, la pluviométrie moyenne, de $470 \mathrm{~mm}$ entre 1946 et 1967, tombe à $270 \mathrm{~mm}$ par an en moyenne de 1968 à 1986 (près de $45 \%$ de recul, figure 1.2). Elle place cette région aux limites d'un climat sahélo-saharien (en deçà de $250 \mathrm{~mm}$ de pluie par an) et du maintien d'une agriculture pluviale. D'après les données de la Direction de l'analyse et de la prévision statistique à Dakar, la durée de la saison des pluies, en moyenne de 80 jours sur la période 1961-1967, tombe quant à elle à moins de 50 jours sur la période 1968-1998 (Sambou et al., 2015).

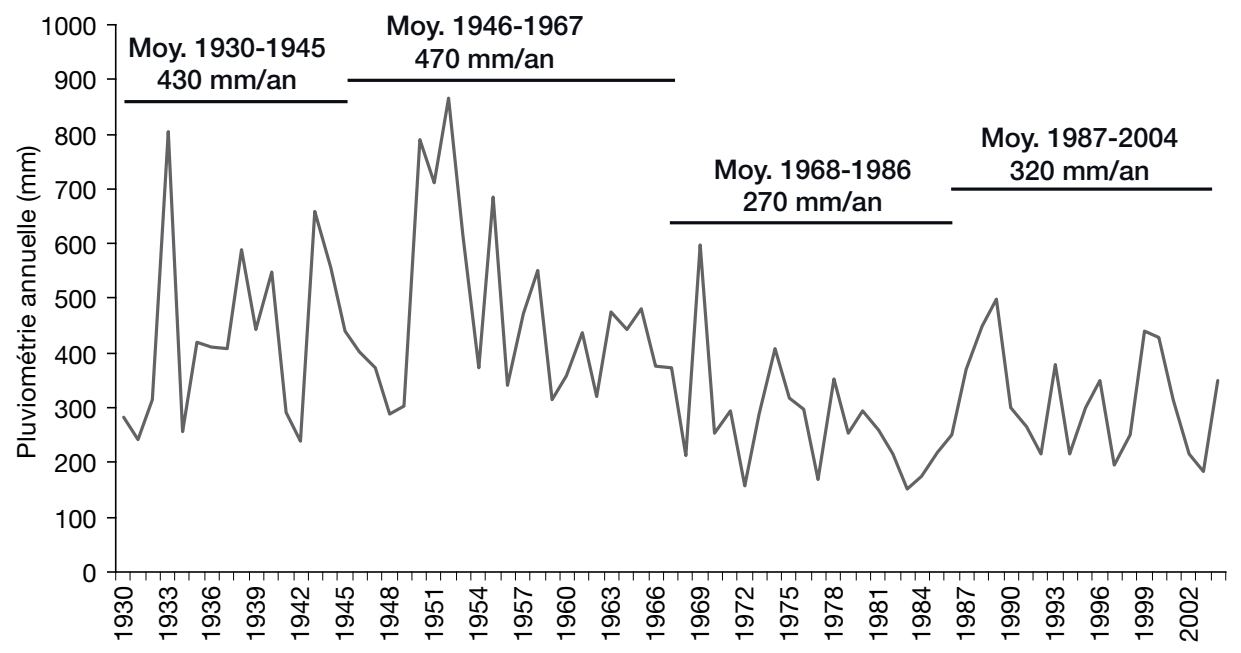

Figure 1.2. Évolution des précipitations annuelles à Louga de 1930 à 2004 (Le Borgne, 1986; données d'Anacim).

Bien que partant d'un niveau moyen sensiblement supérieur ( $700 \mathrm{~mm}$ de pluie par an sur la période 1946-1967), les précipitations enregistrées dans la région de Bambey connaissent aussi un fort recul (35\%), tombant à $450 \mathrm{~mm}$ par an en moyenne entre 1968 et 1986 (avec de nombreuses années autour de $350 \mathrm{~mm}$ ) et faisant basculer la région sous climat sahélien (figure 1.3). D'après les données de l'Anacim (Agence nationale de l'aviation civile et de la météorologie), cette forte baisse de la pluviométrie s'accompagne d'un raccourcissement d'un mois de la durée de la saison des pluies : 105 jours en moyenne de 1946 à 1967, contre 75 jours en moyenne de 1968 à 1999. 


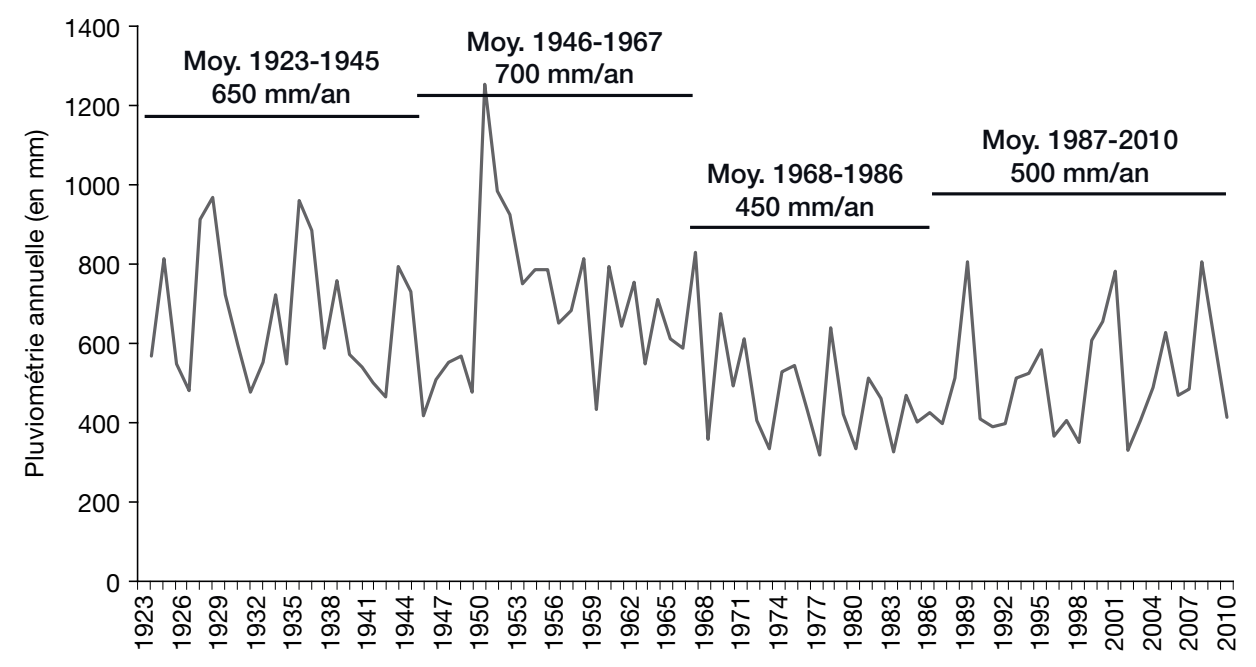

Figure 1.3. Évolution du volume des précipitations annuelles à Bambey de 1923 à 2010 (Le Borgne, 1986; données d'Anacim).

Labaissement induit du niveau de la nappe phréatique réduit d'autant les remontées par capillarité de l'humidité jusqu'aux horizons superficiels du sol, phénomène qui favorise les espèces arborées dont le système racinaire est capable d'explorer des horizons un peu plus profonds. La diminution générale de l'humidité des sols en saison sèche, notamment dans les horizons superficiels, rend ceux-ci d'autant plus sensibles à l'érosion éolienne.

\section{Très faibles récoltes et brutale décapitalisation}

La chute des totaux pluviométriques dans les régions de Louba et Bambey et l'irrégularité interannuelle des conditions de la pluviométrie (nombre de jours de pluie notamment) compliquent la conduite des cultures et l'organisation du calendrier cultural (Roquet, 2008). Si la première pluie n'est pas suivie d'averses suffisamment régulières, les semis sont à refaire. Des séquences sèches en plein cœur de la saison des pluies peuvent survenir avec une plus forte fréquence, et à un stade où les plantes sont particulièrement sensibles au stress hydrique (floraison et maturation notamment) induisant de fortes baisses de rendement.

Les variétés cultivées dans chacune des deux régions jusqu’à la fin des années 1960, adaptées à une saison des pluies plus longue, se révèlent inadaptées à ces nouvelles conditions climatiques : le cycle de croissance et de maturation ne peut plus être achevé, conduisant à une chute des rendements les années de fort déficit hydrique. Chalby et al. (1991) signalent ainsi qu'une variété hâtive d'arachide (90 jours) qui terminait son cycle à Louga 14 années sur 17 de 1953 à 1969, n'est plus adaptée que 3 années sur 17 de 1970 à 1986. Parallèlement, le caractère plus erratique des pluies de fin d'hivernage fait craindre des risques de germination de l'arachide dans le sol avant la récolte. La culture du manioc, qui jouait un rôle important de soudure alimentaire dans la région de Louga, devient impossible. La situation est 
moins catastrophique à Bambey où la pluviométrie et la durée de la saison des pluies permettent l'utilisation de variétés hâtives d'arachide, de sorgho et de mil (90 jours maximum) cultivées jusque-là dans les régions plus septentrionales. Les rendements sont en revanche nettement plus faibles et fragilisés par l'apparition de possibles périodes de sécheresse en cours de culture (Chalby et al., 1991).

Laccès à la traction attelée, héritage du programme agricole des années 1960-1970, et le semis en sec du mil grâce auquel la germination peut débuter sur toutes les parcelles dès le jour des premières pluies (retour de cette pratique dans la région de Louga, nouvelle dans celle de Bambey) sont déterminants face au resserrement de la fenêtre calendaire pour l'ensemble des opérations culturales (semis, sarclages et récoltes). Ils permettent de cultiver une surface par actif bien supérieure à celle qu'autorise un outillage strictement manuel, et de disposer d'une récolte moins réduite les années où les conditions pluviométriques autorisent la réalisation de l'intégralité du cycle cultural.

Malgré l'aide alimentaire mise en place dans les années 1970-1980 (Minvielle et al., 2005) et l'évolution de l'équipement, la répétition à une fréquence excessive de récoltes parfois extrêmement faibles ne permet pas aux familles de survivre sans devoir décapitaliser, le plus souvent en vendant une partie de leurs animaux et dans les cas les plus extrêmes, leurs équipements. Les enquêtes conduites à l'époque dans le bassin arachidier par Auserehl Kelly (1989) indiquent que plus de $70 \%$ des producteurs enquêtés n'ont pas été en mesure de satisfaire leurs besoins essentiels les années de mauvaise récolte (campagne 1983-1984 par exemple).

Face à la chute des ressources fourragères dans l'ensemble de la zone sahélienne, les éleveurs transhumants, leurs troupeaux et les bovins et petits ruminants qui leur sont confiés s'attardent moins longtemps dans le nord du bassin arachidier en saison sèche pour gagner plus rapidement la région du Centre. Ils se déplacent durant la saison des pluies jusque dans la région des «Terres neuves», dans le sud-est du pays plus arrosé et moins peuplé. La sous-alimentation des animaux, rendus d'autant plus vulnérables aux maladies, conduit à des épizooties qui achèvent de décimer les troupeaux. Les éleveurs transhumants voient leur cheptel fondre. Dans les régions de Bambey et de Louga, rares sont les familles d'agriculteurs qui disposent encore de quelques têtes de bétail à la fin des années 1980 .

\section{Mobilité de travail et revenus extra-agricoles face à la crise dans le nord du bassin arachidier}

Face à cette crise, les familles du nord du bassin arachidier font le choix, dès les années 1970, d'envoyer une partie des jeunes en ville en saison sèche. Dans la région de Louga par exemple, les familles les plus aisées envoient ces jeunes actifs se former en ville pour y exercer, au terme d'une ou deux années, une activité qualifiée plus rémunératrice. En retour, ces jeunes peuvent contribuer, par des transferts d'argent, à la vie des membres de la famille élargie restés au village. Durant cette période de très faibles récoltes, ces revenus extra-agricoles sont déterminants pour la survie des familles rurales. 


\section{Fragilisation progressive du marché de l'arachide sénégalaise et rupture de politique agricole au tournant des années 1980}

Parallèlement à cette crise climatique, la politique agricole sénégalaise connaît de profonds bouleversements et une remise en cause des dispositifs de soutien pour la culture d'arachide à partir de 1983, qui fragilisent d'autant les producteurs du bassin arachidier.

\section{Un dispositif compensatoire de la CEE moins avantageux pour l'arachide sénégalaise que les tarifs préférentiels garantis par la France jusqu'en 1965}

Lorganisation du marché de l'arachide en zone franc reposait jusqu'en 1960 sur le contrôle des importations, facilitée par le faible degré de substitution des matières grasses sur le marché français où prédominait l'huile d'arachide. Elle a permis d'assurer une garantie de prix aux producteurs d'arachide et des débouchés aux huiliers. Reconduite durant la première campagne postindépendance par une convention entre le Sénégal et la France, cette organisation est remise en cause par l'adhésion de cette dernière à la CEE. La seconde convention d'association entre les États associés africains et malgaches (EAMA) et les pays membres de la CEE signée à Yaoundé en 1963 entre en application en 1966 pour le Sénégal. Elle marque en effet le début de l'établissement d'une zone de libre-échange entre les EAMA et la CEE (Debien, 1966).

En parallèle, le marché français des oléagineux, jusque-là protégé par des restrictions aux importations de matière grasse en provenance des pays tiers, s'ouvre progressivement, comme celui de ses partenaires communautaires, à la circulation des produits concurrents. Les négociations du Dillon round dans le cadre du Gatt (General agreement on tariffs and trade) marquent le début de l'entrée des oléagineux sans droit de douane sur le marché européen. Les processus intenses de substitution entre produits, qui caractérisent le marché des corps gras, placent alors les exportations sénégalaises en pleine concurrence avec les États-Unis sur le marché communautaire, les obligeant à s'aligner sur les prix mondiaux.

Un dispositif compensatoire prévu par la CEE dès le milieu des années 1960 et spécifique aux exportations des produits oléagineux des EAMA assure bien à ces derniers de bénéficier d'un «prix mondial minimum»stable et supérieur au prix mondial réel, sur la base des quantités importées par la CEE. Ce dispositif tente de compenser, dans une certaine mesure, la baisse des cours mondiaux. Fondé sur une enveloppe annuelle fixe prélevée sur le Feoga (Fonds européen d'orientation et de garantie agricole), il ne permet pas aux pays partenaires d'accroître leur production, à moins d'accepter un prix minimum plus proche du prix mondial (Debien, 1966). Après 1975 et la signature de la première Convention de Lomé, le dispositif est intégré dans le système Stabex qui s'efforce de palier, par des compensations financières, l'alignement sur les prix mondiaux, au sein du marché européen, des 46 pays ACP (Afrique Caraïbes Pacifique) pour de nombreux produits tropicaux. Après un premier effet de relance des exportations des pays ACP, la baisse des cours mondiaux oblige à plafonner l'enveloppe du Stabex pour éviter la faillite du dispositif et réduit d'autant sa portée sur le revenu des producteurs (Ministère français des Relations extérieures, de Coopération et de Développement, 1983). 
Chute des prix de l'arachide, incapacité de remboursement des crédits agricoles, ruine de l'Oncad et arrêt du dispositif de subventions aux intrants

Pensé sur la base d'une organisation du marché français et européen telle qu'elle existait au début des années 1960 (prix soutenus et débouchés garantis), le Programme agricole a été maintenu jusqu'en 1980 et ce, malgré les profonds remaniements opérés sur le commerce de l'arachide sénégalaise, défavorables tant aux producteurs sénégalais qu'à l'équilibre du budget de l'Oncad, et in fine à celui de l'État. Face à l'évolution défavorable des rapports de prix pour les producteurs, de nombreux crédits accordés pour l'achat de semences et d'équipements ne sont pas remboursés. S'ajoutant aux dettes accumulées par l'Oncad et au second choc pétrolier, ce nonremboursement conduit à la faillite de cet office d'État qui disposait du monopole du commerce de l'arachide et des engrais au Sénégal (Freud et al., 1997). Sa dissolution et l'arrêt du Programme agricole remplacé par le Programme de redressement économique et financier (Pref) de 1981 à 1985 conduisent à un assèchement du crédit aux producteurs pour l'achat d'engrais, et à une chute brutale de leur consommation (nulle en 1983, Dieng et al., 2005) en pleine période de déficit pluviométrique.

\section{- Adaptation de l'agriculture à la péjoration pluviométrique dans un contexte de désengagement de l'État et de croissance démographique}

\section{Ajustement structurel renforcé à partir de 1995 (Pasa)}

En réaction à près de deux décennies de fragilisation du marché de l'arachide sénégalaise, la Nouvelle politique agricole (NPA) et le Plan céréalier mis en œuvre de 1985 à 1994 prévoient un redressement des prix agricoles et une protection des céréales locales grâce au monopole de l'État sur l'importation et la commercialisation du riz (Dieng et al., 2005). Les prix fixes pratiqués jusqu'alors sont remplacés par des prix plafonds et planchers, tandis que se maintiennent en parallèle des marchés non contrôlés pour les céréales. Dans les faits, les actions ciblées de grandes ampleurs concernent avant tout l'aménagement de la vallée du fleuve Sénégal et la production nationale de riz (chapitre 5), beaucoup moins l'agriculture du bassin arachidier qui ne reçoit plus, de 1987 à 1995, que $7 \%$ de l'enveloppe du Programme d'investissement agricole (Oya, 2009). Le rôle de l'État dans la commercialisation des céréales, l'approvisionnement en intrants (semences et engrais) et l'accès au crédit est parallèlement légué au secteur privé, tandis que les subventions aux intrants sont supprimées (Dieng et al., 2005).

Le désengagement de l'État en matière d'accès aux intrants s'accompagne ainsi d'une évolution relative des prix très défavorables aux agriculteurs (figure 1.4).

\section{Légère remontée de la pluviométrie, mais maintien de forts aléas}

Le déficit pluviométrique observé à partir de la fin des années 1960 au Sénégal s'est légèrement résorbé depuis la fin des années 1990, de l'ordre de +10 à $+17 \%$ de pluviométrie en moyenne zonale. Cependant, les premières pluies seraient de plus 


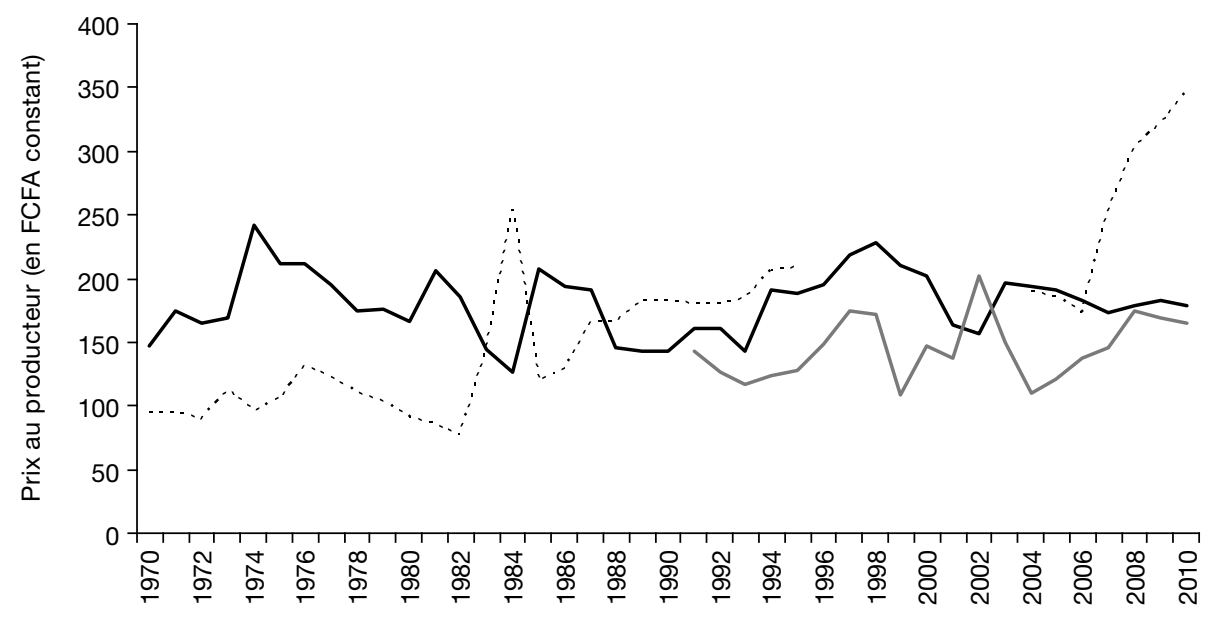

Prix arachide au producteur Prix mil au producteur Prix engrais au producteur

Figure 1.4. Évolutions des prix au producteur de l'arachide, du mil et des engrais en monnaie constante (Freud et al., 1997; Usaid, 2011; données statistiques de la FAO).

en plus assimilables à des «faux-départs » puisqu'elles sont suivies de pauses pluviométriques assez longues, parfois supérieures à deux semaines. Des interruptions des pluies supérieures à sept jours persistent ainsi jusqu'à la première décade de juillet dans les régions centrales (et jusqu'à la dernière décade de juillet dans les régions du nord du Sénégal), tout en présentant une occurrence plus élevée dans le nord et le centre-nord du pays. Le démarrage de la saison des pluies se caractérise alors par une grosse pluie en début de saison. Isolée du reste de la pluviométrie, elle peut causer des pertes sévères sur les semis (Salack et al., 2012). Si des années un peu plus humides se profilent peut-être, les températures demeurent, quant à elles, en progression lente mais régulière, ce qui contribue à renforcer l'évaporation.

À Bambey par exemple, la pluviométrie annuelle fluctue depuis 1987 entre 360 et $800 \mathrm{~mm}$ par an, avec une moyenne de $505 \mathrm{~mm}$ par an sur la période 1987-2010. Bien que la moyenne dépasse les $450 \mathrm{~mm}$ par an enregistrés durant la période 1968-1986 où la sécheresse a connu ses manifestations les plus poussées, le niveau de pluviométrie antérieur n'a pas été retrouvé (figure 1.3). La pluviométrie est demeurée réduite durant les années 1990 et le début des années 2000 avec une saison des pluies toujours limitée à deux mois et demi. Malgré la reprise qui semble s'amorcer (durée moyenne de l'hivernage de 85 jours sur la période 1999-2010), une forte variabilité interannuelle demeure.

Dans le nord du bassin arachidier, après les deux années de profonde sécheresse de 1997-1998 (respectivement 195 et 250 mm de pluie par an à Louga), la pluviométrie semble amorcer depuis lors une tendance haussière, sans pour autant retrouver le niveau d'avant la crise, ni échapper aux années extrêmes : $185 \mathrm{~mm}$ de cumul de pluies et saison des pluies de 10 jours en 2003 et $215 \mathrm{~mm}$ en 2014. On y observe un redressement à 70 jours de la durée moyenne de la saison des pluies sur la période 1999-2012. Ce rallongement s'accompagne du maintien d'une très forte variabilité interannuelle de la durée de la saison des pluies et du démarrage des premières 
pluies pour lequel les situations extrêmes gagnent en fréquence. En effet, une année sur deux se caractérise par des premières pluies retardées ou avancées de plus de 20 jours par rapport à la normale de 2000 à 2010, avec des positions extrêmes début juin ou la dernière semaine d'août. Ces conditions compliquent d'autant le semis en sec à cause du risque accru de germination incomplète et de pourrissement des semences, ou de consommation des graines avant germination par les rongeurs.

\section{Diffusion de variétés à cycle plus court et adaptation des espèces cultivées}

La péjoration climatique a conduit à la sélection et à la diffusion de variétés à cycle plus court. Dans le centre du bassin arachidier, des variétés d'arachide et de mil de 90 jours remplacent celles de 120 jours utilisées avant les années 1970. À Louga, outre les variétés hâtives de niébé et de mil (70 jours) qui existaient déjà avant les années 1970, des variétés d'arachide de 80 jours sont désormais disponibles. Dans le centre et le nord du bassin arachidier, les agriculteurs sèment aujourd'hui une variété de niébé à cycle extrêmement court (45 jours) nommée «niébé secouriste», qui permet d'obtenir une récolte même les années où la pluviométrie est plus critique.

Face à l'évolution défavorable des rapports de prix pour les agriculteurs, la place de l'arachide dans l'assolement a régressé au regard des années 1960, au profit du mil et du niébé. Ainsi, la production d'arachide est en recul, tandis que la demande en arachide vivrière enregistre une hausse sur le marché domestique (urbain et rural). Larachide est consommée sous diverses formes, notamment en pâte d'arachide après la première pression. Elle entre dans la préparation du couscous de mil et contribue, tout particulièrement en zone rurale, à enrichir la ration alimentaire en protéines. C'est pourquoi, dans la région de Bambey, l'arachide produite est aujourd'hui surtout destinée à l'alimentation familiale. Lusine de trituration de Diourbel a fermé et a été remplacée par des activités de décorticage et pressage artisanal effectuées dans les bourgs ruraux par des commerçants et les agriculteurs qui ont eu les moyens de réaliser l'investissement dans une décortiqueuse et une petite presse motorisée.

La progression du mil dans les assolements à des fins d'autoconsommation, voire comme culture de vente, illustre l'essor important de la production de mil au Sénégal depuis 1980 face à la demande urbaine en hausse. Cette production a aussi été favorisée par une politique de soutien à la transformation artisanale, semi-industrielle voire industrielle permettant la mouture de ces céréales et leur intégration dans l'alimentation des urbains, avec un considérable allègement de la durée de préparation pour les ménages (Gueye et al., 2010).

Bien que sensible au parasitisme, le niébé présente l'avantage, contrairement à l'arachide, de s'affranchir facilement d'engrais. Par ailleurs, cette légumineuse au port rampant (comme les variétés d'arachide employées avant la diffusion de la traction attelée) assure une meilleure couverture du sol et contribue à limiter l'évaporation pendant le cycle cultural. Son essor progressif depuis la fin des années 1980 dans le centre du bassin arachidier révèle un glissement de cette culture vers le sud. Récolté en graines pour l'alimentation humaine, le niébé peut être cultivé en association. À Bambey, l'arachide lui est désormais très souvent associée, parfois 
aussi le mil qui bénéficie alors de l'enrichissement du sol en azote permis par cette légumineuse (figure 1.5). Il peut aussi constituer une source de fourrages comme à Bambey où toutes les familles cultivent désormais une parcelle de niébé en culture pure. Celui-ci est récolté en vert, avant maturation des gousses afin de constituer des stocks fourragers complémentaires aux fanes d'arachide. À Louga, le niébé, dont une partie est récoltée pour être vendu en frais, occupe aujourd'hui plus de $50 \%$ de la surface semée dans la majorité des exploitations agricoles.

Le gouvernement sénégalais a d'ailleurs fait la promotion du niébé en remplacement de l'arachide dans le nord du bassin arachidier à partir des années 1980, avec des mesures incitatives telles que l'augmentation du prix relatif officiel du niébé au regard de celui de l'arachide (Ndoye et al., 1989).

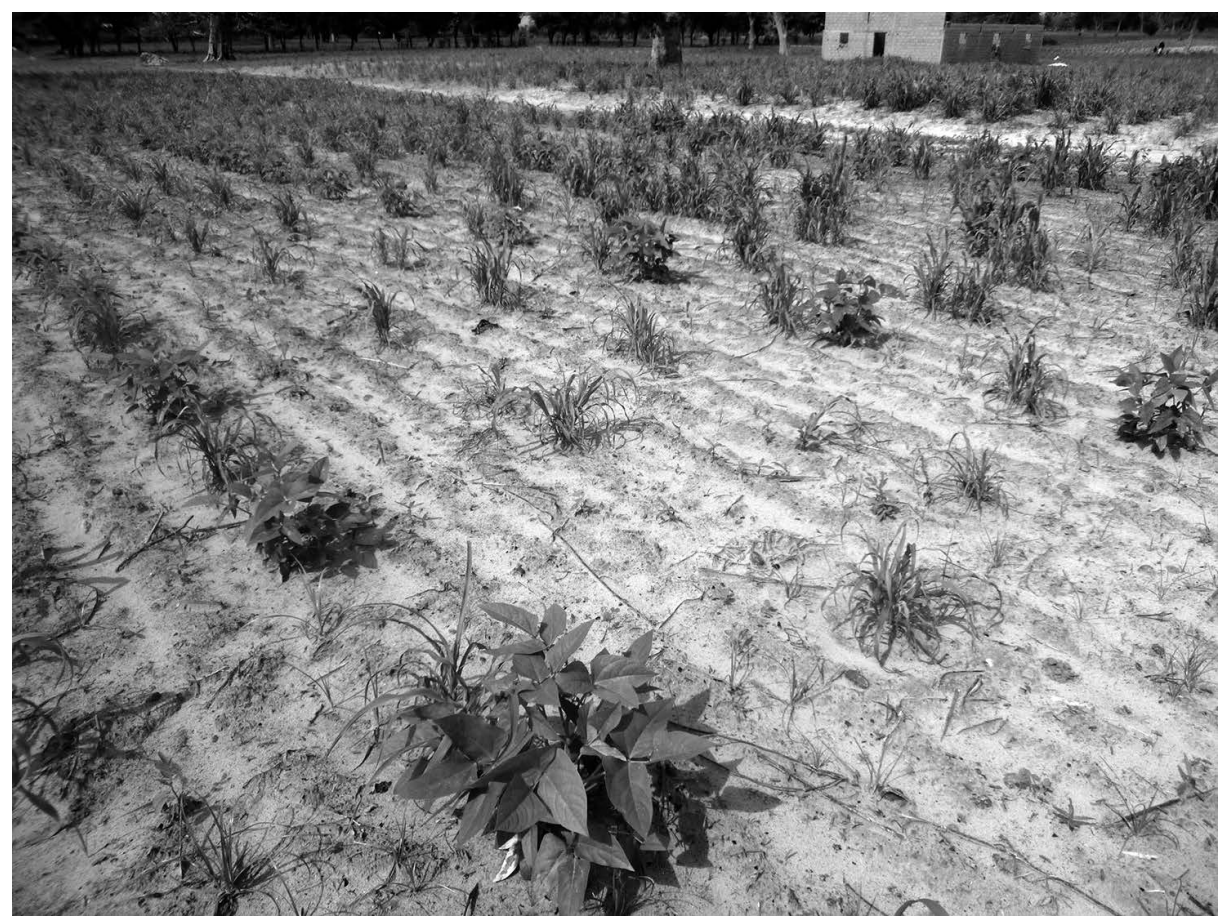

Figure 1.5. Niébé associé au mil (Garambois, 2015).

\section{Intensification en travail et en capital dans la conduite des élevages et la gestion de la matière organique}

\section{Repli sur l'élevage naisseur, les petits ruminants et l'embouche saisonnière}

Depuis 40 ans, le nombre d'animaux reproducteurs (vaches, chèvres et brebis) accuse un net repli. Seule une petite partie des familles ont eu les moyens de racheter quelques bovins et disposent aujourd'hui de suffisamment de fourrages pour les alimenter. De très rares familles ont pu reconstituer un troupeau justifiant de 
reprendre la transhumance, avec tous les risques (vols notamment) que comprennent aujourd'hui ces déplacements. La fréquence des vols d'animaux achève de dissuader les agriculteurs les plus aisés de trop accumuler de bétail. La plupart des familles ne disposent d'ailleurs que de petits ruminants.

En revanche, les régions de Bambey et de Louga connaissent un essor de l'activité d'embouche qui pourrait être lié à la progression de la demande en viande des centres urbains, tout particulièrement en moutons pour les fêtes religieuses. Les animaux à l'engrais présentent l'avantage d'une immobilisation courte du capital, souvent de quelques mois seulement, offrant à la fois une plus grande souplesse de trésorerie et un moindre risque de déficit fourrager. Cette souplesse les rend même accessibles aux jeunes actifs agricoles et aux agriculteurs disposant de peu de terre. La durée et l'intensité de l'engraissement sont directement liées aux ressources fourragères (fanes, son et tourteau produits sur place) et au capital (aliments achetés) dont disposent les familles : les animaux peuvent être engraissés pendant trois à six mois ou au contraire rapidement vendus avec une maigre plus-value en cas d'imprévu.

\section{De profondes évolutions dans l'alimentation des animaux et la gestion de la matière organique}

Face à la diminution des ressources fourragères et à la taille limitée des cheptels, un profond bouleversement de la gestion des fourrages et de la conduite des animaux s'est progressivement mis en place. Les agriculteurs ont commencé, dès les années 1970-1980, à récolter une partie des résidus de culture du mil. Aujourd'hui, ils sont collectés en totalité ou presque. Les canes de mil servent pour une partie à renouveler les palissades entourant les cours des habitations, mais désormais aussi à alimenter les animaux de trait, le bétail et les petits ruminants (reproducteurs ou à l'engrais) de plus en plus souvent conduits en stabulation. Les animaux ne sont donc plus conduits en vaine pâture et les résidus de culture appartiennent à celui qui cultive la parcelle (photo 1.2, planche 1).

Les fanes d'arachide, ainsi que les canes et feuilles de mil et de sorgho sont ainsi précieusement récoltées pour être stockées et distribuées aux animaux durant toute l'année, additionnées de bouillie à base du son des céréales (figure 1.6). Des compléments alimentaires sont apportés aux animaux à l'engrais sous forme de «ripass », complément mêlant céréales broyées et résidus des huileries d'arachide ou de tourteau d'arachide issu de sa transformation artisanale. Lémondage des arbres fourragers en fin de saison sèche permet de nourrir les petits ruminants lorsque les herbes et arbustes des rares espaces non cultivés ne suffisent plus (figure 1.7).

En recul ces quarante dernières années au sein du parc arboré, Faidherbia albida participe de façon moins ample à l'enrichissement des sols en azote, alors que les témoignages d'agriculteurs locaux convergent vers un rendement triple sous sa frondaison (figure 1.8). Il est remplacé par des arbres certes fourragers, mais qui ne sont pas des légumineuses. Les témoignages recueillis dans la région de Bambey traduisent une évolution notable de la composition du parc arboré avec un recul généralisé de la place de Faidherbia albida (espèce plutôt soudanienne), tout particulièrement dans la partie nord de la région. Dans celle-ci, le soump (Balanites 

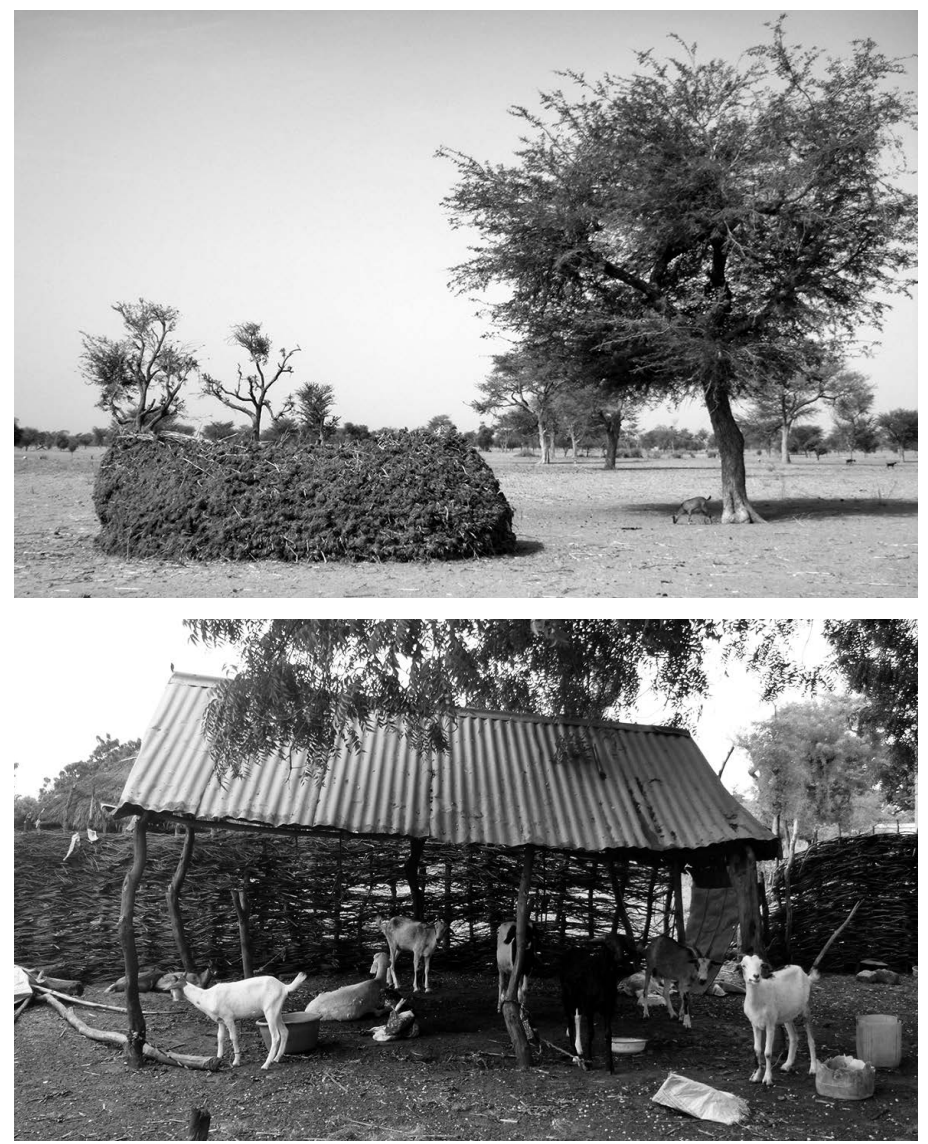

Figure 1.6. Constitution de stocks de paille de mil pour l'alimentation des animaux conduits en stabulation dans l'arrière-cour des habitations (Garambois, 2015).

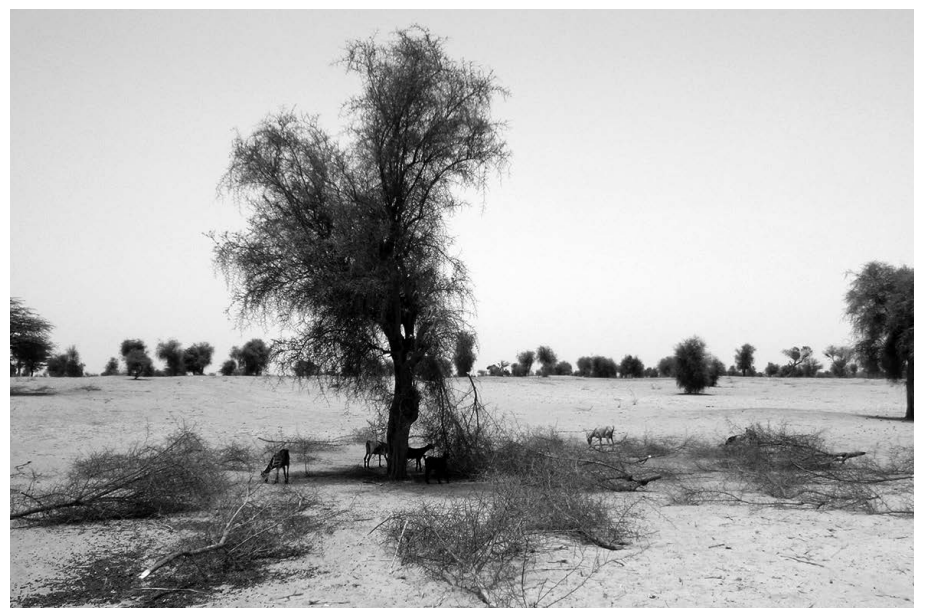

Figure 1.7. Troupeau de petits ruminants consommant le produit de l'émondage d'un sump en fin de saison sèche (Garambois, 2015). 
agyptiaca, une espèce sahélienne) occupe une place de plus en plus prépondérante, alors qu'il se rencontrait avant tout dans la région plus septentrionale du Cayor (Louga) dans les années 1960 (Pélissier, 1966). Le double système racinaire du soump lui permet à la fois de : chercher l'eau à plus de sept mètres de profondeur et dans un rayon de $20 \mathrm{~m}$ grâce à des racines profondes; profiter des faibles pluies et du moindre regain d'humidité du sol grâce à un système racinaire superficiel situé à deux ou trois centimètres de profondeur.

Faidherbia albida est aujourd'hui d'autant moins favorisé au sein du parc arboré que la germination de ses graines est facilitée par leur ingestion préalable par les ruminants. Or, la conduite des ruminants a profondément évolué. Menés de plus en plus en stabulation, les animaux ont nettement moins l'occasion d'ingérer ces graines. Dans ce contexte, l'intensification en travail dans l'alimentation des troupeaux et la gestion de la fumure organique visent à compenser la baisse des disponibilités en fumure organique par une plus grande efficacité des restitutions sur les parcelles cultivées. Certains agriculteurs vont même jusqu'à ramasser au champ des gousses de Faidherbia albida distribuées aux petits ruminants maintenus à l'engrais à proximité des maisons. Cet apport contribue à enrichir leur alimentation, mais surtout l'épandage de leurs déjections sur les parcelles cultivées, et avec elles des graines qui pourront germer, permet d'assurer autrement cette étape de digestion indispensable au maintien de Faidherbia albida au sein du parc arboré.

Enfin, les agriculteurs qui disposent d'assez de fourrages laissent une petite partie des résidus de culture étalés au champ pendant la saison sèche. Le but est, semble-t-il, d'essayer de limiter l'évaporation et l'érosion éolienne lorsque souffle l'Harmattan. Ces pailles sont alors ratissées en fin de saison sèche (figure 1.9) et brûlées. Les cendres sont ensuite dispersées sur la parcelle en préparation du semis.
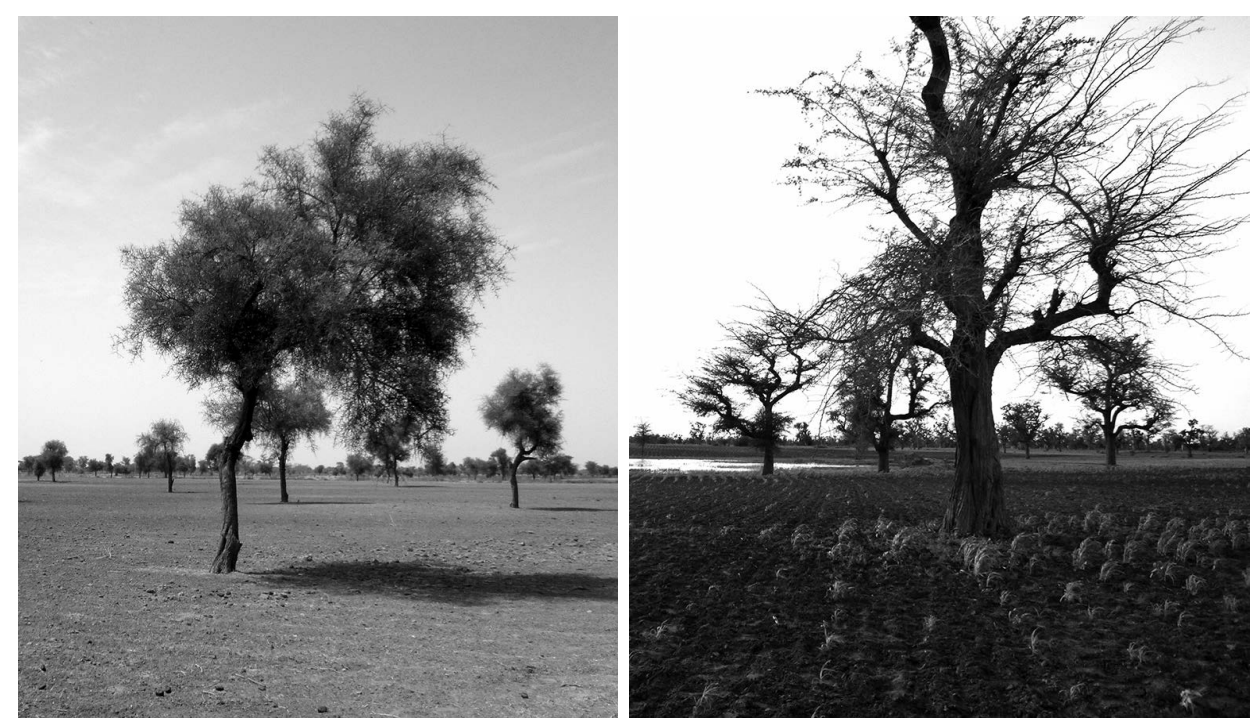

Figure 1.8. Progression de Balanites aegyptia dans le parc arboré (nord de Bambey) et effet de Faidherbia albida sur la croissance des espèces cultivées sous sa frondaison (Garambois, 2015). 


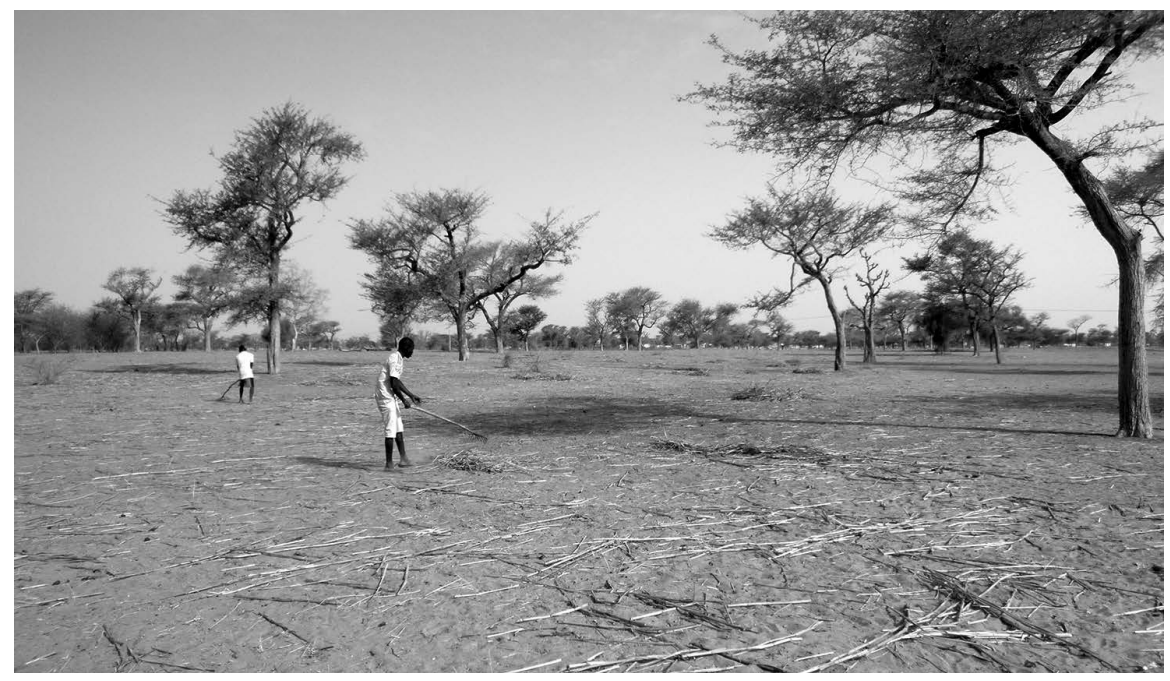

Figure 1.9. Ratissage des pailles de mil laissées au champ durant toute la saison sèche afin de limiter l'évaporation et l'érosion des sols (Garambois, 2015).

\section{" Des inégalités majeures dans l'adaptation et la sensibilité aux aléas}

Si la plupart des ménages ruraux des régions de Louga et Bambey ont trouvé des clés d'adaptation aux profonds bouleversements climatiques et économiques de ces dernières décennies, ils ne sont pas placés à égalité dans ce processus. Le bassin arachidier offre ainsi un exemple éclairant des inégalités en matière d'adaptation et de vulnérabilité aux aléas.

\section{Revenus extra-agricoles et migration, de profondes inégalités d'accès au capital}

Les niveaux de revenu agricole par actif enregistrés par les différentes catégories de producteurs du centre et du nord du Sénégal sont souvent faibles, voire extrêmement faibles, et parfois loin de permettre la survie de ces familles sans compléments de revenu extérieur (infra). Nombre de familles ont ainsi un ou plusieurs membres exerçant une activité en ville, de façon permanente ou temporaire. Le type d'activités est souvent fortement corrélé aux ressources des familles au village. Il peut parfois s'agir d'emplois qualifiés et permanents qui permettent aux jeunes actifs éduqués d'effectuer des envois réguliers et conséquents d'argent à leur famille à des fins d'investissement productif.

Dans la région de Bambey, les migrations sont le plus souvent saisonnières et plutôt en direction de Thiès ou de Dakar. Les activités sont assez diverses : accompagnateur de chauffeurs de bus, petit commerce de rue informel, portage, travaux domestiques, et, pour certains, transport en charrette achetée avec le capital accumulé grâce à 
l'agriculture. Les salaires versés couvrent alors avant tout les frais d'alimentation et du logis sommaire de ces jeunes. La maigre somme restante permet à la famille au village d'acheter un peu de riz, ou peut servir de garantie pour avoir recours à l'usure, afin d'acheter un petit ruminant à engraisser.

Ce phénomène de migration n'est pas nouveau, mais plus récent dans le centre du bassin arachidier. Roquet (2008) mentionne par ailleurs que les migrations saisonnières sont beaucoup plus nombreuses quand la pluviométrie de l'hivernage précédent a été inférieure à la moyenne et que le déficit de production est important. Si la sécheresse n'a pas déclenché le phénomène migratoire, elle semble en revanche en accentuer l'ampleur.

Dans la zone rurale étudiée au sud de Louga, seuls les jeunes ménages de cadets, sous-équipés et ne pouvant compter que sur eux-mêmes pour faire vivre leur famille restent au village toute l'année. Ils conduisent quelques activités complémentaires d'artisanat et louent leurs bras sur place pour des tâches agricoles. Toutes les autres familles ont aujourd'hui au moins deux membres (fils ou jeune frère) travaillant en ville : à Dakar, Thiès ou Louga. La plupart d'entre eux parviennent à revenir ponctuellement au village pour participer aux travaux agricoles lors des pointes de travail. Leurs épouses et leurs enfants demeurent au village. En dehors de la saison des pluies, la plupart des foyers ruraux présentent ainsi un net déséquilibre entre hommes et femmes.

Ces phénomènes migratoires et l'importance des revenus extra-agricoles dans la survie des familles et dans les investissements productifs au village sont plus anciens et plus amples dans le nord du bassin arachidier. Dans cette région, ces migrations de travail ont connu une forte progression dès les années 1970, compte tenu de la chute dramatique des récoltes (Ndoye et al., 1989). Cette migration orientée vers les grandes villes sénégalaises n'a parfois constitué qu'une première étape vers l'expatriation. La région de Louga est en effet celle où la part des migrations en direction de l'Europe a été la plus forte de tout le Sénégal (plus de 75\%), comme l'indique les enquêtes nationales de 1993 et de 2002 (Lessault et al., 2013). Ces départs précoces (dès la fin des années 1980) et lointains ont concerné avant tout les familles les plus riches de la région, qui pouvaient, en pleine période de sécheresse, mobiliser le capital nécessaire pour envoyer l'un des leurs en Europe. Cette démarche relève alors d'un véritable investissement pour la famille, grâce aux envois d'argent depuis l'étranger attendus en retour. Comparativement moins coûteux à l'époque, le coût pour la famille de ces départs en Europe se porte aujourd'hui à près de cinq millions de FCFA (environ 7500 euros). Avec l'un de leurs membres émigrés en Europe et deux ou trois autres occupant un emploi à Dakar, les familles les plus aisées sont aussi celles dont le plus faible nombre d'actifs masculins participent aux activités agricoles. Ce déficit est compensé par l'emploi d'un ou deux salariés agricoles.

\section{Accès inégal à la fertilité, à la traction attelée et au foncier}

Avec l'arrêt de la vaine pâture, la quantité de déjections animales dont une famille peut disposer est désormais corrélée aux résidus de culture dont elle peut disposer sur ses parcelles (et donc à la surface cultivée), et à sa capacité d'accumulation dans 
le bétail et d'achat de compléments. À Bambey, les familles les plus pauvres en sont parfois réduites à remplacer une partie des aliments achetés pour engraisser leur mouton par des bouillies préparées à base de carton déchiqueté.

Cet accès inégal au cheptel et à la fumure organique se double d'un accès différencié aux engrais chimiques. Si l'État sénégalais organise la distribution dans chaque village de quelques sacs d'engrais subventionné à hauteur de $50 \%$ depuis la fin des années 2000, ceux-ci arrivent rarement à temps et en quantité trop faibles pour satisfaire l'ensemble de la demande locale. Lachat de semences sélectionnées d'arachide et d'engrais pour l'arachide ou le mil ne concerne donc aujourd'hui que les familles les plus aisées, qui disposent de la trésorerie suffisante pour acheter des intrants non subventionnés. Dans le nord du bassin arachidier, la spécialisation poussée vers la production d'arachide (environ les deux-tiers de la surface ensemencée) des familles dont l'un des membres est expatrié est directement liée à leur capacité d'achat d'engrais chimiques et de semences d'arachide sélectionnées, grâce aux revenus migratoires.

Linégal accès aux éléments minéraux d'une catégorie de producteurs à l'autre se maintient donc, voire s'accentue, à mesure que le prix des engrais évolue de façon défavorable pour les producteurs et que la fumure organique devient plus rare et d'autant plus précieuse. À Bambey par exemple, on enregistre des écarts considérables entre : - les familles qui ont eu les moyens de reconstituer des élevages de bovins et de petits ruminants et ont développé l'embouche;

- les familles les plus pauvres qui n'ont au mieux que deux ou trois chèvres ou brebis (voire aucun animal).

Ces dernières sont réduites à collecter quelques déjections encore disponibles sur les espaces de vaine pâture (friches résiduelles et bords des chemins) en complément de la poudrette issue du compostage des déchets de cuisine.

Des quantités très différentes de fumure organique peuvent être apportées aux parcelles en fonction à la fois des disponibilités en déjections des familles, de leur capacité de transport et de la distance des parcelles; les plus éloignées du village étant dans l'ensemble moins fumées. Si certaines familles peuvent réaliser un épandage abondant de déjections animales sur leurs parcelles, certaines doivent se contenter de moindres volumes de déjections complétés de poudrette issue des déchets de cuisine et du brûlis des maigres résidus de paille au champ et des déchets de cuisine.

Laccès à la traction attelée et aux différents équipements qui lui sont liés (cultivateur, semoir, souleveuse et charrette) est aussi extrêmement variable. Il détermine les surfaces cultivables par actif et même les cultures qui peuvent être pratiquées, tout particulièrement celles pour lesquelles le semis s'effectue après les premières pluies. Dans la région de Louga, la fenêtre de la saison des pluies est particulièrement réduite. Les semis d'arachide juste après la première pluie doivent impérativement être effectués sous trois à cinq jours maximums, jamais au-delà d'une semaine. Cette opération requiert une journée de travail par hectare en traction asine, mais presque deux fois moins en traction équine. On distingue ainsi :

- les familles qui disposent de la traction équine et de l'ensemble de ses équipements (et d'autant de chevaux, cultivateurs et semoirs attelés que d'actifs masculins en âge de les mener). Elles peuvent cultiver 1,2 ha par actif; 
- les familles disposant seulement d'une traction asine et sans souleveuse. Elles cultivent plutôt 0,6 à 0,8 ha par actif;

- les familles ne disposant pas de la traction attelée. Elles empruntent ponctuellement un équipement ( 0,4 ha par actif) ou travaillent en agriculture manuelle (moins de 0,2 ha par actif). Elles n'ont pas les moyens de produire de l'arachide.

En vigueur depuis 1964, la loi sur le domaine national ne reconnaît ni n'encadre officiellement le faire-valoir indirect. Bien que rarement avoué car illégal, le fermage se rencontre pourtant dans la région. Il peut s'agir par exemple d'agriculteurs âgés, dont les enfants se sont établis en ville pour occuper des emplois plus rémunérateurs, qui cèdent en location une partie de leur terre. Les preneurs peuvent être des familles installées de longue date dans le village, disposant de suffisamment de main-d'œuvre familiale et du niveau d'équipement requis pour cultiver de plus vastes surfaces. Ils peuvent être au contraire parmi les plus pauvres ou arrivés récemment, et au statut très précaire. La loi prévoie qu'une parcelle non cultivée par son propriétaire plus de deux années consécutives doit basculer dans le domaine national. Les propriétaires ne se risquent donc pas à louer une même parcelle plus d'une année ou deux à un même agriculteur. Les preneurs sont d'autant moins enclins à tenter d'accroître la fertilité du sol sur celles-ci.

\section{Inégalités en matière d'autosuffisance et de sécurité alimentaire}

Dans la région de Bambey, la place du mil est aujourd'hui prépondérante dans les assolements et a tendance à croître à mesure que diminue la surface par actif dont disposent les familles. La plupart des familles emblavent en mil 75 à $80 \%$ de leurs terres, tandis que le reste est occupé par une association d'arachide et de niébé strictement dédiée à l'alimentation familiale. On enregistre de profonds écarts de rendements d'un système de production à l'autre. Les familles qui disposent de moins de 0,4 à 0,5 ha par actif sont équipées d'un cultivateur et d'une charrette, mais elles doivent emprunter le semoir. Outre leur animal de bât, ces familles possèdent quelques petits ruminants ou prennent une vache en gardiennage. Elles parviennent à disposer d'un peu de fumure organique et à dégager des rendements en mil de 400 à $450 \mathrm{~kg} / \mathrm{ha}$, suffisants pour assurer à la famille un plat quotidien de mil durant sept à neuf mois de l'année. Le reste des repas dépend de l'achat de riz. Les familles encore plus pauvres, qui possèdent le même équipement mais ne disposent que de 0,3 à 0,4 ha par actif et d'aucun animal reproducteur, enregistrent des rendements plus faibles $(350 \mathrm{~kg} / \mathrm{ha})$ et ne peuvent assurer un plat quotidien de mil que quatre à cinq mois par an. Au contraire, les familles disposant de 0,7 à 0,9 ha par actif, de tout l'équipement de traction attelée, d'un plus grand nombre d'animaux (une vache et une brebis par hectare, ainsi qu'un peu d'embouche) et donc de davantage de fumure organique, peuvent quant à elles s'assurer toute l'année un plat quotidien de mil.

Les familles les plus riches et qui cultivent plus d'un hectare par actif consacrent plutôt 60 à $65 \%$ de leur surface au mil. Le reste est dédié à la culture d'arachide associée au niébé. Ces familles disposent de tout l'équipement de traction attelée et d'une «souleveuse» pour déterrer l'arachide. Elles emploient les femmes des familles les plus pauvres pour la récolte de l'arachide. Ces familles peuvent acheter des engrais et disposent de quantités importantes de fumure organique grâce à leurs 
élevages ovin et bovin. Elles obtiennent ainsi des rendements en mil de près d'une tonne par hectare. Outre une autosuffisance alimentaire garantie toute l'année pour le couscous de mil du soir, elles peuvent dégager des surplus d'arachide et de mil. Certaines d'entre elles regroupent plusieurs foyers nucléaires en famille élargie, disposant chacun d'un équipement complet de traction attelée. La taille du cheptel reconstitué à l'échelle de la famille élargie justifie alors de reprendre la transhumance en saison des pluies.

Dans la région de Louga, la culture du mil revêt une place bien moindre dans les assolements. Surtout, cette place diminue rapidement à mesure qu'augmente celle des revenus extra-agricoles et migratoires dans le revenu total des foyers. Ainsi le mil ne représente que 5 à $10 \%$ des surfaces cultivées par les familles dont l'un des membres est en Europe et où seul un tiers de la main-d'œuvre masculine se consacre à l'agriculture. Cette part grimpe à 20-25\% lorsque 50\% de la maind'œuvre masculine familiale exerce une activité extra-agricole. Elle atteint 30 à $50 \%$ dans les familles nucléaires les plus pauvres, qui n'ont pas ou rarement accès à la traction attelée, ne disposent que de faibles revenus extra-agricoles et privilégient donc l'autoconsommation. À l'inverse, les familles disposant de revenus extra-agricoles élevés peuvent recourir de façon beaucoup plus sûre à des achats alimentaires en se spécialisant plus largement dans la production de légumineuses à graines, notamment le niébé, et en achetant l'essentielle des céréales consommées par la famille (mil et riz).

\section{Un développement inégal des cultures à plus haute valeur ajoutée et des activités de transformation}

Cultivé aujourd'hui par toutes les familles, le bissap a connu un développement rapide depuis une petite dizaine d'années. Gourmande en travail (récolte manuelle des fleurs), cette culture présente l'avantage d'être très rémunératrice et peu coûteuse en intrants. En effet, les semences peuvent facilement être conservées d'une année sur l'autre et l'usage d'engrais n'est pas nécessaire. La variété blanche employée comme condiment dans le couscous de mil ou le plat de riz est généralement réservée à l'alimentation familiale, tandis que la variété rouge, utilisée dans la préparation de boisson, est vendue. Semé en bordure des champs pour ne pas concurrencer les autres cultures, les volumes de bissap produits sont directement liés à la surface par actif dont disposent les familles. Dans la région de Bambey, les familles les plus pauvres commercialisent 20 à $30 \%$ de leur production (deux bassines par an), tandis que les familles les plus riches peuvent vendre jusqu'à $70 \%$ de leur production (30 bassines par an). Du niébé frais, récolté en vert dès 30 jours après le semis, peut également être vendu.

La pastèque est la seule culture maraîchère ne requérant pas d'irrigation qui se développe depuis quelques années dans la région de Bambey. Des acheteurs-revendeurs viennent jusque dans les villages acheter l'intégralité de la récolte sur pied. Pour la plupart des producteurs, le semis est réalisé fin septembre et la récolte a lieu en décembre-janvier, sans requérir de traitement phytosanitaire. Seuls les agriculteurs disposant de suffisamment de trésorerie peuvent se lancer dans la production de pastèque «primeure» (semis en fin juillet et récolte en début octobre). Elle s'avère 
plus rémunératrice, mais au prix de nombreux passages de pesticides à cette saison : un passage d'insecticide par semaine pendant près de trois mois. Les traitements sont alors réalisés à l'aide d'une petite branche d'arbre trempée dans la solution de produit phytosanitaire que l'on secoue au-dessus de la plante. Aujourd'hui, les familles les plus riches et les mieux dotées en terre peuvent consacrer jusqu'à $15 \%$ de leur surface à la culture de la pastèque. Elles se sont équipées d'un pulvérisateur pour assurer une meilleure efficacité des traitements.

Grâce à leurs revenus extra-agricoles, les familles les plus aisées du centre et du nord du bassin arachidier sont nombreuses à avoir investi dans l'achat d'une décortiqueuse de graines d'arachide et d'une presse à cric. Ces équipements leur permettent de valoriser leurs graines d'arachide en allant jusqu'au stade ultime de transformation artisanale - l'huile et les tourteaux (figure 1.10) - tout en amortissant l'investissement par des prestations auprès des autres agriculteurs locaux. Ce commerce et cette transformation artisanale de l'arachide se sont développés en parallèle de la libéralisation progressive de la filière, du recul des rendements en arachide, de l'évolution défavorable des prix relatifs et de la baisse de la valeur ajoutée enregistrée bord champ. Ils compliquent d'autant l'alimentation des huileries industrielles car ils offrent une plus grande souplesse aux producteurs en leur permettant de commercialiser leur arachide quand ils le souhaitent et en dehors de la campagne officielle d'achat des huileries. Dans un contexte de recul des surfaces cultivées en arachide, les usines peinent ainsi à s'approvisionner et à rentabiliser leurs outils industriels dimensionnés sur des volumes bien supérieurs (Gaye, 2010). Ceci explique que cette voie artisanale de transformation, qui détourne des usines une partie des graines d'arachide, est interdite, bien que les raisons officiellement avancées soient d'ordre sanitaire.
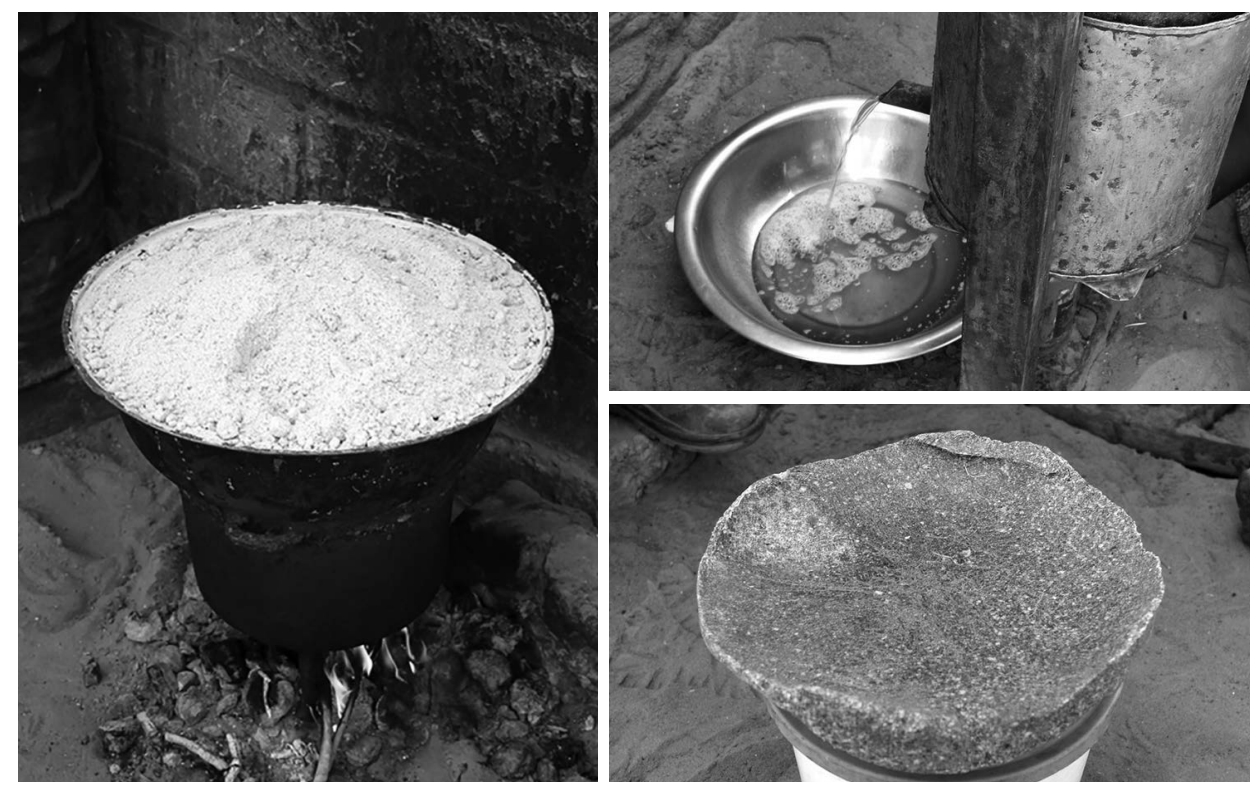

Figure 1.10. Transformation artisanale de l'arachide et produits issus de sa transformation (huile et tourteau) (Le Goff, 2016). 


\section{De profonds écarts de revenus entre ménages agricoles}

\section{Inégalités de revenus agricoles}

Aujourd'hui, les écarts de revenus agricoles enregistrés dans ces régions - présentés ici, autoconsommation comprise - reflètent l'accès inégal des familles aux moyens de production. Cet accès commande en effet à la fois la productivité du travail, la capacité à dégager des surplus vivriers commercialisables et le fait de pouvoir se lancer dans des productions à plus haute valeur ajoutée.

À Bambey, les familles les plus pauvres sont dotées de très faibles surfaces cultivables par actif, sur des terres où elles ne sont parfois que locataires précaires. Elles sont sous-équipées au regard des autres catégories de producteurs. Avec peu ou pas d'animaux d'élevage, elles ne peuvent assurer que de très faibles restitutions de fertilité. Ces familles ne parviennent qu'à assurer le tiers environ de leurs besoins céréaliers et dégagent des revenus par actif extrêmement faibles, inférieurs à 50000 FCFA ( 75 euros). Il peut s'agir de jeunes ménages travaillant en partie à l'extérieur ou de ménages âgés.

Les familles disposant de gammes de surface moyennes (0,4 à 0,6 ha par actif) parviennent à dégager de 75000 à 150000 FCFA (110 à 220 euros) par actif en ayant développé des productions à plus haute valeur ajoutée (pastèque), en complément des cultures vivrières et de quelques têtes de petits ruminants (embouche). Les familles pouvant travailler 0,6 à 0,8 ha par actif et ayant reconstitué leur troupeau ou s'étant lancé plus largement encore dans les productions à haute valeur ajoutée (pastèque et embouche) disposent d'un revenu agricole de 100000 à 200000 FCFA (150 à 300 euros) par actif. Enfin, les catégories de producteurs les mieux dotées en équipement, en capital (trésorerie et cheptel) et en terre (0,8 à 1,1 ha par actif) parviennent à dégager un revenu de 200000 à 300000 FCFA (300 à 450 euros) par actif.

\section{Inégalités renforcées par les migrations de travail dans le nord du bassin arachidier}

Dans la région du nord du bassin arachidier étudiée, les inégalités de revenus agricoles sont tout aussi marquées, d'un facteur un à six. Les foyers les mieux lotis vivent en famille élargie. Il peut s'agir de familles cultivant des surfaces importantes d'arachide (SP 1.1, SP 1.2, SP 1.3 , figure 1.11) grâce à leurs plus vastes surfaces, à leur équipement et à leur cheptel. Il peut s'agir aussi des familles d'éleveurs qui ont pu reconstituer de grands troupeaux transhumants (SP 4). À l'opposé de l'échelle sociale, certains jeunes ménages nucléaires, disposant de peu de terre et de seulement quelques petits ruminants, pratiquent une agriculture manuelle (SP 3.2, figure 1.11). Les écarts de revenus agricoles par actif familial demeurent d'un à trois entre ces agriculteurs précaires et ceux qui disposent de traction attelée, mais d'une moindre trésorerie que les familles les plus aisées (SP 2.1, SP 2.2, SP 2.3, figure 1.11).

Ces écarts de revenu sont amplifiés par les revenus extra-agricoles, mesurés ici après déduction des frais de logement et de transport en ville. Chaque année, les familles dont l'un des membres est expatrié reçoivent quant à elles environ 1000000 FCFA (1500 euros). Les écarts peuvent ainsi grimper d'un facteur un à neuf entre les 
familles dont l'un des membres est en Europe et deux ou trois autres travaillent en ville à temps plein, et les foyers nucléaires tirant leurs revenus extra-agricoles du salariat agricole sur place.

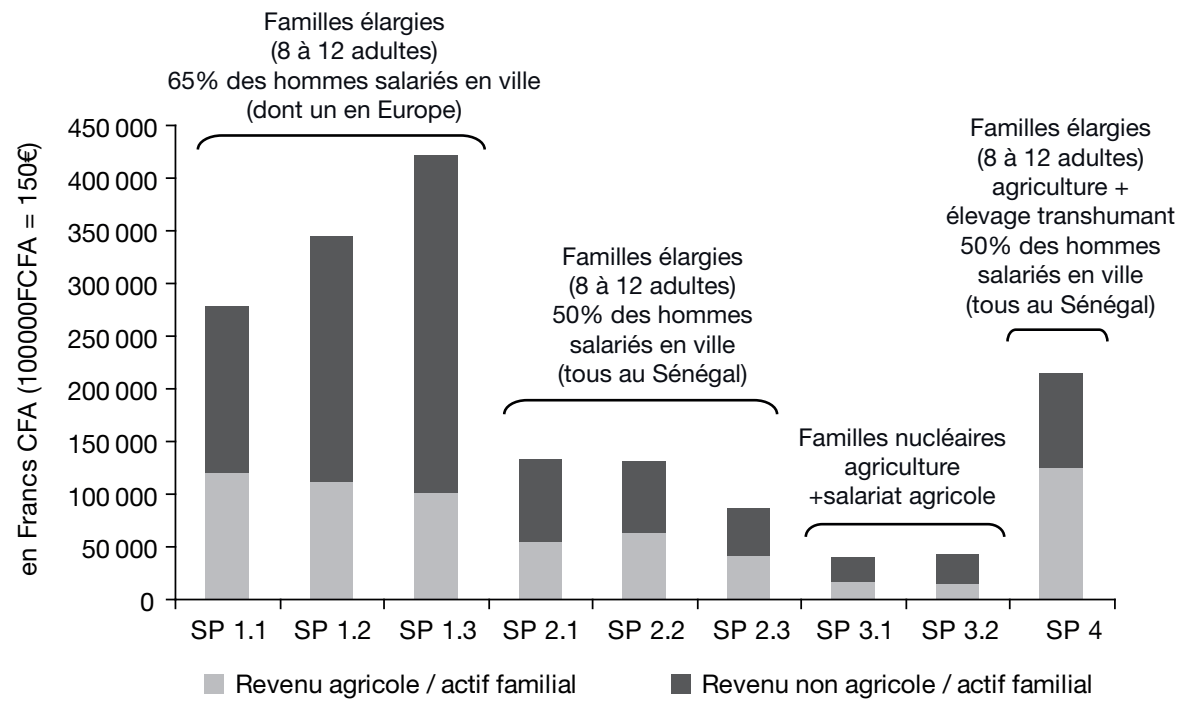

Figure 1.11. Niveau et composition des revenus par actif familial selon les systèmes de production dans la zone rurale au sud de Louga (Le Goff, 2016).

\section{" Le maraîchage, une adaptation par des stratégies d'intensification en capital et en travail ?}

Le sud de la région de Bambey bénéficie d'une nappe semi-profonde d'eau dont la teneur en sels convient à un usage agricole. Des associations de solidarité internationale ont lancé, il y a une trentaine d'années, en réaction aux phénomènes de sécheresse, la mise en place de petits périmètres irrigués villageois (figure 1.12). Des forages d'environ $80 \mathrm{~m}$ de profondeur ont été creusés. Des périmètres irrigués ont été installés sur les parcelles de certains villageois après négociation et rétrocession d'une parcelle au sein du périmètre irrigué. L'attribution des parcelles restantes s'est faite le plus souvent sur la base d'une concertation organisée par les autorités villageoises, en privilégiant les jeunes producteurs jugés en capacité de conduire chacun environ $1200 \mathrm{~m}^{2}$ de cultures maraîchères (surface occupant un actif familial à temps plein).

Outre le financement des infrastructures nécessaires (forage, conduites enterrées et réservoirs individuels équipés d'un compteur d'eau), ces associations ont distribué une palette d'outils à chaque producteur cultivant dans le périmètre irrigué (brouette, râteau, binette, arrosoirs, pelle, plantoir, fourche et corde); ce matériel désormais usé a été remplacé. Elles ont également organisé des stages techniques de trois mois et fourni un fonds de trésorerie faisant office de crédit de campagne. 
La production maraîchère est organisée en deux campagnes. La première a lieu durant la saison des pluies, avec un plan de production identique pour tous les producteurs : $1200 \mathrm{~m}^{2}$ par producteur répartis en 45 planches de chou, 20 planches de tomate, 5 planches de piment et 5 planches d'aubergine. La production est réalisée en groupes, contrôlée par un bureau du groupement de producteurs en charge d'acheter les intrants et de négocier les prix des produits maraîchers avec des intermédiaires (bana-bana) qui achètent la production pour la revendre à Dakar. La seconde campagne porte sur la culture d'oignon. Elle est conduite de façon plus libre par chaque agriculteur, tant au plan technique (d'autant plus dépendante donc de leur capacité à apporter de la fumure organique) qu'en terme de commercialisation. Chaque producteur se charge d'écouler la production de sa seconde campagne auprès des commerçants ou localement.

Soutenus par des ONG durant une dizaine d'années, ces périmètres fonctionnent depuis lors en rythme de croisière sans leur appui. Ils semblent permettre aux agriculteurs d'obtenir des revenus très nettement supérieurs par unité de surface, mais au prix de tâches agricoles exigeantes en travail, d'une grande vigilance en matière de trésorerie et de savoir-faire patiemment élaborés depuis trente ans. Pour l'instant, les agriculteurs des quelques périmètres existants parviennent à trouver des débouchés pour leur production à des prix qui demeurent rémunérateurs. Ces producteurs du bassin arachidier pèsent pourtant peu face aux producteurs de la région des Niayes, largement spécialisés dans le maraîchage. Ils bénéficient en revanche de l'avantage comparatif d'une production maraîchère plus tardive au regard des principaux bassins de production maraîchère du Sénégal.
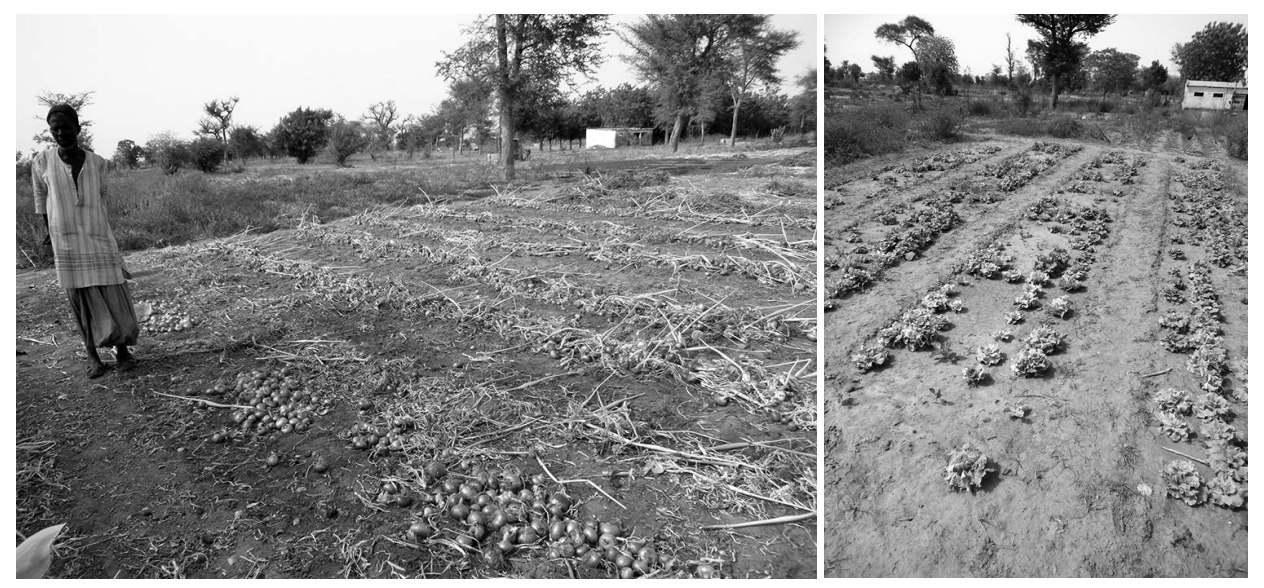

Figure 1.12. Cultures maraîchères en fin de saison sèche en périmètre irrigué collectif dans la région de Bambey (Garambois, 2015).

La région de Louga ne connaît, pour l'instant, qu'un timide développement des cultures maraîchères de contre-saison. Des tentatives ont été menées le long de la conduite du lac de Guiers, puis rapidement interdites. Quelques rares initiatives privées ont vu le jour, ces dernières années, au sein de familles disposant du capital suffisant (parent en Europe) pour investir à plusieurs dans un puits et s'équiper d'une pompe. Ces petits périmètres maraîchers (figure 1.13; photo 1.3, planche 1), 
conduits avec de la main-d'œuvre salariée, sont irrigués grâce à la première nappe, la moins profonde $(35 \mathrm{~m})$ et réservée jusqu'alors à l'alimentation humaine et à l'abreuvement des animaux. Les investissements requis pour puiser dans la nappe située à $80 \mathrm{~m}$ de profondeur restent inaccessibles à des particuliers.

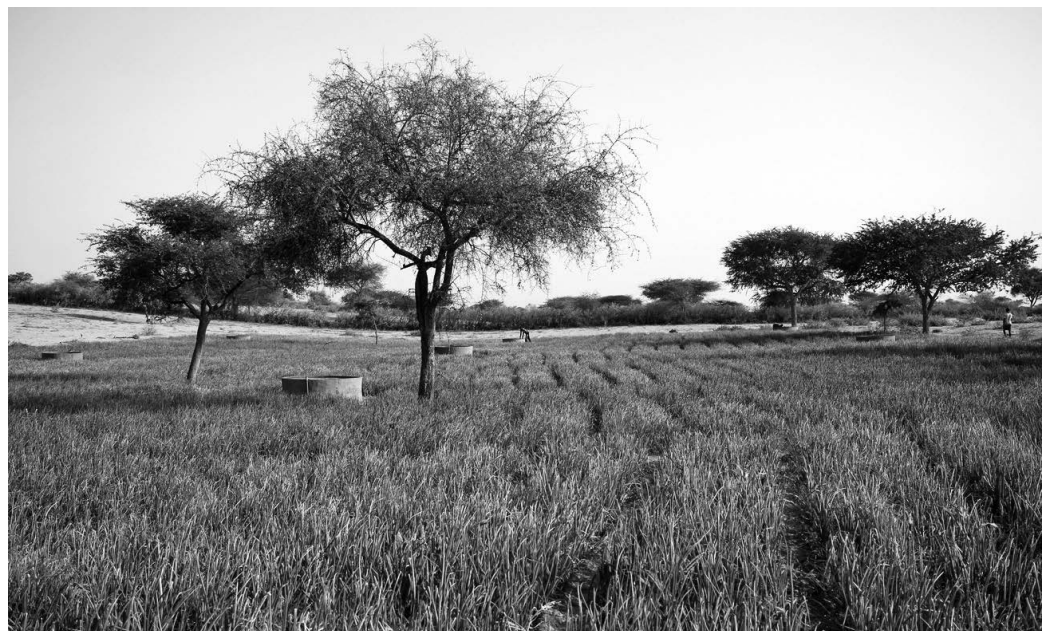

Figure 1.13. Cultures maraîchères de contre-saison en périmètre privé dans le nord du bassin arachidier (Le Goff, 2016).

\section{Conclusion}

Strictement manuelle jusque dans les années 1960, l'agriculture pluviale du nord et du centre du bassin arachidier sahélien a su s'adapter de longue date à des conditions pluviométriques difficiles et aléatoires. Pour cela, elle a su jouer sur le choix d'espèces et de variétés à cycle court, la mobilité des troupeaux, la cueillette, la transformation des produits agricoles et des revenus extra-agricoles (transformation, artisanat et petit négoce). En un demi-siècle, elle a connu de profonds bouleversements : révolution agricole des années 1960, profonde péjoration pluviométrique des années 1970-1990 (chute des rendements et des fourrages disponibles, décapitalisation aiguë) et arrêt quasi total des soutiens publics à l'arachide à partir du début des années 1980. Les ménages ruraux ont pourtant su s'adapter :

- en modifiant en profondeur l'articulation entre cultures et élevages, ainsi que la conduite des troupeaux, et ce grâce à une intensification en travail (collecte des résidus de récolte, animaux en stabulation et transport des déjections sur les parcelles);

- en faisant évoluer leur assolement en faveur du mil et du niébé, mieux adaptés aux aléas pluviométriques et moins gourmands en trésorerie que l'arachide;

- en utilisant plus largement des variétés hâtives, voire très hâtives, développées par la recherche agronomique sénégalaise.

Ces tendances semblent se vérifier à l'échelle du bassin arachidier depuis le milieu des années 2000 (Dieng et al., 2005). Néanmoins, nombre de ménages ruraux ne peuvent assurer que de très faibles restitutions de fertilité à leurs parcelles cultivées 
(matière organique, éléments fertilisants), tandis que la place de Faidherbia albida, véritable "pompe à azote», ne cesse de reculer au sein du parc arboré. Ce phénomène laisse entrevoir l'accentuation de la crise de fertilité de ces systèmes agraires.

À Bambey, les ménages ruraux vivent encore surtout de l'agriculture. Les prémisses de transferts plus intenses de fertilité, qui permettraient à la fois d'accroître les rendements et de favoriser la densification du parc arboré en Faidherbia albida, semblent en germe dans certaines exploitations. Sans être les mieux dotées en foncier et en cheptel, celles-ci disposent néanmoins d'équipements mécanisés. En l'absence de friches pâturables, ces familles s'efforcent de donner une plus grande place au niébé fourrager dans leur assolement afin d'accroître les volumes de fourrages et de fumure animale collectée à l'étable. En concentrant ensuite leur utilisation sur des soles de mil et d'arachide de facto plus réduites, les transferts de fertilité sont amplifiés; ce qui contribue à accroître les rendements, en grains comme en résidus de cultures.

Cette remarquable capacité d'adaptation soulignée par Jouve (1991) à l'échelle de l'ensemble du Sahel et le maintien d'une agriculture pluviale dans ces conditions qui, malgré une certaine reprise de la pluviométrie, demeurent très aléatoires, ne doivent pas faire oublier les profondes inégalités qui demeurent et s'accentuent entre ménages ruraux, ainsi que le rôle central qu'ont joué et que jouent encore les revenus extra-agricoles. Aujourd'hui, certaines familles disposent en effet d'un équipement complet de traction attelée, de surfaces importantes en faire-valoir direct et de fumure organique en relative abondance grâce à une recapitalisation progressive dans le bétail et peuvent acheter des engrais. Elles dégagent ainsi des surplus commercialisables et peuvent, notamment dans le nord, compter sur de conséquents revenus migratoires. Par défaut, les ménages les plus précaires pratiquent, quant à eux, une agriculture manuelle ou sont tributaires de l'emprunt d'équipements attelés. Ils disposent de très faibles surfaces, même en ayant recours au faire-valoir indirect, qui plus est informel et précaire. Ces ménages sont réduits à louer leurs bras au village ou à envoyer leurs enfants en ville en saison sèche pour exercer des activités peu qualifiées et faiblement rémunérées.

Cette inégale faculté d'adaptation et les techniques anti-risques mobilisées de façon spécifique par les ménages ruraux, selon leurs moyens de production, mettent en exergue le rôle central que peuvent jouer les politiques agricoles et foncières pour favoriser l'adaptation de ces agricultures et limiter leur vulnérabilité face au double aléa climatique et des prix.

\section{" Références}

Auserehl K., 1989. Vers une meilleure connaissance de la demande pour les engrais dans le bassin arachidier. Actes du séminaire : La politique agricole au Sénégal, Isra 1 (2), 6-23.

Chalby N., Demarly Y., 1991. L'amélioration des plantes pour l'adaptation aux milieux arides. Paris : John Libbey Eurotext, 228 p.

Chevalier A., 1929. Rapport sur les moyens d'intensifier et d'améliorer la culture de l'arachide au Sénégal. Dakar, 95 p. 
Chevalier A., 1947. Amélioration et extension de la culture des arachides au Sénégal. Revue internationale de botanique appliquée et d'agriculture tropicale (295-296), 173-193.

Clavel D., N'Doye O., 1997. La carte variétale de l'arachide au Sénégal. Agriculture et développement 14, 41-46.

Debien M.T., 1966. Lassociation du Sénégal à la communauté économique européenne et les problèmes de l'arachide. Bulletin de l'Ifan 28 B(3-4), 878-926.

Dieng A., Gueye A., 2005. Revue des politiques agricoles au Sénégal : bilan critique de quarante années de politique céréalière. $25 \mathrm{p}$.

Dieng O., Roucou P., Louvet S., 2008. Variabilité intra-saisonnière des précipitations au Sénégal (1951-1996). Sécheresse 19(2), 87-93.

Freud C., Hanak Freud E., Richard J., Thenevin P., 1997. L'arachide au Sénégal : un moteur en panne. Paris : Khartala-Cirad, $166 \mathrm{p}$.

Gaye M., 2010. L'arachide en crise : baisse des prix, retrait de l'État et concurrence sur le marché des huiles. In : L'agriculture sénégalaise à l'épreuve du marché Duteurtre G., Faye M.D., Dieye P.N. (eds). Paris : Karthala/Isra, 113-136.

Gueye A., Faye M.D., 2010. Mils et sorghos : l'émergence d'un artisanat agro-alimentaire. In : L'agriculture sénégalaise à l'épreuve du marché. Duteurtre G., Faye M.D., Dieye P.N., (eds). Paris : Karthala/Isra, 83-96.

Jouve P., 1991. Sécheresse au Sahel et stratégies paysannes. Sécheresse 2, 61-69.

Le Borgne J., 1988. La pluviométrie au Sénégal et en Gambie. Dakar : Laboratoire de Climatologie, Université Cheikh Anta Diop, 28 p.

Lessault D., Flahaux M.L., 2013. Regards statistiques sur l'histoire de l'émigration internationale au Sénégal. Revue européenne des migrations internationales 29(4), 59-88.

Minvielle J.P., Lailler A., 2005. Les politiques de sécurité alimentaire au Sénégal depuis l'indépendance. Paris : LHarmattan, $187 \mathrm{p}$.

Ministère des Relations extérieures, de la Coopération et du Développement, 1983. Marché mondial des oléagineux : perspectives pour les pays africains producteurs d'arachide. $\mathrm{n}^{\circ} 57,130 \mathrm{p}$.

Ndong J.B., 1995. Lévolution de la pluviométrie au Sénégal et les incidences de la sécheresse récente sur l'environnement. Revue de géographie de Lyon 70(3-4), 193-198.

Ndong J.B., 2003. Caractérisation de la saison des pluies dans le Centre-Ouest du Sénégal. Publications de l'association internationale de climatologie 15, 326-332.

Ndoye O., Ouedraogo I., 1989. Commercialisation des produits agricoles dans le bassin arachidier : situation actuelle et implications pour la politique agricole. Actes du séminaire : la politique agricole au Sénégal. Isra 1(2), 128-140.

Oya C., 2009. Libéralisation de la filière arachide. In : Libéralisation et politique agricole au Sénégal. Dahou T., (éd). Paris : Crepos, Karthala, Enda/Graf/Diapol, 97-125.

Paturel J.E., Servat E., Delattre M.O., 1998. Analyse de séries pluviométriques de longue durée en Afrique de l'Ouest et centrale non sahélienne dans un contexte de variabilité climatique. Journal des sciences hydrogéologiques 43(6), 937-946.

Pélissier P., 1966. Les paysans du Sénégal : les civilisations agraires du Cayor à la Casamance. Paris : Fabrègue, $939 \mathrm{p}$.

Portères R., 1950. L'assolement dans les terres à arachide du Sénégal. Revue internationale de botanique appliquée et d'agriculture tropicale 327-328, 44-50.

Roquet D., 2008. Partir pour mieux durer : la migration comme réponse à la sécheresse au Sénégal? Espaces, populations, sociétés 2008(1), 37-53.

Salack S., Muller B., Gaye A.T., Hourdin F., Cisse N., 2012. Analyse multi-échelles des pauses pluviométriques au Niger et au Sénégal. Sécheresse 23, 3-13.

Sambou P.C., Sagna P., Yade M., 2015. Évolution climatique récente, productions agricoles et stratégies d'adaptation des paysans dans les communautés rurales de Mbediene et de Leona (Département de Louga). Revue de géographie du laboratoire Leïdi 13, 117-131. 
Tandia A.A., Aranyossy J.F., Gaye C.B., 1993. Évaluation de la recharge des nappes phréatiques sous climat semi-aride : exemples du Nord-Sénégal. In : Les ressources en eau au Sahel. AIEA, $201 \mathrm{p}$.

USAID, 2011. Projet «croissance économique» : Analyse de la filière engrais au Sénégal et de son évolution sur la période 2000 à 2010. Rapport de synthèse, 16 p.

Wade M., Duc T.M., Dacosta H., 2005. Les ressources en eau. In : Bilan de la recherche agricole et agroalimentaire au Sénégal. Dakar : Isra/ITA/Cirad, 51-72. 
Chapitre 2

\title{
Agriculture pluviale et petite irrigation : plateaux d'Afrique orientale et australe
}

\author{
Hubert Cochet, Louis Thomazo, Esther Laske \\ et Niel Verhoog
}

Trois sites représentatifs de trois régions d'agriculture essentiellement pluviale, mais où la petite irrigation s'avère aussi essentielle, ont été étudiés dans le cadre de cet ouvrage. Deux d'entre eux sont situés en Zambie : le site de Katongo Kapala dans le district de Mpika (1500 m d'altitude) et celui de Miloso dans le district de Mkushi $(1400 \mathrm{~m})^{1}$. Le troisième site est localisé non loin d'Iringa, sur les hauts plateaux du Sud tanzanien (à $1800 \mathrm{~m}$ d'altitude, figure 2.1).

Dans ces trois régions, la principale culture vivrière et de rente, le maïs, y souffre du raccourcissement de la saison des pluies. Elle est de plus en plus perçue comme une culture «à risque». Les cultures de contre-saison y sont aussi largement pratiquées dans les bas-fonds sur la base de l'humidité résiduelle, dans de petits périmètres irrigués aménagés par les agriculteurs en contrebas des sources ou en détournant les cours d'eau à l'aide de petits barrages élévateurs et de canaux d'amenée.

Létude détaillée de ces trois régions permet donc d'aborder la question de la vulnérabilité de l'agriculture pluviale de cette partie du monde. Elle permet également d'étudier l'irrigation à petite échelle comme voie possible pour développer cette agriculture, la rendre moins sujette aux aléas tout en anticipant l'éventuelle péjoration climatique annoncée sur le long terme.

1. Les sites de Mpika et Miloso ont été identifiés grâce à l'expertise et aux contacts de Clémentine Rémy, consultante travaillant pour le compte de Sofreco dans le cadre du projet IDSP (Irrigation development support project). 


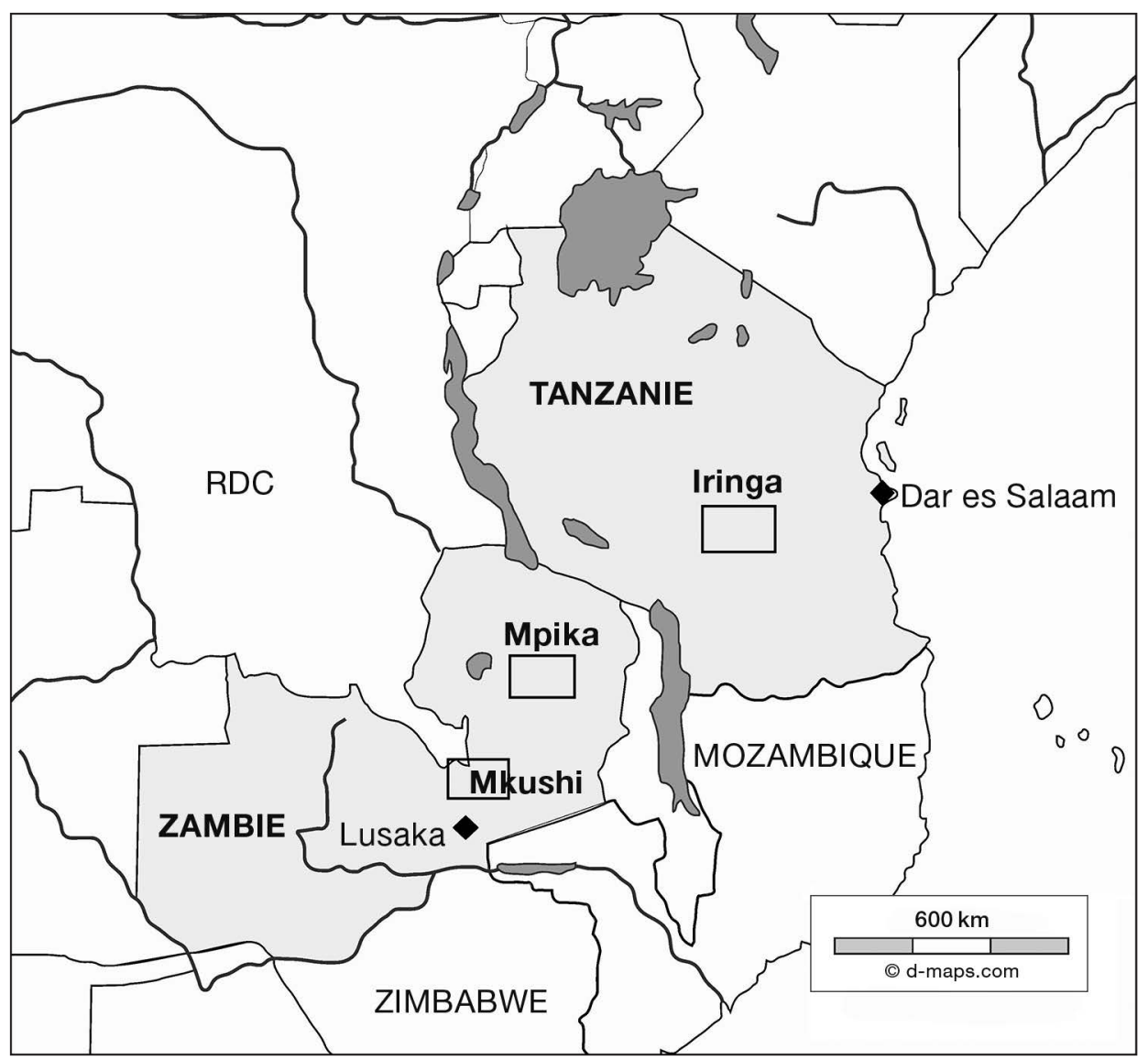

Figure 2.1. Localisation des trois régions étudiées, sur les hauts plateaux tanzaniens et zambiens.

\section{W Changement climatique, l'agriculture pluviale menacée?}

\section{Une saison pluvieuse courte, mais relativement généreuse}

Sur les hauts plateaux du Nord-Zambie, la saison des pluies est relativement généreuse (900 à $1100 \mathrm{~mm}$ de pluie), mais elle ne dure que 4 à 5 mois. Les pluies démarrent normalement courant novembre; s'intensifient de décembre jusqu'en mars (150 à $200 \mathrm{~mm} /$ mois) pour s'interrompre assez brutalement dès les premiers jours d'avril. Les régions de Mkushi et Mpika, dont il sera question dans ce chapitre, ne font donc pas partie de celles qui sont habituellement citées en Zambie comme les plus vulnérables en termes d'exposition aux risques de sécheresse ou d'inondation. Ici, c'est la variabilité interannuelle des pluies qui est très marquée et clairement mentionnée par les producteurs comme principal aléa. À Iringa en Tanzanie, la saison des pluies dure un peu plus longtemps : de mi-novembre à mi-avril. Mais les volumes moyens des précipitations sont bien inférieurs, plutôt de l'ordre de 600-700 mm (figure 2.2). 


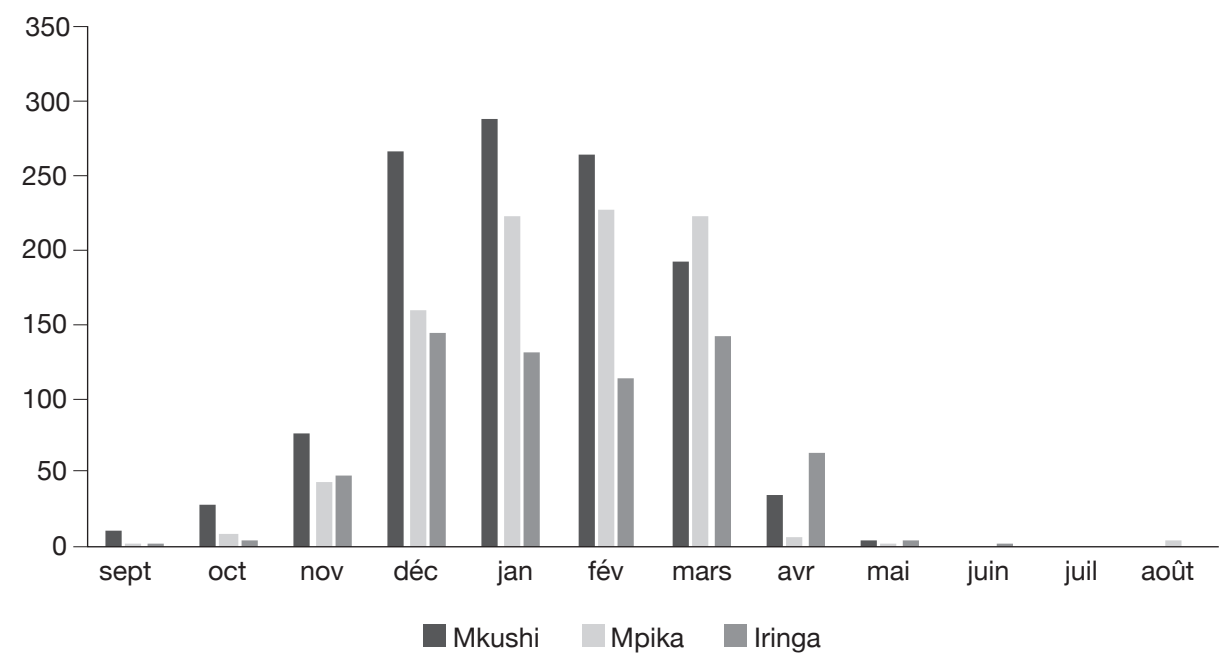

Figure 2.2. Répartition des pluies (en mm) dans les régions de Mkushi et Mpika dans le Nord de la Zambie, et Iringa sur les hauts plateaux du sud-ouest tanzanien.

Ces données ont été compilées à partir des moyennes relevées à la station de Mkushi de 2000 à 2010 (Laske, 2014), à la station météorologique de Mpika de 1993 à 2012 (Thomazo, 2014) et à la station météorologique d'Iringa de 2000 à 2014 (Verhoog, 2015).

\section{Les prévisions du Giec pour l'Afrique australe et orientale}

\section{À l'échelle régionale}

En matière d'évolution des températures, Niang et al. (2014) ne laissent guère de doute sur leur augmentation probable dans le cinquième rapport du Giec, suivant en cela les tendances observées durant les dernières décennies (IPCC, 2014 et 1206).

Concernant l'évolution possible des précipitations, les prévisions sont incertaines et ne permettent pas d'affirmer une tendance très claire. Les baisses de précipitations sont très probables en Afrique australe (comme en Afrique du Nord), de même que les hausses de précipitations envisagées pour certaines régions d'Afrique du Centre et de l'Est (IPCC, 2014, p. 1210). La situation des régions comprises entre la moitié sud de l'Afrique australe et l'Afrique des Grands lacs est beaucoup moins claire; les prévisions diffèrent d'un modèle à l'autre. D'importants changements pourraient survenir sur la répartition saisonnière des pluies, ces dernières pouvant tomber avec davantage d'intensité à certaines périodes du cycle pluvial (IPCC, 2014; p. 1209-1210). En revanche, tous les modèles semblent converger en ce qui concerne l'accroissement probable de la fréquence et de l'intensité des épisodes extrêmes.

\section{En Zambie}

La littérature concernant plus spécifiquement la Zambie a évolué ces dernières années, au fur et à mesure de l'évolution des modèles et des résultats avancés par les experts du Giec. Il y a quelques années, on prévoyait conjointement la hausse des températures et la baisse des précipitations dans l'ensemble du pays (Mulenga 
Bwalya, 2010, p. 6). Les dernières études semblent être plus précises et nuancées. Le consensus se renforce concernant l'accroissement des températures, les modèles ne différant que sur l'ampleur des évolutions attendues (Kanyanga et al., 2013).

En revanche, les quatre modèles de circulation générale (GCM) proposés en matière d'évolution des précipitations livrent des résultats différents, avec notamment un accroissement des précipitations dans certaines régions (Kanyanga et al., 2013). Les prévisions concernant l'augmentation des épisodes extrêmes restent convergentes dans tous les modèles cités (Mulenga Bwalya, 2010, p. 6).

\section{Au sud de la Tanzanie}

Bien que le sud de la Tanzanie fasse partie des régions pour lesquelles une hausse des précipitations est considérée comme probable, les modèles sont aussi loin d'être convergents sur l'ampleur des évolutions attendues (Kilembe et al., 2013). Ainsi, en dépit du fait que tous les modèles suggèrent une augmentation des pluies dans la moitié sud du pays, nous verrons que l'évolution récente des précipitations dans les régions étudiées dans le cadre de ce programme de recherche ne le suggère pas forcément. Par ailleurs, le sud de la Tanzanie est bien l'une des régions qui seraient concernées par un accroissement de la fréquence et de l'intensité des épisodes extrêmes, notamment des fortes pluies. Tous les modèles semblent converger sur ce point.

\section{À propos des prévisions sur l'évolution des rendements du maïs}

Le maïs est la principale céréale cultivée en Zambie et en Tanzanie. En considérant la place considérable du maïs dans la consommation des ménages ${ }^{2}$, les travaux conduits par l'Institut international de recherche sur les politiques alimentaires (Ifpri) sur l'adaptation au changement climatique accordent une place de choix aux modèles de prévision de l'évolution des rendements du maïs. En se basant sur les prévisions d'accroissement des températures et des précipitations dans cette région du monde (supra), Kanyanga et al., (2013) envisagent une amélioration des conditions de production du maïs pluvial en Zambie, et donc un accroissement des rendements, notamment dans les régions où sont situés les deux territoires étudiés dans ce chapitre (Mpika et Mkushi). En ce qui concerne les hauts plateaux d'Iringa, au sud-ouest de la Tanzanie, les arguments avancés par les experts de l'Ifpri vont dans le même sens : un accroissement probable des rendements. Cependant, un modèle sur quatre conduit à une conclusion diamétralement opposée (Kilembe et al., 2013, p. 332). Devant de telles divergences entre les modèles, les auteurs concluent, prudents que :

«Les résultats suggèrent qu'il serait utile de préparer un certain nombre de réponses différentes parmi lesquelles les agriculteurs pourraient choisir le cas échéant. Il est également utile de noter que même s'il peut y avoir des conséquences négatives du changement climatique dans certains endroits, il peut y avoir des résultats positifs dans d'autres endroits [...]» (Kilembe et al., 2013, p. 332).

2. La consommation de maïs blanc représente $28 \%$ des apports énergétiques de la ration en Afrique de l'Est et australe. Cette proportion atteint $50 \%$ en Zambie et au Malawi. Elle est de $25 \%$ en Tanzanie, en hausse dans ce dernier pays (Douillet, 2013). 
Dans la mesure où les politiques publiques mises en place au nom de l'adaptation dans ces deux pays réservent une large place au maïs et à l'élaboration de paquets techniques destinés à en accroître le rendement, une telle prudence par rapport aux résultats de ce type de modèles semble de mise ${ }^{3}$. En effet, ces modèles sont souvent invoqués comme caution scientifique par les responsables politiques. Pourtant, les modèles proposés vont parfois beaucoup plus loin. Par exemple, quand le lien est établi entre le changement climatique et l'évolution des rendements, on cherche à en déduire l'évolution future des prix des denrées en question, puis à modéliser l'impact de ces évolutions sur la pauvreté des ménages. Un lien direct est ainsi établi entre changement climatique et pauvreté, lien présenté comme évident et direct, alors qu'un grand nombre de facteurs jouent aussi un rôle dans cette relation complexe (Leichenko et Silva, 2014; IPCC, 2014).

Lun de ces modèles concerne justement la Tanzanie (Ahmed et al., 2011). Lobjectif annoncé est d'examiner le lien entre le changement climatique, l'évolution du rendement du maïs et la pauvreté par une approche quantitative et modélisatrice, en s'appuyant à la fois sur les tendances passées et les tendances à venir sur un pas de temps de 60 ans (1971-2031). La démonstration repose simultanément sur l'utilisation des différents modèles climatiques disponibles et sur le modèle économique d'équilibre général. Pour les auteurs, la conclusion est limpide : c'est le changement climatique qui, par la baisse des rendements des céréales, explique la pauvreté. Seules les politiques visant à accroître les rendements du maïs — au travers notamment des paquets techniques dont il sera question dans la suite - et dans un contexte de libre concurrence, sont susceptibles de permettre une vertueuse «adaptation» au changement climatique. Nous reviendrons sur ce type de raisonnement en fin d'ouvrage (chapitre 8).

\section{Quel changement climatique à l'échelle locale?}

\section{La région de Mpika, sur les hauts plateaux zambiens}

Dans le cas de la région de Mpika (Northern province), Louis Thomazo (2014) a analysé les données recueillies à la station météorologique de Mpika. Il a ensuite tenté d'en dégager des tendances locales en matière de changement climatique sur les 20 dernières années. En ce qui concerne l'évolution des précipitations, l'impression qui ressort de la lecture de la figure 2.3 est bien la forte variabilité interannuelle. Par ailleurs, le calcul d'une régression linéaire pour cette courbe donne une droite de pente positive (pente de 7,4 mm/an) indiquant une tendance légère à la hausse des précipitations au cours des 20 dernières années ${ }^{4}$.

Par ailleurs, l'étude de la courbe représentant pour chaque année depuis 10 ans de la quantité de pluie tombée le jour le plus pluvieux (figure 2.4) accrédite la thèse d'une hausse nette de l'intensité des événements violents, bien que le recul nécessaire à l'interprétation du phénomène soit encore insuffisant.

3. Dans le dernier rapport du Giec, les experts insistent eux-mêmes, après l'exposé des méthodes et modèles utilisés, sur la prudence à avoir sur les projections.

4. Très proche de zéro $\left(\mathrm{r}^{2}=0,08\right)$, le coefficient de régression relativise ce résultat en marquant très nettement la supériorité de l'effet de l'aléa au cours de ces 20 années sur une tendance quelconque à la hausse ou à la baisse. 


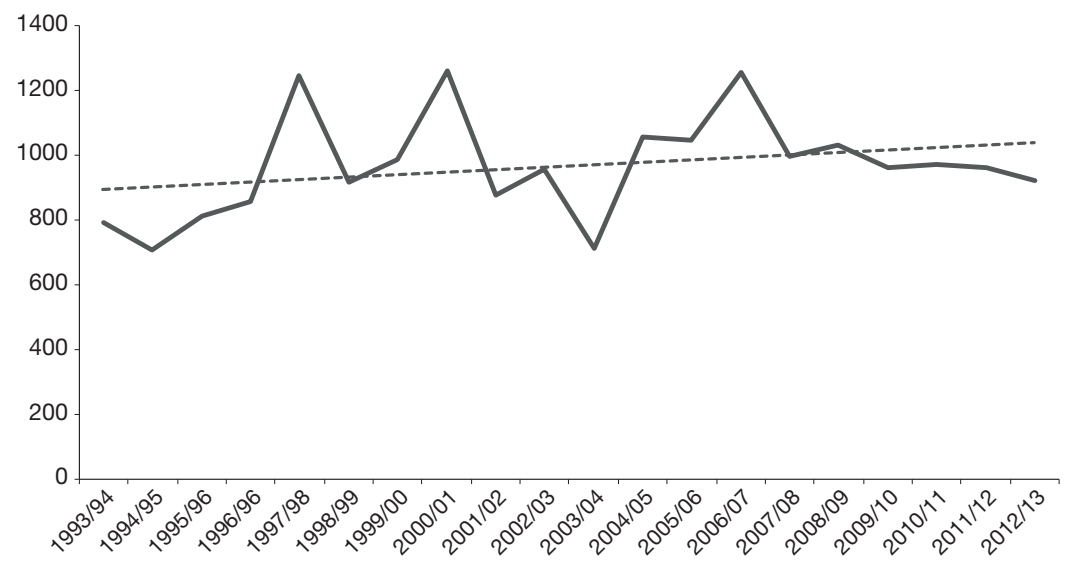

Figure 2.3. Évolution des précipitations annuelles (en mm) à Mpika de 1993 à 2012 (Thomazo, 2014).

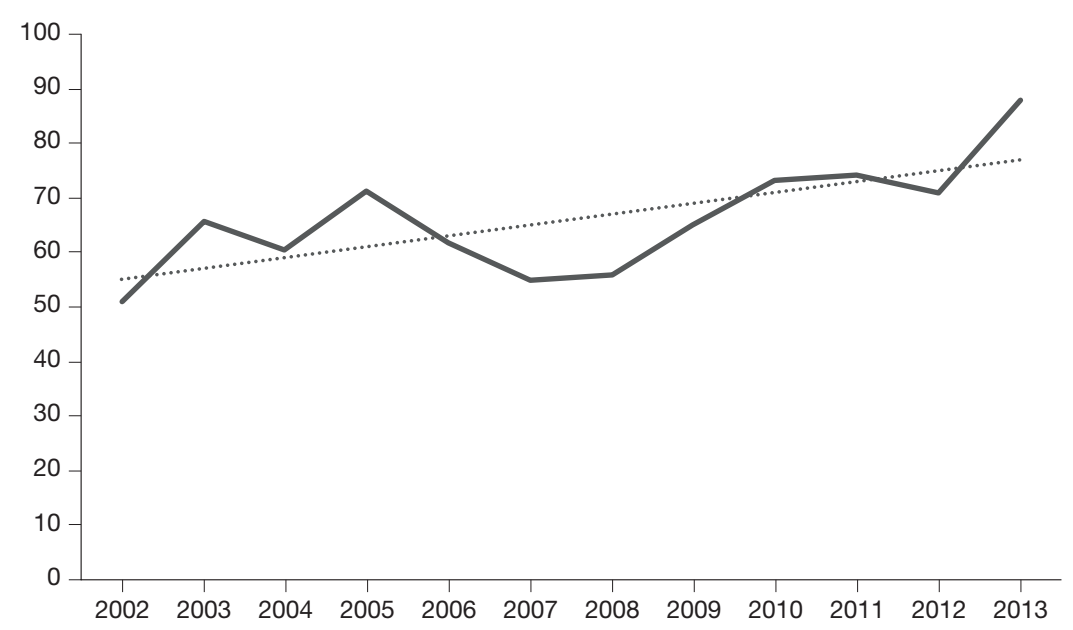

Figure 2.4. Évolution du volume des précipitations (en $\mathrm{mm}$ ) tombées le jour le plus pluvieux de l'année à Mpika de 2002 à 2013 d'après données collectées à la station météorologique de Mpika (Thomazo, 2014).

Concernant les températures, les données collectées à la station météorologique de Mpika permettent de reconstituer l'évolution des températures mois par mois depuis 20 ans. Aucune tendance à la hausse ou à la baisse n'est manifeste quant à la température moyenne annuelle (Thomazo, 2014). Lanalyse des données mensuelles révèle que, parmi les quatre mois les plus chauds de l'année, trois d'entre eux (juillet, septembre et octobre) voient leur température augmenter ces vingt dernières années. La relative stabilité des températures moyennes dissimulerait alors une tendance au refroidissement des mois froids et au réchauffement des mois chauds. Par ailleurs, sachant que la température se rafraîchit toujours en fin de saison sèche grâce à l'arrivée des nuages annonçant les premières pluies, l'augmentation perceptible de température en octobre pourrait indiquer un recul de la 
date d'arrivée des nuages et donc un retard des premières pluies de la saison. Cette tendance est encore non décelable sur les courbes pluviométriques, mais les agriculteurs l'évoquent fréquemment (Thomazo, 2014).

Le constat le plus évident reste l'impact fort des aléas climatiques (volume des précipitations annuelles variant entre 700 et $1250 \mathrm{~mm}$, date variable d'arrivée des premières pluies) sur les pratiques agricoles. Les nombreux entretiens que nous avons réalisés auprès des agriculteurs de cette région le confirment : le caractère aléatoire du climat constitue un frein au développement, bien plus important — plus durement ressenti - que celui entraîné par les bouleversements climatiques à longs termes. À ceci près que ce caractère aléatoire, déjà constaté de longue date, a de fortes chances de s'accroître dans le futur, de même que l'intensité des événements violents déjà constatée.

\section{À Iringa sur les hauts plateaux du sud de la Tanzanie}

Les données disponibles à la station météorologique d'Iringa permettent de comparer le volume annuel des pluies sur la période 1972-2014 (figure 2.5). On ne peut en déduire aucune évolution très marquée, si ce n'est une baisse dans les années 2000 dont la tendance semble s’inverser au début de la décennie suivante.

Lirrégularité des pluies est, ici encore, un fait marquant. Pourtant, il ressort, des entretiens réalisés auprès des agriculteurs les plus âgés, que c'est le raccourcissement de la saison des pluies qui semble avoir été le changement le plus marquant. «Autrefois», disent-ils, les pluies commençaient un peu plus tôt qu'aujourd'hui et se terminaient en juin. La saison des pluies se prolongeait ainsi de presque deux mois (mai et juin) au regard de la situation actuelle. Le maïs pouvait être semé de janvier à mars pour être récolté d'août à septembre, la saison culturale était nettement plus longue. Il est à noter que ce changement aurait eu lieu dès le début des années 1970, même si la période qui suit redevient plus favorable. Il n'est pas perçu

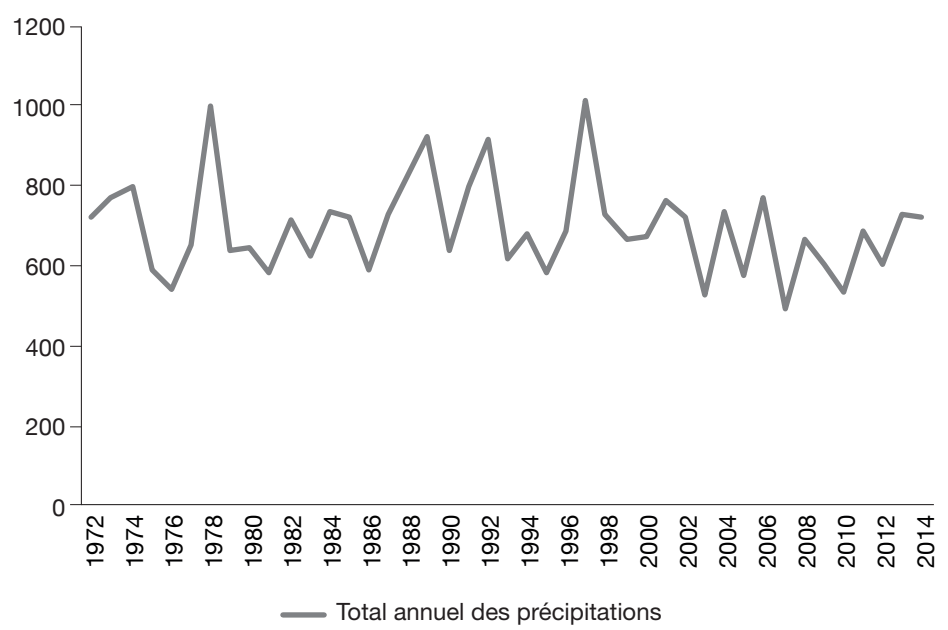

Figure 2.5. Évolution du volume (en mm) des pluies à Iringa de 1972 à 2014 d'après les données recueillies à la station météorologique d'Iringa (Verhoog, 2015). 
par les agriculteurs comme un phénomène récent. Nous verrons que l'interruption plus précoce des pluies renforce considérablement l'intérêt pour les espaces où il est possible de faire deux cycles par an : les bas-fonds et les petits périmètres irrigués.

En Tanzanie, le fait que la période de péjoration climatique (raccourcissement de la saison des pluies) du début des années 1970 corresponde à la période de la politique de Villagisation, porteuse de perturbations majeures, complique bien sûr l'analyse. Dans la mémoire des personnes qui ont vécu cette période, les effets délétères de la péjoration climatique d'une part, du déplacement forcé de l'habitat d'autre part, se conjuguent pour accroître les difficultés des agriculteurs. Dans ce cas, il est bien difficile de faire la part des choses entre les effets du changement climatique d'une part et l'effet des politiques publiques d'autre part. C'est une des difficultés majeures qui surviennent lorsque l'on parle de changement climatique.

\section{" Changements et vulnérabilité, les leçons de l'histoire}

\section{L'enfermement historique de l'agriculture zambienne dans la monoculture de maïs}

Le maïs représente environ la moitié des disponibilités alimentaires de la Zambie qui, avec le Malawi, constitue l'un des deux pays où le maïs occupe la plus grande place dans l'alimentation des populations, devant le Zimbabwe (40\% environ) et l'Afrique du Sud (Douillet, 2013). L'importance du maïs dans les paysages agraires de la Zambie, dans l'alimentation des populations et dans la politique agricole et alimentaire du pays a cristallisé une grande partie des attentions portées au secteur agricole : subvention d'un paquet technique semences améliorées et engrais, constitution de stocks stratégiques et contrôle des exportations. En fait, le caractère dominant de cette culture et la prépondérance d'un mode de culture privilégiant la culture pure et la monoculture sont le fruit de près d'un siècle de développement agricole presque exclusivement consacré à la promotion de ce modèle technique. Il n'est pas douteux que la fragilité de l'agriculture pluviale zambienne et sa vulnérabilité, tant aux aléas climatiques qu'à d'éventuels changements climatiques sur le long terme, soient en partie le résultat de ces choix.

La diffusion de la culture du maïs sur une grande partie du continent africain constitue un exemple saisissant des transformations anciennes et profondes de l'agriculture africaine. Cependant, la diffusion de cette innovation d'un bout à l'autre du continent a emprunté des chemins différents et aboutit aujourd'hui à des situations contrastées.

Lirruption des plantes d'origine américaine (maïs et haricot Phaseolus) dans les systèmes agraires africains commence à la fin $\mathrm{XVI}^{\mathrm{e}}$ siècle lorsque les premières graines en provenance du Nouveau Monde sont semées sur les côtes du Golfe de Guinée et de l'Angola. Seulement deux siècles plus tard, ces plantes sont connues, adoptées et parfois massivement utilisées dans certaines régions, comme dans les collines des Royaumes du Burundi et du Rwanda. Dans ces pays, l'intégration de ces nouvelles cultures dans le calendrier de travail des agriculteurs a contribué à l'émergence d'un nouveau système agraire deux fois plus productif que le précédent, au terme d'une révolution agricole sans précédent (Cochet, 2001). Cette révolution 
agricole est, en tous points, différente de la révolution verte qu'ont connue certains pays du Sud dans la deuxième moitié du $\mathrm{xx}^{\mathrm{e}}$ siècle. En effet, ce nouveau matériel végétal est venu enrichir la panoplie des agriculteurs et a permis de :

- augmenter l'agrobiodiversité;

- généraliser la pratique de la culture associée;

- multiplier les cycles de culture sur la même parcelle;

- favoriser le remplissage progressif du calendrier de travail des agriculteurs;

- accroître de façon décisive la productivité du travail : la quantité de nourriture produite par actif est doublée;

- réduire sensiblement les risques encourus en permettant la multiplication et l'échelonnement des récoltes (Cochet, 2001).

Mais la place prépondérante occupée aujourd'hui par le maïs en Afrique australe en général, et en Zambie en particulier, n'est pas due à ce long processus historique d'adoption du nouveau matériel végétal en provenance du Nouveau Monde. Elle est surtout le fait des politiques agricoles qui, dans ces pays, ont fait de cette culture le pilier du développement agricole promu. Ce soutien public massif ne commence pas avec le gouvernement indépendant de Kenneth Kaunda comme on l'entend parfois. Il constitue déjà un élément central de la politique des gouvernements Blancs des périodes précédentes. Le maïs était déjà présent dans l'agriculture «indigène» en culture associée, au sein d'associations culturales complexes combinant le plus souvent céréales, légumineuses, plantes à racines et tubercules ${ }^{5}$. Cependant, la culture pure du maïs est intensément promue par les autorités de la Rhodésie du Sud, puis par celles de l'éphémère Fédération de la Rhodésie et du Nyassaland (1954-1963) $)^{6}$ au profit exclusif des colons blancs. Tandis que les efforts de sélection génétique, conduits notamment à la station de recherche de Salisbury, travaillent à la satisfaction des besoins des agriculteurs d'origine européenne, l'agriculture «africaine » est du ressort du ministère des Affaires indigènes (Department of native affairs) (McCann, 2005). Sa mission n'est pas de comprendre les pratiques des agriculteurs, mais de les changer au plus vite. C'est pourquoi les recherches en génétique sont réalisées sans prendre en compte les variétés de maïs qui avaient été adoptées, puis sélectionnées par plusieurs générations d'agriculteurs noirs en fonction de leurs besoins et des écosystèmes auxquels ils avaient accès. Les variétés hybrides (de maïs blanc) mises au point sont plutôt adaptées à la production industrielle de la farine de maïs destinée à la confection de la pâte. Cette pâte deviendra l'alimentation de base des travailleurs noirs, notamment dans les mines. Cette production est par ailleurs hautement subventionnée et protégée à partir des années trente par :

- la mise en place d'infrastructures de collecte et de stockage destinées exclusivement à la production des agriculteurs blancs;

- l'établissement de prix différenciés au profit des agriculteurs blancs;

- la mise en place de restriction à la commercialisation et la circulation du maïs produits par les Africains (McCann, 2005, p. 147).

5. Dans le passé, les cultures vivrières ont été surtout basées sur la culture associée, d'abord centrée autour de la culture du sorgho (associé à des haricots du genre Vigna notamment, du voandzou et du pois cajan), puis également autour du maïs depuis l'irruption en Afrique centrale et australe du matériel végétal d'origine américaine (maïs, haricot phaseolus et courges).

6. La Fédération de la Rhodésie et du Nyasaland regroupait la Rhodésie du Sud (futur Zimbabwe), la Rhodésie du Nord (future Zambie) et le Nyasaland (futur Malawi). 
La reprise des travaux d'amélioration génétique après la deuxième guerre mondiale et une politique de soutien efficace conduisent à un accroissement spectaculaire de la production de maïs blanc dans cette région du monde, dès les années cinquante, avant même que la révolution verte ne démarre en Asie. Pour extérioriser leur potentiel de rendement, les variétés hybrides sélectionnées à cette époque (notamment l'hybride SR 52) nécessitent d'être semées le plus tôt possible. Mais cela n'est possible qu'en achevant le travail du sol avant même le début de la saison des pluies - le tracteur est de mise - et en ayant recours à l'usage des engrais de synthèse et au rachat des semences hybrides chaque année : autant d'éléments peu ou pas accessibles aux agriculteurs noirs (McCann, 2005, p. 147).

Lindépendance de la Zambie et l'arrivée au pouvoir de Kenneth Kaunda marquent une rupture majeure. Sans entraver le développement des grandes exploitations tenues par les Blancs, on promeut désormais la production de maïs chez les petits producteurs. Pour surmonter les obstacles qui entravaient l'adoption massive du paquet technique associé à la culture des variétés hybrides de maïs blanc, un programme de subventions des intrants est mis en place, assorti de garanties de prix d'achat aux producteurs. En outre, la recherche génétique locale produit de nouvelles variétés hybrides mieux adaptées aux systèmes de production familiaux : variétés à cycle plus court pouvant être semées plus tardivement, hybrides doubles ou triples pouvant être ressemés une ou deux années supplémentaires sans perte importante de rendement (McCann, 2005, p. 165). La production nationale de maïs augmente alors à vive allure, notamment dans les années quatre-vingt (figure 2.6).

Rupture sociale au bénéfice du plus grand nombre? Sans aucun doute. Mais en dépit d'une meilleure adaptation des variétés proposées aux petits producteurs, le modèle technique promu s'inscrit dans la droite ligne des décennies antérieures : promotion de la culture pure (et du semis en ligne); succession maïs-maïs en continu sur les mêmes parcelles (monoculture) avec apport subventionné de fertilisants de synthèse.

Par ailleurs, le système de vulgarisation mis en place s'appuie sur des agriculteurs modèles, choisis en fonction de leur position sociale dominante et susceptibles croiton, de faciliter la diffusion de l'innovation. Ce modèle pyramidal de vulgarisation est comparable aux modèles mis en place d'un bout à l'autre du continent et encore reproduits aujourd'hui — notamment, hélas, dans le cadre de la vulgarisation de l'agriculture dite «de conservation».

Par exemple, dans la région de Mpika alors dominée par l'agriculture sur abattisbrûlis de forêt claire (type miombo) et la culture de l'éleusine, du manioc, de l'arachide et des haricots, L. Thomazo (2014) explique que les familles «modèles » faisaient défricher, au tracteur pour installer et avec l'aide de travailleurs journaliers, une culture continue de maïs en culture pure avec engrais de synthèse. À partir de 1985, le programme de soutien est élargi à tous les agriculteurs, mais dans la limite de 2 lima (0,5 ha) par producteur.

Ladoption des recommandations techniques concernant la culture du maïs devient le passage obligé pour accéder aux engrais à des prix abordables. Dès lors, les surfaces cultivées en maïs, les rendements obtenus et la production fluctueront au rythme de la capacité des pouvoirs publics à fournir l'engrais et les semences nécessaires en temps opportun, et à acheter la production offerte par les producteurs au prix annoncé. Comme on le sait, la fin des années 1980 marque l'arrêt brutal des 
subventions (crise et ajustement structurel). Il entraîne l'effondrement immédiat de la production (figure 2.6), avec un impact immédiat et dévastateur sur l'ensemble des agriculteurs dont les revenus monétaires sont encore essentiellement basés sur la vente du maïs. Les familles se trouvent face à deux défis : celui de remplacer au moins en partie le maïs dans le régime alimentaire et celui de trouver une autre source de revenu monétaire (Thomazo, 2014).

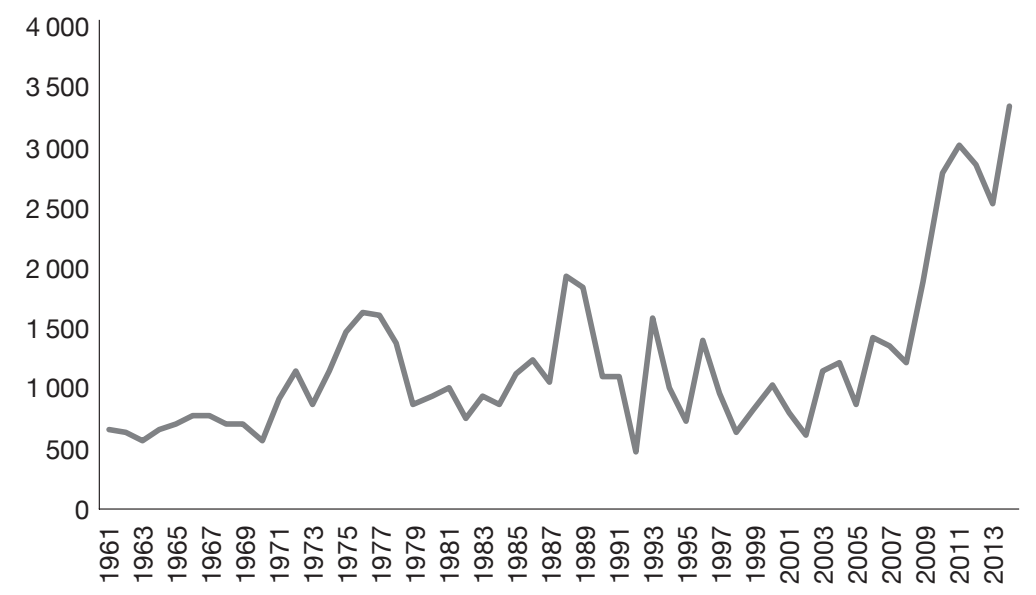

Figure 2.6. Impact de la politique de subvention des intrants sur la production annuelle de maïs en Zambie (x 1000/tonnes) (FAOStat).

Devant les conséquences négatives de l'arrêt des subventions, un système de soutien public est restauré dès le début des années 2000. Il est basé de nouveau sur un programme de subventions aux intrants (Farmer input support program, FISP) et de garanties concernant le prix d'achat aux producteurs et l'écoulement de leur production (Food reserve agency, FRA). Malgré les critiques dont elle fait l'objet, notamment en ce qui concerne son poids dans le budget du ministère de l'Agriculture, cette politique a porté ses fruits, tout comme au Malawi voisin, en matière d'accroissement de la production et de sécurité alimentaire à l'échelle nationale (figure 2.6).

La restauration du système d'aides à la production de maïs, pour efficace qu'elle ait pu être en matière d'augmentation de la production, n'a pas remis en cause les choix du passé, en particulier la préférence pour la culture pure et souvent en continu du maïs. Le maïs était-il la culture la mieux adaptée au climat tropical assez sec des hauts plateaux zambiens? Était-il la culture la mieux adaptée aux sols sableux et à faible réserve utile qui recouvrent une grande partie du pays?

Bien que les agriculteurs aient localement adapté le message technique à leurs conditions particulières et se soient parfois éloignés sensiblement du dogme de la culture pure, il reste que la place prépondérante du maïs dans les systèmes de production les rend sans aucun doute vulnérables aux multiples aléas qui pèsent sur la production. Il s'agit des aléas climatiques bien sûr, mais surtout des aléas liés à la dépendance des agriculteurs vis-à-vis des arrivages d'engrais et de la capacité des pouvoirs publics à en subventionner l'achat, des aléas enfin liés au prix de vente possible du maïs, lui-même lié aux capacités d'achat de la Food reserve agency. 
On constate donc que si l'aléa climatique concerne $a$ priori tous les systèmes de culture et donc tous les systèmes de production, le risque encouru est beaucoup plus important pour le maïs conduit en culture pure tel qu'il a été vulgarisé depuis l'indépendance, et pour les systèmes de production centrés autour de cette production.

\section{Tanzanie, villagisation et paquet technique maïs}

Mise en place à partir de 1974 sous la présidence de Julius Nyerere, la politique de regroupement de l'habitat a eu de graves conséquences dans la région de Kiponzelo, comme dans beaucoup de régions tanzaniennes. Et ce, d'autant plus que cette politique a été mise en place — fâcheux concours de circonstances — en pleine période de péjoration climatique. La villagisation forcée aurait provoqué une chute brutale de la production agricole (évaluée à 30\%), que les autorités politiques ne manquèrent pas d'attribuer à la sécheresse (Raison, 1982). Comme aujourd'hui, bien des difficultés du secteur agricole sont attribuées au changement climatique pour éviter de questionner les modèles agricoles promus. Pour qui s'intéresse aux conséquences croisées du changement climatique et des politiques publiques sur l'agriculture, cette période est donc riche d'enseignements, à condition de remonter, pour la comprendre, à la période qui l'a immédiatement précédé.

\section{Habitat dispersé, accès à des écosystèmes diversifiés et cultures associées : aperçu du système agraire avant la villagisation}

Dans la région de Kiponzelo, non loin d'Iringa, les entretiens historiques conduits par Niel Verhoog ont permis de reconstituer avec précision le type d'exploitations le plus répandu à l'époque. Chaque unité de production occupait une «bande» partant du sommet des reliefs et se terminant dans les dépressions humides situées en contrebas (figure 2.7).

Dispersé, l'habitat était situé sur les bas-versants, souvent en contrebas des sources naissantes et à proximité de la rupture de pente de l'escarpement. Des parcelles de cultures pluviales entouraient l'habitation familiale, parfois délimitées par des lignes de bambous. Le maïs, les différentes variétés de haricots et quelques «légumes» (amarante, radis et tomates) y étaient cultivés en association, de façon de plus en plus dense à mesure que l'on se rapprochait de la maison, source de fertilité (déchets ménagers et cendres du foyer). Outre les rejets domestiques, le renouvellement de la fertilité était assuré par les quelques années de friche (arbustive) qui alternaient avec les années de culture dans les parcelles pluviales, mais aussi par l'épandage de fumure organique provenant de l'élevage (bovins, caprins, porcins et avicoles) largement pratiqué à l'époque.

Dans les massifs forestiers (escarpements, interfluves peu habités), l'éleusine était cultivée sur abattis-brûlis sur des petites surfaces, puis transformée en farine ou en pombe, la bière artisanale. Ce système de culture sur abattis-brûlis (dénommé localement mahonyo) était adapté au faible niveau de biomasse de la forêt claire (type miombo) et à la présence d'une strate herbacée (graminéenne) presque continue, elle aussi caractéristique de la forêt claire ${ }^{7}$.

7. En Afrique australe, ce système de culture sur abattis-brûlis est plus connu sous le nom de Chitemene. Il sera décrit en détail dans les pages qui suivent. 
Dans les dépressions humides qui parsemaient les zones basses, des parcelles de «bas-fonds» étaient cultivées en saison sèche, tandis que d'autres pouvaient être irriguées à partir de sources situées sur les versants. Rappelons également qu'à cette époque, la saison des pluies était nettement plus longue qu'aujourd'hui, les pluies pouvaient se prolonger jusqu'à fin mai, voire début juin.

La taille de ces unités de production variait de 3-4 acres pour les plus modestes, à 10-25 acres pour les plus grandes. Les effectifs du troupeau reflétaient aussi la différenciation socio-économique des exploitations ${ }^{8}$.

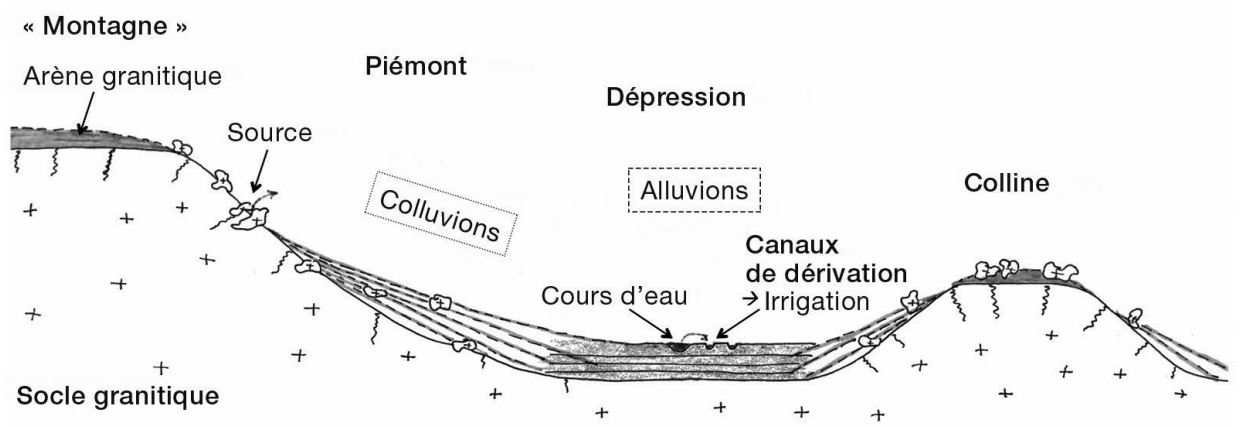

Figure 2.7. Toposéquence caractéristique de la région de Kiponzelo, sur les hauts plateaux du sud de la Tanzanie (Verhoog, 2015).

\section{La villagisation et ses conséquences}

Mise en place entre 1974 et 1976 dans la région Kiponzelo, la villagisation est à l'origine d'une profonde déstabilisation du système agraire. Elle s'est traduite par un accroissement significatif de la vulnérabilité des agriculteurs, notamment vis-à-vis du changement climatique qui intervient à la même époque. Du jour au lendemain, les agriculteurs furent sommés de rejoindre les nouveaux «centres», et d'y construire leur habitation principale en dur. Les maisons des récalcitrants étaient brûlées, et les occupants conduits de force sur les nouveaux espaces mis à leur disposition (entre 0,25 et 0,5 acre). Les conséquences de ce déplacement intempestif de l'habitat ont été les suivantes :

- il fallait désormais se rendre tous les jours à pieds ou en vélo jusqu'aux parcelles cultivées. Cela allongeait le temps de transport quotidien, diminuait d'autant le temps de travail disponible sur place, et donc réduisait la surface agricole exploitable par actif;

- les déplacements et le gardiennage des troupeaux devenaient plus compliqués à cause du rassemblement obligatoire du bétail dans les nouveaux villages. De surcroît, cela augmentait les risques de transmission des parasites et maladies. Les épizooties, le manque de soins et les difficultés accrues de gardiennage entraînèrent une surmortalité du bétail;

8. Jusqu'à l'Indépendance, la région comprenait également quelques grandes plantations coloniales de tabac de plusieurs centaines d'hectares, situées sur les zones planes les plus fertiles et au voisinage des cours d'eau. 
- le renouvellement de la fertilité des sols fut rendu délicat suite à la mort ou la vente du bétail. De plus, il fallait maintenant disposer d'une charrette pour transporter la poudrette du corral jusqu'au champ et donc posséder des bœufs, ce qui devenait de plus en plus difficile;

- les surfaces cultivées et les rendements diminuèrent ainsi de près de $20 \%$.

Ces années-là, le changement climatique en cours imposait un resserrement du calendrier de travail et un élargissement de la période d'étiage fourrager. Mais, la politique de regroupement obligatoire de l'habitat a placé les agriculteurs dans une grande vulnérabilité qui les empêchait de faire face au changement climatique dans des conditions permettant l'adaptation. En outre, l'obligation de cultiver certaines parcelles collectivement dans le cadre des coopératives nouvellement créées contribuera aussi à détourner une partie de la force de travail vers des parcelles au final fort peu productives.

Décidées à la même période que la villagisation, d'autres mesures de la politique agricole auraient pu améliorer le sort des agriculteurs en les aidant à faire face au changement climatique :

- construction, dans chaque village, de bains antiparasites pour les bovins;

- diffusion à crédit de semences et d'engrais aux agriculteurs (via les coopératives);

- garantie d'écoulement de la production de maïs (également via les coopératives);

- démantèlement (après l'Indépendance) des plantations coloniales de tabac avec réaffectation des terres aux agriculteurs.

Mais ces efforts furent anéantis par les effets délétères de la villagisation elle-même.

\section{Du paquet technique vulgarisé par la FAO au programme One acre fund}

Après la campagne nationale du maïs fondée sur les principes de la révolution verte et lancée par la Banque mondiale en 1975, ce fut sous l'égide de la FAO qu'un nouveau paquet technique maïs fut diffusé dans la région à partir de 1985. La FAO proposait plusieurs types de maïs hybrides dans un paquet technique que les agriculteurs pouvaient se procurer en groupe et à crédit. Il comprenait, pour une acre, cinq sacs d'engrais et quatre litres de semences. Le succès de ce paquet technique fut très limité parce que ses promoteurs ne mentionnaient ni les cultures associées traditionnellement au maïs auxquelles il fallait renoncer, ni la récolte précoce désormais interdite du maïs en vert au moment de la soudure, ni le coût des engrais et des semences.

Depuis la mise en place du programme de promotion de la FAO dans les années 1980, la promotion de la culture du maïs n'a pas cessé d'être au cour des politiques agricoles tanzaniennes, notamment dans la région d'Iringa. Aujourd'hui, alors même que les agriculteurs cherchent à diversifier leurs systèmes de production en $\mathrm{y}$ aménageant davantage de parcelles dans les bas-fonds (humidité résiduelle) ou de nouveaux périmètres irrigués, l'essentiel de l'appareil de vulgarisation — même s'il est désormais largement sous-traité de facto aux ONG et investisseurs privés - est toujours focalisé sur l'amélioration du rendement du maïs.

C'est le cas du programme One acre fund (OAF) proposé depuis 2014 par une organisation américaine. Le paquet technique comprend, en culture pluviale et pour une acre : les semences hybrides enrobées, $50 \mathrm{~kg}$ de di-ammonium phosphate 
(DAP 18-46-0) appliqué dans le trou de plantation à l'aide d'une mesurette fournie par le programme, $50 \mathrm{~kg}$ d'engrais KEN (dont la composition serait à préciser) appliqué en deux fois (stade 3 feuilles et floraison) et enfin $10 \mathrm{~kg}$ d'urée.

Les agriculteurs soulignent l'avantage de ce programme en matière d'accès au crédit, aux semences et aux intrants de synthèse de qualité. En outre, le fait de pouvoir rembourser le prêt par étapes successives et sans montant minimum est apprécié des agriculteurs.

Pourtant, bien que le rendement soit au rendez-vous quand les conditions climatiques sont favorables (sept à huit sacs de $100 \mathrm{~kg}$ de grains/acre), le coût de ce paquet technique apparaît prohibitif. En 2015, les semences et les engrais livrés à crédit coûtaient 210000 shillings tanzaniens (TZS). En outre, il fallait acheter l'urée et les pesticides (insecticides), et payer le transport de la récolte du champ à la maison. Le coût total était estimé à $260000 \mathrm{TZS}$, auquel il fallait encore rajouter la prestation de service du tracteur et l'égrenage mécanique. Or, la valeur estimée de la production était à peine supérieure : 320000 TZS dans le meilleur des cas, c'est-à-dire avec un prix élevé de 40000 TZS par sac) $)^{9}$.

Ainsi, en cas de mauvaise récolte, l'exploitant devra trouver l'argent nécessaire ailleurs pour rembourser le prêt, au risque de se voir saisir ses biens mis en garantie. Nous manquons de recul pour évaluer l'impact de ce programme mis en place en 2014 dans la région étudiée. Cependant, des expériences similaires, conduites en Éthiopie depuis une vingtaine d'années (le Sakasawa-Global, 2000), incitent à la prudence. En effet, elles se sont avérées dramatiques pour de très nombreux agriculteurs incapables de rembourser leurs prêts à l'issue d'une année défavorable sur le plan climatique (Planel, 2008; Cochet, 2009).

\section{W La diversité réduit la vulnérabilité des exploitations familiales face aux aléas de la culture pluviale}

En dépit de l'impact des politiques de promotion de la culture «intensive» du maïs, le maïs n'est pas toujours conduit en culture pure, loin de là. Bien que les cultures associées au maïs - le plus souvent le haricot Phaseolus et la courge, la «trilogie américaine» - soient plus discrètes que le maïs lui-même et de ce fait peu visibles dans le paysage - il faut pénétrer dans la parcelle pour les découvrir —, elles n'en sont pas moins assez répandues, notamment dans les petites exploitations familiales.

\section{Au nord de la Zambie (Mpika), le système de culture chitemene et son évolution contemporaine}

La place du maïs dans l'agriculture familiale des hauts plateaux du Nord de la Zambie semble moins hégémonique qu'il n'y paraît. Une large gamme de cultures y est pratiquée, pour la plupart vivrières, les surplus vendus assurant l'essentiel du revenu monétaire. Ici, l'ancien mode d'exploitation du milieu sur abattis-brûlis, adapté au

9. Enquête faite auprès de Fausta le 17/06/2015 par N. Verhoog et H. Cochet. 
miombo (forêt claire à Brachystegia et Julbernadia) est encore largement pratiqué. Les principes de ce système de culture - connu sous le nom de chitemene $^{10}$ méritent d'être rappelés. En effet, les évolutions contemporaines de cette agriculture ne peuvent pas être comprises sans référence claire à ce «point de départ».

\section{Le système de culture chitemene}

Le chitemene est un système de culture sur abattis-brûlis adapté au faible niveau de biomasse de la forêt claire et à la présence d'une strate herbacée (graminéenne) presque continue, elle aussi caractéristique de la forêt claire. Du coup, les deux fonctions agronomiques principales du recrû arboré qui fondent la logique agronomique de la culture sur abattis-brûlis, à savoir la reproduction de la fertilité et la destruction du tapis herbacé (et du stock semencier correspondant), ne peuvent pas être assurées par le simple recrû arboré, fusse-t-il d'assez longue durée. C'est pourquoi les agriculteurs de cette région du monde ont développé une pratique originale, typique de ce milieu et relativement efficace. De la surface de recrû abattue chaque année, seule une petite partie est cultivée. Après l'abattis, on transporte en effet les branches coupées vers le centre de la parcelle abattue pour les amonceler en véritable bûcher, sur un espace bien plus réduit que la parcelle abattue et qui sera le seul effectivement semé. La concentration de la biomasse sur un espace plus réduit permet alors deux choses : concentrer la fertilité — et retrouver ainsi l'efficacité d'un recru arboré beaucoup plus dense - et intensifier le brûlis. L'intensification du brûlis permet la destruction partielle des touffes de graminées de la strate herbacée, destruction complétée par un long travail de sarclage.

Par ailleurs, ce déplacement manuel de biomasse vers le centre de la parcelle modifie aussi la technique d'abattage. Comme les troncs ne pourraient pas être déplacés facilement, on préfère ne pas les couper. On grimpe dans les arbres pour n'émonder que les branches jugées transportables. Il en résulte un paysage singulier et une différenciation très nette dans la dynamique du recrû. Ce recrû s'installera ultérieurement entre le centre de la parcelle effectivement cultivée et la périphérie émondée, mais ni brûlée ni cultivée (photo 2.1, planche 2) :

- au centre, lieu de concentration de la fertilité. Le recrû sera retardé par plusieurs années de culture (au moins trois) et le rabattage annuel des rejets de souche. Les grands arbres, élagués au moment de l'abattis, sont tués par le brûlis particulièrement intense en raison de l'accumulation de biomasse. Leurs troncs secs signalent de loin le cœur cultivé (ou qui l'a été) d'une parcelle de chitemene;

- en périphérie, le recrû est immédiat. Il n'y a ni brûlis ni frein quelconque à l'émergence et au développement immédiat des rejets, la strate herbacée profitant de ce surcroît passager de lumière pour se densifier. Cette auréole est aussi caractérisée par le recrû des grands arbres (seulement émondés) et leur silhouette caractéristique. À y regarder de près, on remarque que de vastes espaces de miombo ne sont aujourd'hui composés que d'arbres ayant connu au moins une phase d'émondage lié au chitemene. Cela témoigne du caractère anciennement généralisé et durable (sous certaines conditions) de cette pratique.

10. Le chitemene a été décrit dans le Nord de la Zambie par plusieurs auteurs, notamment Audrey Richards dès l'époque coloniale (1939), Chidumayo plus récemment (1987). 
Thomazo (2014) a reconstitué avec soin les associations et successions de culture caractéristiques de ce mode d'exploitation du milieu :

- en première année de culture et sans travail du sol préalable, c'est toujours l'éleusine associée au manioc, parfois à la courge et à quelques placettes de maïs;

- succède à cette association une culture d'arachide ou de voandzou, elle-même associée au manioc bouturé l'année précédente et toujours en place;

- le manioc reste seul en place la troisième année, pendant laquelle il sera peu à peu récolté;

- une culture de haricot ou d'arachide peut ensuite venir prolonger cette séquence culturale une, deux ou trois années supplémentaires.

\section{Quand la place vient à manquer}

Le système dénommé chisebe (abattis-brûlis du pauvre) constitue une évolution de la culture sur abattis-brûlis vers des systèmes à friche de plus courte durée, surtout herbacée et à faible niveau de biomasse, semblable à une savane. Il nécessite cette fois-ci de recourir au travail du sol. Il est conduit de la manière suivante : faute de surface disponible en quantité suffisante, le principe de la concentration des branchages sur la partie qui sera cultivée est abandonné. Le produit de l'abattis est rassemblé en petits tas qui, après brûlis, recevront des cultures particulières (pommes de terre, courges, concombres et pastèques), tandis que le reste de la parcelle est labouré à la houe, à plat. Le manioc est bouturé en premier sur l'ensemble du champ. Ensuite, l'éleusine est semée à la volée, également sur l'ensemble de la parcelle. En deuxième année, on retrouve l'association manioc + arachide. Le maïs n'est cultivé qu'à partir de la troisième année, associé à d'autres plantes (haricot ou arachide) en continu pendant 3 ou 4 ans. On peut basculer alors dans un système de culture sur billons, où travail du sol et sarclage constituent dès lors de lourdes tâches.

\section{Paquet technique maïs et aléas climatiques}

Les politiques de promotion de la culture du maïs (supra) incitent les agriculteurs à se lancer dans la culture en continue du maïs qui, outre la disponibilité en engrais, nécessite un lourd travail du sol : une véritable rupture par rapport au système chitemene. Le système de culture chisebe (décrit précédemment) évolue alors, après deux ou trois années de culture associée, vers cette monoculture de maïs. L'histoire des 50 dernières années semble alors se jouer en fonction d'un équilibre changeant entre chitemene (jamais abandonné complètement), chisebe et culture du maïs en continu $^{11}$. Cet équilibre dépend surtout du foncier disponible et de l'accès aux engrais, cet accès variant selon les périodes (supra) et selon les familles. Lorsque les subventions aux engrais furent interrompues notamment à la fin des années 1980, beaucoup d'agriculteurs retournèrent à leur champ de chitemene. En effet, le chitemene faisait office de mode d'exploitation «refuge» et, par-là, anti-risque.

Dans la région étudiée dans le cadre de ce programme de recherche (Katongo Kapala, dans le district de Mpika), Thomazo a analysé en détail l'impact, en terme de rendement, des différents aléas climatiques identifiés (arrivée tardive des premières

11. Culture continue parfois remplacée par les agriculteurs par une rotation maïs et légumineuses (par exemple : haricot / maïs / arachide / maïs). 
pluies, épisode de sécheresse immédiatement après les premières pluies et orage violent) sur les différents systèmes de culture. Il ressort de cette analyse que les rendements des systèmes de culture en association - chitemene, chisebe et association maïs + haricot - sont souvent moins affectés par les incidents climatiques que les systèmes conduits en culture pure. De plus, on remarque que le rendement du maïs pluvial, quel que soit son mode de culture, est très influencé par la date d'arrivée des pluies ou d'éventuels épisodes de sécheresse. La vulnérabilité de l'exploitation s'accroît donc au fur et à mesure que :

- la place du maïs dans l'assolement s'accroît;

- la part faite aux cultures associées diminue.

C'est pourquoi les exploitations agricoles dont la production principale est le maïs en monoculture, subissent de plein fouet la baisse de rendements du maïs lors des années de retard des premières pluies.

Dans la région de Mkushi, beaucoup plus proche de Lusaza et étudiée en détail par Esther Laske (2014), le «tout maïs» résiste aussi à la réalité des faits. À l'exception des grandes entreprises agricoles d'un seul tenant (farm block en place depuis les années cinquante) et sous pivot d'irrigation, le paysage est encore peu artificialisé et largement dominé par la forêt claire à Brachystegia (type miombo) plus ou moins dégradée. Entre des zones de bas-fonds encore très peu cultivées et les lignes de crête des principaux interfluves, les versants en pente douce sont les lieux privilégiés des cultures. On y trouve, dans la partie basse et au voisinage des bas-fonds, une auréole encore boisée où sont installés les hameaux; le sous-bois est soigneusement nettoyé. Puis, au voisinage immédiat des maisons, il y a de petites parcelles de maïs (associé aux courges, haricots et voandzou), quelques billons de patate douce, des manguiers et des touffes de bananiers. En remontant sur le versant, les parcelles deviennent plus grandes, souvent conduites en culture pure : maïs, soja et arachide, plus rarement éleusine ou manioc.

Rencontré le 14 mai 2014 sur l'une de ces parcelles, A. Axani nous explique comment il associe, après un labour en traction attelée, le maïs semé en ligne à la courge et au haricot ${ }^{12}$; ce qui ne l'empêche pas d'utiliser le kit de semences enrobées et engrais distribué dans le cadre du Farmer input support program (FISP).

Enfin, que ce soit dans la région de Mpika au nord-ouest de la Zambie ou dans celle de Mkushi, les agriculteurs complètent leurs dispositifs, lorsqu'ils en ont la possibilité, par de petites parcelles irriguées consacrées aux cultures destinées à la vente ou à l'autoconsommation. C'est ainsi que les familles dégageant les meilleurs revenus et mieux armées face aux aléas de différentes natures auxquels elles sont confrontées, sont toujours celles qui peuvent combiner, sur des espaces différents, l'agriculture pluviale et l'agriculture irriguée.

\section{De l'importance de disposer d'un environnement diversifié, l'exemple de Kiponzelo (Iringa, Tanzanie)}

Bien que globalement tabulaire à petit échelle (l'échelle régionale), le relief de la région d'Iringa est localement assez accentué : escarpement avoisinant les $2000 \mathrm{~m}$ d'altitude à l'ouest, collines intermédiaires et dépressions herbeuses vers

12. Tous les dix pieds, il sème en poquet une graine de maïs, de courge et de haricot dans le même trou. 
1650-1700m. De nombreux cours d'eau et sources provenant des hauteurs ont permis l'aménagement de petits périmètres irrigués. Les écosystèmes accessibles aux agriculteurs sont donc très variés, tant sur la composition des sols que sur l'usage que l'on peut en faire (figure 2.7).

Les différentes unités de paysage sont donc les suivantes :

- l'escarpement ouest. Bien que les sols puissent être propices aux cultures par endroit, c'est la difficulté d'accès à cet espace qui entrave sa mise en culture. De grandes zones de pâturage y dominent alors et permettent aux éleveurs d'y envoyer paître leur troupeau en saison des pluies;

- les versants convexes de l'escarpement ouest. En contrebas de la partie supérieure du versant, en pente forte et encombrée de blocs de granite, une rupture de pente marque la transition vers la partie inférieure du versant. De nombreuses sources apparaissent à cette rupture de pente et desservent de petits périmètres irrigués. Ce fut aussi le lieu privilégié de l'habitat avant la villagisation opérée dans les années 1970; - les bas-versants, dont la pente s'adoucit progressivement (colluvion) en s'approchant des bas-fonds, sont intensément cultivés, principalement en cultures pluviales (maïs associé). De nombreux arbres utiles parsèment le paysage et offrent de l'ombre aux travailleurs, ainsi qu'un apport supplémentaire de fertilité (chute des feuilles, légumineuses). Entre les champs, souvent pour délimiter les propriétés, se tend un maillage de buttes de bambous formant une sorte de bocage. Bambous dont la sève est récoltée pour en faire une boisson alcoolisée très prisée. On y trouve aussi de petits périmètres irrigués par gravité (photo 2.2, planche 2). Les petits canaux aménagés entre les parcelles dans le sens de la pente sont régulièrement barrés de petits seuils élévateurs. Ces seuils permettent à la fois de ralentir l'écoulement de l'eau vers l'aval et de rehausser le niveau de la nappe dans les parcelles par infiltration latérale. Les parcelles sont pour partie cultivées en saison des pluies en culture pure de maïs notamment, mais surtout pendant la saison sèche en maraîchage : choux chinois, radis noirs, pois, haricots, tomates, oignons, poivrons, aubergines, ails, carottes et épinards;

- les zones de bas-fonds humides cultivées en contre-saison, ou avec deux cycles de culture par an, aménagées en planches surélevées. Ces espaces se distinguent nettement des petits périmètres irrigués situés sur les versants. Néanmoins, leur mise en valeur est en bien des points semblable (morphologie, forme et taille des parcelles, cultures et succession de cultures) et un même vocable les désigne : les vignungu. Deux types de champs de bas-fond sont à distinguer. Là où la nappe d'eau ne risque pas de submerger les cultures (plutôt en bordure), on constitue des planches qui peuvent être mises en culture toute l'année. En contrebas, là où la nappe d'eau est plus conséquente, les parcelles en forme de buttes ou "pavés » sont davantage bombées et surélevées. Elles ne seront cultivées qu'en saison sèche (photo 2.2, planche 2). Complémentarité avec les parcelles de piémont, léger décalage des opérations agricoles et cultures spécifiques (maïs épis vendu en vert, par exemple) font de ces parcelles de bas-fond des espaces très prisés;

- les dépressions humides toute l'année. Il s'agit de zones globalement planes dont l'humidité s'accroît de la périphérie vers le centre. Ces zones sont utilisées comme pâturage de saison sèche et de statut souvent collectif;

- enfin, les interfluves, collines à sommets plats et versants convexes à pente très douce, sol sableux sur arène granitique. Ces interfluves sont eux-mêmes à subdiviser 
entre les sommets encore couverts de forêt claire à Brachystegia et Julbernadia (type miombo) fortement dégradée, et les bas-versants cultivés en saison des pluies. Ici aussi, de petits périmètres irrigués ont parfois été aménagés en détournant l'eau d'un ruisseau.

À la lecture de ce paysage étagé et diversifié, on mesure l'importance, pour un agriculteur, d'avoir accès autant que possible à l'ensemble de ces écosystèmes Cet accès multiplie le champ des possibles. Mieux encore, la combinaison de plusieurs cultures et systèmes de culture, dont les exigences en termes de temps de travail ne coïncident pas complètement permet d'accroître la productivité globale du travail - la valeur ajoutée nette produite par travailleur - en saturant la force de travail familiale disponible tout au long de l'année. C'est notamment le cas lorsque les cultures pluviales et les cultures de contre-saison peuvent être conduites conjointement. L'accès à l'irrigation apparaît comme un élément clé de ce processus. En outre, l'irrigation donne aussi accès à des cultures à plus forte valeur ajoutée du fait de leur meilleure valorisation marchande.

\section{" L'accès à la petite irrigation, une clé pour la diversité et pour l'augmentation de la productivité du travail et du revenu}

\section{Dans le district de Mpika, au nord de la Zambie}

La région de Katongo Kapala (district de Mpika) dispose d'assez nombreux canaux d'irrigation (avec prise d'eau simple sur les rivières existantes) aménagés à l'initiative de petits collectifs d'agriculteurs à partir des années soixante. Cependant, tout le monde n'a pas accès à l'irrigation. Un extrait de la typologie présentée par L. Thomazo (2014) pour cette région donne les résultats suivants :

- les familles les moins bien loties sont celles qui n'ont eu accès qu'à de petites parcelles ( $<1 \mathrm{ha}$ ) de savane (un seul écosystème accessible) où ils ont tenté de se spécialiser dans la production de maïs grâce au soutien de l'État. En s'appuyant sur l'assurance que la vente de maïs rapportera quelque argent et n'ayant que très peu de ressources financières autres, elles se concentrent sur la mise en place d'une petite parcelle de culture associée : maïs + haricot ou arachide + citrouille + patate douce, en rotation avec des cultures pures de légumineuses. La valeur ajoutée dégagée par unité de surface est relativement élevée grâce à la culture associée. Mais, le revenu est très faible (l'équivalent de 80 à 100 euros/actif/an) du fait de la trop petite taille des exploitations, et largement inférieur au seuil de pauvreté;

- les familles ayant un accès large à la forêt claire pratiquent encore le chitemene (supra). Les rendements sont bons et assurent en grande partie l'alimentation de la famille en manioc, citrouille, éleusine, arachide et haricot. Une partie de l'éleusine peut être même stockée puis vendue. En complément, ces familles pratiquent des rotations plus courtes dans les parties les moins boisées de leur propriété (le système chisebe). D’une part, elles espèrent ainsi assurer une production minimum de manioc 
pour leur propre alimentation. D'autre part, elles ouvrent ainsi des parcelles où l'on mettra en place, après la récolte du manioc, une rotation haricot $/ \mathrm{maïs} / \mathrm{arachide} / \mathrm{maïs}$ en bénéficiant des subventions de l'État pour le maïs. En outre, la localisation de l'exploitation au cour de la forêt claire facilite le petit élevage (chèvres et volaille), qui y trouve facilement les ressources fourragères nécessaires. Ces exploitations n'ont pas accès à l'irrigation. Mais la combinaison de différentes activités et le fait que les deux systèmes de culture pratiqués ne mobilisent pas la force de travail familiale au même moment permettent à ces familles de dégager un revenu légèrement supérieur au seuil de pauvreté, de l'ordre de 200 à 250 euros/actif et par an;

- dès que les producteurs ont accès à de petites surfaces irrigables et peuvent y mettre en place un jardin à maïs, tomate et autres légumes en complément des autres parcelles cultivées, leur situation s'améliore nettement. C'est le cas des petites exploitations qui dégagent des revenus d'environ 300 euros par actif et par an avec seulement 0,25 ha irrigué en complément des autres parcelles de l'exploitation. C'est aussi le cas des exploitations un peu plus grandes qui, avec 2-3 limas (0,5 à 0,75 ha) de jardin irrigué, dégagent des revenus de 500 à 600 euros/actif/an. Ces revenus peuvent s'accroître si un élevage vient compléter le système de production.

Outre l'impact très positif (quoique limité par les difficultés d'accès au marché) sur les revenus des agriculteurs, l'irrigation permet aussi de mieux résister à d'éventuels épisodes secs pendant la saison des pluies en permettant un arrosage d'appoint.

\section{Dans le district de Mkushi, Zambie}

Avec des canaux de dérivation et l'irrigation gravitaire puis le pompage direct dans la rivière Mkushi, la région de Mkushi a connu un développement important de l'irrigation dans des exploitations de grande taille installées dans les années cinquante au profit des agriculteurs blancs (farm blok), sur la rive droite de la rivière Mkushi. À partir des années 1980, le maraîchage irrigué se développe rapidement dans les petites exploitations familiales de la rive gauche. La tomate, culture de rente, est aujourd'hui dominante dans la région et a contribué largement à l'accroissement du revenu des agriculteurs $^{13}$. Mais les moyens dont disposent les agriculteurs pour mobiliser la ressource en eau et pour irriguer leurs parcelles s'avèrent dérisoires et constituent une limite sévère au développement de l'irrigation. Un extrait de la typologie présentée par E. Laske (2014) pour cette région donne les résultats suivants :

- la majorité des familles de la région $(90 \%)$ ne dispose que d'arrosoirs. Le jardin irrigué est donc de très petite taille $(<0,1$ ha) et installé dans les bas-fonds où l'exhaure de l'eau est possible à l'arrosoir, en creusant un simple trou en bord de parcelle. Le jardin est surtout consacré à la tomate (deux ou trois cycles/an). Ne disposant par ailleurs que d'outils manuels pour le travail du sol, ces agriculteurs ne peuvent cultiver que de petites surfaces en cultures pluviales (1-1,5 ha) : le maïs bien sûr, mais aussi l'éleusine, la patate douce, l'arachide et le haricot en rotation de courte durée. Le revenu dégagé est alors de l'ordre de 300 à 600 euros/actif/an.

13. Lomniprésence de cette culture de rente chez les petits producteurs, l'utilisation intensive de pesticides, la très forte variabilité des prix des intrants et de la tomate, ainsi que la dépendance vis-à-vis du marché posent aujourd'hui question. Ils constituent, pour les agriculteurs, autant d'aléas qui font de la culture de la tomate une activité risquée. 
Ce revenu peut s'accroître si l'agriculteur a accès à la traction attelée en propriété ou en prestation de service. Elle permet d'augmenter la surface cultivée en sec, la surface irriguée restant limitée par le matériel d'irrigation;

- les familles ayant pu aménager sur un petit cours d'eau secondaire un barrage élévateur (+ canal d'amenée) disposent de davantage d'eau. Elles sont alors en mesure d'irriguer une surface plus importante à la raie, de l'ordre de 0,6 à 0,7 ha. Le nombre de cycles de culture peut alors être porté à trois par an, ainsi que pour les tomates et d'autres cultures maraîchères diversifiées. Le revenu agricole atteint des niveaux nettement plus élevés, supérieur à 1000 euros/actif familial/an. Là aussi, c'est la diversité des cultures tant en irrigué qu'en culture pluviale qui est garante de l'accroissement et de la stabilité du revenu;

- un très petit nombre de familles disposent d'une motopompe et peuvent ainsi prélever directement la ressource nécessaire dans la rivière. Il s'agit d'exploitations patronales faisant appel à de nombreux journaliers tout au long de l'année. La surface irriguée atteint alors un à deux hectares. La surface totale cultivée peut atteindre 10 ha, parfois même davantage. La productivité du travail n'y est pas plus élevée que dans les exploitations précédentes, sauf pour l'arrosage. Cependant, le revenu de la famille peut atteindre des niveaux beaucoup plus élevés dans la mesure où les nombreux tâcherons et ouvriers permanents sont rémunérés à un niveau très inférieur à celui de leur productivité.

Enfin, cette région est aussi caractérisée par de très grandes exploitations à salariées, moto-mécanisées et aujourd'hui spécialisées dans les cultures annuelles (blé et soja, par exemple) sous pivot d'irrigation. Elles occupent toute la rive droite de la rivière Mkushi et accaparent la très grande majorité de la ressource en eau disponible. Bien que dégageant de très hauts niveaux de revenu pour leur propriétaire, elles ne créent que peu de valeur ajoutée par unité de surface au regard des exploitations de petite taille de la rive gauche, beaucoup plus intensives en travail.

\section{L’exemple de Kiponzelo, en Tanzanie}

Ici aussi, le facteur limitant la production maraîchère est l'accès aux espaces propices à la culture de contre-saison (bas-fonds, sources de montagne ou cours d'eau). Les parcelles favorables sont stratégiques dans la mesure où leur accès conditionne la possibilité de produire des légumes, et donc d'avoir des cultures à forte valeur ajoutée. Avec l'accès au marché et la possession d'un élevage pourvoyeur de fertilité organique, la petite irrigation apparaît ici essentielle.

Parmi les systèmes de production identifiés et analysés en détail par N. Verhoog (2015), nous retiendrons, à titre illustratif, les catégories qui suivent.

Une première catégorie présente des résultats modestes du fait d'un accès limité aux parcelles cultivables en saison sèche. Ces exploitations combinent ainsi trois types de champs :

- premièrement, le champ autour de l'habitation exclusivement consacré aux cultures vivrières telles que maïs, haricots (nains et grimpants), courges et tournesols, bananiers, manioc, patates douces, amarante. Le peu de fertilité organique disponible (déchets ménagers et déjections de volailles) lui sera dédié, ainsi que parfois un peu d'engrais de synthèse; 
- ensuite, un autre champ de maiis pluvial, plus éloigné de la maison et où la culture associée est également de mise (haricot et courges) au moins sur une partie de la parcelle;

- puis, viennent les parcelles de bas-fonds. Pendant la saison sèche, ces champs sont cultivés avec des haricots en culture pure, des pois, des radis et du chou chinois (arrosage au seau). Ils sont ensuite semés en maïs et haricots avant le redémarrage des pluies, et donc encore arrosés quelques semaines avant que les pluies ne prennent la relève.

Dans ces exploitations, seuls quelques sacs de maïs seront gardés pour l'autoconsommation, le reste du maïs étant vendu directement après la récolte pour abonder une maigre trésorerie. Les mauvaises années, l'agriculteur devra acheter du maïs pour nourrir sa famille pendant la période de soudure (février-mars), la situation pouvant devenir critique en cas de prix élevés. Les exploitants pratiquant ce système sont donc vulnérables face aux changements climatiques. Ils dégagent un très faible revenu : de l'ordre de 120 euros/actif/an, autoconsommation comprise. Ayant accès à très peu de surface cultivable en contre-saison, la plupart de ces producteurs s'emploient alors à l'extérieur (confection de briques, journalier dans une autre exploitation ou petit commerce).

Un deuxième ensemble est constitué d'exploitations un peu plus grandes (3,54,5 acres). Outre le champ proche de la maison, toujours présent et où règnent les cultures vivrières associées, ces exploitations disposent de champs de saison sèche plus vastes. Lapport d'engrais est plus important, celui-ci pouvant être complété par une fertilité organique provenant d'un petit élevage (un porc à l'engraissement, une truie et sa suite). La culture du chou chinois est en grande partie destinée à la vente. Il est semé en pépinière, puis repiqué et fertilisé à la poudrette de parc. En ce qui concerne la culture du maïs, lorsqu'un «soin particulier» lui est accordé (semences certifiées, fertilisation et traitements plus importants, sarclage attentionné), il est possible de récolter les plus gros épis en vert en mars-avril-mai et de les vendre bord champ à des revendeurs. Le revenu agricole reste plus que modeste, de l'ordre de 200 euros/actif/ an. Il peut être complété par une activité extérieure comme la confection de briques.

Un troisième ensemble de familles dispose de quatre à six acres. Ces familles font appel à la traction attelée en prestation de service, cultivent la pomme de terre et le maïs (vendu en épi) et disposent d'un élevage un peu plus conséquent, un élevage porcin notamment. Le labour en traction attelée permet de gagner du temps. Mais les retards au semis sont fréquents car les agriculteurs restent tributaires des propriétaires d'attelages. Aujourd'hui, leurs exploitations sont dépourvues de bétail bovin alors que les parents en avaient souvent avant la villagisation. Ce troisième ensemble de familles cultive aussi bien le maïs dit «local» (variété fermière) que le maïs «hybride» (semences certifiées). Le premier est semé à proximité de la maison, principalement pour l'autoconsommation, le second pour la vente. Un champ d'éleusine est encore installé d'août à mai; l'éleusine est notamment destinée à rentrer dans le procédé de fabrication du pombe, la bière artisanale de maïs. Les résultats économiques sont meilleurs, le revenu agricole familial s'établit autour de 300 euros/actif/an.

Un quatrième ensemble de familles dispose de surfaces un peu plus grandes (5-7,5 acres) et se distingue nettement des précédentes par leur relative spécialisation en maraîchage irrigué de saison sèche et le recours à la force de travail salariée 
(journaliers). Dotés d'une trésorerie conséquente pour acheter les semences et les intrants nécessaires, ces agriculteurs sont surtout préoccupés par la gestion des parasites et des maladies. En permettant d'étaler semis, repiquages et récoltes, l'irrigation favorise une amélioration substantielle du revenu des agriculteurs. La majorité de la valeur ajoutée brute totale $(60 \%)$ provient alors du marâichage. Les résultats économiques sont plus élevés et le revenu par actif familial dépasse les 500 euros/an.

Un cinquième ensemble regroupe les exploitations qui pratiquent également le maraîchage irrigué, mais à plus grande échelle (10-15 acres) et en faisant largement appel aux journaliers. Les exploitations de ce type disposent de larges surfaces à potentiel maraîcher et de plusieurs sources d'eau (bas-fonds, sources et cours d'eau). Cela permet de maximiser le rendement de chaque culture en lui dédiant l'écosystème qui lui est le plus adapté. L'eau peut manquer lorsque les parcelles sont loin de la source d'eau ou à cause d'une baisse du débit ou des difficultés d'arroser. Alors, les pompes mécaniques à pédales (plus rarement les motopompes) permettent de pallier ce manque et de sécuriser le rendement des cultures (photo 2.3, planche 2). Les résultats économiques de ces exploitations sont nettement meilleurs. Le revenu agricole par actif familial atteint l'équivalent de 1000 euros/an, du fait de la production de légumes à forte valeur ajoutée (tomates, oignons et poivrons) et d'une grande quantité d'épis de maïs vendus en vert.

Un sixième cas est constitué d'exploitations plus grandes encore. Tout en pratiquant le maraîchage de contre saison, ces exploitations sont engagées dans une production de maïs pluvial à grande échelle, vendu directement en ville (Iringa), et donc à meilleur prix; ce qui suppose une organisation plus complexe (transport, contacts commerciaux, connaissances et suivi du marché) et la vente de volumes importants (achetés pour partie aux agriculteurs voisins). Des semences améliorées sont utilisées lors de la plantation, ainsi que des apports d'engrais importants. Les surfaces, consacrées exclusivement au maïs étant très vastes, le labour à la charrue est indispensable (bœufs ou tracteur à façon). Laccès au marché extérieur et la possibilité de vendre le maïs à meilleur prix permettent d'obtenir des résultats économiques plus élevés, mais ceux-ci restent modestes : environ 320 euros/actif/an. Notons qu'il existe aussi, dans la région, de plus grandes exploitations qui se consacrent au maïs pluvial. Elles sont parfois dotées d'un tracteur. Leurs revenus sont bien sûr supérieurs, quoique la valeur ajoutée dégagée par unité de surface reste faible et étroitement tributaire des pluies.

Enfin, d'autres exploitations ont réussi à conserver ou à se voir attribuer un cheptel bovin. Grâce à la fertilité organique qu'elles peuvent en retirer, les rendements obtenus et leurs capacités de cultures sont nettement au-dessus des exploitations les plus pauvres.

\section{La gestion sociale de l'eau : les acquis de l'organisation paysanne}

Dans les trois régions étudiées, en Zambie et sur les hauts plateaux du Sud tanzanien, les agriculteurs ont su s'organiser collectivement pour aménager et gérer de petits périmètres irrigués assez efficaces en termes d'accroissement et de sécurisation du revenu. Il en est ainsi, par exemple, du petit périmètre d'Isupilo (photo 2.4, planche 3) vieux d'une quinzaine d'années et regroupant une vingtaine 
d'irrigants. Lirrigation se fait par gravité selon le même système observé ailleurs : l'eau circule dans le sens de la pente entre les planches, avec de petits seuils élévateurs pour en ralentir la circulation et favoriser l'infiltration. Certains agriculteurs ont des tuyaux répartiteurs pour faciliter le changement d'eau de rigole en rigole (photo 2.5, planche 3).

Une véritable gestion sociale de l'eau a été instituée :

- corvée de curage des canaux une fois par an en juin et amendes pour les absents (5000 TZS);

- prises d'eau individuelles en aval du canal;

- eau à volonté, sauf si les irrigants situés en aval en manquent (pas de conflit, pour l'instant...);

- les irrigants qui disposent de parcelles au-dessus du canal, et donc non irrigables par gravité, peuvent cependant puiser sans limitation dans le canal, mais à l'arrosoir.

\section{" Conclusion}

Les résultats économiques obtenus pas les agriculteurs des régions présentées dans ce chapitre sont très faibles - quelques centaines d'euros par actif et par an - à l'image de ceux de la majorité des agriculteurs du continent engagés dans une agriculture surtout pluviale et essentiellement manuelle. Les politiques volontaristes de promotion de la culture du maïs et les efforts faits en matière d'amélioration variétale et de diffusion des engrais ont parfois porté leurs fruits, lorsque les financements permettaient de subventionner efficacement ces intrants et que ces derniers étaient disponibles en temps opportuns. Néanmoins, il est clair que ce n'est pas le « tout maïs» qui a permis d'améliorer durablement la condition des ruraux. Ceux qui arrivent à dégager des revenus meilleurs et plus réguliers, et qui peuvent mettre leur famille à l'abri des aléas de toute nature auxquels ils sont confrontés, sont presque toujours ceux qui mettent en œuvre des systèmes de production diversifiés. Ces agriculteurs misent tout à la fois sur un large éventail d'écosystèmes accessibles, sur la culture associée et sur la petite irrigation. Étant entendu que mettre à profit cette diversité n'est envisageable que pour ceux qui disposent d'un matériel minimum : outils manuels en bon état pour le travail du sol, les sarclages et la récolte, bien sûr; mais aussi petit matériel d'arrosage, traction animale et charrette. Par ailleurs, qu'un accès plus facile à des variétés améliorées, aux engrais de synthèse et aux produits phytosanitaires puissent contribuer significativement à améliorer la situation des agriculteurs et à sécuriser leur revenu n'est pas douteux. À condition que l'usage de ces intrants n'engage pas les agriculteurs dans une simplification excessive des combinaisons culturales mises en place et a fortiori, dans une monoculture porteuse de risques considérables et particulièrement sensible à l'accroissement des aléas de nature climatique, commerciale ou politique.

\section{W Références}

Ahmed S.A., Noah S., Diffenbaugh N.S., Thomas W., Hertel T.W., David B., Lobell D.B., Ramankutty N., Rios A.R., Rowhani P., 2011. Climate volatility and poverty vulnerability in Tanzania. Global environmental change 21, 46-55. 
Chidumayo E.N., 1987. A shifting cultivation land use system under population pressure in Zambia. Agroforestry systems 5, 15-25

Cochet H., 2001. Crises et révolutions agricoles au Burundi. Paris : INAPG/Karthala, 468 p.

Cochet H., 2009. L'agriculture éthiopienne face à l'accroissement du risque. Présenté aux Dialogues franco-éthiopiens «Ethiopie : une société vulnérable au défi du risque climatique et environnemental», Addis-Abeba : Centre français d'études éthiopiennes, 6 mars 2009.

Douillet M., 2013. Maïs en Afrique de l'Est et australe : la sécurité alimentaire régionale liée à l'amélioration du fonctionnement des marchés, Le Déméter, 205-226.

Kanyanga, J., Thomas, T.S., Hachigonta S., Sibanda, L.M., 2013. Zambia. In: East African agriculture and climate change: a comprehensive analysis. Waithaka M., Nelson, Gerald C., Thomas T.S., Kyotalimye M., (eds). Washington: Ifpri, 255-287.

Kilembe C., Thomas T.S., Waithaka M., Kyotalimye M., Tumbo S., 2013. Tanzania. In: East African agriculture and climate change: a comprehensive analysis Waithaka M., Nelson, Gerald C., Thomas T.S., Kyotalimye M. (eds). Washington: Ifpri, 313-345.

IPCC, 2014. Climate change 2014: impacts, adaptation, and vulnerability. Part B: Regional aspects. Contribution of working group ii to the fifth assessment report of the intergovernmental panel on climate change. [Barros V.R., Field C.B., Dokken D.J., Mastrandrea M.D., Mach K.J., Bilir T.E., Chatterjee M., Ebi K.L., Estrada Y.O., Genova R.C., Girma B., Kissel E.S., Levy A.N., MacCracken S., Mastrandrea P.R., White L.L., (eds)]. Cambridge: Cambridge University Press, $688 \mathrm{p}$.

Laske E., 2014. Dualisme agricole le long de la rivière de Mkushi, Province centrale, Zambie. Mémoire de fin d'étude, UFR Agriculture Comparée et Développement Agricole, AgroParisTech/AFD/ $\operatorname{IDSP}(71 \mathrm{p}$.)

Leichenko R., Silva J.A., 2014. Climate Change and Poverty: Vulnerability, Impacts, and Alleviation Strategies. WIREs Clim Change 5, 539-556.

Leménager T., Ehrenstein V., 2016. Des principes agroécologiques à leur mise en pratique. Quels effets environnementaux en Zambie et quels enseignements pour les bailleurs de fonds? Revue Tiers Monde, 226-227, 65-93.

McCann J.C., 2005. Maize and grace. Africa's encounter with a New world crop 1500-2000. Harvard University Press.

Mulenga Bwalya S., 2010. Climate change in Zambia: opportunities for adaptation and mitigation through Africa bio-carbon initiative. Lusaka: Center for international forest research, Southern Africa regional office.

Planel S., 2008. La chute d'un éden éthiopien : le Wolaita, une campagne en recomposition. Paris : IRD ( $\grave{A}$ travers champs), $430 \mathrm{p}$.

Porter J.R., Xie L., Challinor A.J., Cochrane K., Howden S.M., Iqbal M.M., Lobell D.B., Travasso M.I., 2014. Food security and food production systems. In : IPCC, 2014. Climate change 2014: impacts, adaptation, and vulnerability. Part A: Global and sectoral aspects. Contribution of working group II to the Fifth assessment report of the intergovernmental panel on climate change. Cambridge: Cambridge University Press, 485-533.

Raison J.P., 1982. Les erreurs géographiques de l'ujamaa tanzanienne. Paris : Orstom (Tropiques, lieux et liens), 402-420.

Richards A.I., 1939. Land, labor and diet in Northern Rhodesia, an economic study of the Bemba tribe, international african institute. London: Oxford university press, $425 \mathrm{p}$.

Thomazo L., 2014. Diagnostic agraire à Katongo Kapala et dans ses environs, Mpika district, Zambie. Mémoire de fin d'étude, UFR Agriculture comparée et Développement agricole. Paris : AgroParisTech/AFD/IDSP, 119 p.

Verhoog N., 2015. Diagnostic agroéconomique, un système agraire autour de Kiponzelo (Iringa, Tanzanie) : Adaptation au changement climatique. Mémoire de fin d'étude, UFR Agriculture comparée et Développement agricole, AgroParisTech/AFD, 119 p. 


\section{Partie II \\ Riziculture \\ en zone inondable \\ face à l'aléa}





\section{Chapitre 3 \\ Agriculture en zones inondables, aléas de la crue et absence d'aménagement : sud de la Tanzanie \\ Hubert Cochet, Jean-Luc Paul, Céline Tewa et Philippe Le Clerc}

Deux régions ont été identifiées pour étudier le cas des zones inondables à vocation rizicole, mais à faible niveau d'aménagement : la basse vallée du fleuve Rufiji dans le Sud de la Tanzanie et la région d'Ifakara sur le Kilombero, affluent du fleuve Rufiji (figure 3.1). Ces deux petites régions offrent un terrain de choix pour réfléchir aux modalités de prise en compte, par les agriculteurs, des risques liés aux aléas climatiques. Les agriculteurs y sont en effet confrontés à deux types d'aléas, tous liés au climat:

- le volume et la répartition des pluies (date de la première pluie significative, répartition des suivantes);

- le volume et le calendrier de la crue (positionnement et durée) dont dépendent à la fois les surfaces récoltées et l'efficacité de la fertilisation (dépôts par la crue), ainsi que les rendements obtenus.

Ces régions font par ailleurs partie du «corridor» de développement prôné par la Saggot (Southern agricultural growth corridor of Tanzania) et où se côtoient différents modèles agricoles (agriculture familiale et grands projets d'investissement comprenant des aménagements pour la riziculture). 


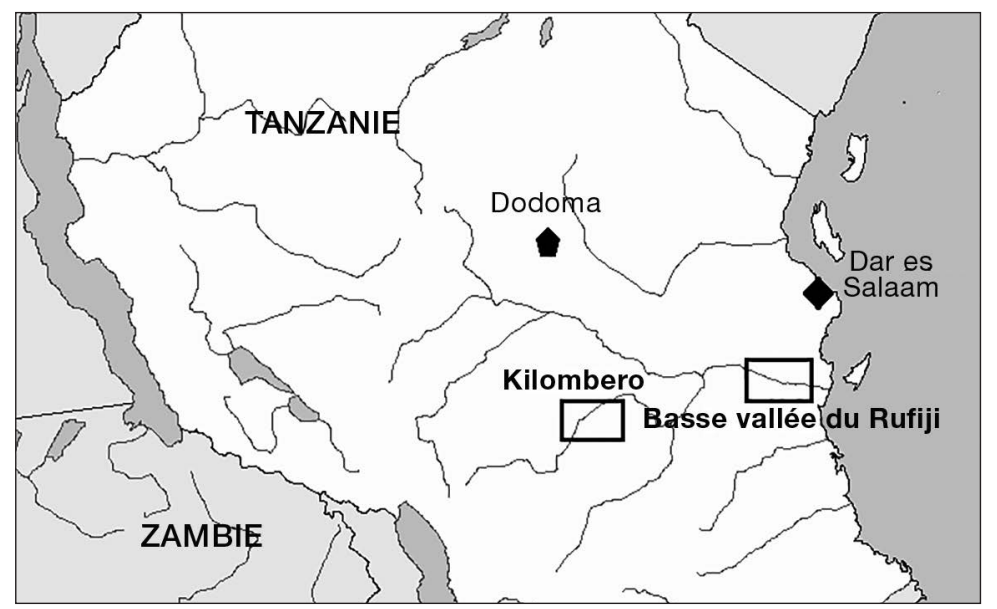

Figure 3.1. Localisation des régions étudiées, dans le bassin du fleuve Rufiji.

\section{" La vallée inondable du fleuve Rufiji et de ses affluents au sud de la Tanzanie}

Les projections concernant l'évolution possible des précipitations en Afrique de l'Est sont relativement incertaines et ne permettent pas d'affirmer une tendance très claire (chapitre 2). Bien que le Sud de la Tanzanie fasse partie des régions pour lesquelles une hausse des précipitations est considérée comme probable (Kilembe et al., 2012), nous verrons que l'évolution récente des précipitations dans les deux régions étudiées incite à la prudence. En effet, une nette diminution des précipitations est bien documentée dans la basse vallée du fleuve Rufiji. Mais en amont, la tendance semble plutôt à la hausse dans la vallée de son affluent le Kilombero (infra). Cette région d'Afrique orientale est aussi l'une de celles qui seraient concernées - tous les modèles convergent sur ce point — par un accroissement de la fréquence et de l'intensité des épisodes extrêmes, notamment des inondations. Les années 1997, 2007 et 2014 témoignent de ces épisodes extrêmes.

\section{Calendrier des pluies, calendrier de la crue et aléas climatiques}

\section{Dans la basse vallée du Rufiji}

La saison des pluies est relativement longue, de fin octobre à mai. Elle est suivie d'une saison sèche de juin à mi-octobre (figure 3.2). En fait, le léger infléchissement des précipitations en février trahit la présence d'une courte période sèche que la moyenne fait disparaître en raison de la variabilité interannuelle de son occurrence. Elle fait la transition entre la saison des petites pluies (mvuli) et la saison des grandes pluies (masika). Ces deux saisons sont mises à profit par les agriculteurs pour réaliser deux cycles de cultures pluviales (maïs principalement, mais aussi le riz inondé par le ruissellement des eaux pluviales). Le calendrier de la crue dépend des précipitations en amont, il est décalé par rapport au calendrier des précipita- 
tions locales. À la fin de la petite saison des pluies, adviennent des «crues flash» qui peuvent avoir un effet destructeur sur les cultures les plus exposées. Cette période est suivie par un bref retour à l'étiage, puis par la crue principale. La crue permet deux saisons de culture : la culture de riz inondé dont l'implantation a été réalisée à la fin de la petite saison des pluies, et la culture de maïs de décrue. Le riz qui sera inondé par la crue est semé en poquet, en semi direct et à sec. Le début de son cycle est donc pluvial, il dépend de la petite saison des pluies. Lors de la crue, la montée des eaux doit donc être compatible avec la rapidité de sa croissance. En l'absence totale de maîtrise de l'eau, la submersion du riz est possible (année 2013-2014 par exemple), tout comme son flétrissement au stade précoce par manque de pluie ou plus tardivement par absence de crue (année 2008-2009 par exemple). En outre, une crue trop faible favorise le développement des adventices et pénalise la reproduction de la fertilité dans les parcelles non-inondées.

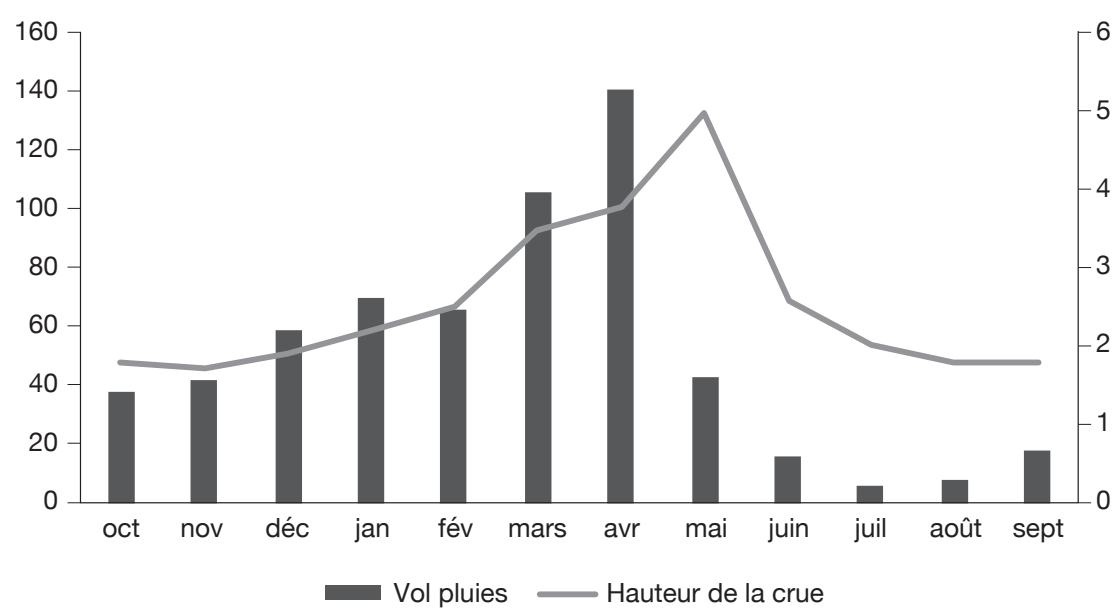

Figure 3.2. Calendrier des pluies et calendrier de la crue (précipitations en mm relevées à la station météorologique d'Utete, moyenne 1999-2012, la courbe de la crue est donnée à titre indicatif).

Par ailleurs, les précipitations sont marquées par une très forte irrégularité interannuelle. Tandis que la moyenne des précipitations s'établit à $867 \mathrm{~mm}$, le volume des pluies a varié entre 500 et $1300 \mathrm{~mm}$ durant ces dernières décennies (figure 3.3). Par ailleurs, la basse vallée ayant fait l'objet de travaux scientifiques approfondis en hydrologie, des données assez précises sont disponibles sur l'évolution des précipitations, avec un recul historique non négligeable. Duvail et al. (2014) mettent ainsi en évidence un net décrochement des précipitations depuis une quinzaine d'années (figure 3.3). L'ampleur est comparable au décrochement connu par l'Afrique de l'Ouest pendant les années 1970 et 1980 (chapitre 1).

Ce net infléchissement des pluies ces 15 dernières années est largement évoqué par les agriculteurs (Tewa, 2014). Depuis 1999, les précipitations n'ont dépassé qu'une seule fois la moyenne établie sur la période précédente $(850 \mathrm{~mm})$. Cette évolution se caractérise par une diminution importante du volume des précipitations et de la durée de la saison des petites pluies. 


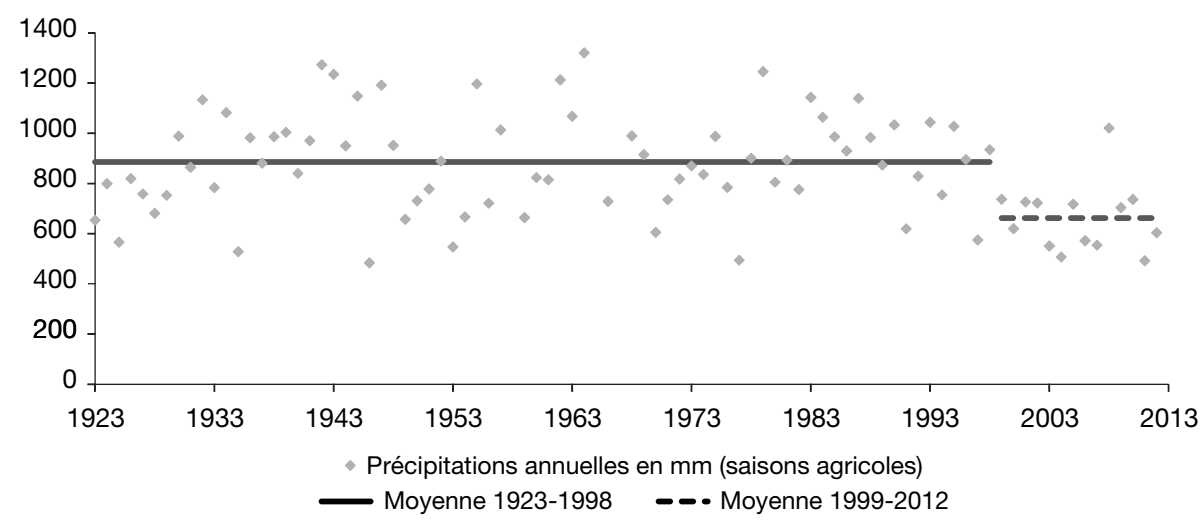

Figure 3.3. Évolution du volume annuel des précipitations (en $\mathrm{mm}$ ) à Utete et moyenne des périodes 1923-1998 et 1999-2012 (Duvail et al., 2014).

En matière d'évolution de la crue sur le temps long, on ne dispose pas d'enregistrements de longue durée. Ce n'est que depuis une quinzaine d'années que Duvail et al. (2014) ont entrepris des mesures précises. Sur la durée des observations, le maximum de hauteur de la crue est compris entre 6,5 et 4,2 m, soit un écart de deux mètres. Cela a des conséquences importantes pour l'agriculture. La crue est perçue par la population comme un bénéfice et non comme un désastre (Duvail et Hamerlynck, 2007). Elle est en effet à la base du renouvellement de la fertilité des parcelles inondées, de la possibilité d'une culture de décrue libérée de l'aléa pluviométrique et du rechargement en eau et en poissons des lacs (principaux lieux de pêche).

Hamerlynck et al. (2010) ont tenté de répondre à la question de la vulnérabilité face à ces aléas. Ils définissent trois situations de crue :

- la situation «idéale », où la crue annuelle est en adéquation avec le système agricole de la région. La probabilité d'une telle situation est de 0,25 , soit une fois tous les quatre ans;

- la situation où la crue annuelle ne recouvre pas la totalité des parcelles de la plaine inondable, situation dont la probabilité serait de 0,60 (soit six ans sur 10); - la situation de crue excessive, cause d'importants dommages pour les cultures pluviales et inondées. Mais c'est l'assurance d'une importante extension des cultures de décrue et d'augmentation des potentialités halieutiques. La probabilité serait de 0,15. La crue de 2014 appartient à cette dernière catégorie. Aucune crue de cette ampleur, aux dires des agriculteurs interrogés, n'avait eu lieu depuis celle de l'année culturale 1997-1998 attribuée au phénomène El Niño.

\section{Dans le Kilombero}

\section{Le volume des pluies : variabilité interannuelle et évolution sur le long terme}

La saison pluvieuse est plus ramassée dans le Kilombero. Les pluies ne débutent vraiment qu'au mois de décembre, plus tard que dans la basse vallée du Rufiji (figure 3.4). En revanche, le volume de pluies y est nettement plus conséquent et s'établit au voisinage de $1500 \mathrm{~mm}$ (moyenne des 20 dernières années). 


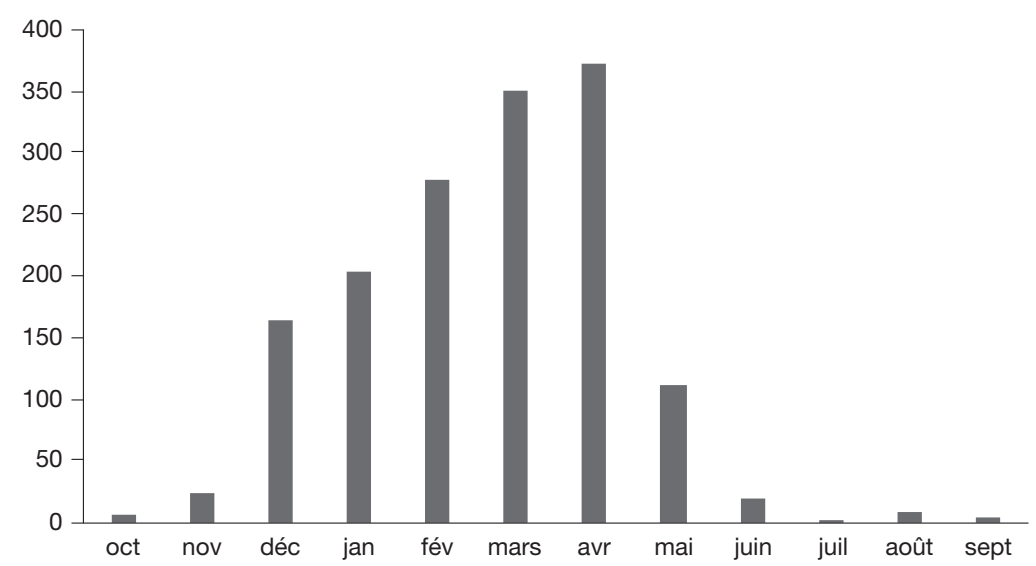

Figure 3.4. Répartition des précipitations (en mm) à Ifakara, vallée du Kilombero, de 2001 à 2010 (station d'expérimentation rizicole d'Ifakara et plantation Illovo à Kidatu).

Une série longue d'enregistrements quotidiens des pluies (1927-1972), que nous avons pu nous procurer dans l'ancienne station expérimentale aujourd'hui fermée de la Mission catholique d'Ifakara ${ }^{1}$, et les séries plus récentes disponibles localement ont permis de reconstituer l'évolution des volumes de précipitations au cours des 90 dernières années (figure 3.5). Elle a révélé d'importants changements et fournit une base de confrontation aux témoignages des personnes enquêtées.

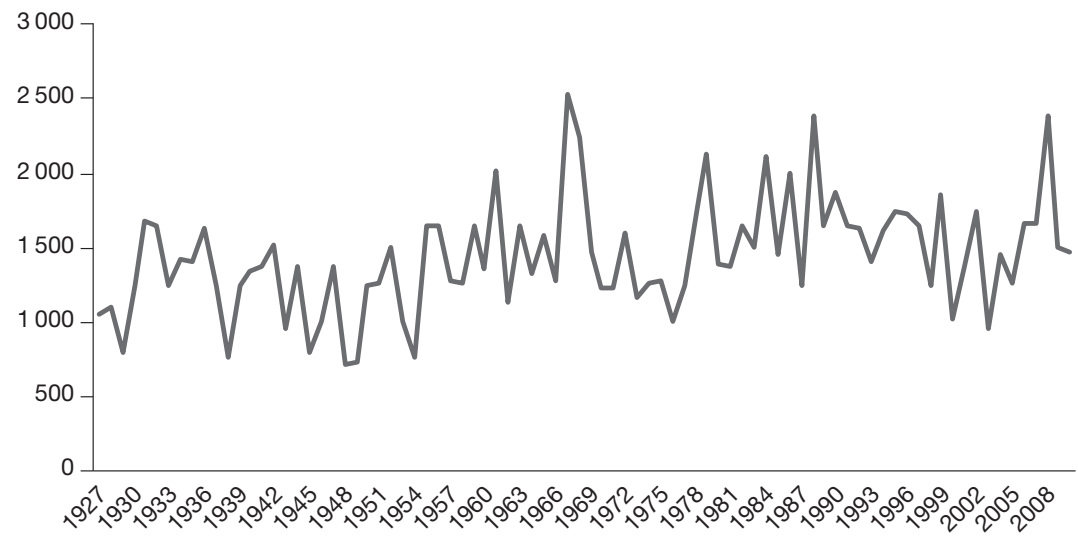

Figure 3.5. Évolution des précipitations (en mm) à Ifakara de 1927 à 2010, vallée du Kilombero.

Données extraites des fiches climatiques journalières de la mission catholique d'Ifakara 1927-1972 et du Centre de recherche sur le riz 1968-2010 (Le Clerc, 2015).

Le graphique révèle une fluctuation interannuelle très élevée des précipitations, oscillant entre 750 et $2500 \mathrm{~mm}$. La très grande irrégularité des pluies est ici une réalité ancienne avec laquelle les populations ont toujours dû composer. Deux

1. L'exploitation de telle série inédite par des non-spécialistes est délicate et mériterait quelques tests préalables. Par exemple, le test de Pettitt pour vérifier l'homogénéité de la série, ainsi que nous l'a conseillé G. Beltrando (communication personnelle du 13/01/2016). 
périodes sèches récentes apparaissent clairement : celle des années 1970 — dont le lien avec la sécheresse enregistrée au même moment dans le Sahel est bien établi et qui est évoquée très fréquemment par les agriculteurs âgés, et celle, plus récente mais semble-t-il aussi marquée, de la fin des années 1990 début des années 2000.

Mais l'information la plus originale que livre ce graphique est qu'il aurait existé par le passé une période sèche bien plus longue et plus marquée que les deux précitées, notamment durant les années 1940-1955. Les actuelles déclarations des agriculteurs, «il y a de moins en moins de pluies aujourd'hui», doivent donc être relativisées. Leurs grands-parents ont manifestement connu bien pire situation. Il serait donc particulièrement intéressant d'identifier les réponses des agriculteurs à ces épisodes beaucoup plus secs, et de comprendre les raisons pour lesquelles une telle adaptation paraît plus difficile aux agriculteurs d'aujourd'hui.

Enfin, la tendance des dernières années serait une augmentation du niveau moyen des pluies, et plus encore à une fréquence accrue des très fortes pluies, comme en 2007, 2014 et 2016.

\section{La répartition saisonnière des pluies : vers un resserrement des précipitations}

Nous avons découpé cette série de longue durée d'enregistrements journaliers en périodes de 20 ans : 1930-1950 (période 1), 1950-1970 (période 2), 1970-1990 (période 3) et 1990-2010 (période 4, figure 3.6). Nous avons ensuite confronté les moyennes bimensuelles sur chacune de ces périodes aux déclarations les plus récurrentes des agriculteurs :

- «Auparavant, on observait une baisse des précipitations en février. Ce n’est plus le cas aujourd'hui»;

- «L'arrivée des pluies est décalée : nos parents semaient en décembre à l'arrivée des premières pluies, aujourd'hui cette étape a plutôt lieu en janvier ».

Pour l'ensemble de la période 1930-1990, février est effectivement une période de légère inflexion des précipitations, tandis que sur la période 1990-2010 les précipitations subissent au contraire, ce mois-là, une hausse brutale (figure 3.6). Concernant l'arrivée des pluies, on constate bien aujourd'hui (période 1990-2010) un net retard de l'arrivée des pluies en comparaison des 40 années précédentes (1950-1990). Cette situation caractérise aussi la période 1930-1950, avec cependant des précipitations annuelles qui étaient sensiblement inférieures à celles d'aujourd'hui. La perception par les agriculteurs d'un retard de la saison des pluies, de son resserrement consécutif et de l'augmentation des précipitations de février correspond donc bien à une réalité.

\section{Davantage de crues de grande ampleur}

Le calendrier de la crue est légèrement décalé par rapport au pic de précipitations. Le maximum est en général atteint en fin avril-début mai avec un niveau des eaux de 4 à $5 \mathrm{~m}$ au-dessus de l'étiage, voire plus d'un mètre supplémentaire les années de très fortes précipitations. Compte tenu de la topographie très plane de la vallée et en l'absence d'aménagement, les variations interannuelles de la surface inondée et de la hauteur de la lame d'eau sont donc importantes. La crue est un aléa que les agriculteurs doivent gérer à l'échelle de chacune de leurs parcelles. 


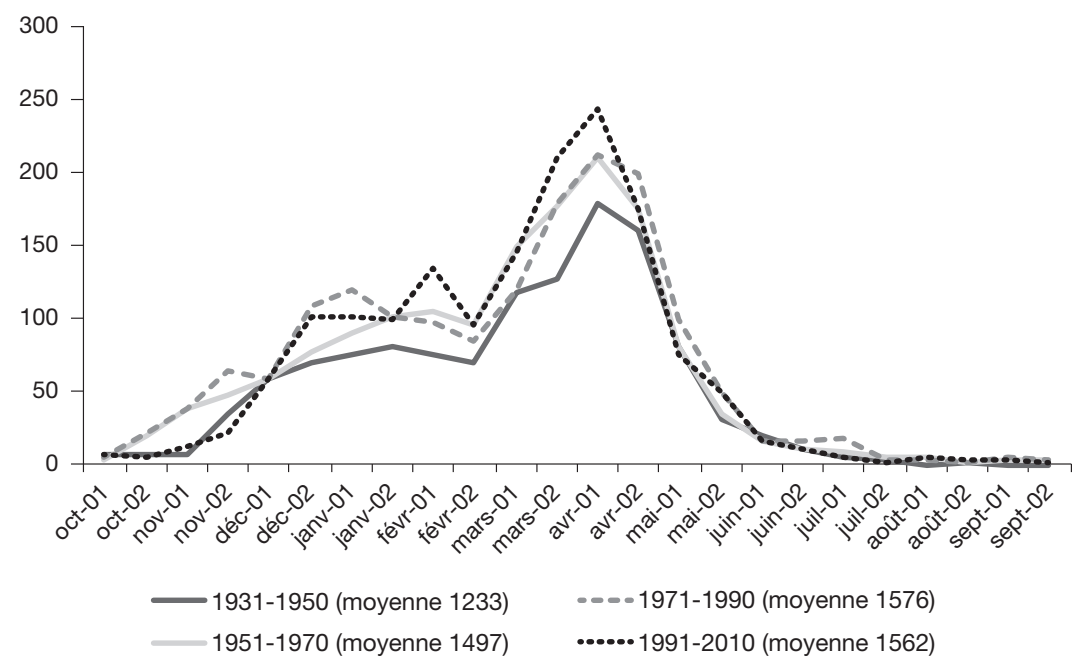

Figure 3.6. Évolution des volumes bimensuels de pluie (1930-2010) par période de 20 ans (en $\mathrm{mm}$ ).

Données issues des fiches climatiques de la mission catholique d'Ifakara et du centre de recherche Katrin (Le Clerc, 2015).

Au contraire de la basse vallée du Rufiji (supra), les informations détaillées sur le calendrier de la crue du Kilombero et de ses affluents sont trop rares ou trop lacunaires pour être réellement exploitables. Il reste les témoignages des personnes âgées résidentes des zones inondables depuis les années 1940, selon lesquelles aucune crue comparable à celles de 1997 et 2014 (toutes les deux associées par les climatologues au phénomène El Niño) ne serait advenue auparavant (Le Clerc, 2015). Plus généralement, nombreux sont les agriculteurs à déclarer qu' «on observe de fortes inondations plus fréquemment aujourd'hui».

\section{Hétérogénéité du milieu}

Tant dans la basse vallée du Rufiji que dans celle du Kilombero, la dynamique fluviale a créé un milieu fort complexe qu'aucun aménagement ne vient homogénéiser. Nous verrons que les performances technico-économiques relatives de ces deux systèmes agraires, et notamment les revenus dégagés par les familles qui y habitent, reposent sur l'exploitation savante de ce milieu complexe et peu artificialisé.

\section{Dans la basse vallée du Rufiji}

Cette vallée a été modelée par les crues du fleuve Rufiji depuis des milliers d'années. La vallée actuelle et sa plaine d'inondation sont bordées au nord et au sud par des terrasses alluviales anciennes dont les talus dominent la plaine inondable d'une ou deux dizaines de mètres (figure 3.7).

On peut identifier les différentes unités de paysage suivantes :

- l'unité la plus vaste et la moins prisée par les agriculteurs est constituée de terrasses alluviales anciennes, notamment celle de la rive gauche (au nord, sur la 


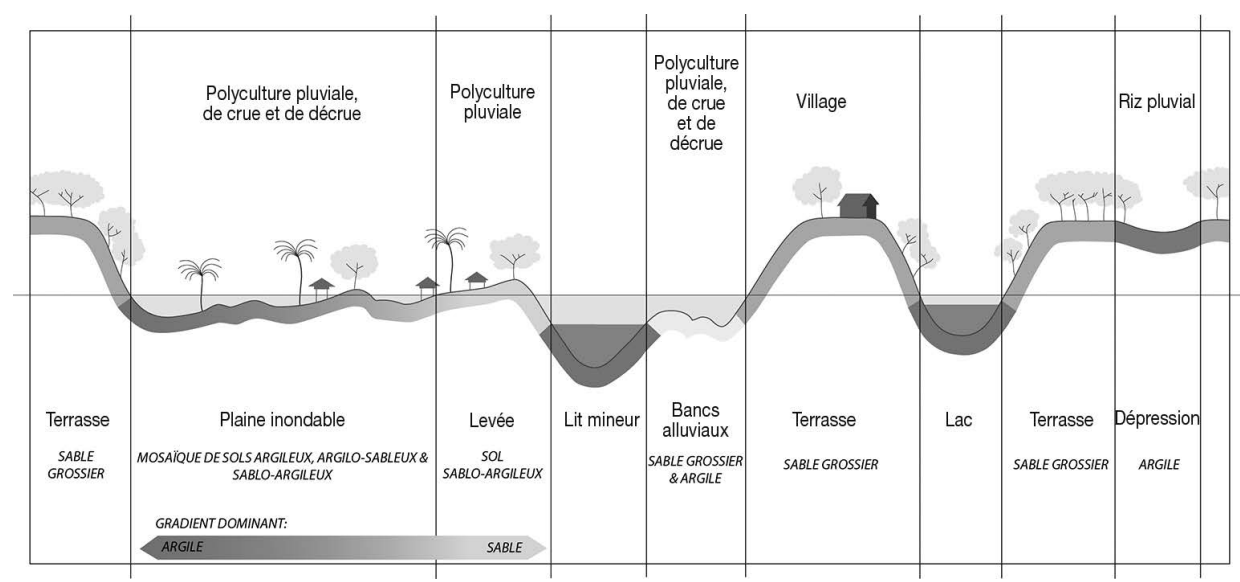

Figure 3.7. Transect de la vallée du Rufiji (Paul, 2018).

partie droite de la figure 3.7). On y trouve les villages issus de la villagisation de la période Ujamaa (1967-1968), alignés le long de l'unique piste qui longe le fleuve. Cette vaste unité est hétérogène. Elle est dominée par des sols de structure sableuse (sans doute développés sur des alluvions anciennes) et une formation arborée de type miombo (forêt claire). Cette forêt est exploitée par les éleveurs récemment arrivés et encore peu nombreux, et de rares chasseurs. Pour les villageois, cette unité est l'unique source de bois de chauffe et de bois d'œuvre (charpente, colombage, pirogue, pilon, mortier et meubles). Par endroits, elle comprend des cuvettes de quelques hectares aux sols plus argileux (njacha). Mises en culture à l'initiative des locaux après la villagisation, elles sont aujourd'hui beaucoup moins intensément occupées. Les villageois leur reprochent de ne pouvoir porter qu'une seule culture, du riz pluvial inondé par l'eau de ruissellement, en une seule saison, la grande saison des pluies. Par ailleurs, ces cuvettes «perchées » sur les terrasses alluviales anciennes (figure 3.7) ne sont pas fertilisées par la crue du fleuve. Lincertitude qui pèse sur la production agricole de cette zone est donc très élevée, beaucoup plus que dans les autres zones où, comme nous allons le voir, on peut combiner deux cultures principales (riz et maïs) et trois saisons de culture;

- des lacs occupent des lits de rivières fossiles creusés dans ces terrasses. La faiblesse de l'étendue de leur bassin versant rend indispensable leur recharge épisodique ou régulière par la crue (Hamerlynck et al., 2010; Duvail et al., 2014). Ces lacs constituent une unité particulière surtout dédiée à la pêche, bien que le seuil qui les sépare du fleuve puisse être cultivé en pluvial (maïs), pendant la crue (riz) ou en décrue (maiis) sur de petites surfaces;

- des bancs de sable (tingi/matingi) occupent les concavités des méandres du lit mineur du fleuve. Ils sont régulièrement remodelés par la crue (figure 3.7). Bien que de formes souvent comparables (en fuseaux parallèles au cours principal du fleuve), ils diffèrent par leur surface, leur hauteur (caractère plus ou moins bombé), leur âge et donc par la végétation qui les couvre. Exclusivement sableux et sans végétation à leur apparition, ils sont progressivement colonisés par un couvert végétal herbacé. Ainsi, se forme une roselière qui, lors de la crue, ralentit le flot et favorise le dépôt des particules fines charriées par le fleuve. Certains villageois 
visitent régulièrement ces roselières. Lorsqu'ils jugent que l'accumulation est suffisante (soit une trentaine de centimètres au moins), ils décident leur mise en culture. Au sein d'un même banc, surtout si sa surface est importante, des variations topographiques créent un patchwork édaphique. Les zones très basses, argileuses, et les plus exposées à l'inondation sont réservées à la culture de maïs de décrue. Les zones basses, argileuses, sont propices à la riziculture. Mais on peut y implanter un maïs de petite saison des pluies. Les zones de micro-altitudes intermédiaires, à l'abri des crues moyennes, sont destinées à la culture du maïs de petite et de grande saison des pluies. Sur les sommets bombés de certains bancs, très sableux mais presque toujours à l'abri de l'inondation, on cultive du maïs de grande saison des pluies. Ici, la présence d'un manguier, d'un anacardier ou de bananiers témoigne de la très faible occurrence de l'inondation; les villageois y construiront alors leur case de champ (ndungu/madungu);

- le lit mineur du fleuve est séparé de la plaine inondable par un bourrelet de berge qui reste à l'abri de l'inondation, sauf en cas de crue exceptionnelle comme en 1998 à l'occasion d'un épisode El Niño prononcé. Le bourrelet et le glacis qui le relient à la plaine inondable sont plantés de manguiers et d'anacardiers (figure 3.7). Anciens sites privilégiés d'habitation avant la villagisation, ces endroits ont été réinvestis récemment. Les sols y sont plutôt sableux et surtout propices à la culture du sésame, parfois à celle du manioc et du maïs;

- en arrière du bourrelet de berge, se situe la plaine d'épandage stricto sensu. Lorsque la crue est suffisante, c'est-à-dire quand le débit atteint au moins $2500 \mathrm{~m}^{3} / \mathrm{s}$ (Duvail et al., 2014), l'eau y pénètre par quelques effondrements du bourrelet et circule selon un réseau complexe de chenaux et de marais, puis rejoint le fleuve en aval (figure 3.7). Propices à la sédimentation des particules les plus fines parce que l'eau y stagne ou n'y circule en général que très lentement, cette zone est caractérisée par ses sols beaucoup plus argileux et limoneux. Une inondation saisonnière favorise la riziculture. La tendance générale est que l'altitude diminuant au fur et à mesure que l'on s'éloigne du bourrelet de berge, les sols deviennent de plus en plus argileux. Les marais temporaires les plus argileux sont des lieux de la riziculture inondée par excellence. Les zones inondables au sol plus léger peuvent accueillir un semis de maïs de petite saison des pluies, suivi par un cycle de riz inondé puis éventuellement d'une culture de maïs ou de coton de décrue. Là où des zones ont été exondées, du maïs et du sésame peuvent être semés au début de la grande saison des pluies. Enfin, la plaine inondable est un important lieu de pêche, mais cette pêche est ici très saisonnière.

Bien que la plaine inondable cumule les risques liés aux aléas de la crue et de la saison pluvieuse, elle semble attirer les agriculteurs depuis longtemps. La basse vallée du Rufiji était même connue de longue date pour ses surplus céréaliers (Hamerlynck et al., 2010). Au contraire, les vastes espaces des terrasses alluviales anciennes, situées de part et d'autre et à l'abri de l'inondation, ne semblent pas attirer durablement les cultivateurs. Pourtant pourvues localement de zones argileuses a priori propices à la riziculture, les agriculteurs ne sont pas en mesure de maintenir la fertilité de ces sols, car ils n'ont pas de moyen pour se procurer des engrais de synthèse. Depuis l'époque de la villagisation, plusieurs de ces zones ont ainsi été successivement cultivées (10-15 ans), puis délaissées. 


\section{Dans le Kilombero}

La vallée du Kilombero présente un profil transversal différent. Contrairement à la basse vallée du Rufiji, la vallée inondable n'y est pas limitée par des terrasses alluviales anciennes au talus très net. En revanche, la dépression du Kilombero étant un fossé d'effondrement encadré de vigoureux reliefs, son profil transversal est «perturbé» par la présence de cônes alluviaux. Formés par les affluents du Kilombero, rive gauche et rive droite, ces cônes viennent occuper une partie de la vallée inondable du Kilombero lui-même (figure 3.8). À partir d'un certain niveau d'inondation, la crue du fleuve ne concerne donc pas uniquement la vallée inondable du Kilombero stricto sensu, mais également la partie aval de ces cônes alluviaux. D'autre part, cette partie aval est soumise à la crue de l'affluent lui-même (figure 3.9). Ces cônes alluviaux possèdent des bourrelets de berge de part et d'autre de l'affluent qui les constituent, voire également des fragments de bourrelets témoins d'anciens passages de l'affluent (Jatzold et Baum, 1968).
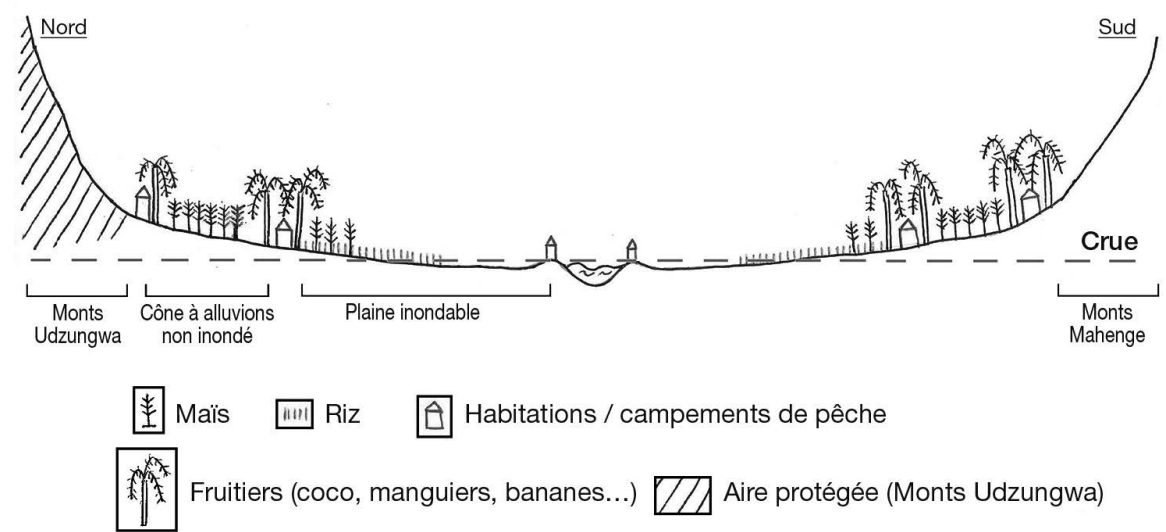

Figure 3.8. Profil en large de la vallée du Kilombero à hauteur d'Ifakara (Le Clerc, 2015; Jatzold et Baum, 1968).

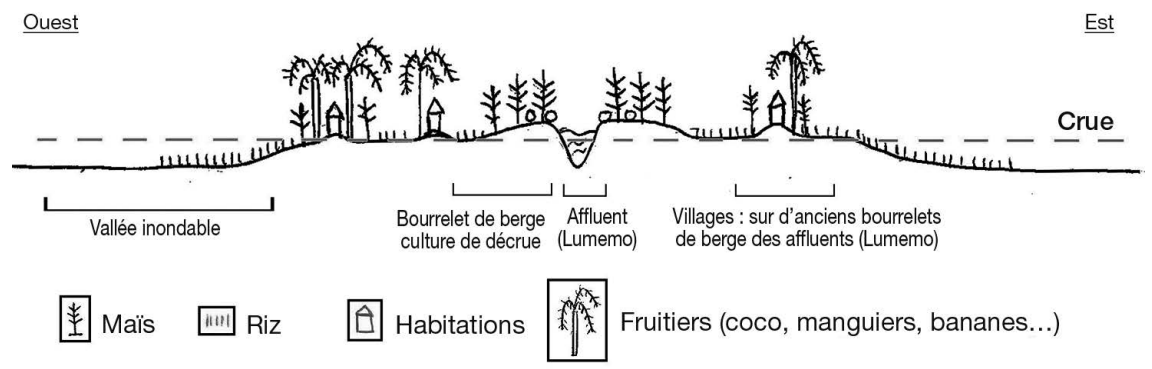

Figure 3.9. Profil est-ouest en large du cône alluvial d'Ifakara (Le Clerc, 2015; Jatzold et Baum, 1968).

Les principales unités de paysage s'ordonnent donc, d'une part, en fonction de l'éloignement au fleuve (le long d'une toposéquence perpendiculaire à l'axe de la vallée) et, d'autre part, en fonction de la position sur le cône alluvial. Il en résulte 
les différentes unités de paysage décrites ci-dessous, en partant des unités les plus basses et les plus durablement inondées jusqu'aux unités toujours exondées :

- des zones inondées chaque année par la crue du Kilombero et durablement recouvertes d'une épaisse lame d'eau. Domaine d'activité des pêcheurs pendant la crue, cette vaste zone est dominée par une formation herbeuse à Phragmytes mauritianus, Pennisetum purpureum, Megathyrsus maximus, Hyparrhenia sp. de part et d'autre du lit mineur du fleuve. Elle apparaît très hétérogène dès lors que la crue se retire. Cette zone est composée, d'une part, de petites zones sableuses, en position haute et correspondant à des restes d'anciens bourrelets de berge. Quelques îlots de petite taille portent même des manguiers, cocotiers et campements de pêche. D'autre part, on y trouve des zones moins sableuses un peu plus basses, mais encore relativement élevées, assez vite exondées au cours du retrait de la crue. Certaines parcelles y sont alors défrichées et du maïs y est directement semé en poquet. D'autres zones plus basses correspondant à des chenaux ou cuvettes, plus argileuses et dont la crue se retire en dernier. On y voit alors apparaître les billons de culture de l'année précédente. Certains d'entre eux seront remis en culture;

- des plaines herbeuses régulièrement inondées par le Kilombero, mais où la lame d'eau est moindre et sans aucun arbre. En année normale, ces plaines sont propices à la culture du riz (un cycle de saison des pluies), la crue intervenant généralement au cours de la montaison du riz. Entre deux cycles de culture, ces espaces sont recouverts d'une végétation basse dont l'espèce dominante est Cyperus distans, l'une des principales adventices du riz;

- des plaines arborées en s'éloignant de la rivière. La végétation laisse apparaître progressivement quelques arbres épars, généralement localisés sur des monticules correspondant à d'anciennes termitières. Ici aussi, l'inondation, bien qu'un peu moins marquée, dépose chaque année son lot d'alluvions assurant le renouvellement annuel de la fertilité du sol. Cette unité de paysage se confond avec les parties des cônes alluviaux les plus proches du fleuve Kilombero. À l'écart des cônes alluviaux, cette unité se raccorde au piémont par de grandes étendues de très faible pente, rarement inondées ou alors peu de temps et avec une lame d'eau mince, piquetées d'arbres;

- des zones parfois inondées par la crue des affluents du Kilombero, mais pas par le Kilombero lui-même, du moins en année normale. Bien que là encore, les frontières soient des plus floues. Ces sols alluviaux y sont considérés comme les plus fertiles de la région. Toutefois, la proximité de l'affluent implique un risque de débordement et d'inondation très important en mars-avril. C'est sur ces terrains que la culture de décrue (en saison sèche) est possible. Deux cycles de culture par an peuvent y être réalisés : soit deux cycles successifs de maïs (maïs pluvial en décembre-avril et de décrue en juin-octobre), soit un cycle de maïs pluvial suivi de maraîchage de décrue (aubergine, gombo, courge, concombre et pastèque);

- les bourrelets de berge (actuels et anciens) des affluents du Kilombero. Lieux privilégiés de l'habitat, ils sont plantés de différents arbres fruitiers (cocotiers, palmiers à huile et manguiers);

- enfin, la partie «haute» des cônes alluviaux n'est jamais inondée, aux sols plutôt sableux. Elle fait la jonction (rupture de pente) avec les versants escarpés de la vallée du Kilombero, zone elle-même très hétérogène. Seule la culture pluviale du maïs ou de sésame y est pratiquée. 


\section{$\rightarrow$ Gestion du risque à l'échelle de la parcelle : cultures associées, anticipation du risque et rattrapage}

\section{Dans la basse vallée du Rufiji}

Dans le Rufiji, la gestion du risque au niveau de la parcelle présente au moins deux particularités. D’une part, la double dépendance des systèmes de culture à la pluie et à la crue implique un cumul des aléas, notamment en ce qui concerne la riziculture. D'autre part, en raison de la proximité de l'immense réserve du Selous, la prégnance de la macrofaune sauvage sur le domaine cultivé est très forte. Confrontées à ces deux particularités, les populations de la plaine inondable du Rufiji ont élaboré des stratégies spécifiques depuis longtemps. Cependant, l'évolution climatique récente perturbe leur efficacité. Par souci de clarté, nous allons d'abord décrire ces stratégies anti-aléatoires anciennes et nous analyserons ensuite la manière dont les villageois réagissent aux changements en cours.

Traditionnellement, les villageois semaient du maïs de petite saison des pluies dès que les premières pluies le permettaient. Seul l'aléa pluviométrique pesait sur cette culture. Après la récolte, le calendrier cultural dépendait de la zone concernée. Dans les zones inondables, on implantait du riz, culture soumise au double aléa hydro-climatique. En effet, une crue mal synchronisée aux pluies endommage la culture par submersion ou, au contraire, par stress hydrique. Dans les zones à l'abri des inondations moyennes, était implantée une culture de maïs ou de sésame de grande saison des pluies. Dans des zones intermédiaires, on associait riz et maïs. Le pari est que suivant les conditions particulières de l'année, l'on bénéficierait de la récolte de l'une ou de l'autre des cultures. Enfin, lors du retrait de la crue, on implantait un maïs de décrue ou, jusque dans les années 1960, du coton. En simplifiant le calendrier cultural aux seules cultures principales (le riz et le maïs), l'agriculteur disposait de quatre périodes de semis sur l'année, comme l'indique le schéma suivant (figure 3.10).

$\begin{array}{llll}\text { Oct. Nov. Déc. Jan. } & \text { Fév. Mars Avril Mai Juin } \\ \text { Maïs de petite saison des pluies } & \\ & \begin{array}{c}\text { Riz (pluvial en début de cycle } \\ \text { puis inondé) }\end{array} \\ & \text { Maïs de grande saison des pluies }\end{array}$

.. Maïs de décrue

Maïs de décrue...

Figure 3.10. Calendrier cultural dans le Rufiji occidental simplifié aux deux cultures principales (Paul, 2018).

Du point de vue de la gestion du risque, cet étalement des cultures dans le temps venait contrebalancer les restrictions qui pèsent sur la dispersion des parcelles au sein des différentes zones agroécologiques. En effet, cette dispersion est limitée par la nécessité d'une présence humaine quasi-continue à la parcelle pour protéger la culture les déprédations occasionnées par la faune sauvage. En témoigne l'omniprésence dans le paysage des cases de champ sur pilotis (madungu). 


\section{La stratégie d'élargissement de l'association maïs-riz comme réponse anti-aléatoire aux évolutions climatiques}

Avec le raccourcissement de la petite saison des pluies et la baisse corrélative des hauteurs de précipitations, le maïs est aujourd'hui semé beaucoup plus tardivement. Ceci conduit à un télescopage des cycles des deux cultures. Le riz est ainsi intercalé aux pieds de maïs non encore récolté. La succession maïs/riz est ainsi devenue une «succession/association» de culture dans la mesure où les deux cycles se chevauchent très largement. Première conséquence, bien que les agriculteurs optent désormais pour des variétés à cycle plus court, le maïs est exposé à la crue (photo 3.1, planche 4). Ce fut le cas durant la saison 2013-2014, de nombreuses parcelles ayant été récoltées précipitamment, alors que l'eau était déjà montée. Deuxième conséquence : le semis du riz au sein du champ de maïs est plus laborieux que dans un champ déjà récolté.

Par ailleurs, là où l'inondation était naguère considérée comme quasi-assurée, elle est devenue aléatoire. Les agriculteurs ont donc étendu à de plus nombreuses parcelles la stratégie de culture associée du maïs de grande saison des pluies et du riz. Ici donc, le riz est semé le mois qui suit le semis de maïs. Les deux cultures croissent ensemble en pluvial. Suivant les conditions hydro-climatiques de l'année, on espère que l'une ou l'autre culture offrira une récolte significative. Bien sûr, en cas d'insuffisance de pluie et d'absence de crue, ou en cas de crue trop précoce et trop marquée, les deux cultures sont détruites.

Enfin, les parcelles ne sont pas planes. Alors, les semis étagés et étalés du maïs et du riz, des parties basses de la parcelle jusqu'à ses parties hautes (les dénivelés étant limités à quelques dizaines de centimètres), constituent un moyen supplémentaire d'accroître les chances de récolter quelque chose, même dans les conditions de pluies et de crues des plus défavorables.

La saison 2013-2014 offre un bel exemple d'année où se sont cumulés les effets délétères des deux aléas principaux : celui d'une saison des pluies défavorable (arrivée tardive des pluies) et celui d'une crue exceptionnellement forte. Les pluies ayant démarré très tard, le semis du maïs a été lui-même très tardif alors même que la crue a été plus importante et plus précoce que d'habitude. De nombreuses parcelles de maiis ont ainsi été noyées avant la maturation du grain, d'autres ayant été récoltées en catastrophe dans $80 \mathrm{~cm}$ ou un mètre d'eau avant que les épis ne soient noyés par l'inondation. Dans cette configuration particulièrement défavorable, les semis trop tardifs du riz ont pu entraîner sa submersion complète et sa destruction au moment de l'arrivée subite de la crue.

\section{Les tactiques de rattrapage comme réponses à l'augmentation des aléas dus aux évolutions climatiques}

Lassociation-succession maïs/riz est aussi pratiquée sur les bancs de sable des méandres du lit mineur du fleuve (figure 3.7). Ainsi, la crue dévastatrice de 2014 offre une occasion privilégiée d'observer les risques considérables encourus par les agriculteurs et les efforts déployés pour en limiter la portée. Cette année-là, la quasitotalité du maïs de «petite saison des pluies» cultivé sur les bancs de sable a été submergés par l'inondation. Cette inondation entraîna également la destruction des 
bananiers, de la canne à sucre et d'autres cultures mineures, tandis que la culture de riz subissait d'importants dégâts en raison d'une submersion trop précoce.

Dans ces conditions, la réponse traditionnelle est la mise en place d'une culture de maïs de décrue. Cependant, c'est un rattrapage à moyen terme, les premières récoltes n'étant envisageables qu'à partir du mois de septembre. Pour éviter une période de disette, l'unique rattrapage possible à court terme reposait sur le reste de parcelles de riz. Début mai, seuls émergeaient encore les plants de riz semés sur les parties légèrement plus élevées des parcelles, la partie bombée des bancs de sable. Dès lors, il fut encore possible de compenser partiellement les pertes en prélevant des plants sur les placettes épargnées par l'inondation pour les repiquer, au moment de la décrue, dans les parties basses où le riz avait été noyé prématurément (photos 3.2 et 3.3, planche 4). Utilisée habituellement de manière marginale pour agrandir la surface cultivée, cette technique de repiquage revêt ici un caractère particulier. Au prix d'un surcroît considérable de travail, elle autorise un certain rattrapage de la saison agricole et une atténuation notable des risques de disette.

Ainsi, les modalités de mise en culture de ces zones inondables — bancs de sables cultivables et zones d'épandage de la crue - révèlent une préoccupation permanente des agriculteurs de limiter les risques inhérents au double aléa des pluies et de la crue. La mise à profit de l'hétérogénéité intra-parcellaire du milieu, la combinaison de successions et d'associations de cultures aux caractéristiques diverses et l'extension maximale du calendrier de culture permettent de créer une diversité de situations agronomiques correspondant chacune à l'anticipation d'un scénario hydro-climatique particulier. Cependant, ces stratégies se révèlent souvent insuffisantes, comme durant la saison 2013-2014. Des techniques de rattrapage sont alors mobilisées. Dans tous les cas, les villageois sont régulièrement appelés à prendre des décisions tactiques pour adapter, voire bouleverser leur stratégie initiale.

Cette agriculture savante, qui réussit à tirer le meilleur parti d'un milieu peu anthropisé, a suscité l'intérêt de plusieurs auteurs. Elle a été qualifiée de Risk management system par A. Sandberg (2004). En référence à cet auteur, Hamerlynck et al. (2010, p. 224) écrivent que «les agriculteurs de la plaine inondable du Rufiji ont remarquablement joué de l'interaction entre cultures de petites pluies et cultures de grandes pluies, entre inondations et agriculture de décrue, en lien avec l'utilisation subtile de la variabilité topographique qui caractérise la nature des sols et la fréquence de leur submersion $»^{2}$.

\section{Dans le Kilombero}

La vallée du Kilombero et son potentiel rizicole avaient retenu assez tôt l'attention des Colons, puis des services de vulgarisation agricole de la Tanzanie indépendante. Linsertion aux échanges marchands y fut plus poussée, ainsi que le développement de l'usage du tracteur et des intrants chimiques. C'est pour cela qu'il faut remonter assez loin dans l'histoire pour retrouver, en conversant avec les agriculteurs âgés,

2. The Rufiji floodplain farmers have come to grips with the interplay between short rains crops, long rains crops, floods and recession agriculture and the subtle use of the topographical variability, which defines the nature of the soils and their flooding frequency (traduit par les auteurs de ce chapitre). 
des pratiques culturales évoquant d'assez près ce qui a été vu dans le cas de la basse vallée du Rufiji.

La saison des pluies étant ici plus ramassée (supra), il n'y a jamais eu véritablement de succession maïs et riz comme dans la basse vallée du Rufiji. Auparavant, le semis du riz avait lieu «aux pluies de Noël» : c'est-à-dire, les premières grosses pluies de décembre. Le riz est alors semé à la volée dans le maïs implanté quelques semaines auparavant $^{3}$. À cette époque (période 1950-1970 sur la figure 3.6), la saison des pluies commençait un peu plus tôt et les conditions étaient considérées comme plus favorables à l'agriculture. Le maïs étant semé précocement et récolté bien avant le riz, il abrégeait la période de soudure. L'association maïs-riz constituait donc, ici aussi, une façon de gérer au mieux les effets croisés du double aléa des pluies et de la crue.

Par ailleurs, les entretiens que nous avons réalisés en 2015 dans cette région montrent comment l'utilisation conjointe de différentes variétés de riz limitait les risques encourus ${ }^{4}$. Lagriculteur subdivisait son terrain en plusieurs lots sur lesquels étaient semées différentes variétés ${ }^{5}$, permettant de limiter les risques de diverses origines (climat, crue et maladies). Ces variétés se distinguaient par :

- une durée de cycle variable permettant de s'adapter aux fluctuations des pluies et de la crue;

- des variétés tardives récoltées en juin, d'autres plus précoces récoltées dès le mois de mars ou avril. Ces dernières n'étaient pas très prisées mais permettaient de passer la période de soudure. Elles portent d'ailleurs une dénomination particulière de Msonga (Msonga meli, Msonga useneguse);

- des variétés alimentaires plus «denses», d'autres destinées à la production de bière; - des résistances variables aux maladies.

Indépendamment de la souplesse permise par la combinaison de plusieurs variétés, précoces ou au contraire tardives, les techniques de récoltes et les modalités culinaires de préparation du riz augmentaient aussi les possibilités d'étalement des récoltes et donc de la consommation ${ }^{6}$ :

- récolte quotidienne des premières panicules ayant atteint la maturité pour une consommation immédiate;

- récolte avant maturité, au stade laiteux et consommation sous forme de «pepeta». Les grains au stade laiteux, non décortiqués, sont grillés au feu puis écrasés à l'aide d'un mortier;

- récolte juste avant la maturité (riz mchopeko). Les grains sont bouillis à l'eau puis séchés au soleil.

3. De tout-petits jardins potagers occupaient les buttes surélevées à l'abri de l'inondation. On y cultivait les courges, aubergines, gombos, aubergines africaines et manioc.

4. Dans le Rufiji, une dizaine de variétés de riz est utilisée. Elles diffèrent notamment par la longueur du cycle (3 à 6 mois), la hauteur de montaison et les qualités organoleptiques, etc. On sait qu'avec les évolutions climatiques actuelles, les agriculteurs du Rufiji ont délaissé les variétés à cycle long au profit des variétés à cycle moyen ou court. Il est probable que des enquêtes historiques approfondies révèleraient qu'ici, comme dans la vallée du Kilombero, l'utilisation de cet éventail de variétés correspondait à des stratégies anti-risque. 5. Les premiers inventaires variétaux datent de 1903 : un capitaine allemand envoya au gouvernement colonial 26 cultivars en vue de tester leurs caractéristiques. Il ressortit de cette étude qu'un long processus local de sélection avait permis le développement d'une importante diversité agroécologique (Stuhlman, 1909).

6. On retrouve des techniques de récolte et de préparation culinaire similaires dans le Rufiji. 
Enfin, dans la vallée inondable, la récolte des repousses de riz était parfois possible les années très humides, sur les parcelles les plus basses. En effet, les grains tombant à la récolte et germant sur un sol encore humide permettaient une petite récolte complémentaire. En cas de crue trop importante, la faiblesse des rendements de la première récolte était alors compensée en partie par cette seconde récolte (Jatzold et Baum, 1968).

Les agriculteurs âgés déclarent unanimement que les récoltes de l'époque étaient bien meilleures qu'aujourd'hui : les récoltes de deux à trois acres permettaient de nourrir une famille toute l'année durant. Le grenier n'était jamais vide ou alors très peu de temps avant la nouvelle récolte.

Mais ces pratiques anciennes seront fortement modifiées, dès les années 1950, par l'émergence d'exploitations commerciales de riz ou de coton de taille plus importante de 10-20 acres (4-8 ha). Il s'agissait alors, pour le gouvernement colonial, de favoriser l'essor d'agriculteurs «avant-gardistes » via un accès facilité à la motorisation et aux intrants, dans l'espoir de tirer vers le haut les agriculteurs avoisinants par la transmission d'un savoir «par-dessus la haie»(Coulson, 1982).

\section{- Gestion du risque à l'échelle du système de production : dispersion, complémentarité et atténuation du risque}

\section{Dans la basse vallée du Rufiji}

À l'époque de la villagisation Ujamaa (1967-1968 et 1973-1974), les habitants du Rufiji durent quitter leurs hameaux de la plaine inondable et se rassembler dans les villages situés sur les terrasses alluviales. Lagriculture pluviale alors préconisée par les services de l'État se révéla rapidement inadaptée et les villageois inventèrent un nouveau système de culture : la riziculture inondée des dépressions argileuses des terrasses (figure 3.7). Cependant, ce système était uniquement tributaire de la pluie, avec un éventail de cultures quasiment réduit au riz et un calendrier cultural très contraint. Les villageois se trouvaient dans une situation de précarité accrue. Ainsi, au milieu des années 1980, dès que la pression des pouvoirs publics se relâcha, la plupart des agriculteurs se redéployèrent dans la plaine inondable, sur les bancs de sables du fleuve. La fertilité y était meilleure et surtout la palette de conditions du milieu plus importante. Malgré les aléas et notamment le risque d'inondation, les bancs «de sable» et les zones d'épandage de la crue n'avaient donc rien perdu de leur attractivité.

On sait que la combinaison de différentes activités par une même famille est gage de diminution de la vulnérabilité. Dans cette partie de la vallée du Rufiji, cette diversification s'appuie avant tout sur l'association pêche-agriculture. La pêche, activité masculine, fournit une part importante des revenus. Elle assure au moins $40 \%$ des besoins alimentaires en permettant l'achat de farine de maïs en période de soudure, d'huile de cuisine ou de sel. Elle couvre aussi la majorité des dépenses 
monétaires non-alimentaires (Paul et al., 2012). Lagriculture, activité mixte à dominante féminine, est essentiellement vivrière, bien que les surplus de riz et de maïs puissent être vendus et que le sésame et l'anacardier soient cultivés pour la vente. Le premier gage de sécurité est donc la conduite parallèle des activités de pêche et d'agriculture; ce qui suppose la présence équilibrée d'hommes et de femmes adultes au sein du foyer. Les femmes seules (veuvage et divorce) sont toujours dans des situations marquées de précarité.

Mais les stratégies de diversification concernent également l'agriculture en tant que telle. Laccès à différentes «facettes » paysagères permet avant tout une plus grande sécurité alimentaire. Il permet aussi l'obtention de revenus monétaires complémentaires à ceux de la pêche. Cependant, plusieurs facteurs s'opposent à cet accès.

Le premier facteur est, en raison de la proximité de la réserve du Selous, la forte prégnance de la macrofaune (phacochères, babouins, antilopes, passereaux, voire hippopotames et éléphants). Durant tout le cycle de culture, du semis à la récolte, la surveillance diurne et nocturne du champ s'impose. Ainsi s'explique la constellation du paysage par des cases de champ sur pilotis (madungu). Lépouse et les enfants en bas âges s'y installent durant la saison culturale. En outre, la mise en culture d'un champ n'est jamais un acte isolé. Pour repousser la faune indésirable au plus loin, on s'assure toujours que le voisinage sera lui-même cultivé par des parents, des alliés ou des amis. Ainsi, si pour une saison culturale donnée, un foyer tente de cultiver plusieurs terroirs (banc de sable, plaine inondable ou dépressions argileuses des terrasses alluviales), il privilégie la surveillance de l'un d'entre eux et expose les autres parcelles à un fort risque de déprédation par la faune sauvage. En revanche, le changement de terroir d'une saison à la suivante, au cours de la même année, est fréquent. Il n'entraîne pas cette exposition au risque.

Le second facteur limitant l'accès à des terroirs diversifiés est la faible étendue de certains d'entre eux. Si une réserve foncière significative existe encore dans la plaine inondable, le bourrelet de berge et son glacis ont une faible extension. Or, c'est uniquement là que la culture de l'anacardier est possible ${ }^{7}$, la seule culture de rente d'importance depuis la quasi-disparition du coton après la villagisation. Les villageois qui disposent de parcelles sur le bourrelet de berge ont, en général, un accès direct à la plaine inondable au sud et, à certains endroits, aux bancs de sable du lit mineur du fleuve au nord. Les bancs de sable ont également une extension limitée. Leur principale caractéristique est la forte exposition à la crue : c'est un avantage lors d'une crue de trop faible ampleur qui ne pénètrerait pas complètement la plaine d'épandage. C'est aussi un inconvénient dans le cas de la survenue d'une crue importante et rapide. Les foyers contraints de cultiver uniquement ce terroir sont donc très vulnérables, tandis que ceux qui exploitent également un autre terroir y trouvent un complément fort utile.

Outre l'exploitation de la diversité intra-parcellaire évoquée dans le paragraphe consacré à «Dans la basse vallée du Rufiji» de ce chapitre, les stratégies de diversification agricole s'appuient donc sur la mise en valeur plutôt successive que synchrone des différents terroirs au cours de l'année. La question de l'accès aux différents terroirs est donc cruciale. D'un point de vue juridique, l'accès à la plaine inondable

7. Plus à l'est, les précipitations permettent la culture de l'anacardier sur les terrasses alluviales. 
est relativement aisé, tant que celle-ci échappe à l'accaparement pour des projets de l'agriculture industrielle. Cependant, la structure démographique des foyers s'oppose quelque fois à cet accès. Les foyers âgés, les familles monoparentales, les familles dont l'époux s'adonne quasi-exclusivement à la pêche, les familles de faible taille et sans lien de parenté fort avec d'autres familles sont peu mobiles. Elles sont souvent contraintes de se limiter à l'exploitation des terroirs aisément accessibles à partir du village : les dépressions argileuses des terrasses et les bancs de sable du fleuve. Leur situation est plus précaire. Enfin, quelques familles de tradition agricole pluviale arrivées à l'occasion de la villagisation exploitent essentiellement le glacis non inondable du bourrelet de berge. Leur dépendance aux conditions pluviométriques les place également en situation précaire. À titre d'exemple, le tableau suivant caractérise quelques situations agricoles à partir du travail de Tewa (2014); ce tableau n'est pas exhaustif.

Tableau 3.1. Caractérisation de quelques situations agricoles dans l'ouest du district du Rufiji (Tewa, 2014)

\begin{tabular}{|c|c|c|}
\hline Accès aux terroirs & Caractérisation & $\begin{array}{l}\text { Revenu agricole } \\
\text { par actif et par an } \\
\quad \text { (Euros, 2014) }\end{array}$ \\
\hline $\begin{array}{l}\text { Bourrelet de berge et son glacis } \\
\text { Plaine inondable } \\
\text { Éventuellement bancs de sable }\end{array}$ & $\begin{array}{l}\text { Grâce aux possibilités } \\
\text { de diversification : } \\
\text { Saturation du calendrier de travail } \\
\text { Bonne productivité du travail } \\
\text { Diminution des risques }\end{array}$ & $800-900$ \\
\hline Bancs de sable uniquement & $\begin{array}{l}\text { Forte exposition au risque } \\
\text { hydrologique } \\
\text { Diversification limitée aux stratégies } \\
\text { intra-parcellaires }\end{array}$ & 250 \\
\hline Bourrelet de berge et son glacis & $\begin{array}{l}\text { Forte exposition au risque climatique } \\
\text { Diversification limitée } \\
\text { aux cultures pluviales } \\
\text { Possibilité de culture de l'anacardier }\end{array}$ & 500 \\
\hline $\begin{array}{l}\text { Dépressions argileuses } \\
\text { Bancs de sable (en décrue) }\end{array}$ & $\begin{array}{l}\text { Forte exposition au risque climatique } \\
\text { Dépendance à la crue pour les cultures } \\
\text { de décrue }\end{array}$ & 500 \\
\hline
\end{tabular}

\section{Dans la vallée du Kilombero}

Dans cette région, la villagisation des années 1970 n'a pas empêché l'accès à des écosystèmes diversifiés. Elle n'eût donc pas d'effets délétères comme dans la basse vallée du Rufiji (supra) ou la région d'Iringa (chapitre 2). Bien que le peuplement humain de la vallée du Kilombero fût à l'origine dispersé, les familles étant installées sur de petites buttes à l'abri des inondations, plusieurs mouvements de rassemblement des habitations sur les bourrelets de berge des cônes alluviaux avaient déjà eu lieu par le passé, de sorte que l'habitat s'y trouvait déjà assez bien regroupé. 
Ici, cette époque correspond aussi à la construction de la voie de chemin de fer DarEs-Salam - Lusaka. À la fin du chantier, des groupes d'ouvriers qui avaient participé au chantier se sont installés définitivement dans la région, participant à son essor démographique, à l'émergence de nouveaux villages tout au long de la voie ferrée et à la constitution d'une classe de travailleurs sans terre. Ce dernier point n'est pas sans importance pour l'évolution ultérieure des systèmes de production de la région.

\section{Importance de la combinaison maïs/riz à l'échelle de l'exploitation}

Jusqu'aux années 1960, le maïs était uniquement semé en association avec le riz à faible densité. Sa fonction était de fournir un aliment de soudure «en attendant la récolte de riz» (supra). Dans les décennies suivantes, le maïs occupera une place plus importante et surtout sera cultivé sur des parcelles propres. En effet, tandis que le riz était semé de plus en plus tard (infra) et que l'usage du tracteur se généralisait peu à peu pour la préparation du sol, il devenait plus difficile de poursuivre l'association de culture (avec un semis plus précoce du maïs, comme auparavant). Dès lors, il était plus facile de semer le maïs sur des parcelles séparées, d'autant que l'allongement possible de la période de soudure liée au décalage des semis du riz renforçait le maïs dans son rôle de culture de soudure. Peu à peu, tous les agriculteurs se sont donc mis à cultiver le riz et le maïs sur des champs distincts. D'ailleurs, le maïs était de plus en plus cultivé sur des parcelles toujours exondées, localisées un peu plus haut sur la toposéquence de la vallée. Ce développement de la culture du maïs a été aussi encouragé par le National maize plan promu à partir du milieu des années 1970 (chapitre 2), bien que la vallée du Kilombero ne fasse pas partie des principales régions ciblées.

L'histoire récente est donc marquée par le recul de l'association maïs-riz au profit des mises en culture sur des parcelles distinctes au sein de l'exploitation. Le riz occupe la majeure partie des terres, tandis qu'un ou deux acres sont réservés au maïs principalement destiné à l'autoconsommation. Dans l'esprit des agriculteurs, la culture principale est le riz, le maïs restant destiné à la période de soudure (mars-juin).

\section{Disperser les parcelles de riz pour diminuer les risques}

Compte tenu de la grande variabilité des pluies, notamment au début de la saison pluvieuse, et du caractère imprévisible tant du niveau des eaux en mars/avril que de la durée de l'inondation, cultiver plusieurs sites permet, tout comme dans la basse vallée du Rufiji, de répartir le risque et d'assurer chaque année un niveau minimum de production. Les agriculteurs tentent donc systématiquement d'avoir plusieurs parcelles de riz localisées sur des sites différemment exposés à la crue. Cette stratégie est cependant limitée par la capacité de l'agriculteur à financer la campagne agricole (infra). Elle est de plus en plus difficile à mettre en œuvre avec l'augmentation de la pression foncière, la raréfaction relative des terres et leur éloignement accru par rapport aux habitations. Par conséquent, les jeunes agriculteurs récemment installés doivent parfois se contenter d'une unique parcelle, s'exposant de façon plus directe à l'impact des fluctuations annuelles du climat et de la crue. 


\section{W Intégration plus poussée aux échanges marchands et «modernisation agricole» dans la vallée du Kilombero : vers de nouveaux aléas?}

\section{Intégration aux échanges marchands et réduction de la diversité variétale}

Lutilisation conjointe de variétés précoces et tardives et l'étalement dans le temps de chaque opération culturale (semis, désherbage et récolte) avaient un triple objectif : éviter des pics de travail trop intenses; s'adapter aux conditions climatiques fluctuantes et au niveau imprévisible de la crue; et donc écourter le plus possible la période de soudure.

Aujourd'hui, certains agriculteurs mentionnent encore cet étalement des semis de mi-décembre à début février, mais l'entrée dans l'économie de marché a conduit à une réduction importante de l'agrobiodiversité. En effet, le Kilombero étant devenu un important bassin rizicole, les variétés choisies par les agriculteurs sont de fait celles qui se valorisent le mieux sur le marché et pour lesquelles le Kilombero est reconnu : des variétés très aromatiques, mais à cycle long. La durée des cycles de culture a donc tendance à s'homogénéiser autour de cinq à six mois. Ainsi, l'éventail des variétés cultivées se réduit aujourd'hui à une petite dizaine. Une mauvaise récolte ne peut donc plus être compensée par l'utilisation de variétés à cycle court permettant de limiter la période de soudure. On comprend d'autant mieux l'importance du maïs et son développement au cours des années 1980.

Cependant, les agriculteurs sont attachés à leurs variétés traditionnelles, d'autant plus qu'elles restent très adaptées aux conditions de la vallée et encore très prisées sur les marchés urbains ${ }^{8}$. Bien que sensibles à la verse, ces variétés à taille haute (un mètre de haut) permettent de mieux s'adapter à l'hétérogénéité intra-parcellaire et à la hauteur changeante de la lame d'eau. Leur diversité permet aussi d'étaler encore un peu les pointes de travail.

\section{Le difficile financement de la campagne agricole}

Aujourd'hui, la trésorerie des agriculteurs est souvent en partie consacrée à couvrir les frais de la culture du riz : quasiment tous les exploitants font appel au service du tracteur pour les étapes de labour et d'hersage. Même dans les petites exploitations, l'agriculteur fait toujours appel au service d'un tracteur en décembre pour le labour précédent le semis, puis pour le passage de la herse faisant suite aux semailles. Chacune de ces opérations est effectuée pour un coût de 40000 shillings tanzaniens (TZS) par acre. Il faudra par ailleurs, dans les exploitations de plus grande taille, prévoir des fonds pour payer les journaliers pour le désherbage manuel ou l'achat d'herbicide, pour la récolte et, le cas échéant, le transport. Concernant les

8. Beaucoup plus, par exemple, que les variétés de taille moyenne et semi-aromatiques promues par les centres de recherche comme le Saro 5. 
intrants, seul un herbicide est communément utilisé pour le riz : le 2,4D (Acide 2,4-dichlorophénoxyacétique) $)^{9}$.

Faute d'un accès favorable au crédit, c'est la vente du paddy qui couvre les frais de campagne. Par conséquent, c'est l'état du stock de paddy de l'année précédente qui détermine la surface emblavée, limitée bien entendu par la capacité maximale de la main-d'œuvre familiale (généralement établie à 2 acres/actif). Une année de bonne récolte et de prix de vente élevés permet ainsi à un exploitant de cultiver l'ensemble de ses parcelles l'année suivante. Une mauvaise récolte (crue exceptionnelle), des dépenses imprévues (maladie par exemple) ou une chute des prix limiteront directement la capacité d'emblavement. Ainsi, la surface cultivée des exploitations familiales oscille d'année en année selon les fluctuations conjuguées du climat, des prix et des aléas familiaux.

\section{Le décalage de la date de semis: perturbation climatique ou dépendance accrue au marché?}

Aujourd'hui, les producteurs sèment tout le riz au mois de janvier. Or, les personnes âgées évoquent systématiquement, pour les périodes plus anciennes, un semis au mois de décembre «au moment des premières pluies» (supra). Ce décalage des semis du riz est-il uniquement la conséquence du retard généralisé des pluies ces dernières décennies ou est-il aussi une conséquence du recours accru aux intrants et au service du tracteur dans un contexte de financement déficient de la campagne agricole?

Comme les avances aux cultures sont en général financées par la vente, au fur et à mesure des besoins, de la récolte de paddy de l'année précédente, on tente dans la mesure du possible de vendre le paddy au meilleur prix. Décembre étant une période de hausse des prix, les agriculteurs reportent autant que possible la vente de leur paddy, quitte à retarder excessivement le semis du riz et à l'exposer trop précocement à la crue. La recherche de ce difficile équilibre entre le meilleur prix de vente du paddy et la date de semis contribue à expliquer que le riz soit semé désormais en janvier, nettement plus tard que dans les années 1960 ou 1970, pour être récolté de mai à juillet.

Ainsi, il semble bien que le décalage du semis vers le mois de janvier soit tout autant la conséquence d'un retard des pluies, comme cela est souvent présenté par les agriculteurs de la vallée, qu'un effet des difficultés de financement de la culture, notamment du tracteur ${ }^{10}$. Cet exemple illustre les difficultés rencontrées lorsqu'il s'agit d'évoquer, avec les agriculteurs, le changement climatique et ses conséquences et l'intérêt rencontré à «parler du climat sans en parler» (voir dans l'introduction de cet ouvrage). Il est ainsi plus aisé de resituer les conséquences possibles d'une modification durable du climat dans l'ensemble de celles résultants de changements d'une autre nature.

9. Très peu d'agriculteurs font appel aux engrais, hormis dans les zones peu fertiles. La crue joue encore un rôle majeur dans la reproduction de la fertilité. Le maïs destiné à l'autoconsommation, surtout en période de soudure, est en général cultivé par la main-d'œuvre familiale et sans intrant.

10. Par ailleurs, la disponibilité encore insuffisante des tracteurs joue également un rôle certain dans le décalage des semis, d'autant plus que les parcelles sont difficiles d'accès. Le propriétaire du tracteur donne en effet la priorité aux parcelles les plus grandes et les mieux placées. 


\section{Une différenciation socio-économique accrue}

La monétarisation croissante de la région de Kilombero, la baisse des prix relatifs des céréales et de la force de travail (liés notamment à la mise en place du plan d'ajustement structurel) et un accès croissant au tracteur pour le travail du sol, ainsi que la présence d'une force de travail salariée (journaliers) sont autant de facteurs qui ont favorisé l'accroissement des surfaces cultivées et de la production pour certaines familles. Mais cet élargissement de la surface cultivée repose alors sur une force de travail rémunérée à la journée et ayant, elle, un accès très limité à la terre.

Par ailleurs, dès lors que maïs et riz furent cultivés sur des parcelles séparées et avec un calendrier de culture quasiment synchrone, ces deux cultures sont devenues concurrentes du point de vue du travail. Leur combinaison se traduit, au-delà d'une surface de quelques acres, par d'importantes pointes de travail. C'est pourquoi aujourd'hui, les producteurs font quasi-systématiquement appel à la main-d'œuvre extérieure pour le désherbage et la récolte ${ }^{11}$. C'est là que l'accès à une main-d'œuvre à bas coût permet à une catégorie d'exploitants - les mieux dotés — d'étendre les surfaces cultivées. Larrivée d'entrepreneurs privés proposant les services de labour au tracteur facilitait également l'extension des surfaces cultivées. Dès les années 1990, les familles ayant les moyens d'étendre ainsi leurs surfaces ont pu très vite produire environ quatre fois leur consommation annuelle (Kato, 2007).

Les résultats économiques des principaux types d'exploitations rencontrés dans la région Kilombero ont été estimés par Le Clerc (2015). À titre d'exemple, nous décrirons les cas suivants :

- le système de production le plus courant dans la région correspond à celui mis en place par des exploitations familiales de deux actifs cultivant entre 2,5 et 6 acres (1 à 2,5 ha). Les terres sont réparties entre la culture du riz inondé de fond de vallée (zones argileuses) et de maïs de saison des pluies situé sur les terres exondées du cône alluvial. Leurs exploitants, dont le siège d'exploitation est souvent installé sur les anciens bourrelets de berge (avec jardin-verger), pratiquent souvent la pêche de manière quasi quotidienne; ce qui leur assure une part importante du revenu. Le maïs est semé sur un à deux acres pour l'autoconsommation, sans intrant ni recours à la force de travail extérieure. Le reste de la surface est semé en riz (2 à 5 acres), en faisant appel au service du tracteur pour le labour et le hersage. On utilise souvent l'herbicide antidicotylédone (2,4-D), mais pas de fertilisation chimique jugée trop onéreuse. Comme pour l'ensemble des exploitations familiales de petite taille, la vente du riz a lieu au fur et à mesure de l'année. Le stock de riz est habituellement épuisé en janvier, la majorité de la production étant vendue avant que les prix n'atteignent leur plus haut niveau. Autour des maisons, on trouve généralement cocotiers, bananiers, palmiers à huile et un petit potager. Ces cultures assurent un revenu régulier tout au long de l'année. Les revenus dégagés par ce type d'exploitations (autoconsommation comprise) sont très faibles, de l'ordre de 220 à 370 euros/actif/an ${ }^{12}$. Les phénomènes climatiques extrêmes constituent donc une menace permanente et un frein au développement économique de ces petites exploitations familiales dans la mesure où,

11. Récolté trop mûr, le riz trop est plus cassant et se vend moins cher à la décortiqueuse.

12. 220 à 370 euros/actif/an, c'est à peine plus que dans la base vallée du Rufiji, alors que les agriculteurs n'y ont pas accès au tracteur et n'utilisent quasiment pas d'intrant dit «moderne». 
faute de financement alternatif, leurs capacités de production reposent uniquement sur les performances de l'année précédente;

- les agriculteurs ayant accès à des parcelles proches du lit mineur du fleuve et propices au maraîchage de début de saison sèche, une fois que la crue s'est retirée, s'en sortent mieux. Bien que ces parcelles, très fertiles, ne puissent pas être cultivées en riz en saison des pluies - la lame d'eau y est trop importante en avril -, elles sont très propices au maraîchage de contre-saison. L'irrigué se fait au seau ou à l'arrosoir. Outre les 2,5 à 4 acres (1-1,6 ha) de culture de riz inondé dans les zones argileuses et un à deux acres de culture de maïs de saison des pluies, les légumes sont cultivés sur 0,5 acre. C'est le maximum de surface permis par la charge de travail nécessaire à l'arrosage manuel. Les ressources financières issues du maraîchage permettent de faire plus facilement appel à la main-d'œuvre extérieure en temps opportun afin d'espérer une production plus élevée et de qualité supérieure. Le revenu dégagé peut alors atteindre l'équivalent de 700 à 900 euros/actif/an;

- il existe aussi des exploitations un peu plus grandes, avec 5-7 acres dont 3-5 dédiées à la culture de riz inondé (4 t/ha) et deux au maïs $(4,5 \mathrm{t} / \mathrm{ha})$, ayant recours aux intrants chimiques et employant de très nombreux journaliers. Les rendements y sont plus élevés et le revenu agricole dépasse alors les 1300 euros/actif/an;

- enfin, on trouve de grandes exploitations patronales motorisées avec un tracteur d'occasion et un tractoriste. La surface est plus conséquente, comprise entre 50 et 70 acres. À l'exception du travail du sol, l'ensemble de l'itinéraire cultural est réalisé à la main par de la ma main-d'œuvre extérieure, avec désherbant (2,4-D), mais sans recours aux engrais de synthèse. Les rendements sont donc semblables à ceux de la petite exploitation familiale; la valeur ajoutée annuelle n'y dépasse pas les 400 euros/ha. Le tracteur est surtout rentabilisé en prestation de service, la demande étant très forte dans la vallée du Kilombero.

\section{" Grands projets d'aménagement du milieu et riziculture «intensive» : diminuer l'aléa et la vulnérabilité?}

\section{Dans la basse vallée du fleuve Rufiji}

Depuis les débuts de la colonisation, la basse vallée du fleuve Rufiji a été, comme d'autres régions ayant des caractéristiques comparables, l'objet d'ambitieux projets d'aménagements. Ces projets reposent notamment sur la construction de barrages d'envergure ayant pour fonctions combinées la production d'électricité, le contrôle de la crue et l'irrigation de la partie aval de la vallée (Duvail et al., 2010). Larrivée récente de nouveaux investisseurs étrangers et les changements législatifs facilitant leur accueil relancent aujourd'hui ces grands projets. Ceux-ci sont présentés par leurs promoteurs comme une voie privilégiée vers l'adaptation au changement climatique (National irrigation master plan, NIMP, 2002). En réduisant fortement les impacts de l'aléa par une artificialisation poussée du milieu, ces projets seraient en mesure d'accroître substantiellement la production agricole tout en la sécurisant à long terme. La création massive d'emplois pour les populations locales et l'amélioration consécutive de leur niveau de vie sont aussi avancées au titre des avantages induits par de tels projets. 
Dans la basse vallée du Rufiji, une vingtaine d'investisseurs, le plus souvent étrangers, seraient actuellement sur les rangs (Tewa, 2014). Sur le site que nous avons étudié, le projet devrait aboutir à la création d'une exploitation de riziculture irriguée couvrant plus de 8000 ha de la plaine inondable. Pour assurer aux investisseurs une sécurité foncière à long terme, l'État a préalablement demandé aux autorités villageoises de valider un zonage du territoire communal pour distinguer notamment la zone actuellement cultivée d'une «réserve foncière ». C'est cette «réserve foncière» que l'État tanzanien entend louer à bail aux investisseurs nationaux ou étrangers, si possible avec l'accord de l'assemblée villageoise plénière, ou de manière autoritaire comme l'y autorise la législation.

Comme nous l'avons écrit ailleurs (Cochet, 2014), la plupart des projets d'investissement pressentis dans les pays du Sud concernent des espaces bénéficiant de conditions éminemment favorables à l'agriculture : fertilité des sols, ressources en eau et accessibilité. Le plus souvent, ces espaces sont occupés depuis longtemps par des sociétés agricoles caractérisées par une densité de population relativement forte et des systèmes de production intensifs en travail. Certaines de ces caractéristiques se retrouvent dans la basse vallée de la Rufiji, mais aussi dans plusieurs grands deltas africains où se concentrent les activités agricoles et d'élevage : deltas intérieurs du Niger (Mali), de l'Awash (Éthiopie), du Chari (Cameroun et Tchad) et du Tana (Kenya). Les investissements réalisés à grande échelle par des agents publics ou privés étrangers se traduisent par une substitution de systèmes agraires préexistants par de nouveaux systèmes. Ce ne sont pas des conquêtes de terres «vierges » souvent fallacieusement mises en avant; c'est-à-dire inexploitées et pour lesquelles le coût d'opportunité de la terre, des ressources hydriques et de la force de travail serait nul. Les réels progrès en matière de production, de valeur ajoutée et de création d'emplois se révèlent donc bien incertains et sont à analyser au cas par cas (ibidem). Une réflexion approfondie sur les projets concernant la basse vallée du Rufiji, en terme d'évaluation économique, n'est pas envisageable dans le cadre de ce chapitre. En effet, les travaux de terrain réalisés dans le cadre de ce programme de recherche n'étaient pas orientés dans ce sens. Cependant, la connaissance acquise sur la dynamique du système agraire qui serait concernée par ce type de projet nous permet d'avancer que le problème central de la création d'un grand barrage, c'est la disparition de la crue. Cette suppression signifie la fin de la pêche, l'assèchement des lacs, la fin de l'agriculture inondée et de décrue. Or nous avons vu que le revenu agricole des familles de la basse vallée du Rufiji dépendait étroitement de leur capacité à combiner différents systèmes de culture tirant partie des différentes «facettes» du milieu. La plaine d'épandage de la crue est, parmi ces différents espaces, la plus recherchée par les agriculteurs en raison de son plus fort potentiel, malgré les risques encourus. Or, c'est précisément cet espace-là qui est aujourd'hui l'objet de la convoitise des projets d'aménagement. Il risque d'échapper totalement aux habitants de la région, voire être le théâtre d'une éviction massive.

Malgré le versement d'indemnités par le gouvernement tanzanien (quel montant? $)^{13}$ et d'éventuels salaires distribués par le projet, dont le nombre est en

13. Les indemnités d'éviction risquent bien, comme c'est le cas dans de nombreuses régions du monde, d'être basées sur une sous-estimation forte de la valeur ajoutée produite par les agriculteurs sur ces espaces. Cette sous-estimation est basée sur la méconnaissance des pratiques locales, la non prise en compte de la culture associée et la non prise en compte de l'autoconsommation dans le calcul du revenu. 
général très fortement surestimés au moment de l'annonce du projet, un tel projet risque fort de se traduire par un accroissement de la vulnérabilité et de la précarité des populations soit :

- en les privant de l'accès à l'un ou l'autre des espaces exploités ;

- en diminuant toute les possibilités de compensation et de gestion de l'hétérogénéité du milieu.

Par ailleurs et au-delà des coûts d'investissement souvent très élevés de tels projets, leur capacité à générer une valeur ajoutée par unité de surface serait plus élevée que les systèmes de production «traditionnels». Il reste à le démontrer dans la durée, de même que la capacité des ouvrages prévus à résister aux crues de très grande ampleur dont la fréquence et l'intensité risquent, nous l'avons vu, de s'accroître.

Lobjectif des aménagements est de diminuer les risques encourus, au regard des aléas climatiques, via l'artificialisation et l'homogénéisation du milieu avec l'espoir d'accroître les rendements et de diminuer leur variabilité. Cependant, le paradoxe est précisément que la probabilité qu'ils accroissent la vulnérabilité des populations est élevée.

\section{Dans la vallée du Kilombero}

C'est pour faciliter l'investissement direct étranger (IDE) qu'il a été créé, en 2010, le Sagcot (Southern agricultural growth corridor of Tanzania). Il vise à développer la production agricole dans un corridor reliant Dar-es-Salaam à la Zambie. Sous la forme d'un partenariat public-privé, le Sagcot est ainsi la première initiative d'une série de corridors sur lesquels seront focalisés de vastes programmes de développement de la production agricole en vue «d'assurer la sécurité alimentaire du pays, de réduire la pauvreté et d'accroître la résilience face au changement climatique». Selon un schéma désormais bien connu, il est proposé, dans un premier temps, de promouvoir l'installation de grandes exploitations intensives en capital et à hauts rendements. L'espoir est que ce développement économique induise un accès facilité aux intrants, au crédit, aux services de moto-mécanisation, au marché et à la formation aux petites exploitations environnantes. Celles-ci verraient alors, à leur tour, leur rendement augmenter.

Au sein du «cluster» du Kilombero, trois sites ont été identifiés en vue de l'installation d'exploitations à capitaux privés sur de grandes surfaces. Deux d'entre elles, d'une surface d'environ 5200 ha chacun, seraient destinées à la riziculture : les sites de Ngalimila et de Kihansi dans le sud-ouest de la vallée (Sagcot, 2012).

Ici, nous n'aborderons pas la question de l'occupation actuelle de ces espaces par les populations de la vallée et les conséquences possibles en terme d'éviction et la mise en place de ces deux projets. En revanche, l'analyse portera sur le programme d'accompagnement qui serait mis en place pour que l'innovation fasse «tache d'huile» auprès des petits producteurs.

Pour aborder cette question, nous nous sommes intéressés à l'entreprise rizicole Kilombero plantations limited (KPL) implantée depuis 2008 à proximité de la ville de Mngeta, au sud-ouest de la région étudiée, dans le cadre de ce programme de recherche. KPL est dotée d'une concession de 5000 ha pour 99 ans. Depuis 
2010, il a mis en place, en partenariat avec l'Usaid, un programme de vulgarisation agricole auprès des exploitants des alentours visant à l'accroissement de la production rizicole par utilisation de semences sélectionnées, d'intrants et d'un itinéraire cultural spécifique.

Nous nous sommes inspirés des méthodes couramment utilisées en matière d'évaluation économique de projet. Elles reposent sur la mesure d'un différentiel entre la situation résultant de la mise en place du projet d'une part, et celle qui aurait prévalu si le projet n'avait pas été mis en place (scénario contrefactuel ou «sans projet») d'autre part. En l'absence de diagnostic de la situation préprojet sur le lieu même d'implantation du projet KPL, il a été choisi de prendre comme «situation de référence» le système agraire de la vallée du Kilombero décrit dans les pages qui précèdent. Dans la mesure où il s'agit d'une région proche de celle concernée par le projet du point de vue des conditions biophysiques (géomorphologie, conditions pédoclimatiques et hydrologiques), et du point de vue socio-économique (origine du peuplement et densité démographique, techniques de culture et d'élevage, modalité d'accès aux marchés, etc.), ce choix semble raisonnable et de nature à limiter les biais inhérents à ce genre de comparaisons.

Lentreprise KPL propose ainsi une formation agricole au système d'intensification de la riziculture (System of rice intensification, SRI). Ce paquet technique comprend notamment des variétés sélectionnées à paille courte (Saro 5), le semis en ligne et la fertilisation (NPK et urée). Selon le positionnement topographique des parcelles, il est possible de réaliser un semis direct (par exemple en riz pluvial sur les zones exondées proches des montagnes) ou des casiers rizicoles avec pépinières pour les parcelles inondables. Après chaque session de formation, les agriculteurs repartent avec les intrants nécessaires pour mettre ce paquet technique en pratique chez eux, sur une petite surface. En cinq ans, plus de 7400 exploitants auraient bénéficié de ces formations ${ }^{14}$.

Il ressort des entretiens réalisés par Le Clerc auprès d'agriculteurs impliqués dans la mise en pratique de ce nouveau paquet technique les quelques observations suivantes :

- les parcelles cultivées en SRI permettent d'obtenir des rendements nettement supérieurs, jusqu'à 7 t/ha de paddy. Le revenu obtenu de la vente de paddy permet de rembourser les prêts liés au SRI. Par ailleurs, les exploitants qui mettent en place cet itinéraire technique sur l'une de leurs parcelles utilisent aussi les engrais de synthèse ou les pesticides sur les autres parcelles de riz et de maïs de leur exploitation, obtenant alors de meilleurs rendements. Les exploitants bénéficiaires de ce programme ne limitent pas l'usage des intrants aux seules parcelles de SRI;

- pourtant, et cela semble paradoxal, l'adoption du paquet technique SRI ne concerne qu'une surface très limitée dans les exploitations concernées. En effet, les exploitations familiales de petite taille n'appliquent ce paquet technique que sur une seule acre, tandis que les exploitations patronales l'appliquent sur $20 \%$ de leurs terres au maximum. Le reste est cultivé selon les techniques «habituelles».

14. D'après le responsable du programme chez Kilombero plantations limited (KPL) à Mngeta, interrogé le 15/05/2015 par Le Clerc. 
Pourquoi les agriculteurs ne consacrent-ils qu'une surface si limitée à ce nouvel itinéraire technique, pourtant efficace en termes d'accroissement du rendement? Plusieurs raisons peuvent être avancées :

- le semis en ligne ou a fortiori le repiquage nécessite beaucoup trop de temps pour être généralisé à l'ensemble des parcelles. Pour les exploitants interviewés, la mise en place de ces pratiques se traduit par une hausse importante des dépenses de main-d'œuvre et d'intrants qui ne peut se faire que sur de petites surfaces;

- les variétés traditionnelles de la vallée se vendent beaucoup mieux. Il est souvent difficile d'écouler la production issue de semences sélectionnées parce qu'elles sont moins aromatiques (Saro 5);

- cet itinéraire technique nécessitant de fortes ressources financières par unité de surface (main-d'œuvre et intrants), le recours au crédit est incontournable;

- d'autre part, bien que ces systèmes permettent de se prémunir au moins en partie de l'aléa climatique, notamment pour les parcelles repiquées, le risque financier apparaît démesuré et peut rendre l'agriculteur encore plus vulnérable en cas de mauvaise récolte. Cet enjeu est crucial dans le Kilombero.

Dans la région étudiée, nous avons vu que pour une majorité d'exploitations, notamment les plus modestes, la surface réellement cultivée dépend de la récolte de l'année précédente. On conçoit ainsi que le budget global à consacrer à une année de culture au système d'intensification de la riziculture est si élevé qu'une mauvaise récolte serait catastrophique pour les ménages, si toute la surface disponible était conduite de cette manière. Le fait de dédier une partie de ses parcelles au système SRI et l'autre partie au système «traditionnel» permet d'espérer une meilleure récolte en année normale, sans engager de frais trop conséquents. C'est aussi une manière d'accroître son revenu tout en limitant le risque face à l'aléa climatique. Étant donné la grande variabilité climatique, la capacité des agriculteurs à supporter une année de rendement faible semble être au cour de leurs raisonnements concernant les pratiques culturales.

Dans la vallée de Kilombero, comme dans de nombreuses régions du monde, le premier objectif des pouvoirs publics, des entreprises et des promoteurs de projets qui les accompagnent est toujours l'augmentation des rendements, présentée comme une fin en soi. Or, pour une exploitation familiale, l'objectif n'est pas d'atteindre les meilleurs rendements, car une telle stratégie est toujours liée à des risques agronomiques et économiques élevés. Il s'agit d'abord d'assurer un revenu permettant de faire vivre le foyer et, éventuellement, d'investir. Ainsi, l'exploitation familiale se caractérise par un souci permanent de limiter les risques d'obtenir un revenu incompatible avec la survie de la famille.

Dans le cas du programme mis en place par l'entreprise Kilombero plantations limited (KPL), l'itinéraire technique vulgarisé et censé - conformément aux recommandations de Sagcot - accroître la résilience face au changement climatique se traduit en fait par un accroissement du risque encouru par les agriculteurs. C'est cet accroissement du risque qui est la principale limite à la diffusion du paquet technique.

L'utilisation fréquente par les agriculteurs des intrants fournis par le projet au-delà de la parcelle concernée par l'itinéraire technique recommandé est aussi riche d'enseignement. C'est souvent la preuve que les agriculteurs ont grand besoin des intrants qui leur sont proposés, mais pas toujours des techniques qui leur sont associées. 
Cette utilisation illustre, encore une fois, que la promotion d'un paquet technique trop rigide, un et indivisible, peut se révéler contreproductif. Il suffit en effet d'une technique inadaptée aux contraintes des agriculteurs (par exemple le semis en ligne trop gourmand en temps de travail) pour bloquer l'ensemble du processus de diffusion et notamment l'utilisation de nouveaux intrants, à moins de les «détourner» vers d'autres usages jugés plus productifs.

\section{$\rightarrow$ Conclusion}

Dans les vallées inondables du Kilombero et du Rufiji (Sud-Tanzanie), les performances relatives du système agraire et les revenus dégagés par les foyers reposent sur l'exploitation savante d'un milieu complexe et peu artificialisé. Ici, les stratégies d'atténuation du risque ne peuvent pas être appréciées sans une connaissance fine des micro-hétérogénéités du milieu et des pratiques mises en œuvre pour en tirer profit, notamment à l'échelle de la parcelle. La culture associée maïs/riz sur les bancs de sables et dans la plaine inondable de la basse vallée du Rufiji offre un exemple éloquent de cette adaptation fine et évolutive aux aléas des pluies et de la crue. Dans cette vallée, la culture associée n'est pas seulement une «stratégie» d'anticipation et de réduction du risque qui permet de «ne pas mettre tous les œufs dans le même panier » ou une pratique de limitation des risques d'ordre sanitaire. Elle est aussi un moyen d'adaptation et de pilotage in itineri tenant compte des caractéristiques du début de la saison des pluies (date de la première pluie significative, espacement des premières pluies et volumes des précipitations $)^{15}$.

D'autres exemples pourraient illustrer ce propos. C'est ainsi que Crane et al. (2011) décrivent l'adaptation à l'échelle de la saison culturale des pratiques dans une région du Sud-Mali : sur des sols très hétérogènes (sables/argiles) et compte tenu de l'aléa de la pluie, les agriculteurs sèment conjointement sorgho et mil dans le même poquet. Après levée des plants et à la vue des premières pluies de la saison et du taux d'humidité des sols, les agriculteurs ne conservent que les plants de sorgho si la saison s'annonce plutôt bonne ou, au contraire, que les plants de mil si les pluies paraissent insuffisantes.

D'autre part, une approche en termes de système de production et de système d'activité permet de comprendre comment l'accès à différents écosystèmes, la combinaison de différents systèmes de culture et de différents systèmes extra-agricoles (comme ici la pêche) limitent les risques, à l'échelle cette fois de la famille en s'appuyant le plus largement possible sur les complémentarités offertes par l'éventail d'activités accessible aux agriculteurs. Les familles en meilleure posture dégageant les meilleurs revenus et mieux armées face aux aléas de différentes natures sont toujours celles qui peuvent combiner, sur des espaces ou des facettes paysagères variés, le plus grand nombre de cultures et d'activités extra-agricoles. Cette combinaison est bien sûr dépendante de la disponibilité des moyens de production (outillage, bétail et intrants), de la main-d'œuvre et des conditions d'accès aux marchés.

15. À propos de la culture associée comme pratique de gestion du risque, nous rejoignons ainsi Richard (1993, p. 67). 
En effet, l'aléa n'est pas seulement climatique, loin de là. Les difficultés de financement de la campagne rizicole rencontrées par les cultivateurs de la vallée du Kilombero nous l'ont montré. Ici encore, d'innombrables exemples pourraient renforcer ce propos. Ainsi, à propos des villageois Masa-Bugudum du Nord-Cameroun, Jean Wencélius (2016) démontre que les difficultés d'accès aux facteurs de production (semences et charrue) ou l'incapacité à s'en procurer au bon moment, la défection d'un actif sur lequel on comptait (déplacement ou obligations sociales), ou encore la morbidité et la fatigue inhérente à la période de soudure pèsent pour beaucoup dans la non-réalisation de certains projets de mise en culture. Elles pèsent bien davantage que l'aléa climatique que les agriculteurs ont finalement appris, de longue date, à intégrer dans leurs stratégies ou à compenser d'une façon ou d'autre. Pour eux, l'incertitude climatique est une certitude : les «vrais» aléas, ceux qui sont «imprévisibles», viennent d'ailleurs.

\section{Méférences}

Cochet H., 2014. Accaparements fonciers et grands projets agricoles privés : exclusions paysannes ou création d'emploi? In : Les exclusions paysannes : Quels impacts sur le marché international du travail. Boussard J.M., Cochet H., Coste J., Delevoye J.P. et al., (eds). Paris : AFD, (Conférences et séminaires 12) 12/2014, 53-62.

Coulson A., 1982. Tanzania: a political economy. Oxford: Oxford University Press, 348 p.

Crane T.A., Roncoli C., Hoogenboom G., 2011. Adaptation to climate change and climate variability: The importance of understanding agriculture as performance. Wageningen journal of life sciences 57, 179-185.

Duvail S., Hamerlynck O., 2007. The Rufiji river flood: plague or blessing? International journal of biometeorology 52(1), 33-42.

Duvail S., Médard C., Paul J.L., 2010. Les communautés locales face aux grands projets d'aménagement des zones humides côtières en Afrique de l'Est. Politique africaine 117, 149-172.

Duvail S., Mwakalinga A.B., Eijkelenburg A., Hamerlynck O., Kindinda K., Majule A., 2014. Jointly thinking the post-dam future: exchange of local and scientific knowledge on the lakes of the lower Rufiji, Tanzania. Hydrological sciences journal 59(3-4), 713-730.

Hamerlynck O., Duvail S., Hoag H., Yanda P., Paul J.L., 2010. The Large-scale irrigation potential of the lower Rufiji floodplain: reality or persistent myth? In : Shared waters, shared opportunities: hydropolitics in East Africa Calas B., Mumma Martinon C.A., (eds). Nairobi: Ifra, Mkuki Na Nyota, 219-234.

Jatzold R., Baum E., 1968. The Kilombero valley, characteristic features of economic geography of a semihumid East african floodplain and its margins. Dillingen: Weltforum Verlag Munchen, 154 p.

Kato F., 2007. Development of a major rice cultivation area in the Kilombero valley, Tanzania. African study monographs suppl. 36, 3-18.

Kilembe C., Thomas T.S., Waithaka M., Kyotalimye M., Tumbo S., 2012. Tanzania, chapter 11. In: East african agriculture and climate change: a comprehensive analysis Waithaka M., Nelson G.C., Thomas T.S., Kyotalimye M. (eds). Washington: Ifpri-Cgiar, 313-345.

Le Clerc P., 2015. Adaptation des agriculteurs d'une vallée inondable à l'aléa climatique, Diagnostic agro-économique de la vallée du Kilombero, Tanzanie. Mémoire de master Recherche «Pays émergents et en développement», UFR Agriculture Comparée et Développement Agricole. Paris : AgroParisTech, AFD, 147 p.

Paul J.L., Duvail S., Hamerlynck O., 2012. Appropriation des ressources «naturelles » et criminalisation des communautés paysannes : le cas du Rufiji, Tanzanie. Civilisations 60(1), 143-175. 
Richard P., 1993. Cultivation: knowledge or performance. In: An anthropological critique of development: the growth of ignorance Hobert M. (ed.). London: Routledge, 61-78.

Sagcot, 2012. Investment partnership program, opportunities for investors in the rice sector. Slideshow presentation, October 2012.

Sandberg A. 2004. Institutional challenges to the robustness of floodplain agricultural systems. Paper presented at the Third Penannual Workshop on the Workshop conference, Indiana University, 2-6 June 2004.

Stuhlmann F., 1909. Beiträge zur kulturgeschichte von Ostafrika. Berlin: Deutsch-Ostafrika, Bd. X, Dietrich Reimer (Ernst Vohsen), 905 p.

Tewa C., 2014. Favoriser la gestion du risque climatique par les agriculteurs et les pêcheurs : Diagnostic agro-économique de la Région de Kipo (zone de plaine inondable le long de le fleuve Rufiji, Tanzanie). Mémoire de fin d'étude, UFR Agriculture Comparée et Développement Agricole, AgroParisTech, AFD, Sokoine University of Agriculture, 105 p.

Wencelius J., 2016. Produire de bonnes semences, Perpétuer le lignage. Relations de parenté et reproduction de la diversité des sorghos chez les Masa-Bugudum du Cameroun. Thèse de doctorat en anthropologie, Université Paris-Ouest Nanterre La Défense. 


\section{Chapitre 4 \\ Aléas de la crue, aménagements et politiques : le Mékong du Cambodge au Vietnam

\author{
Olivier Ducourtieux, Elsa Champeaux, \\ Charlotte Verger-Lécuyer et Florie-Anne Wiel
}

\section{" Le bassin versant du Mékong : enjeux des changements climatiques et globaux}

\section{Enjeux environnementaux, sociaux et économiques}

Dixième fleuve le plus long du monde (4900 km), le Mékong draine un bassin versant de $810000 \mathrm{~km}^{2}$ où vivent 70 millions de personnes dans six pays (Chine, Birmanie, Laos, Thailande, Cambodge et Vietnam). Son débit est régi par l'alternance des moussons, avec une saison des pluies estivale et une saison sèche hivernale. Le fleuve prend sa source au Tibet en Himalaya. Cependant, la fonte des neiges ne compte que pour moins de $10 \%$ de son débit final dans le delta du Mékong ${ }^{1}$ (MRC, 2005). L'essentiel du volume d'eau provient des précipitations sur la seconde moitié de son cours, en Asie du Sud-Est tropicale, notamment du Laos où les affluents du fleuve apportent $70 \%$ du débit à son embouchure (Chu Thai Hoanh et al., 2010a; Eastham et al., 2008; Icem, 2013a; Johnston et al., 2010).

1. Dans le delta du Mékong, le débit est de $15000 \mathrm{~m}^{3} / \mathrm{s}$ en moyenne, $150000 \mathrm{~m}^{3} / \mathrm{s}$ en octobre. 
Le Mékong cristallise les contrastes et les contradictions de l'Asie du Sud-Est qu'il traverse : population très nombreuse (600 millions d'habitants), croissance soutenue et émergence de nouvelles économies tournées vers l'exportation (Thaïlande et Vietnam), zone critique de biodiversité menacée ${ }^{2}$ par la déforestation, urbanisation et aménagements hydro-électriques controversés sur le cours du fleuve ou ses affluents (Dugan et al., 2010; Molle et al., 2009; Matthews et al., 2014).

\section{Le changement climatique dans le bassin du Mékong}

Les études sur l'impact du réchauffement global sur le bassin versant du Mékong, et plus généralement sur la région du Grand Mékong, sont récentes voire en cours, avec des projections en partie divergentes (Chu Thai Hoanh, 2010a-b; Eastham et al., 2008; Icem 2013a-b; Icem, 2014a-b-c-d; Johnston et al., 2010; Lacombe et al., 2010; Lacombe et al., 2013; IPCC, 2014c). Cependant, le $\mathrm{Giec}^{3}$ reprend le consensus des auteurs vers un accroissement des précipitations sur l'Asie du Sud-Est (IPCC, 2014c, p. 1355). Les ruissellements dans le bassin versant du Mékong (figure 4.1) pourraient être multipliés par 2,5 au cour de la saison des pluies, avec une variabilité interannuelle accrue (Eastham et al., 2008; Icem, 2013a; Lacombe et al., 2010; Teng et al., 2016).

Dans la région, le changement climatique se traduira alors par une hausse limitée, en comparaison d'autres régions du monde (IPCC, 2014b), de la température de 1,5 à 2,5 ${ }^{\circ} \mathrm{C}$ à l'horizon 2050 (Icem, 2013b; IPCC, 2014c), des précipitations accrues, des crues du Mékong plus marquées en intensité, avec une fréquence plus élevée des évènements extrêmes, notamment des inondations. Ces modifications ne manqueront pas d'impacter les activités humaines, qu'il s'agisse de l'agriculture (Icem, 2014a-c), la pêche (Icem, 2014b) ou autre (Icem, 2014d).

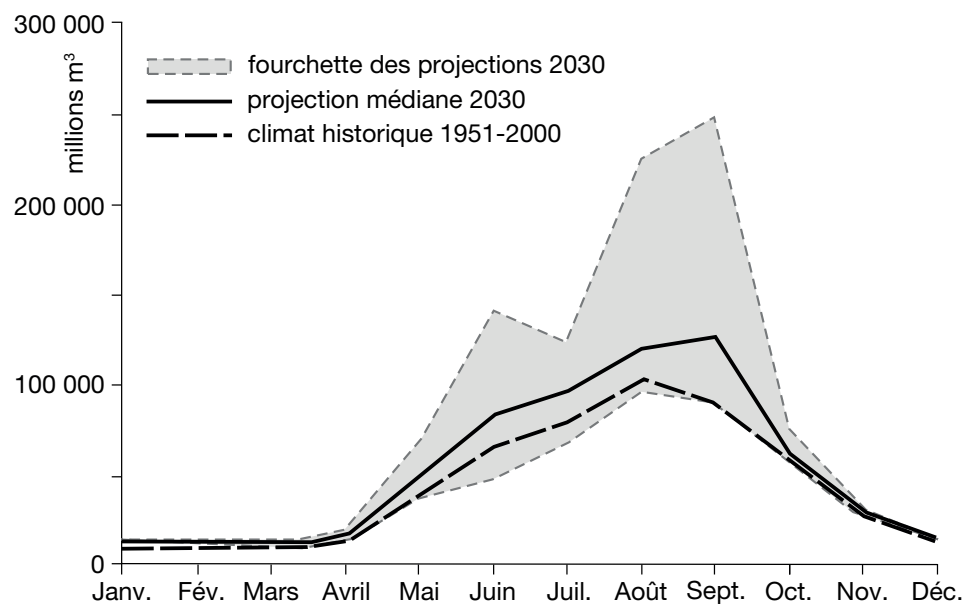

Figure 4.1. Ruissellement dans le bassin versant du Mékong (Eastham et al., 2008, p. 8).

2. 20000 espèces de plantes, 1200 espèces d'oiseaux, 430 espèces de mammifères, 800 espèces de reptiles et amphibiens, 1700 espèces de poissons identifiées dans la région du Grand Mékong; $50 \%$ des espèces de plantes vasculaires sont endémiques et $42 \%$ de celles de vertébrés (source : IUCN).

3. Groupe d'experts intergouvernemental sur l'évolution du climat (Giec ou IPCC en anglais). 
Au Cambodge et au Vietnam, les tendances générales décrites pour le bassin versant restent applicables au niveau local (Arias et al., 2012; Doch et al., 2015; Murphy et al., 2013; Roth et al., 2012), avec des effets déjà observables (Ham et al., 2015) :

- une augmentation de la pluviométrie, notamment au cour de la saison des pluies; - une modification de la distribution annuelle des précipitations, passant d'un régime bimodal avec une baisse relative des pluies en août vers un régime monomodal au pic en septembre.

Dans le delta du Mékong, les modélisations convergent vers des scénarios similaires, avec un accroissement modéré des précipitations de $0,4 \%$ d'ici à 2030 et de $1,2 \%$ d'ici à 2080. La température moyenne annuelle hausserait de $0,6^{\circ} \mathrm{C}$ en 2030 et de $1,8^{\circ} \mathrm{C}$ en 2080 (Teng et al., 2016). Le niveau de la mer croît actuellement de l'ordre de $3 \mathrm{~mm} / \mathrm{an}$. À l'avenir, la tendance pourrait s'accélérer avec des projections à $+1 \mathrm{~m}$ en $2080 \mathrm{du}$ fait de la dilatation thermique de la mer de Chine (MoNRE, 2009; Smajgl et al., 2015).

Par la conjonction de son exposition à l'aléa climatique (le risque accru d'inondation principalement) et des faibles capacités économiques pour l'adaptation, le Cambodge et le Vietnam sont classés parmi les pays les plus exposés au changement climatique par de nombreux auteurs (Kreft et al., 2015).

Pour les paysans de nos zones d'étude, les aléas climatiques ne changeront pas en nature mais augmenteront en fréquence et en intensité. La résilience de leur économie sera affectée, avec des intervalles réduits de récupération entre deux accidents, comme des inondations catastrophiques.

\section{" La diversité, pour la résilience et l'adaptation dans un milieu anthropisé mais à l'aléa non maîtrisé}

\section{La plaine inondable du Tonlé Sap au Cambodge}

La région étudiée ${ }^{4}$ se situe au sud-ouest de la ville de Kampong Thom, capitale de la province éponyme au Cambodge (figure 4.2), sur les berges du lac Tonlé Sap. L'hydrologie de ce lac est originale (Kummu et al., 2014) :

- en saison sèche, le lac couvre $2700 \mathrm{~km}^{2}$ pour $1,5 \mathrm{~m}$ de profondeur en moyenne. Il alimente la rivière Tonlé Sap dont les eaux se jettent dans le Mékong à Phnom Penh; - en saison des pluies, le débit du Mékong décuple et son niveau devient tel que le sens de circulation de l'eau s'inverse dans la rivière Tonlé Sap, pour remplir le lac devenu exutoire. La surface du lac est multipliée par six : $16000 \mathrm{~km}^{2}$, soit $10 \%$ de la surface du Cambodge. Sa crue se confond avec celle du Mékong pour couvrir plus de la moitié de la plaine centrale du Cambodge.

Dans le lac, le flux annuel moyen atteint $45 \mathrm{Gm}^{3}$ d'eau dont $54 \%$ proviennent du Mékong, 29\% des affluents du lac et $14 \%$ des précipitations directes (Matsui et al., 2006). Du fait de l'étendue de la crue du Tonlé Sap, la surface couverte d'alluvions récentes potentiellement très fertiles est vaste $\left(32000 \mathrm{~km}^{2}\right)$.

4. Le choix de ce site doit beaucoup à Jean-Christophe Diépart, chercheur sur les questions foncières au Cambodge, et à André Pouillès-Duplaix, alors directeur de l'agence Cambodge-Laos de l'AFD. Nous leur exprimons ici nos vifs remerciements. 


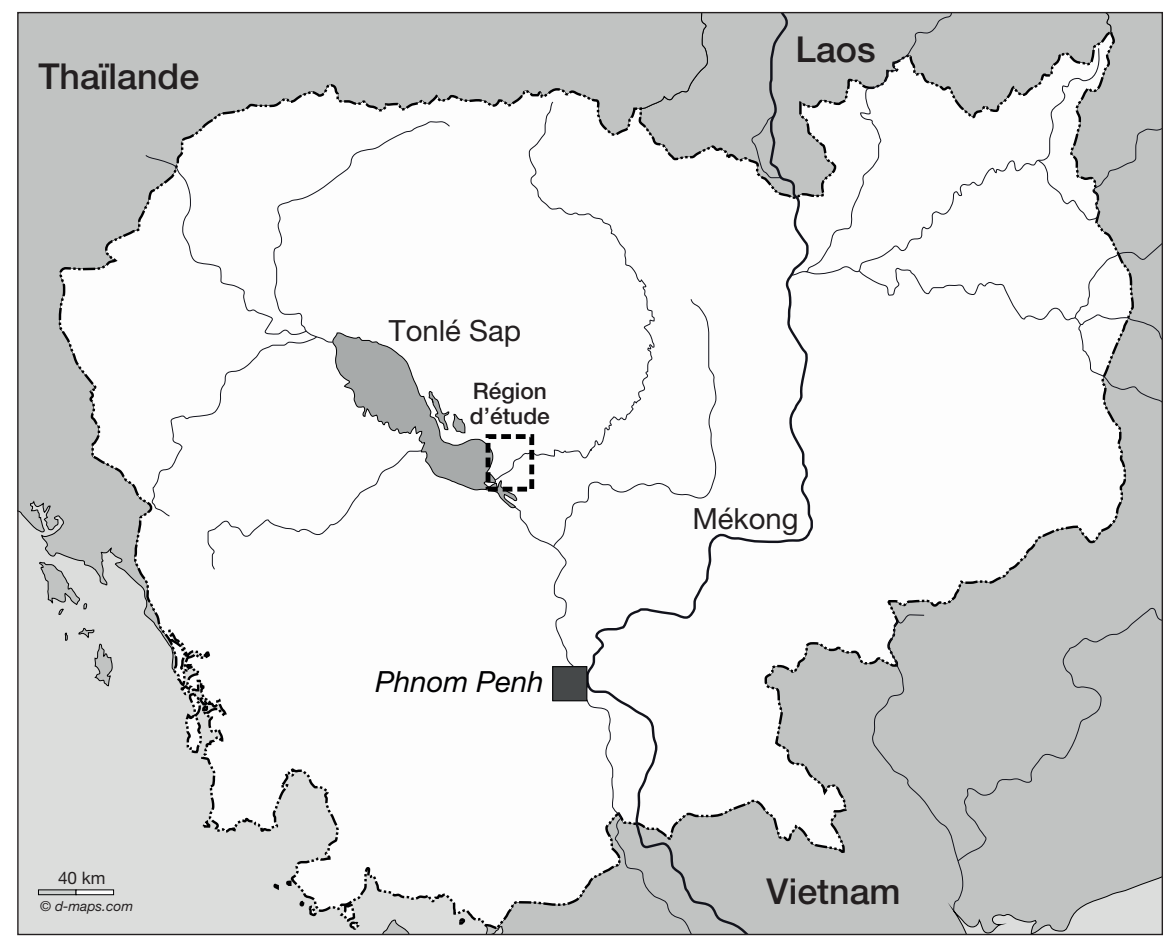

Figure 4.2. Le Mékong et le lac Tonlé Sap au Cambodge.

Cette région est cultivée de longue date, avec l'émergence dès le $\mathrm{IX}^{\mathrm{e}}$ siècle d'un État centralisé puissant dont le pouvoir repose sur la richesse de la riziculture irriguée et inondée : l'empire hydraulique khmer d'Angkor ( $\mathrm{IX}^{\mathrm{e}}-\mathrm{XIII}{ }^{\mathrm{e}}$ siècles). Parmi les hypothèses expliquant le déclin et la disparition de cet empire, celle d'une sécheresse de plusieurs années souligne l'importance sociale, économique et politique de l'aléa climatique dans la région (Nuorteva et al., 2010).

À la forte variation saisonnière du régime des eaux du Mékong, s'ajoute une variabilité interannuelle très marquée liée à la variabilité des précipitations dans le bassin (Eastham et al., 2008; Icem, 2013a; figure 4.3).

Les précipitations locales, en moyenne de $1500 \mathrm{~mm}$ par an, se concentrent de mai à octobre (85\%, figure 4.4), avec une forte variabilité en début et en fin de saison des pluies (respectivement avril-mai et novembre). Cette variabilité est un facteur de risque pour les cultures sur des champs en position topographique «haute», non submergés par la crue du fleuve.

Les paysans de la région jouent sur la hauteur de crue du Tonlé Sap, le décalage temporel des apports hydriques des précipitations locales et de la crue pour développer un calendrier rizicole complexe, avec deux cycles culturaux de saison des pluies, un cycle de décrue et deux cycles irrigués en saison sèche (figure 4.5).

Ces paysans doivent cependant composer avec l'incertitude du calendrier de la crue et de son niveau, avec les risques de submersion des cultures ou de sécheresse selon les années, pour subvenir aux besoins de leur foyer. 


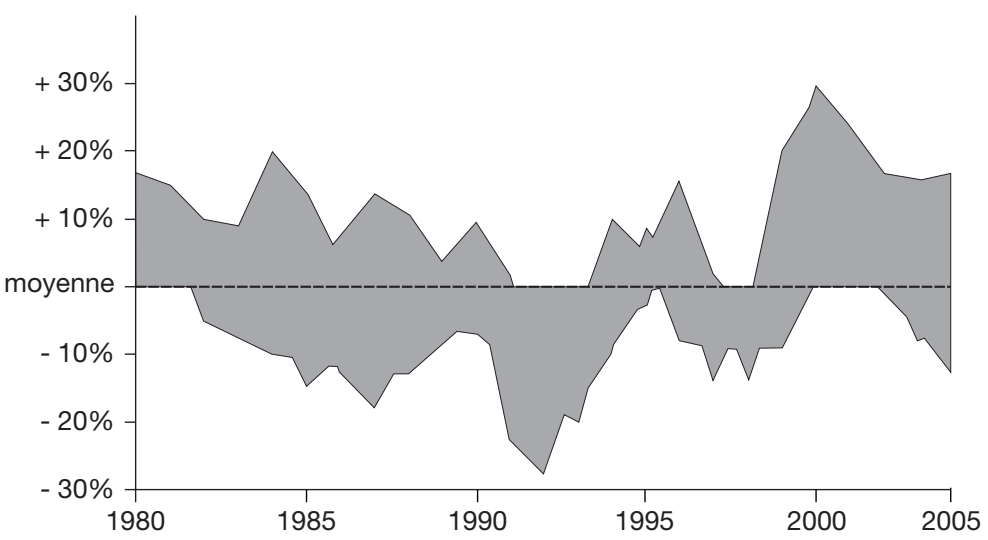

Figure 4.3. Variabilité des précipitations dans le bassin du Mékong. Écart des totaux annuels par rapport à la moyenne 1980-2005 (Icem, 2013a, p. 41).

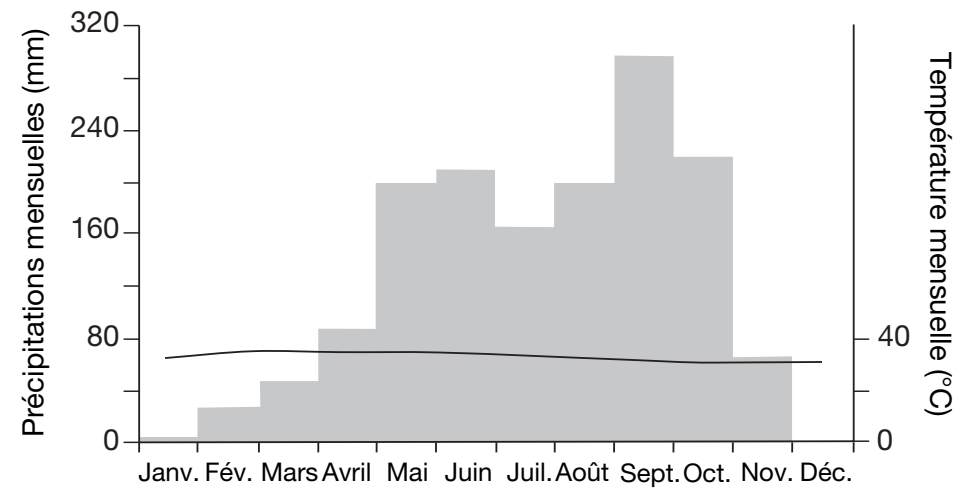

Figure 4.4. Diagramme ombrothermique de la station de Kampong Thom en 2000-2010 (Lécuyer et al., 2014, p. 10).

\section{L’hétérogénéité du milieu à petite échelle dans un espace fortement anthropisé}

La région étudiée se caractérise par une absence de relief : moins d'une quinzaine de mètres d'altitude de différence entre le fond du lac et les points les plus élevés (terre-plein de la route nationale par exemple). Cependant, du fait de l'étendue de la crue annuelle du Tonlé Sap, les microreliefs ont une importance considérable pour les paysans dans la mise en valeur de l'écosystème.

Si le visiteur non entraîné peine à discerner des différences dans cette vaste plaine en saison sèche, cinq étages agroécologiques différents sont visibles (Lécuyer et al., 2014) en fonction de leur altitude relative (figure 4.6 et figure 4.7) :

- le lit mineur du lac, toujours en eau même au cœur de la saison sèche. C'est un espace dédié à la pêche, ainsi qu'à l'habitat des villages flottants de pêcheurs (photo 4.1, planche 5); 


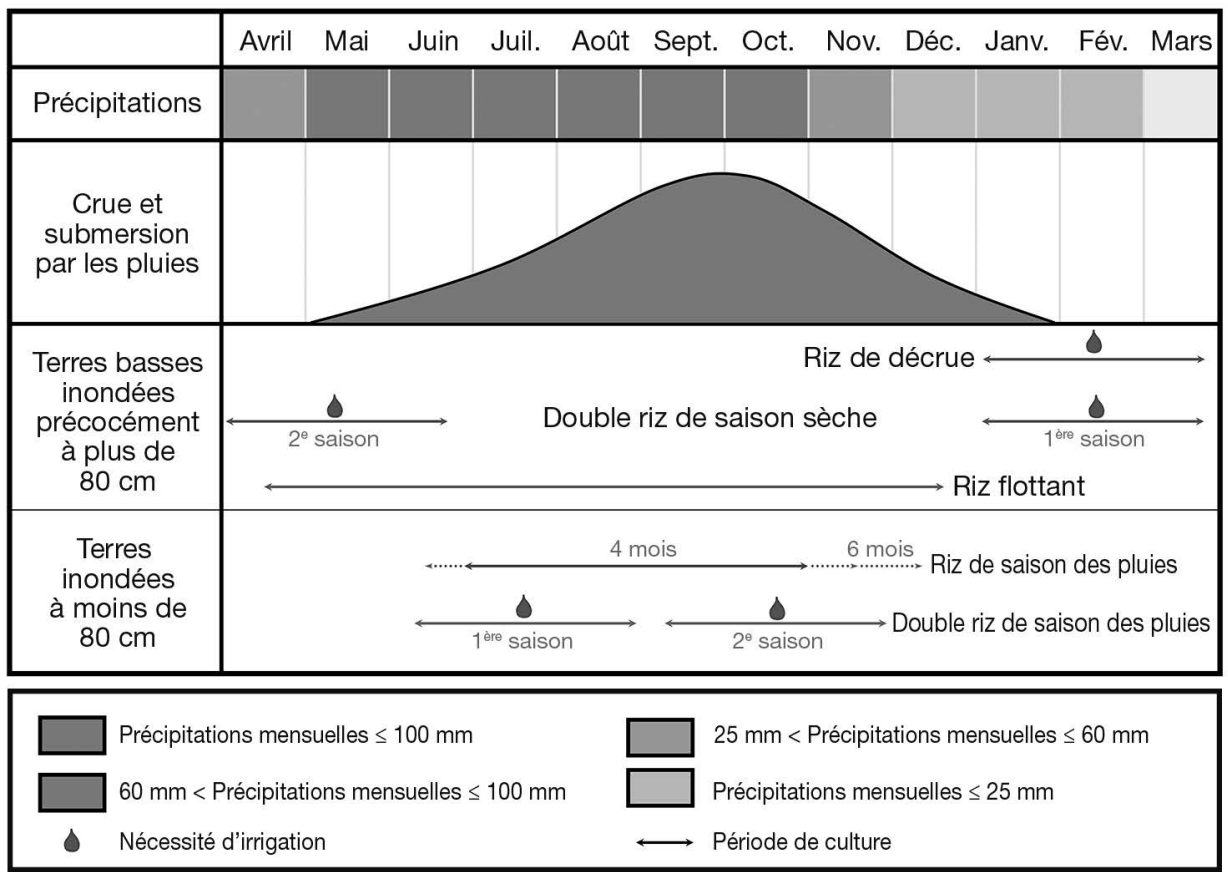

Figure 4.5. Précipitations, régime de crue et cycles culturaux (Lécuyer et al., 2014, p. 18).

- la forêt alluviale, exondée en saison sèche et inondée sous 3 à 10 m d'eau en saison des pluies. Espace de pêche et de récolte de bois, la forêt tend à régresser du fait de l'extension des surfaces cultivées en riz flottant depuis 1979;

- les plaines basses, vastes prairies pâturées en saison sèche et inondées en saison des pluies. Si la hauteur d'eau ne dépasse pas $3 \mathrm{~m}$, il est possible d'y cultiver du riz flottant ${ }^{5}$. Dernières terres asséchées, il est également possible d'y cultiver du riz en décrue, irrigué à partir de bassins de retenue d'eau creusés un peu au-dessus;

- les plaines hautes, exondées en saison sèche, elles sont généralement faiblement et temporairement inondées en saison des pluies. Prairies pâturées en saison sèche, elles sont aménagées en casiers dans des périmètres irrigués pour la riziculture, avec un ou deux cycles annuels de culture selon la hauteur de la lame d'eau d'inondation. Les espaces les plus élevés (12-15 m d'altitude) sont toujours exondés, sauf crue catastrophique, et sont utilisés pour les voies de communication (routes et pistes), l'implantation des habitations groupées en villages ou pour quelques vergers (manguiers surtout);

- le bourrelet de berge du Stung Sen ${ }^{6}$, toujours exondé, où passe une route et implanté de villages. De là, les paysans peuvent pêcher dans la rivière ou y pomper pour irriguer des rizières en contrebas sur l'arrière-berge.

5. Variétés de riz à longue tige, dont les talles s'allongent depuis le plateau racinaire au fur et à mesure de la lente montée du niveau d'eau (l'adjectif «flottant» est impropre mais consacré). Si la crue est rapide, les plantes sont noyées et perdues.

6. Le Stung Sen est un affluent du Tonlé Sap traversant la ville de Kampong Thom (figure 4.6). 
Forestière à son origine, la région a de longue date été fortement transformée par l'homme, avec un niveau poussé d'anthropisation culminant avec l'aménagement des périmètres irrigués.

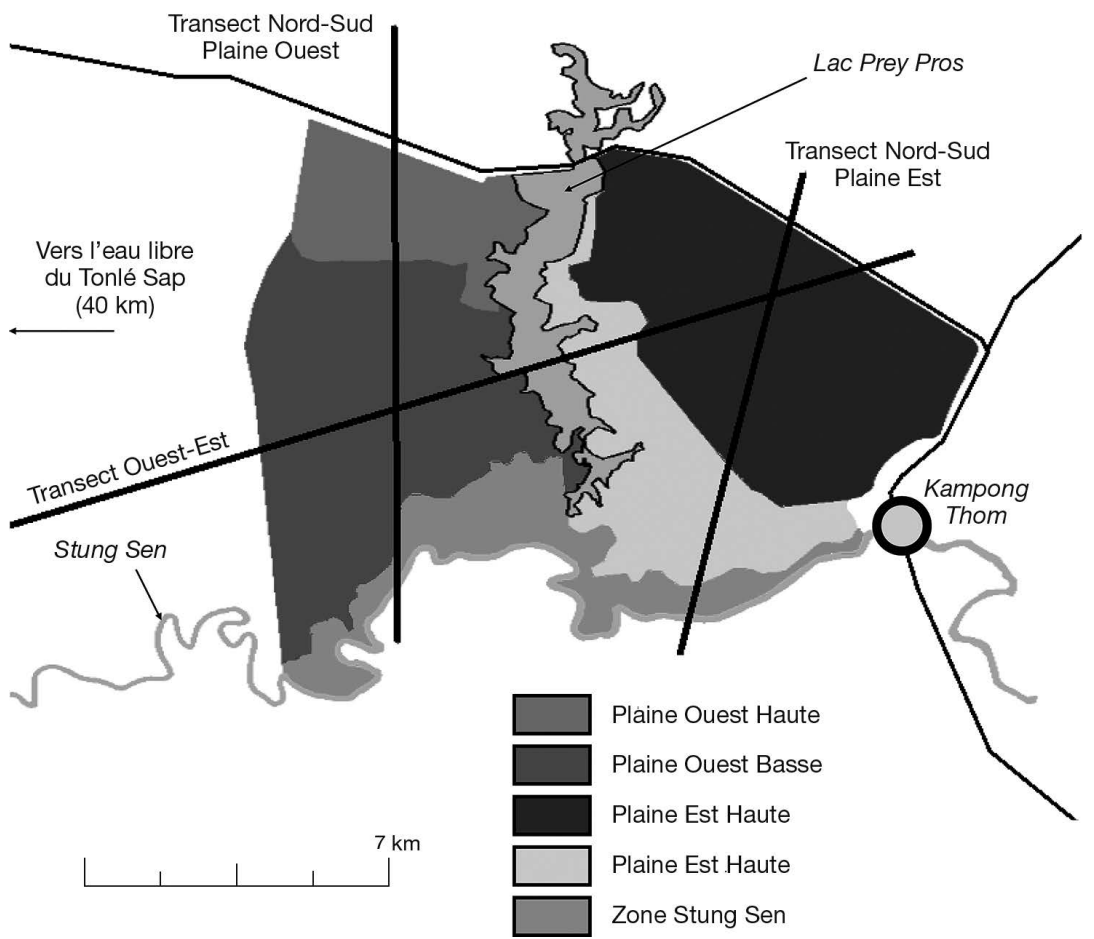

Figure 4.6. Zonage de la région ouest de Kampong Thom (Lécuyer et al., 2014, p. 17).

\section{Résilience de l'agriculture paysanne : une adaptation multiscalaire à l'aléa}

\section{La gestion du risque à l'échelle de la parcelle : la riziculture}

Si la monoculture du maïs est un facteur de risque majeur face à l'aléa climatique sur les terrains zambiens (chapitre 2), l'association d'espèces cultivées sur la même parcelle est une stratégie de prévention et de limitation dans la vallée du fleuve Rufiji en Tanzanie (chapitre 3).

En revanche, la monoculture du riz est, de longue date, la pratique paysanne de référence pour mettre en valeur la plaine inondable du Tonlé Sap. La tolérance à la submersion partielle ou temporaire de l'espèce Oriza sativa permet la culture d'espaces inondés par la crue, tout en supprimant le travail de sarclage et une partie des risques sanitaires (nématodes notamment). La sélection massale séculaire dans la région a permis de renforcer ce caractère de tolérance et d'obtenir un panel de variétés aux caractéristiques finement adaptées aux différents étages de l'écosystème. Les paysans de la région d'étude disposent ainsi de trois variétés de 
riz flottant (photopériodiques), de plusieurs dizaines de variétés de riz de saison des pluies (photopériodiques, deux cultivars dominants) et de deux variétés de riz de saison sèche ${ }^{7}$ (non photopériodiques).
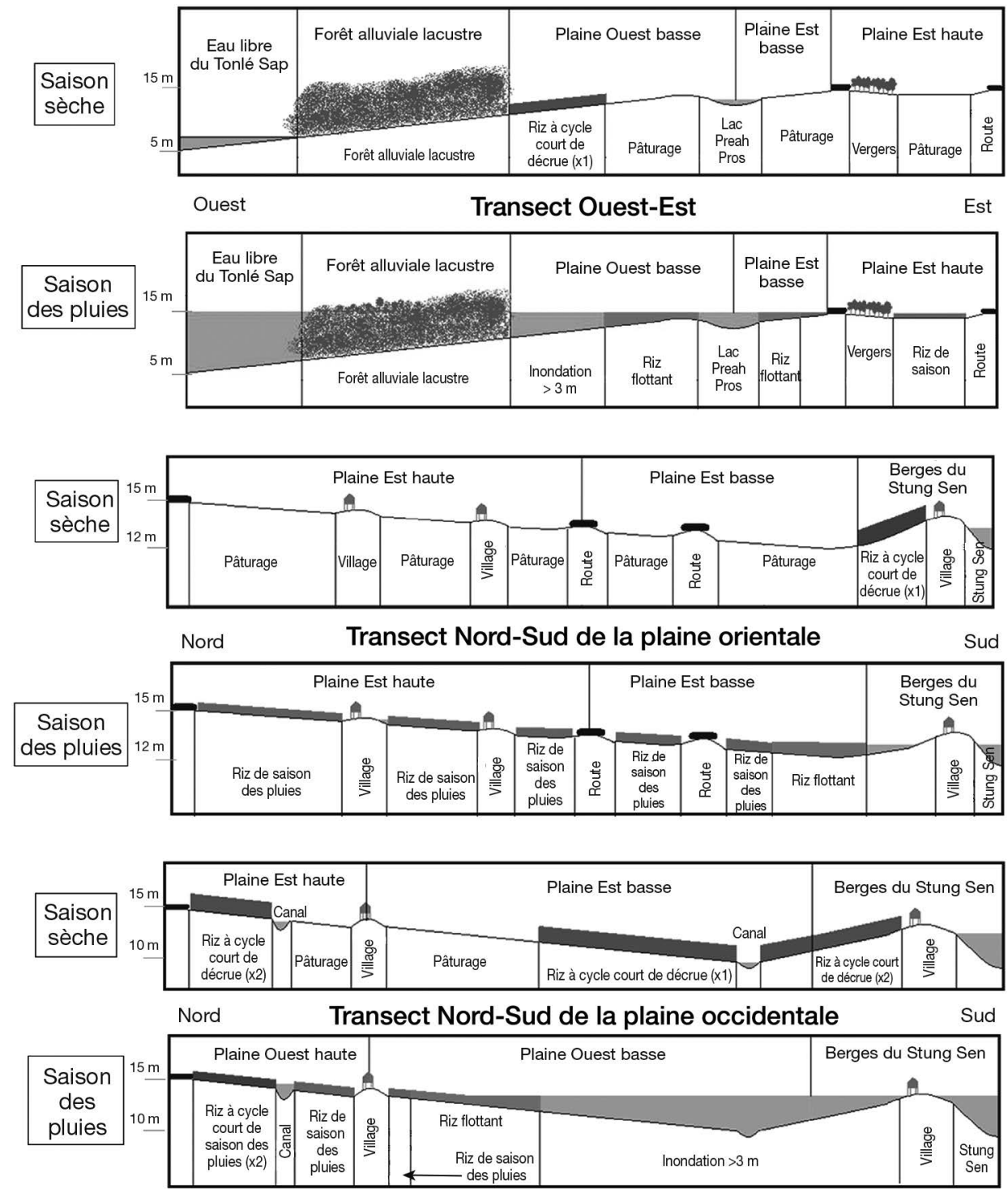

Figure 4.7. Toposéquence des étages agroécologiques des berges du Tonlé Sap (Lécuyer et al., 2014, p. 16-20).

En saison des pluies, les variétés de riz flottant permettent aux paysans de cultiver des parcelles submergées sous plusieurs mètres d'eau (1 à $4 \mathrm{~m})$. À la même saison, les paysans cultivent des variétés photopériodiques de dates de maturation différentes

7. Ce sont les seules variétés issues de la recherche agronomique (Irri) utilisées dans la région. 
pour utiliser les différents étages du milieu en fonction des dates probables d'arrivée et de retrait de la crue et en fonction de l'altitude. De plus, sur certaines terres limites en termes de hauteur d'eau en saison des pluies, les agriculteurs sèment plusieurs variétés de riz, afin de limiter les risques. Cela a aussi pour effet d'étaler les périodes de semis, de repiquage et de récolte (Lécuyer et al., 2014). Les variétés non-photopériodiques et à fort potentiel de rendement sont réservées aux parcelles dont le contrôle de l'eau est maximal : les rizières irriguées en saison sèche ou en décrue.

Le repiquage, pratiqué notamment pour la riziculture de saison des pluies (hors riz flottant), est également une stratégie de limitation des risques. Il permet d'anticiper les risques d'inondation. De mai à août, les précipitations sont parfois insuffisantes pour satisfaire à une culture de riz. Le repiquage permet alors de se protéger de ce risque de sécheresse, puisque le riz est alors dans une unique parcelle propice pour l'irrigation gravitaire. De plus, le repiquage permet une grande adaptabilité face aux aléas climatiques. Ainsi, plusieurs leviers sont utilisés par les agriculteurs pour s'adapter au climat changeant (Lécuyer et al., 2014) :

- la date de semis en pépinière. Le travail du sol étant à faire sur une plus petite surface, il est plus facile de le faire rapidement et ce, dès les premières pluies;

- la date de repiquage peut être adaptée à la hauteur de l'eau située dans la parcelle à repiquer, mais aussi au degré de maturité du riz à repiquer ou à la hauteur de l'eau dans la pépinière.

Le repiquage est ainsi une stratégie anti-aléatoire permettant de maximiser la surface récoltée par rapport à la surface cultivable, au prix d'un travail accru. Outre les différences de rendements, la résilience de telles pratiques face aux aléas climatiques est exemplaire. Cela explique qu'il soit toujours très présent dans le paysage, malgré le manque important de main-d'œuvre. Les agriculteurs conservent le maximum de surface repiquée que la main-d'œuvre disponible le permet. Cependant, les irrégularités des pluies en début de saison humide provoquent parfois la sécheresse ou l'inondation des parcelles. Le semis doit alors être recommencé. Si l'inondation a lieu tardivement (peu avant le repiquage), il n'est plus possible de préparer d'autres plants en pépinière. On complète alors le repiquage par du semis direct sur les terres les plus hautes, les moins inondées (Lécuyer et al., 2014).

La riziculture sur les berges du Tonlé Sap n'est donc pas une monoculture normative. C'est une grande diversité de systèmes de culture (tableau 4.1) aux performances différenciées ${ }^{8}$ soigneusement conçus et pratiqués par les paysans pour s'adapter finement au microrelief de la région, au régime hydrique aléatoire et aux facteurs de production disponibles : force de travail (étalement des travaux), terre (deux cycles sur la même parcelle, mise en cultures de tous les étages agroécologiques) et capital (pour l'irrigation).

Parmi les systèmes de riziculture, le SRI (système de riziculture intensive) est l'un des plus récents (Lécuyer et al., 2014). Il est cependant peu répandu dans la région. Le principe de repiquer des plants très jeunes (5-10 jours) donc courts accroît les risques de perte en cas de crue rapide et précoce. La maîtrise partielle de l'eau en saison des pluies, qui risque de s'affaiblir avec le renforcement de l'aléa climatique, limite les

8. Pour la présentation détaillée de ces différents systèmes de culture, il convient de se reporter au mémoire de C. Lécuyer et F-A. Wiel (2014, p. 71-100). 
possibilités de développement du SRI en saison des pluies dans la plaine inondable. Si ce système de culture permet d'accroître les rendements à un coût limité, c'est au prix d'un travail supplémentaire pour une main-d'œuvre pas toujours disponible et d'une sensibilité accrue aux aléas climatiques affectant la maîtrise de l'eau.

Tableau 4.1. Différents systèmes de riziculture des berges du Tonlé Sap à Kampong Thom (Lécuyer et Wiel, 2014, p. 95)

\begin{tabular}{|c|c|c|c|c|}
\hline $\begin{array}{c}\text { Système } \\
\text { de culture }\end{array}$ & $\begin{array}{l}\text { Cycle } \\
\text { (mois) }\end{array}$ & Zone & $\begin{array}{c}\text { Taille de la parcelle } \\
\text { (ha) }\end{array}$ & $\begin{array}{c}\text { Rendement } \\
\text { (t/ha) }\end{array}$ \\
\hline Riz flottant & $6(5-12)$ & Plaine Est basse & $<0,5$ & $1-1,5$ \\
\hline Riz flottant & $7-8(5-01)$ & $\begin{array}{l}\text { Plaine Ouest } \\
\text { basse }\end{array}$ & $>1$ & $1,5-2$ \\
\hline Riz de saison des pluies & $4(7-10)$ & $\begin{array}{c}\text { Plaines } \\
\text { Est-Ouest hautes }\end{array}$ & $0,3-1$ & $\begin{array}{c}2-2,5 \\
\text { (avec repiquage) }\end{array}$ \\
\hline Riz de saison des pluies & $6(7-12)$ & $\begin{array}{c}\text { Plaines } \\
\text { Est-Ouest hautes }\end{array}$ & $0,3-1$ & $\begin{array}{c}1,2-1,5 \\
\text { (semis direct) }\end{array}$ \\
\hline $\begin{array}{l}\text { Double cycle de saison } \\
\text { des pluies, cycle } 1\end{array}$ & $3(6-8)$ & $\begin{array}{c}\text { Plaine Ouest } \\
\text { haute (irriguée) }\end{array}$ & $\begin{array}{c}1 \\
\text { (subdivisée en 2-4) }\end{array}$ & 3,5 \\
\hline $\begin{array}{l}\text { Double cycle de saison } \\
\text { des pluies, cycle } 2\end{array}$ & $3(9-11)$ & $\begin{array}{c}\text { Plaine Ouest } \\
\text { haute (irriguée) }\end{array}$ & $\begin{array}{c}1 \\
\text { (subdivisée en 2-4) }\end{array}$ & 3 \\
\hline Riz de saison sèche & $3(1-3)$ & Plaine Ouest basse & $<0,5$ & 7 \\
\hline $\begin{array}{l}\text { Double cycle de saison } \\
\text { sèche, cycle } 1\end{array}$ & $3(1-3)$ & Sung Sen (irrigué) & $<0,5$ & $4-5$ \\
\hline $\begin{array}{l}\text { Double cycle de saison } \\
\text { sèche, cycle } 2\end{array}$ & $3(4-6)$ & Sung Sen (irrigué) & $<0,5$ & $2-2,5$ \\
\hline
\end{tabular}

\section{La gestion du risque à l'échelle du système de production : accès à différents étages écologiques et combinaison de systèmes de culture}

Comme les paysans de la vallée du Rufiji en Tanzanie (chapitre 3), ceux des berges du Tonlé Sap cherchent à combiner plusieurs systèmes de riziculture dans les différents étages agroécologiques afin de :

- étaler les pointes de travail. Cela permet de cultiver une plus grande surface ou, quand celle-ci est limitée, de consacrer la main-d'œuvre familiale à d'autres activités (élevage, cultures exondées, pêche et chasse, salariat agricole, migration vers du salariat éloigné);

- limiter les risques face à l'aléa climatique, qu'il s'agisse de submersion destructive ou d'assèchement des parcelles selon le calendrier d'arrivée et de retrait de la crue et son intensité.

Cependant, chaque famille n'a pas nécessairement accès à tous les écosystèmes. Dans la région, la différenciation socio-économique repose historiquement sur cette capacité à cultiver plusieurs étages.

Dans les villages existants avant la prise du pouvoir par les Khmers rouges en avril 1975, les différences sociales et économiques antérieures sont partiellement gommées par ce régime génocidaire. En effet, 2,2 millions de personnes ${ }^{9}$ (sur 7,9 millions d'habitants)

9. 1,7 à 3,4 millions selon les estimations de Heuveline (2001). 
meurent en trois ans de faim ou d'épuisement aux travaux exténuants dans les coopératives rurales et les chantiers d'irrigation mal conçus et sans tenir compte du coût d'opportunité du travail paysan ${ }^{10}$. D'autres personnes sont exécutées (Pillot, 2007; Heuveline, 2001). La population est déplacée à grande échelle dans le pays.

Il faudra attendre 1979, après le renversement de Pol Pot par les Vietnamiens, pour que les premières familles, parmi les survivants, reviennent dans la région de Kampong Thom, tandis que celles qui l'occupaient repartent vers leur village d'origine. Ces premiers «revenants» s'approprient les rares bubalins survivants. Loccupant vietnamien et le nouvel État instaurent rapidement une organisation collective moins coercitive que les «coopératives» khmers rouges, les Krom Samaki ${ }^{11}$. Les rizières de saison des pluies sont cultivées collectivement. Cependant, les familles disposant d'un nombre important d'actifs, ou ayant récupéré un bubalin, peuvent en plus divertir une fraction de leur force de travail pour défricher la forêt alluviale. Elles cultivent alors en propre des parcelles de riz flottant, leur permettant d'entamer un processus d'accumulation précoce en terre et en riz. Cette épargne est ensuite rapidement réinvestie dans des bubalins, puis des motoculteurs et des pompes pour accroître la productivité du travail. Ces familles défrichent ainsi de plus en plus dans la forêt alluviale pour accroître la surface cultivée, creusant ainsi rapidement un écart de revenu et de sécurité alimentaire avec les familles ne disposant pas initialement de la force de travail surnuméraire.

Bien que les exploitations tendent à se morceler lors des héritages ${ }^{12}$, les exploitations les plus grandes et aux résultats économiques les plus élevés aujourd'hui sont celles des «primo-revenants» ou de leurs descendants. Parmi la douzaine de systèmes de production identifiés dans la région, la différence de surface est conséquente (de 0,2 à 3 ha), tout comme le revenu agricole : de 30 à 1000 euros de revenu agricole annuel par actif et de 300 à 1600 euros pour le revenu total annuel par actif.

Pour les migrants récemment installés dans la zone, l'accès à la terre est difficile, sauf pour les familles disposant d'un capital. Celles-ci s'installent sur le bourrelet de berge du Stung Sen et investissent dans des rizières irrigables en saison sèche, s'affranchissant ainsi largement des risques climatiques. Sans capital, il faut passer par la location coûteuse de rizière ou l'installation sur les terres les plus marginales (plaine basse) avec des parcelles très réduites. Le risque lié à l'aléa climatique y est maximal.

\section{La gestion du risque à l'échelle du foyer : les activités extra-agricoles, dont les migrations, pour réduire la pauvreté et atténuer les risques}

Le revenu agricole ne représente qu'au plus les trois quarts du revenu total des familles, et parfois moins d'un cinquième. Pour compléter ce revenu, la force de travail familial est mobilisée pour des activités autres que la riziculture telles que : - jardin potager autour de l'habitation (toutes les familles) ou, à plus grande échelle, maraîchage sur les terres exondées (plaine haute et bourrelet de berge du Stung Seng);

10. Mobilisés manu militari comme force de travail juste après la prise du pouvoir pour des chantiers d'infrastructure d'irrigation, les paysans ne purent semer en pépinière et repiquer le riz de la saison des pluies 1975, d'où une famine rurale dans les mois qui suivirent.

11. Littéralement, Krom Samaki signifie groupe d'entraide, de solidarité et d'amitié.

12. Si la réforme foncière de titrisation de 1991 n'a été appliquée que marginalement dans la région d'étude, la tenure foncière est de facto sûre et confine à la propriété privée (Diépart et Sem, 2014). 
- culture d'arbres fruitiers (manguiers et anacardiers) autour de l'habitation (toutes les familles) ou vergers de quelques ares pour les familles ayant accès à des terres exondées dans la plaine haute;

- élevage de volailles (toutes les familles), de porcins (très limité) et de bovidés (bubalins et bovins, tant pour le travail du sol que pour la commercialisation) en nombre limité (1-3 têtes/famille);

- pêche (dans les mares, les canaux et le Stung Sen) et chasse (capture de rongeurs et d'insectes);

- salariat agricole journalier pour les familles les plus pauvres ${ }^{13}$ et prestation de services (location d'attelages ou de motoculteurs, de moissonneuses-batteuses) pour les plus aisées;

- activités de services (transport) et commerciales dans le village (épicerie) ou à Kampong Thom pour les familles disposant d'une trésorerie suffisante pour constituer un fonds de roulement.

Dans des proportions variables, toutes ces activités permettent aux familles paysannes de compléter leur calendrier de travail et leur revenu. Peu d'entre-elles seraient à même de vivre de la seule activité rizicole, alors que le cumul des différentes activités confère un revenu total par actif supérieur au coût d'opportunité du travail dans la région (Lécuyer et Wiel, 2014).

En plus de la contribution au revenu, la diversification des activités permet de réduire la vulnérabilité face aux risques climatiques. La combinaison des systèmes de riziculture dans différents étages agroécologiques et à différentes saisons avec les activités autres répond au double objectif de l'accroissement de la productivité du travail et de la réduction de la vulnérabilité à l'inondation ou la sécheresse.

Cette logique est poussée plus loin dans de nombreuses familles, avec la migration d'une partie des actifs, les plus jeunes, en dehors de la zone d'étude pour accéder à des emplois. Si les familles les plus aisées font jouer leurs réseaux pour accéder à des opportunités rémunératrices (commerce) ou porteuses de pouvoir (fonction publique), les plus pauvres sont limitées aux emplois salariés les moins rémunérateurs :

- à Phnom Penh dans l'industrie (confection, bâtiment, etc.) et les services (domestiques, prostitution, etc.);

- dans les régions collinaires de l'Ouest, du Nord-Ouest ou du Nord-Est, sur le front pionnier agricole, comme journaliers dans les concessions (exploitation forestière, plantation d'hévéas) ou dans les exploitations agricoles familiales les plus aisées parce qu'elles sont arrivées précocement (Diépart et Sem, 2014);

- en Thailande comme journalier (plantations d'hévéas, pêche en mer), dans les emplois de base de l'industrie et des services. Souvent de statut précaire, cette main-d'œuvre expatriée est dépendante des aléas de la conjoncture économique et politique en Thaïlande.

Pour les familles les plus pauvres, ces emplois liés à la migration ne contribuent que marginalement au revenu du foyer. Souvent, le jeune parti à la capitale revient régulièrement au village et repart avec du riz donné par les parents pour survivre

13. Ce qui peut contribuer à leur vulnérabilité au risque climatique, quand les actifs doivent ajourner les activités urgentes dans leurs parcelles pour des tâches salariées. 
en ville. En revanche, ces emplois permettent de réduire l'impact du morcellement des terres lors des héritages pour conserver des surfaces suffisantes pour la famille, et ce dans différents étages agroécologiques. Ils peuvent aussi servir de relais en cas d'évènement extrême amenant à l'abandon de l'exploitation agricole familiale.

\section{La désaisonnalisation de la riziculture par l'irrigation de saison sèche : une stratégie de réduction de la vulnérabilité conditionnée par l'accès au capital}

Depuis le début des années 2000, des familles ont progressivement investi dans la moto-mécanisation sur la base des motoculteurs polyvalents, servant au travail du sol (photo 4.2, planche 5), au transport (figure 4.8) ou à l'irrigation (figure 4.9).

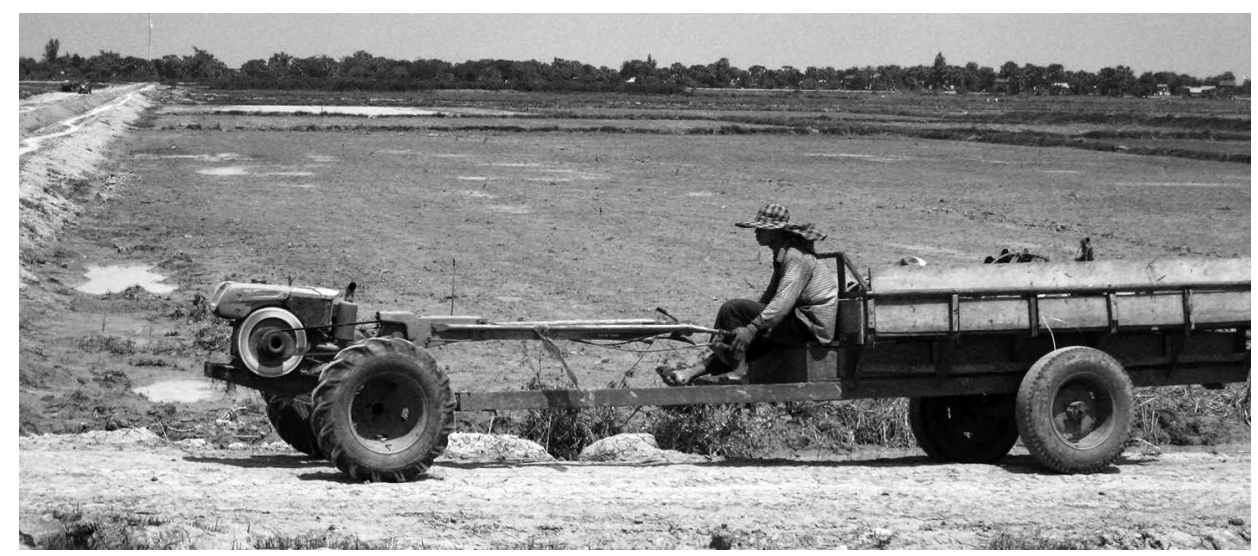

Figure 4.8. Motoculteur pour le travail du sol et le transport (Ducourtieux, 2014).

Pour les familles ayant les moyens de les acquérir, ces engins permettent d'accroître la productivité du travail. Ils permettent aussi de réduire les risques liés à l'implantation du riz en début de saison des pluies - dus à une crue au calendrier et à l'intensité aléatoires - par la rapidité et la flexibilité (labours à sec ou en eau) du travail motorisé. Pour le riz de saison des pluies, les agriculteurs doivent bien souvent attendre les premières pluies pour labourer, sans pour autant trop retarder le semis. Sinon, le risque d'inondation de la culture en début de saison des pluies est augmenté (Lécuyer et Wiel, 2014).

Si fertilisante pour les sols de la région, la crue du Tonlé Sap est source d'incertitude et de risques pour les paysans du fait de son calendrier et de son intensité aléatoires. Cet aléa est appelé à s'intensifier. Pour réduire leur vulnérabilité, des familles ont changé radicalement de calendrier de culture sur tout ou partie de leurs rizières, elles sont maintenant cultivées en saison sèche (deux cycles, tableau 4.1). Cela implique un recours à l'irrigation.

Cette approche n'est possible que pour les paysans ayant accès aisément à l'eau en saison sèche : proximité de canaux dans la plaine basse à l'ouest, arrière-berge du Stung Sen (figure 4.7 et tableau 4.1). Ils doivent aussi avoir les moyens d'investir dans la pompe et le motoculteur (figure 4.9). Déconnecté du régime de crue, ce système de culture est très sûr; c'est également le plus créateur de valeur ajoutée, tant par unité de surface que de travail. 


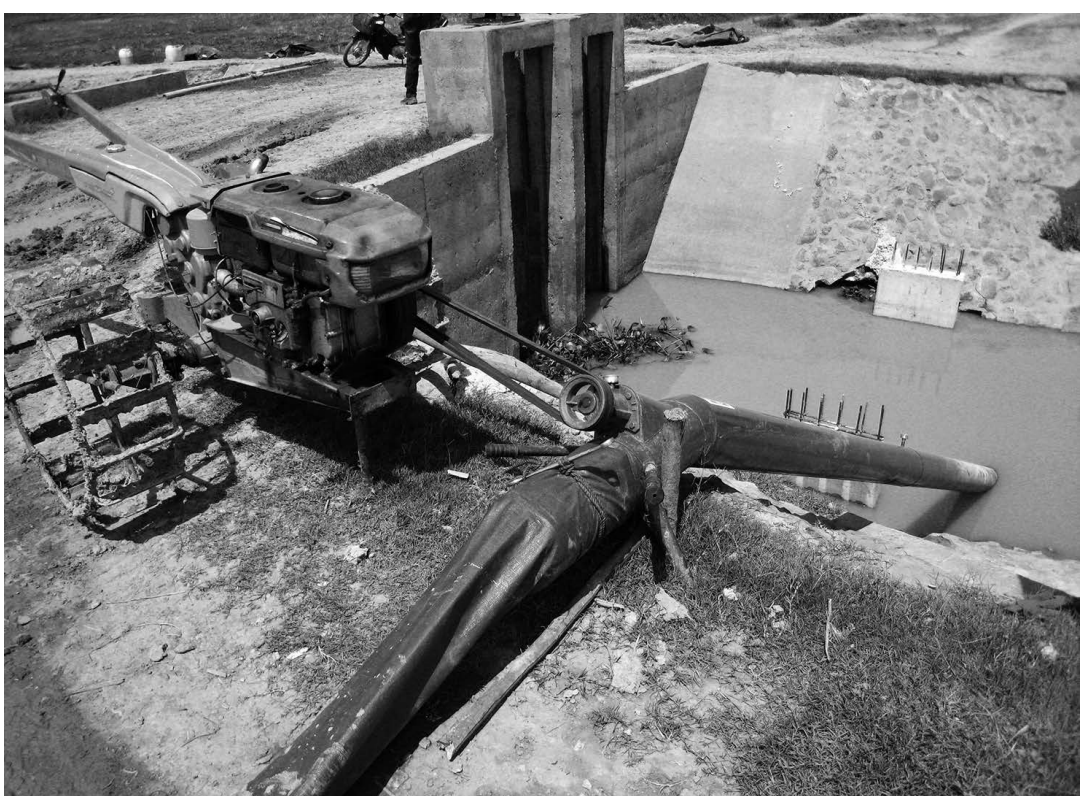

Figure 4.9. Pompe d'irrigation entraînée par un motoculteur (Ducourtieux, 2014).

L'extension du réseau d'irrigation pourrait élargir l'accès à la riziculture de saison sèche. C'est la motivation des investissements publics dans les périmètres irrigués au nord-ouest de la zone d'étude et sur la rive gauche du Stung Sen, au sud de la zone (figure 4.10 et figure 4.11). Ces infrastructures publiques semblent pourtant rencontrer des difficultés rédhibitoires : tandis que les chantiers de réhabilitation se succèdent depuis leur création à l'époque des Khmères rouges, ils sont totalement ou partiellement hors service depuis des années. La démesure de l'infrastructure entraîne une gestion complexe et des coûts de fonctionnement et d'amortissement insupportables pour les paysans.
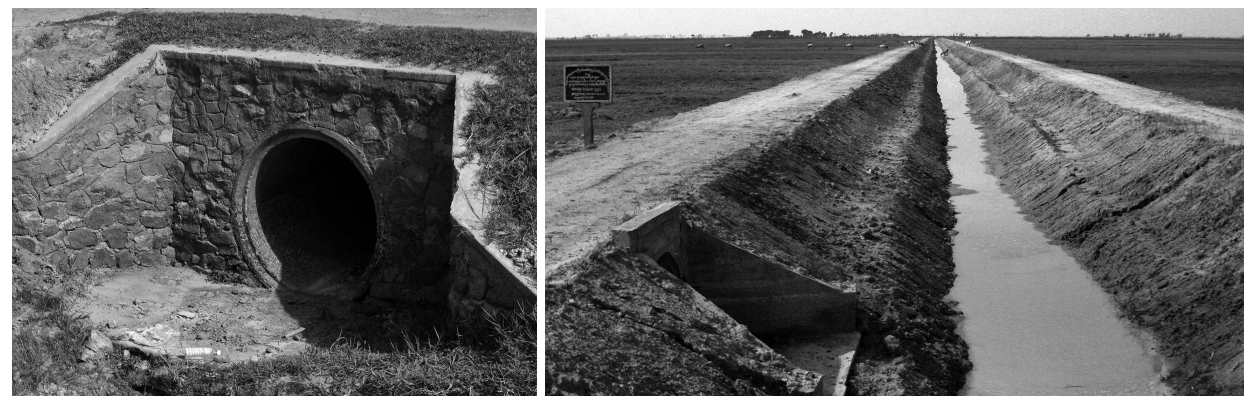

Figure 4.10. Canaux de périmètre irrigué collectif (Ducourtieux, 2014).

Buse maçonnée de l'époque Khmère rouge, canal primaire réhabilité récemment.

Plus à l'ouest et plus au sud de la zone d'étude, des aménagements de grande taille sont observables (figure 4.13). Il s'agit de concessions octroyées par l'État à des investisseurs privés pour construire des bassins de retenue remplis par la crue, irriguant en décrue des périmètres rizicoles de plusieurs centaines d'hectares (figure 4.12). 


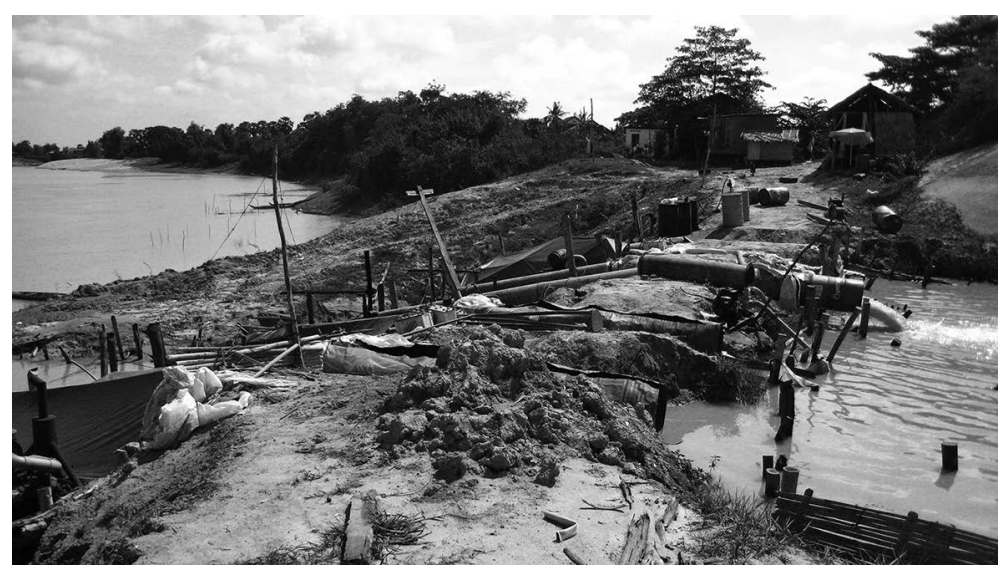

Figure 4.11. Jeu de pompes pour l'irrigation d'un périmètre irrigué collectif à partir du Stung Sen (Ducourtieux, 2014).

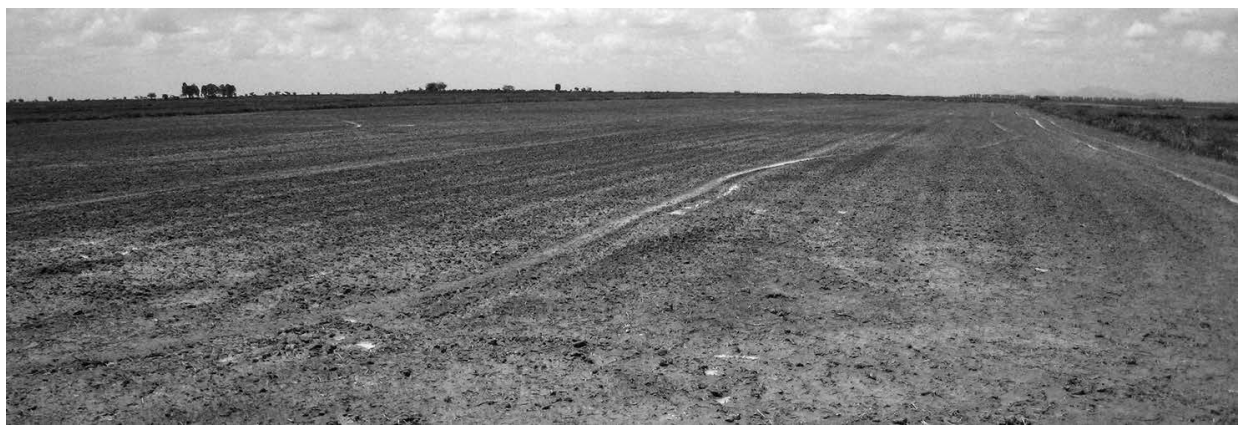

Figure 4.12. Bassin de retenue privé et parcelle de grande taille (Ducourtieux, 2014).

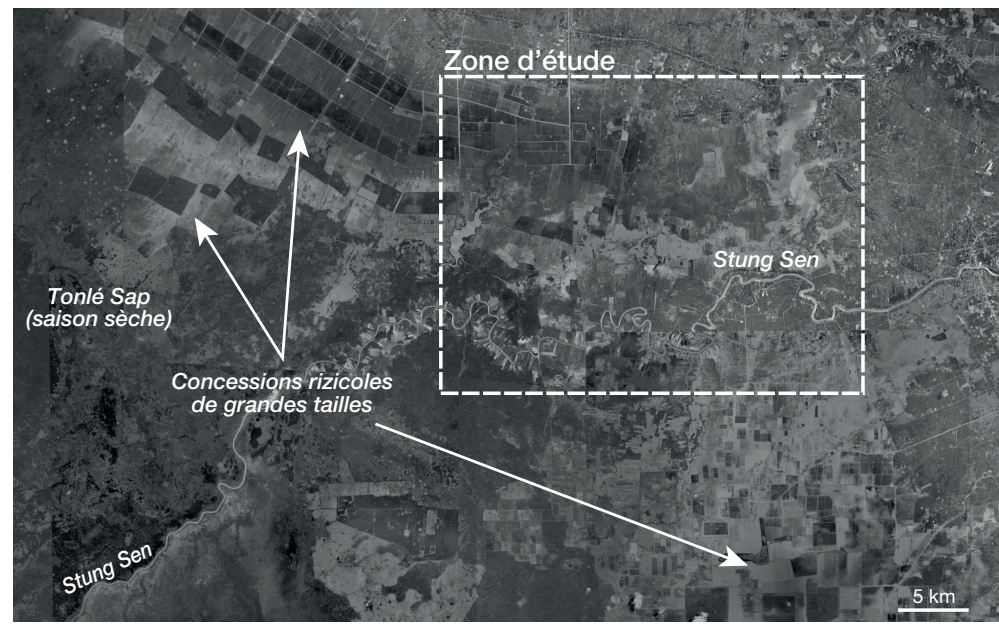

Figure 4.13. Image satellite de la région de Kampong Thom.

La région d'étude est encadrée. Les flèches soulignent les concessions rizicoles visibles sur l'image satellite (Google Earth). 
Initié en 2008, ce projet visait à céder un million d'hectares à l'Émirat du Koweït contre du pétrole (contrat de 546 millions de dollars). Face à la dénonciation croissante des accaparements fonciers internationaux, l'Émirat s'est retiré. Le gouvernement Khmer a ensuite attribué ces espaces ${ }^{14}$ à des entrepreneurs nationaux, pour la plupart de Phnom Penh et bien introduits dans les réseaux clientélistes du pouvoir. Ces entrepreneurs sont attirés par les cours soutenus du riz sur le marché mondial ${ }^{15}$. Bien que produisant une valeur ajoutée à la surface inférieure à celle des activités paysannes ${ }^{16}$, ces projets excluent les paysans d'espaces productifs et pouvant être aménagés pour améliorer leur niveau de vie et réduire leur vulnérabilité aux risques climatiques.

\section{Conclusion}

Sur les berges du Tonlé Sap au Cambodge, les paysans ont développé, de longue date, une riziculture complexe dans un milieu fortement artificialisé et avec un panel de variétés très fourni pour :

- exploiter la plus grande étendue possible de la plaine alluviale et de ses étages différenciés par le microrelief. Ils y cultivent du riz flottant, du riz de décrue, du riz de saison des pluies à un ou deux cycles, double cycle de riz irriguée en saison sèche; - limiter les risques de l'aléa climatique, notamment les incertitudes calendaires de l'inondation, l'intensité de la crue et la sécheresse;

- maximiser la productivité du travail.

Dès le début des années 1980, les familles ayant mieux traversé les vicissitudes de l'histoire récente du pays (guerre civile et régime Khmer rouge notamment) ont pu accumuler du capital. Ce capital a été rapidement mobilisé pour cultiver les plus grandes surfaces possibles dans des étages agroécologiques complémentaires et investi dans la moto-mécanisation de l'agriculture (motoculteur et pompe). Ces équipements contribuent à sécuriser la production agricole face à l'aléa climatique en conférant une plus grande flexibilité au calendrier de travail du fait de la vitesse accrue. Ils ont permis aussi de dessaisonaliser la riziculture (irrigation de saison sèche). Lirrigation de saison sèche semble être une approche à privilégier pour réduire la vulnérabilité face à un aléa climatique appelé à s'intensifier. Cependant, la concentration des terres irrigables dans les mains des ménages les plus aisés, et surtout dans celles d'investisseurs urbains extérieurs à la région, se fait au détriment des familles les plus vulnérables n'ayant accès qu'aux zones les plus exposées à la crue. Pour ces dernières, l'émigration d'une partie des actifs familiaux vers Phnom Penh et ses emplois secondaires et tertiaires, vers les fronts pionniers agricoles des collines de l'Ouest et du Nord du pays, ou vers la Thaïlande contribue à accroître le revenu familial total et à diversifier ses sources, atténuant ainsi leur vulnérabilité.

14. Ces espaces sont acquis de manière coercitive auprès des paysans exploitant antérieurement ces terres.

15. Les entrepreneurs sont aussi attirés par la facilité «tout sauf les armes» qui permet aux exportateurs cambodgiens d'accéder au marché de l'Union européenne sans droits de douane depuis 2009 (Lécuyer et Sem, 2014).

16. J.C. Diépart, communication personnelle sur une recherche menée en 2009 à Sravov, à une dizaine de kilomètres à l'est de la région d'étude. 


\section{" L'artificialisation poussée du milieu : un aléa sous contrôle pour de fortes dynamiques de développement, à l'avenir incertain}

\section{Entre terre et eaux, le delta du Mékong}

Avec $55000 \mathrm{~km}^{2}$, le delta du Mékong est un des méga-deltas asiatiques (figure 4.14) : 18 millions de personnes y vivent (330 habitants $/ \mathrm{km}^{2}, 20 \%$ de la population du Vietnam), notamment en cultivant 7,5 millions d'hectares de terres formées par les alluvions du fleuve accumulées depuis plus de 6000 ans (Takagi et al., 2016).

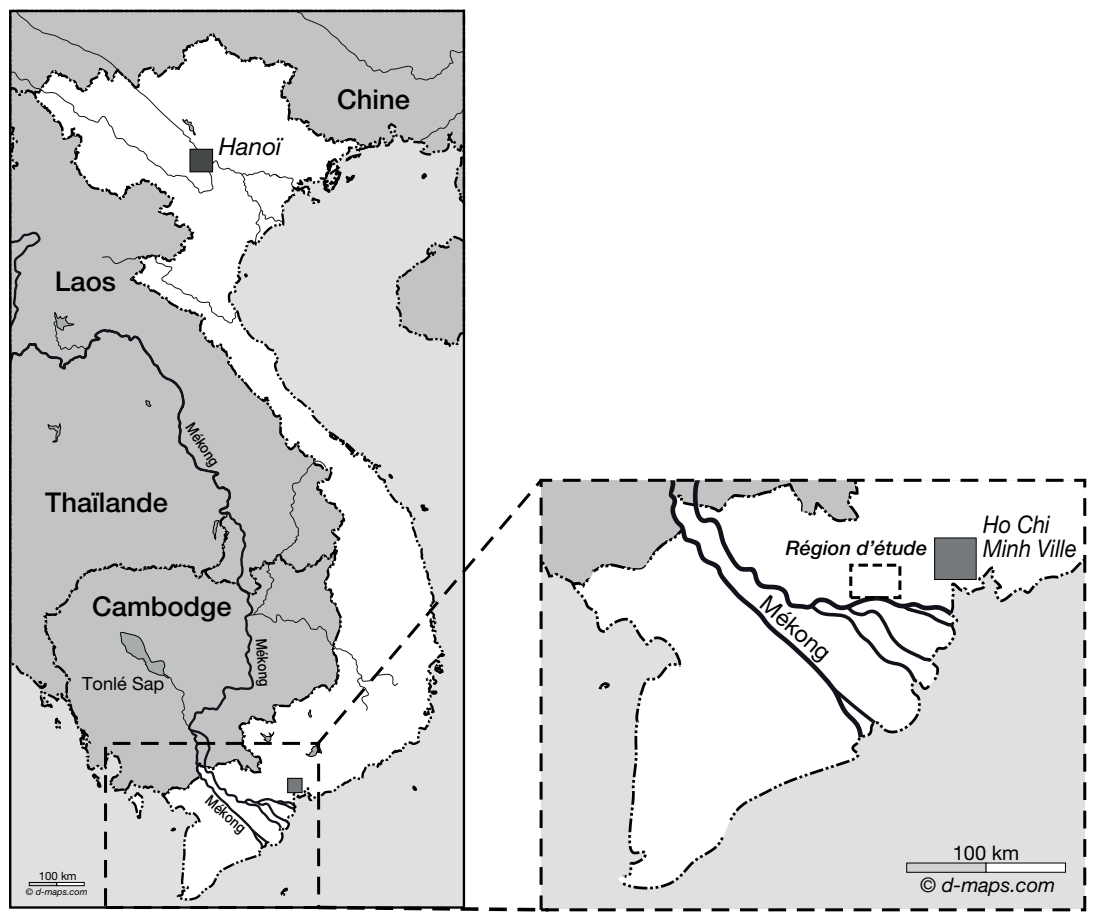

Figure 4.14. Le delta du Mékong au Vietnam.

Bien que limitrophe de la mégapole de Ho Chi Minh Ville ${ }^{17}$, le delta du Mékong ne contribue qu'à moins de $10 \%$ de la production industrielle du pays. La région est pourtant cruciale pour l'économie du pays par les productions agricoles et aquacoles de ses habitants.

La riziculture est une composante clef de l'économie et de la culture vietnamienne. En dépit des vicissitudes de l'histoire, la production nationale est croissante depuis la fin des années 1970 et le pays assure sa souveraineté alimentaire depuis le début des années 1990 (figure 4.15). Il commence alors à s'imposer comme un des acteurs

17. Ho Chi Minh Ville comptait 8,5 millions d'habitants en 2016. 
majeurs du marché mondial du riz en disputant à la Thaillande le deuxième rang des exportateurs, derrière les États-Unis. Aujourd'hui, le Vietnam exporte environ 15\% de sa production annuelle et contribue à $20 \%$ des échanges mondiaux (figure 4.16).

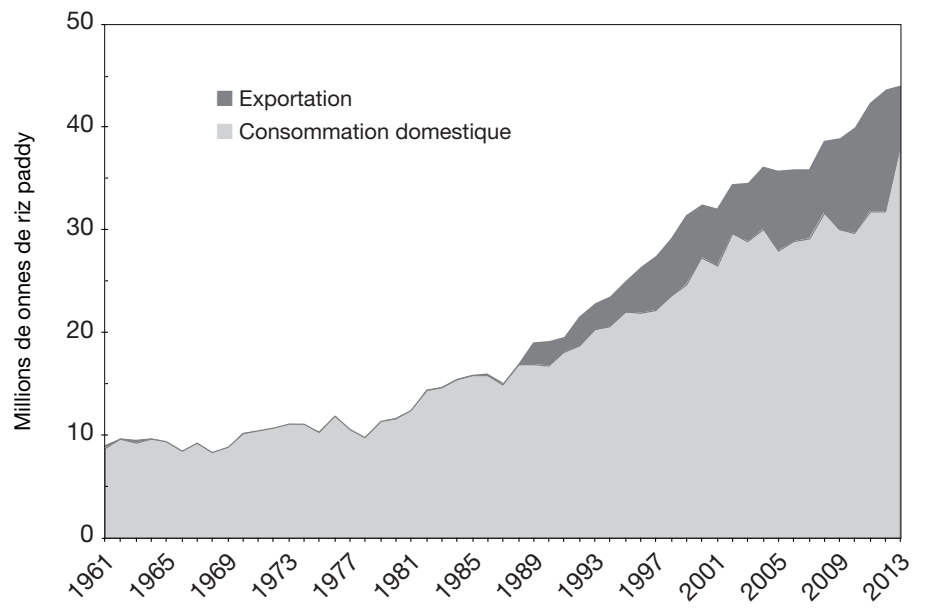

Figure 4.15. Évolution de la production de riz au Vietnam (FAOStat, 4/2017).

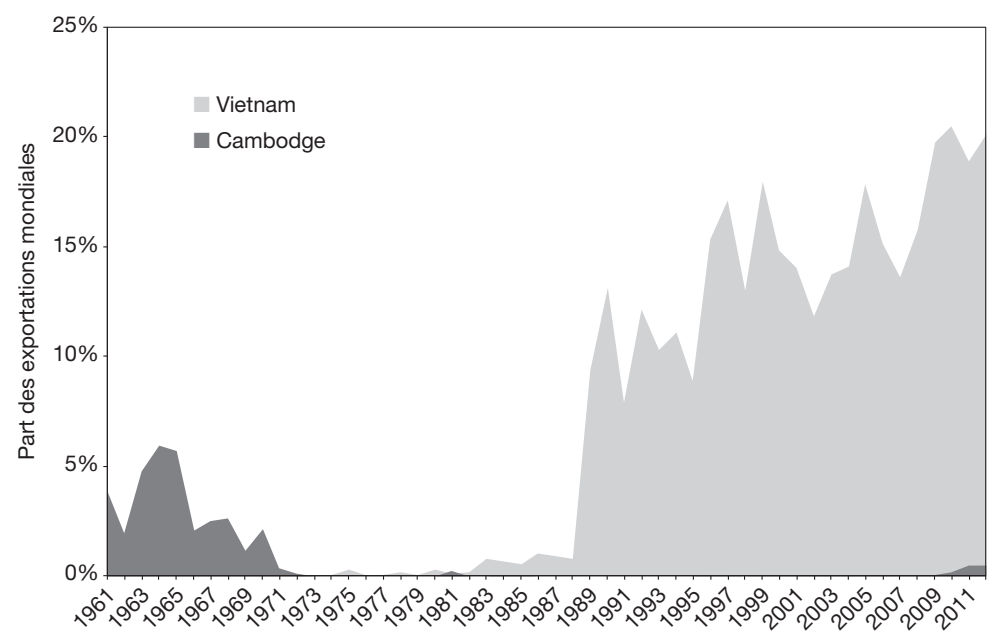

Figure 4.16. Part des exportations vietnamiennes dans le marché mondial du riz (FAOStat, 4/2017).

Les paysans du delta du Mékong tiennent une place centrale dans ces résultats : avec 25 millions de tonnes de riz paddy produits en 2015, le delta concentre $57 \%$ de la production nationale (General statistics office, 2016). Comptant pour moins de $3 \%$ de la surface rizicole mondiale, la production du delta du Mékong couvre 10-12\% des échanges internationaux, contribuant ainsi à la sécurité alimentaire de nombreuses régions du monde déficitaires en céréales. Une éventuelle contraction des récoltes de riz dans le delta — due au changement climatique par exemple aura des effets délétères globaux, dépassant largement les limites de la région. 
Embouchure du Mékong à l'extrême sud du Vietnam, le delta est une plaine alluviale de faible altitude $-0,5-5 \mathrm{~m}$ au-dessus du niveau de la mer - , parcourue par les quatre bras du Mékong et un réseau très dense de tributaires et de canaux. L'hydrologie est complexe et agrège :

- des précipitations importantes (1400 mm/an) et saisonnées (figure 4.17);

- le débit saisonnier du fleuve ( 2500 à $27000 \mathrm{~m} 3 / \mathrm{s}$ ) dépendant des précipitations sur les $810000 \mathrm{~km}^{2}$ du bassin versant;

- les marées dont l'influence de l'onde est décroissante sur $100 \mathrm{~km}$ depuisl'embouchure.

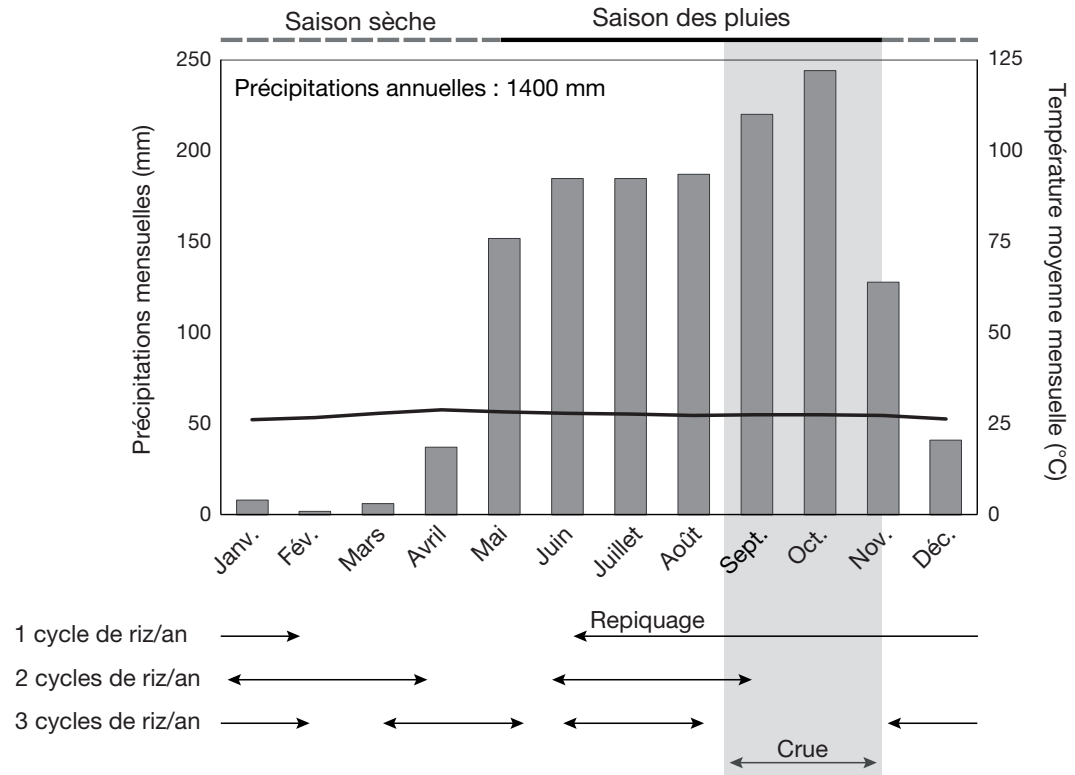

Figure 4.17. Diagramme ombrothermique de Cái Bè et calendriers de culture du riz, moyenne 1982-2012 (Champeaux, 2016; Climate-data.org).

La crue du Mékong est ambivalente. Dévastatrice quand elle dépasse le niveau des digues isolant les terres des cours d'eau, elle contribue à l'alluvionnement du delta et à la vidange des eaux saumâtres remontant dans les terres en saison sèche. Historiquement indispensable pour l'irrigation des rizières en saison des pluies, elle implique des aménagements conséquents et une savante gestion de l'eau pour drainer et mettre en valeur les zones les plus basses de la plaine alluviale.

La commune de Thiện Trí dans le district de Cái Bè, province de Tiền Giang, a été retenue comme région d'étude (figure 4.23 et figure 4.8$)^{18}$. Du fait de l'éloignement de l'embouchure, les eaux de surface sont douces, sans intrusion d'eau de mer. Londe de marée est cependant très marquée dans la zone, avec une inversion des flux deux fois par jour dans les cours d'eau. Lamplitude dépasse deux mètres entre la marée haute de vives eaux et la marée basse.

18. Le choix de ce site doit beaucoup aux professeurs Nguyễn Ngoc Thùy, directeur des relations internationales, et Nguyen Van Ngai, doyen de la Faculté d'économie de l'université Nông Lâm d'Hô-ChiMinh-Ville. Nous leur exprimons nos vifs remerciements. 


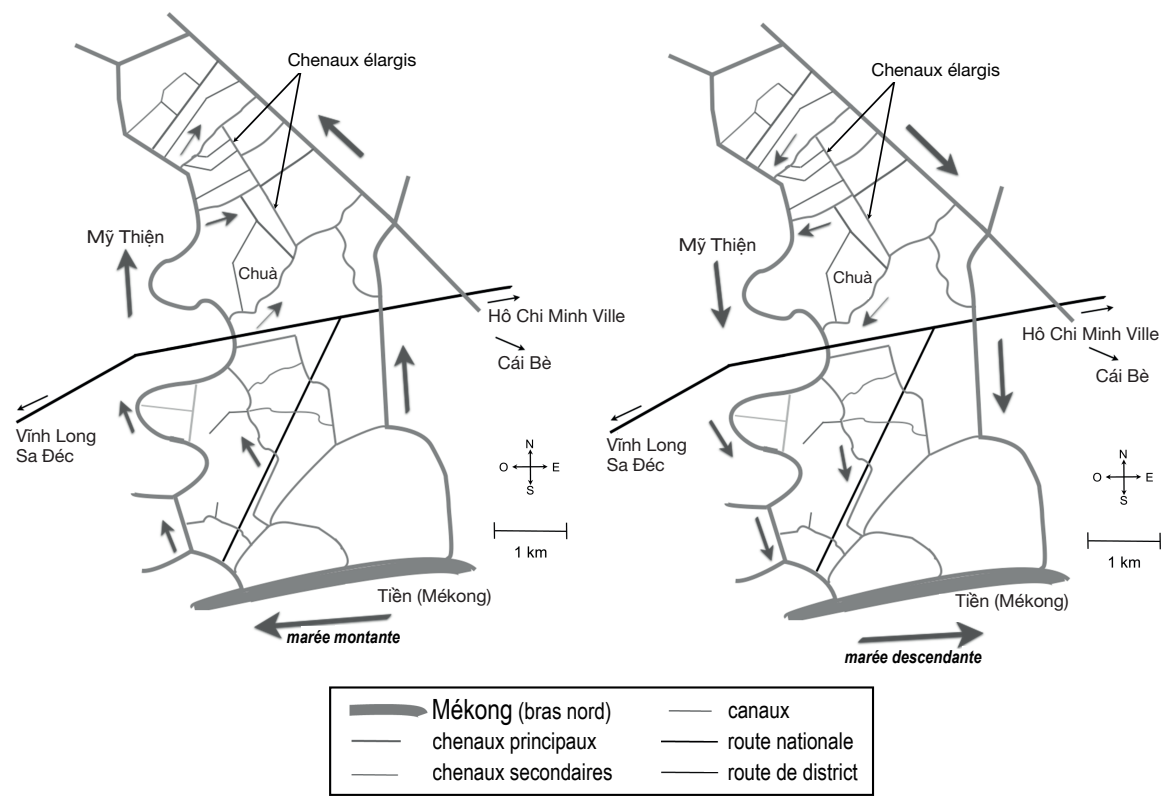

Figure 4.18. Marées et flux dans les chenaux de la commune de Thiện Trí, delta du Mékong (Champeaux, 2016, p. 12).

Dans la plaine inondable, une pente très faible $(0,03 \%$ en moyenne) distingue le bourrelet de berge du Mékong, plus sableux, des zones les plus basses, plus argileuses, pour un dénivelé de deux mètres. Ce microrelief, peu perceptible, explique l'exposition différenciée des terres à l'inondation lors de la crue (septembrenovembre) et du cycle journalier des marées (figure 4.19) :

- au sud, le sommet du bourrelet de berge est toujours émergé. Les habitations y sont implantées, comme les élevages et les vergers;

- au nord, les terres les plus basses, marécageuses, sont inondées quelle que soit la marée. Il n'est possible de les mettre en valeur qu'à condition de les endiguer pour les isoler de la crue;

- entre ces extrêmes, les terrains les plus au sud ne sont inondés que lors des marées hautes de vives eaux ${ }^{19}$. Une vaste partie centrale est inondée deux fois par jour, à marée haute. La mise en valeur de ces terres passe par la capacité à utiliser l'alternance quotidienne de la marée pour drainer et irriguer les parcelles, notamment pour la riziculture.

\section{Le contrôle de l'eau pour la production de riz, une constante politique à travers les aléas de l'histoire}

À l'issue de la Seconde Guerre mondiale, la commune de Thiện Trí est principalement cultivée en riz. Le cycle annuel commence avec la saison des pluies pour des rendements d'environ 2 tonnes/ha de paddy (figure 4.20). Le sommet du bourrelet de

19. Lors des marées hautes de vives eaux, l'eau peut monter jusqu'à 1,6m en moyenne au-dessus du niveau altimétrique de référence de la mer. 
berge est forestier. Les paysans complètent leurs revenus et leur alimentation avec les jardins et les petits élevages autour des maisons, toujours sur le bourrelet de berge.

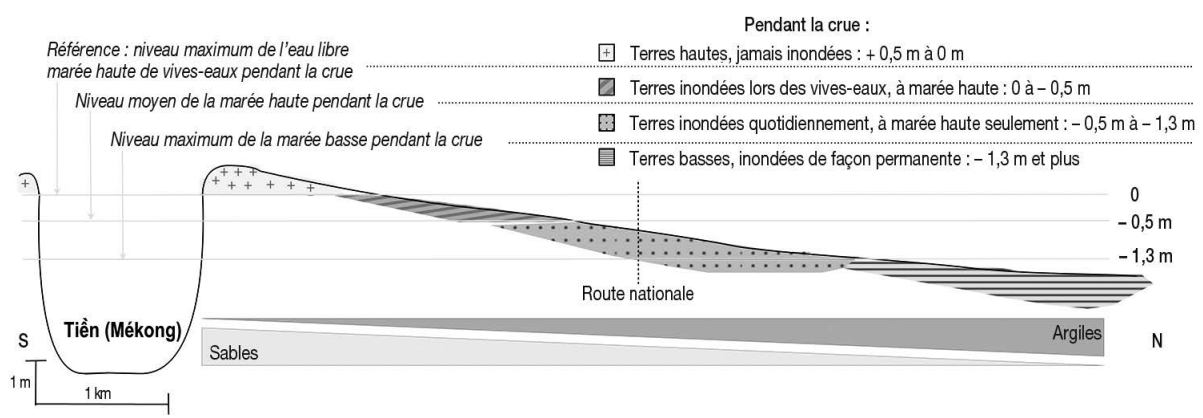

Figure 4.19. Coupe sud-nord de la commune de Thiện Trí et niveaux de l'eau lors de la crue 20 (Champeaux, 2016, p. 22).

La gestion de l'eau est sommaire, avec quelques vannes en bois dans les bourrelets de berge des chenaux. Quand les niveaux d'eau ne sont pas extrêmes, ces vannes permettent d'irriguer les casiers rizicoles à marée haute et de les drainer à marée basse (figure 4.21). En saison sèche, le niveau d'eau est trop bas, même à marée haute; les rizières ne sont pas cultivées et les animaux pâturent librement l'espace. Quand la crue est importante, le niveau d'eau dépasse les bourrelets de berge et couvre les terres, au détriment des rendements si l'inondation dure. Inondées pendant les deux à trois mois de crue, les zones les plus basses au nord sont marécageuses et ne sont pas cultivées (Champeaux, 2016).

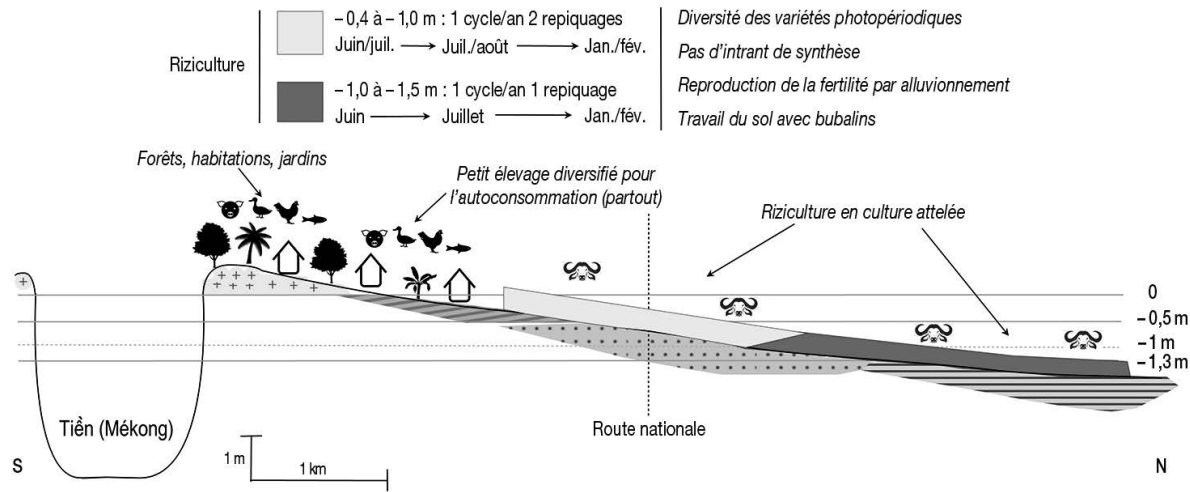

Figure 4.20. Toposéquence sud-nord de la commune de Thiện Trí à la fin des années 1950 (Champeaux, 2016, p. 30).

La différenciation sociale de la population est très marquée dans la région. Plus des deux-tiers de la population louent des petites surfaces (0,2-3 ha/famille) à des propriétaires absentéistes vivant dans les bourgs (Cái Bè) ou les villes (Mỹ Tho et Vĩnh Long, voire Saïgon). Un quart des paysans sont sans terre et sont journaliers chez les petits propriétaires en faire-valoir direct (10\% de la population, 0,5-2 ha/famille). La rente

20. Des bourrelets de berge et des levées de terre (digues) reproduisent la même séquence entre les principaux chenaux et les zones les plus basses de la plaine. 
foncière est très élevée ${ }^{21}$. Plus de la moitié des familles ne couvrent pas leurs besoins en riz, elles complètent leur revenu en vendant leur force de travail. Seules $15 \%$ des exploitations, les plus grandes (2-3 ha), possèdent des bubalins utilisés pour le travail du sol. Les autres louent la prestation ou, pour les plus petites, font le travail manuellement. Hormis l'alluvionnement par la crue, les rizières ne sont pas fertilisées; les déjections animales sont réservées aux jardins (Champeaux, 2016).
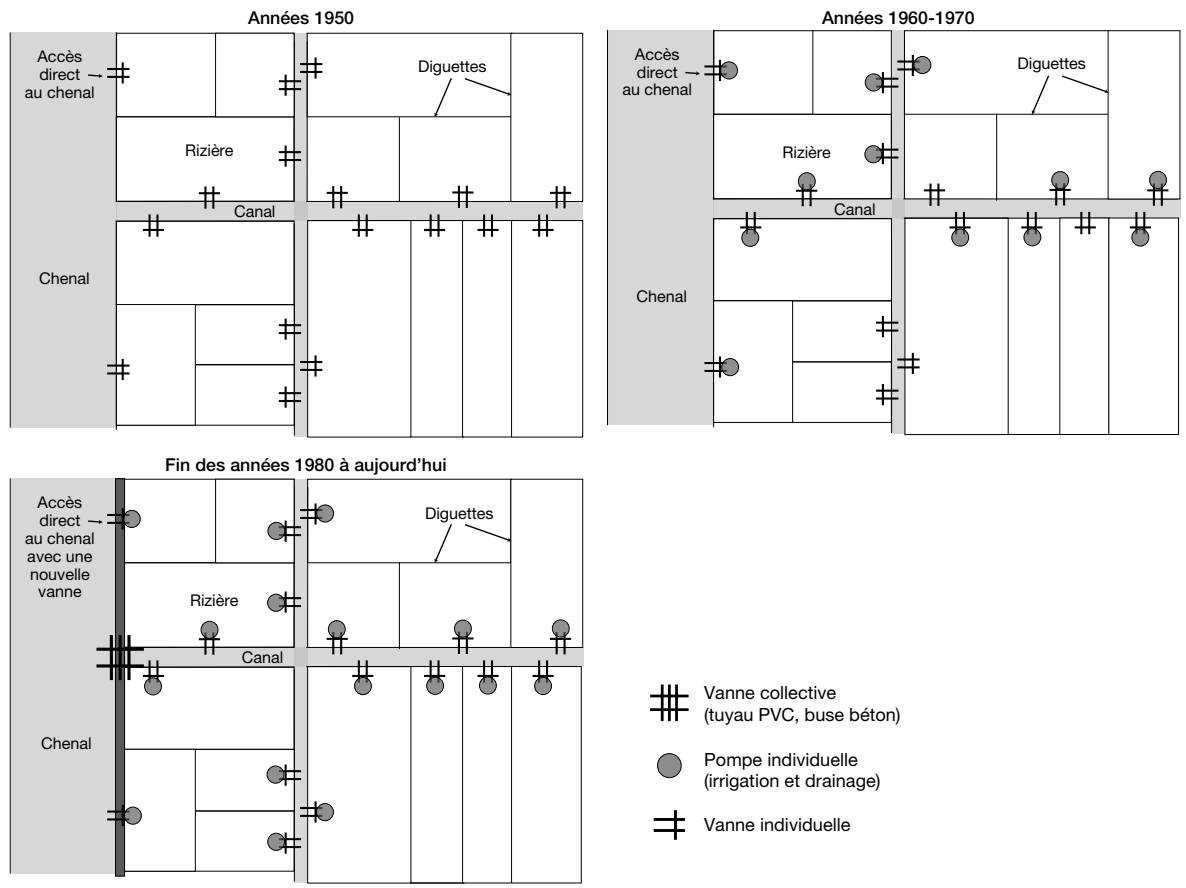

Figure 4.21. Évolution de la gestion de l'eau dans les périmètres irrigués du nord de la commune de Thiện Trí (Champeaux, 2016, p. 34, 42 et 48).

Avec les conflits de la guerre d'Indochine (1945-1954), puis de celle du Vietnam (1954-1975), l'insécurité s'installe dans le pays et la commune de Thiện Trí n'est pas épargnée. Du fait des risques dans le recouvrement des loyers, les grands propriétaires urbains libèrent leur capital en vendant leurs terres à des petits propriétaires locaux ou aux fermiers les mieux établis. Le gouvernement du Vietnam du Sud, sous la pression insistante des États-Unis qui financent la démarche, va initier deux réformes agraires. Elles visent à favoriser le faire-valoir direct pour, en supprimant le fardeau de la rente foncière, capter le soutien de la masse des paysans ${ }^{22}$ potentiellement tentés par la propagande communiste sur la réforme agraire au Nord-Vietnam.

21. La rente foncière croît avec la surface, de $650 \mathrm{~kg}$ de riz paddy $/ \mathrm{ha}$ ( $25 \%$ de la récolte moyenne) pour une surface louée de moins d'un hectare, à 1,5 tonne/ha ( $65 \%$ de la récolte moyenne) pour une surface de trois hectares. Les propriétaires ne laissent aux paysans que le strict minimum pour reproduire leur force de travail familiale. Le fermage augmente avec l'endettement, notamment les années suivant les mauvaises récoltes. Il peut mener à une dépendance extrême vis-à-vis du propriétaire (Champeaux, 2016). 22. La démarche politique est comparable aux réformes agraires de Taïwan (1949-1951) et de Corée du Sud (1953-1955), également impulsées et financées par les États-Unis. 
La première réforme (1955-1956) est timide ${ }^{23}$ et ne porte que sur la redistribution des terres au-delà d'un plafond de 100 ha, tout en plafonnant théoriquement les loyers. Les propriétés de plus de 100 ha n'existant plus à Thiện Trí, elle n'a pas d'effet dans la commune (Dufay et al., 1995). La seconde, plus radicale, est lancée en 1970. Intitulée Land for cultivators, elle comprend l'interdiction du faire-valoir indirect et un plafond de propriété de trois hectares. Cette réforme est politiquement motivée par les affrontements qui s'intensifient dans le delta et la difficulté à contrôler la population. Les villageois sont regroupés le soir le long de la route nationale dans des «villages sécurisés», gardés par l'armée du Vietnam du Sud, et accèdent péniblement à leurs champs éloignés en journée. Dans la commune, la réforme agraire se traduit par la disparition du fermage; la différenciation sociale se réduit, avec $75 \%$ de la population exploitant des surfaces rizicoles de 0,2 à 3 ha $(50 \%$ avec moins d'un hectare) en faire-valoir direct. Cependant, les paysans sans terre sont exclus des redistributions et continuent à vivre de salaires journaliers.

En parallèle, l'État sud-vietnamien subventionne la diffusion de nouveaux paquets techniques : premières variétés de riz non-photopériodiques à cycle court et à haut potentiel de rendement de la révolution verte, intrants subventionnés et motopompes individuelles. Les motopompes facilitent le drainage (en période de crue) et l'irrigation (en saison sèche), permettant aux paysans de déconnecter, au moins partiellement, la gestion de l'eau dans les périmètres irrigués de l'onde de marée et du niveau de l'eau dans les chenaux (figure 4.21).

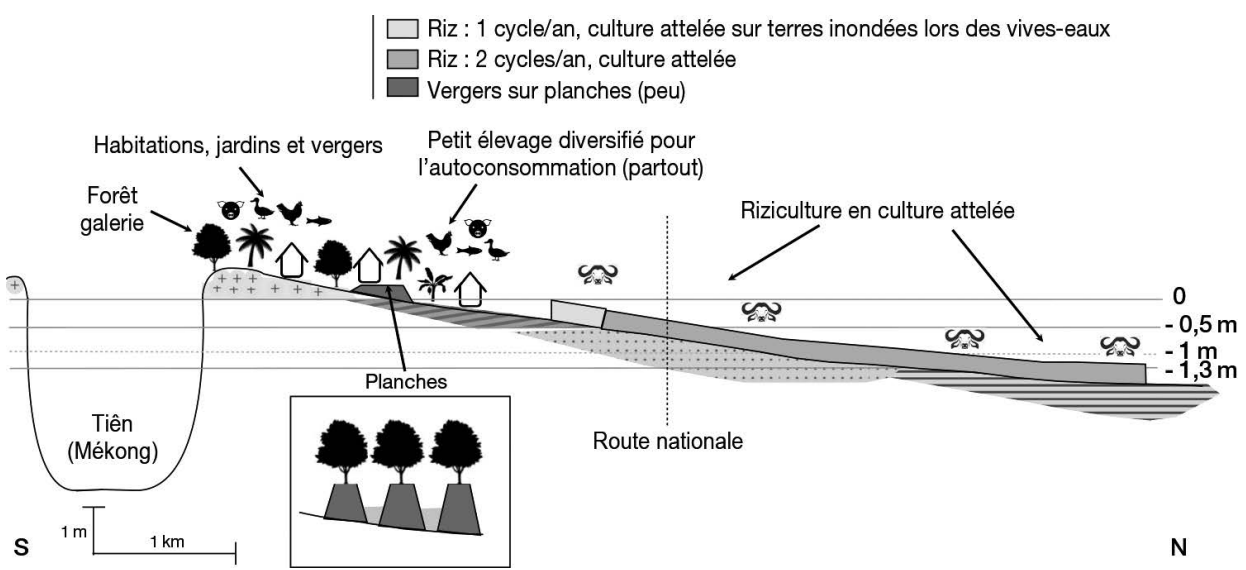

Figure 4.22. Toposéquence sud-nord de la commune de Thiện Trí au début des années 1970 (Champeaux, 2016, p. 30).

Avec des variétés de riz indépendantes de la longueur du jour, les conditions sont réunies pour l'apparition et la généralisation progressive d'un deuxième cycle de culture sur une large surface de la plaine inondable (figure 4.17 et figure 4.22). Les paysans utilisent également des nouvelles variétés de riz à cycles courts pour éviter de cultiver pendant la crue ${ }^{24}$, quand les rizières toujours peu endiguées sont exposées

23. Lindice de Gini de la répartition du foncier dans le delta du Mékong passe de 0,84 en 1955 à 0,80 en 1966 (Dao The Tuan, 2007).

24. Ces variétés à paille courte supportent très mal l'inondation. 
à l'inondation. Avec deux récoltes, la production annuelle passe à 5 tonnes/ha, puis progressivement à 13-15 tonnes quand les rendements s'accroissent avec la généralisation de l'utilisation d'engrais chimiques importés et subventionnés (figure 4.23). Le financement du saut technologique est possible avec la disparition de la rente foncière et les subventions publiques (Le Coq, 2001).

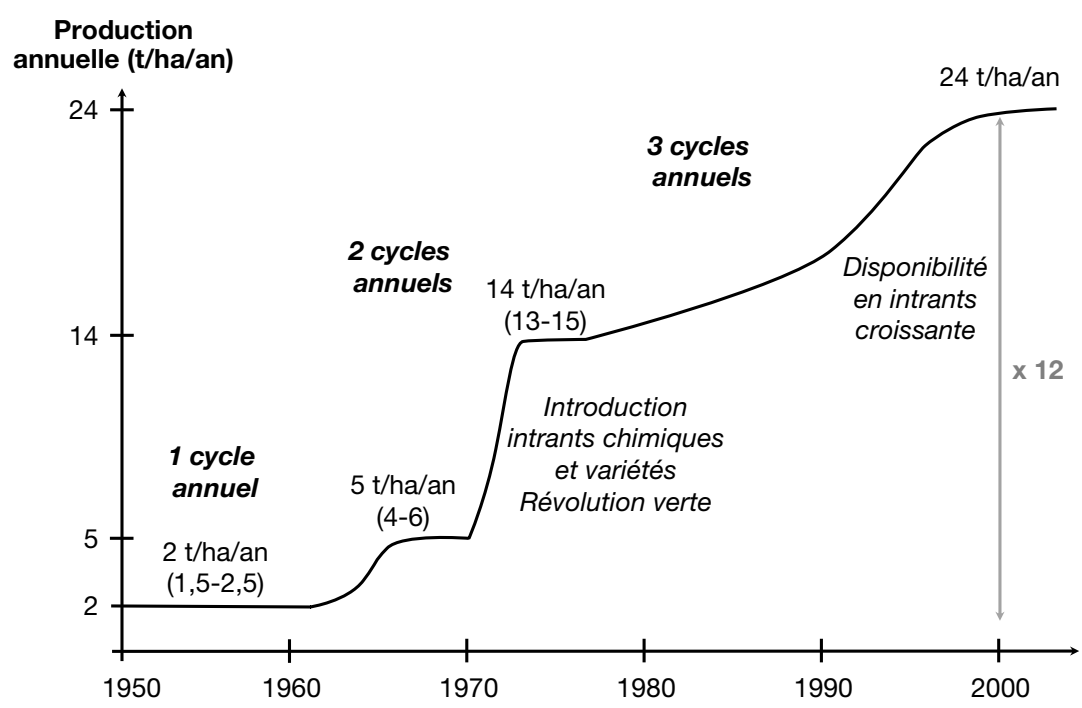

Figure 4.23. Évolution de la production annuelle de riz dans la commune de Thiện Trí (Champeaux, 2016, p. 66).

Sur le bourrelet de berge, la forêt galerie disparaît. Elle est progressivement défrichée et remplacée par des vergers qui s'étendent progressivement vers le nord. Avec la nouvelle sécurité foncière et leurs moyens accrus, les paysans investissent dans des vergers drainés par l'aménagement de planches (figure 4.22; photo 4.4, planche 6).

Après la réunification de fait du Vietnam en avril 1975, une nouvelle réforme agraire est initiée dans le delta. Elle vise à redistribuer les terres à raison de 0,1 ha de rizière par actif. Son effet est limité dans la commune de Thiện Trí, seulement un quart des paysans sans terre reçoivent des parcelles pour s'installer. Alors que l'économie vietnamienne est exsangue à l'issue de plus de 30 ans de conflits, la priorité gouvernementale est à la sécurité alimentaire. L'idéologie communiste est mise de côté par le nouveau régime : il n'y a pas de collectivisation dans le delta du Mékong (Dao The Tuan, 2007; Le Coq, 2001). L'État investit dans des infrastructures visant à sécuriser et accroître la production rizicole : l'ouverture de canaux et l'endiguement commencent en 1978 (figure 4.24 et figure 4.25). Les digues sont construites en chantier collectif le long des chenaux pour surélever les bourrelets de berge. Elles comportent des vannes découplant les chenaux et canaux primaires du réseau secondaire d'irrigation et de drainage (figure 4.22 et figure 4.24).

Il est maintenant possible de caler un troisième cycle de riz dans l'année, à la condition de réduire au minimum le temps consacré aux travaux préparatoire à chaque cycle. La moto-mécanisation du travail du sol se développe avec l'introduction, 
planifiée et subventionnée par l'État, de motoculteurs polyvalents (transport et labours) et des premiers tracteurs. La généralisation progressive de l'usage des motoculteurs au cours des années 1980-1990 s'accompagne de celle des trois cycles annuels de riziculture. Faute d'espace de pâture (figure 4.25), l'élevage bubalin va régresser jusqu'à disparaître dans les années 2000.

Dans les rizières les plus hautes, il n'est possible de cultiver qu'un seul cycle de riz par an faute de pouvoir irriguer par pompage en saison sèche, quand l'eau est trop éloignée (figure 4.22 et figure 4.23). Les paysans convertissent progressivement ces rizières en vergers, assurant un revenu familial accru et des rentrées de trésorerie plus continues sur l'année.

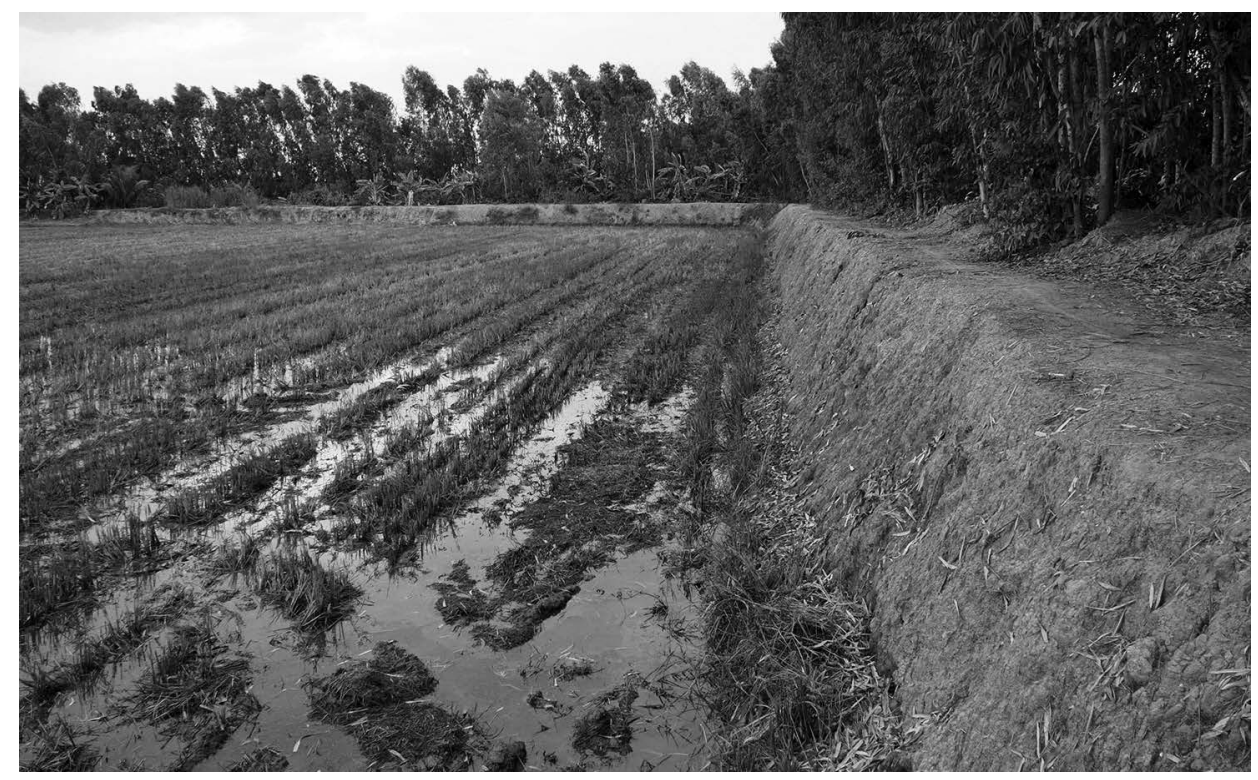

Figure 4.24. Digues dans la commune de Thiện Trí (Champeaux, 2016).

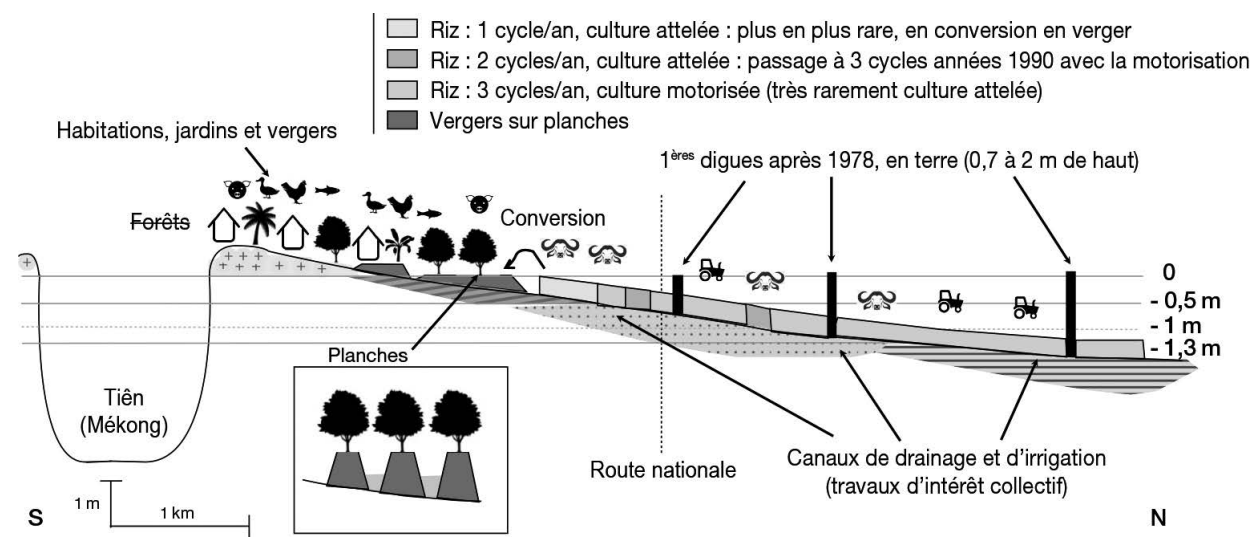

Figure 4.25. Toposéquence sud-nord de la commune de Thiện Trí dans les années 1980-1990 (Champeaux, 2016, p. 54). 
S'il est maintenant théoriquement possible d'obtenir près de 24 tonnes de riz par $\mathrm{an}^{25}$, les difficultés d'approvisionnement en intrants via les coopératives obèrent les résultats loin du potentiel. Il faut attendre la réorganisation progressive de circuits d'approvisionnement privés après la promotion de l'économie de marché ${ }^{26}$ pour que les intrants, les semences, les pièces détachées, les services, les crédits de campagne et les commerçants soient accessibles en temps et en heure pour les paysans. En quarante ans, la production de riz par unité de surface est multipliée par douze (figure 4.23), tout en s'affranchissant progressivement des aléas de la crue par un endiguement croissant conduit et financé par l'État. Au début des années 2000 en effet, les digues sont rehaussées et bétonnées, de nouvelles sont construites, y compris au sud pour protéger les terres hautes (figure 4.26).

$\mathrm{Au}$ nord, la généralisation de la moto-mécanisation pour le travail du sol et la récolte passe généralement par le recours à des prestataires de services privés disposant de tracteurs et de moissonneuses-batteuses (photo 4.3, planche 5). Cela permet aux paysans de réduire au minimum les périodes où la production photosynthétique est nulle dans les parcelles, au profit de la croissance du riz dans trois cycles annuels.

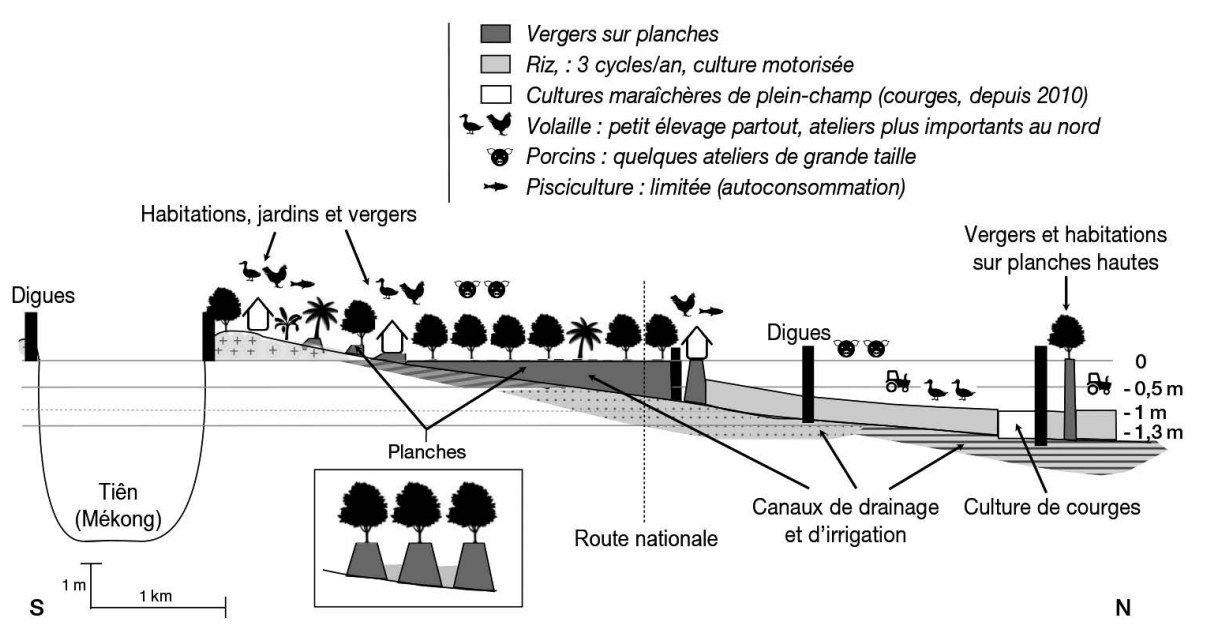

Figure 4.26. Toposéquence sud-nord de l'actuelle commune de Thiện Trí (Champeaux, 2016, p. 64).

Le développement économique de la mégapole de Ho Chi Minh Ville, et plus généralement des zones urbaines du Vietnam, accroît la demande en produits frais. La valeur ajoutée par unité de surface des vergers étant supérieure à celle des rizières, les agriculteurs ont intérêt à convertir leurs exploitations, dont la plupart font moins d'un demi-hectare. L'endiguement dans la moitié sud de la commune permet aux paysans de drainer les terres intermédiaires et de les convertir en vergers (figure 4.26 et figure 4.27).

25. Sur l'ensemble du delta du Mékong, la culture de trois cycles de riz reste limitée. La double-culture domine (Duy Ba Nguyen et al., 2015).

26. La politique de l'économie socialiste de marché (Dổi Mới), initiée par le parti unique et l'État en 1986, se traduit par une libéralisation de l'économie au cours des années 1990. 


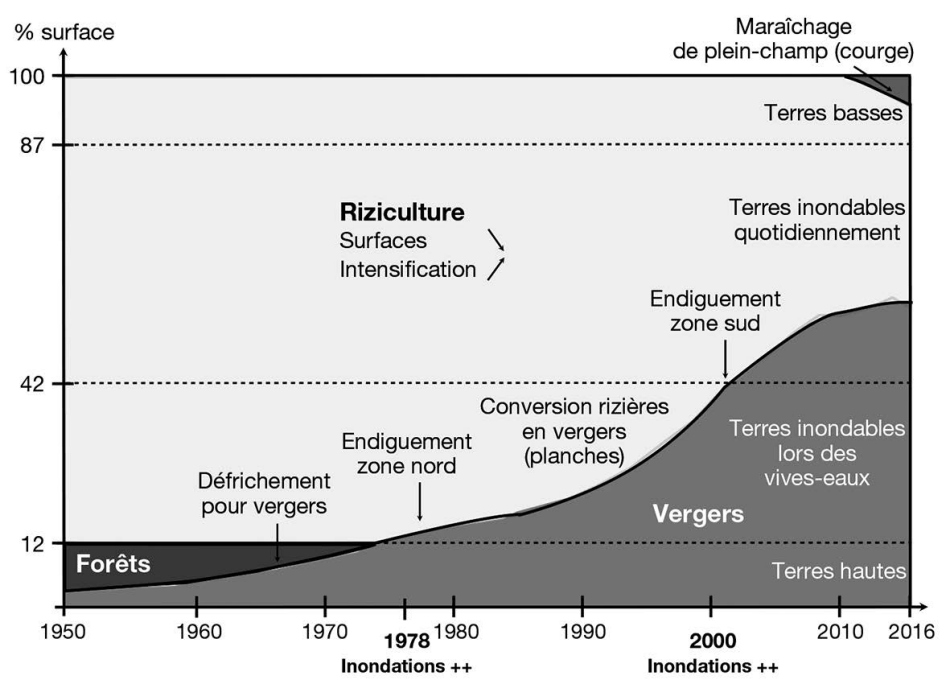

Figure 4.27. Évolution de l'utilisation des terres dans la commune de Thiện Trí de 1950 à 2016 (Champeaux, 2016, p. 62).

Dans cette «économie socialiste de marché», l'État est très présent avec une priorité constante de sécurité et de souveraineté alimentaire en riz. Les subventions directes sont très limitées (environ 20 euros/ha), mais l'État intervient indirectement par :

- le financement et la coordination des programmes de construction d'infrastructures d'irrigation, d'endiguement et de communication (routes);

- le subventionnement des entreprises agréées pour acheter le riz paddy aux paysans. Il permet de garantir un prix bord-champ rémunérateur et stable, déconnecté des variations du marché mondial (Bo Chen et Saghaian, 2016);

- le contrôle des exportations via les entreprises publiques (50\% des exportations), des quotas de volume et du prix minimum d'exportation imposés aux entreprises privées regroupées dans la Vietnam food association (VFA);

- la quasi absence des taxes d'importation sur les intrants et la libéralisation de leur commercialisation depuis les années 1990. La généralisation de l'usage massif des fertilisants est facilitée par le développement d'une production nationale d'engrais azotés à partir du pétrole extrait en Mer de Chine depuis le début des années 2000 (50\% de la demande nationale);

- la facilitation de l'accès aux crédits de campagne et d'équipement, à taux subventionnés, octroyés par des banques publiques;

- la quasi absence d'impôt pour les ménages agricoles.

\section{Une économie agricole prospère}

En 50 ans, l'agriculture du delta du Mékong s'est profondément transformée. Sur un territoire ravagé par 30 ans de guerre, la paysannerie locale a fait de la région un acteur économique majeur de l'économie nationale avec $68 \%$ de la production vietnamienne de fruits (General statistics office, 2016), et du marché mondial du riz (20\% du commerce mondial, figure 4.16). Durant le demi-siècle de cette 
métamorphose, l'État a accompagné la mutation d'une paysannerie peinant à satisfaire ses besoins de base et étranglée par la rente foncière en une agriculture familiale commerciale performante.

La valeur ajoutée nette créée par un actif est importante, variant de 1000 à 18000 euros/an selon les systèmes de production (Champeaux, 2016) dans la commune de Thiện Trí. Le revenu national net par habitant atteint 1500 euros en moyenne en 2015 au Vietnam (Banque mondiale, 2016). Pour la plupart des familles, les revenus obtenus sont au moins comparables à ceux des opportunités d'emplois accessibles à Ho-Chi-Minh-Ville et dans les villes du delta, limitant ainsi l'attraction urbaine et les migrations associées. Cependant, la petite taille des exploitations ${ }^{27}$ implique de ne pas les diviser lors des successions intergénérationnelles pour qu'elles restent viables. Dans chaque famille, ne reste sur l'exploitation, avec les parents, que le fils repreneur et son épouse. Les autres frères émigrent vers les villes ou les régions agricoles de montagne à revenus inférieurs (Déry, 2004; De Koninck, 2013). Les sœurs rejoignent l'unité économique de leur mari. La croissance démographique est très faible en zones rurales du delta : 0,1\% entre 2010 et 2015, contre $8 \%$ pour les zones urbaines (General statistics office, 2016).

Ces résultats économiques conséquents sont obtenus au prix d'un travail énorme dans l'exploitation familiale. La combinaison des aménagements des parcelles, de leur entretien, de l'entretien des digues, de l'itinéraire technique sur trois cycles annuels de riz, de la conduite des élevages porcins et aviaires (confinés), des productions maraîchères, de la mise en marché des productions et de l'approvisionnement sature le calendrier de travail annuel de tous les actifs de l'exploitation, voire implique le recours à des salariés extérieurs. Ceux-ci sont les laissés-pour-compte des dynamiques de développement du delta. Descendant des paysans sans terre du milieu du $\mathrm{XX}^{\mathrm{e}}$ siècle, ils ont été ignorés par l'État, sud-vietnamien ou communiste, lors des réformes agraires successives. De génération en génération, ils vivent du salariat journalier (300 à 900 euros/an/actif; Champeaux, 2016). Nombreux sont les paysans sans terre ayant migré vers les zones urbaines et le mouvement continuera à l'avenir; ils ne comptent aujourd'hui que pour moins de $5 \%$ des foyers du delta.

\section{Un avenir exposé aux changements globaux}

Encouragée par l'État depuis plus de 50 ans dans le delta du Mékong, la révolution verte a permis l'émergence d'une agriculture familiale prospère contribuant au développement économique soutenu du pays. Cependant, les options politiques retenues exposent les paysans aux risques induits par le changement climatique et plus généralement aux changements globaux.

\section{Changement climatique et transgression marine}

Le risque le plus médiatisé (Perrin et al., 2016; Vaulerin, 2016) car le plus marquant est la montée du niveau moyen de la Mer de Chine du fait de sa dilatation thermique (MoNRE, 2009; Mai Van Khiem, 2014) : le delta du Mékong est la région la plus menacée d'Asie du Sud-Est (Le Minh Nhat, 2015).

27. La taille des petites exploitations familiale est de 1,6 ha en moyenne (Champeaux, 2016). 
Dans les projections des chercheurs du ministère vietnamien des Ressources naturelles et de l'Environnement (MoNRE), la hausse pourrait atteindre $75 \mathrm{~cm}$ (scénario moyen) en 2100 par rapport au niveau moyen de 2005, voire $100 \mathrm{~cm}$ (scénario haut). Cela se traduirait, toute chose égale par ailleurs, par une transgression sur 20 à $40 \%$ des terres du delta (MoNRE, 2009), dont l'altitude ne dépasse pas 2,5 m. Dans la province de la région d'étude (Tiền Giang), cela concernait près d'un tiers des surfaces, notamment les terres les plus basses au nord de la commune de Thiện Trí (figure 4.19 et figure 4.26). En rythme annuel, les modélisations du changement climatique donnent une hausse comprise entre 0,3 à $0,6 \mathrm{~cm} / \mathrm{an}$.

\section{Changement climatique et risques d'inondation}

Dans la région, le changement climatique se traduit déjà par une hausse mesurable des précipitations. La tendance est appelée à s'amplifier en saison des pluies dans le delta (MoNRE, 2009), ainsi qu'à l'échelle du bassin versant du Mékong (figure 4.1) avec une variabilité interannuelle accrue (Eastham et al., 2008; Icem, 2013a; Lacombe et al., 2010). Cela implique des crues plus importantes et plus aléatoires (IPCC, 2012; Teng et al., 2016), phénomène déjà notable au cours du $\mathrm{Xx}^{\mathrm{e}}$ siècle (Delgado et al., 2009). Les crues exceptionnelles, dépassant les capacités des digues existantes, ont marqué la mémoire des paysans par l'ampleur des dégâts occasionnés (1978 et 2000 notamment). Si ces aléas exceptionnels deviennent de plus en plus fréquents, la péjoration risque d'entraver la mise en valeur des zones les plus basses du delta, comme le nord de la commune de Thiện Trí, qui pourrait redevenir inculte, comme dans les années 1950 (figure 4.20).

\section{La subsidence accélérée du delta du Mékong}

Du fait de la compaction des alluvions sous leur propre poids, leur porosité tend à diminuer, réduisant d'autant leur épaisseur. Ainsi, le delta «s'enfonce» par rapport au niveau de la mer. Dans le delta du Mékong, ce phénomène tend à se réduire avec l'endiguement progressif des terres, qui interrompt l'alluvionnement, moteur de la subsidence ${ }^{28}$.

Cependant, la subsidence est également provoquée par les prélèvements d'eau douce dans les nappes phréatiques, qui se rabattent avec la multiplication des pompages. Plus d'un million de puits ont été forés dans le delta depuis les années 1980 pour couvrir les besoins domestiques et industriels, avec $430000 \mathrm{~m}^{3}$ d'eau prélevés quotidiennement (Schmidt, 2015). Avec un rabattement de l'aquifère pouvant atteindre $70 \mathrm{~cm} / \mathrm{an}^{29}$, la subsidence induite en surface varie de 1,5 à $5 \mathrm{~cm} / \mathrm{an}$. Cet effet du changement global (Takagi et al., 2016) ${ }^{30}$ vient s'ajouter à la transgression marine due à la dilatation thermique de la Mer de Chine (changement climatique) à un rythme sept fois supérieur.

28. La subsidence ne s'interrompt pas immédiatement avec l'arrêt de l'alluvionnement. Elle continue pendant quelques années, tout en tendant à s'annuler du fait de l'inertie de la compaction et de la minéralisation progressive de la matière organique.

29. Le rabattement moyen de l'aquifère a été mesuré sur la période 1995-2010 dans 106 puits (Erban et al., 2014).

30. La hausse des prélèvements en eau souterraine est due à la combinaison du développement de l'industrie dans la région, de la croissance démographique urbaine et de l'amélioration du niveau de vie de la population. 
La hausse relative du niveau moyen de la mer est la somme en valeur absolue de la hausse thermique et de la subsidence. Lendiguement est la principale mesure actuelle pour contrecarrer la transgression marine. Or, le phénomène est continu et tend à croître en vitesse et en intensité. Alors, quelles seront les limites technologiques et budgétaires de la «course à l'armement» qu'est le rehaussement récurrent des digues?

\section{La salinisation incidente des eaux et des sols}

Lest et le sud du delta du Mékong sont baignés par des eaux de surface salines, du fait de la pénétration de la marée. La combinaison de la subsidence et de la transgression marine implique également une pénétration accrue des eaux salines dans le delta, avec une extension des zones salées et une remontée vers l'ouest, en amont, des zones saumâtres (Smajgl et al., 2015).

Les niveaux de salinité des zones salées et saumâtres sont délétères pour la plupart des productions agricoles, mais propices à l'aquaculture, la pénéiculture notamment. Même si le riz est une plante halotolérante, la production est fortement réduite avec la hausse de la salinité. De cinq tonnes de riz paddy par hectare et par cycle en moyenne pour le delta du Mékong, le rendement chute à trois tonnes pour les variétés tolérantes et moins d'une tonne pour les variétés sensibles (Smajgl et al., 2015).

Toujours dans la combinaison des effets du changement global au-delà du seul changement climatique, la multiplication des barrages hydroélectriques sur les affluents et le cours majeur du Mékong depuis une dizaine d'années tend à transférer une partie du débit du fleuve de saison des pluies en saison sèche. La raison en est le stockage dans les réservoirs pour produire de l'énergie en continue sur l'année. Lécrêtage partiel de la crue pourrait limiter son effet de «chasse d'eau» dans le delta, qui favorise le rinçage des entrées marines de la saison sèche (Molle et al., 2009; Matthews et Geheb, 2014). Le développement de l'hydroélectricité dans le bassin versant du Mékong contribuerait ainsi à accentuer les effets des entrées d'eaux salines dans le delta, mais limiterait, dans une proportion qui reste à déterminer, les crues exceptionnelles et leurs effets délétères.

\section{Autres facteurs et effets du changement global}

En sus des principales causes de changement traitées précédemment, d'autres facteurs vont probablement interagir dans des proportions moindres (ou moins spécifiques à la région), comme par exemple :

- la hausse des températures constitutives du changement climatique pourrait réduire les rendements des cultures, notamment en riz (Teng et al., 2016). Si la quantification du phénomène reste fragile et discutée (IPCC, 2014b; chapitre 7), il est manifeste que la priorité donnée à la sélection de variétés de riz à cycle court pose problème. Notamment, quand la hausse de la température se traduit par un cycle végétatif accéléré, cela réduit la période de croissance de la plante et donc la construction du rendement;

- l'érosion de l'agrobiodiversité rizicole dans le delta avec l'adoption généralisée d'une poignée de variétés de la révolution verte. Par exemple, une seule variété (IR504), sélectionnée pour son haut potentiel de rendement, est aujourd'hui cultivée 
dans le millier d'exploitations rizicoles de la commune de Thiện Trí. La recherche agronomique vietnamienne a commencé à travailler sur l'obtention de variétés aux caractéristiques plus diversifiées (résistance à la submersion, résistance à la sécheresse, etc.). Mais le chemin reste long avant de les proposer aux agriculteurs; - le développement de l'hydroélectricité, déjà introduit, se traduira par une charge sédimentaire réduite en aval dans le fleuve, diminuant d'autant les dépôts alluvionnaires dans le delta. Cela aura un effet sur la subsidence et sur le renouvellement de la fertilité des cultures. Si le recours massif aux engrais couvre les besoins des plantes cultivées, la teneur en matière organique du sol se réduit et les problèmes de pollution des eaux sont majeurs ${ }^{31}$ (Sebesvari et al., 2012);

- l'évolution du marché intérieur des fruits frais et de la viande de porc, l'évolution des marchés mondiaux du riz, de la crevette, etc.

Pour tous ces facteurs, il est souvent difficile d'isoler ceux tenant spécifiquement au changement climatique du fait des effets synergiques ou antagonistes d'autres facteurs de changements globaux, qu'ils soient sociétaux, techniques, infrastructurels, économiques, etc.

\section{Les politiques de prévention et d'adaptation}

Avec une longue façade maritime du pays, l'exposition à la transgression marine du grenier du delta du Mékong et de celui du fleuve Rouge, l'État vietnamien s'est impliqué dans la définition de politiques de prévention des effets négatifs du changement climatique et d'adaptation de l'économie nationale dès le début des années 2000.

Les mesures furent d'abord institutionnelles avec la création d'un comité gouvernemental interministériel ${ }^{32}$ chargé de la conception politique et de sa coordination. La première disposition fut la publication d'un décret du Premier ministre ${ }^{33}$ en 2008 portant sur :

- le développement d'études et de recherches pour identifier et caractériser les effets prévisibles du changement climatique;

- le développement institutionnel nécessaire pour prendre en compte ces effets;

- la sensibilisation des institutions à tout niveau et de la population au changement climatique.

Dans ce cadre institutionnel, les centres de recherche et les universités (notamment celles des deltas) ont engagé une multitude de projets de recherche sur le changement climatique. Les rapports et publications sont aujourd'hui abondants.

Dans un second temps, le gouvernement a préparé la «Stratégie nationale sur le changement climatique » en 2011. En 2012, cette stratégie a été déclinée dans le plan national d'action pour répondre au changement climatique 2012-2020, ainsi qu'une

31. La pollution est exacerbée par l'utilisation également massive de pesticides. La pollution des eaux de surface pousse à utiliser l'eau profonde pour l'usage domestique, contribuant ainsi à l'accélération de la subsidence.

32. Le secrétariat du comité gouvernemental interministériel est hébergé au ministère des Ressources naturelles et de l'Environnement.

33. Decision on approval of the National Target Program to respond to climate change. $n^{\circ} 158 / 2008 / \mathrm{QD}-\mathrm{TTg}$, The Prime Minister, Hanoi 12/12/2008. 
série de textes sectoriels comprenant des objectifs de réduction des émissions de gaz à effet de serre, de protection de l'environnement (recyclage des déchets et protection de la forêt) et de lutte contre la pauvreté, ainsi que de conversion vers une économie verte économe en carbone.

Ce volontarisme politique et cette profusion de textes législatifs et exécutifs ont permis d'attirer beaucoup d'agences bilatérales et multilatérales d'aide publique au développement ${ }^{34}$ (Le Minh Nhat, 2015). Malheureusement, les mesures concrètes directement applicables au bénéfice des paysans du delta du Mékong restent à inventer (Main Van Khiem, 2014).

Le projet envisagé est d'isoler le delta de la mer par une série de digues et de portes géantes sur les bras du fleuve, à l'instar des polders néerlandais. Ce projet pharaonique et radical nécessiterait de cinq à huit milliards d'euros d'investissement et plus de 500 millions d'euros d'entretien annuel (Smajgl et al., 2015). En plus de ces montants, il faudrait prévoir d'autres moyens financiers au cas où l'infrastructure serait endommagée ou insuffisante pour faire face aux nombreux typhons affectant la côte est du Vietnam. Lintensité de ces typhons pourrait s'accroître à l'avenir.

\section{Conclusion : impact des changements globaux sur l'agriculture de Thiên Trí}

Dans une région exposée annuellement à la crue du Mékong, les paysans et l'État ont appris à prévenir les risques de l'inondation tout en utilisant au mieux l'eau et les alluvions drainées. L'État a permis le contrôle de l'aléa et la réduction du risque par des investissements réguliers et croissants dans les infrastructures d'endiguement et d'irrigation. Les réformes agraires successives ont permis l'émergence d'une agriculture familiale efficiente. En maximisant la valeur ajoutée après avoir investi dans des équipements (moto-mécanisation) et des plantations, les agriculteurs ont fait du delta une région prospère, un «grenier à riz» (et à fruits) du pays. Cependant, cette réussite est de plus en plus exposée aux nouveaux risques du changement global : transgression marine, subsidence accélérée et risque accru d'inondation.

La spécialisation poussée des différentes exploitations agricoles accentue la sensibilité à l'aléa. N'accédant qu'à un écosystème unique, les agriculteurs le mettent en valeur aux mieux de leurs capacités. Néanmoins, ils restent vulnérables si les conditions du milieu ou du marché sortent du domaine de sécurité construit au cours de l'histoire. Par exemple, les crues exceptionnelles à venir, plus fréquentes, pourraient dépasser la hauteur des digues et exposer les paysans des systèmes de production agricole des zones les plus basses si la nappe d'eau perdure sans être drainée.

\section{W Conclusion}

Avec le volontarisme politique au Cambodge et, plus encore, au Vietnam, les études et les recherches se sont multipliées pour identifier et caractériser les effets

34. Parmi ces agences, on note la présence de la Banque mondiale, Asian development bank, le Pnud, le JICA, l'USAid, l'Agence française de développement ou la Coopération néerlandaise. 
du changement climatique dans le bas Mékong. Si les phénomènes physiques sont longuement analysés et modélisés, la caractérisation des effets du changement climatique sur les agriculteurs souffre systématiquement, ou presque, des défauts suivants : - les agriculteurs sont considérés ${ }^{35}$ comme une catégorie homogène d'agents économiques. La différenciation socio-économique n'est pas prise en compte. Est également ignoré l'accès inégal aux différents écosystèmes, dont dépend pourtant la résilience, la vulnérabilité et les capacités d'adaptation des différents systèmes de production agricole aux effets du changement global;

- les effets projetés du changement climatique sont comparés à une situation de référence qu'est la base actuelle, sans tenir compte du fait que le contrefactuel (qu'adviendrait-il sans changement climatique?) est également un scénario dynamique, changeant;

- les effets du changement climatique sont modélisés «toutes choses égales par ailleurs», sans prendre en compte les interactions avec d'autres dynamiques du changement global, ni la réactivité des agriculteurs face à l'adversité.

Les deux régions étudiées ne sont distantes que de $300 \mathrm{~km}$ dans la basse vallée du Mékong. Mais les systèmes agraires diffèrent radicalement par les agroécosystèmes, les pratiques agricoles, les rapports sociaux, les politiques et les dynamiques historiques de différenciation socio-économiques. Cela confère aux différents systèmes de production des niveaux de résilience et de vulnérabilité variables, tout comme leurs capacités d'adaptation. Les paysans cambodgiens cherchent à diversifier leurs systèmes de culture en accédant à différents étages écologiques pour limiter les effets de l'aléa peu maîtrisé qu'est la crue. Quant à ceux du delta du Mékong, ils ont profité de la réduction du risque par l'endiguement financé par l'État pour se spécialiser et accroître la productivité du travail familial. Ladaptation au changement climatique, et plus généralement aux changements globaux, ne repose pas sur une solution unique, mais sur des actions ciblées et sélectionnées avec soin à partir de la connaissance fine des dynamiques locales.

\section{Méférences}

Arias M.E., Cochrane T.A., Piman T., Kummu M., Caruso B.S., Killeen T.J., 2012. Quantifying changes in flooding and habitats in the Tonle Sap lake (Cambodia) caused by water infrastructure development and climate change in the Mekong Basin. Journal of environmental management 112, 53-66.

Bo Chen, Saghaian S., 2016. Market integration and price transmission in the world rice export markets. Journal of agricultural and resource economics 41(3), 444-457.

Champeaux E., 2016. Diagnostic agraire : delta du Mékong, commune de Thi n Trí, Ti n Giang, Vietnam. Mémoire de fin d'étude, UFR Agriculture comparée et Développement agricole. Paris : AgroParisTech, AFD, 129 p.

Chu Thai Hoanh, Jirayoot K., Lacombe G., Srinetr V., 2010a. Comparison of climate change impacts and development effects on future Mekong flow regime. In : Proceedings of the conference Modelling for Environment's Sake, International congress on environmental modelling and software, Fifth biennial meeting. Ottawa, 9 p.

35. Parmi les rares exceptions, citons la publication de Le Dang Hoa et ses collègues de l'Université Nong Lam à Ho Chi Minh Ville (Le Dang Hoa et al., 2017). 
Chu Thai Hoanh, Jirayoot K., Lacombe G., Srinetr V., 2010b. Impacts of climate change and development on Mekong flow regime, First assessment. MRC Technical Paper 29. Vientiane: Mekong river commission, $104 \mathrm{p}$.

Dao The Tuan, 2007. Consecutive agrarian reforms and success in family farming. In: Land policies and agrarian reforms (Merlet M., ed). Tome 2/2. Paris: Agter, 15-18.

De Koninck R., Rousseau J.F., 2013. Pourquoi et jusqu'où la fuite en avant des agricultures sud-est asiatiques? L'Espace géographique 42(2), 143-164.

Delgado J.M., Apel H., Merz B., 2009. Flood trends and variability in the Mekong River. Hydrology and earth system sciences 6(3), 6691-6719.

Déry S., 2004. La colonisation agricole au Viêt Nam. Québec : Presses de l'Université du Québec, $310 \mathrm{p}$.

Diépart J.C., Sem T., 2014. Cambodian peasants and the formalization of land rights: historical overview and current issues. Paris: AgroParisTech/CTF, 94 p.

Doch S., Diépart J.C., Chinda H., 2015. A multi-scale flood vulnerability assessment of agricultural production in the context of environmental change: The case of the Sangkae River watershed, Battambang province. In: Learning for resilience (Diépart J.C., ed). Phnom Penh: The Learning Institute, 19-50.

Dufay A., Nguyen Duyen Linh, Veloso A., 1995. Étude d'une région agricole du delta du Mékong. Mémoire de fin d'étude, UFR Agriculture Comparée et Développement Agricole. Paris : INAPG.

Dugan P.J., Barlow C., Agostinho A.A., Baran E., Cada G.F., Chen D., Cowx I.G., Ferguson J.W., Jutagate T., Mallen-Cooper M., Marmulla G., Nestler J., Petrere M., Welcomme R.L., Winemiller K.O., 2010. Fish migration, dams, and loss of ecosystem services in the Mekong Basin. Ambio 39(4), 344-348.

Duy Ba Nguyen, Clauss K., Senmao Cao, Naeimi V., Kuenzer C., Wagner W., 2015. Mapping rice seasonality in the Mekong delta with multi-year envisat ASAR WSM data. Remote sensing 7(12), 15868-15893.

Eastham J., Mpelasoka F., Mainuddin M., Ticehurst C., Dyce P., Hodgson G., Ali R., Kirby M., 2008. Mekong river basin water resources assessment: impacts of climate change. Disckson: CSIRO, $153 \mathrm{p}$.

Erban L.E., Gorelick S.M., Zebker H.A., 2014. Groundwater extraction, land subsidence, and sealevel rise in the Mekong Delta, Vietnam. Environmental research letters 9(8): 084010.

General statistics office, 2016. Statistical yearbook of Vietnam 2015. Hanoi: Statistical Publishing House.

Ham K., Someth P., 2015. Impacts of social-ecological change on farming practices in the stung hreybak watershed, Kampong Chang, Cambodia. In : Learning for Resilience (Diépart J.C., ed). Phnom Penh: The Learning Institute, 51-76.

Heuveline P., 2001. The Demographic analysis of mortality crises: the case of Cambodia, 1970-1979. In : Forced migration and mortality (Reed H., Keely C., eds). Washington D.C.: National Academy Press, 102-129.

Icem, 2013a. Mekong ARCC climate change impact and adaptation study for the lower Mekong basin: main report. Bangkok: Usaid, 294 p.

Icem, 2013b. Mekong ARCC Mekong adaptation and resilience to climate change: synthesis report. Bangkok: Usaid, 233 p.

Icem, 2014a. Mekong ARCC climate change impact and adaptation on agriculture. Bangkok: Usaid, $228 \mathrm{p}$.

Icem, 2014b. Mekong ARCC climate change impact and adaptation on fisheries. Bangkok: Usaid, $159 \mathrm{p}$.

Icem, 2014c. Mekong ARCC climate change impact and adaptation on livestock. Bangkok: Usaid, $160 \mathrm{p}$.

Icem, 2014d. Mekong ARCC climate change in the lower Mekong basin: an analysis of economic values at risk. Bangkok: Usaid, $38 \mathrm{p}$. 
IPCC, 2012. Managing the risks of extreme events and disasters to advance climate change adaptation. A Special report of working groups I and II of the Intergovernmental panel on climate change (Field C.B., Barros V., Stocker T.F., Qin D., Dokken D.J., Ebi K.L., Mastrandrea M.D., Mach K.J., Plattner G.K., Allen S.K., Tignor M., Midgley P.M., eds). Cambridge: Cambridge University Press, $582 \mathrm{p}$.

IPCC, 2014b. Climate change 2014: impacts, adaptation, and vulnerability. Part A: Global and sectoral aspects. contribution of working group II to the Fifth assessment report of the intergovernmental panel on climate change (Field C.B., Barros V.R., Dokken D.J., Mach K.J., Mastrandrea M.D., Bilir T.E., Chatterjee M., Ebi K.L., Estrada Y.O., Genova R.C., Girma B., Kissel E.S., Levy A.N., MacCracken S., Mastrandrea P.R., White L.L., eds). Cambridge: Cambridge University Press, $1132 \mathrm{p}$.

IPCC, 2014c. Climate change 2014: impacts, adaptation, and vulnerability. Part B: Regional aspects. Contribution of working group II to the Fifth assessment report of the intergovernmental panel on climate change (Barros V.R., Field C.B., Dokken D.J., Mastrandrea M.D., Mach K.J., Bilir T.E., Chatterjee M., Ebi K.L., Estrada Y.O., Genova R.C., Girma B., Kissel E.S., Levy A.N., MacCracken S., Mastrandrea P.R., White L.L., eds.). Cambridge: Cambridge University Press, 688 p.

Johnston R., Lacombe G., Hoanh C.T., Noble A., Pavelic P., Smakhtin V., Suhardiman D., Pheng K.S., Sze C.P., 2010. Climate change, water and agriculture in the Greater Mekong subregion. IWMI research report, 136. Colombo: International Water Management Institute, $60 \mathrm{p}$.

Kreft S., Eckstein D., 2015. Global climate risk index 2015: who suffers most from extreme weather events? Weather-related Loss Events in 2013 and 1994 to 2013. Briefing paper. Bonn: German Watch, $32 \mathrm{p}$.

Kummu M., Tes S., Yin S., Adamson P., Jozsa J., Koponen J., Richey J., Sarkkula J., 2014. Water balance analysis for the Tonle Sap lake-floodplain system. Hydrological processes 28, 1722-1 733.

Lacombe G., Chu Thai Hoanh, Smakhtin V., 2010. Multi-year variability or unidirectional trends? Mapping long-term precipitation and temperature changes in continental Southeast Asia using PRECIS regional climate model. Climatic change 113(2), 285-299.

Lacombe G., Smakhtin V., Chu Thai Hoanh, 2013. Wetting tendency in the central Mekong basin consistent with climate change-induced atmospheric disturbances already observed in East-Asia. Theoretical and applied climatology 111(1-2), 251-263.

Le Coq J.F., 2001. Libéralisation économique au Viêt-Nam, intensification rizicole et diversification: étude du cas de la région d'Ô Môn (delta du Mékong). Thèse de doctorat, Chaire d'Agriculture comparée et Développement agricole. Paris : INA-P G.

Le Dang Hoa, Li E., Nuberg I., Bruwer J., 2018. Vulnerability to climate change and the variations in factors affecting farmers' adaptation: a multigroup structural equation modelling study. Climate and development 10(6), 509-519. 10.1080/17565529.2017.1304885.

Le Minh Nhat, 2015. Climate change impacts and adaptation efforts in Vietnam. Communication du ministère des Ressources naturelles et de l'Environnement. Hanoï : MoNRE, 25 p.

Lécuyer, C., Wiel F.A., 2014. Diagnostic Agraire, plaine rizicole de Kampong Thom, Cambodge: Adaptation des pratiques agricoles au changement climatique, Mémoire de fin d'étude, UFR Agriculture comparée et Développement agricole. Paris : AgroParisTech, AFD, 179 p.

Mai Van Khiem, 2014. Vietnam national strategy on climate change, Communication à la conférence $2^{\text {nd }}$ Mekong climate change forum (6-8/10/2014). Siem Reap: MRC, 25 p.

Matsui S., Keskinen M., Sokhem P., Nakamura M., 2006. Tonle sap: experience and lessons learned brief. International waters, $14 \mathrm{p}$.

Matthews, N., Geheb, K., 2014. Hydropower development in the mekong region: political, socio-economic and environmental perspectives. London: Routledge, $218 \mathrm{p}$.

Molle F., Foran T., Kakonen M., (eds), 2009. Contested waterscapes in the mekong region: hydropower, livelihoods and governance. London: Earthscan, $416 \mathrm{p}$.

MoNRE, 2009. Climate change, sea level rise scenarios for Vietnam. Hanoi: Ministry of natural resources and environment, $34 \mathrm{p}$. 
MRC, 2005. Overview of the hydrology of the Mekong basin. Vientiane: Mekong River Commission, $73 \mathrm{p}$.

Murphy T.I., Sampson M.K., 2013. The stress of climate change on water management in Cambodia with a focus on rice production. Climate and development 5(1), 77-92.

Nuorteva, P., Keskinen M., Varis O., 2010. Water, livelihoods and climate change adaptation in the Tonle Sap lake area, Cambodia: learning from the past to understand the future. Journal of water and climate change 1(1), 87-101.

Perrin C., Aïchi L., Giraud E., 2016. Climat : vers un dérèglement géopolitique ? Rapport d'information n¹4 (2015-2016) de la Commission des affaires étrangères, de la défense et des forces armées du Sénat. www.senat.fr/rap/r15-014/r15-0141.pdf.

Pillot D., 2007. Jardins et rizières du Cambodge, les enjeux du développement agricole. Paris : Karthala, $522 \mathrm{p}$.

Roth C.H., Grunbuhel C.M., 2012. Developing multi-scale adaptation strategies: a case study for farming communities in Cambodia and Laos. Asian journal of environment and disaster risk management 4(4), 441-462.

Schmidt C., 2015. Alarm over a sinking delta, Science 348(6237), 845-846.

Sebesvari Z., Thi Thu Le Huong, Van Toan Pham, Arnold U., Renaud F.G., 2012. Agriculture and water quality in the vietnamese Mekong delta. In: Renaud F., Kuenzer C., (eds). The Mekong delta system: interdisciplinary analyses of a river Delta. London: Springer, 331-361.

Smajgl A., Toan T.Q., Nhan D.K., Ward J., Trung N.H., Tri L.Q., Tri V.P.D., Vu P.T., 2015. Responding to rising sea levels in the Mekong delta. Nature climate change (5), 167-174.

Takagi H., Nguyen Danh Thao, Le Tuan Anh, 2016. Sea-level rise and land subsidence: impacts on flood projections for the Mekong Delta's largest city. Sustainability 8(9), p. 959-973.

Teng P.S., Caballero-Anthony M., Anderias Lassa J., 2016. The Future of rice security under climate change. Singapore: Centre for non-traditional security studies (NTS), 81 p.

Vaidyanathan G., 2011. Dam controversy: remaking the Mekong. Nature 478(7369), 305-307.

Vaulerin A., 2016. Delta du Mékong : le triangle des inquiétudes. Libération (du 7 février 2016). www.liberation.fr/planete/2016/02/07/delta-du-mekong-le-triangle-des-inquietudes_1431029. 
Planche 1

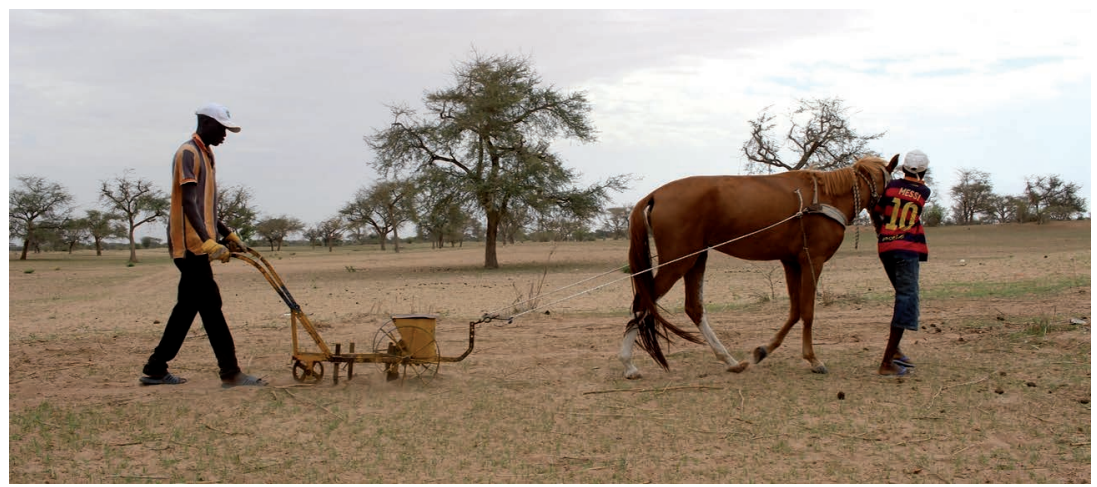

Photo 1.1. Recours à la traction attelée dans le bassin arachidier, primordial dans l'adaptation à la sécheresse (Le Goff, 2016).

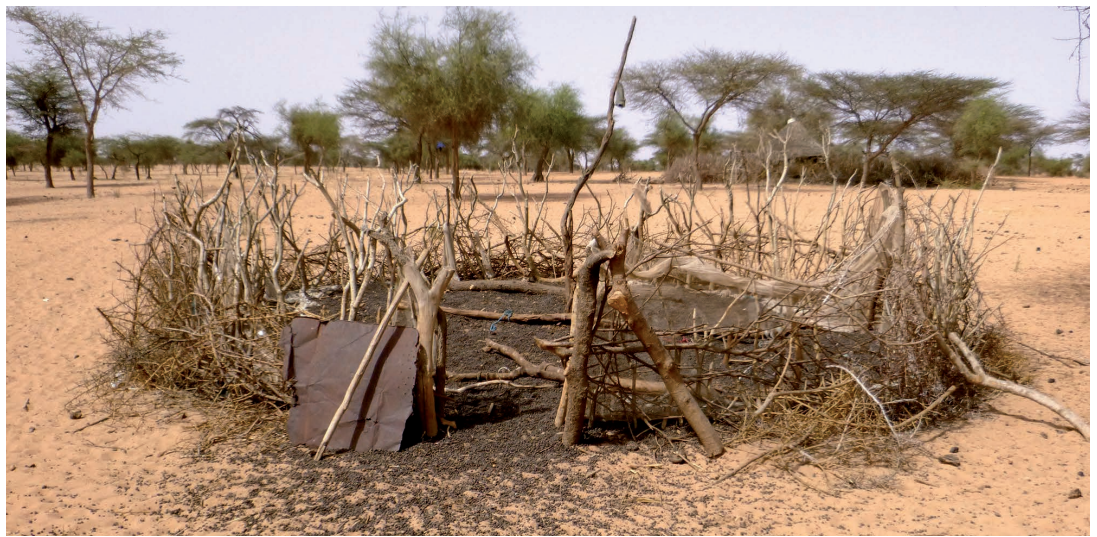

Photo 1.2. Enclos pour ruminants, une des adaptations facilitant les transferts de fertilité dans le bassin arachidier (Garambois, 2016).

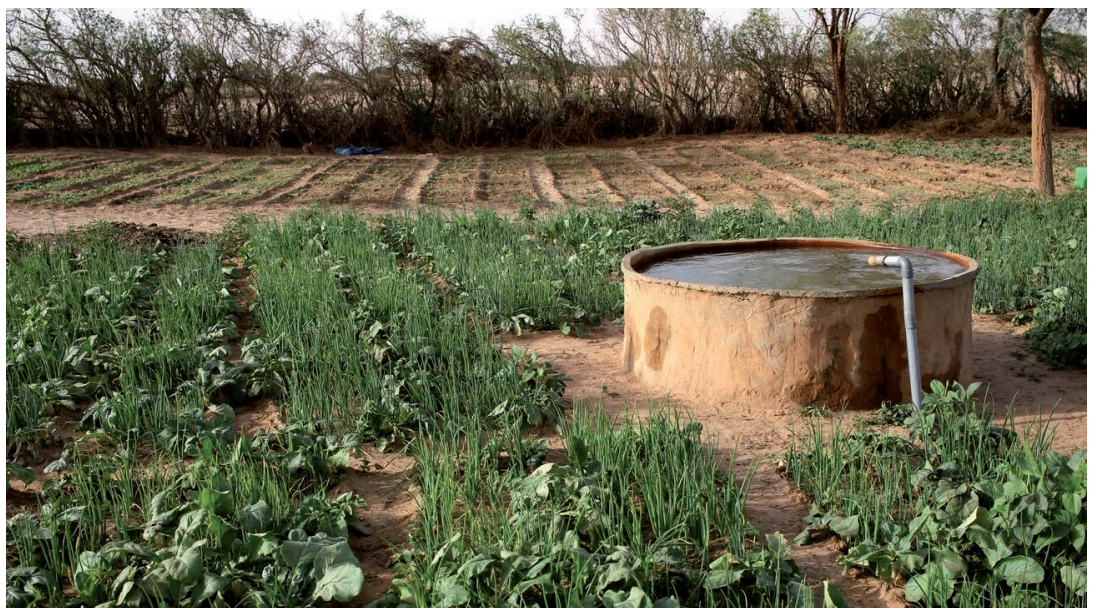

Photo 1.3. Petit périmètre irrigué alimenté grâce à des puits favorisant les cultures maraîchères de contre-saison dans le bassin arachidier (Le Goff, 2016). 

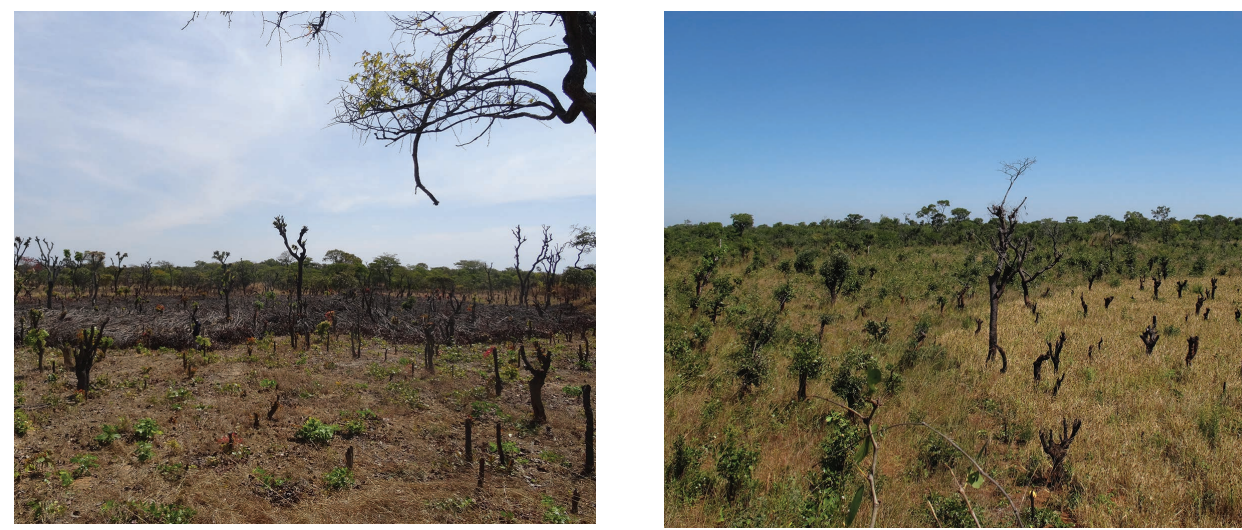

Photo 2.1. Parcelle cultivée en chitemene dans le nord de la Zambie (Rémy, 2014 à gauche et Cochet, 2014 à droite).

À gauche : bûcher constitué au centre de la parcelle pour le brûlis. À droite : l'éleusine de première année, prête à être récoltée (éleusine dans la partie centrale, auréole émondée, non mise en culture à gauche).

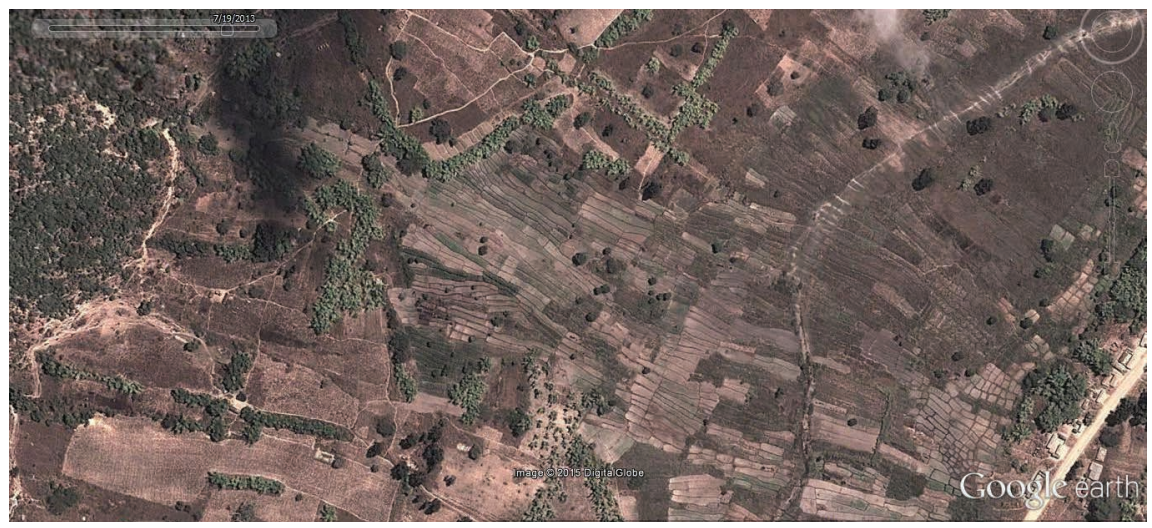

Photo 2.2. Petit périmètre irrigué à partir de sources (au centre) et parcelles de bas-fond cultivées en planches et buttes surélevées (à droite) sur les hauts plateaux du sud tanzanien (Google Earth).

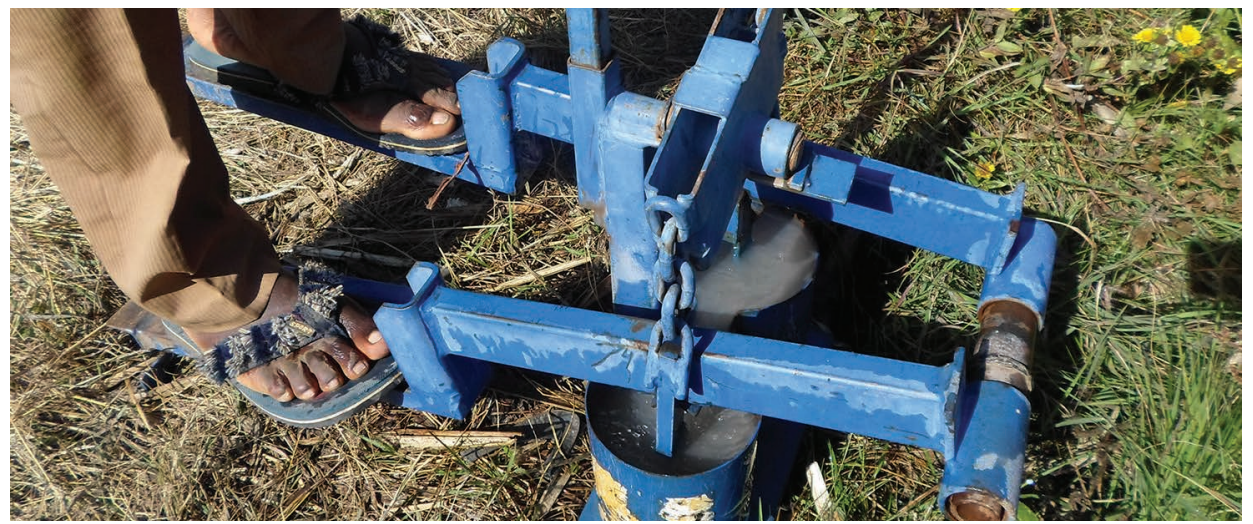

Photo 2.3. Importance du petit matériel d'irrigation : une pompe à pédale dans un petit périmètre irrigué des hauts plateaux du sud de la Tanzanie (Verhoog, 2014). 


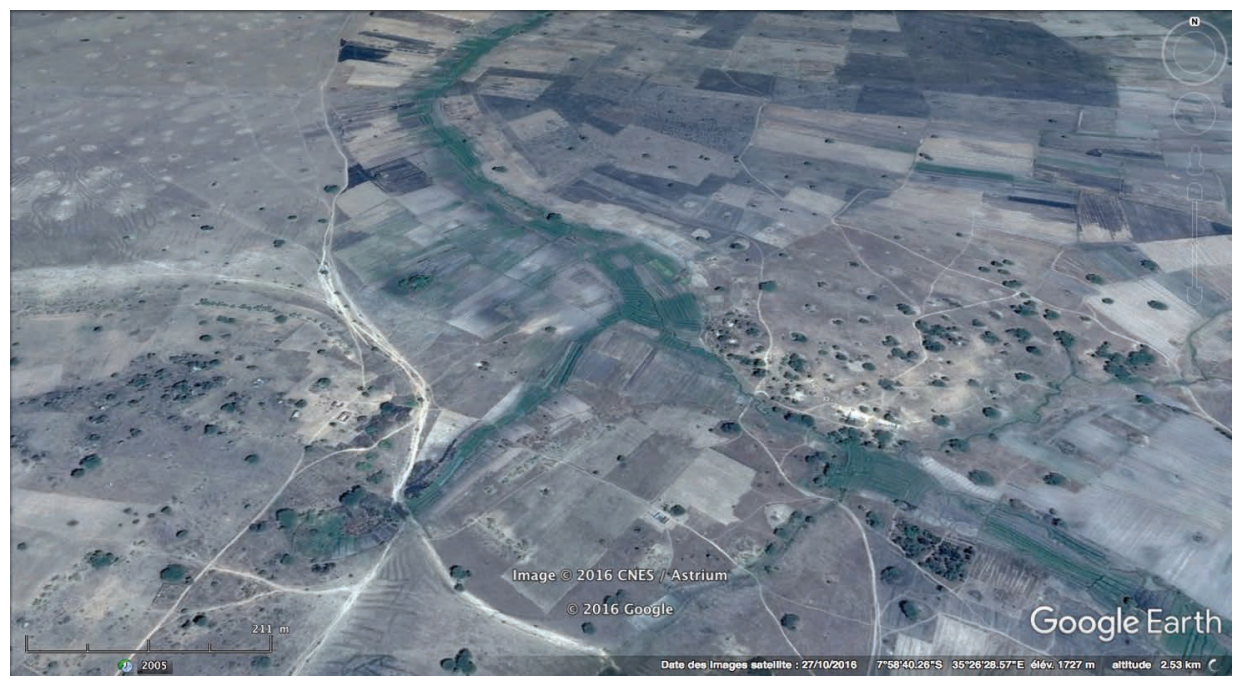

Photo 2.4. Petit périmètre irrigué d’Isupilo, dans la région de Kiponzelo (sud de la Tanzanie) (Google Earth).
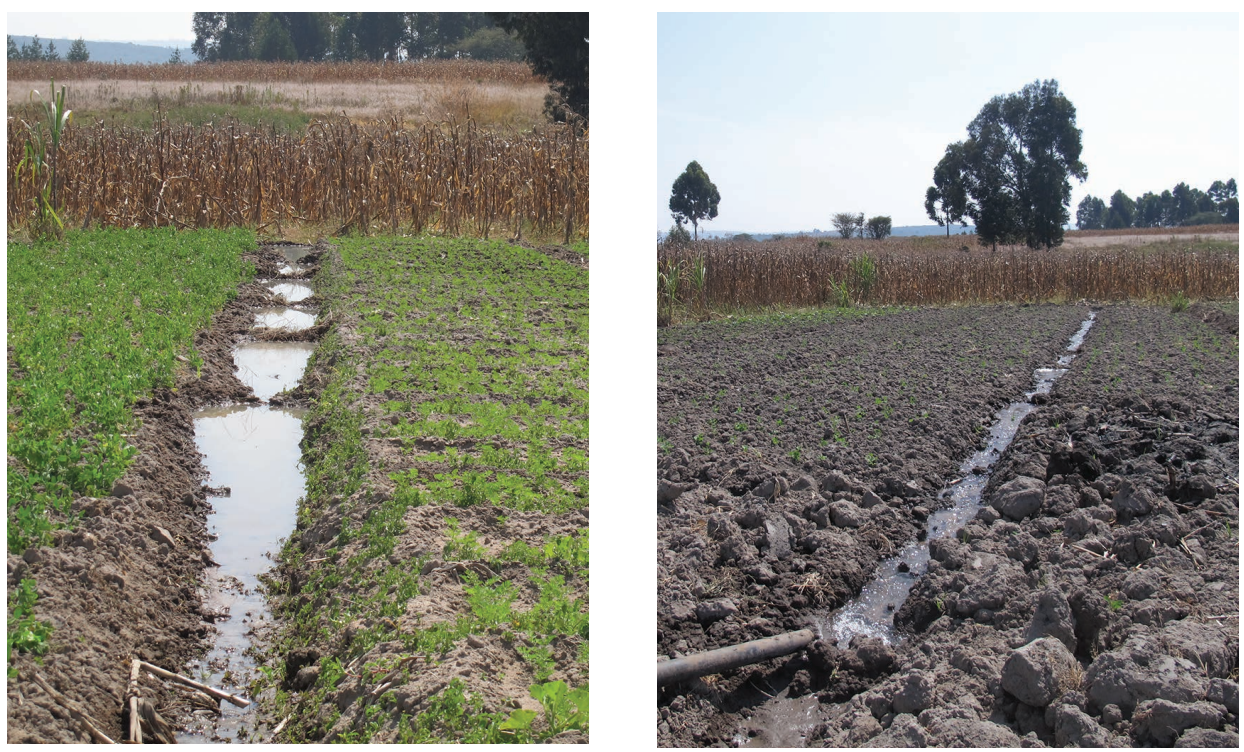

Photo 2.5. Circulation de l'eau et petit matériel (tuyau) dans le périmètre irrigué d'Isupilo, sud de la Tanzanie (Cochet, 2014). 


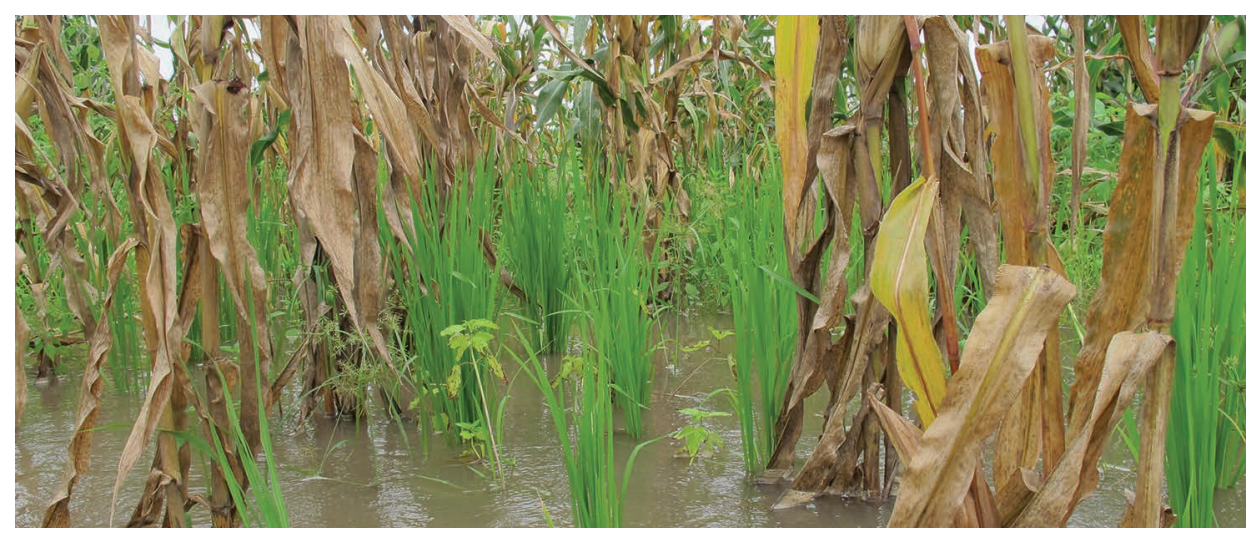

Photo 3.1. Culture associée maïs-riz et gestion de l'aléa dans la plaine inondable du bas-Rufiji, sud de la Tanzanie (Cochet, 2014).

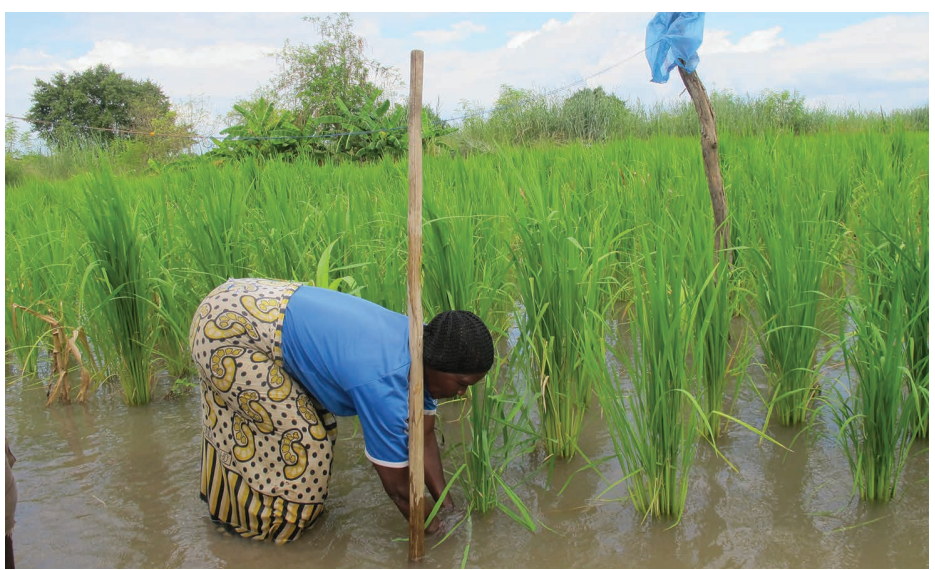

Photo 3.2. Repiquage de rattrapage dans la basse vallée du Rufiji, sud de la Tanzanie (Cochet, 2014).

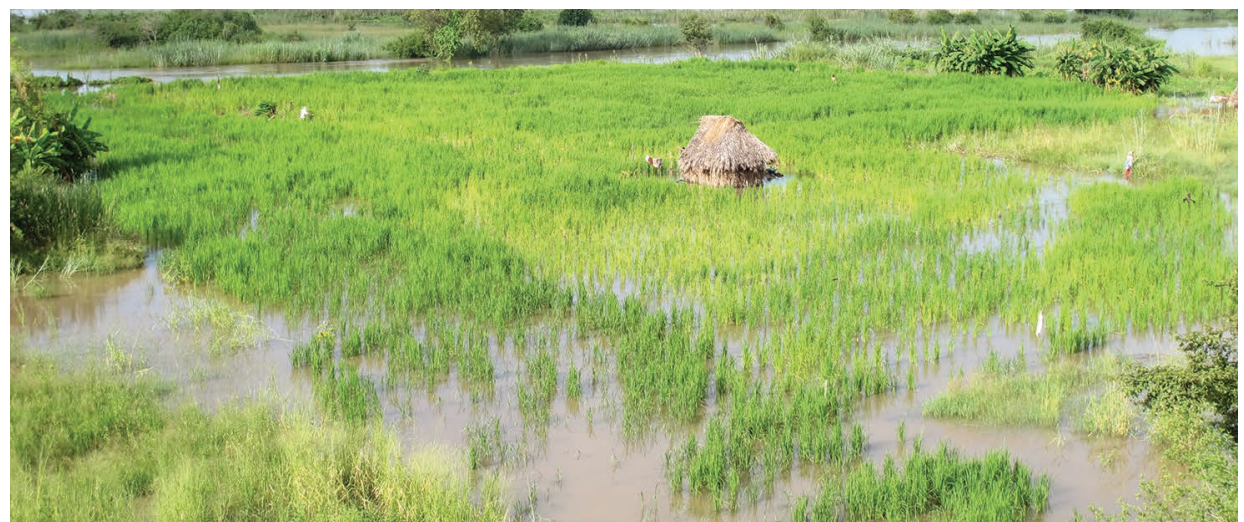

Photo 3.3. Inondation complète des bancs de sable et repiquage de rattrapage dans la basse vallée du Rufiji, sud de la Tanzanie (Cochet, 2014).

La partie basse de la parcelle fraîchement repiquée est située au premier plan. La partie ayant résisté à l'inondation est au deuxième plan, à l'arrière de la case. 


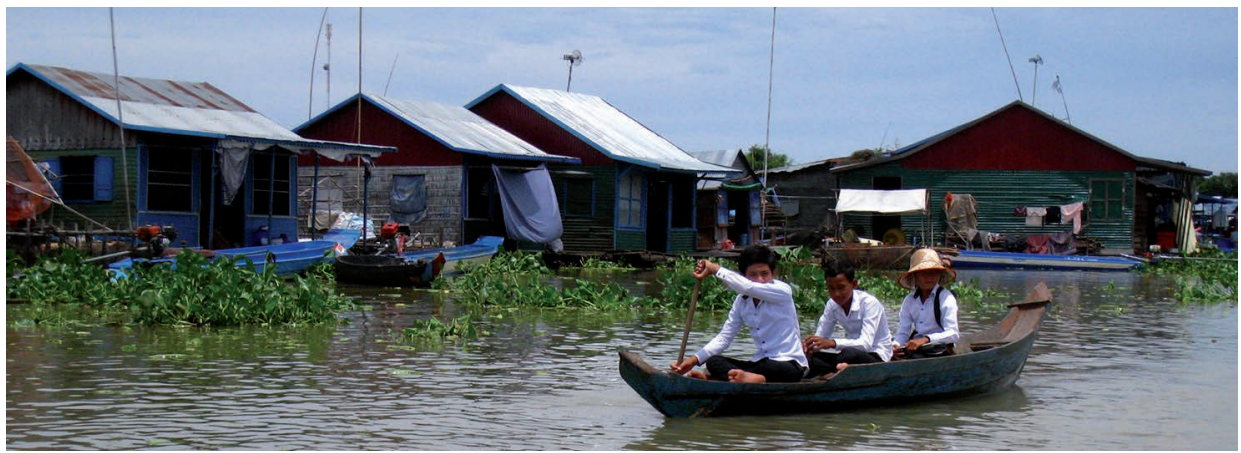

Photo 4.1. Écoliers dans un village de pêcheurs sur le lac Tonlé Sap, Cambodge (Ducourtieux, 2014).

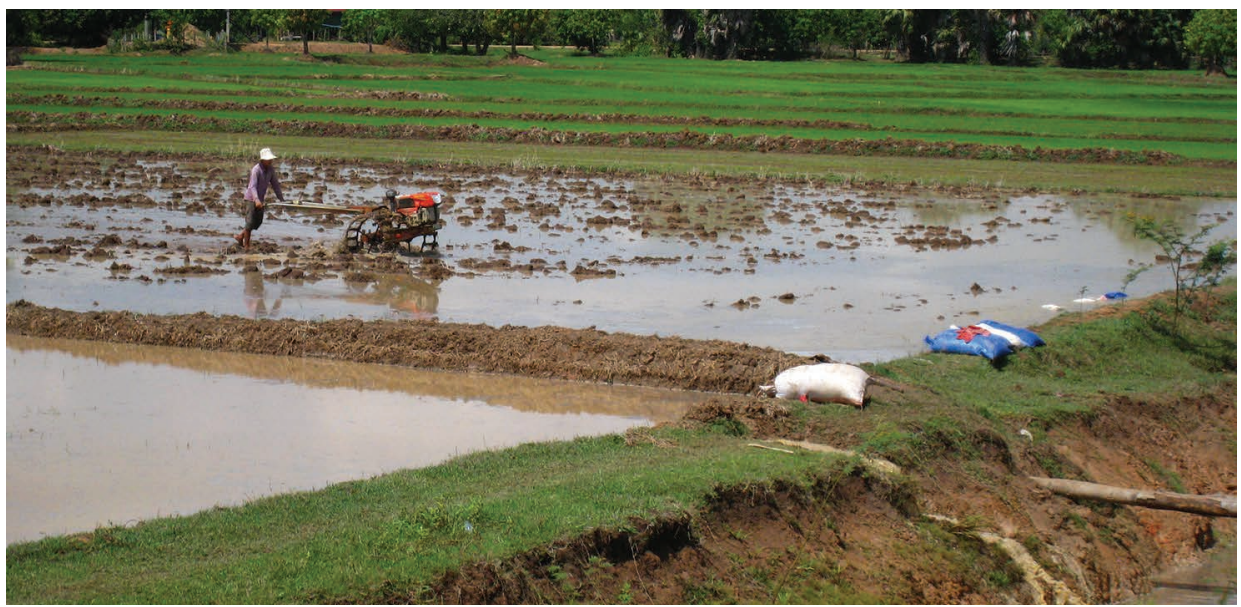

Photo 4.2. Rizières irriguées en plaine haute des berges du Tonlé Sap, Kampong Thom, Cambodge (Ducourtieux, 2014).

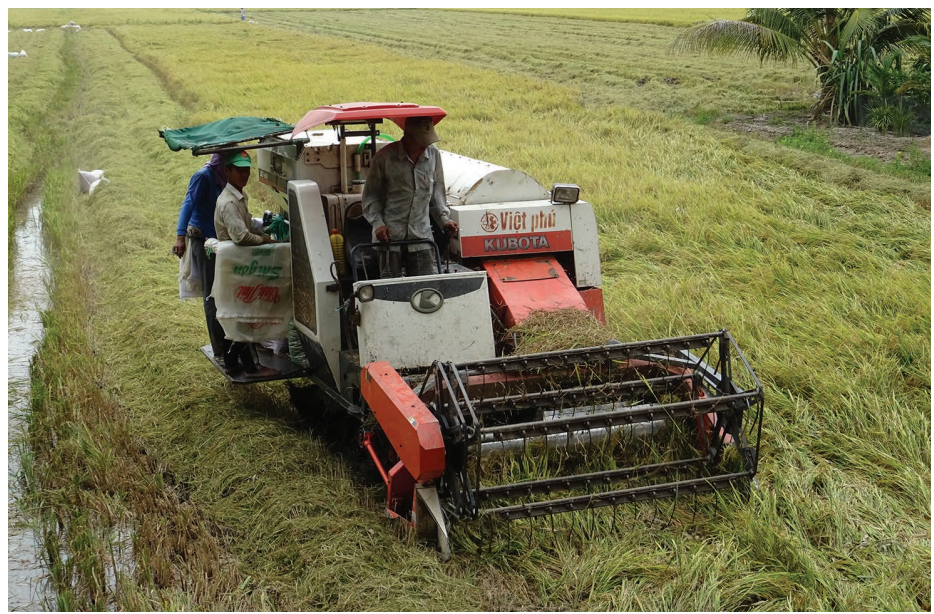

Photo 4.3. Moissonneuse-batteuse dans les rizières de Thin Trí, delta du Mékong, Vietnam (Ducourtieux, 2016). 


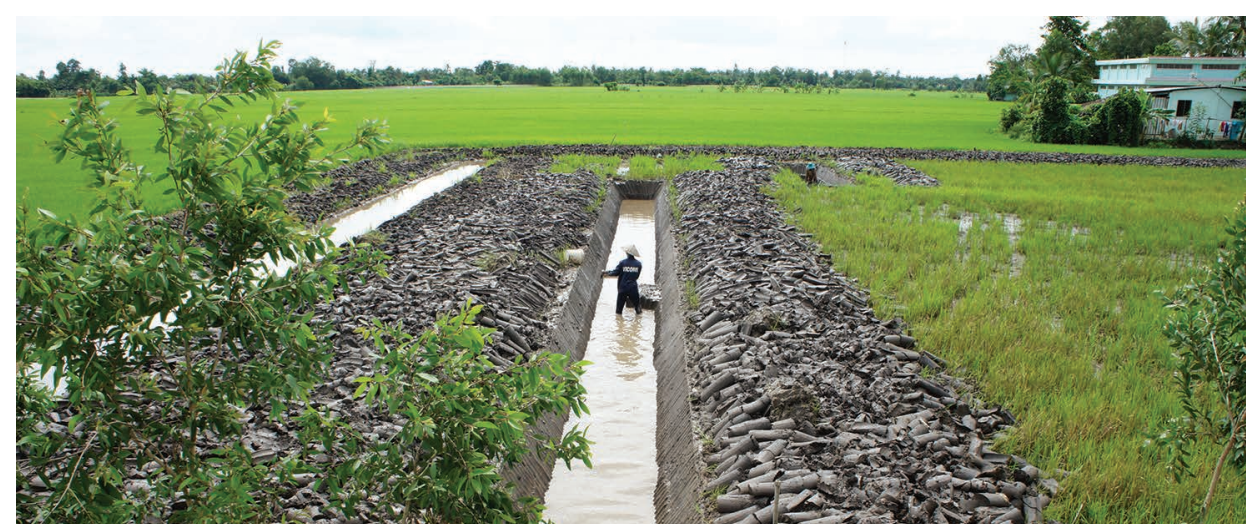

Photo 4.4. Terrassement manuel pour le drainage de verger (conversion de rizière) à Thin Trí, delta du Mékong, Vietnam (Champeaux, 2016).

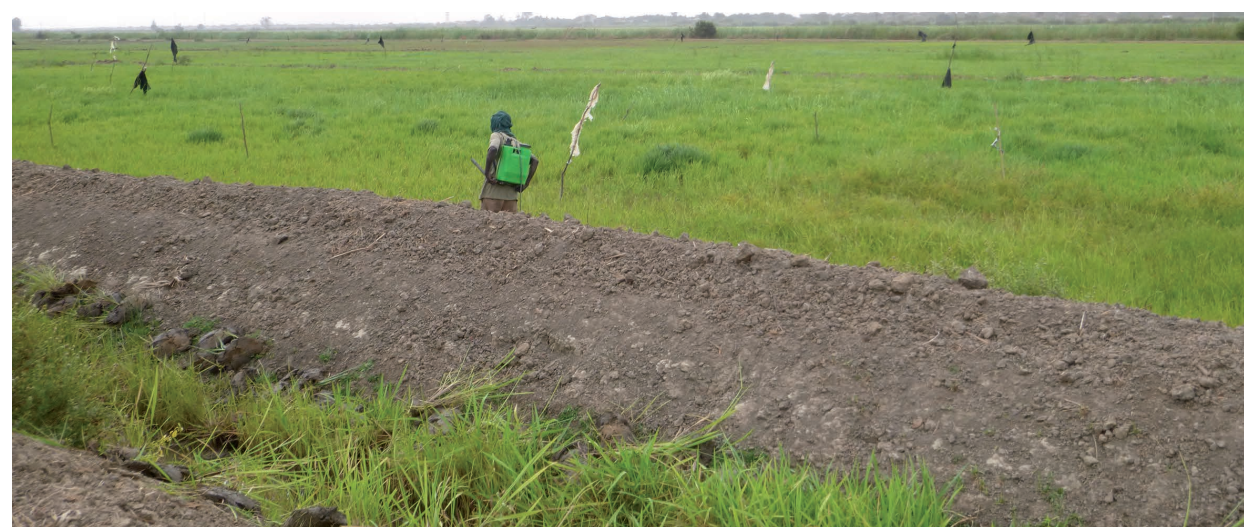

Photo 5.1. Riziculture au sein des grands périmètres irrigués installés dans le delta du fleuve Sénégal (ici usage localisé d'herbicides à l'aide d'un pulvérisateur à dos) (Garambois, 2016).

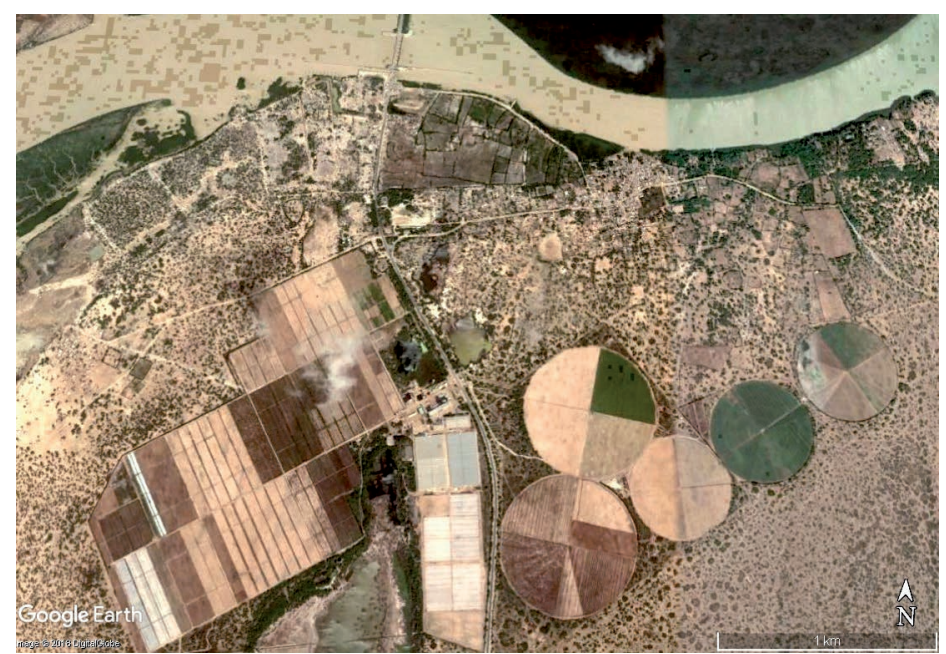

Photo 5.2. Petites parcelles d'agriculteurs familiaux au contact de l'agrobusiness en plein essor dans le bas delta (ici vastes parcelles équipées de pivots d'irrigation) (Google Earth). 


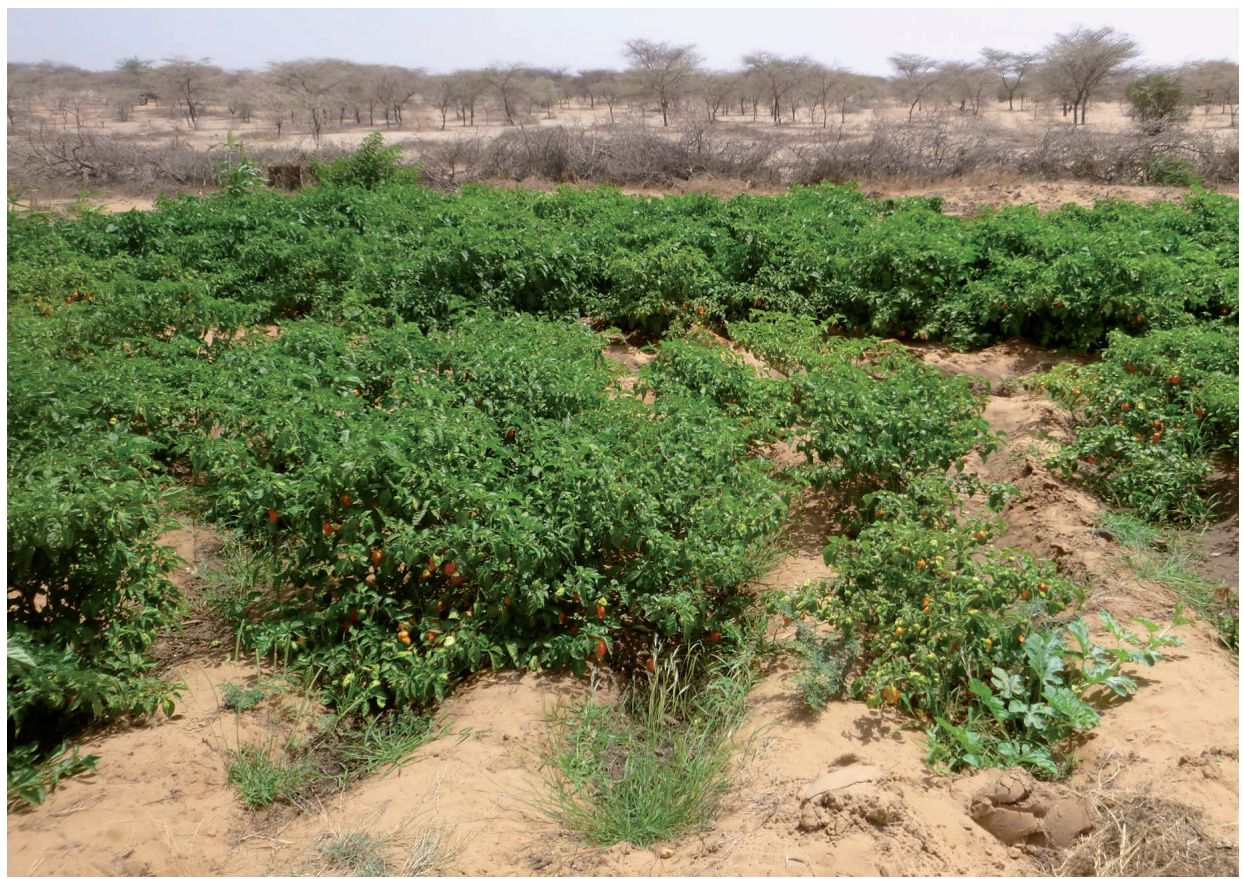

Photo 5.3. Installation de périmètres irrigués sur les terres de dunes du bas delta (ici dans le cadre du PDMAS) (Garambois, 2016).

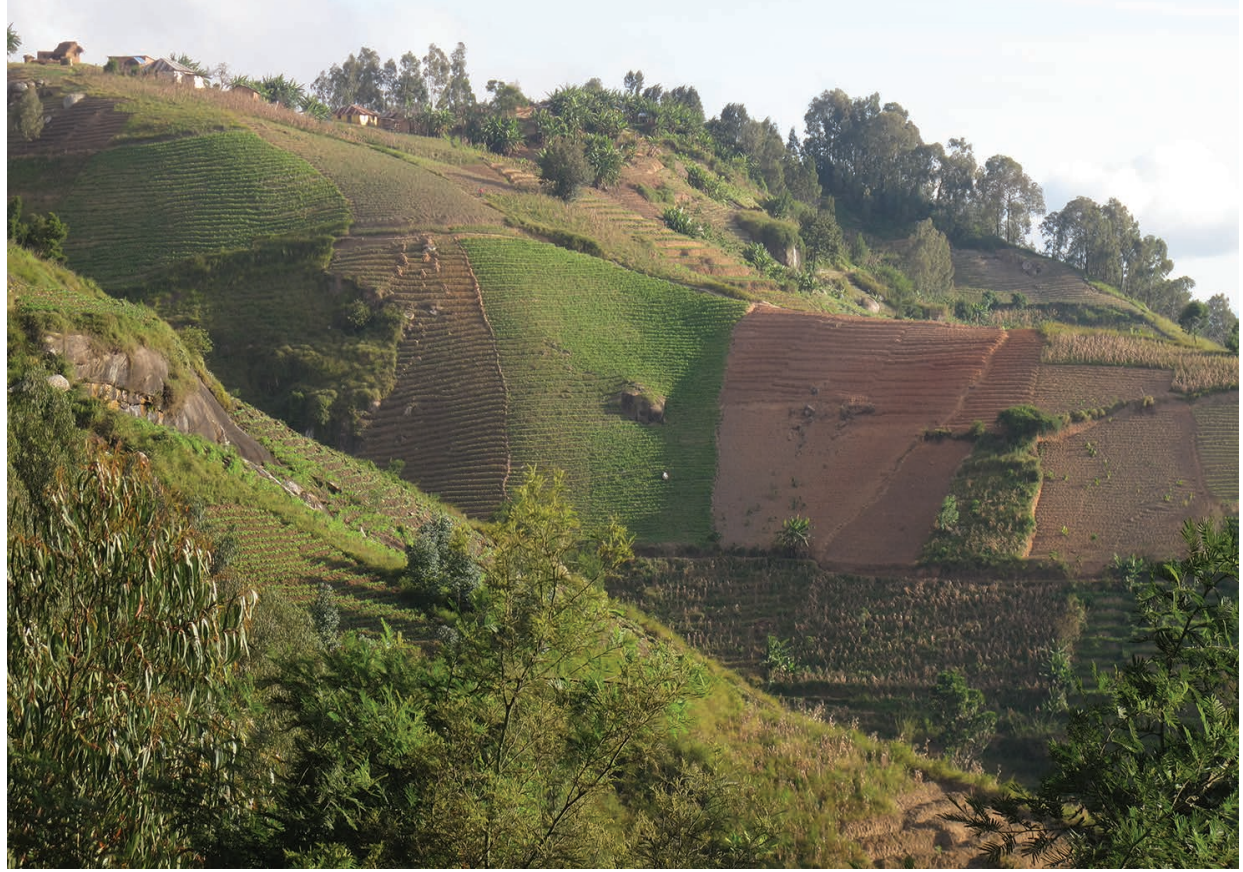

Photo 6.1. Versants aménagés en marches d'escalier en contrebas du village de Nyandira, région des monts Uluguru, Tanzanie (Cochet, 2016). 
Planche 8

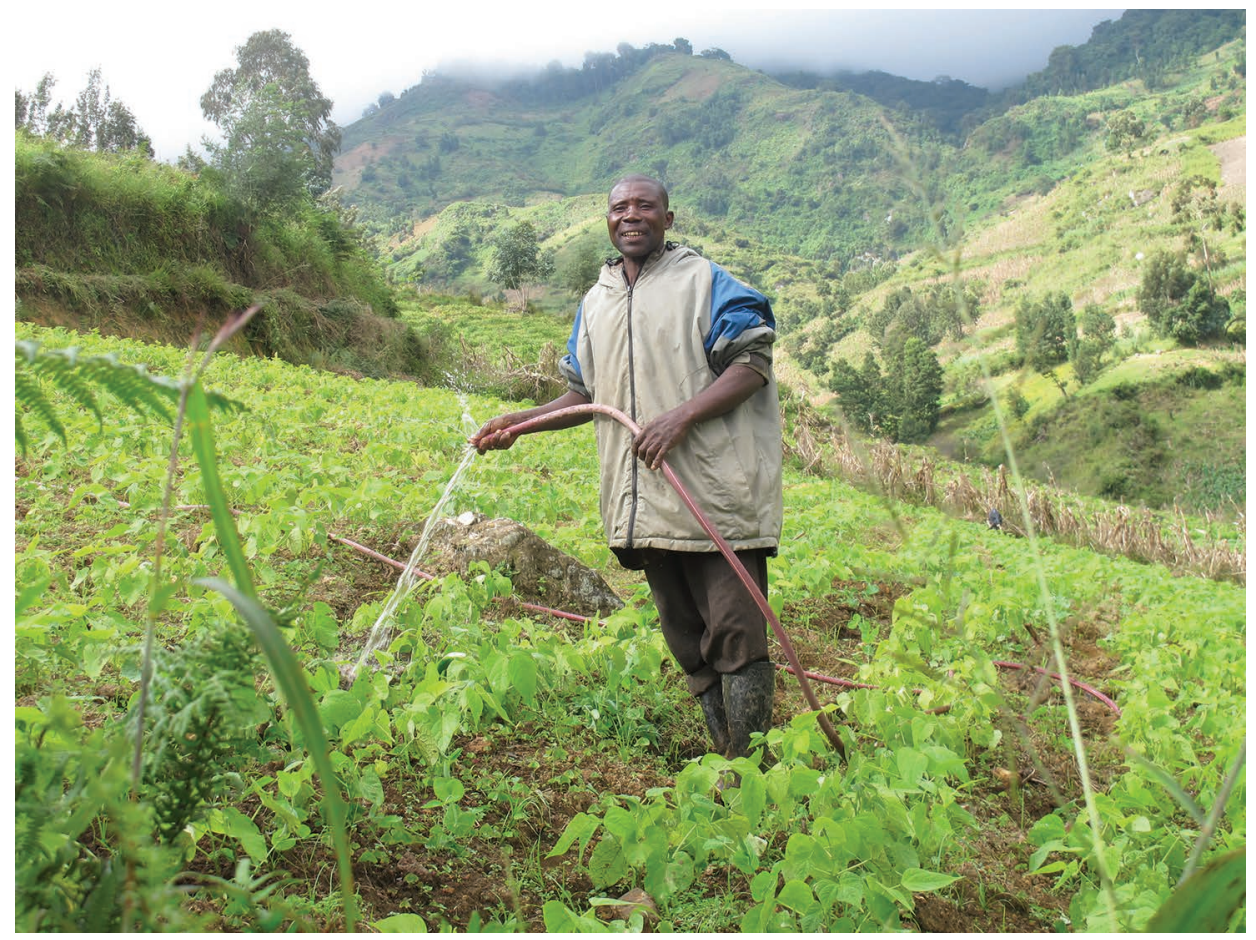

Photo 6.2. Arrosage des haricots au tuyau à partir d'un canal primaire, région des monts Uluguru, Tanzanie (Cochet, 2016).

Le canal primaire est visible en haut à gauche, en bordure supérieure de la parcelle.

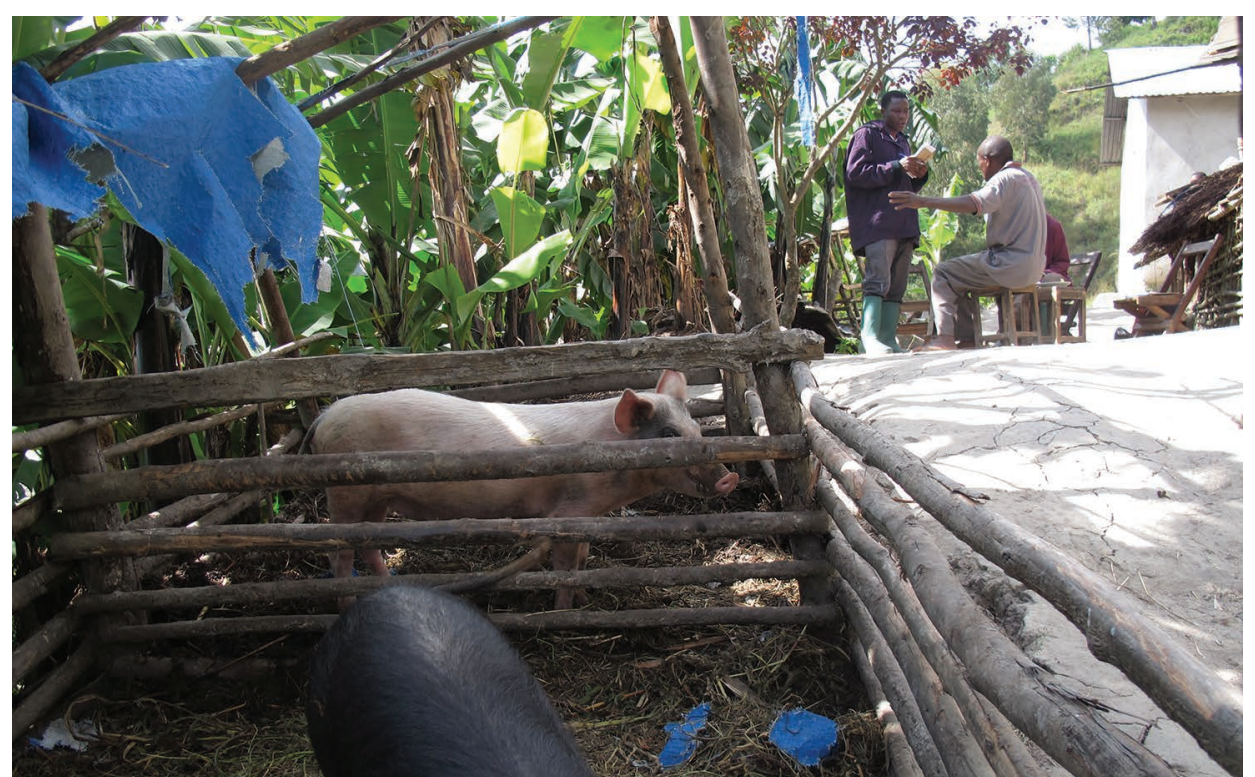

Photo 6.3. Porcherie au voisinage immédiat de la maison, région des monts Uluguru, Tanzanie (Cochet, 2016).

En contrebas, la bananeraie bénéficie des écoulements de purin. 


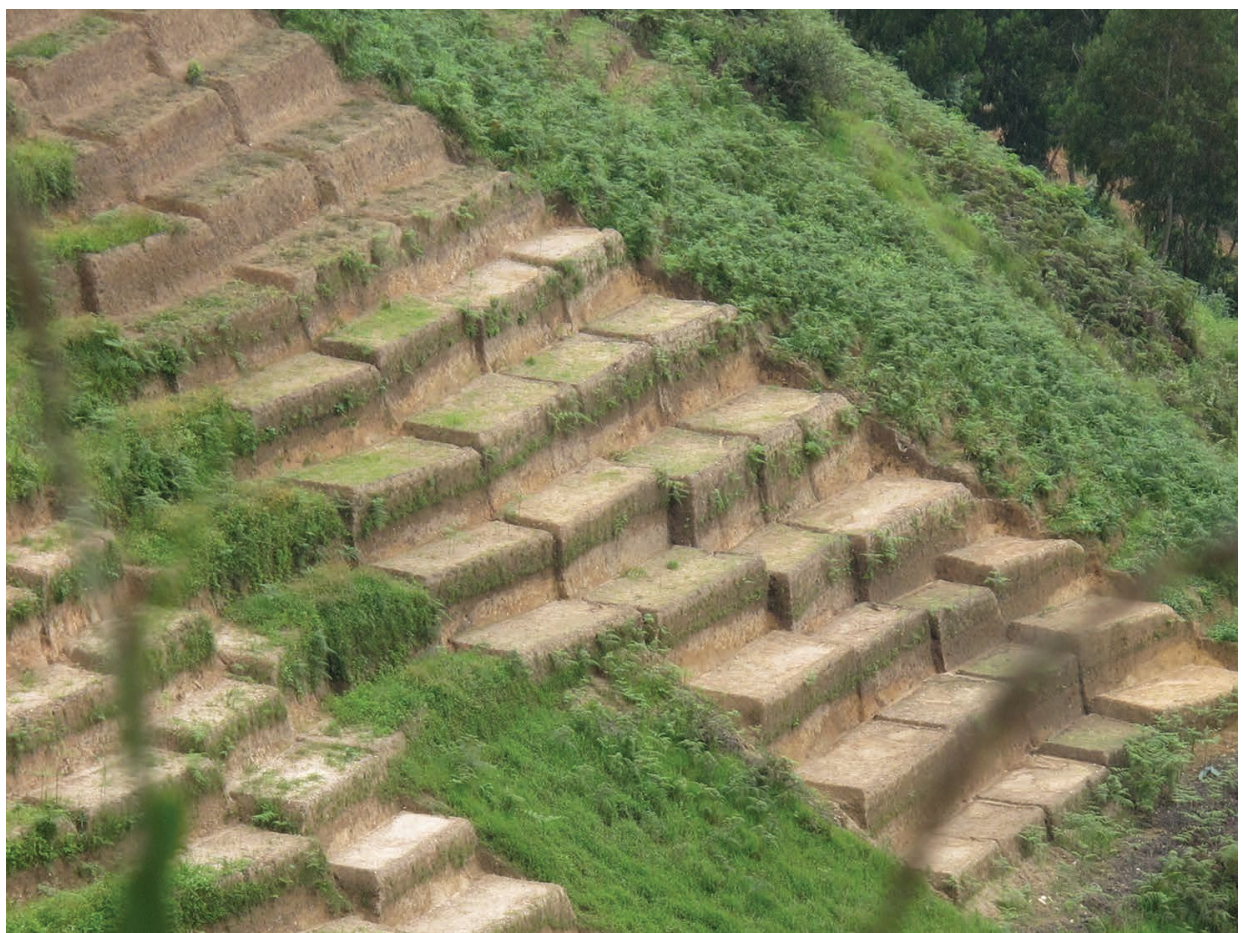

Photo 6.4. Le mythe techniciste de la terrasse radicale, région des monts Uluguru, Tanzanie, (Cochet, 2016).

Érosion accrue et abandon, comme le démontre ce versant aménagé en contrebas de la paroisse de Tchenzema.

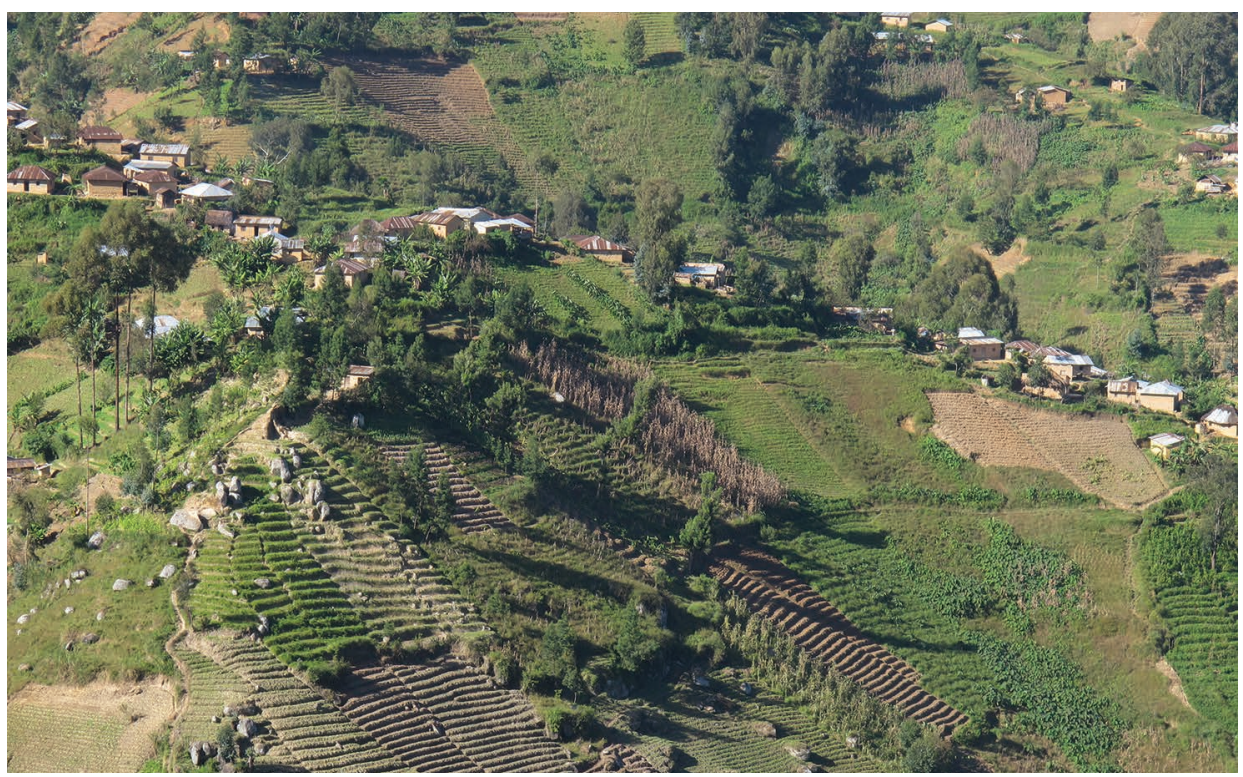

Photo 6.5. Versant aménagé en gradins en escaliers en contrebas d'un hameau de Tchenzema, région des monts Uluguru, Tanzanie (Cochet, 2015). 


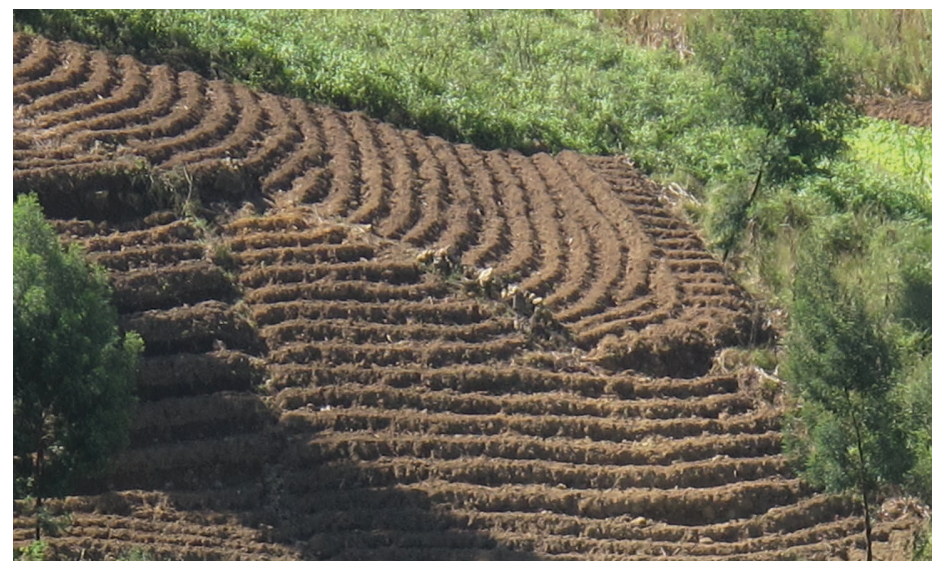

Photo 6.6. Labour en billons sur pente modérée, région des monts Uluguru, Tanzanie (Cochet, 2016).

Partie plane en bas de parcelle et billons orientés perpendiculairement.

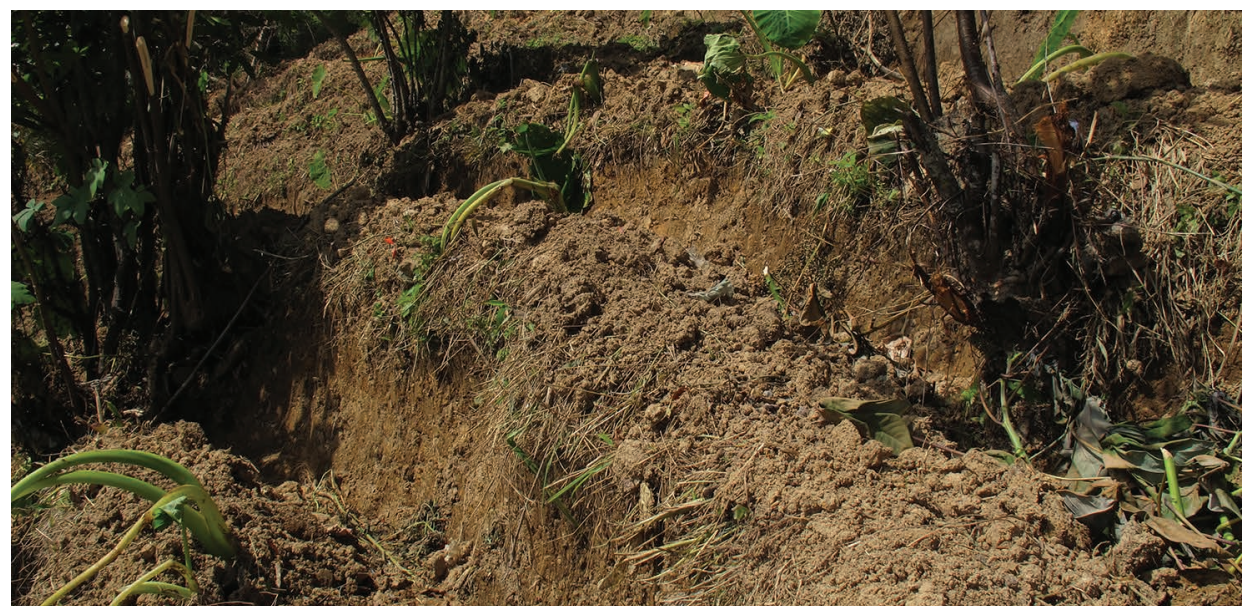

Photo 6.7. Labour en marches d'escalier sur les pentes fortes des monts Uluguru, Tanzanie (Cochet, 2016).

Landain de biomasse, notamment sa partie non déracinée, affleure à la base du billon. Les pieds de taro et de bananiers sont maintenus et contribuent à renforcer l'ensemble.

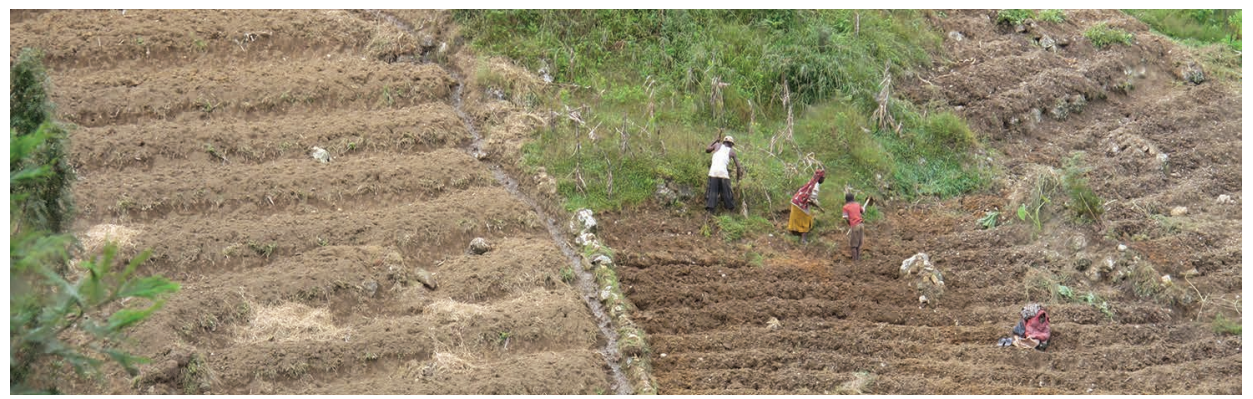

Photo 6.8. Labour de billonnage sur pente forte dans les monts Uluguru (Cochet, 2016). Le canal secondaire d'irrigation dont le bord est empierré est visible sur la partie gauche de la photo. 


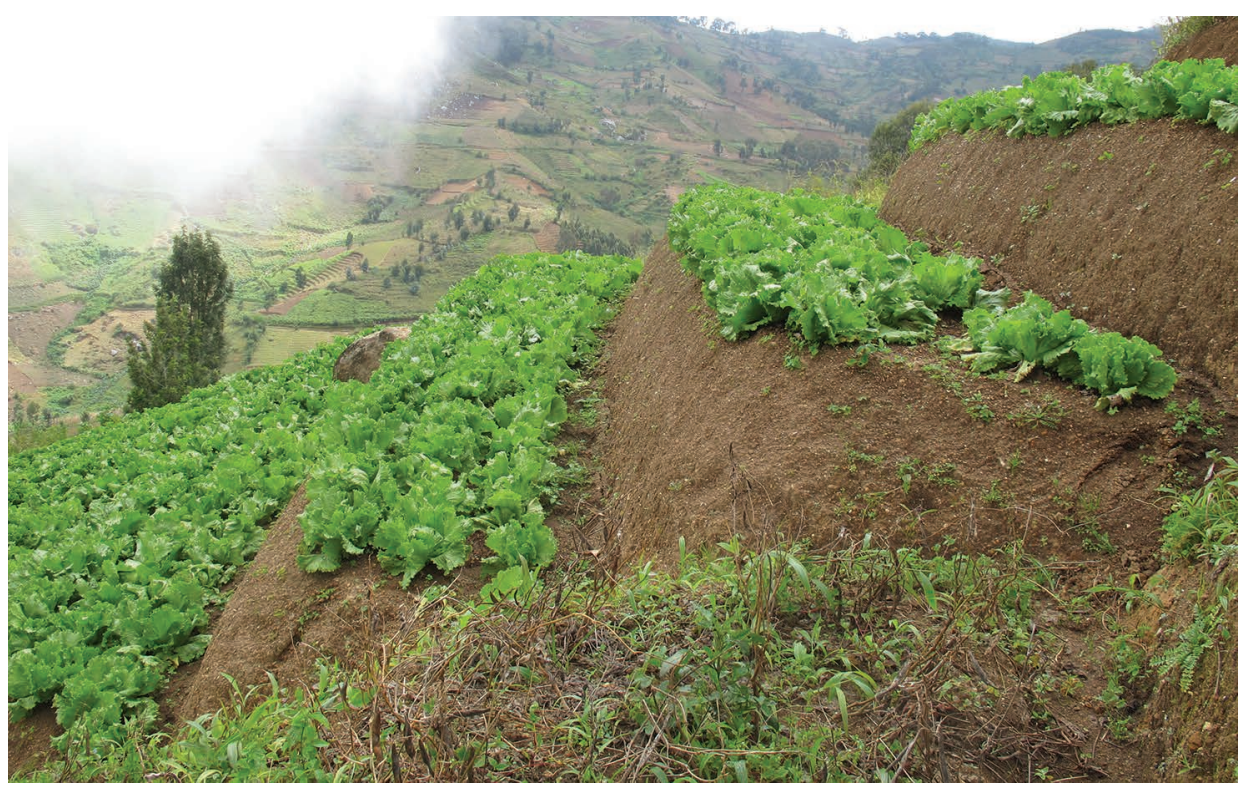

Photo 6.9. Terrasses légumières dans les monts Uluguru, Tanzanie (Cochet, 2016).

Leau issue du canal secondaire en bordure de parcelle est introduite sur chaque terrasse par une rigole au pied du talus.

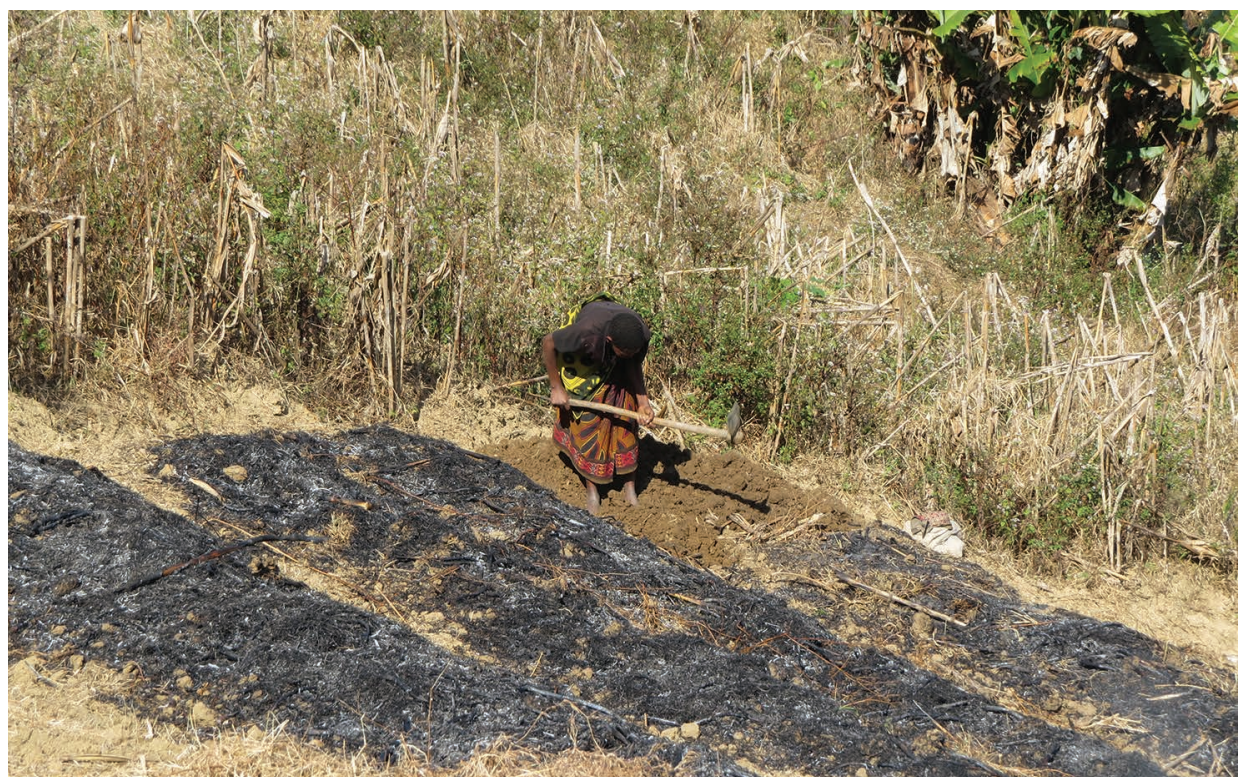

Photo 6.10. Brûlis de la biomasse sur terrasses radicales, labour à la houe, région des Monts Uluguru, Tanzanie (Cochet, 2016). 



\title{
Chapitre 5 \\ Sécheresse, grande hydraulique et modèles de développement : delta du fleuve Senégal
}

\author{
Nadège Garambois, Samir El Ouaamari, Mathilde Fert, \\ LÉa Radzik et Thibault Labetoulle
}

La région du delta du fleuve Sénégal (figure 5.1) connaissait déjà, avant l'épisode de sécheresse des années 1970-1980 qui a marqué l'ensemble du Sahel, de faibles totaux pluviométriques. Elle était aussi particulièrement sujette aux variations interannuelles de la pluviométrie et de la crue du fleuve, rendant l'agriculture pluviale hasardeuse (Lericollais, 1975). Ladaptation ancienne et systémique des agriculteurs et éleveurs à des conditions climatiques et hydrographiques aléatoires et ponctuellement extrêmes n'en était que plus centrale. La série de déficits extrêmement lourds, à la fois pluviométriques et de la crue du fleuve, qu'ont connu la moyenne et basse vallée du fleuve à partir des années 1970, a, comme dans le bassin arachidier (chapitre 1), profondément fragilisé l'agriculture de cette région.

Aujourd'hui, la vallée du fleuve Sénégal assure pourtant l'essentiel de la production nationale de riz ( $83 \%$ en 2012; MAER, 2014), production inconnue dans la région avant les années 1960 . Cette production est le résultat d'une politique d'aménagements hydrauliques de très grande ampleur menée ces cinquante dernières années. Largement soutenue par les bailleurs internationaux, celle-ci a été initiée dès la période coloniale. Elle a connu ses premiers grands développements, notamment la mise en place de barrages en amont et en aval sur le fleuve, au cours de la profonde sécheresse des années 1970-1980. La région du delta (figure 5.2), initialement peu 


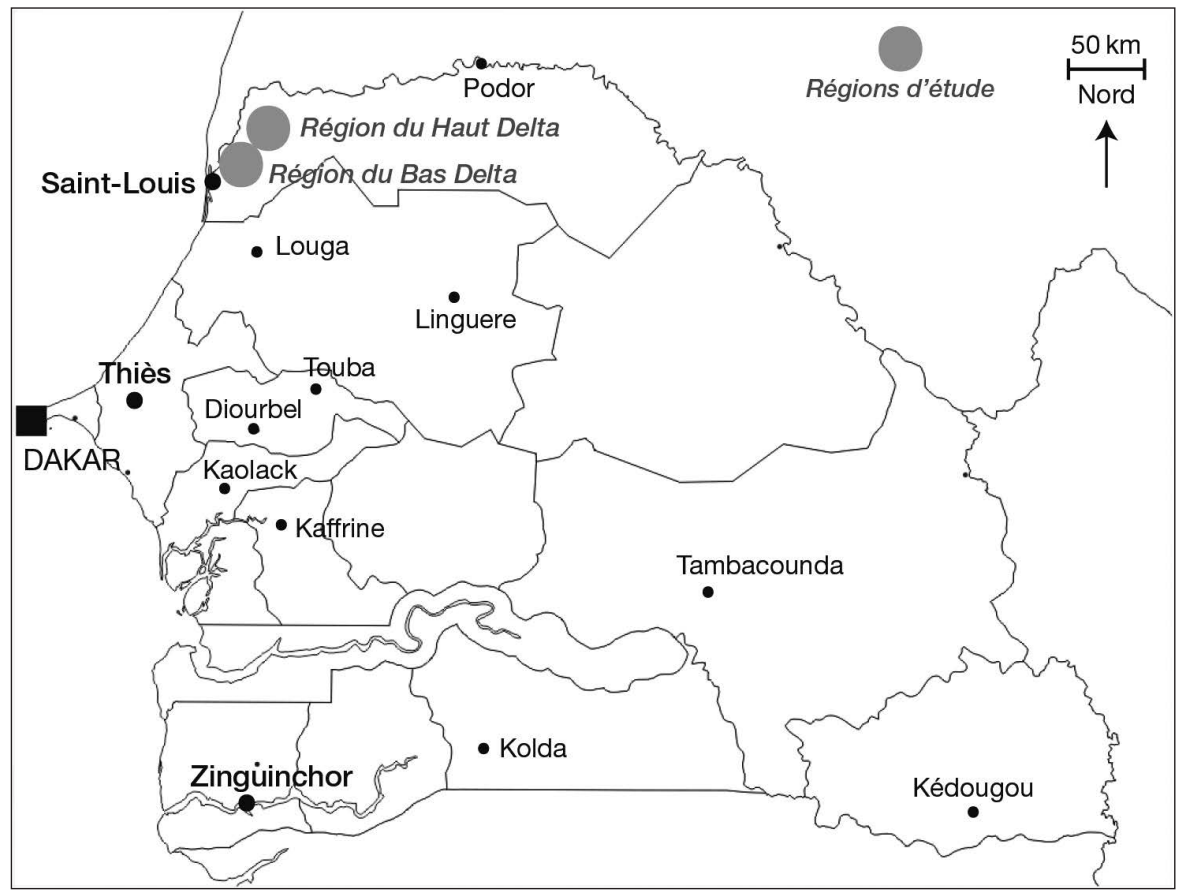

Figure 5.1. Localisation des régions du bas delta et du haut delta du fleuve Sénégal.

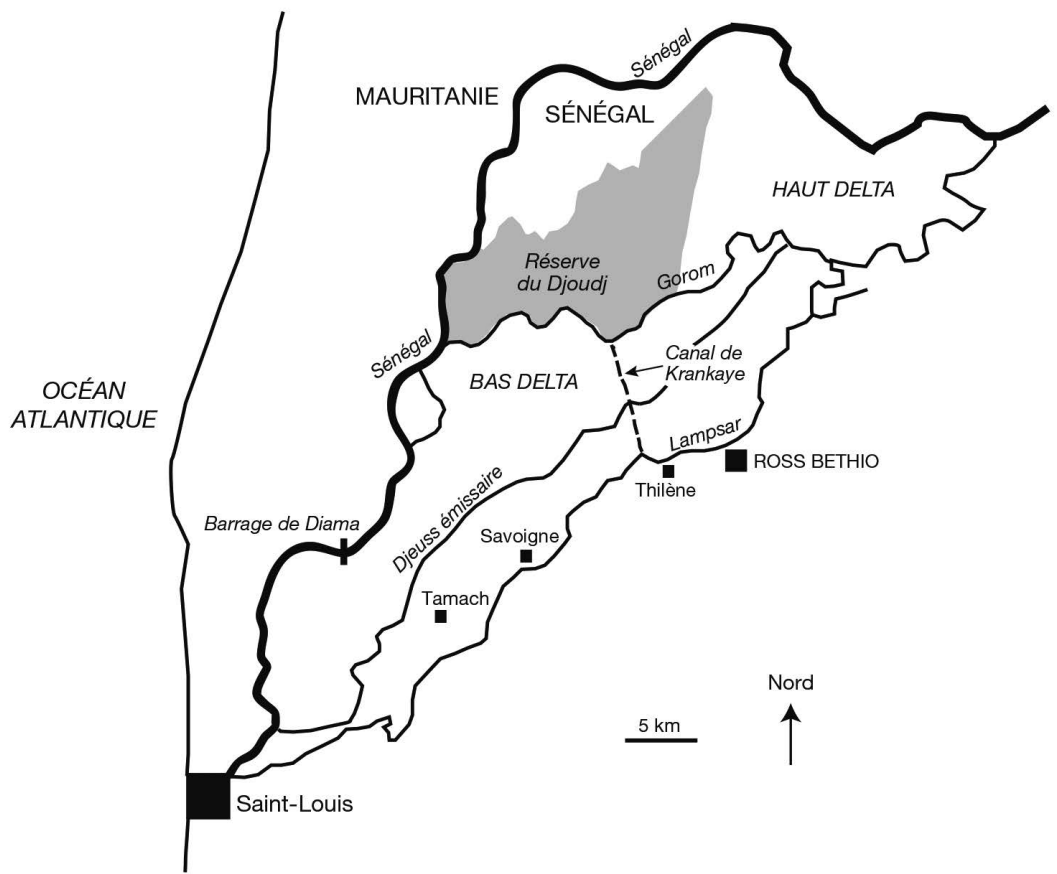

Figure 5.2. Organisation schématique du réseau hydrographique et des principaux axes hydrauliques actuels de la région du delta du fleuve Sénégal. 
peuplée, est celle dont l'agriculture a été la plus bouleversée par cette politique de développement de l'irrigation. À la fin des années 2000, elle abritait à elle seule la moitié des superficies aménagées de l'ensemble de la vallée (Dahou, 2009). Aujourd'hui encore, elle présente toujours un fort potentiel de développement, notamment dans le bas delta.

Pensés initialement aussi comme une politique d'adaptation au changement climatique, ces aménagements sont désormais de plus en plus affichés comme relevant d'une stratégie d'autosuffisance alimentaire. Or, malgré la concentration de la majorité $(60 \%)$ des investissements publics alloués au secteur agricole dans les aménagements hydro-agricoles, renforcées par des investissements privés croissants, les importations de riz demeurent colossales au Sénégal : les deux tiers du riz consommé en 2014 (FAO) et 8,5\% de la valeur totale des importations (ANSD, 2008). On s'interroge ici sur le rôle joué par ces aménagements dans l'adaptation de l'agriculture du delta du fleuve Sénégal au profond et brutal bouleversement climatique auquel sont soumis les agriculteurs depuis les années 1970 et leur effets économiques, sociaux, alimentaires et environnementaux, ainsi que sur les modèles de développement dont ils sont porteurs, jusqu'à la dernière vague d'aménagements en date marquée par l'essor de l'agriculture entrepreneuriale.

\section{- L'agriculture du delta du fleuve Sénégal et la profonde sécheresse des années 1970-1980: aux limites de l'adaptation des agriculteurs?}

\section{Une agriculture sous climat sahélien dès la première moitié du $x x^{e}$ siècle, soumise à un double aléa pluviométrique et de la crue du fleuve}

La région du delta du fleuve Sénégal est située à l'extrémité septentrionale du Sénégal. Elle enregistre une pluviométrie encore plus faible - depuis que des mesures sont effectuées, dès 1892 pour la station de Saint-Louis — que celle du nord du bassin arachidier (chapitre 1). Contrairement au bassin arachidier, cette région connaît un climat sahélien dès la première moitié du xx $\mathrm{x}^{\mathrm{e}}$ siècle (figure 5.3) et elle est soumise à une forte variabilité interannuelle de la pluviométrie. Le cumul annuel de pluviométrie est compris entre 250 et $400 \mathrm{~mm}$, la limite des $400 \mathrm{~mm}$ de pluie étant supposément aussi celle de l'existence d'une agriculture pluviale.

Avant les aménagements hydrauliques de la seconde moitié du $\mathrm{xx}^{\mathrm{e}}$ siècle qui ont bouleversé les écosystèmes du delta, le paysage de la région se structure autour du fleuve Sénégal et de ses principaux défluents (Djeuss, Lampsar). Il s'organise entre trois principaux étages agroécologiques inégalement soumis à la crue, en raison de leur position topographique :

- les «cuvettes» en position basse sont les plus longuement inondées;

- en position topographique intermédiaire, les levées et dépôts fluvio-deltaïques dans le haut delta ou les terrasses marines et vasières dans le bas delta (région 
davantage soumise dans son histoire géologique à l'influence des transgressions marines) sont moins longuement envahies par l'eau;

- les dunes fixées demeurent exondées toute l'année.

La décrue s'opérait progressivement d'octobre à janvier, depuis les côtes altitudinales plus élevées jusqu'aux plus basses. En période d'étiage, l'eau salée remontait en sens inverse depuis l'estuaire du fleuve dans le lit mineur jusqu'à Richard-Toll. Elle était refoulée dans les marigots de vidange et stagnait en saison sèche dans les parties basses des cuvettes. Comme la pluviométrie, la crue se caractérise alors par un fort aléa, à la fois dans son intensité (hauteur d'eau) et dans sa date d'arrivée. Les sols de la région sont à l'époque marqués par leur caractère halomorphe, fonction de leur durée respective d'envahissement par la langue salée, ainsi que par la durée et l'intensité de la saison des pluies et de la saison sèche (Michel et al., 1984).

\section{Une agriculture sahélienne adaptée de longue date aux aléas}

Face à l'aléa de la pluviométrie et au climat sahélien, l'agriculture du delta ne repose que partiellement sur les cultures pluviales dès la première moitié du $\mathrm{xx}^{\mathrm{e}}$ siècle. Les agriculteurs pratiquent alors durant l'hivernage une rotation type (mil/niébé/pastèque/ arachide/friche de 3 à 5 ans) sous parc arboré, sur les terres exondées des dunes. Ces cultures pluviales ont des récoltes incertaines les années de faible pluviométrie. Elles sont complétées par des cultures de décrue qui jouent un rôle clé dans cette agriculture. Au rythme de la décrue, manioc, maïs, patate douce, maraîchage (piment, aubergine amère et tomate) sont installés sur les espaces recouverts sinon par la crue du fleuve durant l'hivernage, à l'exception des cuvettes où reflue la langue salée en saison sèche et dont les sols sont trop halomorphes pour être mis en culture. Lapport régulier d'alluvions par la crue du fleuve et l'ennoiement de ces étages dédiés aux cultures de décrue autorisent une mise en culture chaque année. Semés en pluvial en juin, le niébé et le mil sont récoltés respectivement dès septembre et octobre et assurent l'alimentation des familles jusqu'à la récolte des cultures de décrue à partir de février.

Les troupeaux de ruminants sont conduits en saison des pluies sur les savanes arborées des dunes, en arrière des campements d'hivernage. Ils consomment la strate herbacée présente à cette saison sur ces espaces. Ces troupeaux sont ensuite conduits en vaine pâture sur les parcelles de cultures pluviales après la récolte, puis en avançant dans la saison sèche et au rythme de la décrue, sur les espaces inondés en saison des pluies, peu à peu dégagés, où se développe progressivement une strate herbacée. $\mathrm{Au}$ plus fort de la saison sèche, les feuilles et les fruits des arbres du parc arboré des dunes complètent l'alimentation si l'herbe vient à manquer sur les parcours des espaces de décrue. Le parcage nocturne des animaux sur les parcelles qui seront mises en culture l'année suivante assure ainsi des transferts de fertilité. La région du delta est aussi le lieu de transhumance d'éleveurs du Ferlo septentrional ou de Mauritanie. Enfin, pratiquée en saison sèche tous les deux à trois jours, la pêche prend le relais du lait caillé dans l'alimentation protéique des familles à cette saison.

De type semi-sédentaire, l'habitat suit l'utilisation alternée des différents étages écologiques au cours de l'année, pour les cultures comme pour l'élevage bovin. Les villages sont ainsi installés sur les dunes en saison des pluies et en bordure des espaces de décrue en saison sèche. Le foncier n'est à l'époque pas le facteur limitant 
pour cette agriculture strictement manuelle. La surface cultivée par actif agricole est en revanche limitée par les pointes de travail sur les cultures, tout particulièrement le désherbage. Chaque actif peut ainsi mettre en valeur environ 0,5 ha sur les dunes en cultures pluviales et 0,2 ha de cultures de décrue chaque année.

La différenciation sociale repose donc avant tout sur la taille du cheptel, qui peut commander une certaine spécialisation des exploitations agricoles. Elle dépend aussi de la localisation des villages par rapport au fleuve Sénégal et à ses défluents, qui commande tout à la fois l'accès aux ressources piscicoles et la proximité à la frontière mauritanienne pour exercer des activités de commerce transfrontalier. Les familles disposant de grands troupeaux (100 à 300 têtes) sont spécialisées dans l'élevage. Avec un cheptel de quelques dizaines de têtes de bétail, les familles combinent cultures, élevage et pêche. Celles ne possédant que quelques têtes sont installées au pied des dunes, en bordure du fleuve ou de ses défluents. Elles combinent les cultures pluviales, les cultures de décrue et la pêche en saison des pluies et en saison sèche, en confiant leurs animaux aux bergers des villages des dunes. Celles qui ne possèdent pas leur propre pirogue versent une partie du produit de leur pêche au propriétaire de l'embarcation. En complément, ils se rabattent sur des activités exigeantes en travail, mais pas en capital : production de charbon de bois, tressage de nattes, etc.

Sans maîtriser les phénomènes naturels (crue du fleuve et pluviométrie), les agriculteurs ont su finement adapter leurs pratiques à cette courte saison des pluies et aux aléas hydriques et pluviométriques. Dans la foulée de Lericollais (1975), nos enquêtes montrent en effet que cette agriculture constituait à l'époque un système complexe et anti-aléatoire. Elle reposait, pour cela, sur une combinaison de productions et d'activités (culture, élevage, pêche et cueillette) permise par l'utilisation complémentaire des différents étages écologiques à la fois dans l'organisation du calendrier de travail (cultures pluviales et cultures de décrue, semis progressif des cultures de décrue au rythme du recul de la crue), dans la diversité des productions (céréales, tubercules, légumineuses graines, légumes, produits de l'élevage, produits de la pêche et combustible) et dans le calendrier alimentaire.

La mobilité au plus près des ressources (déplacement des campements semi-sédentaires entre période de crue et saison sèche), la constitution de stocks alimentaires de sécurité (greniers, techniques de stockage des produits animaux sous forme de viande séchée, en poudre ou cuite et conservée dans la graisse), le troc entre producteurs aux degrés de spécialisation variable, les réserves de trésorerie que constitue le cheptel (capital sur pied) et les autres activités déployées selon le capital disponible (charbon de bois, artisanat et commerce) : tout concoure à renforcer la robustesse de ce système agraire caractérisé à l'époque par une faible densité de population, face aux aléas pluviométriques, hydriques et économiques.

\section{Les limites de l'adaptation du système agraire ancien du delta à la sécheresse des années 1970-1980}

\footnotetext{
À l'instar du bassin arachidier (chapitre 1), la région du delta du fleuve Sénégal connaît une nette péjoration de la pluviométrie dès le début des années 1970. La péjoration s'observe également tout le long de la vallée et entraîne une réduction massive et généralisée de la crue du fleuve, contribuant à bouleverser doublement l'agriculture de la région.
} 
La description des conditions pluviométriques et hydriques dans la vallée du Sénégal en 1972 est édifiante (Lericollais, 1976) : diminution de la pluviométrie annuelle à $152 \mathrm{~mm}$ à la station de Saint-Louis, réduction du débit moyen du fleuve Sénégal par trois, réduction extrême des surfaces inondées, étiage précoce se traduisant par une forte remontée de l'eau de mer et de la langue salée dans la basse vallée du fleuve Sénégal. La récolte des cultures de décrue n'atteint pas $10 \%$ de la production moyenne habituelle. Celle des cultures pluviales est nulle pour le mil et l'arachide, très limitée pour le niébé. La perturbation de la reproduction hivernale des poissons, du développement et du charriage des alevins dans les eaux de crue conduit à une réduction par deux du volume de la pêche cette année-là. La très faible pluviométrie dans le delta ne permet pas la reconstitution du tapis herbacé sur les terres de parcours des dunes. Parallèlement, comme dans tout le Ferlo septentrional, la strate arborée est durement touchée, alors que les fruits constituent pourtant des ressources essentielles : source de devises (gomme arabique), activités de charbonnage, ressource fourragère en saison sèche et source de bois domestique (Poupon, 1976). Si les coupes d'arbres, notamment pour le charbonnage, contribuaient déjà à réduire progressivement le couvert arboré dans la région, la sécheresse prolongée accentue largement la dénudation des sols. Cette dénudation favorise la morpho-dynamique éolienne et avive le modelé dunaire (Roquet, 2008).

Cependant, 1972 n'est que la première année d'une longue série de déficits intervenus jusqu'au début des années 1990 (figure 5.3). La moyenne annuelle entre 1968 et 1992, au plus fort de la sécheresse, s'élève à $223 \mathrm{~mm}$ de pluie, soit une chute de plus d'un tiers en comparaison de la période 1946-1967. À cette période, la pluviométrie moyenne était déjà faible au regard de celle enregistrée les décennies précédentes. La région bascule ainsi, en moyenne annuelle, sous la limite des $250 \mathrm{~mm}$ séparant le climat sahélien du climat sahélo-saharien. Parallèlement, la répartition intraannuelle des pluies évolue (figure 5.4). Les pluies utiles des quatre mois de saison des pluies (juillet à octobre) sont réduites en moyenne d'un quart en début et en fin de saison entre la période $1922-1945$ et 1968 -1992, et de près de $50 \%$ au cœur de la saison des pluies (août-septembre). Les rares épisodes pluvieux durant la saison

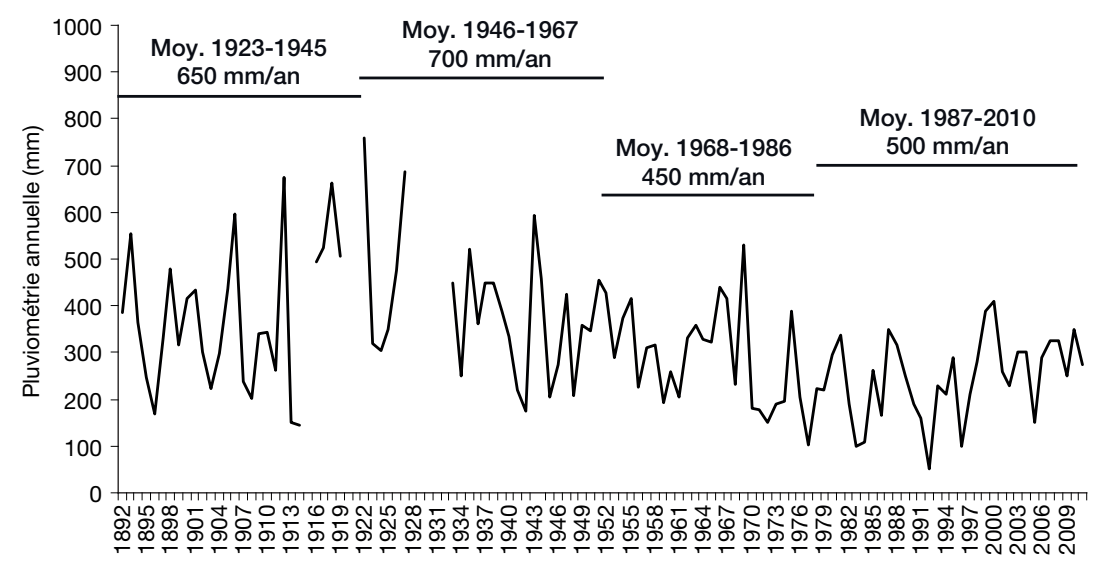

Figure 5.3. Évolution de la pluviométrie annuelle à Saint-Louis de 1892 à 2011 (Le Borgne, 1988; Kamara, 2013). 


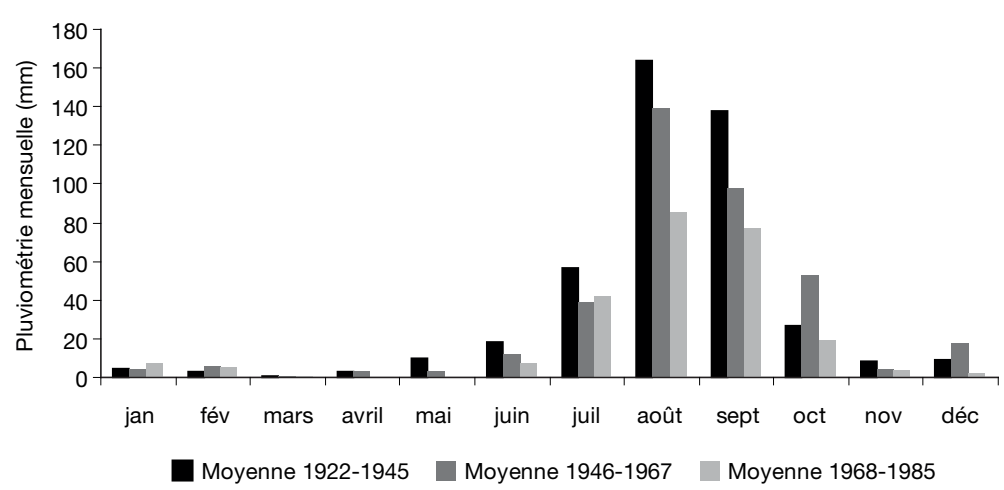

Figure 5.4. Pluviométrie mensuelle moyenne à Saint-Louis (Le Borgne, 1988).

sèche sont au contraire plus nombreux durant cette longue phase de sécheresse. Ils contribuent à perturber le métabolisme des espèces arbustives et arborées par de faux départs de végétation.

Par le passé, les agriculteurs ont su s'adapter à l'aléa en ensemençant des surfaces en cultures de décrue plus réduites les années de faible crue du fleuve (Lericollais, 1976). Les années où la pluviométrie connaissait un recul, ils ont su compenser les moindres récoltes de cultures pluviales par d'autres productions ou activités. Néanmoins, ces déficits majeurs et répétés de la pluviométrie et de la crue mettent excessivement à mal cette agriculture. La crise affecte toutes les composantes du système agraire. En effet, la très faible pousse des herbacées et arbustes de la steppe finit par atteindre le couvert arboré et ne permet pas d'alimenter suffisamment les troupeaux. La crise engendre également un rendement faible ou nul des cultures pluviales, une forte réduction des surfaces ensemencées en cultures de décrue et des faibles rendements, un amenuisement des ressources piscicoles, etc. Durant cette période, la survie des familles repose régulièrement sur une aide alimentaire d'urgence (Reboul, 1984). La décapitalisation dans le cheptel est brutale : Lericollais (1976) avance une baisse des trois quarts des effectifs en 1972 dans certains secteurs de la vallée. Les services de l'élevage du secteur de Dagana, qui couvrent la basse vallée du fleuve, indiquent une réduction par trois des effectifs (décès ou vente en catastrophe et à bas prix) que les déplacements de plus grande amplitude par transhumance ne suffisent pas à compenser.

\section{- La politique de développement dans le delta jusqu'aux années 1990 : endiguer la crise climatique?}

\section{L'accélération des aménagements avec la crise climatique : sécurisation par la maîtrise totale de l'eau et l'extension des surfaces irriguées}

Au cours des années 1950-1960, l’État sénégalais a initié l'aménagement de grands périmètres rizicoles dans le delta, sous l'égide de la Société d'aménagement et d'exploitation des terres du delta (Saed). Cet aménagement a été assorti de la 
création de villages à proximité des périmètres, où se sont installés des familles du delta ou, pour certaines, issues de la moyenne vallée du fleuve Sénégal (Lericollais, 1975). Afin de substituer dans l'urgence les cultures irriguées aux cultures pluviales et de décrue durement compromises par la sécheresse, l'État accélère et renforce cet aménagement.

Pour pallier l'inefficience des seuls aménagements primaires, les aménagements secondaires et tertiaires de ces grands périmètres sont mis en ouvre dès les années 1970. Dès lors, la gestion de la lame d'eau devient possible à l'échelle de la parcelle et permet d'enregistrer un rendement d'environ 4 à 5 tonnes de paddy par hectare sur un cycle.

Parallèlement, afin d'étendre les surfaces irriguées à des coûts plus raisonnables, la Saed facilite la mise en place de périmètres irrigués villageois (PIV) dans le haut delta, grâce au financement de l'acquisition de motopompes flottantes par des groupes villageois et à l'appui des travaux de terrassement. Le coût d'investissement de ces petits périmètres est sensiblement plus faible par hectare que dans les grands périmètres pour des rendements en paddy équivalents (Tricart, 1990). S’ils occupent des surfaces nettement plus réduites que les grands périmètres, ces périmètres villageois contribuent néanmoins à la sécurité alimentaire des familles du haut delta. Cependant, l'absence fréquente de système de drainage conduit les agriculteurs à abandonner certains d'entre eux après seulement quelques années (Dahou, 2009; enquêtes des auteurs).

Loin des objectifs ambitieux initialement fixés en termes de surfaces, ce sont néanmoins près de 14000 hectares de terres du delta qui sont aménagées en maîtrise totale de l'eau à la fin des années 1980 (Seck, 1991; Maiga, 1995).

C'est cependant la construction de deux ouvrages majeurs sur le fleuve Sénégal, planifiée et exécutée au cours des années 1980, qui acte le bouleversement complet de l'agriculture du delta à partir des années 1990. Le barrage aval de Diama qui vise à éviter la remontée de la langue salée en saison sèche (en période d'étiage) est achevé en 1986. Le barrage-réservoir amont de Manantali est achevé en 1988. Il permet de maîtriser la crue du fleuve et d'assurer une disponibilité en eau toute l'année pour la riziculture et le maraîchage irrigués. Parallèlement à ces grands ouvrages, des travaux complémentaires sont entrepris dans les années 1980 dans le bas delta le long du Lampsar, défluent du fleuve Sénégal. Ils portent sur la séparation des réseaux d'irrigation et de drainage sur le réseau primaire, l'équipement en stations de pompage électrifiées des canaux primaires et des principaux fossés d'évacuation des eaux, ainsi que la mise en place d'un dense réseau de diguettes et le nivelage des parcelles (aménagements tertiaires). L'ensemble de ces aménagements permet une régulation précise de la crue et l'arrêt définitif des remontées d'eau de mer dans les périmètres irrigués.

\section{Un bouleversement de l'agriculture du delta, déterminant dans l'adaptation des agriculteurs à la sécheresse}

La mise en place de ces barrages et la maîtrise totale de la crue du fleuve se traduisent par la progression spectaculaire des surfaces dédiées à la riziculture irriguée au cours des années 1990; tout spécialement dans le haut delta où les dépressions 
qui se prêtent bien à l'installation de la riziculture irriguée sont particulièrement nombreuses (figure 5.5). D'après les données de la Saed (2015), de 14000 ha à la fin des années 1980, ces surfaces sont de 38000 ha à la fin des années 1990.

Le maintien d'un niveau minimum d'eau toute l'année et la diffusion de variétés de riz de quatre mois permettent de pratiquer la culture de riz de contre-saison de mars à juillet et rendent désormais possible la réalisation de deux campagnes de riz par an. Dans le bas delta, de nouveaux périmètres rizicoles sont aménagés, particulièrement le long du Lampsar où la Saed distribue des parcelles aménagées de 0,2 à 0,3 ha par actif. Des cultures maraîchères de contre-saison (oignon et tomate) peuvent également s'intercaler dans les rotations entre deux années dédiées à la culture de riz. Leur essor est facilité par la création de la Société de conserverie du Sénégal (Socas) au début des années 1970, qui a pour but de répondre à la demande sénégalaise en concentré de tomate et de tenter de réduire les importations. Sous l'influence de la proximité de l'usine de la Socas ${ }^{1}$ et grâce à l'établissement des contrats avec les producteurs, la culture de tomates de contre-saison connaît une forte progression dans le bas delta. Lextension du réseau d'irrigation et de drainage s'accompagne également d'une multiplication de petites parcelles maraîchères irriguées manuellement le long des canaux et axes de drainage. Avec l'arrêt des cultures pluviales imposé par les déficits pluviométriques, et le recul puis la disparition des surfaces en cultures de décrue liée à la construction des barrages, les agriculteurs utilisent aussi ces petites parcelles irrigables pour certaines cultures jusqu'alors conduites en pluvial (niébé et arachide).

Il semble que le développement de la riziculture inondée et des cultures irriguées (riz et maraîchage) dans le haut et le bas delta ait ainsi joué un rôle important dans l'adaptation des systèmes de production agricole à cette profonde sécheresse, au prix d'une intensification importante en travail. Les agriculteurs ont ainsi pu continuer à cultiver une céréale de base (riz au lieu du mil) et des légumineuses, et développer des cultures maraîchères destinées à la vente (tomate notamment) qui permettent des achats complémentaires de riz. Les producteurs n'en cherchent pas moins, dès les années 1970, des revenus extra-agricoles. La Société de conserverie du Sénégal et surtout la Compagnie sucrière du Sénégal installée à la même époque au nord du delta (Richard-Toll) sont les premiers employeurs du delta (Tourrand et al., 1994). Outre le salariat dans ces sociétés, les familles du delta recherchent d'autres revenus complémentaires en essayant de se faire embaucher à Saint-Louis ou en confortant leurs activités artisanales ou commerciales.

Ces transformations apportées à l'agriculture du delta, véritable changement d'état de ce système agraire, permettent de limiter les effets de la crise et des aléas climatiques. Jusque dans les années 1980, elles reposent sur une intervention systématique des organismes publics, dans toutes les composantes de la politique agricole :

- gestion du foncier avec le classement en «zones pionnières» des terres du delta dès 1964, qui confère à la Société d'aménagement et d'exploitation des terres du delta (Saed) une totale maîtrise foncière;

- organisation des marchés (monopole de l'achat et de l'écoulement des céréales nationales par la Caisse de péréquation et de stabilisation des prix, CPSP);

1. Celle-ci installe en complément son propre périmètre irrigué en régie $(550$ ha) quelques années plus tard. 
- subvention des intrants, accès au crédit, prise en charge des investissements et aménagements à des fins agricoles;

- gestion de l'eau d'irrigation et conduite des cultures pratiquées au sein des périmètres irrigués selon un modèle basé sur le recours à la moto-mécanisation et aux intrants chimiques. Cette conduite repose sur des itinéraires techniques très normés allant jusqu'à la fixation par la Saed des dates de récolte.
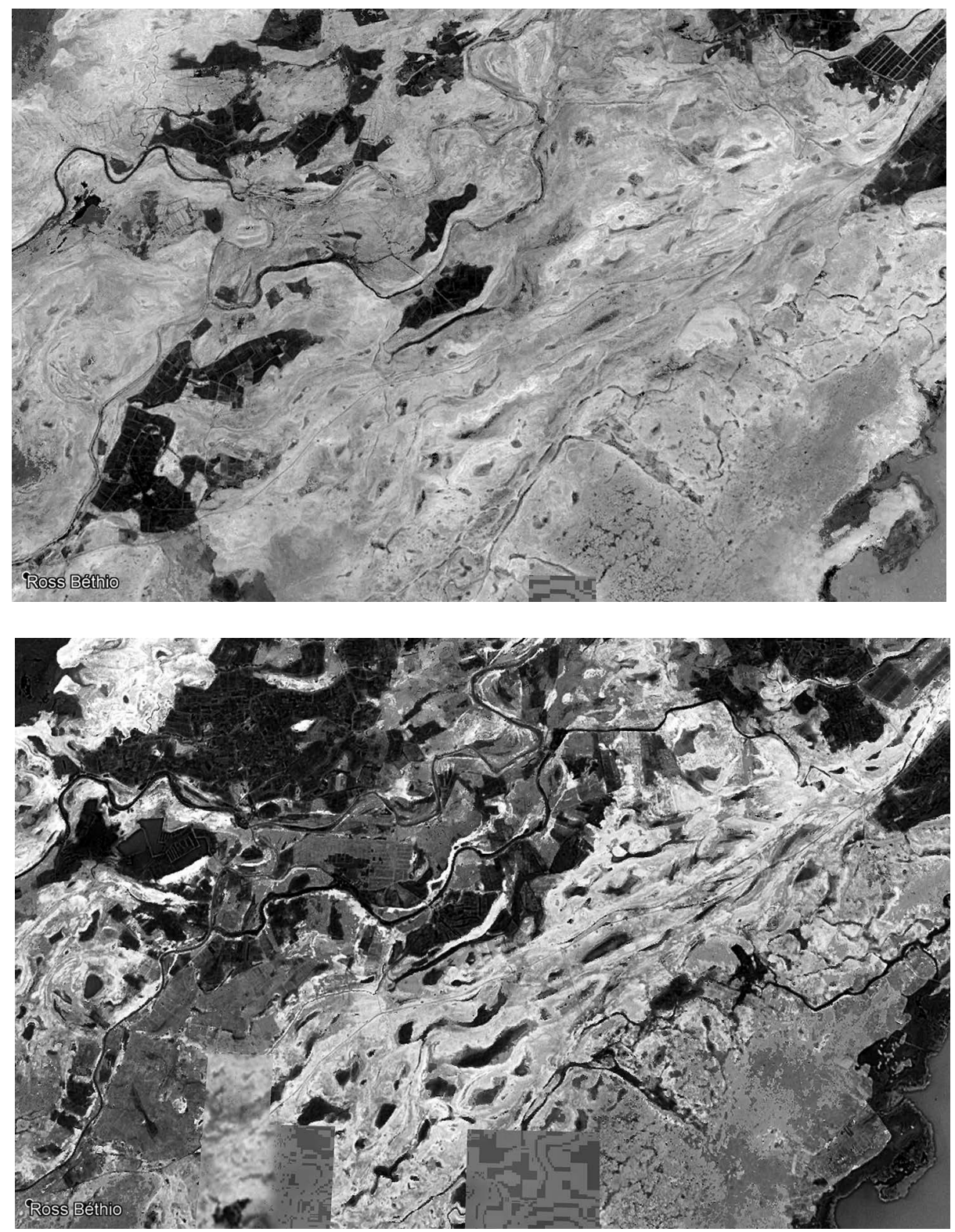

Figure 5.5. Effets de la mise en place des barrages le long du fleuve Sénégal sur l'extension des périmètres irrigués dans le haut delta, décembre 1984 en haut et décembre 1999 en bas (Google Earth). 
Ces interventions, déterminantes dans la sécurisation des producteurs, s'accompagnent néanmoins d'une forte dépendance technique et financière des producteurs à la Société d'aménagement et d'exploitation des terres du delta Saed (Seck, 1986). Les producteurs sont réduits au rôle de simples exécutants au sein des périmètres irrigués dans lesquels ils n'auraient jamais eu les moyens d'investir en propre. Seuls les périmètres irrigués villageois (PIV) sont gérés de façon autonome par les agriculteurs.

La progression des périmètres irrigués entraîne par ailleurs le recul des espaces dédiés aux cultures de décrue et au pâturage de saison sèche. Elle conduit nombre d'éleveurs du haut delta à s'orienter plus largement vers les cultures et à se sédentariser. Une nouvelle articulation entre cultures et élevage se met en place. La consommation des pailles et du son de riz par les bovins en saison sèche s'efforce de compenser le recul des parcours autrefois disponibles sur les terroirs de décrue. Santoir (1994) avance que la présence de périmètres hydro-agricoles offre des sousproduits fourragers et d'autres sources de revenus agricoles et qu'elle a pu contribuer à amortir le recul massif et les fortes fluctuations des fourrages spontanés disponibles durant la sécheresse des années 1970-1980, pour les producteurs du delta du fleuve. Cet auteur souligne aussi que les transhumances, auparavant orientées vers le nord et le lit majeur du fleuve Sénégal, se sont parallèlement réorientées vers le sud, où la pluviométrie est supérieure. Elles se sont d'ailleurs étendues jusqu'à l'extrême sud-est du pays, dans la région des Terres neuves, où une colonisation agricole est à l'œuvre depuis les années 1970 (Devillers et al., 2016).

\section{Une rupture dans la politique agricole et foncière au tournant des années 1980}

La grande continuité dans l'objectif des aménagements (maîtrise totale de l'eau à l'échelle de la parcelle, allongement de la durée d'accès à l'irrigation au cours de l'année, extension des surfaces irrigables) contraste avec le bouleversement des conditions de production et d'accès aux ressources que connaissent les producteurs à partir des années 1980.

Au cours des années 1960-1970, la sécurisation technique et économique des producteurs se caractérise par leur encadrement étroit par les organismes d'État, au premier rang desquels la Saed, aussi bien au plan technique et financier que dans l'accès au foncier irrigable. La sécurisation passe également par des tentatives de régulation du marché intérieur du riz dans les années 1970. Créé en 1971, l’Office national de coopération et d'assistance au développement (Oncad) fédère et administre alors l'ensemble des fonctions d'appui aux producteurs et vise à promouvoir la production nationale. Il est chargé de l'importation et du stockage du riz importé, de l'approvisionnement et de la distribution d'intrants subventionnés à hauteur de $50 \%$ et de l'octroi de crédits de campagne. À partir de 1973, l'Oncad s'appuie sur la Caisse de péréquation et de stabilisation des prix (CPSP). Cette caisse dispose d'un monopole sur l'achat et l'écoulement des céréales nationales et sur les importations de céréales (aide alimentaire américaine incluse). Elle dispose d'un système de régulation (quotas pour le blé et taxes) devant lui permettre de contrôler le prix intérieur des céréales. L'État s'efforce de soutenir le prix du riz entier proposé aux 
producteurs sénégalais - forme sous laquelle est vendue l'essentiel de la production locale - en apposant une taxe ad valorem sur le riz importé et en procédant à des contingentements d'importation (Benz, 1996).

Le plan d'ajustement structurel auquel est soumis le Sénégal dès 1981 et la nouvelle politique agricole (NPA) qui en découle (initiée en 1984) bouleversent le cadre productif des agriculteurs du delta à partir des années 1980, alors que se poursuivent en parallèle les aménagements hydro-agricoles. Face au laxisme dans le remboursement des crédits de campagne et d'équipement, la faillite de l'Oncad en 1979 illustre le déséquilibre économique de la filière rizicole (Lavigne-Delville, 1993). Elle s'accompagne du «désengagement» progressif de la Saed tout au long des années 1980 et 1990 et de la délégation progressive de la gestion de l'eau aux producteurs au sein des grands aménagements, grâce à la formation d'Unions hydrauliques. Ces unions prennent en charge la collecte des redevances, l'entretien des canaux et des ouvrages de distribution, ainsi que l'acquisition éventuelle d'équipements collectifs. Désormais, la Saed n'assure plus que la coordination de l'approvisionnement en intrants et la collecte, ainsi que la transformation et la commercialisation du riz. Laccès au crédit assuré par la CNCAS (Caisse nationale de crédit agricole du Sénégal) est basé sur des prêts à court terme pour les intrants et à moyen terme pour les équipements. Ces crédits sont accordés aux seuls producteurs possédant une terre et structurés en Groupement d'intérêt économique (GIE), qui peuvent être familiaux ou liés aux Unions hydrauliques. Les producteurs doivent également composer avec un arrêt de la subvention des intrants.

Avec la loi relative aux communautés rurales de 1972 qui prévoit le basculement des «zones pionnières» en «zones de terroir», la Saed se voit retirer la gestion du foncier. Les communautés rurales, par l'intermédiaire des Conseils ruraux élus en leur sein, deviennent responsables de l'attribution et de la gestion des terres (Boutillier, 1989). Cette volonté décentralisatrice de transfert de la gestion du foncier aux communautés rurales directement concernées peut paraître louable. Néanmoins, la gestion qui en découle n'est pas exempt d'inégalités à cause des dérives clientélistes liées à la rentabilité nouvelle que confèrent potentiellement ces aménagements à une partie des terres agricoles (Dahou, 2004).

\section{De nouvelles fragilités malgré la progression de l'irrigation : spécialisation, endettement et insécurité foncière}

Dès lors, l'extension des surfaces irrigables (supra) porte avant tout sur la mise en place de périmètres privés qui connaissent un essor rapide dès les années 1980, tout particulièrement dans le haut delta. Si les surfaces des aménagements publics ne progressent pratiquement pas avec moins de 13000 ha au milieu des années 1990, celles des aménagements privés passent en une décennie (de 1987 à 1996) de moins de 4000 ha à plus de 29000 ha (Dahou, 2009). Elles constituent donc l'essentiel de l'extension des surfaces irriguées au cours des années 1990.

Ces périmètres privés bénéficient d'une gestion beaucoup plus souple que les grands périmètres des années 1970. Il s'agit en revanche d'aménagements de moins bonne facture, moins pérennes et ne permettant souvent pas d'enregistrer des rendements en riz aussi élevés que ceux atteints, à partir des années 1990, dans les grands 
périmètres. La progression des surfaces irriguées se traduit également par une spécialisation accrue des producteurs autour de la riziculture, notamment dans le haut delta. Cette spécialisation les fragilise davantage en cas de mauvaise récolte. En parallèle, les coûts de production augmentent à cause de l'arrêt de la subvention des intrants et de la prise en charge par les producteurs des frais de maintenance et d'équipement des unités hydrauliques. Ce déploiement des périmètres privés s'accompagne donc d'une progression rapide de l'endettement des producteurs. Face aux énormes besoins en capital (à court et moyen termes) que suppose l'extension des surfaces irriguées, et face aux crédits octroyés sur la seule base de la détention de foncier, sans expertise préalable quant à la viabilité technique et à la solidité financière des structures emprunteuses, la Caisse nationale de crédit agricole (CNCAS) se retrouve lourdement endettée dès le début des années 1990 (Dahou, 2006).

En outre, les producteurs de riz du haut delta subissent de plein fouet la dévaluation du franc CFA en 1994, qui contribue à renchérir le prix des intrants. La même année, ils souffrent également du démantèlement de la Caisse de péréquation et de stabilisation des prix (CPSP) qui achetait jusque-là le riz local à un prix soutenu (par une taxe ad valorem de $15 \%$ et des quotas d'importations), relayée par des opérateurs privés. Si une taxe ad valorem à l'importation de 15 FCFA $/ \mathrm{kg}$ est maintenue, l'évolution relative des prix du riz et des intrants s'avère très défavorable aux producteurs, qui subissent ainsi, en monnaie constante, une baisse du prix du riz de $25 \%$ entre le début des années 1990 et la période 1996-2007 (figure 5.6).

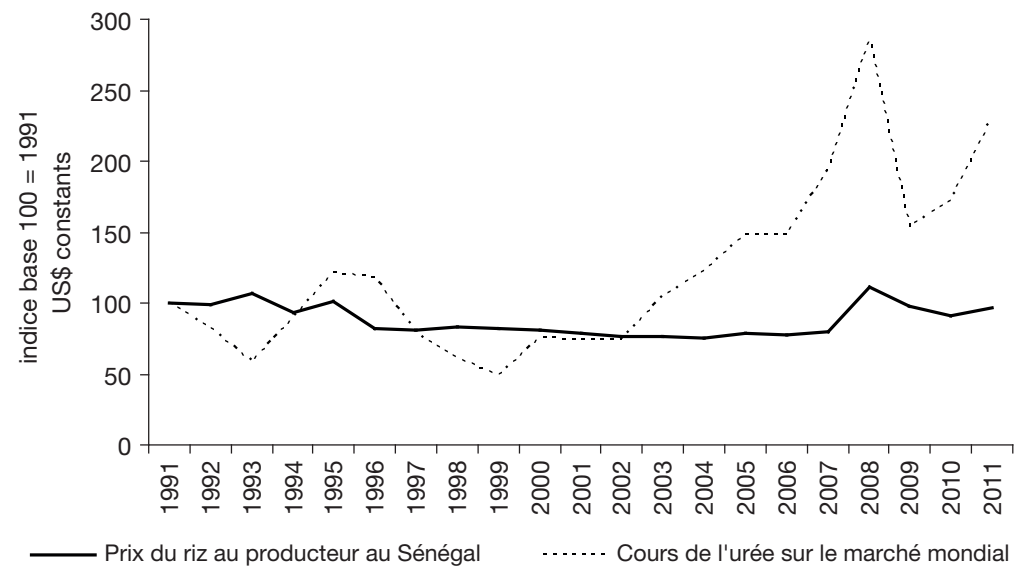

Figure 5.6. Évolutions du prix du riz au producteur au Sénégal et des cours de l'urée sur le marché mondial de 1991 à 2011 (d'après les données FAOStat et de la Banque mondiale, 1991).

L'extension des surfaces rizicoles irriguées entre le milieu des années 1980 et le milieu des années 1990, avant ces bouleversements de politique agricole, a bien permis d'accroître l'autonomie en riz du pays, grâce à une production nationale permettant de couvrir en moyenne le tiers des besoins du pays au début des années 1990. En revanche, cette production nationale tombe à moins du quart de la consommation nationale en moyenne entre 1995 et 2007 . Sa progression sur cette période $(+25 \%)$ connaît en effet un rythme plus lent que celle de la démographie et les importations de riz qui explosent, en faisant plus que doubler sur la même période (figure 5.7). 
Nos enquêtes montrent également que le nouveau contexte de production, d'accès au foncier et d'endettement des producteurs familiaux offre des conditions favorables aux personnes à forte disponibilité en capital et disposant des relations et du réseau d'influence nécessaires à l'attribution de droits sur de vastes surfaces agricoles par les autorités des communautés rurales. Au besoin, ces derniers recourent à des pratiques clientélistes, au sujet desquelles Boutillier (1989) formulait déjà des craintes il y a près de trente ans. Ces détenteurs de capitaux procèdent également à des arrangements à l'amiable avec nombre de villageois qui ne disposent pas du capital nécessaire à la réalisation d'aménagements secondaires et tertiaires. Ces derniers formulent des demandes de terres auprès de la Communauté rurale. Les surfaces obtenues sont ensuite intégralement aménagées par l'investisseur, qui leur rétrocède une partie et se réserve l'exploitation de l'essentiel des parcelles aménagées en ayant recours à de la main-d'œuvre salariée. Dans le haut delta, l'essor des périmètres privés s'accompagne ainsi, dès les années 1990, d'une première vague de développement de systèmes patronaux conduits par les familles les plus aisées. Des systèmes de type capitaliste commencent ainsi à se développer dès cette époque (rejoignant les observations de Boutillier en 1989), portés par des investisseurs sénégalais et, dans une moindre mesure, des investisseurs internationaux.

\section{" De l'adaptation au changement climatique au renforcement de l'autosuffisance alimentaire : quel modèle de développement pour l'agriculture du delta?}

\section{Une nouvelle vague d'aménagements hydrauliques sous l'effet de la flambée des prix des céréales de 2008}

Depuis 2008, la flambée des prix des céréales et la crise alimentaire qui s'est ensuivie, le delta du fleuve Sénégal connaît une nouvelle vague d'aménagements hydrauliques. Dès 2009, afin de renforcer le schéma hydraulique du delta, de réhabiliter certains périmètres abandonnés et d'accroître les surfaces irrigables, différents programmes ont été menés de façon conjointe avec l'appui de bailleurs étrangers. Dans le haut delta, le Projet de promotion des partenariats rizicoles dans le delta (3PRD) a permis de soutenir le débit du Gorom (connecté au fleuve Sénégal, figure 5.2). Il prévoyait l'aménagement de 2500 ha de terres irrigables dédiées à la riziculture sur les terres de dunes. Dans le bas delta, le Programme pour le développement des marchés agricoles au Sénégal (PDMAS) a porté sur le renforcement du débit du Lampsar grâce à la construction du canal de Krankaye à partir du Gorom (figure 5.2).

Financé par l'État américain à hauteur de 540 millions de dollars, le Millenium challenge account (MCA) mené de 2010 à 2015 visait lui aussi à compléter et renforcer le schéma hydraulique du delta en :

- sécurisant par des adducteurs les 40000 ha déjà irrigables;

- étendant de 10000 ha la surface irriguée;

- transformant l'un des émissaires du fleuve Sénégal, le Djeuss, utilisé jusque-là pour l'irrigation, la pêche et l'élevage (abreuvement, pâturage en saison sèche sur 
les terres envahies par sa crue en saison des pluies) en drain principal des périmètres irrigués du haut et du bas delta.

Dans le haut delta, tous les réseaux de drainage des périmètres rizicoles ont bien été connectés au drain principal (Djeuss, figure 5.2). Ces travaux ont, semble-t-il, permis de sécuriser l'irrigation gravitaire sur les parcelles les plus éloignées des canaux principaux et de rendre à nouveau cultivables des petits périmètres privés, sommairement aménagés dans les années 1990 et vite abandonnés. Ces réhabilitations ont permis d'étendre les surfaces irrigables cultivées. Dans le bas delta, l'endiguement et le changement d'usage du Djeuss ont bouleversé le schéma hydraulique et se sont accompagnés de la mise en place de deux canaux «compensateurs». Ceux-ci desservent les parcelles irriguées jusqu'alors par les usagers à partir du Djeuss. Ils offrent aussi la possibilité d'étendre l'irrigation à de nouvelles surfaces, dans des dépressions (cuvettes) et surtout sur les étages des anciennes terrasses marines et les terres de dunes, à condition d'être équipé d'une motopompe.

Dans le delta, ce renforcement de la capacité d'irrigation s'inscrit dans une volonté affichée de l'État sénégalais, depuis une dizaine d'années, de consolider l'autosuffisance alimentaire du pays en augmentant notamment la production de riz (figure 5.8). Cette volonté s'est traduite, dès 2008, par la Goana (Grande offensive agricole pour la nourriture et l'abondance) et le PNAR (Programme national d'autosuffisance en riz) basés sur l'octroi de subventions à l'équipement (dons de motopompes) et aux intrants (subventions aux engrais). Elle s'est manifestée aussi par l'annulation des dettes des producteurs afin de leur permettre de contracter de nouveaux emprunts auprès de la CNCAS. En parallèle des aménagements hydrauliques, ces mesures politiques ont été prolongées par la mise en place du Pracas (Programme d'accélération de la cadence de l'agriculture sénégalaise, 2014-2017) qui visait, entre autres, à atteindre l'autosuffisance du Sénégal en riz et en oignon à l'horizon 2017. La hausse initialement envisagée de la production nationale de paddy était de 1,6 million de tonnes (MAER, 2014), équivalente à l'ensemble des importations de riz du pays et deux fois supérieure à la production nationale en 2014 (figure 5.8). Ce programme prévoyait notamment la distribution de matériel subventionné, des subventions aux intrants, l'annulation des dettes des producteurs (budget de près de 20 millions d'euros) et l'appui à l'aménagement de nouveaux périmètres sur 5000 ha en trois ans (budget de 7,5 millions d'euros). En 2015, 2000 ha ont ainsi été nouvellement aménagés avec l'appui de la Société d'aménagement et d'exploitation des terres (Saed), à $50 \%$ au profit de Groupements d'intérêt économique familiaux et à $50 \%$ pour des investisseurs. En 2016, 1000 ha ont été aménagés et affectés en lots de 5, 10, 20 et jusqu'à 100 ha.

\section{Des prix aux producteurs de moins en moins régulés et un accès inégal au crédit}

Depuis 2000, le Sénégal a aligné la taxe appliquée au riz importé sur le tarif extérieur commun pratiqué par les pays de l'Union économique et monétaire ouest-africaine (UEMOA) (10\%) et il a supprimé le régime de contingentement des importations. Le prix du riz au producteur sénégalais est donc directement indexé sur le prix pratiqué sur le marché international. Après une quinzaine d'années de baisse, le prix 


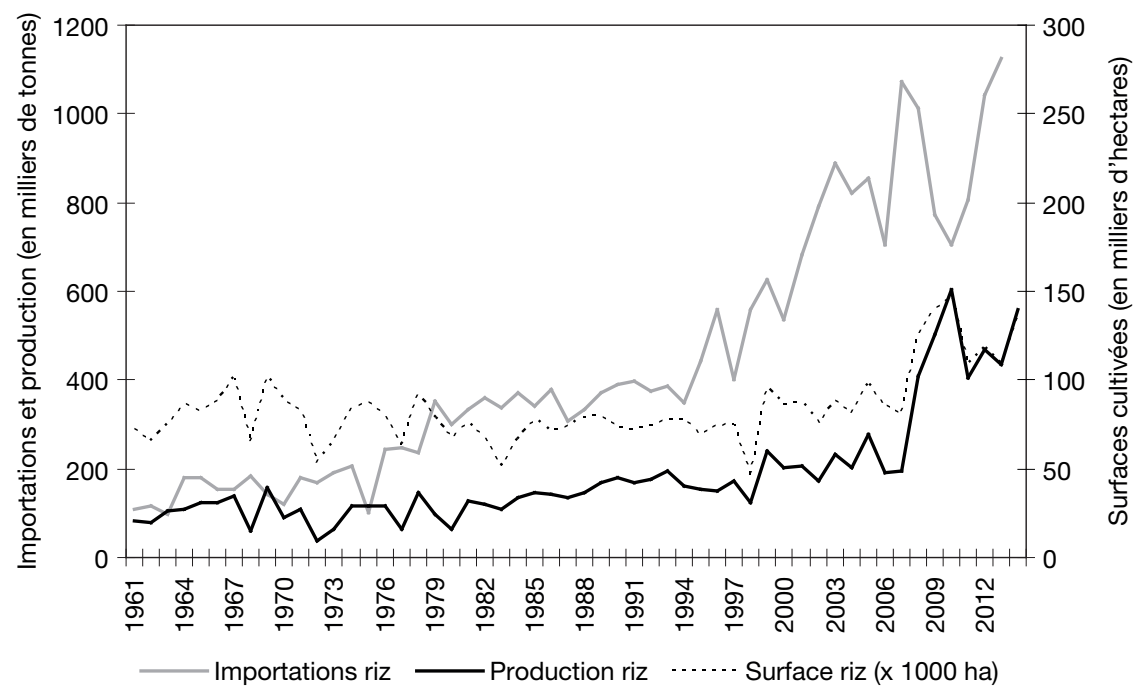

Figure 5.7. Surface, production et importations de riz au Sénégal de 1961 à 2014 (données FAOStat).

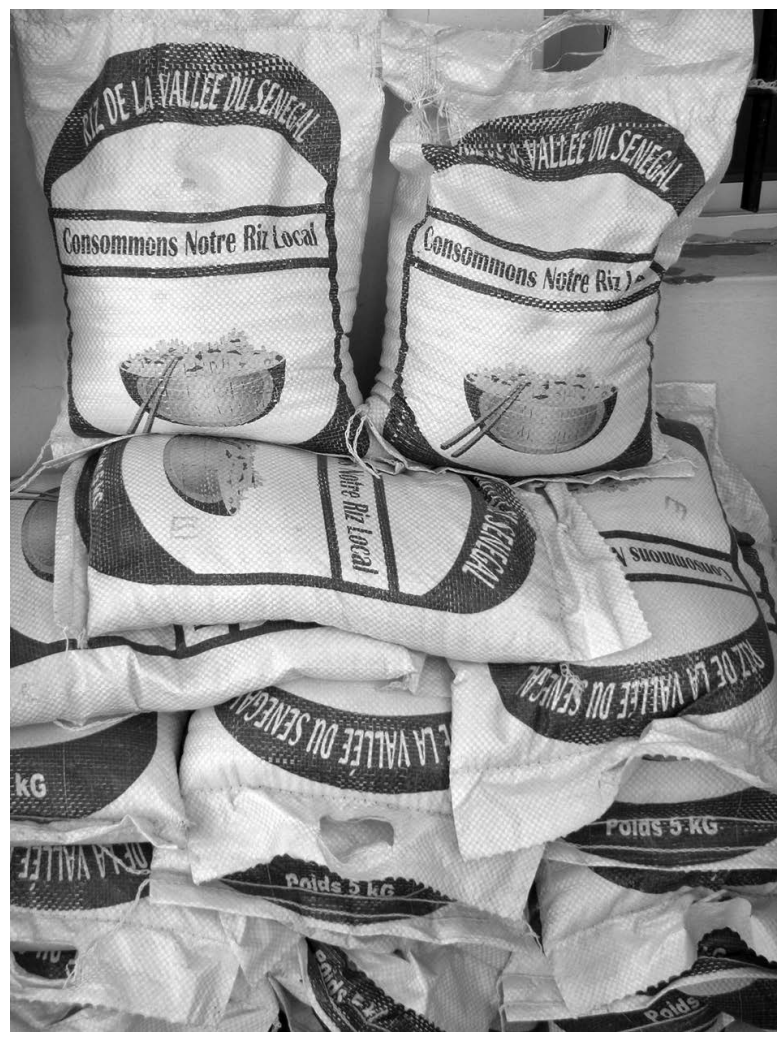

Figure 5.8. Sacs de riz produit dans la vallée du Sénégal en vente sur le marché de SaintLouis (Garambois, 2016). 
du riz au producteur sénégalais a retrouvé, en monnaie constante, son niveau de la première moitié des années 1990 (figure 5.6) grâce au renchérissement du prix du riz sur le marché mondial depuis la fin des années 2000. Ce contexte de prix plutôt à la hausse contribue aussi probablement à expliquer l'intérêt récent des investisseurs pour le secteur rizicole.

Aujourd'hui, la commercialisation du riz est assurée par le secteur privé sénégalais. En parallèle des grands opérateurs, des initiatives commencent à émerger pour permettre aux agriculteurs familiaux de mieux maîtriser le prix de vente et la commercialisation de leur riz. C'est ainsi qu'un magasin a été récemment installé dans le nord du bas delta, avec l'appui des bailleurs étrangers, qui permet d'effectuer décorticage, ensachement, stockage, et bientôt calibrage (grains et brisures) et tri du riz selon les variétés et les qualités. Ces initiatives visent à s'adapter à la demande des marchés urbains sénégalais, où le riz représente plus de la moitié des céréales consommées (Fall, 2010).

Loignon sénégalais bénéficie encore d'une taxe à l'importation de 26,5\% qui contribue à soutenir le prix au producteur. Mais il reste très concurrencé par l'importation d'oignons hollandais dont les fins de stocks sont vendues à très bas prix sur le marché international (David-Benz et al., 2010). La production de tomate, très majoritairement destinée à la transformation industrielle (double-concentré), est vendue sous contrat à la Société de conserverie du Sénégal (Socas). Le prix au producteur est ici fixé dans le cadre du Comité national de concertation de la tomate industrielle (Fall et al., 2010). En revanche, les marchés de la tomate fraîche et des autres productions maraîchères ne sont pas encadrés. Ils connaissent une fluctuation des prix marquée et la concurrence directe des autres bassins de production maraîchers sénégalais, en premier lieu celle de la région des Niayes.

Les producteurs de riz du delta s'approvisionnent aujourd'hui en intrants auprès des fournisseurs privés en bénéficiant d'une avance sur récolte (bons de la CNCAS) sous forme de crédits de campagne centralisés à l'échelle de leur GIE, puis de l'Union hydraulique. Le remboursement s'effectue en théorie juste après la récolte du riz, mais il peut, dans les faits, être plus tardif. En effet, les crédits pour la campagne suivante ne sont octroyés qu'à condition que l'ensemble des producteurs membres d'un même GIE aient tous remboursé leur crédit, et les retards de remboursement peuvent entraîner parfois un report à la campagne suivante. D'autre part, d'après nos enquêtes, l'hétérogénéité des situations économiques d'un producteur à l'autre au sein d'un même GIE conduit à des échanges à l'amiable d'intrants entre producteurs. Certains producteurs n'utilisent pas l'intégralité des engrais qu'ils ont commandés et dont la quantité est fondée sur un itinéraire technique à l'hectare déterminé par la Société d'aménagement et d'exploitation des terres du delta - Saed. Une partie de ces engrais à crédit peut être cédée - revente ou en échange de l'usage d'une motopompe par exemple — à des producteurs plus aisés membres du GIE, qui peuvent les employer sur certaines de leurs parcelles situées en dehors du périmètre du GIE. Un semblable système de crédit de campagne est mis en place par la Société de conserverie du Sénégal (Socas) pour la culture de la tomate.

Laccès à des crédits de campagne auprès de la CNCAS pour l'achat d'intrants est beaucoup plus hypothétique hors périmètre rizicole, notamment pour les productions maraîchères pratiquées sur les dunes. Il oblige les agriculteurs à adopter 
d'autres stratégies. Ceux-ci choisissent alors des productions maraîchères moins exigeantes en trésorerie et privilégient l'autofinancement grâce à :

- des activités extérieures ou en jouant sur les complémentarités de trésorerie entre les productions d'hivernage et les productions de contre-saison. Ces complémentarités sont facilitées par l'étalement des récoltes entre les étages agroécologiques; - la mise en location d'une partie des terres pour une campagne d'hivernage ou de contre-saison;

- l'utilisation de l'élevage (pour ceux qui en possède un) comme source de trésorerie; - le recours au microcrédit, mais à des taux non bonifiés de 10 à $14 \%$.

\section{Adaptation, mais renforcement des inégalités au sein de l'agriculture familiale}

Dans le haut delta, l'agriculture familiale s'est largement spécialisée depuis les années 1990 dans la riziculture en irrigation gravitaire, menée dans les casiers des grands périmètres (figure 5.9a; photo 5.1, planche 6). Aménagés pour certains dès les années 1960, la plupart d'entre eux ont vu leur gestion transférée aux Unions hydrauliques à partir des années 1980. D'après nos enquêtes, chaque foyer nucléaire dispose en général aujourd'hui de 2 à 3 ha dans ces grands casiers, où deux campagnes de riz peuvent être conduites par an. Ces surfaces sont complétées par 0,5 à 1 ha dans les petits périmètres (périmètres irrigués villageois ou foyers) où les producteurs pratiquent une campagne de riz par an et souvent un peu de maraîchage (figure 5.9b et $5.9 \mathrm{c})$. Les jeunes ménages les plus précaires n'ont souvent hérité que de 0,5 ha dans un grand périmètre dédié à la production de riz. Ils pratiquent plus largement le maraîchage (sur 0,5 ha) en louant une motopompe pour irriguer ensuite à la raie (figure 5.9d). À l'exception des Peuls souvent organisés en familles élargies et dont le troupeau collectif de 30 à 40 bovins peut être confié à l'un des jeunes membres de la fratrie, personne ne possède de ruminants.

Depuis les années 1990, les exploitations familiales côtoient des systèmes patronaux mis en œuvre par les agriculteurs suffisamment aisés pour avoir formulé des demandes d'allocations foncières dès cette époque et qui ont pu progressivement aménager des périmètres privés. Ces allocations foncières peuvent parfois s'étendre sur plusieurs dizaines d'hectares. Ces agriculteurs patronaux cèdent alors l'usage de la majorité de la surface à des investisseurs — riches urbains de Dakar, Rosso ou Richard Toll - qui réalisent à leurs frais l'aménagement de l'ensemble de la parcelle, et leur rétrocèdent ensuite en échange quelques hectares aménagés. Ces agriculteurs aisés, équipés d'une motopompe, possèdent ainsi aujourd'hui 4 à 5 ha situés aux deux tiers dans les grands périmètres ou dans les petits périmètres, ainsi qu'un périmètre privé dédié à la riziculture, où une campagne, souvent de contresaison, peut alors atteindre jusqu'à 20 ha.

Dans le bas delta, nos enquêtes montrent que les ménages les plus précaires (souvent jeunes) disposent de moins d'un hectare, d'une motopompe en copropriété et n'ont pas d'animaux. Plus des trois quarts de leurs cultures sont situés dans les grands périmètres irrigués où ils alternent une année à deux campagnes de riz et une année de culture d'oignon (riz/riz//oignon). Le reste de leurs parcelles cultivées est pris en location sur des terres de dunes dédiées à des cultures maraîchères de contre-saison peu 
exigeantes en capital (aubergine, gombo et concombre). Leur récolte précoce joue un rôle clé dans le calendrier de trésorerie (système de production A ou SP A). Des ménages un peu plus âgés, équipés d'une motopompe et d'un pulvérisateur à dos mais toujours dépourvus d'élevage, sont à peine mieux lotis. Ils exploitent 1 à 1,2 ha en strict faire-valoir direct (SP B), avec toujours moins de la moitié de leur surface dédiée aux mêmes cultures maraîchères, plus risquées et plus gourmandes en trésorerie que le riz. Comparativement, le riz occupe donc une place importante de leur assolement. Le seul revenu agricole ne suffit pas à faire vivre ces familles, qui doivent s'orienter vers des activités salariées complémentaires pour dégager un revenu total par actif légèrement supérieur à celui des salariés agricoles de la région (figure 5.10).

D'autres exploitations familiales ne sont pas limitées en terres $(0,45$ à 0,6 ha par actif familial contre 0,3 ha dans la catégorie précédente), mais leurs parcelles sont situées sur les dunes et très peu dans les dépressions. Elles sont équipées d'une motopompe, d'un ou deux pulvérisateurs à dos et d'un troupeau de 10 à 20 chèvres. Dans ces conditions, elles se sont largement, voire exclusivement spécialisées dans les productions maraîchères, qui occupent au moins les trois quarts de leur assolement

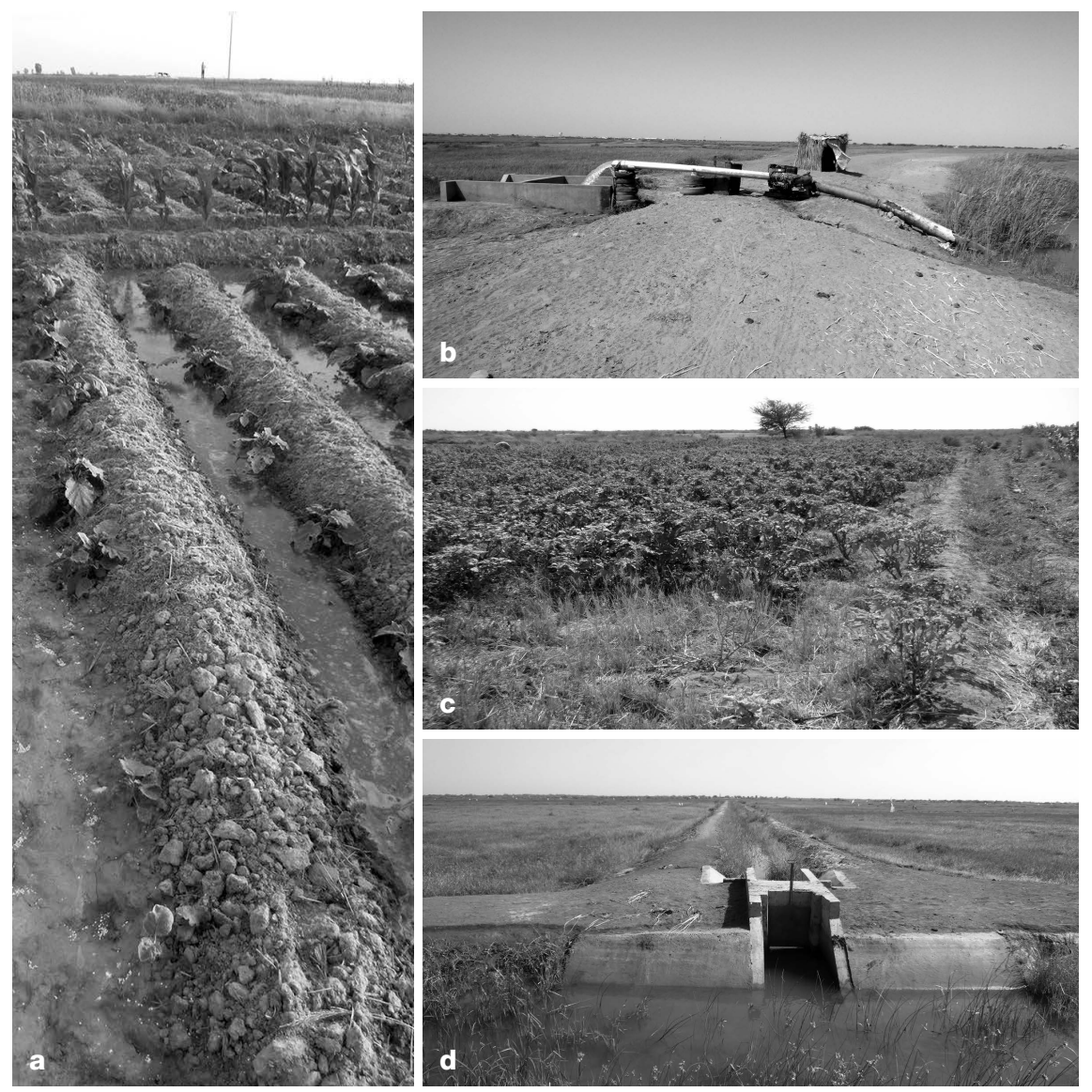

Figure 5.9. Cultures maraîchères et rizicoles irriguées dans le haut delta : périmètres villageois (a), périmètres privés (b et c), grands périmètres (d) (Garambois, 2016). 
(SP C et SP D). Ces exploitants combinent des productions exigeantes en trésorerie (oignons et piments) et en fumure organique (piment), et d'autres cultures moins risquées (aubergine amère). Néanmoins, ils mettent en location la moitié de leurs terres, faute d'une trésorerie suffisante pour les exploiter en propre.

Mieux dotés en terres avec 0,8 ha par actif familial (SP E) et en proportions équilibrées entre périmètres rizicoles ([riz/riz//oignon] ou [riz/riz//friche 1 an]) et terres de dunes dédiées aux cultures maraîchères, certains producteurs familiaux ont progressivement évolué vers des systèmes patronaux, où plus de la moitié du travail agricole est fourni par des salariés. Le riz occupe environ le tiers de leur assolement et les deux tiers restants sont consacrés à des cultures plus exigeantes en trésorerie (tomate, oignon et piment). Ces producteurs sont également en capacité de réaliser un peu d'embouche ovine.

Les familles les plus aisées sont les seules à avoir conservé un troupeau bovin et caprin avec des mères reproductrices, conduit au niveau de la famille élargie, qu'elles complètent d'embouche ovine. Ces agriculteurs ont disposé des appuis nécessaires pour se voir attribuer de vastes surfaces (5 à 10 ha par actif familial) dont l'essentiel est pour l'instant mis en location, ce qui leur assure une confortable rente foncière (SP F). Cette aisance foncière et financière leur a permis de se spécialiser assez largement dans les cultures maraîchères (oignon et piment).

En considérant l'ensemble des sources de revenus agricoles, extra-agricoles et la rente foncière, les écarts de revenus par actif entre les foyers les plus pauvres et les familles les plus aisées peuvent ainsi varier d'un facteur un à cinq (figure 5.10).

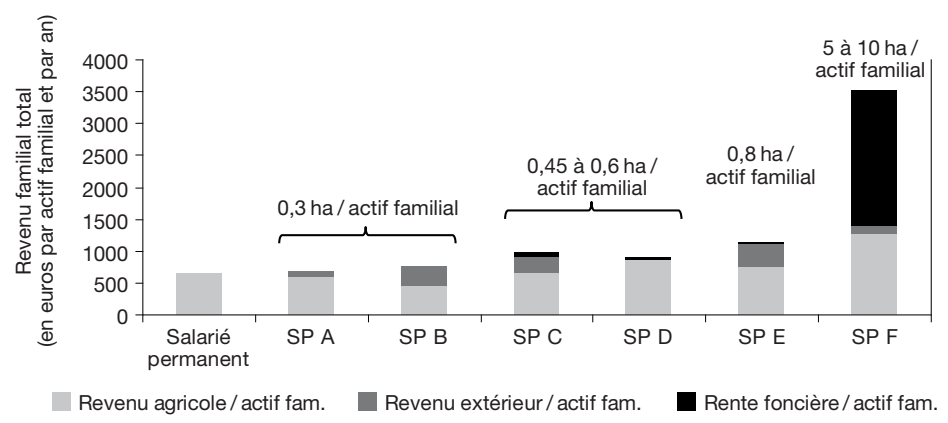

Figure 5.10. Niveau et composition des revenus par actif des principaux systèmes de production (enquêtes réalisées en 2016).

Nos enquêtes montrent que la place des revenus extra-agricoles (emploi salarié) est non négligeable dans les revenus totaux des familles du bas delta. Ces revenus jouent un rôle clé en matière de trésorerie pour financer les campagnes de riz et surtout de maraîchage. La place centrale de la main-d'œuvre salariée dans le fonctionnement des systèmes de production ressort de la lecture de la figure 5.11. Limmense majorité des exploitants y ont recours :

- pour couvrir certaines pointes de travail (récolte notamment) de façon journalière; - par l'emploi de salariés saisonniers durant la contre-saison, notamment pour les cultures maraîchères;

- par l'emploi de salariés permanents, présents dix mois par an sur l'exploitation. 
Si la main-d'œuvre journalière est plutôt recrutée localement (jeunes actifs souvent issus des ménages plus pauvres), la main-d'œuvre saisonnière ou permanente est le plus souvent originaire d'autres régions du Sénégal, majoritairement de Casamance. Elle est composée de jeunes actifs qui migrent dans la région du delta du fleuve Sénégal durant la saison sèche, période où la charge de travail agricole est moindre dans leur région d'origine. Les systèmes patronaux (SP E par exemple) sont ceux qui mobilisent le plus de main-d'œuvre salariée.

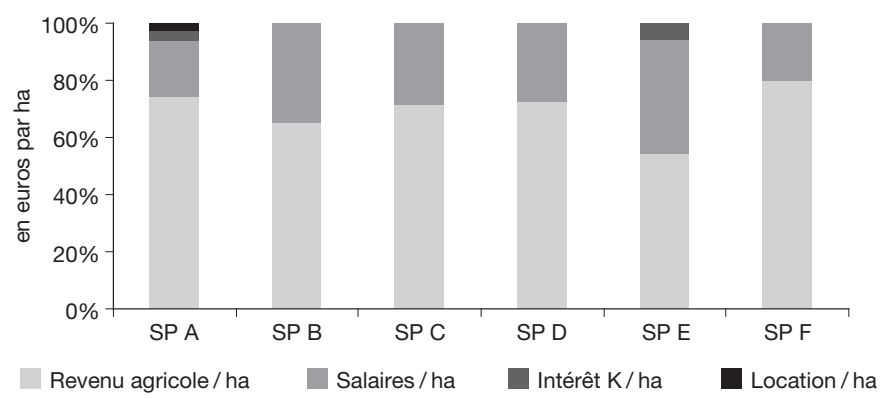

Figure 5.11. Répartition de la valeur ajoutée créée par hectare entre revenu agricole, salaires des ouvriers agricoles, location du foncier et intérêts du capital emprunté (enquêtes réalisées en 2016).

\section{Le choix assumé d'une agriculture à plusieurs vitesses pour le delta}

Dans le haut delta, la forte progression des périmètres privés s'est traduite, dès les années 1990, par le développement de systèmes de production capitalistes reposant exclusivement sur le salariat et spécialisés dans la production de riz. Ces exploitations vont de 40 à 50 ha jusqu'à plus de 100 ha. Dans ce dernier cas, la riziculture est associée à un élevage bovin de plusieurs dizaines de têtes (réservoir de trésorerie) confié à un bouvier et complété d'activités de prestation de service (travail du sol et moisson) pour rentabiliser leurs équipements motorisés de grande capacité.

Dans le bas delta, ces mesures et aménagements récents se sont soldés par une nouvelle vague de course au foncier, dans laquelle les agriculteurs patronaux et les investisseurs sont tout particulièrement avantagés par leur disponibilité élevée en capital (emprunt ou autofinancement), pour l'équipement comme pour la trésorerie de chaque campagne (intrants et main-d'œuvre). À son tour, le bas delta connaît ainsi, depuis quelques années, une vague de développement de systèmes capitalistes à la faveur du renforcement et de l'extension des grands aménagements hydrauliques, mais aussi des modalités d'attribution du foncier et des appuis à l'investissement par les pouvoirs publics.

L'extension du réseau d'irrigation primaire et le renforcement de son débit a conduit à une flambée des demandes d'attribution foncière et, semble-t-il, à l'attribution de la majorité des terres du bas delta. Ces demandes concernent tout particulièrement les espaces des dunes dont une partie a déjà commencé à être exploitée, mais aussi les dépressions qui n'étaient pas jusque-là desservies par les canaux primaires. 
D'après nos enquêtes, les formes capitalistes d'agriculture se matérialisent dans différents types d'exploitations, pour la plupart détenues par des investisseurs nationaux :

- des fonctionnaires retraités du secteur agricole originaires du bas delta. Ils délèguent à des salariés la mise en valeur de cinq à dix hectares en maraîchage (infra, SP G);

- des investisseurs issus de Dakar, Thiès ou Touba ayant souvent d'autres exploitations agricoles dans d'autres régions du Sénégal. Ils aménagent progressivement 10 à 20 ha sur les dunes, équipés en système d'arrosage par aspersion ou en goutteà-goutte, pour des cultures maraîchères spécialisées à haute valeur ajoutée destinées aux marchés nationaux de niche (pomme de terre, niébé rouge, etc.);

- ces mêmes investisseurs ou des étrangers en poste à Dakar ayant également accédé plutôt à des terres dans les dépressions (cuvettes). Leurs plus grandes surfaces (25 à 30 ha) sont pour le moment valorisées en riz à moindre coût (infra, $\mathrm{SP} \mathrm{H}$ ) afin, à terme, de pouvoir combiner (après désalinisation suffisante des terres) la riziculture et le maraîchage;

- certains investisseurs originaires de la région (dont des élus locaux) ont pu bénéficier de vastes attributions en plusieurs lots de 30 à 70 ha dans des dépressions ou sur les dunes. Ils peuvent être équipés de pivots (figure 5.12). Ils combinent la riziculture, les productions maraîchères et parfois l'élevage en confiné (poulets de chair, ateliers d'engraissement (feed-lots ou parcs d'engraissement de bovins)). Celui-ci valorise alors les sous-produits et d'éventuelles productions fourragères complémentaires (maïs et légumineuses).

Linvestissement se limite le plus souvent à l'aménagement des parcelles (défriche éventuelle, clôtures, gradeur et installation des diguettes) et à l'achat et l'installation du matériel d'irrigation (groupe motopompe, tuyaux, pivot, asperseurs, système de goutte à goutte), beaucoup plus rarement de matériel motorisé (tracteur, offset pour le planage, pulvérisateur, moissonneuse-batteuse). Les investisseurs font plutôt appel, pour la préparation du sol, le semis, les traitements et la récolte du riz, à des entreprises de prestation de services qui se développent dans la région, tout en comptant néanmoins sur une main-d'œuvre salariée pour de nombreuses tâches demeurées manuelles.

Les calculs, effectués sur la base de nos enquêtes auprès de ces investisseurs, montrent que l'achat et l'exploitation de 30 ha pour la production de riz irrigué $(\mathrm{SP} \mathrm{H})$ est rentable pour des taux d'intérêt réels inférieurs à $17 \%$ (évaluation financière menée sur vingt ans). Or, les taux d'intérêt bancaires réels en vigueur au Sénégal n’ont pas dépassé les $8 \%$ ces dix dernières années (Banque mondiale). Pour un taux d'intérêt réel de $5 \%$, le bénéfice cumulé sur vingt ans, après actualisation, est de 40000 euros, qui demeure néanmoins sensible aux variations de prix du riz. Le taux de rentabilité interne élevé de ce type de projet d'investissement témoigne de son caractère peu risqué. Il laisse la latitude à ces investisseurs, une fois les terres dessalées par plusieurs années de culture irriguée de riz, de consacrer une partie de la surface à des productions plus exigeantes en capital, plus risquées. La rentabilité de ces nouvelles cultures est plus sensible aux variations des taux d'intérêt, mais potentiellement beaucoup plus rémunératrice pour des taux d'intérêt modérés. 

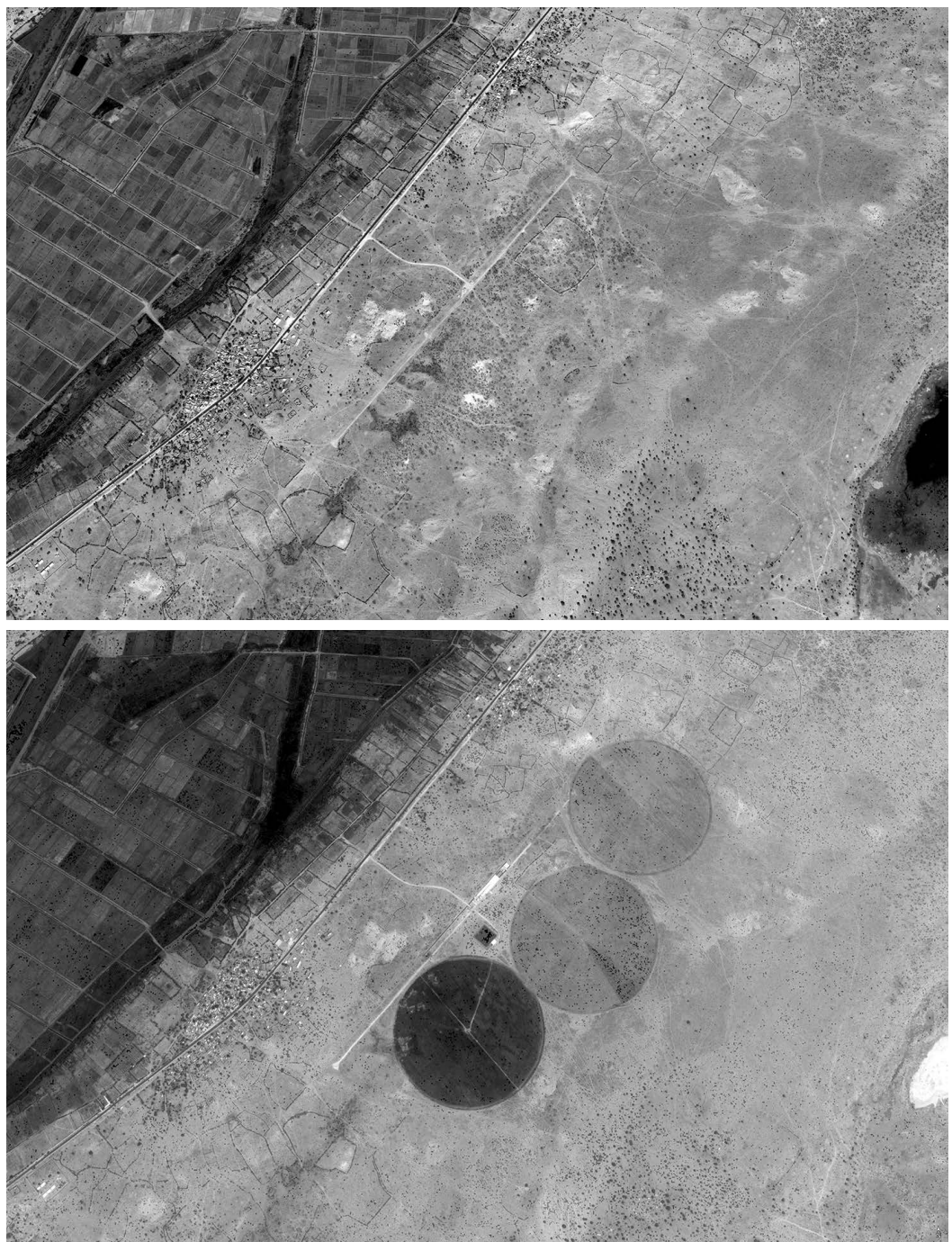

Figure 5.12. Installation récente d'une exploitation capitaliste sur les terres de dunes dans le sud du bas delta, équipée de trois pivots, combinant productions maraichères et élevage avicole (février 2015 en haut, juillet 2016 en bas) (Google Earth).

Une dernière catégorie d'investisseurs (5) rassemble des entreprises d'agro-business détenues par des investisseurs internationaux, le plus souvent en place depuis les années 2000. Leurs surfaces exploitées ont pu être étendues ces dernières années jusqu'à atteindre plusieurs centaines d'hectares sur les dunes, répartis en différents îlots (avec des sous-baux de deux ans pour les parcelles dépassant 100 ha; photo 5.2, planche 6). Ces investisseurs possèdent leur propre matériel motorisé (figure 5.13) et sont équipés de pivot, asperseur ou système d'irrigation goutte-à-goutte. Ils sont spécialisés dans des productions maraîchères ou fruitières destinées à l'exportation (melon, pastèque, courge, bananes et agrumes) dont les produits hors calibre sont écoulés sur le marché local ou national. 


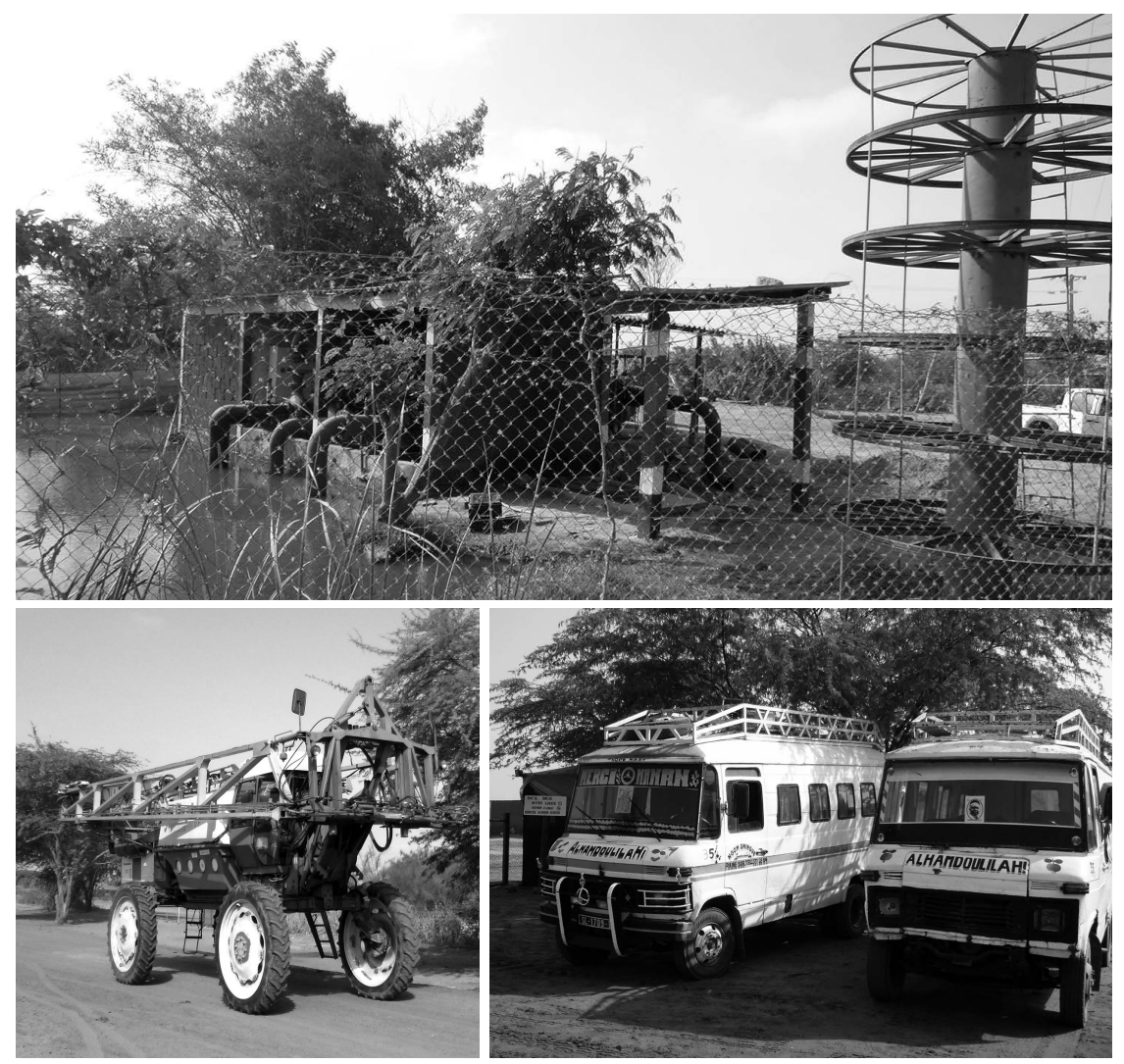

Figure 5.13. Station de pompage, équipement motorisé de grande capacité et minibus véhiculant les ouvriers agricoles d'une exploitation agricole à capitaux étrangers du bas delta (Garambois, 2016).

Nos enquêtes et les informations recueillies par Camara (2013) donnent un aperçu non exhaustif des sociétés agricoles à capitaux étrangers actuellement installées dans le bas delta (tableau 5.1).

Favorisées par leur capacité d'autofinancement mise au service des aménagements hydrauliques tertiaires et de l'achat d'équipements, ces formes d'agriculture capitaliste n'apparaissent pour autant pas, pour des types de productions équivalentes, plus performantes en termes de création de richesse que l'agriculture familiale. D'après nos enquêtes et calculs, pour un système de production donné, une parcelle située dans les cuvettes argileuses et cultivée avec deux campagnes de riz par an (riz/riz) dégage une valeur ajoutée brute par hectare inférieure de $25 \%$ par rapport à une succession biennale (riz/riz/oignon). Cette valeur ajoutée est inférieure d'au moins $35 \%$ par rapport à une succession annuelle comprenant deux campagnes de cultures maraîchères (par exemple tomate/pastèque + courge) pratiquées sur les terres de dunes (pour lesquelles le recours à une motopompe est en revanche nécessaire). Les valeurs ajoutées nettes enregistrées par hectare à l'échelle des systèmes de production sont donc d'autant plus élevées que la part des terres exploitées dans les cuvettes consacrées au moins une année sur deux à la culture du riz est réduite, 
et que le système de production est spécialisé dans les productions maraîchères. La corrélation est alors directe au capital et à la trésorerie des familles. Pour un même degré de spécialisation (par exemple 100\% des terres consacrées à des cultures maraîchères), il apparaît que la création de richesse par unité de surface est sensiblement la même, pour des productions maraîchères semblables (tomates, oignons, piments), entre système de production de type capitaliste à forte disponibilité en capital (SP G) et système de production familial (SP C). La stricte spécialisation rizicole ne se rencontre, dans le bas delta, qu'au sein de systèmes de production de type capitaliste (SP H), elle est bien plus faiblement créatrice de richesse par unité de surface (figure 5.14).

Tableau 5.1. Caractéristiques de certaines sociétés agricoles à capitaux étrangers installées depuis les années 2000 dans le bas delta (enquêtes de 2016; Camara, 2013)

\begin{tabular}{|c|c|c|c|c|c|c|}
\hline Société & $\begin{array}{c}\text { Origine } \\
\text { principale } \\
\text { des } \\
\text { capitaux }\end{array}$ & $\begin{array}{c}\text { Date } \\
\text { d'installation }\end{array}$ & $\begin{array}{c}\text { Surface agricole } \\
\text { disponible } \\
\text { (affectation }+ \\
\text { location) (année) }\end{array}$ & $\begin{array}{l}\text { Surface } \\
\text { agricole } \\
\text { cultivée } \\
\text { (année) }\end{array}$ & $\begin{array}{l}\text { Principales } \\
\text { productions }\end{array}$ & $\begin{array}{c}\text { Destinations } \\
\text { principales } \\
\text { des produits }\end{array}$ \\
\hline $\begin{array}{l}\text { GDS } \\
\text { (Grands } \\
\text { domaines du } \\
\text { Sénégal) }\end{array}$ & France & 2003 & - & $\begin{array}{l}200 \text { ha } \\
(2011)\end{array}$ & $\begin{array}{c}\text { Tomate, } \\
\text { cerise, } \\
\text { asperge, maïs } \\
\text { doux }\end{array}$ & $\begin{array}{l}\text { Union } \\
\text { européenne }\end{array}$ \\
\hline Soldive & France & 2006 & $\begin{array}{l}165 \text { ha loués } \\
(2016)\end{array}$ & $\begin{array}{l}>120 \mathrm{ha} \\
(2016)\end{array}$ & $\begin{array}{c}\text { Melon } \\
\text { charentais }\end{array}$ & France \\
\hline $\begin{array}{l}\text { SCL } \\
\text { (Société } \\
\text { de cultures } \\
\text { légumières) }\end{array}$ & $\begin{array}{c}\text { France, } \\
\text { Maroc et } \\
\text { Angleterre }\end{array}$ & 2006 & $\begin{array}{c}300 \text { ha affectés } \\
+200 \text { ha loués } \\
(2011)\end{array}$ & $\begin{array}{l}500 \mathrm{ha} \\
(2011)\end{array}$ & $\begin{array}{l}\text { Maïs doux, } \\
\text { asperge, } \\
\text { courge et } \\
\text { arachide }\end{array}$ & Angleterre \\
\hline $\begin{array}{l}\text { STS } \\
\text { (Société } \\
\text { de tomates } \\
\text { séchées) }\end{array}$ & Italie & 2007 & $\begin{array}{l}200 \text { ha affectés } \\
\text { (2011) }\end{array}$ & $\begin{array}{l}110 \mathrm{ha} \\
(2011)\end{array}$ & Tomate & Italie \\
\hline
\end{tabular}

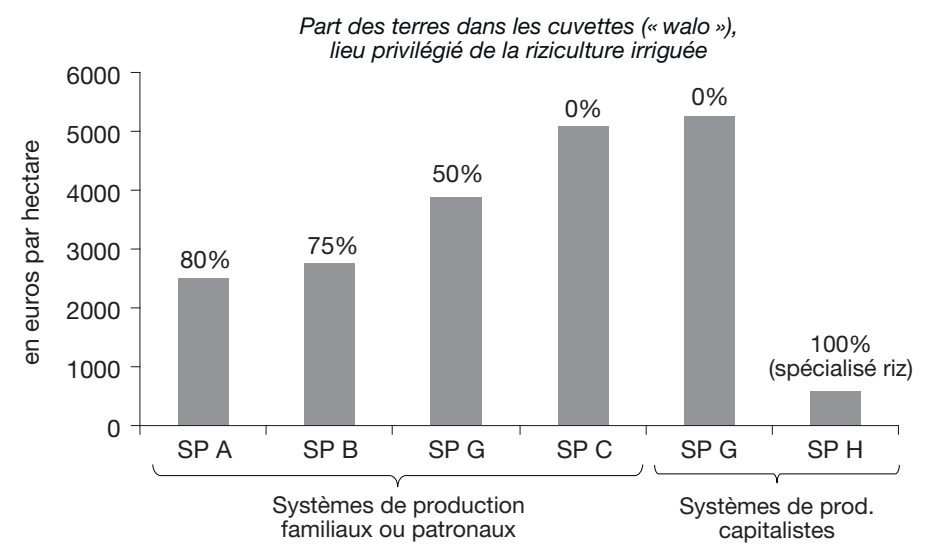

Figure 5.14. Valeur ajoutée nette dégagée par hectare pour différents systèmes de production du bas delta, caractérisés par la place variable du riz dans l'assolement (enquêtes réalisées en 2016). 


\section{Le déploiement de nouveaux formats de projets avec les partenariats publics-privés (PPP) : la garantie d'une plus grande équité?}

Financés par des bailleurs de fonds étrangers, deux principaux projets de type partenariat public-privé (PPP) sont en cours dans le delta du fleuve Sénégal. Ils prévoient de s'adresser à différentes catégories de producteurs en proposant des surfaces à exploiter variant de quelques hectares à des lots de 50 ou 100 ha. Intégralement financés par les bailleurs pour les aménagements primaires, ces projets prévoient des niveaux de subventions variables d'une catégorie de producteurs à l'autre pour les aménagements secondaires et tertiaires, en fonction de la surface du lot attribué. Lun de ces projets est conduit dans le cadre du Programme pour le développement des marchés agricoles au Sénégal (PDMAS) et porte sur l'extension de 2500 ha des surfaces maraichères dans le bas delta (photo 5.3, planche 7). Le second, le Projet de promotion des partenariats rizicoles dans le delta (3PRD), porte quant à lui sur l'aménagement d'un périmètre irrigué de 2500 ha dans le haut delta.

Dans le cadre du PDMAS, les attributions portent sur 2500 ha aménagés répartis en cinq périmètres installés sur les terres de cinq villages du bas delta. Ces aménagements se sont soldés par des attributions foncières de lots de 2 à 100 ha au sein de ces nouveaux périmètres, assorties de subventions à l'investissement et à l'équipement de niveau variable selon les surfaces allouées. Ce programme comprenait tout à la fois une rétrocession partielle des terres aux villages expropriés et l'attribution de lots de plus de 10 ha à des opérateurs privés disposant des ressources nécessaires à la valorisation de plus vastes surfaces. Les objectifs initiaux de la répartition des terres étaient de confier environ :

$-50 \%$ de ces périmètres aux exploitants agricoles organisés en groupements d'intérêt économique, avec des surfaces réservées aux femmes et aux jeunes;

$-25 \%$ pour des petites et moyennes entreprises (lots de 10 ou 20 ha);

- $25 \%$ pour l'agro-industrie (de 20 à 100 ha) (PDMAS, 2009).

Nos enquêtes menées dans ces cinq périmètres témoignent néanmoins de modalités d'affectation des parcelles très différentes d'un village à l'autre. Ces affectations peuvent aller de l'attribution de lots inférieurs à 10 ha aux seules familles du village détentrices, avant les aménagements, d'un droit d'usage sur ces terres (cas du périmètre de Polo), à l'attribution des deux tiers des surfaces aménagées à un entrepreneur étranger comme la Société de cultures légumières (SCL) dans le cas du périmètre de Massar Gabou (tableau 5.1). Le projet prend en charge l'essentiel des coûts des aménagements terminaux (subvention portée à $80 \%$ des coûts) et d'équipement des exploitants familiaux, à condition qu'ils s'équipent en irrigation de type goutte-à-goutte ou par micro-aspersion. Cependant, le capital nécessaire à la couverture des frais d'aménagement demeure élevé : environ 1200 euros par hectare en assurant en propre $20 \%$ des coûts totaux. Il est équivalent à l'ensemble des revenus dégagés par un actif agricole familial durant un, voire deux ans (figure 5.11). Le coût de mise en valeur de lots de plus d'un hectare demeure ainsi trop discriminant pour la plupart des producteurs familiaux issus de ces villages, notamment ceux qui ne sont pas équipés en propre d'une motopompe et qui ne disposent pas de la main-d'œuvre familiale ou de la trésorerie pour embaucher la main-d'œuvre 
salariée nécessaire. Lorsque les foyers plus pauvres parviennent à se constituer en GIE collectif pour faire une demande groupée, les surfaces attribuées ne dépassent pas 0,1 ha par famille. Certains de ces GIE n'ont pour l'instant pas pu démarrer de campagne faute de matériel, espérant à défaut céder leurs terres en location.

Le périmètre irrigué installé dans le haut delta dans le cadre du projet de promotion des partenariats rizicoles dans le delta (3PRD) (figure 5.15), autre exemple de projet de type partenariat public-privé, porte sur 2500 ha. Il prévoit des attributions de lots de 5 ha à 100 ha dont la distribution était basée, en 2016, sur la répartition suivante : - 51 attributaires de 5 ha ( 255 ha, soit $14 \%$ de la surface totale);

- 36 attributaires de 10 ha (360 ha, 20\%);

- 32 attributaires de 25 ha ( 800 ha, $45 \%)$;

-5 attributaires de 50 ha (250 ha, $14 \%)$;

-1 attributaire de 100 ha $(6 \%)$.

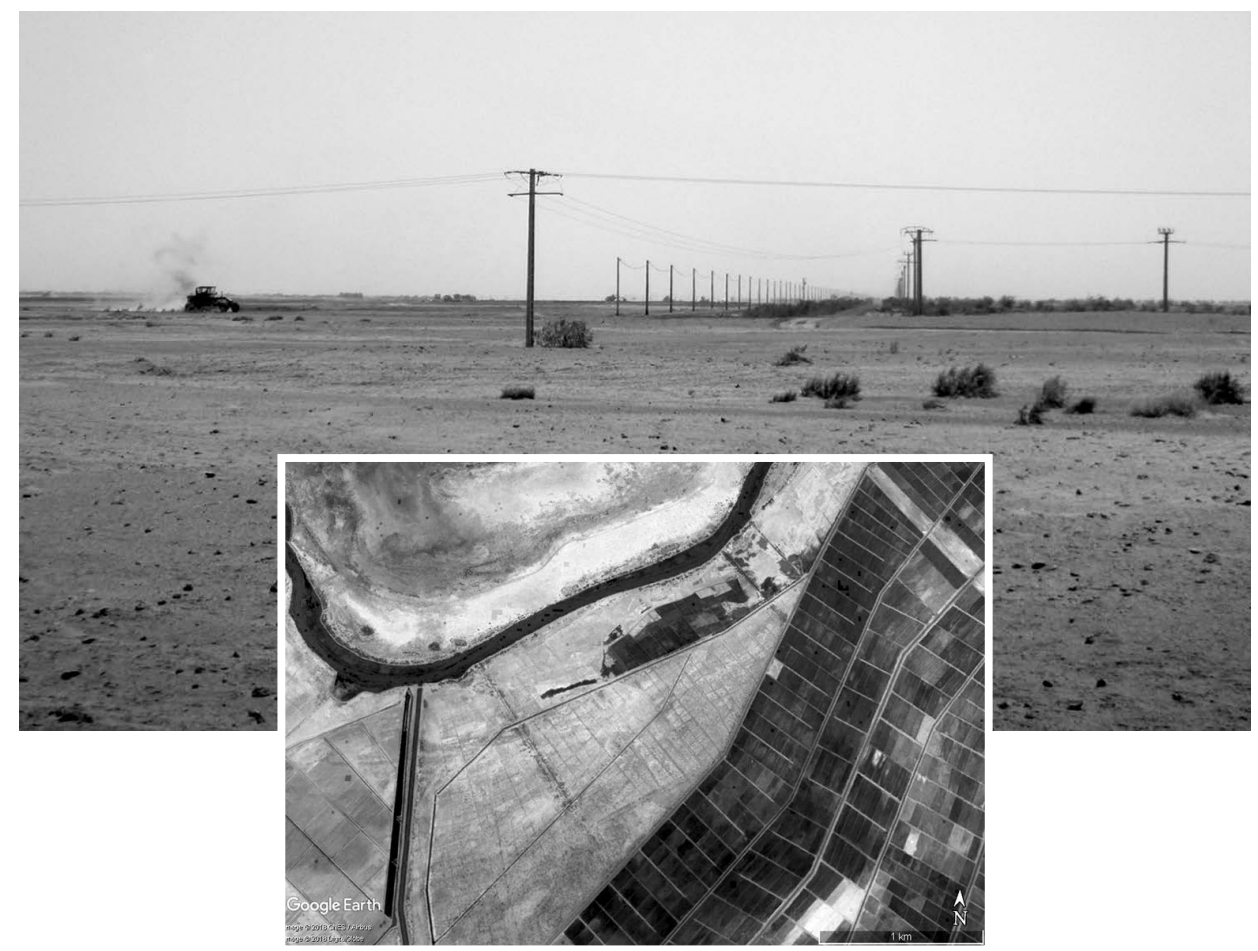

Figure 5.15. Travaux en cours en 2016 au sein du futur périmètre 3PRD dans le haut delta en haut et vue satellite du périmètre 3PRD en 2018 en bas (Garambois, 2016; Google Earth, 2018).

Ici aussi, le taux de subvention de l'investissement, dégressif à mesure que la surface allouée augmente ( $95 \%$ pour 5 ha, $85 \%$ pour 10 ha, $70 \%$ pour 25 ha et $40 \%$ au-delà), vise à soutenir plus largement les attributaires des plus «petits» lots. Pour un lot de 5 ha, l'investissement initial représente néanmoins plus de 1000 euros. Cette somme est inaccessible aux producteurs familiaux du haut delta limités par leur surface, même en se réunissant en GIE familial élargi. 
Par ailleurs, le cahier des charges du projet impose aux futurs producteurs un rendement minimum de 7 tonnes de riz paddy par hectare et par an, sous peine de se voir retirer le droit d'exploiter et le paiement d'une redevance de 150 euros par hectare et par an. La constitution de la réserve foncière nécessaire à l'installation de ce périmètre s'est faite en expropriant les villageois qui détenaient jusque-là un droit d'usage sur ces parcelles. Basée sur l'historique de production, l'indemnisation a été fixée à la valeur de deux années de mise en culture. Les agriculteurs qui ne cultivaient pas ces surfaces depuis plus de deux ans n'ont reçu, quant à eux, aucune indemnité.

Paradoxalement, le PDMAS est inspiré de l'exemple du village de Thilène situé dans le nord-est du bas delta. Or, le cas de la section villageoise de Thilène est emblématique de stratégies à rebours du mode d'attribution des parcelles prévues dans le cadre du PDMAS et tout particulièrement du 3PRD. Cet échelon administratif centralise en effet l'expression des besoins des agriculteurs en crédit de campagne et d'équipement pour le compte des unions hydrauliques. Face au désengagement de l'État, la section villageoise de Thilène a ainsi pu, dès la fin des années 1990, s'impliquer à plusieurs reprises en toute autonomie et de façon collective afin de favoriser l'extension des surfaces irrigables pour les villageois. Différentes stratégies ont été déployées pour accéder au capital nécessaire à la mise en valeur des terres de dunes en agriculture irriguée tout en maîtrisant les attributions foncières et en garantissant une plus grande équité entre villageois dans les affectations.

Les premières initiatives, autofinancées à l'échelle du village, ont porté sur la création de deux nouveaux petits périmètres (20 ha et 30 ha) destinés en priorité aux jeunes. Dans les années 2000, la volonté d'aménager un périmètre de plus grande taille (400 ha) et qui ne bénéficie pas pour autant qu'aux seules familles aisées de Thilène, a conduit la section villageoise à rechercher collectivement des financements extérieurs complémentaires auprès d'investisseurs et à procéder à une véritable concertation dans les attributions foncières. Ces investisseurs extérieurs au village financent ainsi une partie des aménagements contre l'octroi d'un droit d'exploitation sur une durée limitée. Les surfaces aménagées sont ensuite attribuées aux différentes familles du village, en tenant compte des surfaces qu'elles ont reversées au collectif pour constituer le périmètre de 400 ha, du capital, des équipements et du temps de travail qu'elles ont mis à disposition lors des travaux d'aménagements, ainsi que de leur statut jugé prioritaire (jeunes, familles moins bien dotées en terres irrigables jusqu'alors).

\section{Des effets environnementaux et sanitaires préoccupants}

Lélevage connaît un recul majeur dans le delta du fleuve Sénégal depuis plusieurs décennies. La longue période de sécheresse des années 1970 à 1990 a conduit les agriculteurs et les éleveurs du delta à réduire la taille de leur cheptel. Le bouleversement de la mise en valeur des différents étages agroécologiques, entraîné par les aménagements hydrauliques dans le haut comme dans le bas delta, a fortement réduit les espaces dévolus aux activités pastorales :

- grignotage progressif des espaces pâturables au rythme de la progression des parcelles irriguées;

- mise en défens (clôtures) des surfaces croissantes occupées par les exploitations patronales et capitalistes, rendues inaccessibles aux troupeaux même durant les périodes d'inter-cultures (parfois de plusieurs mois). 
Les agriculteurs sont conduits à faire reposer de plus en plus l'alimentation de leurs animaux sur leurs ressources fourragères propres : résidus de cultures collectés (paille et fanes) et friches herbeuses. Aujourd'hui, les agriculteurs familiaux ayant encore de petits troupeaux (petits ruminants et plus rarement bovins) sont donc aussi ceux qui disposent de plus vastes surfaces et qui peuvent se permettre de ne pas mettre en culture leurs terres tout au long de l'année. Ils privilégient une seule campagne (riz ou maraîchage) suivie d'une friche de quatre à six mois. Le parcage à proximité des habitations des animaux nourris avec les sous-produits des cultures (figure 5.16) permet quelques transferts de fumure organique effectués en priorité sur certaines cultures maraîchères (piment). Pour cela, ils doivent disposer d'une charrette pour transporter ces déjections. Lessentiel des apports de fertilité est néanmoins basé sur les engrais de synthèse, avec des conséquences à la fois sur le taux de matière organique des sols et sur la dépendance des familles aux achats d'intrants.
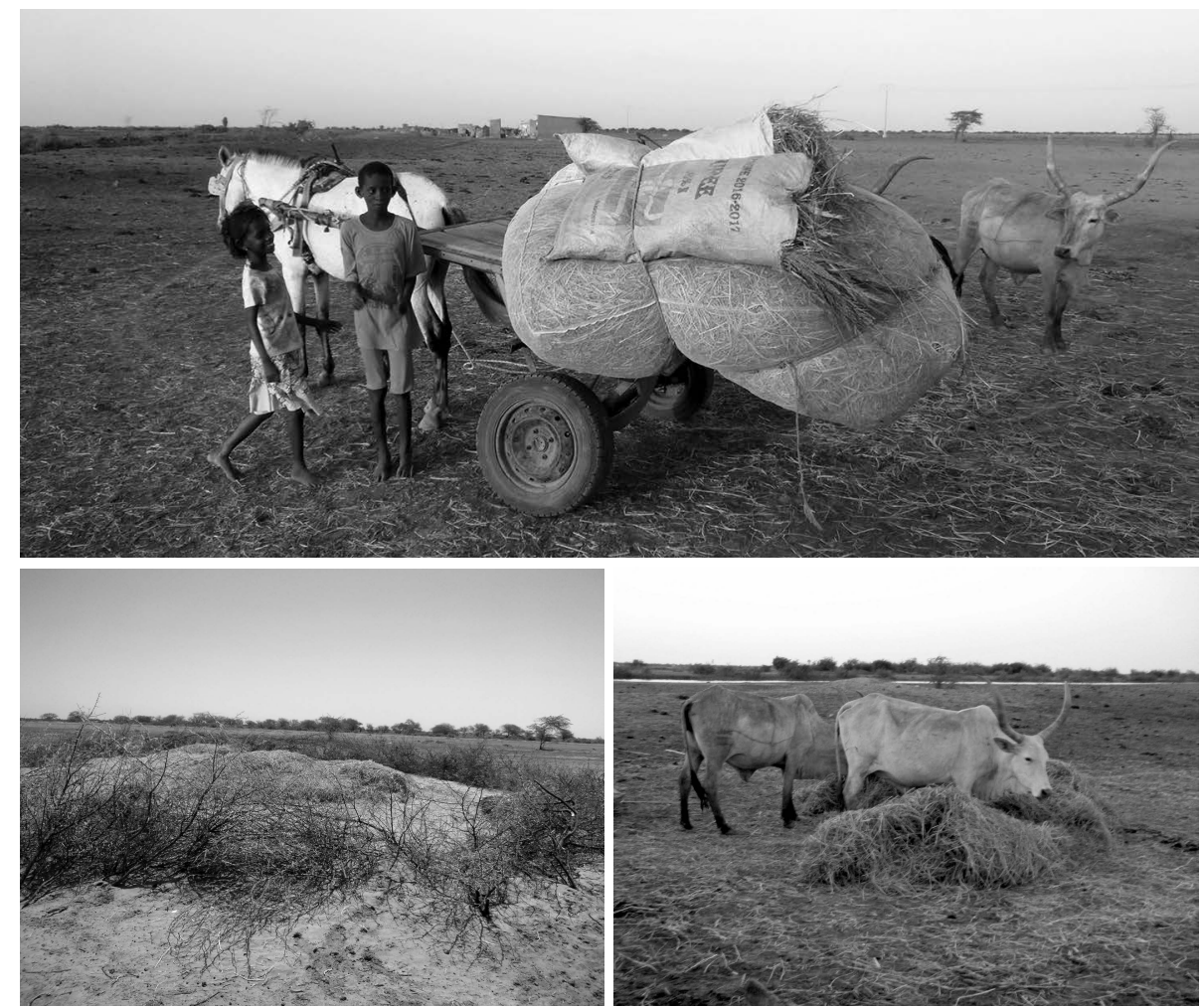

Figure 5.16. Alimentation des bovins gardés à proximité des habitations à partir des sousproduits de la riziculture : transport, stockage, distribution (Garambois, 2016).

Le bouleversement du schéma hydraulique mis en œuvre dans le cadre du Millenium challenge account contribue à étendre les surfaces et à sécuriser l'accès à l'eau aussi pour les agriculteurs familiaux. En parallèle, il se solde néanmoins d'effets environnementaux et sanitaires préoccupants. Désormais exutoire des eaux chargées de résidus de pesticides et d'engrais chimiques, le Djeuss ne centralise pas encore pour autant l'ensemble des eaux de drainage du bas delta, dont certaines demeurent 
dirigées vers des dépressions naturelles. Par ailleurs, le projet n'a pas mis fin, dans les faits, à certaines activités productives réalisées sur le Djeuss avant sa transformation en drain principal. Des activités de pêche ont toujours cours (figure 5.17), au prix de risques sanitaires importants. Elles sont pratiquées notamment par des pêcheurs maliens installés dans des campements en bordure du Djeuss, et qui expédient ensuite le poisson séché sur place au Mali. Pour les agriculteurs qui ne disposent pas de parcelles à proximité des canaux, les axes de drainage servent toujours de source d'eau d'irrigation pour de petites parcelles maraîchères.

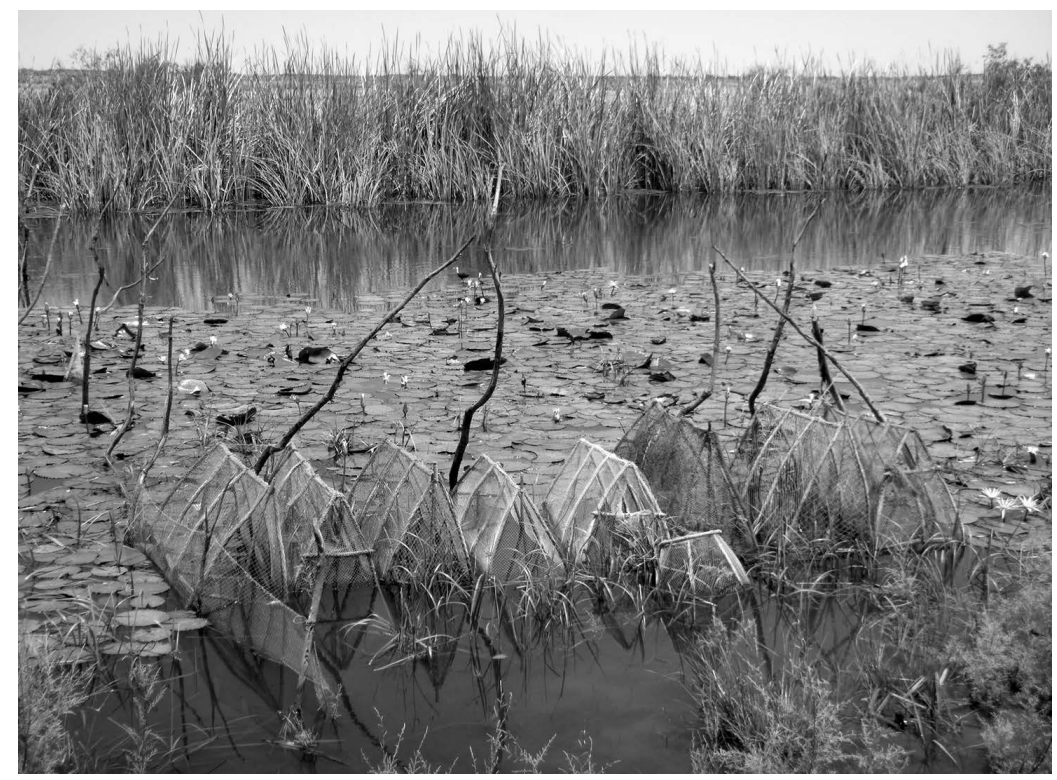

Figure 5.17. Pêche dans les drains du réseau hydraulique du delta (Garambois, 2016).

Lextension des canaux, des drains et des surfaces irriguées contribue également à accroître les espaces de développement des moustiques, problème sanitaire que la distribution de moustiquaires ne règle que partiellement. Elle augmente le risque de bilharziose, dont les premiers cas apparus après la construction des barrages tendent à se multiplier (Observatoire de l'environnement, 2006). Enfin, le recul des essences arborées observé dès les années 1970 ne semble également pas seulement imputable à la sécheresse. Les aménagements des zones de dépression, autrefois envahies par la crue et abritant une dense population d'Acacia nilotica, contribuent à la quasi disparition de cette espèce dans le delta du fleuve (Roquet, 2008).

\section{W Conclusion}

Bien que finement adaptée à des conditions pluviométriques et de la crue du fleuve difficiles et aléatoires, l'agriculture du delta du fleuve Sénégal a été profondément affectée par la sécheresse des années 1970-1980. Sans occulter le bouleversement induit sur les écosystèmes du delta, les aménagements hydro-agricoles mis en œuvre 
dans la région depuis les années 1960 ont, dans ce contexte climatique, joué un rôle central dans le maintien et le développement de l'agriculture de la région et dans son adaptation à la sécheresse. Ces aménagements sont cependant loin d'avoir bénéficié à la seule agriculture familiale. Le désengagement de l'État dans la gestion du foncier et l'appui aux investissements, à partir du milieu des années 1980, a favorisé les producteurs les mieux dotés en capital et contribué à une première vague de développement de systèmes patronaux et capitaliste, dès les années 1990 dans le haut delta, en créant les conditions d'investissements suffisamment rémunérateurs pour l'élite urbaine sénégalaise. Le renforcement des aménagements primaires dans le delta depuis moins de dix ans se traduit déjà par une seconde vague d'essor de ces formes d'agriculture, qui créent aujourd'hui une concurrence pour le foncier sans précédent dans le bas delta.

Après des décennies de déficit drastique, le delta du fleuve Sénégal (comme tout le nord du pays) enregistre, depuis le début des années 2000, une hausse timide de la pluviométrie. Sans retrouver le niveau de 1946-1968, la moyenne des précipitations enregistrées à la station de Saint-Louis sur la période 2001-2010 s'élève à $311 \mathrm{~mm}$ (Ndong, 2015). Elle explique les tentatives réussies de réintroduction des cultures pluviales sur les terres de dunes par les familles ayant un accès limité au foncier, lorsque la pluviométrie dépasse les $300 \mathrm{~mm}$. Une concurrence manifeste s'installe ainsi dans le bas delta pour l'utilisation de ces terres de dunes entre les exploitations de type patronal et surtout capitaliste d'une part, et les exploitations familiales d'autre part. Les premières sont capables d'effectuer rapidement les investissements nécessaires pour se raccorder au réseau d'irrigation et de drainage. Cela n'est pas le cas des secondes, soucieuses de la mise en valeur de ces espaces à une échelle plurigénérationnelle, probablement aussi grâce à l'irrigation, mais davantage connectées aux activités d'élevage et attentives au redéploiement de cultures pluviales si le rebond de la pluviométrie devait se confirmer.

Lattribution de la majorité des terres du haut delta s'est faite dès la fin des années 1990, à la faveur des nouvelles possibilités d'irrigation offertes par les deux barrages mis en place sur le fleuve Sénégal dans les années 1980. Lessentiel des terres du bas delta semble avoir été à son tour distribué ces dernières années, sans que les villageois ne soient toujours bien informés des attributions décidées par leur conseil rural. Quelques rares villages du bas delta se sont organisés pour mettre une partie de leurs terres non encore aménagées en réserve pour les générations futures, évitant ainsi leur attribution aux seules familles les plus aisées ou à des investisseurs. Néanmoins, la situation foncière apparaît, dans l'ensemble, particulièrement préoccupante.

En effet, le niveau des prix des produits agricoles et la productivité du travail de la plupart des agriculteurs familiaux ne leur permettent pas de dégager les surplus et de réaliser une accumulation de capital suffisamment rapide pour espérer investir dans les aménagements à la parcelle et dans le matériel d'irrigation au rythme que commanderaient les aménagements primaires colossaux mis en œuvre ces dernières années. Ils sont ainsi totalement défavorisés face aux exploitants patronaux et surtout face à l'élite urbaine sénégalaise (voire aux investisseurs étrangers), en position de force dans les attributions foncières grâce à leur capacité d'investissement élevée et parfois à des pratiques clientélistes. Face à cette situation, des projets relevant de 
partenariats public-privé se déploient ces dernières années à la faveur du renforcement des possibilités d'irrigation dans la région. Mais, ils ne s'adressent dans les faits, lorsqu'ils ne sont pas issus d'initiatives villageoises, que marginalement aux familles agricoles les plus en difficulté et ils contribueraient plutôt à renforcer les inégalités sociales. Ces premières tentatives inviteraient donc à la plus grande prudence, alors que d'autres projets de même nature se profilent sur des surfaces plus vastes encore, à l'image du PDIDAS (Projet pour le développement inclusif et durable de l'agrobusiness au Sénégal) qui concernerait 10000 ha sur les rives du lac de Guiers voisin.

«L'accélération de la cadence» en agriculture, dont les pouvoirs publics sénégalais semblent avoir fait leur adage au nom d'un légitime objectif d'autosuffisance alimentaire, apparaît, dans les faits, déconnectée des réalités de l'agriculture familiale du delta et devient une source d'accaparements fonciers majeurs. Les propos volontaristes de Macky Sall, président de la République du Sénégal, en introduction du récent Programme d'accélération de la cadence de l'agriculture sénégalaise (Pracas) prennent, dans ce contexte, une résonance toute particulière : «Si tout le monde s'y met, d'ici peu, nous allons changer radicalement le visage du Sénégal grâce à l'agriculture» (MAER, 2014). En voulant aller (trop) vite, ne risque-t-on pas d'écarter la majorité des producteurs du delta de ces processus de développement et de précariser la génération à venir des producteurs familiaux, à rebours des impératifs de durabilité pourtant affichés dans le Pracas?

\section{"Références}

Benz H., 1996. Riz local et riz importé en Afrique : les déterminants de la compétitivité. Les filières riz du Sénégal et de la Guinée face aux exportations de la Thaïlande et des États-Unis. Tome 2. Paris : École des Hautes Études en Sciences Sociales, 325 p.

Boutillier J.L., 1989. Irrigation et problématique foncière dans la vallée du Sénégal, Cahiers des sciences humaines 25(4), 469-488.

Dahou T., 2004. Entre parenté et politique : Développement et clientélisme dans le delta du Sénégal. Paris : Karthala-Enda, Graf Sahel, 364 p.

Dahou T., 2009. Lautosuffisance rizicole, chronique d'un échec annoncé. In : Dahou T. (éd). Libéralisation et politique agricole au Sénégal. Paris : Crepos-Karthala-Enda/Graf/Diapol, 149-71.

David-Benz H., Diop M., Fall C., Wade I., 2010. Oignon : une production en plein essor pour répondre à la demande urbaine. In : Duteurtre G., Faye M.B., Dièye P.N., (eds). L'agriculture sénégalaise à l'épreuve du marché. Paris : Isra-Karthala, 171-196.

Devillers J., Frissard C., 2016. Évolutions du système agraire des Terres-Neuves de Koumpentoum, Sénégal, de 1950 à nos jours et perspectives d'évolution. Mémoire de fin d'étude, UFR Agriculture comparée et Développement agricole. Paris : AgroParisTech, AFD, 142 p.

Fall A.A., 2010. Riz : désengagement de l'État, flambée des importations et... retour de l'État? In : Duteurtre G., Faye M.B., Dièye P.N. (eds). L'agriculture sénégalaise à l'épreuve du marché. Paris : Isra-Karthala, 57-81.

Fall A.A., David-Benz H., Huat J., 2010. Tomate locale et production de concentrés : la force des contrats entre paysans et industrie, In : Duteurtre G., Faye M.B., Dièye P.N. (eds). L'agriculture sénégalaise à l'épreuve du marché. Paris : Isra-Karthala, 197-215.

Fert M., Radzik L., 2016. Analyse-diagnostic d'une petite région agricole dans le sud-ouest du delta du fleuve Sénégal : une région caractérisée par un développement récent du maraîchage. Mémoire de fin d'étude, UFR Agriculture comparée et Développement agricole. Paris : AgroParisTech, AFD, $186 \mathrm{p}$. 
Kamara S., 2013. Développements hydrauliques et gestion d'un hydrosystème largement anthropisé : le delta du fleuve Sénégal. Thèse de doctorat. Avignon : Université d'Avignon et des Pays du Vaucluse; Université Gaston Berger de Saint-Louis, 461 p.

Le Borgne J., 1988. La pluviométrie au Sénégal et en Gambie. Dakar : Laboratoire de Climatologie, Université Cheikh Anta Diop, 28 p.

Lericollais A., 1975. Peuplement et migrations dans la vallée du Sénégal. Cahiers Orstom, Série Sciences humaines 12(2), 123-135.

Lericollais A., 1976. La sécheresse et les populations de la vallée du Sénégal. In : La désertification au sud du Sahara. Colloque de Nouakchott (17-19/12/1973). Dakar-Abidjan : Les Nouvelles éditions africaines, 111-116.

Lavigne Delville P., 1993. Les paradoxes du désengagement. Les périmètres irrigués villageois du fleuve Sénégal. In : Blanc-Pamard C. (éd.). Dynamique des systèmes agraires : politiques agricoles et initiatives locales : adversaires ou partenaires. Paris : Orstom, 217-238.

Michel P., Sall M., 1984. Dynamique des paysages et aménagement de la vallée alluviale du Sénégal. In : Blanc-Pamard C., Bonnemaison J., Boutrais J., Lassailly-Jacob V. et Lericollais A. (eds). Le développement rural en questions : paysages, espaces ruraux, systèmes agraires; Maghreb-Afrique noire-Mélanésie. Paris : Orstom,89-109.

MAER, 2014. Programme d'accélération de la cadence de l'agriculture sénégalaise (Pracas), Volet agricole du plan Sénégal émergent (PSE). Dakar : Ministère de l'Agriculture et de l'Équipement rural, $110 \mathrm{p}$.

Maiga M., 1995. Le bassin du fleuve Sénégal : de la traite négrière au développement sous-régional autocentré. Paris : L'Harmattan.

Ndong J., 2015. Évolution climatique récente sur le littoral sénégalais, Revue de géographie de l'université de Ouagadougou, 4(2), 151-168.

Observatoire de l'environnement, 2006. Rapport annuel sur l'état de l'environnement et des ressources naturelles du bassin du fleuve Sénégal. Dakar : OMVS.

PDMAS, 2009. Mise en valeur de 2500 ha dans la zone du delta du fleuve Sénégal : présentation du programme et du cahier des charges de l'agro-investisseur. Dakar : Ministère de l'Agriculture et de la Pisciculture.

Poupon H., 1976. Influence de la sécheresse de l'année 1972-1973 sur la végétation d'une savane sahélienne du Ferlo septentrional, Sénégal. In : La désertification au sud du Sahara. Colloque de Nouakchott (17-19/12/1973). Dakar-Abidjan : Les Nouvelles éditions africaines,96-101.

Reboul C., 1984. Barrages contre le développement? Les grands aménagements hydrauliques de la vallée du fleuve Sénégal. Revue Tiers-Monde 25(100), 749-760.

Roquet D., 2008. Partir pour mieux durer : la migration comme réponse à la sécheresse au Sénégal? Espaces, populations, sociétés, (1),37-53.

Santoir C., 1994. Décadence et résistance du pastoralisme. Les Peuls de la vallée du fleuve Sénégal. Cahiers d'études africaines, 34(1-3), 231-263.

Seck S., 1986. La maîtrise de l'eau et la restructuration sociale induite par l'organisation de la production irriguée dans le bassin du fleuve Sénégal. Cahiers de la recherche développement, 12,13-20.

Seck S., 1991. Sur la dynamique de l'irrigation dans la vallée du fleuve. In : Crousse B., Mathieu P., Seck S. (eds). La Vallée du fleuve Sénégal : évaluations et perspectives d'une décennie d'aménagements. Paris, Karthala.

Tourrand J.F., Landais E., 1994. Aménagements hydrauliques et développement : stratégies paysannes d'adaptation dans le delta du fleuve Sénégal (1984-1991), Natures-sciences-sociétés, 2(3), 212-228.

Tricart J.L.F., 1990. Technocrates et milieu naturel au Sénégal, Annales de géographie, 553, 328-335. 



\section{Partie III}

Adaptation et résilience en région de montagne 



\title{
Chapitre 6 \\ Étagement altitudinal, diversité et irrigation : les monts Uluguru, Tanzanie
}

\author{
Hubert Cochet et Thérèse Hartog
}

La question de l'adaptation des agricultures du Sud au changement climatique se pose-t-elle différemment en région de montagne? En montagne, les agriculteurs doivent composer avec l'altitude, la pente et les phénomènes érosifs qu'elle facilite, l'étagement. À cela s'ajoutent parfois les difficultés de communication. De par le monde, de telles situations sont trop nombreuses, trop variées et trop dissemblables pour espérer répondre de façon globale à cette question. Versants raides et entièrement cultivés par une population agricole très dense (250 à 350 habitants $/ \mathrm{km}^{2}$ ), aménagement systématique des versants, irrigation généralisée et diversité des productions : les monts Uluguru, — seul exemple de région de montagnes traité dans cet ouvrage — offrent cependant un exemple riche d'enseignements ${ }^{1}$.

\section{"Les monts Uluguru : un exemple de montagnes densément peuplées et bien arrosées}

\section{Le château d'eau des monts Uluguru}

Les monts Uluguru constituent un petit massif montagneux isolé en marge des basses terres de l'Est tanzanien (figure 6.1), isolé aussi au regard des grands espaces

1. Le travail de terrain réalisé en 2016 a été grandement facilité par les contacts anciennement établis par Jean-Luc Paul dans cette région et à l'université de Morogoro. Qu'il en soit ici chaleureusement remercié. 
historiquement moins peuplés qui l'entouraient. Mais désormais, ce massif est assez bien relié à Morogoro, du moins son versant ouest (le haut-Mgeta), et au grand marché de Dar Es Salam par la route nationale qui relie ces deux villes.

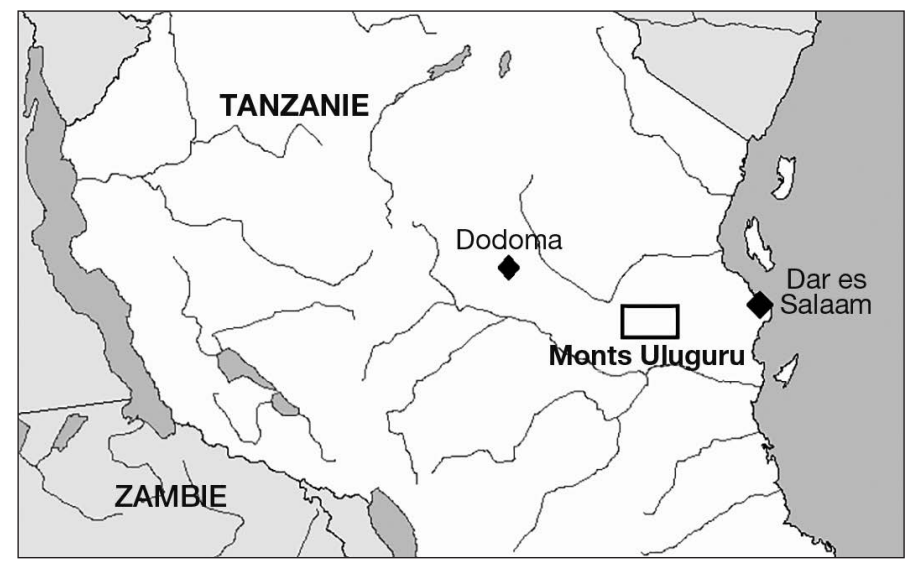

Figure 6.1. Localisation des monts Uluguru.

Premier relief rencontré par les masses d'air humides en provenance de l'océan Indien, les monts Uluguru connaissent, du point de vue de la pluviométrie, une opposition de versants très marquée. Tandis que le versant orienté à l'est reçoit de plein fouet les premières pluies (effet orographique), le versant ouest, terrain de cette étude, est sous le vent et, à altitude comparable, nettement moins arrosé. Mais il reçoit cependant plus de $1000 \mathrm{~mm}$ de pluie vers $1200 \mathrm{~m}$ d'altitude (à Langali), $1300-1400 \mathrm{~mm}$ à Tchenzema vers $1700 \mathrm{~m}$ d'altitude (figure 6.2) et bien davantage sur les hauts versants et les sommets.

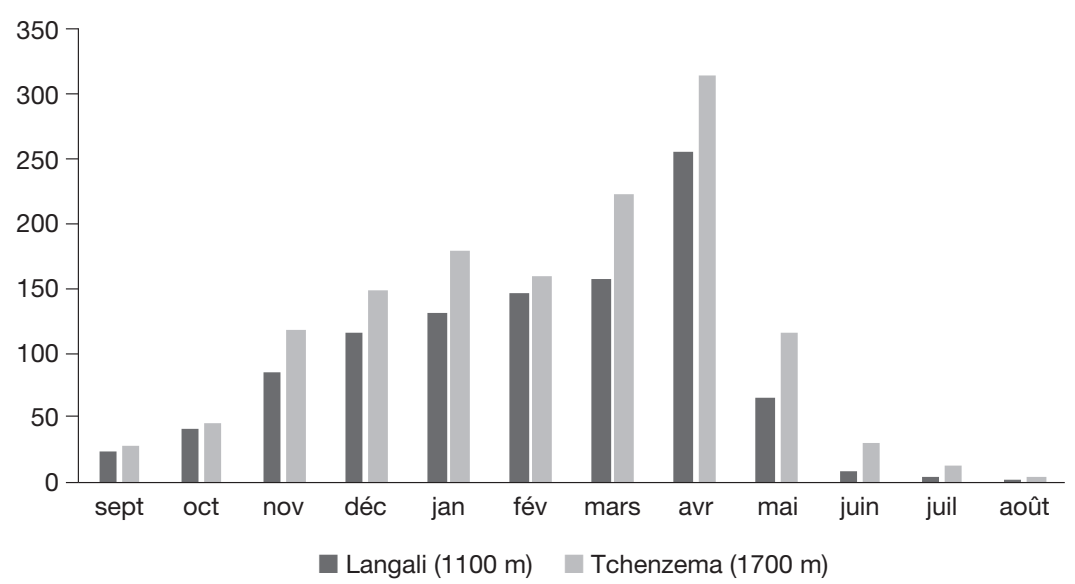

Figure 6.2. Répartition des pluies et gradient climatique altitudinal, moyennes relevées entre 1960 et 1977 (source : auteurs, à partir des données rassemblées par Coniat, 1993).

La région étudiée (une partie du haut-Mgeta) est donc caractérisée par un étagement altitudinal important et par un gradient climatique marqué. En effet, la saison des 
pluies se prolonge en montant en altitude et les volumes de précipitation augmentent. Quant aux températures, elles baissent, allongeant alors le cycle de croissance des plantes, notamment celui du maïs (figure 6.3).

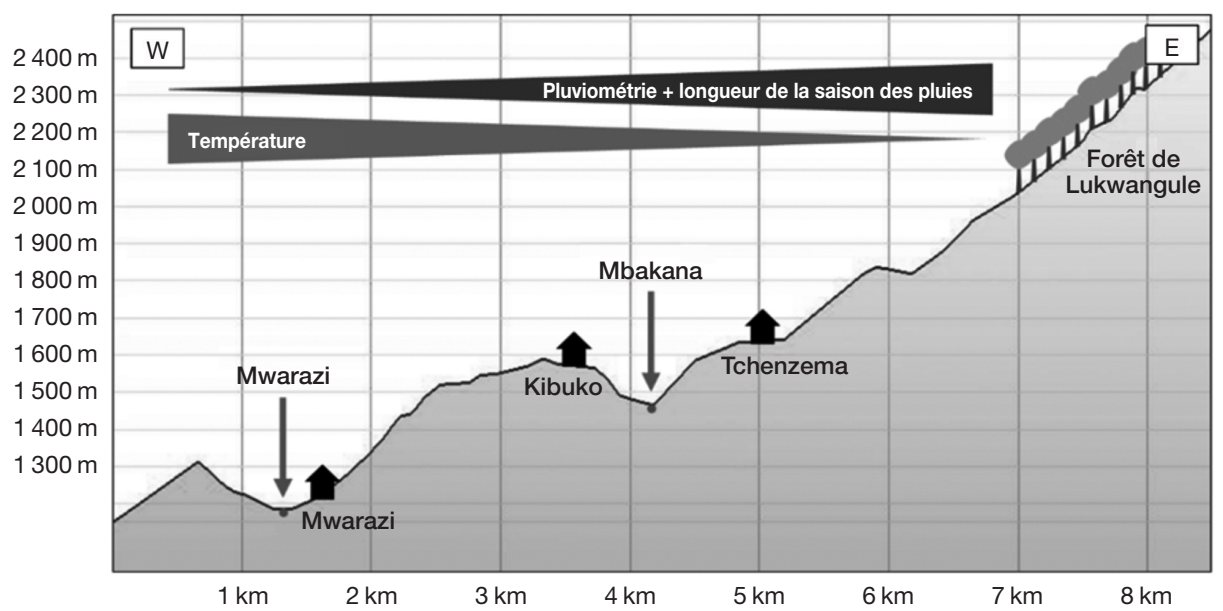

Figure 6.3. Gradient de température et de pluviométrie le long du versant sous le vent (ouest) des monts Uluguru (Hartog, 2016).

Relativement généreuse, la saison des pluies est propice à la multiplication des cycles de culture la même année; d'autant plus que le développement de l'irrigation a permis, comme nous le verrons, de démultiplier les facilités offertes par le climat.

\section{Les agriculteurs parlent peu du changement climatique}

Les évolutions possibles du climat dans cette région du monde ont déjà été évoquées dans les chapitres précédents (chapitres 2 et 3). Si les prévisions concernant les volumes globaux de précipitations sont incertaines, l'accentuation des épisodes violents l'est moins. En région de montagne comme dans les zones inondables de Kilombero et du bas Rufiji dans le Sud-Tanzanie (chapitre 3), cela pourrait bien aggraver les difficultés des agriculteurs. Cependant, les données climatiques auxquelles nous avons eu accès sont assez anciennes (supra) et les séries plus récentes, qui auraient permis une comparaison avec les plus anciennes, n'ont pas pu être consultées, à supposer qu'elles existent vraiment pour la région concernée.

La fonction de château d'eau des sommets forestiers du massif, si importante pour alimenter en saison sèche le réseau d'irrigation, ne semble pas a priori menacée. En revanche, si les monts Uluguru n'échappent pas à l'accroissement de la fréquence et de l'intensité des épisodes extrêmes, ils seront particulièrement touchés par les risques d'érosion par ruissellement, en raison des pentes et celui, toujours présent, de glissements de terrain.

Laccroissement probable des températures provoquera sans aucun doute le relèvement des étages écologiques et le déplacement possible des cultures (et des cortèges parasitaires) vers le haut. Les plus bas étages du versant, sous le vent (ouest), 
pourraient alors pâtir d'une diminution des précipitations ou, ce qui revient au même, d'un accroissement de l'évaporation et donc d'une sécheresse relative plus forte.

Mais les agriculteurs rencontrés ne parlent guère spontanément du «changement climatique »; les rares témoignages recueillis à ce sujet ayant surtout évoqué, comme dans bien des régions, le problème de l'arrivée (de plus en plus?) erratique des pluies en octobre.

\section{" Cultiver la diversité : l'intensification progressive du système agraire Luguru}

Le massif des monts Uluguru, de taille limitée et relativement isolé au sein des basses terres de la Tanzanie orientale, a été peuplé tardivement, à partir du XVIII ${ }^{\mathrm{e}}$ siècle. Les étapes de ce peuplement et les structures familiales (matrilinéaires) qui y furent associées ont été analysées en détail par Jean-Luc Paul (2003), ainsi que la structure foncière qui en a résulté.

D'abord cultivés en abattis-brûlis pendant la phase pionnière, les versants des monts Uluguru ont connus de profonds et rapides changements en matière de pratiques culturales et d'aménagement du milieu. Cette région offre ainsi un exemple spectaculaire d'intensification progressive des pratiques culturales en lien, bien sûr, avec l'accroissement rapide du peuplement et la fermeture précoce du front pionnier. C'est aussi un exemple par rapport à l'intégration aux échanges régionaux, notamment par le développement du maraîchage.

\section{De l'agriculture sur abattis-brûlis au labour et à l'aménagement progressif des versants}

Le cortège des plantes cultivées était initialement dominé par l'éleusine et le sorgho, une dolique (Lablab niger) et des plantes à racines et tubercules (taro et igname). Cet ensemble était complété, probablement dès les $\mathrm{XVIII}^{\mathrm{e}}$ et $\mathrm{XIX}^{\mathrm{e}}$ siècles, par l'apport des plantes d'origine américaine, notamment le maïs, le haricot (Phaseolus) et le manioc. Les outils utilisés correspondaient au travail de la culture par abattis-brûlis : hache (hwago), serpe (sengo) et bâton à semer (muhaya), ainsi qu'une sorte de houe de bois (chibode) utilisée pour le sarclage en saison des pluies (Paul, 2003).

Il est probable que les agriculteurs Luguru aient, dès le début de la colonisation du massif, profité de la diversité que représentent les différents étages écologiques pour répartir leurs parcelles sur toute la gamme altitudinale qui leur était accessible. Le cycle de culture principal était généralement callé sur la saison des pluies, les semis intervenant au début de la saison pluvieuse, en octobre-novembre. À l'étage le plus élevé, le maïs était plutôt semé en fin de saison des pluies, en mai. À cette altitude en effet, le prolongement des pluies, les brouillards et l'humidité résiduelle du sol permettaient au maïs de débuter son cycle en mai et juin, au début de la saison «sèche». Les températures plus basses rallongeaient par ailleurs la durée de son cycle jusqu'en février-mars de l'année suivante (figure 6.5, p. 190). La durée variable du cycle végétatif en fonction de l'altitude, des températures et des variétés utilisées 
permettait déjà aux agriculteurs d'étaler les cycles de culture au sein du calendrier de travail et d'augmenter ainsi les surfaces cultivées par actif, et donc la productivité globale du travail.

La plus grande partie des versants fut mise en culture sur abattis-brûlis, à l'exception de la partie sommitale du massif, au-dessus de 1800-2000 m d'altitude, maintenue sous couvert forestier. Laccumulation sur place du croît démographique et des nouveaux arrivants réduisit l'espace disponible par actif et les périodes de recrûs forestiers furent rapidement écourtées. Dès lors, les forêts secondaires séparant deux phases de mise en culture laissèrent place, peu à peu, aux recrûs arbustifs puis herbacés. D'importantes modifications du mode d'exploitation du milieu ont alors accompagné l'évolution du couvert végétal : en matière de contrôle des adventices d'une part, et de reproduction de la fertilité d'autre part. Ces modifications peuvent être regroupées en deux principales étapes.

\section{Première étape : de l'abattis-brûlis à la défriche-brûlis sur friche herbacée}

Une première étape peut être caractérisée par une transition du système d'abattisbrûlis à une agriculture de défriche-brûlis sur couvert herbacé. Dès le début du $\mathrm{Xx}^{\mathrm{e}}$ siècle en effet, les témoignages des premiers missionnaires font état d'un paysage largement déboisé et dominé par les cultures et les friches herbacées. J.L. Paul (2003) met en relation l'évolution du cortège cultural utilisé par les agriculteurs avec cette évolution du couvert végétal et les difficultés accrues qu'elle a entraînée pour le contrôle des adventices. C'est ainsi que l'éleusine, céréale à paille fine et courte et très sensible aux adventices, aurait été rapidement remplacée par le sorgho (sans doute au XIX ${ }^{\mathrm{e}}$ siècle); avant que ce dernier ne cède à son tour la place au maïs. Par ailleurs, les agriculteurs auraient délaissé leur houe en bois (chibode) pour une houe de fer (durant la deuxième moitié du XIX ${ }^{\mathrm{e}}$ siècle) bien mieux adaptée à la maîtrise du couvert herbacé (idem).

En matière de reproduction de la fertilité des parcelles cultivées, et au fur et à mesure de la diminution du volume de biomasse abattue et brûlée, les agriculteurs ont mis en place un système particulier de préparation du sol associé à la défriche et au brûlis. Les personnes les plus âgées que nous avons interrogées sont encore en mesure de décrire ce système. Ce travail consistait d'abord à faucher la végétation herbacée et éventuellement les recrus arbustifs à l'aide d'une serpe (sengo) durant les mois d'août et de septembre, soit deux mois avant le début de la saison des pluies. Cette biomasse était ensuite laissée à sécher, puis brûlée sur l'ensemble de la parcelle au cours du mois d'octobre, les bordures du champ devant au préalable être nettoyées sur quelques mètres pour éviter que le feu ne se propage aux champs voisins. Une fois cette tâche réalisée, un travail du sol à la houe, localisé, permettait de déchausser les racines des touffes restantes. Cette biomasse était alors rassemblée de façon à former des sortes d'andains disposés le long des courbes de niveau², tous les 20-30 m. Cette pratique permettait à la fois de limiter l'érosion grâce aux bourrelets ainsi

2. Il s'agit du «système Mgeta» : billons d'herbe et d'adventices placés le long des courbes de niveau, en guise de méthode de conservation et évoqué dans la littérature concernant l'histoire de cette région (Temple, 1972, p. 113). 
réalisés (et rechargés chaque année) et de réaliser une sorte de compost étalé tous les cinq ans environ sur l'ensemble de la parcelle, après destruction des bourrelets. La matière organique était ainsi en partie conservée et non totalement brûlée. Le semis se faisait ensuite sans autre travail du sol. Un désherbage manuel à la houe était nécessaire au cours du mois suivant l'arrivée des premières pluies.

Par ailleurs, l'élevage ovin et caprin, qui se développe au cours de cette période, permet l'activation d'un transfert de fertilité depuis les surfaces herbagères vers les parcelles directement attenantes à la maison. En effet, les déjections accumulées grâce au parcage nocturne des troupeaux à proximité des maisons (ou à l'intérieur) étaient régulièrement «balayées » vers la bananeraie et les champs situés en contrebas de l'habitation. Ces plantations bénéficiaient ainsi de ce nouvel apport de fertilité.

Cette transition d'un système d'abattis-brûlis à un système de défriche-brûlis (figure 6.4) signe ainsi une première phase d'intensification en travail du système agraire.

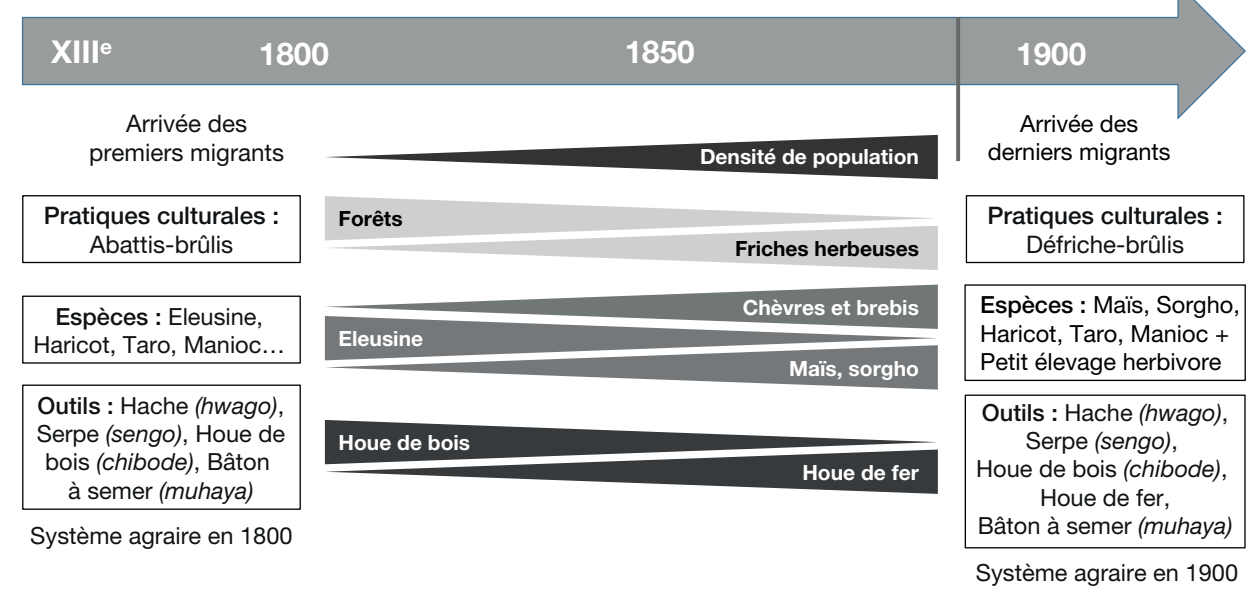

Figure 6.4. Schéma récapitulatif des principales transformations au cours du XIX ${ }^{\mathrm{e}}$ siècle (Paul, 2003).

\section{Deuxième étape : aménagement des parcelles et travail du sol}

Une deuxième étape peut être mise en évidence. Elle consacre la généralisation du travail du sol sous forme de véritable labour, associée à la mise en place de la culture continue et à la généralisation progressive de différentes pratiques d'aménagement des versants en escalier (ladder terraces, matuta ya ngazi).

Tandis que les cultures d'origine américaine - maïs, haricot Phaseolus, patate douce et manioc - occupent de plus en plus de place dans le cortège des plantes cultivées, le début du maraîchage ${ }^{3}$ et le développement de l'irrigation ${ }^{4}$ rendent possible la mise en culture de tous les étages écologiques en saison sèche et la multiplication

3. Le maraîchage avait été initié par les colons et interdit aux autochtones dans un premier temps (Coniat, 1993).

4. Lirrigation existait déjà, les explorateurs la mentionnaient à leur passage à la fin du XIX ${ }^{\mathrm{e}}$ siècle (Coniat, 1993; Paul, 2003). 
des cycles de culture sur la même parcelle. Auparavant, seuls les étages les plus élevés bénéficiant déjà de pluies plus abondantes et de l'humidité atmosphérique étaient cultivés en saison sèche.

La politique coloniale ${ }^{5}$ n'était pas propice à ces transformations et contribuait plutôt à détériorer les conditions de vie des autochtones. Heureusement, le relâchement ultérieur de la pression coloniale et le départ des derniers colons allemands ${ }^{6}$, puis l'Indépendance permettront à ces nouvelles techniques culturales de contribuer de façon décisive à l'évolution du système agraire. C'est au cours des années cinquante et soixante que le maraîchage commence à prendre une réelle ampleur, alors que le marché se développe et que les réseaux d'irrigation continuent de s'étendre. Les premières pistes ayant permis le désenclavement de la région, la commercialisation des légumes est prise en charge par les coopératives (Uluguru farmers cooperative association (UFCA) dès les années cinquante, puis par les commerçants privés. Les principaux légumes cultivés alors sont le chou, le chou-fleur (tous deux pour les étages écologiques les plus froids), plus rarement l'oignon et la pomme de terre. Généralement, chou et chou-fleur sont repiqués en fin de saison des pluies, après récolte des cultures vivrières de maïs et de haricot. Ils sont irrigués en deuxième partie de cycle. En haute altitude, le chou et le choufleur peuvent être associés au maïs pendant la première phase de développement de ce dernier (figure 6.5).

Les années 1950 ont également vu le développement de la culture d'arbres fruitiers de climat tempéré (pruniers, pêchers, pommiers et poiriers). Ils furent importés dans la région par les colons au début du siècle, mais leur plantation par les autochtones était strictement interdite durant toute la première moitié du $\mathrm{xx}^{\mathrm{e}}$ siècle. Après le départ des colons, les agriculteurs profitèrent de leur nouvelle liberté pour planter ces arbres aux abords et dans leurs parcelles.

Parallèlement, alors que la population continue d'augmenter au cours de cette période, l'amenuisement des exploitations aboutit à une diminution des friches pluriannuelles et, simultanément, des cheptels de petits ruminants.

Quant à la préparation du sol, on passe d'un travail du sol superficiel à plat et après défriche-brûlis avec compostage partiel de la matière organique (supra), à un travail du sol en billons assimilable à un véritable labour avec enfouissement total de la matière organique. Cette évolution nécessite une intensification importante en travail qui se justifie par le besoin des populations de pallier une diminution de la fertilité des sols, suite à l'augmentation de fréquence des cycles culturaux.

Identifiés à l'époque coloniale comme une région déjà «surpeuplée» et en proie à une érosion décrétée intense, les monts Uluguru ont été la cible d'une politique particulièrement autoritaire de lutte contre l'érosion. Cette politique visait à aménager les versants en terrasses radicales. Nous verrons plus loin que cette politique, loin d'atteindre les objectifs affichés, se solda par un cuisant échec et fut rapidement abandonnée.

5. Pression fiscale considérablement accrue (Hut taxe et impôt de capitation), corvées coloniales, évictions foncières et mises en place de grandes exploitations coloniales dans cette région au climat plus frais et très prisées des colons (Coniat, 1993).

6. Il s'agit des colons allemands qui étaient restés sur place malgré la mise en place du mandat britannique au lendemain de la $1^{\mathrm{e}}$ Guerre mondiale. 

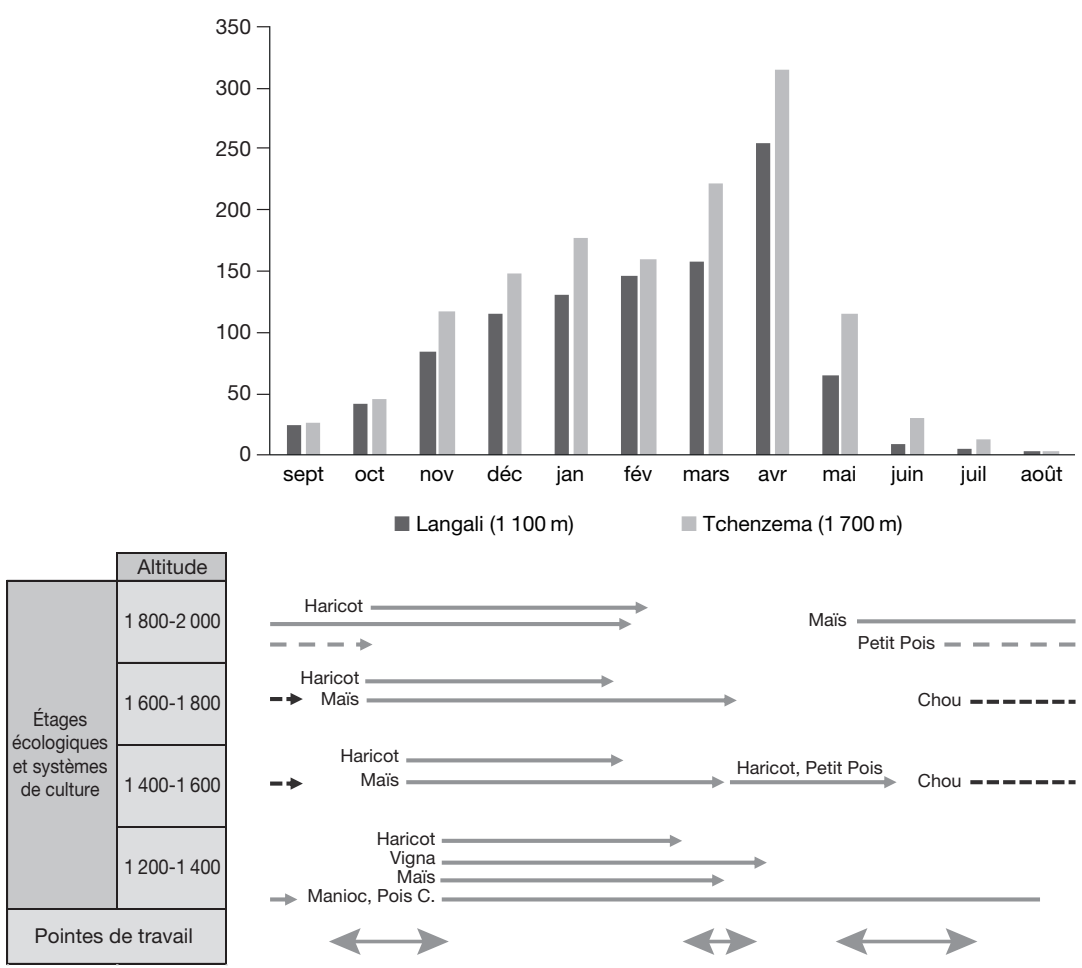

Figure 6.5. Calendrier des pluies et calendrier de travail, monts Uluguru de 1950 à 1970.

Pour autant, les versants des monts Uluguru n'en ont pas moins été soigneusement aménagés en terrasses et escaliers de différentes factures, mais par les paysans euxmêmes et dans une grande diversité de pratiques (photos 6.1 et 6.5, planches 7 et 9). C'est à cette même époque que les agriculteurs commencent à utiliser les déjections animales dans les champs plus éloignés des habitations, surtout sur les cultures maraîchères, et que se développe l'élevage porcin.

\section{Extension de l'irrigation, généralisation du maraîchage, recours aux intrants chimiques et remplissage progressif du calendrier des cultures}

\section{Le développement des réseaux d'irrigation}

Le réseau d'irrigation n'a cessé de se développer depuis les années cinquante jusqu'à aujourd'hui, plus particulièrement depuis les années 1990. Ce développement est tel qu'il est aujourd'hui difficile de trouver une exploitation n'ayant aucun accès à l'irrigation. Le développement de l'irrigation s'est manifesté de différentes façons : - d'abord, une augmentation importante du nombre de canaux à partir des rivières principales et de leurs affluents, certains canaux pouvant atteindre plusieurs kilomètres de long. Au début des années quatre-vingt, les enquêtes agricoles menées sur une centaine d'unités de production situées sur le finage du village de Nyandira indiquaient que le réseau touchait déjà $47 \%$ des parcelles et $87 \%$ des exploitations 
(Paul, 1985, p. 10). À titre d'exemple, Coniat (1993, p. 163) dénombrait déjà 15 prises d'eau, soit 30 connections (un départ de canal sur chaque rive pour chaque prise) sur le torrent Mindu étagées de 1900 à $1450 \mathrm{~m}$ d'altitude. Le plus souvent, les canaux secondaires consistaient en de simples ruisseaux dévalant la pente perpendiculairement au canal primaire pour desservir ensuite les parcelles situées de part et d'autre. Larrosage de chaque plant (de choux par exemple) se faisait à l'aide d'une assiette en puisant dans de micro bassins aménagés çà et là en bordure de parcelle;

- plus récemment, le développement de l'utilisation des tuyaux d'arrosage, en lieu et place de l'irrigation par écoulement associée à l'utilisation d'assiettes (photo 6.2, planche 8). Le tuyau d'arrosage permet une utilisation plus précise et plus économe de la ressource. Plusieurs agriculteurs peuvent alors irriguer en même temps à partir du même canal primaire. Le branchement des tuyaux directement dans le canal primaire évite aussi les dégâts occasionnés par le ruissellement dans le canal secondaire. L'achat d'un tuyau d'irrigation dépend cependant de la capacité d'investissement des agriculteurs, et beaucoup continuent d'irriguer «à l'assiette »; - enfin, l'organisation en groupe d'irrigants et une tendance à la monétarisation de l'accès à l'eau. Il est en effet fréquent que les personnes ayant eu l'initiative du creusement d'un nouveau canal se constituent en groupe. Ils réclament des frais d'adhésion annuels ou définitifs aux personnes n'ayant pas participé à la construction du dit canal, mais souhaitant l'utiliser. Cette monétarisation des droits d'eau concerne principalement les canaux les plus récents. Cependant, d'autres groupes d'agriculteurs revendiquent tout de même des droits pour des canaux plus anciens construits par leurs parents.

\section{La généralisation du maraîchage}

Alors que la densité démographique continuait d'augmenter et que la taille des exploitations diminuait fortement avec l'installation de la nouvelle génération, les agriculteurs des monts Uluguru se sont tournés résolument vers les cultures maraîchères. Ces cultures procurent un revenu plus élevé à l'unité de surface, permettant la survie et la reproduction de l'exploitation.

Le cortège de cultures maraîchères s'élargit alors au cours des années 1960 et 1970, avec l'arrivée de nouveaux légumes (salades, épinards, chou chinois, concombre et poivron) qui s'intègrent — de façon encore limitée — au système agraire Luguru. Ce début d'intégration montre d'ores et déjà la volonté des paysans de diversifier leurs sources de revenus. Les premiers légumes (chou et chou-fleur) avaient été insérés dans les systèmes de cultures vivrières qui prédominaient auparavant (supra). Désormais, les nouveaux légumes sont mis en culture au voisinage de la maison sur des parcelles dédiées, irriguées et de plus en plus aménagées en véritables terrasses. Dans les années 1980, Paul (1985 et 1988) distinguait clairement ce nouveau «système maraîcher» des «systèmes mixtes» apparus plus tôt. Les enquêtes agricoles qu'il avait réalisées à Nyandira (supra) indiquaient que seuls $7 \%$ des parcelles de l'échantillon étudié étaient cultivés avec ces nouveaux légumes, concernant $25 \%$ des exploitations alors que chou et chou-fleur étaient déjà présents dans $94 \%$ des unités de production (Paul, 1985, p. 12).

Depuis les années 1980, ce maraîchage assez diversifié s'est généralisé. Les nouvelles cultures maraîchères à plus forte valeur ajoutée et moins pondéreuses que le chou et le chou-fleur (relativement à leur prix), s'avèrent très attractives en dépit de leurs 
coûts de production parfois élevés. La culture de la tomate se développe au cours des années 2000 et connaît un succès important. Le chou et le chou-fleur ont toujours une place de choix, mais ils côtoient désormais la salade, le chou-chinois, le poireau, etc.

\section{Reproduction de la fertilité : développement de l'élevage porcin et recours aux intrants chimiques}

Cependant, les exportations importantes d'éléments minéraux imputables aux cultures maraîchères pèsent sur la fertilité des sols, dans un contexte où les transferts de fertilités verticaux et horizontaux internes au système ont considérablement diminué (diminution des surfaces en friches et des surfaces boisées, régression de l'élevage de petit ruminants). Aussi, les agriculteurs intègrent rapidement différents intrants chimiques sur les parcelles dédiées au maraîchage, tout en augmentant les surfaces consacrées à ces cultures au sein de leur assolement.

Les engrais chimiques sont disponibles sur le marché de la région vers la fin des années soixante. Mis à disposition gratuitement par le gouvernement dans les années soixantedix, les engrais de synthèse deviennent rapidement payants au cours des décennies suivantes. Ils seront surtout utilisés pour les cultures maraîchères, bien que certains agriculteurs commencent déjà à les utiliser également pour les cultures vivrières.

Rendu possible par les intrants chimiques, le développement du maraîchage s'accompagne par ailleurs d'une augmentation du cheptel porcin (photo 6.3, planche 8). Cet élevage, dont la présence était discrète jusqu'alors, se développe dès les années 1960-1970 grâce, notamment, à l'utilisation de «son» de maïs importé des minoteries des régions environnantes (Morogoro). Le son était mélangé avec différents produits de l'exploitation : feuilles de bananiers et de manioc, taro, fruits gâtés, etc. L'élevage est directement associé au maraîchage dont les besoins en fumure sont importants. Son développement permet donc d'accroître les apports de matières organiques, les importations de son en provenance de la plaine constituant un transfert de biomasse depuis l'extérieur de la région. Ainsi, il y avait déjà un élevage de cochons (un ou deux, 1,3 en moyenne) au début des années 1980 dans $62 \%$ des exploitations du village de Nyandira et cet élevage joue un rôle de premier plan dans la fertilisation des cultures maraîchères (Paul, 1988, p. 31 et p. 42). Dans le même temps, l'élevage de petits ruminants avait reculé au fur et à mesure de la disparition progressive des friches intercalaires et des espaces de parcours. Ce recul est en partie compensé, plus récemment, par le développement de l'élevage caprin laitier issu de programmes de diffusion mis en place dans les années 1990.

Ainsi, l'emploi de fumure organique et d'engrais de synthèse s'est considérablement accru au cours des vingt-cinq dernières années. Leur emploi s'étend au sein de chaque exploitation non plus seulement aux cultures maraîchères, mais également aux cultures vivrières. Dans les années 1980, Paul (1988, p. 16) estimait à $28 \%$ le nombre d'exploitations utilisant des engrais pour la culture de maïs, «occasionnellement et sur de petites surfaces ». Nous estimons aujourd'hui, sur un échantillon de 64 parcelles de maïs analysées, toutes associations de cultures confondues, que $90 \%$ ont été fertilisées. Ces pratiques de fertilisation des cultures vivrières concernent par ailleurs tout type d'exploitations, des plus petites au plus «grandes». Cette extension de l'emploi d'intrants témoigne avant tout d'une dégradation de la fertilité des sols, 
essentiellement imputable aux exigences des cultures maraîchères, à l'exportation des récoltes et à l'insuffisance des restitutions organiques.

Au cours des années 1970, apparaissent également, sur le marché de la région, les premiers produits phytosanitaires. Ces produits semblent avoir été utilisés en premier lieu dans les zones plus hautes, où la densité de cultures maraîchères et d'utilisation du territoire était plus importante. Les agriculteurs commencèrent à utiliser ces produits chimiques plus tard dans les zones situées en contrebas, dans les années 1990. Leur utilisation est aujourd'hui systématique en maraîchage, voire abusive sur la tomate, au point de préoccuper sérieusement les organismes de développement intervenant dans la région.

Par ailleurs, la généralisation de l'irrigation, le développement des cultures marâ̂chères et l'amélioration de l'accès au marché ont permis à la fois une multiplication des cycles de cultures et un ajustement dans le temps des cycles de culture, y compris les cycles des cultures vivrières. Ils ouvrent ainsi la voie à une meilleure utilisation de la force de travail familiale (figure 6.6), dans un contexte d'amenuisement des tenures paysannes. Cette diversification a par ailleurs permis une meilleure adaptation aux variations annuelles des prix du marché7.

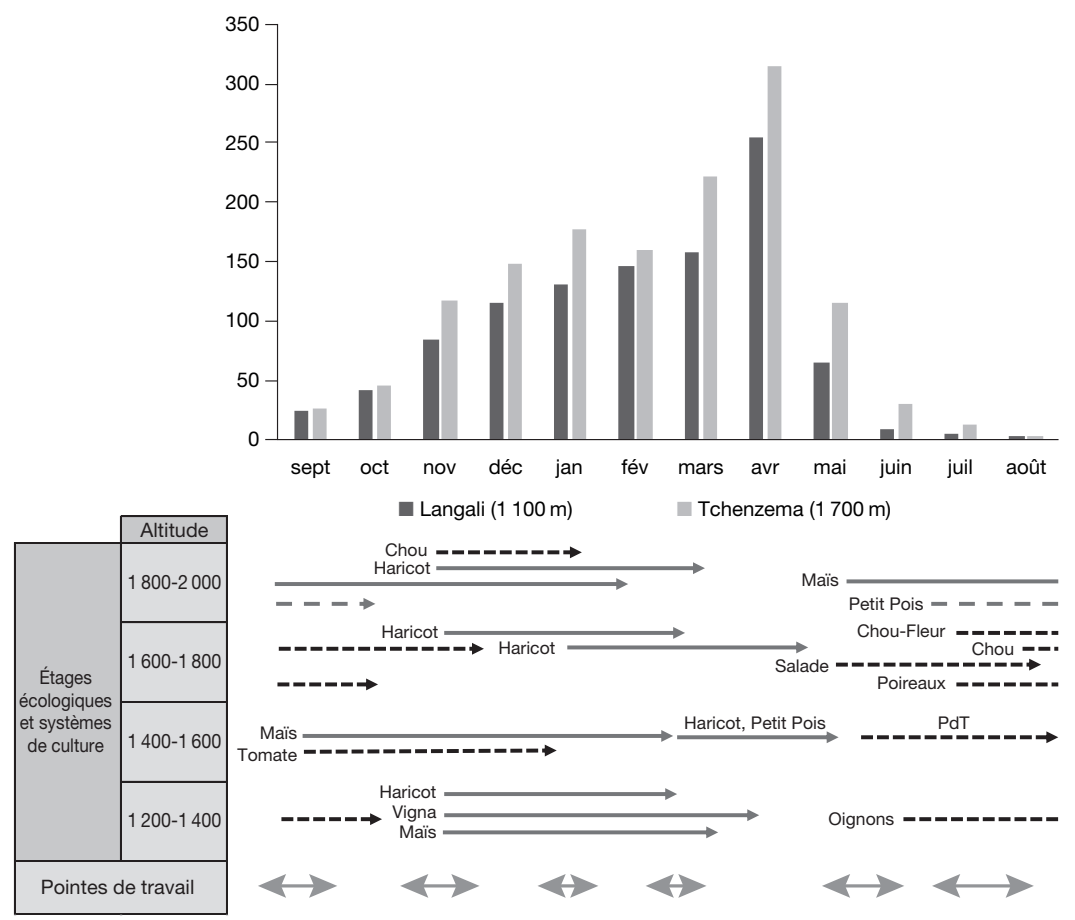

Figure 6.6. Calendrier des pluies et calendrier de travail actuel dans les monts Uluguru.

7. En revanche, la culture des arbres fruitiers, dont un développement avait connu un relatif succès dans la région à partir des années cinquante, occupe une place limitée dans le système agraire. Cette limitation a pu être mise en relation avec le système de tenure foncière encore influencé par la matrilinéarité (Coniat et Raison, 1997). Peu de jardins-vergers sont visibles dans le paysage, contrairement à d'autres régions montagneuses voisines (Nord-Tanzanie et Burundi par exemple). 


\section{- Accéder à différents étages écologiques, maintenir et accroître la diversité des cultures, avoir accès aux intrants et aux marchés}

Tous les agriculteurs de la région des monts Uluguru réalisent des cultures vivrières et maraîchères (avec un ratio qui dépend de leur trésorerie et de leur accès à l'irrigation) sur des parcelles réparties dans les différents étages écologiques. Ils investissent parallèlement dans l'élevage en fonction de leur revenu. Les types d'exploitations établis dans cette analyse se distinguent donc principalement par leurs accès à la terre, à l'irrigation et au marché.

\section{Une différenciation accrue}

Bien que les exploitations agricoles soient en moyenne de très petite taille (quelques acres), d'importantes différences apparaissent entre les plus petites - moins d'une acre et un faible accès à l'irrigation — et les plus grandes — jusqu'à dix acres en grande partie irrigués. Aux inégalités d'accès dues à l'ordre et aux conditions d'arrivée des différents lignages dans la région pendant la phase pionnière, se sont rajoutées les inégalités inhérentes aux conditions d'accès à l'irrigation, aux cultures maraîchères et au marché (proximité des routes notamment). Au cours des vingt dernières années, le réseau de canaux s'est fortement développé, facilitant l'accès à l'eau pour de nombreuses familles. Néanmoins, certaines zones restent toujours dépourvues d'accès à d'irrigation ou sont situées en bout de réseau et privées d'eau en quantité suffisante. De plus, la pression liée à cette ressource entraîne aujourd'hui une monétarisation de plus en plus fréquente de l'accès à l'eau. Ainsi, un jeune couple ayant reçu des parcelles en quantité et qualité suffisantes, par exemple deux à trois acres dont une au moins irriguée et en bord de route, peut entrer dans un processus d'accumulation du capital et augmenter petit à petit sa surface en achetant de nouvelles parcelles. Pour d'autres familles n'ayant pas accès à l'irrigation et trop limitées en terres, la situation est toute autre.

Avec l'essor des cultures de rente, l'augmentation de la pression foncière et les difficultés d'accès à la terre, le fossé s'est creusé entre les familles ayant des exploitations de grande taille, s'orientant vers les cultures de rente et ne pouvant fournir seules la quantité de travail nécessaire, et les familles n'ayant pas suffisamment de terres pour satisfaire leurs besoins et contraintes de vendre une partie de leur force de travail pour assurer leur survie. Cette différenciation fut décrite par J.L. Paul (1985). Il expliquait alors que le système d'achat-vente de la force de travail concernait surtout les plus grandes et les plus petites exploitations agricoles. Les exploitations agricoles moyennes restaient fidèles au système d'entraide qui prévalait jusqu'alors. Sur un échantillon d'une soixantaine d'exploitations agricoles, $35 \%$ des agriculteurs avaient alors recours au salariat, $11 \%$ à la vente de force de travail et $87 \%$ à l'entraide (Paul, 1988). Lanalyse de la situation actuelle tend à montrer que cette marchandisation de la force de travail s'est accentuée, de sorte que la majorité des exploitants emploient au moins une fois de la main-d'œuvre salariée dans l'année. Lemploi de la main-d'œuvre salariée concerne non seulement les grandes exploitations, mais 
également les exploitations de taille moyenne, voire même les petites exploitations. Il n'est pas rare que des agriculteurs achètent et vendent tour à tour leur force de travail au cours de la même année. Enfin, de nombreux travailleurs, surtout des jeunes, vivent essentiellement de la vente journalière de leur force travail pour les travaux des champs ou comme porteur.

\section{Typologie simplifiée des unités de production}

\section{De très petites exploitations ayant peu accès à l'irrigation et au marché, contraintes de vendre une partie de leur force de travail}

Cette première catégorie regroupe les exploitations les plus petites ( 0,5 à 1,5 acre) ayant un accès très limité à la terre, à l'irrigation et au marché. Leurs exploitants se retrouvent dans une grande fragilité financière, qui rend la production maraîchère (exigeante en intrants) difficile à mettre en ouvre. Ces agriculteurs sont parfois obligés de travailler en tant que journalier dans d'autres exploitations afin non seulement de pourvoir aux besoins du ménage durant une partie importante de l'année, mais également d'être en mesure d'acheter les intrants (semences, engrais et produits phytosanitaires) et de payer la redevance relative à l'accès au canal. Cela a pour conséquence de retarder le déroulement des travaux de l'exploitation; le chou sera vendu à son prix le plus bas.

Les systèmes de culture mis en place dépendent bien sûr de l'étage altitudinal. Lagriculteur réalise toujours un cycle de culture vivrière durant la saison des pluies. Cette culture se résume le plus souvent à une culture de maïs en association avec du haricot, par exemple à l'étage le plus élevé du profil (1900 m, figure 6.6). Durant la saison sèche, l'agriculteur peut par exemple produire des légumineuses (haricot, petit pois) ou des légumes (chou, chou-fleur, salade, chou-chinois ou carottes) sur une petite surface de 0,3 et 0,2 acre située un peu plus bas $(1700 \mathrm{~m})$. L'exploitant y sème maïs et haricot en début de saison humide (octobre-novembre), puis durant la saison sèche haricot et chou en irrigués, avec engrais et traitements insecticides.

Ces exploitants ne possèdent généralement pas ou très peu d'animaux. Certains arrivent parfois à engraisser un porc, mais ils sont bien souvent obligés de le vendre avant terme à un prix désavantageux, faute de trésorerie. Le porc est nourri principalement à l'herbe et au «son» de maïs issu de l'exploitation. Du son supplémentaire peut être acheté en fonction des rentrées d'argent, à raison de deux sceaux par mois. Le fumier récupéré est utilisé dans les champs, en particulier pour le chou.

Le matériel agricole se résume à deux houes, une hache et une machette. N'ayant pas les capacités d'investissement suffisantes, ces agriculteurs sont obligés de louer pulvérisateur portatif et tuyau d'irrigation à la journée. Les bâtiments d'élevage sont réduits à des enclos couverts reconstruits chaque année avec du bois récolté en forêt.

Les revenus annuels de ce type d'exploitations sont très faibles : de 200000 à 500000 schillings tanzaniens (TZS), soit seulement 40 à 100 euros/actif/an. Ces exploitations ne pourraient pas subsister sans le travail nécessairement réalisé à l'extérieur par l'agriculteur et les membres de sa famille. Ces faibles revenus 
s'expliquent notamment par la trop petite taille de l'exploitation, l'accès à un ou deux étages écologiques seulement et le faible éventail de possibilités offertes à l'agriculteur en termes de combinaisons culturales. C'est pourquoi une centaine de journées de travail seulement peuvent y être consacrées chaque année. Cela illustre bien le sous-emploi «forcé» de la force de travail de ces familles.

\section{De petites exploitations ayant un bon accès à l'irrigation et au marché}

Cette seconde catégorie d'exploitations agricoles regroupe des parcelles de 2 ou 3 acres irrigables et orientées vers la culture de légumes. En général, ces exploitations produisent au moins deux ou trois cultures maraîchères différentes, ce qui leur permet d'atteindre un revenu bien plus élevé que la catégorie précédente. Cependant, ces agriculteurs prennent des risques importants. En effet, les cultures maraîchères nécessitent beaucoup d'intrants, tandis que prix du marché sont volatiles. De fait, il est fréquent que ces exploitations aient un fonctionnement en "accordéon » avec des résultats économiques élevés durant les bonnes années; ou des résultats pouvant être catastrophiques les mauvaises années, obligeant les agriculteurs à décapitaliser.

Sur 2 ou 3 acres irriguées et réparties sur trois étages écologiques différents, il est possible de réaliser deux cycles de culture sur l'ensemble des parcelles. Dans ce cas, les cultures à haute valeur ajoutée sont favorisées : tomate, oignon, chou, etc. Les successions mises en place peuvent être par exemple :

- vers $1900 \mathrm{~m}$ d'altitude, maïs et haricot de saison des pluies associés, suivis de choux en saison sèche;

- à 1600 m, maïs et tomate associés, semés dès le mois de septembre et irrigués en attendant les pluies, puis haricot ou petit pois en fin de saison humide;

- vers 1400 m d'altitude, maïs associé au haricot en saison des pluies, oignons irrigués ensuite (figure 6.6).

Engrais et produits phytosanitaires sont largement utilisés, en particulier pour les cultures maraîchères, mais également pour les cultures vivrières.

Ces petites exploitations ayant un bon accès à l'irrigation et au marché disposent de l'ensemble du matériel nécessaire à son fonctionnement : deux houes, une hache, une machette, un tuyau d'irrigation de $25 \mathrm{~m}$ et un pulvérisateur portatif. Les bâtiments d'élevage sont réduits à des enclos couverts construits avec des bois récoltés en forêt. Les deux porcs élevés à l'engraissement sont achetés à l'âge de trois mois et vendus à l'âge de dix à douze mois. Durant toute cette période, ils sont nourris principalement au son de maïs acheté toutes les semaines au marché, ainsi qu'aux sous-produits de l'exploitation.

Outre la force de travail familiale (généralement un couple), quelques journées de travail sont achetées à l'extérieure au moment des pointes de travail. Cela peut se révéler crucial pour accroître la surface cultivée au moment opportun, au-delà de ce que serait en mesure de faire l'agriculteur et sa femme.

Les revenus de l'exploitation sont nettement supérieurs, de l'ordre de 500 à 600 euros/actif/an. Ils sont suffisants durant les bonnes années pour éviter à l'agriculteur de travailler à l'extérieur. La culture de différents étages écologiques permet un meilleur emploi de la force de travail familial : plus de 200 journées de travail 
par an y sont consacrées. Les cultures à plus haute valeur ajoutée (tomate notamment) permettent d'avoir une plus forte rémunération du travail. Cependant, en cas de mauvaise récolte ou de chute des cours, l'agriculteur se voit bien souvent obligé de décapitaliser ou, si cela ne suffit pas, de travailler à l'extérieur comme journalier. Ces exploitations restent donc fragiles, mais elles ont le potentiel d'atteindre de bons résultats économiques. Ces revenus leur permettent, dans certains cas, d'investir petit à petit dans la terre et de s'agrandir.

\section{Des exploitations de taille moyenne, intensives et orientées vers les cultures maraîchères}

Cette catégorie d'exploitations regroupe des unités de plus grande dimension (environ 5 acres), dont la plus grande partie est irrigable (80\%). Ces exploitations ont accès à une large palette de conditions climatiques étagées le long des versants. Cette dispersion des parcelles selon le gradient altitudinal, loin d'être un handicap, leur permet de produire des cultures maraîchères diversifiées et en quantité généralement entre quatre et six légumes différents. Cela leur permet de diminuer les risques encourus. Ces exploitations ont également des élevages de tailles plus importantes. Elles n'ont généralement aucune difficulté à se procurer l'ensemble du matériel nécessaire à leur fonctionnement : houes, hache et machette, ainsi que deux tuyaux de $50 \mathrm{~m}$ et deux pulvérisateurs portatifs. Les bâtiments d'élevage sont permanents, construits en matériaux plus durables. Les deux actifs familiaux de l'exploitation sont épaulés par le recours aux journaliers sur l'ensemble de l'année pour l'équivalent d'une cinquantaine de journées de travail, notamment aux moments des labours et des semis, période clef du calendrier de travail.

Tandis qu'un cycle de maïs pluvial est toujours réalisé sur les parcelles situées en altitude, l'agriculteur oriente la majorité de ses parcelles vers les cultures maraîchères irriguées, par exemple :

- choux de saison sèche après un cycle de maïs + haricot de saison des pluies vers $1700 \mathrm{~m}$;

- salade de saison sèche après un cycle de haricot pluvial vers $1600 \mathrm{~m}$;

- pomme de terre en saison sèche après un cycle de maïs et tomate (irriguées en début de cycle) vers $1500 \mathrm{~m}$;

- salade et poivron irrigués dans l'étage plus chaud vers 1400 m d'altitude.

Ces agriculteurs ont recours systématiquement aux intrants de synthèse.

Par ailleurs, ils ont pu investir à la fois dans l'élevage de porcs (reproduction et engraissement) et de chèvres laitières menées au piquet. Pendant la lactation, ces chèvres bénéficient chaque jour d'un complément alimentaire sous forme de son de maïs. Ce dernier n'étant produit sur l'exploitation qu'en quantité insuffisante, les exploitants sont obligés d'en acheter au marché.

Cet accès à un large éventail de cultures et la surface moins contraignante de ces exploitations permettent aux agriculteurs de valoriser beaucoup mieux la force de travail familiale disponible : 400 journées de travail familial environ. La surface cultivée est élargie grâce à l'embauche de journaliers aux moments des pointes de travail, une cinquantaine de journées de travail supplémentaires. Le revenu agricole annuel s'établie alors à plus de 1500 euros par actif familial. 


\section{De grandes exploitations polyvalentes}

Certaines exploitations sont nettement plus grandes, environ 8 ou 9 acres réparties sur plusieurs étages écologiques dont les trois quarts sont irrigables. Les agriculteurs peuvent à la fois diversifier leurs cultures maraîchères et non maraîchères; ce qui leur donne un avantage en termes de revenu et de limitation des risques encourus. Grâce au large accès à l'irrigation et à différents étages écologiques, les exploitants ont la possibilité de diversifier davantage leurs cultures à la fois maraîchères et non maraîchères. Sur les parcelles les plus accessibles et irriguées, sont préférentiellement cultivées des cultures maraîchères, alors que les parcelles plus éloignées sont réservées à la culture de légumes secs et aux cultures vivrières.

Plusieurs ateliers d'élevage y sont aussi présents : quelques porcs à l'engraissement et une truie mise à la reproduction, ainsi qu'un petit troupeau de chèvres laitières. Toujours destiné à l'autoconsommation, l'élevage de poulets est de taille plus conséquente grâce aux larges surfaces de cultures de maïs qui permettent de dégager un surplus en grain utilisé pour nourrir les poulets. La production de son de maïs reste cependant insuffisante et nécessite d'être complétée par des achats. Lexploitant bénéficie ainsi de quantités importantes de fumure animale.

Toutes ces activités permettent d'occuper la force de travail familiale tout au long de l'année, environ 500 journées de travail pour un couple d'agriculteur. Elles accroissent ainsi la productivité globale du travail (valeur ajoutée par actif présent sur l'exploitation). Par ailleurs, il est nécessaire, pour faire fonctionner l'exploitation, d'employer des journaliers pendant les pointes de travail pour un total d'environ 200 journées de travail; ce complément de main-d'œuvre est décisif pour pouvoir accroître la surface cultivée.

Le matériel de ces exploitations, bien que reposant toujours sur un outillage manuel, est plus complet pour les cultures (pulvérisateurs portatifs, tuyaux d'arrosage) et l'élevage (bâtiments en dur, y compris pour la volaille).

Ces exploitations se caractérisent ainsi par une très grande diversité de sources de revenus issus à la fois des cultures et de l'élevage. Le revenu par actif familial atteint 2000 euros/an, voire davantage.

\section{Des exploitations de taille moyenne, situées à plus basse altitude et ayant peu accès à l'irrigation}

Plusieurs exploitations de taille moyenne, se situant dans les zones de plus basse altitude, ont un moindre accès à l'irrigation et sont orientées principalement vers la culture de céréales, de légumineuses et de tubercules, ainsi que les cultures pérennes (arbres fruitiers et canne à sucre). Sur les quatre à cinq acres dont elles disposent, ces exploitations diversifient en général leurs cultures non maraîchères en jouant sur les différents étages écologiques et les différentes associations de culture possibles. Dans les étages les plus chauds, il est ainsi fréquent d'observer maïs, haricots (Phaseolus et Vigna), pois cajan et manioc en association. Dans les altitudes plus hautes, l'agriculteur privilégie le maïs associé au haricot et parfois à la courge. Le petit-pois est également souvent cultivé, notamment durant la saison sèche. Une part réduite de la surface (moins de $20 \%$ ) est irrigable et réservée aux 
cultures maraîchères, notamment la tomate (associée au maïs). Ces exploitations sont souvent situées en bout de réseau d'irrigation. Sauf pour les cultures de tomates irriguées, très peu d'intrants chimiques sont utilisés dans ce type d'exploitations, le fumier des cochons permettant en partie de se passer des engrais de synthèse.

La productivité du travail et le revenu de ces exploitations sont plus faibles que dans les trois types précédemment décrits (le revenu est de l'ordre de 450 à 500 euros par actif) du fait d'un moindre accès aux étages écologiques supérieurs, à l'eau et aux cultures à plus forte valeur ajoutée (hors la tomate). Ces agriculteurs prennent relativement peu de risques liés aux fluctuations de prix sur les marchés : leurs coûts de production sont moindres et les cours des cultures non maraîchères sont dans l'ensemble plus stables. En revanche, si les accroissements de températures envisagés se manifestaient avec force dans ces étages déjà plus chauds de la région et dans un contexte où l'eau d'irrigation risque d'être de plus en plus sollicitée par les voisins des étages supérieurs, il est probable que ces agriculteurs seront plus vulnérables à l'avenir.

\section{" Aménagements paysans, lutte antiérosive et adaptation : les leçons de l'histoire}

Nous l'avons vu, les monts Uluguru furent identifiés dès l'époque coloniale comme une région «surpeuplée» et en proie à une érosion intense. Ils furent donc la cible d'une politique particulièrement autoritaire de lutte contre l'érosion dont l'outil principal visait à aménager les versants en terrasses radicales. Dans la mesure où les politiques actuelles en matière d'adaptation au changement climatique (chapitre 8) font une large part à la lutte contre la dégradation des terres (érosion, surpâturage, déforestation, salinisation, diminution du taux de matière organique et appauvrissement des sols), l'exemple des monts Uluguru est riche d'enseignements. Il illustre, comme beaucoup d'autres situations en Afrique et ailleurs, l'inadéquation des programmes et projets gouvernementaux aux contextes locaux et aux pratiques et logiques paysannes. Loin d'atteindre les objectifs affichés, les remèdes ont trop souvent été pires que le mal.

\section{L'exemple du programme Ulus, de lutte contre la dégradation des terres mis en place par les autorités coloniales}

Par sa mise en musique autoritaire par le pouvoir colonial, les réactions y compris violentes qu'il suscita de la part des locaux et son abandon précipité, ce projet d'aménagement a laissé des traces dans la mémoire collective, beaucoup plus que dans le paysage qu'il était censé remodeler durablement. P.H. Temple (1972) en a fait une analyse critique publiée dans la série géographie physique de la revue Geografiska Annaler et sur laquelle nous nous appuierons.

Mise en place par les colons britanniques dans les monts Uluguru au début des années 1950, la politique de lutte antiérosive fut l'une des plus ambitieuses jamais entreprise à cette époque. Auparavant, la réserve forestière du plateau sommital 
des monts Uluguru avait été mise en place par l'administration allemande et ses limites matérialisées. Les habitants, situées à l'intérieur furent déplacées, leurs parcelles abandonnées. L'intérêt de cette réserve ne fait aujourd'hui guère de doute pour sauvegarder le château d'eau constitué par les sommets du massif. Cependant, l'accroissement consécutif de la pression anthropique sur les alentours entraîna la diminution des temps de friche sur les versants en pente forte qui entourent le massif protégé, comme le souligna très tôt Savile (1945-1946; cité par Temple, 1972). Il contribua alors à précipiter la crise du système basé sur l'abattis-brûlis.

On préconisa ensuite le développement des cultures pérennes (caféiculture) et le creusement de canaux de contour, parallèles aux courbes de niveau, pour enrayer le ruissellement, comme au Burundi et Rwanda voisins ${ }^{8}$. Devant l'inefficacité de ces mesures, il fut même proposé de vider la région de sa population pour en faire une réserve intégrale (Temple, 1972, p. 115). Les plantations coloniales de sisal des bassesterres n'avaient-elles pas besoin, au même moment, de main-d'œuvre en quantité ?

À la fin des années 1930, les premières expérimentations de cultures en terrasses (bench terraces) sont mises en place en 1936-1937 (Temple, 1972, p. 114), ouvrant la voie à l'élaboration du programme Ulus (Uluguru land usage scheme) qui sera mis en place entre 1945 et 1955. Tandis qu'est renforcée l'interdiction de brûler, les pentes les plus abruptes sont mises en défens. Les fonds débloqués en 1947 sont destinés en priorité à la construction des terrasses radicales (bench terraces) censées être la seule protection efficace contre le ruissellement et le glissement de terrain (photo 6.4, planche 9). À partir de 1953, chaque foyer doit construire $500 \mathrm{~m}^{2}$ de terrasses par an, tandis que les mesures de coercition sont renforcées (Temple, 1972, p. 117). Le plan interdit aussi certaines pratiques de drainage, comme les drains ou fossés empierrés qui permettaient pourtant d'évacuer les excès d'eau en limitant le plus possible les pertes en terres.

$\mathrm{Au}$ début, les paysans des monts Uluguru se laissèrent faire, davantage préoccupés qu'ils étaient par l'interdiction de brûler, les mises en défens des pentes fortes, et inquiets à cause des rumeurs de migrations forcées vers les terres basses. Ils se révoltent pourtant en 1955 et l'ampleur de la jacquerie conduit les autorités britanniques à passer l'éponge 9 .

Léchec retentissant de ce programme de lutte contre l'érosion et la détérioration des terres a été analysé par plusieurs auteurs dès les années qui ont suivi son abandon. Les techniques proposées étaient inadéquates, notamment celle de la terrasse radicale si difficile à édifier, au talus si fragile et exposé à l'érosion, exhumant par ailleurs les horizons plus profonds et moins fertiles du sol, tout en

8. Au Burundi et au Rwanda, l'accroissement démographique et l'intensification des pratiques furent constatés par les colons : diminution des pâturages et des friches, accroissement des surfaces cultivées, multiplication des cycles de cultures, mise en culture des pentes fortes, etc. À leur avis, ces éléments rendaient l'aggravation de l'érosion évidente et indiscutable. Il fallait donc faire quelque chose... Les «indigènes» durent creuser des fossés isohypses antiérosifs de plusieurs centaines de milliers de kilomètres $(140000 \mathrm{~km}$ de fossés répertoriés en 1945) surtout sur les pâturages, précisément les espaces les moins sujets à l'érosion. En effet, les travaux de mesure, le piquetage et la surveillance y étaient plus aisés. Par ailleurs, la résistance des populations y était moins forte que sur les terres assolées (Cochet, 2001).

9. Une description plus précise de l'enchaînement des évènements lors de l'insurrection est donnée par Coniat (1993, p. 126-128). 
accroissant considérablement les risques de glissement de terrains (photo 6.4). Depuis longtemps, l'érosion avait été présentée comme alarmante, bien qu'aucune démonstration n'y vienne à l'appui (Temple, 1972, p. 115) et qu'aucun diagnostic des pratiques paysannes ne soit entrepris, notamment en ce qui concerne les modalités de labours en billons (supra) ou les terrasses en escalier (ladder terraces) que les agriculteurs avaient déjà commencé à confectionner dès les années 1930 (Coniat, 1993; photo 6.1, planche 7 et photo 6.5 , planche 9$)^{10}$.

Par ailleurs, la densité démographique fut grossièrement surestimée pour appuyer la théorie de la catastrophe imminente : estimée à 290 habitants $/ \mathrm{km}^{2}$ en 1945, le recensement de 1967 fournira le chiffre de 119 habitants $/ \mathrm{km}^{2}$ (Temple, 1972, p. 116). Les autorités coutumières ne furent pas consultées.

\section{Lutte antiérosive et aménagement des versants : la voie paysanne dans les monts Uluguru}

Léchec des autorités coloniales était patent en matière de lutte antiérosive. Mais il n'a pas empêché les versants des monts Uluguru d'être méticuleusement sculptés à la houe et aménagés en terrasses et escaliers de différentes factures par les paysans eux-mêmes et dans une grande diversité de pratiques, en fonction notamment de la pente du versant.

\section{Labours de billonnage et aménagement des versants}

Aujourd'hui, toutes les parcelles sont labourées et cultivées en billons parallèles aux courbes de niveau (photo 6.5, planche 9). Dans tous les cas, les parcelles, laissées quelques semaines ou quelques mois en friche entre deux cycles de culture, sont initialement recouvertes d'herbes et de résidus des cultures précédentes, les billons du cycle précédent étant encore assez marqués. Dès lors, deux principaux types de labour peuvent être distingués en fonction de la pente du versant.

Un premier type de labours correspond aux versants en pente relativement modérée. Le travail commence par le bas de la parcelle et progresse vers son sommet. Les agriculteurs déchaussent à la houe les herbes germées sur l'ancien billon et les rabattent en contrebas, à l'emplacement de la raie qui séparait ce billon de son voisin l'année précédente. Dans le cas où d'encombrants résidus de culture sont encore présents (cannes de maïs par exemple), ils sont préalablement coupés ou arrachés, puis couchés dans l'ancienne raie. Lancien billon est ensuite cassé et la terre ainsi retournée vient recouvrir la biomasse disposée dans l'ancienne raie. Cette dernière devient alors le futur billon de l'année, tandis que cet houage aboutit à la formation de la nouvelle raie à l'emplacement de l'ancien billon. Les billons se décalent donc d'année en année vers le bas de la parcelle, provoquant une descente progressive de la terre, ce type de travail du sol a souvent été considéré comme un facteur érosif

10. Lassociation des cultures vivrières - manioc-patate douce, maïs-légumineuses (haricot, niébé ou pois), sorgho-maïs-haricot ou pois-patate douce - et les cultures de rente (maïs-chou-haricot) stabilisèrent la parcelle contre l'érosion en nappe grâce à la présence d'une couverture végétale constante (Coniat, 1993, p. 131). 
dans cette région, comme dans d'autres régions montagneuses voisines (Cochet, 2001) ${ }^{11}$. À tort, car ce processus aboutit à la formation d'un bourrelet en aval du champ. Ce bourrelet marque la séparation avec le champ voisin situé en contrebas et contribue ainsi à la constitution de pseudo-terrasses façonnant le versant (photo 6.6 , planche 10). La stabilisation du talus raide (parfois vertical) qui sépare alors les deux parcelles est essentielle. Ce talus peut être parfois végétalisé, mais cette pratique est encore assez peu répandue dans les monts Uluguru. Ici, il est renforcé par le fait que le bourrelet de bas de parcelle est également cultivé en billons, cette fois-ci dans le sens perpendiculaire aux billons précédents, c'est-à-dire dans le sens de la pente, très faible, voire nulle sur ce bourrelet. Ce changement d'orientation du travail du sol présente un double avantage. D'une part, il évite de constituer un billon sur le rebord du talus; billon qui serait inévitablement instable. D'autre part, l'enfouissement de la matière organique permet «d'armer» l'extrémité du billon et de limiter la descente de la terre chez le voisin en contrebas.

Le deuxième type de labours est réservé aux pentes les plus abruptes, celles-ci sont façonnées en véritables escaliers. Dans ce cas, les herbes (et d'éventuels résidus de récolte) sont d'abord grattées à la houe et ramenées sur la marche inférieure, formant ainsi un étroit andain. Puis, le rebord de la marche supérieure est retaillé, ainsi que le talus presque vertical qui la soutient. La terre ainsi détachée sert à recouvrir l'andain de biomasse préalablement formé et à constituer un nouveau billon. Dans cette configuration, une partie de la végétation de l'ancienne marche n'est pas déchaussée et reste enracinée. Il en résulte une plus forte résistance des marches ainsi «retaillées» aux agents érosifs, une partie du sol restant en place. Ces particularités rendent le travail de billonnage possible dans les pentes les plus fortes en limitant les phénomènes d'érosion. D'éventuelles cultures pérennes sont aussi épargnées par ce travail du sol (banane et taro par exemple), comme on peut l'observer sur la photo 6.7 (planche 10) de cet ouvrage ${ }^{12}$.

11. Au Burundi aussi, on commence toujours le labour en bas de la parcelle pour progresser vers le haut. La terre est rejetée vers le bas. Cette pratique provoque une descente progressive de la terre le long du versant, parfois qualifiée d'érosion «sèche». Parfois, il a été conseillé aux agriculteurs d'adopter un labour dans le sens des courbes de niveau. Pourtant, cette technique est presqu'impossible à mettre en œuvre sur les pentes fortes. Pour effectuer un tel labour (ou même de haut en bas comme le préconisent certains), la position à adopter serait tellement inconfortable qu'il serait impossible d'obtenir un retournement complet des mottes de terres et un bon enfouissement de la matière organique. Le procès qui est fait au labour de bas en haut est d'ailleurs fort injuste. Tel que le pratiquent les paysans burundais, il est à l'origine des pseudo-terrasses inclinées que l'on peut observer en maints endroits dans les campagnes burundaises. Il aboutit en effet à la constitution d'un bourrelet en bas de parcelle et d'une dépression relative au sommet de la parcelle, résultat de la dernière raie de labour. En quelques années ou quelques dizaines d'années, le profil de la parcelle est adouci. Le versant est alors constitué d'une série de pseudo-terrasses inclinées (de véritables «terrasses progressives») séparées par des talus très raides. Après plusieurs générations de labour de «bas en haut», les talus atteignent plusieurs mètres de hauteur et supportent de véritables terrasses horizontales comme il est possible de l'observer dans certaines régions. Dès que la terrasse devient horizontale, on alterne alors le sens du labour chaque année pour qu'une contre-pente opposée à celle du versant n'apparaisse pas et que la parcelle reste plane. Ce type de labour, pourtant dénoncé comme principal facteur érosif, devient alors une véritable technique de conservation des sols et d'aménagement des versants (Cochet, 2001).

12. On peut reconnaître ce type de terrasses en escalier (matuta ya ngazi) dans la description qu'en avait donnée Grant en 1956 (Coniat, 1993, p. 114). Très peu de cas de rupture étaient signalés avec ce type d'aménagement. 
Dans les parcelles les plus caillouteuses, les pierres ramassées sur le champ sont rassemblées sur les côtés (parfois au centre) de façon à former des drains pour l'écoulement des eaux excédentaires et limiter les pertes en terre. Elles peuvent aussi servir à renforcer les canaux secondaires (photo 6.8, planche 10).

Dans les deux types de labours décrits ci-dessus, l'une des fonctions essentielles du labour est bien d'enfouir la matière organique; qu'elle soit constituée par les résidus de culture ou par des végétaux développés pendant le cycle cultural (adventices) ou après les récoltes. Le maintien au moins partiel de la matière organique dans le sol est à ce prix. L'apport de fumure animale peut compléter ce processus.

\section{Les «vraies » terrasses ou terrasses «radicales»}

Malgré l'échec retentissant du projet Ulus dans les années cinquante (supra), quelques tentatives ultérieures de vulgarisation de terrasses radicales ont laissé des traces, notamment pour les cultures légumières de proximité (de la maison). La terrasse est alors construite ex nihilo et aboutit à la constitution de terrasses horizontales plus grandes. Leur largeur est limitée par la raideur des pentes (photo 6.9, planche 11). Les talus très raides ainsi construits restent très fragiles et ne manquent pas d'être rapidement entaillés par de petites griffes d'érosion. C'est pour cela que, contrairement aux tentatives issues du projet Ulus et de ses suites, ce type de terrasses est plutôt observé aujourd'hui sur les parcelles en faible pente, souvent à proximité des habitations ou des routes, et consacré exclusivement à la succession de cultures maraîchères irriguées.

Aux inconvénients de ce type de terrasses déjà signalés plus haut, ajoutons que ces structures permanentes permettent difficilement d'enfouir la matière organique, contrairement aux labours de billonnages dont il a été question plus haut. En fin de saison sèche, lorsqu'il s'agit d'installer les cultures irriguées de contre-saison, les agriculteurs sont contraints de brûler la matière organique présente, notamment les herbes préalablement déchaussées. C'est là la seule manière de s'en débarrasser (photo 6.10, planche 11). Ensuite, les agriculteurs réalisent un labour superficiel afin d'enfouir les cendres. Dans ce cas, le phosphore et le potassium sont restitués au sol, mais carbone et azote partent en fumée : les engrais de synthèse sont de mise. Si le labour a lieu en fin de saison des pluies, et que la biomasse mobilisée n'est pas trop volumineuse, les agriculteurs la rassemblent en bordure de la terrasse, puis la recouvrent de terre. Ce travail permet alors, outre l'enfouissement au moins partiel de la biomasse, de restaurer le rebord de la terrasse qui a pu être érodé par les pluies du cycle précédent. La terrasse retrouve son profil horizontal grâce à «l'armature» constituée par la biomasse entassée en bordure et on évite ainsi la diminution de la surface de la terrasse. Enfin, dans certains cas et notamment pour les terrasses plus larges, les agriculteurs peuvent réaliser un travail de billonnage sur chaque terrasse, perpendiculairement à l'axe longitudinal de la terrasse, pour retrouver ainsi les avantages décrits à propos du labour de billonnage. 


\section{W Conclusion}

Comme dans de nombreuses régions du continent africain et d'ailleurs, l'agriculture des monts Uluguru est purement manuelle, sans énergie animale ou fossile. La productivité horaire du travail est très faible. Ce sont l'allongement des périodes travaillées et le remplissage du calendrier de travail tout au long de l'année qui permettent de réels gains de productivité du travail par actif et par an. En permettant à chaque famille de vivre sur une base foncière de plus en plus réduite, ce processus d'intensification a aussi permis de faire face à un accroissement démographique soutenu. La diversité des cultures mises en place et leur étalement tout au long de l'année sont donc cruciaux pour produire autant ou davantage sur une moindre surface et envisager tout accroissement de productivité. En effet, toute forme de spécialisation productive (une seule production) aboutirait au résultat inverse : saturation rapide de la force de travail familiale pendant la pointe de travail et sous-emploi chronique le reste de l'année. Par ailleurs, un tel développement du maraîchage de rente augmenterait considérablement les risques encourus, notamment le risque-prix (intrants/production), s'il n'était basé que sur une seule production ou un trop petit nombre.

C'est pour cela que l'accès à des écosystèmes diversifiés (qui impose donc une certaine dispersion des parcelles et non leur regroupement en blocs de plus grande dimension), l'accès à l'irrigation, ainsi que le recours à des systèmes de culture les plus diversifiés possibles s'avèrent si importants. Pourvu que l'accès aux moyens de production minimum soit garanti et sûr et que l'accès au marché soit possible dans des conditions de prix acceptables, une telle diversité d'activités est à la base, outre des accroissements de productivité, de la diminution des risques encourus (risques climatiques, agronomiques, risque prix, etc.). Elle permet ainsi d'accroître la résilience des exploitations paysannes de petite taille et leur capacité d'adaptation aux changements globaux, y compris climatique. L'accroissement important de la fréquence des traitements phytosanitaires pose cependant question. Outre l'augmentation des coûts générée par leur usage et le risque-prix inhérent, une dépendance aux intrants ne manquera pas, si elle s'accroît encore, de menacer la résilience du système agraire et de mettre à mal les progrès réalisés ces dernières décennies.

Quant aux questions relatives à la reproduction de la fertilité et à la lutte contre la dégradation des terres, l'agriculture des monts Uluguru offre un exemple concret des efforts entrepris par les agriculteurs pour y faire face et préserver l'avenir, malgré les moyens dérisoires à leur portée, les tentatives d'aménagement à la hussarde orchestrées par les pouvoirs publics et les projets de développement ${ }^{13}$. Beaucoup resterait à faire dans ce domaine, en particulier pour renforcer encore le rôle de l'élevage (porcin notamment) dans la reproduction de la fertilité et celui des arbres, encore trop peu nombreux, dans celui de stabilisation et renforcement des gradins et limites parcellaires (embocagement).

13. Un élément qui a favorisé l'aménagement progressif des versants mérite d'être souligné : le peu d'impact de la villagisation dans la région des monts Uluguru. Cette villagisation aurait sans doute provoqué de graves perturbations si elle avait été imposée, ici comme dans d'autres régions de Tanzanie (chapitre 4). 


\section{W Références}

Cochet H., 2001. Crises et révolutions agricoles au Burundi. Paris : INAPG-Karthala, 468 p.

Coniat D., 1993. Les Transformations de l'espace rural, des activités agricoles et de l'environnement sur le terroir du haut-Mgeta (1890-1990) (Tanzanie, monts Uluguru, district de Morogoro, division de Mgeta). Thèse de doctorat. Paris : Université Paris 1. www.theses.fr/1993PA010728.

Coniat D., Raison J.P., 1997. Utilisation du sol et aménagement de l'espace dans le haut-Mgeta (monts Uluguru). In : Raison J.P. (eds). Essais sur les montagnes de Tanzanie. Paris : Karthala-IfraGéotropiques, 227-261.

Hartog T., 2016. Diagnostic agraire de la région du Haut-Mgeta dans les monts Uluguru (Morogoro, Tanzanie) : Quelle adaptation des agriculteurs au changement climatique? Mémoire de fin d'étude, UFR Agriculture Comparée et Développement Agricole. Paris : AgroParisTech-AFD, 74 p.

Paul J.L., 1985. Premier rapport d'étape sur la zone de Mgeta. Rapport de l'enquête sur les systèmes agraires menée à Nyandira en juillet 1985. Franco-Tanzanian Project. Morogoro: Sokoine University of Agriculture, Crop Science Department/Cimade, 27 p.

Paul J.L., 1988. Farming systems in the upper Mgeta (Morogoro district). Franco-Tanzanian horticulture development project. Morogoro: Sokoine University of Agriculture, Crop Science Department/Cimade, $87 \mathrm{p}$.

Paul J.L., 2003. Anthropologie historique des hautes terres de Tanzanie orientale : stratégies de peuplement et reproduction sociale chez les matrilinéaires. Paris : Karthala-Ifra, 342 p.

Raison J.P. (ed), 1997. Essais sur les montagnes de Tanzanie. Paris : Karthala-IFRA-Géotropiques, $267 \mathrm{p}$.

Temple P.H., 1972. Soil and water conservation policies in the Uluguru mountains Tanzania, studies of soil erosion and sedimentation in Tanzania. Geografiska annaler Series A, Physical geography 54(3-4), 110-123. 



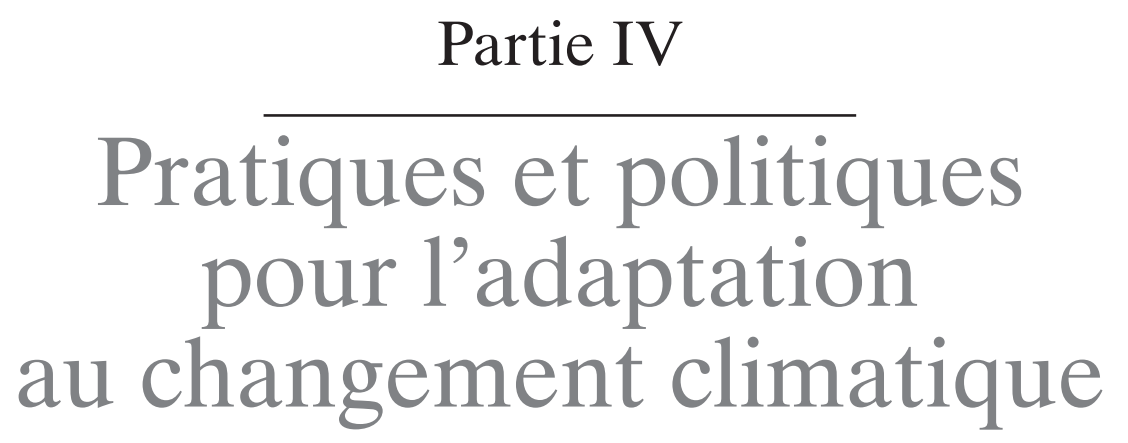





\title{
Chapitre 7
}

\section{Résilience et adaptation, du changement climatique aux changements globaux}

\author{
Nadège Garambois, Hubert Cochet \\ et Olivier Ducourtieux
}

Les différents cas concrets présentés dans les chapitres 1 à 6 illustrent des contextes géographiques et des degrés d'exposition contrastés au changement climatique et à l'accroissement des aléas climatiques (pluviométrie et crue). Ils offrent ainsi une palette de situations riche d'enseignements et invitent à une comparaison des modalités concrètes d'adaptation des exploitations agricoles aux changements et aléas climatiques dans les douze terrains étudiés, afin d'en tirer des conclusions de portée plus générale. Ces travaux révèlent également des possibilités inégales d'adaptation aux changement et aléas climatiques d'une catégorie de producteurs à une autre. Ils invitent à mieux comprendre cette hétérogénéité au sein de l'agriculture familiale, en s'attachant au rôle des conditions d'accès aux ressources et aux moyens de production dans ces processus. Enfin, l'ensemble de ces travaux met en lumière que le facteur climatique — son évolution et ses aléas — n'est pas le seul élément qui a conditionné l'évolution des systèmes de production agricole, loin de là. Les agriculteurs ont dû, et doivent encore, s'adapter à tout un ensemble de changements globaux, dont le climat n'est qu'une des facettes. Les choix réalisés en matière de politiques publiques ont ainsi été déterminants; certaines politiques agricoles ayant aggravé l'effet du changement climatique, tandis que d'autres faisaient preuve d'efficacité quant à l'accroissement et à la sécurisation du revenu des producteurs. 


\section{" L'adaptation systémique des exploitations agricoles aux changements et aléas climatiques, quelques situations types}

\section{Bouleversements climatiques majeurs : péjoration pérenne de la pluviométrie ou recul majeur de la crue des cours d'eau}

Certaines régions dédiées aux agricultures pluviales ont pu connaître, outre une forte variabilité de la pluviométrie, une réduction de la durée de la saison des pluies parfois accompagnée d'une très nette péjoration des précipitations. Dans ce cas, les agriculteurs ont dû à la fois faire évoluer en profondeur leurs systèmes de culture et d'élevage, mais aussi s'adapter à une forte variabilité interannuelle. C'est le cas du Sud-Tanzanie (Iringa, chapitre 2) placé sous 600 à $700 \mathrm{~mm}$ de pluie en moyenne, mais où la pluviométrie annuelle oscille entre 500 et $1000 \mathrm{~mm}$ par an. Les agriculteurs de cette région témoignent d'un raccourcissement de la saison des pluies, tombée de sept-huit mois à six mois. Dans la partie sahélienne du bassin arachidier sénégalais (chapitre 1), le raccourcissement de la durée des pluies (tombée à 75 jours en moyenne à Bambey et à 50 jours à Louga sur la période 1968-1999) s'est traduit, depuis plusieurs décennies, par une pluviométrie moyenne de 450-500 $\mathrm{mm}$ de pluie (région de Bambey), voire de 270-320 mm (région de Louga), montrant une chute respective des précipitations de $35 \%$ et $45 \%$.

Le raccourcissement de la fenêtre calendaire des cultures a conduit les agriculteurs à repenser le type de cultures, leur conduite et le choix des variétés en fonction de la durée de leur cycle. Le recul majeur de la pluviométrie se traduit par une réduction de la biomasse potentiellement produite par unité de surface sur les cultures pluviales, ainsi que sur les parcours réservés au pâturage des animaux, renforcé par l'allongement de la durée de l'étiage fourrager. Labaissement du niveau de la nappe phréatique limite, quant à lui, les remontées par capillarité et tend à favoriser les espèces ayant des appareils racinaires permettant d'explorer des horizons plus profonds du sol.

Dans certaines régions situées de longue date en climat sahélien et à proximité d'un cours d'eau majeur pouvant donc associer des cultures pluviales et des cultures de décrue, le bouleversement climatique a été double, à l'image de celui qu'a connu le delta du fleuve Sénégal. La chute de la pluviométrie tout au long du cours du fleuve a conduit à un recul particulièrement fort de la crue dans son delta et à une réduction majeure des surfaces où les cultures de décrue étaient possibles. Ce recul de la crue a réduit d'autant (en volume et en superficie concernée) l'apport d'éléments fertilisants par alluvionnement, et contribué à la forte réduction des ressources fourragères sur les espaces normalement envahis par la crue et habituellement dédiés, lors de la décrue, au pâturage. Il a aussi conduit à l'effondrement des populations de poissons et des activités de pêche artisanale. Ces bouleversements sont venus aggraver la crise rencontrée pour les cultures pluviales : pluviométrie moyenne de $220 \mathrm{~mm}$ par an sur la période 1968-1998, avec près de la moitié des années sous les $100 \mathrm{~mm}$ (chapitre 5). 


\section{Renforcement des aléas : variabilité accrue des précipitations ou de l'ampleur de la crue}

Dans les régions d'agriculture pluviale placées sous des climats où les précipitations excèdent en moyenne les $1000 \mathrm{~mm}$ de pluie par an, à l'image des hauts plateaux de Zambie (chapitre 2), les données climatiques ne permettent pas de distinguer de profondes évolutions du climat au cours de ces vingt dernières années. Concernant par exemple les volumes pluviométriques ou les températures, la tendance haussière demeure légère. Dans ces régions, les éléments décrits comme les plus déterminants par les agriculteurs sont le caractère très aléatoire de la pluviométrie (700 à $1250 \mathrm{~mm}$ de pluie selon les années) et la hausse de la fréquence des évènements pluvieux violents.

En agriculture inondée ou de décrue, les cas étudiés témoignent parfois d'une plus forte variabilité non seulement des précipitations, mais aussi de la crue - comme dans la vallée du fleuve Rufiji et de ses affluents en Tanzanie (chapitre 3) - avec des écarts de plus ou moins deux mètres de hauteur de crue. Sans aménagement visant à maîtriser la crue, cette forte variabilité peut conduire, selon les années, soit à de véritables inondations endommageant les cultures, soit à contraindre les agriculteurs à n'ensemencer qu'une partie des parcelles qu'ils dédient en année de crue «normale» aux cultures inondées. S'ajoutent, depuis la fin des années 1990, une baisse nette des précipitations durant la petite saison des pluies et un caractère aléatoire des premières pluies, ainsi qu'un raccourcissement de la grande saison des pluies, préjudiciables aux cultures pluviales et qui rappellent le contexte du centre du bassin arachidier (chapitre 1).

Autour du lac Tonlé Sap au Cambodge, comme à Thiên Tri dans le delta du Mékong au Vietnam (chapitre 4), les rares terres exondées sont occupées par l'habitat, des jardins-vergers et les routes. Lagriculture repose de longue date sur la riziculture inondée menée au sein de ces vastes plaines alluviales. Dans le Tonlé Sap, la mise en culture de la plaine d'épandage est soumise à des variations croissantes de la crue dans son démarrage, le rythme de la montée des eaux, l'ampleur de la crue, puis le rythme du retrait de l'eau. Les agriculteurs doivent composer avec un unique écosystème cultivé, au sein duquel la maîtrise totale de l'eau qui permet la pratique d'une riziculture irriguée durant la saison des pluies ne concerne qu'une partie des parcelles. Le reste des terres est occupé par une riziculture inondée soumise aux aléas croissants du calendrier et du niveau de la crue. Ces deux paramètres peuvent entraîner, selon les années et la position des parcelles au sein de la vallée d'épandage, des risques de submersion ou au contraire d'inondation insuffisante, dommageable pour la culture du riz.

Dans le delta du Mékong, la crue est soumise non seulement à la pluviométrie et à la crue propre du fleuve, mais aussi au rythme de la marée, sans intrusion saline ici. Elle commande une variation intra-journalière du niveau de l'eau, ajoutant encore un degré de complexité dans la gestion de l'aléa de la crue. La mise en culture de cet écosystème particulièrement complexe a été rendue possible par son aménagement progressif (construction de digues surélevées, canaux et chenaux) visant à maîtriser le niveau de l'eau à l'échelle de la parcelle, dans un contexte d'hyper-variabilité de la crue. Cette région est aujourd'hui soumise à une pluviométrie croissante et à la montée du niveau de la mer, qui affectent directement la crue et font craindre l'augmentation de la fréquence des crues exceptionnelles et dévastatrices, dont les manifestations passées, bien que rares, demeurent vives dans la mémoire collective des agriculteurs. 


\section{Adaptation dans le choix des espèces et variétés, dans la conduite des cultures et par le renforcement de l'agrobiodiversité}

Les études de terrain présentées dans cet ouvrage montrent que, face à la péjoration climatique et à l'accroissement des aléas pluviométriques en culture pluviale ou de la crue en culture inondée, les agriculteurs s'efforcent de rendre plus robustes leurs systèmes de culture. Ils renforcent, dans la mesure de leurs moyens, l'agrobiodiversité et les régulations biologiques au sein de leurs parcelles cultivées.

Les travaux de terrain conduits sur les hauts-plateaux tanzaniens témoignent de la plus grande sensibilité du maïs au retard des premières pluies au regard d'autres cultures, et du risque accru à pratiquer la culture pure de maïs. Ils montrent également que les rendements des cultures pratiquées en associations sont souvent moins affectés par les accidents climatiques que lorsqu'il s'agit de cultures pures (chapitre 2).

Lorsque l'aléa de l'arrivée des premières pluies se double d'une péjoration climatique majeure, les agriculteurs ont tendance à renforcer, au sein de leur assolement, la place des espèces et variétés les plus susceptibles de leur assurer une récolte. Dans le bassin arachidier, le maintien des cultures pluviales pratiquées avant la sécheresse, qui a débuté à la fin des années 1960, a été rendu possible par l'emploi de variétés à cycle plus court, en phase avec les nouvelles conditions pluviométriques. Le plus souvent, les agriculteurs privilégient des espèces dont la culture est moins sensible au retard des premières pluies ou à de faibles précipitations. La progression de la culture du niébé dans le bassin arachidier, en culture pure ou en association avec du mil ou de l'arachide, est très illustrative de ces stratégies. Moins rentable les bonnes années climatiques, mais aussi moins coûteuse à mettre en place que l'arachide, elle associe aux avantages des légumineuses une palette variétale qui permet de se rabattre, les pires années climatiques, sur un niébé de 45 jours dit «niébé secouriste», et de garantir malgré tout une récolte minimale. Certains agriculteurs ont aussi pu se lancer dans des cultures pluviales à plus haute valeur ajoutée et requérant une faible pluviométrie (pastèque), dans la limite des débouchés s'offrant à eux (chapitre 1).

Dans les régions combinant recul de la pluviométrie et aléa de la crue (fleuve Rufiji en Tanzanie), la succession maïs pluvial et riz inondé sur une même parcelle submergée une partie de l'année a ainsi évolué en une association maïs + riz. En effet, une bonne récolte de maïs en premier cycle grâce à une pluviométrie favorable peut compenser une mauvaise récolte de riz au cycle suivant en cas d'arrivée trop tardive de la crue, et inversement (chapitre 3).

Cette diversité biologique et la plus grande place laissée dans l'ensemble aux espèces cultivées susceptibles de mieux faire face à de forts aléas apparaissent comme de puissants leviers anti-risques.

\section{Nouvelles articulations entre cultures et élevages et renforcement de la place des légumineuses au sein des cultures pluviales}

Face à la réduction ou à la forte variabilité des ressources fourragères disponibles - recul de la biomasse sur les parcours, réduction des résidus de culture consécutive 
à la baisse des rendements - et au recul du cheptel, qui trouvent, entre autres, leur origine dans la péjoration climatique, les agriculteurs ont pu faire évoluer en profondeur leurs systèmes d'élevage (type d'animaux et d'élevage, modes d'alimentation).

Ainsi, dans le bassin arachidier sahélien, après une forte décapitalisation dans le bétail au plus fort de la période de sécheresse des années 1970-1980, les agriculteurs ont ensuite reconstitué de plus petits troupeaux, qui laissent une plus large place aux petits ruminants. Ils ont également effectué une profonde intensification en travail dans l'alimentation de leur cheptel et dans les transferts de fumure organique au profit des parcelles cultivées, augmentant ainsi l'efficacité de ces transferts et l'étroitesse des liens entre cultures et élevage. Désormais, les animaux sont le plus souvent conduits en stabulation, nourris avec les résidus de récolte directement collectés sur les parcelles cultivées par chaque famille : paille et son de mil, fanes d'arachide et de niébé, voire parcelles de niébé fourrager strictement dédiées à l'alimentation du cheptel. Leurs déjections sont ensuite transférées sur les parcelles sous forme de poudrette. Lémondage des arbres du parc arboré, notamment des Acacia albida, complète l'alimentation en période d'étiage fourrager. Cette pratique pose cependant quelques difficultés lorsqu'elle devient excessive. Elle menace alors la pérennité de cette essence essentielle à l'équilibre du système agraire, pour ses fonctions fertilisantes et fourragères (chapitre 1).

Dans le delta du fleuve Sénégal (chapitre 5), la sécheresse a poussé les pouvoirs publics à accélérer les aménagements hydrauliques et le développement de la riziculture irriguée. Les agriculteurs conduisaient autrefois leurs animaux sur parcours (terres exondées en saison des pluies et espaces de décrue en saison sèche). Ils alimentent aujourd'hui leurs animaux en partie en stabulation grâce à la collecte des pailles de riz, qui n'a néanmoins pas suffi à empêcher le net recul du cheptel bovin.

Malgré l'intensification de ces transferts, le recul du cheptel à l'échelle régionale explique en partie le maintien, voire la progression, de la place des légumineuses au sein des assolements observés en cultures pluviales lorsque les conditions d'accès aux engrais chimiques sont plus difficiles (bassin arachidier sahélien, chapitre 1; hauts plateaux tanzaniens, chapitre 2).

\section{Face aux aléas, les cultures de contre-saison (irriguées ou de bas-fonds) offrent une possibilité décisive de diminution de la vulnérabilité}

Dans les régions d'agriculture pluviale confrontées à l'évolution défavorable des conditions climatiques (raccourcissement de la durée des pluies, renforcé parfois d'un recul des précipitations), les agriculteurs qui le pouvaient se sont tournés vers l'utilisation des bas-fonds ou l'aménagement de petits périmètres irrigués exploitables en saison sèche et moins soumis aux aléas pluviométriques. Lutilisation accrue de ces espaces avait aussi l'avantage de solliciter la main-d'œuvre familiale à une période où le calendrier de travail n'était pas saturé.

Sur les hauts plateaux tanzaniens, l'aménagement de petits périmètres irrigués dotés de systèmes d'irrigation gravitaire a ainsi permis de sécuriser la culture du maïs en saison des pluies et de conduire des cultures maraîchères de contre-saison. 
Selon leurs conditions de submersion en saison des pluies, cette mise en culture des bas-fonds peut se faire toute l'année ou seulement en saison sèche. Quoique dédiés eux aussi à la culture du maïs, la mise en valeur de ces bas-fonds permet cependant d'avoir accès à de nouvelles productions beaucoup plus rémunératrices, comme le maïs épi récolté et vendu en frais, par exemple. Dans le Nord-Zambie, l'utilisation de petites parcelles irriguées dédiées à des cultures de vente ou à l'autoconsommation, complémentaires aux cultures pluviales, réduit aussi de façon très notable la vulnérabilité des familles (chapitre 2).

Lessor du maraîchage de contre-saison dans les monts Uluguru (Tanzanie), grâce au développement continu des réseaux d'irrigation gravitaire sur les versants par les agriculteurs, offre un autre exemple, spectaculaire, du remplissage progressif du calendrier de travail des agriculteurs et de la diversification de leurs productions et sources de revenu (chapitre 6).

Enfin, les aménagements hydrauliques de la vallée du fleuve Sénégal, initiés dès les années 1950 dans le nord du delta avant même la sécheresse des années soixante-dix et quatre-vingts, furent aussi l'occasion de fournir aux agriculteurs qui avaient accès aux périmètres irrigués, l'opportunité de diversifier et de sécuriser, au moins en partie, leur revenu. Laménagement hydraulique des espaces dédiés aux cultures de décrue au profit de la riziculture inondée, puis irriguée, mais aussi des cultures maraîchères de contre-saison, a connu une nette accélération à partir des années 1970-1980. En effet, des aménagements de plus grande ampleur ont ensuite visé une sécurisation rapide des conditions de culture par la maîtrise totale de l'eau. Cette maîtrise a été achevée avec la construction des barrages amont et aval de Manantali et Diama, qui ont permis de contrôler la crue du fleuve et d'empêcher les remontées salines depuis son exutoire. La plupart des parcelles de ces périmètres sont aujourd'hui alimentées en eau gravitaire à partir de canaux secondaires, eux-mêmes alimentés par des stations de pompage ou directement à partir de motopompes individuelles ou collectives installées sur les canaux principaux. Ces aménagements ont été complétés par la mise en place de périmètres irrigués sur les terres exondées d'abord dédiés aux cultures maraichères (chapitre 5).

\section{Adaptation à la faible maîtrise de l'eau en zone inondable}

Nous avons vu (chapitre 3) comment les agriculteurs de la plaine d'inondation de la basse vallée du fleuve Rufiji (Tanzanie) avaient progressivement décalé les semis du maïs qui précède le riz, du fait de l'arrivée plus tardive des pluies, au point que l'ancienne succession maïs et riz est devenue en réalité un semis du riz sous couvert du maïs, où les deux cycles se chevauchent très largement. Le cycle du riz offre alors une possibilité de rattrapage pour les agriculteurs qui l'ont semé à temps. Inversement, une bonne récolte de maïs de première saison implique un début précoce des précipitations et des volumes suffisants. Elle peut alors venir compenser un cycle rizicole peu favorable du fait d'une arrivée trop tardive de la crue ou de son retrait trop précoce. Les agriculteurs mettent aussi à profit l'hétérogénéité intra parcellaire, les champs n'étant pas plans, loin de là. Les semis sont alors étagés et étalés des parties basses de la parcelle jusqu'à son «sommet». Cette pratique constitue un moyen supplémentaire de récolter quelque chose, même dans les conditions de pluies et de crues plus défavorables. En outre, lorsque l'inondation trop précoce et 
trop rapide détruit les semis de riz, les agriculteurs prélèvent certains plants de riz dans les parties moins endommagées de la parcelle (légèrement surélevées), au prix d'une quantité importante de travail, pour les repiquer dans les parties basses des parcelles où l'inondation trop forte a détruit le premier semis.

Dans le bassin du Tonlé Sap au Cambodge, c'est la diversité variétale et l'adaptation des pratiques aux conditions variées de l'inondation qui sont sources de résilience et de diminution des risques. Le repiquage, plus largement pratiqué que dans la vallée du Rufiji (Tanzanie), joue ici aussi un rôle adaptatif majeur en permettant d'ajuster étroitement la date de repiquage à la hauteur de l'eau inondant les parcelles. L'ultime recours, si l'aléa climatique a affecté la pépinière même, peut alors être le semis direct sur les terres les plus hautes et donc les moins inondées (chapitre 4).

Le caractère hypervariable et intra-journalier du niveau de l'eau dans la vallée du Mékong (Vietnam) du fait de sa triple composante (pluviométrie, crue du fleuve et marée) a progressivement conduit à rechercher une maîtrise totale de l'eau. Il s'agit à la fois de développer une riziculture irriguée pour maîtriser l'aléa et d'utiliser au maximum le potentiel productif de la combinaison fertile d'une eau abondante et d'une plaine richement alluvionnée chaque année. Dès les années 1970, l'accès conjoint à des motopompes facilitant le drainage en période de crue et l'irrigation en saison sèche, à des variétés non-photopériodiques de riz à cycle court et à haut potentiel de rendement et à des intrants subventionnés a permis de conduire, sur une partie de la plaine, deux cycles de riz par an et d'accroître le rendement par hectare. Cette révolution verte, technique, doit également ses résultats à la réforme agraire l'accompagnant : la suppression de la rente foncière et de l'incertitude dans l'accès durable au foncier a conféré aux trois quarts des paysans la sécurité et les moyens d'investir dans leur exploitation familiale. Lachèvement des travaux d'endiguement et d'ouverture de canaux à la fin des années 1970, et la généralisation progressive de l'usage des motoculteurs au cours des années 1980-1990 permettent de caler trois cycles de riz dans l'année dans la plupart des rizières. Une troisième grande série d'aménagements conduits et financés par l'État dans les années 2000 visant à rehausser à nouveau et cette fois à bétonner les digues, permet de sécuriser le développement sur les terres hautes de vergers installés sur des planches (cultures à plus haute valeur ajoutée que le riz), (chapitre 4).

\section{Utilisation complémentaire de terroirs variés comme technique anti-aléatoire}

En agriculture inondée (vallée du fleuve Rufiji en Tanzanie, chapitre 3) et de décrue (vallée du fleuve Sénégal dans les années 1950, chapitre 5), les semis étalés, au rythme de l'avancée ou du recul de la crue et l'exploitation de parcelles étagées soumises dans des conditions variables à la crue ou à son reflux contribuent à limiter les risques. Ici, c'est l'exploitation de parcelles soumises de façon hétérogène à la crue qui diminue le risque encouru. La combinaison de cultures pluviales et de cultures inondées ou de décrue, pratiquées sur des terroirs distincts soumis à des aléas différents (pluviométrie ou crue), offre une plus grande robustesse aux systèmes de production agricoles, à condition d'avoir accès à ces espaces différenciés et complémentaires. Dans le bassin du Tonlé Sap au Cambodge, c'est la possibilité 
pour une famille de combiner différents systèmes rizicoles étagés, et donc localisés dans des conditions différentes au regard de la crue et de la décrue, qui lui confère une moins grande vulnérabilité (chapitre 4).

Dans les monts Uluguru, au sud de la Tanzanie, c'est l'accès à plusieurs étages écologiques qui, avec l'irrigation, permet aux familles de combiner le plus grand nombre possible de cultures et de variétés cultivées en ajustant le positionnement des cycles de culture aux conditions du milieu et à la disponibilité de la force de travail familiale. Cette diversité permet ainsi, tout en limitant les risques, d'employer efficacement la force de travail familiale tout au long de l'année et donc d'accroître la productivité globale du travail et le revenu agricole (chapitre 6).

Ainsi, l'accès à différents écosystèmes et la combinaison de différents systèmes de culture et, le cas échéant, différents systèmes d'élevage (y compris la pêche), permettent de limiter les risques et de profiter le plus largement possible des complémentarités offertes par l'éventail d'activités accessibles aux agriculteurs. La combinaison, par une même famille, de l'exploitation de différents espaces est gage de limitation de la vulnérabilité. Les groupes domestiques ayant la possibilité d'exploiter tous ces différents terroirs s'en sortent en général mieux que les autres. Les familles en meilleure posture, dégageant les meilleurs revenus et mieux armées face aux aléas de différentes natures sont toujours celles qui peuvent combiner, sur des espaces différents, le plus grand nombre possible de cultures et activités complémentaires. Toutefois, elles doivent disposer des moyens de production nécessaires, d'une capacité de travail adaptée et d'un accès aux marchés dans des conditions acceptables.

$\mathrm{Au}$ contraire, l'histoire nous apprend comment des expériences particulièrement coercitives portant sur le regroupement forcé de l'habitat des ménages ruraux et sur le travail obligatoire au sein de parcelles collectives, à l'image de la villagisation menée en Tanzanie dans les années 1970, s'inscrivent à rebours de ces stratégies d'adaptation. Elles ont conduit à allonger les temps de transport quotidien, rendant particulièrement difficile l'accès aux écosystèmes les plus éloignés du nouveau village, compliquant la conduite des animaux et entraînant leur surmortalité. Malgré les dispositifs d'appui fournis aux agriculteurs pour la production de maïs, cette politique autoritaire a rendu beaucoup plus difficile pour les agriculteurs l'adaptation de leurs systèmes de production à la péjoration climatique qui a sévi en parallèle.

\section{Des leviers d'adaptation anciens, basés sur les savoir-faire des agriculteurs}

Les études de cas retracées dans cet ouvrage révèlent que la palette des techniques anti-risques mobilisées par les agriculteurs placés dans des conditions climatiques hyper-aléatoires relève souvent d'une capacité d'adaptation ancienne. Celle-ci est étroitement liée à la fine connaissance que les agriculteurs ont de leurs conditions de milieu et à l'élaboration progressive de savoir-faire.

Le cas des régions déjà sahéliennes dans la première moitié du $\mathrm{xx}^{\mathrm{e}}$ siècle (nord du bassin arachidier sénégalais et delta du fleuve Sénégal) offre aussi un exemple éloquent de ces savoir-faire. Les familles du delta combinaient alors toute une palette de productions grâce à une combinaison complexe et anti-aléatoire de cultures 
pluviales et de cultures de décrue, de poly-élevage et de pêche. Elles mobilisaient alors de façon complémentaire l'utilisation différenciée des terroirs et jouaient sur la mobilité des troupeaux (transhumance) pour mieux s'adapter à la variabilité de la pousse de l'herbe sur les parcours. La faible densité de population, la multiplication des formes de stockage des produits alimentaires (céréales, viande et poisson) à différentes échelles (greniers par foyer, de la famille élargie, du village), le troc entre producteurs aux degrés de spécialisation variables (dont éleveurs pastoraux) et les activités extra-agricoles complémentaires constituaient autant de facteurs contribuant à la robustesse de ce système agraire et à limiter la vulnérabilité des différentes catégories de producteurs (chapitre 5).

Le déplacement des isohyètes vers le sud a placé, dès la fin des années 1960, le centre du bassin arachidier dans des conditions pluviométriques proches de celles de sa partie nord avant la sécheresse. Les agriculteurs du centre ont ainsi pu mobiliser les espèces et variétés qui avaient été sélectionnées auparavant par les agriculteurs situés plus au nord. Le concours de la recherche agronomique a permis de sélectionner et de diffuser rapidement des variétés de mil, de niébé et d'arachide aux cycles particulièrement courts. Ces nouvelles variétés ont contribué à faciliter l'adaptation de l'agriculture, tout particulièrement dans le nord du bassin arachidier où la pluviométrie était descendue à la limite du maintien d'une agriculture strictement pluviale (chapitre 1).

Dans lesvallées inondables du Kilombero et du Rufiji au sud de la Tanzanie(chapitre 3), la survie des familles repose sur une connaissance fine des micro-hétérogénéités de la plaine inondable et l'exploitation savante de ce milieu très complexe et peu artificialisé. La culture associée maïs + riz sur les bancs de sable et la plaine d'inondation de la basse vallée du Rufiji offre un exemple éloquent de cette adaptation fine et évolutive aux aléas des pluies et de la crue. Ici, la culture associée n'est pas seulement une «stratégie» d'anticipation et de réduction du risque qui permet de «ne pas mettre tous les œufs dans le même panier». Elle est aussi un moyen d'adaptation et de pilotage in itineri, en tenant compte de ce qui s'est passé en début de saison des pluies (date de la première pluie significative, espacement des premières pluies et volumes des précipitations).

\section{"L'accès aux ressources et aux moyens de production, facteur d'inégales adaptation et robustesse des systèmes de production agricoles familiaux}

\section{Des réponses spécifiques en fonction des contextes et de l'accès aux ressources des familles}

Les résultats des études de cas présentées dans les précédents chapitres de cet ouvrage montrent que mêmes les familles les plus en difficultés - celles dont l'accès au foncier, au bétail (et donc à la fumure organique) et aux moyens de production est le plus limité et le moins diversifié — tentent malgré tout de s'adapter aux changements qui les affectent. Par exemple, face à l'arrêt des subventions aux semences 
et aux intrants pour l'arachide, la plupart des familles du bassin arachidier sénégalais équipées au moins d'un semoir (et parfois aussi d'un cultivateur) ont fait le choix de rééquilibrer la part de leurs cultures entre arachide et niébé (chapitre 1). Elles préservent un minimum de cultures d'autoconsommation (mil) avant d'envisager les cultures de vente si les revenus extérieurs ne sont pas suffisamment sécurisés. En outre, ces familles ne peuvent assurer que de très faibles restitutions de fertilité sur leurs parcelles sous forme organique comme minérale, et ont renforcé la place des légumineuses dans leur assolement. Parfois, on observe même une spécialisation relative des familles les plus pauvres, disposant des plus faibles surfaces et du plus faible équipement, autour de la production de certaines légumineuses graines assez largement destinées à la vente. Ces familles, qui ne peuvent pas espérer produire suffisamment de céréales pour se nourrir sur leurs maigres surfaces agricoles, se livrent ainsi à une «substitution de calories». Elles font le choix de se spécialiser dans des cultures vivrières marchandes plus rémunératrices par calorie produite (légumineuses graines) afin d'acheter les céréales de base (calorie moins chère) nécessaires à leur alimentation. Dans le nord du bassin arachidier, cette stratégie repose surtout sur la culture du niébé; la culture d'arachide, très soumise à l'aléa pluviométrique, étant beaucoup trop risquée pour ces familles.

De semblables stratégies s'observent dans le Nord-Zambie où tous les agriculteurs n'ont pas la possibilité de combiner les cultures pluviales et les cultures irriguées : même sans accès à l'irrigation, les familles parviennent à jouer sur l'accès complémentaire à différents terroirs pour dégager un revenu au-delà du seuil de pauvreté, tout en privilégiant l'autoconsommation familiale comme technique anti-risque.

Laccès à des terroirs variés, ayant des potentialités complémentaires et différemment exposés aux aléas reste cependant la clé de voûte d'une moindre vulnérabilité et d'une capacité d'adaptation renforcée. C'est ainsi que les paysans du Tonlé Sap cherchent toujours à tirer parti des micro-hétérogénéités du bassin pour combiner différents systèmes rizicoles le long de la toposéquence et du calendrier de la crue et de la décrue (chapitre 4). Dans la vallée du fleuve Rufiji, cette diversification s'appuie avant tout sur l'association pêche-agriculture, le premier âge de sécurité étant donc la conduite parallèle des activités de pêche et d'agriculture, ce qui suppose la présence équilibrée d'hommes et de femmes adultes au sein du foyer. Elle s'appuie ensuite sur l'accès à différents terroirs et à leur exploitation conjointe; exploitation plutôt successive que simultanée en raison de la nécessité impérieuse de surveillance des parcelles contre les intrusions de la faune sauvage. Les familles sont inégalement exposées aux aléas selon qu'elles n'accèdent qu'à des parcelles sujettes à l'inondation sur des sols sableux, les rendant plus vulnérables en cas de faible crue (humidité résiduelle insuffisante), qu'à des parcelles exondées dédiées à l'agriculture pluviale (soumise à l'aléa de la pluviométrie) ou qu'elles peuvent combiner l'accès à ces différents espaces et accéder aux parcelles les plus fertiles de la plaine d'épandage (chapitre 3).

Dans les systèmes agraires où l'agriculture pluviale domine, l'accès à quelques parcelles irrigables apparaît alors comme un puissant moyen d'augmentation de cette diversité et d'accroissement de résilience des exploitations agricoles. Sur les hauts plateaux tanzaniens (chapitre 2), l'interruption plus précoce des pluies 
renforce considérablement l'intérêt pour les espaces (bas-fonds et petit périmètre irrigué) où il est possible de faire deux cycles de culture de maïs par an. Laccès à l'irrigation est ici un facteur essentiel d'accroissement de la productivité du travail (cultures de vente plus exigeantes en capital, mais nettement plus rémunératrices par unité de surface) et de robustesse face à des conditions pluviométriques moins favorables certaines années.

Malgré des conditions de commercialisation parfois délicates — et elles-mêmes aléatoires - pour les productions maraichères de contre-saison, l'accès à l'irrigation, même sur de faibles surfaces, peut s'avérer déterminant dans les niveaux de revenu enregistrés par les familles, mais demeure très inégalement accessible. C'est le cas de l'irrigation gravitaire dans le Nord-Zambie (chapitre 2) sur des périmètres artisanaux qui ne requiert pas de lourds investissements, mais pose la question de l'accès aux espaces où cette irrigation est possible. Dans le bassin arachidier sénégalais (chapitre 1), en l'absence d'eaux de surface, l'aménagement de périmètres irrigués maraîchers repose sur la construction de puits et sur des capacités d'investissement dont ne disposent, en dehors des projets d'ONG, que les rares familles dont l'un des membres est expatrié en Europe. La pratique de ces cultures maraîchères suppose également que ces agriculteurs disposent de la fumure organique suffisante pour assurer la restitution de fertilité et le maintien du taux de matière organique de ces parcelles, alors même que ces cultures sont exigeantes en matière de fertilité et ne dégagent pas ou peu de résidus de cultures pour les animaux d'élevage.

En Zambie centrale (chapitre 3) et dans le delta du fleuve Sénégal (chapitre 5), de véritables périmètres irrigués ont connu un développement plus ample et plus ancien, principalement tournés vers la production de riz et le maraîchage (oignon, tomate industrielle, etc.) Les conditions d'accès à des parcelles irriguées en gravitaire ou à une motopompe placée le long des canaux primaires ou des principaux cours d'eau demeurent très inégales dans ces deux régions. Avec un accès très limité à ces périmètres et seulement équipées d'un outillage manuel (arrosoir), la plupart des familles de la région de Mkushi (Zambie) ne peuvent ainsi conduire des cultures maraîchères de contre-saison que sur de très faibles surfaces (moins de 0,1 ha). Les familles un peu plus favorisées ont pu installer leur propre petit périmètre irrigué à la raie ( 0,6 à 0,7 ha). Les familles les plus riches sont équipées d'une motopompe et disposent d'un à deux hectares de cultures maraîchères pour lesquelles elles recourent à de la main-d'œuvre salariée très faiblement rémunérée.

L'exemple des régions de la Zambie centrale et du delta du fleuve Sénégal illustre bien le fait que l'accès à des terroirs diversifiés et aux potentialités complémentaires doit aussi s'accompagner d'un accès suffisant aux moyens de production : équipement d'irrigation, traction animale et outils adaptés, équipement de stockage et de transformation post-récolte. Dans le nord et le centre du bassin arachidier sénégalais (chapitre 1), c'est aussi l'accès aux équipements de traction attelée, au foncier et au bétail qui commande, depuis plusieurs décennies, la surface pouvant être semée et la place respective des différentes cultures (mil, arachide et niébé) au sein de l'assolement. La péjoration climatique et le resserrement de la fenêtre calendaire ont rendu l'accès au semis et au désherbage mécanisés plus crucial encore, tout particulièrement pour l'arachide, seule culture qui ne peut être semée en sec, au risque de perdre une semence très coûteuse en cas de retard des pluies. 
Enfin, dans les différentes régions étudiées, les familles les mieux dotées s’inscrivent souvent dans une spécialisation assez poussée autour de productions vivrières destinées à la vente sur les marchés urbains (gros bourgs et villes) dans l'ensemble plus risquées et plus gourmandes en capital :

- arachide dans le bassin arachidier sénégalais;

- tomate industrielle, oignon et piment dans le bas delta du fleuve Sénégal;

- maïs et maraichage en Zambie et dans le Sud-Tanzanie;

- riz irrigué dans le Tonlé Sap (Cambodge);

- riz irrigué et fruits dans le delta du Mékong (Vietnam).

D'ailleurs, cette spécialisation relative n'empêche pas d'assurer en priorité l'autoconsommation familiale. Cette dernière est facilitée par une trésorerie abondante, l'accès aux parcelles les plus propices et des équipements et aménagements permettant de limiter les risques. Les plus grandes exploitations du Sud-Tanzanie (Kiponzelo), largement dédiées aux productions maraîchères et équipées de pompes mécaniques ou à essence, en sont la parfaite illustration. Dans le nord du bassin arachidier sénégalais, la spécialisation poussée des familles les plus aisées autour des légumineuses graines (arachide notamment) destinées à la vente repose très clairement sur la sécurisation, en parallèle, de l'alimentation de la famille par les revenus extérieurs migratoires.

\section{Des inégalités cumulatives à l’origine de profonds écarts de productivité du travail, de surplus dégagé et de capacité d'adaptation}

Les inégalités sociales entre agriculteurs observées dans l'ensemble des régions étudiées concernent à la fois :

- les surfaces et le type de parcelles auxquels les agriculteurs ont accès (accès aux écosystèmes potentiellement les plus productifs);

- leur niveau d'équipement et de capital permettant de mettre les parcelles en valeur (aménagement et équipements hydrauliques);

- leur capacité à renouveler la fertilité des écosystèmes cultivés, qui dépend ellemême de la durée du recrû en abattis ou défriche-brûlis, de la densité du parc arboré à légumineuses sur les parcelles cultivées, de la taille du cheptel et des possibilités de transferts de fumure (charrette ou transport à dos d'homme), ainsi que du recours aux engrais de synthèse et aux amendements.

Les différentes catégories de producteurs n'ont dès lors pas les moyens de déployer avec la même ampleur des stratégies adaptatives d'intensification en capital (outillage, irrigation, cheptel et semences).

Ces inégalités s'avèrent cumulatives. En dégageant de plus forts surplus et en comptant parfois sur de solides apports financiers familiaux (urbains, expatriés), les familles les plus riches sont aussi les mieux placées pour investir dans les équipements leur permettant de valoriser plus largement leur production agricole en ne s'arrêtant pas au «bord-champ». Elles se lancent dans la transformation artisanale mais mécanisée de leurs propres produits agricoles (transformation de l'arachide au centre et au nord du Sénégal) ou se dotent de moyens de transport motorisés pour écouler leur production maraîchère et céréalière directement auprès du 
consommateur final (cas de la région d'Iringa, Sud-Tanzanie). Elles rentabilisent ces investissements en complétant ces activités par des prestations de service aux autres producteurs ou en développant l'achat-revente auprès de voisins n'ayant pas les moyens d'accéder aux marchés urbains.

Dans ce contexte, les familles agricoles les plus pauvres apparaissent particulièrement vulnérables aux conditions climatiques changeantes et à la variabilité des prix agricoles. Elles ne parviennent pas à produire suffisamment de céréales pour assurer leur autoconsommation et dégagent des revenus agricoles trop faibles pour acheter les aliments nécessaires à la couverture de leurs besoins élémentaires. Cela les oblige à travailler ponctuellement comme salarié agricole. Une mauvaise année climatique peut ainsi les plonger dans une période de soudure plus longue et les contraindre à se rabattre plus largement sur une activité salariée (parfois loin de leur foyer) pour assurer la survie de la famille.

Dans le centre du bassin arachidier (chapitre 1), où les familles vivent toujours principalement de leur activité agricole, les écarts de revenus par actif et par an varient d'un facteur cinq entre les jeunes ménages pauvres, peu dotés en terre et sous-équipés, et les familles les plus aisées pouvant commercialiser des surplus de mil et d'arachide. Dans la basse vallée du fleuve Rufiji et dans un contexte où les différences entre familles en terme d'équipement sont insignifiantes, les écarts de revenus sont pourtant d'un à quatre entre les ménages dont les parcelles sont localisées sur les espaces les plus fragilisés par l'aléa de la crue et ceux disposant d'un accès à l'ensemble des terroirs et aux parcelles inondées les plus fertiles.

Dans les régions d'agriculture pluviale des hautes terres de Zambie et de Tanzanie (chapitre 2), les revenus agricoles n'atteignent que quelques centaines d'euros par actif et par an, à l'image de ceux de la majorité des agriculteurs du continent engagée dans une agriculture surtout pluviale et essentiellement manuelle. Ceux qui arrivent, malgré tout, à dégager de meilleurs revenus, plus réguliers, et peuvent mettre leur famille à l'abri des aléas de toute nature sont presque toujours ceux qui mettent en œuvre des systèmes de production misant tout à la fois sur un large éventail d'écosystèmes accessibles, sur la culture associée et sur la petite irrigation. Dans le massif des monts Uluguru (chapitre 6), caractérisé par des versants particulièrement escarpés, l'étalement altitudinal des parcelles agricoles, lorsqu'il peut être mis à profit par un accès aux différents étages écologiques, constitue, avec l'accès à l'eau et la proximité au marché (bord de piste), la clef du succès. Aux inégalités d'accès provenant de l'ordre et des conditions d'arrivée des différents lignages dans la région pendant la phase pionnière, se sont rajoutées celles inhérentes aux processus de différenciation assez accentués depuis la deuxième moitié $\mathrm{du} \mathrm{Xx}^{\mathrm{e}}$ siècle et surtout liées aux conditions d'accès à l'irrigation, aux cultures maraichères et au marché. Par ailleurs, avec l'essor des cultures de rente, mais également l'augmentation de la pression foncière et les difficultés d'accès à la terre, le fossé s'est creusé entre : les familles ayant des exploitations de grande taille et faisant appel à la force de travail extérieure à la famille, et les foyers n'ayant pas suffisamment de terres pour satisfaire leurs besoins et contraints de vendre une partie de leur force de travail pour assurer leur survie (chapitre 3).

Sur les berges du Tonlé Sap au Cambodge (chapitre 4), les familles les mieux dotées déploient des techniques d'adaptation très intensives en capital. Lacquisition d'un motoculteur polyvalent leur permet de gagner considérablement en productivité 
physique du travail, tout en réduisant les risques liés à l'implantation du riz en début de saison des pluies. En effet, la rapidité du labour motorisé, alliée à la possibilité d'un travail du sol en sec, permet d'élargir la fenêtre calendaire en s'affranchissant de l'humidification du sol par les premières pluies, indispensable à un travail du sol mécanisé (traction attelée) ou strictement manuel. Parallèlement, les familles disposant de parcelles à proximité des canaux remplacent une partie de leur riziculture inondée de saison des pluies — soumise à l'aléa de la crue — par une riziculture irriguée de saison sèche. Plus créatrice de valeur ajoutée par unité de surface comme par unité de travail à condition de réunir les conditions d'accès au capital et à l'eau, le développement de la riziculture irriguée contribue à creuser considérablement les écarts de revenus entre producteurs.

$\mathrm{Au}$ Vietnam (chapitre 4), les revenus par actif des familles dotées en terre et en équipements sont supérieurs aux revenus des emplois citadins peu qualifiés. En revanche, ceux des familles «oubliées » des réformes agraires sont nettement plus faibles, alimentant une émigration rurale continue depuis un demi-siècle.

\section{Les limites de la diffusion de paquet technique : dépendance, accroissement du risque et inégalités d'accès}

En parallèle des évolutions des conditions climatiques, les agriculteurs ont souvent été confrontés à des cadres techniques normés et imposés :

- plutôt indicatifs pour l'arachide dans le bassin arachidier;

- fortement incitatifs en Zambie pour le maïs (culture pure, semis en ligne et monoculture promus en s'appuyant sur des agriculteurs témoins «modèles» dans les villages);

- étroitement encadrés pour la production de riz dans le delta du fleuve Sénégal.

Aujourd'hui, l'achat aidé d'engrais dans les grands périmètres du delta du fleuve Sénégal, effectué par chaque producteur au sein des Unions hydrauliques en quantité fixée par hectare, ne présume pas de leur distribution et de leur usage effectif au sein de chaque Union. Les agriculteurs les plus pauvres, qui n'ont pas la trésorerie nécessaire pour acheter ces engrais subventionnés, vendent parfois de façon informelle leur droit d'achat. Pour cela, ils s'entendent avec un producteur plus riche qui leur prête l'intégralité de la somme couvrant l'achat de l'engrais et qui récupère ensuite la plus grande part de celui-ci pour l'utiliser sur les parcelles de ses périmètres privés, non éligibles aux engrais subventionnés (chapitre 5).

Des années 1950 jusqu'aux programmes d'ajustement structurel (PAS) initiés dès les années 1980, la diffusion de ces paquets techniques subventionnés s'est adossée tout à la fois au contrôle et au soutien des prix des produits agricoles pour lesquels les agriculteurs étaient incités à se spécialiser, ainsi qu'aux politiques facilitant l'accès aux équipements agricoles (traction attelée dans le bassin arachidier sénégalais dans les années 1960). Durant cette période, cet appui au secteur agricole a contribué, par exemple en Zambie (maïs) et au Sénégal (arachide), à l'accroissement de la productivité physique du travail et à une forte progression de la production et du revenu des producteurs. Ce cadre de politique agricole sécurisant a néanmoins aussi contribué à une certaine spécialisation des systèmes de production et les a rendus moins autonomes en matière de restitution de fertilité et donc plus dépendants de la fertilisation minérale. 
Avec l'arrêt des subventions aux intrants et des garanties d'achat et du prix aux producteurs, le recours à ces paquets techniques est alors devenu inaccessible et beaucoup trop risqué pour la plupart des producteurs. Sans soutien parallèle suffisant des prix agricoles, seules les familles agricoles les plus riches, dont l'alimentation est assurée par une production céréalière suffisante ou par des achats grâce à l'argent de parents émigrés, ont les moyens d'acheter semences "améliorées» et engrais. Elles maintiennent (voire renforcent) cette spécialisation en améliorant la valorisation de leurs produits : transformation (illégale) en huile et tourteau des arachides déclassées dans le bassin arachidier sénégalais par exemple. Dans le bassin arachidier comme sur les hauts-plateaux tanzaniens, seules ces familles ont les moyens de se lancer dans ces productions très rémunératrices, mais coûteuses à mettre en place et risquées les années où les conditions climatiques sont moins favorables.

La vulgarisation du système d'intensification de la culture du riz (SRI) dans la vallée du Kilombero dans le sud de la Tanzanie (chapitre 3) fournit un autre exemple de paquet technique potentiellement efficace, mais porteur de risque accru pour les agriculteurs. Ce paquet comprend notamment des variétés sélectionnées à paille courte, le semis en ligne et la fertilisation minérale. Malgré l'obtention de rendements nettement supérieurs (jusqu'à 7 t/ha de paddy) quand les conditions sont optimales, l'adoption du paquet technique SRI ne concerne pourtant, sur une exploitation donnée, qu'une surface très limitée. En effet, le budget global d'une année de culture en SRI est si élevé qu'une mauvaise récolte serait catastrophique pour les ménages si toute la surface disponible était conduite de cette manière. Le fait de ne consacrer qu'une petite partie de ses parcelles au système SRI et l'autre partie au système «traditionnel» permet d'espérer une meilleure récolte en année normale, sans pour autant engager de frais trop conséquents. C'est aussi une manière d'accroître son revenu tout en limitant le risque face à l'aléa climatique.

Sur les berges du Tonlé Sap, la maîtrise partielle de l'eau en saison des pluies, qui risque de reculer avec le renforcement de l'aléa climatique, limite les possibilités de développement du SRI dans la plaine inondable car le repiquage des plants très jeunes (5-10 jours), donc courts, accroît les risques de perte en cas de crue rapide et précoce, et que la conduite de cette technique implique une maîtrise totale de l'eau pour alterner les phases d'inondation et d'assèchement de la parcelle, seulement possible pour les exploitations qui accèdent aux rizières irriguées en saison sèche. Par ailleurs, l'accroissement potentiel du rendement à l'hectare est tributaire d'une quantité de travail accrue, à une période de l'année où la main-d'œuvre est déjà peu disponible, et d'un risque aggravé face à l'aléa de la crue (chapitre 4).

Ici comme dans de nombreuses régions du monde, le premier objectif avancé par les pouvoirs publics, les entreprises et les projets qui les accompagnent est toujours l'augmentation des rendements, présentée comme une fin en soi pour les producteurs. Or, pour une exploitation familiale, l'objectif n'est pas nécessairement d'avoir les meilleurs rendements, mais de dégager un revenu suffisant qui permette de faire vivre le foyer, de limiter les risques d'obtenir un revenu incompatible avec la survie de la famille et, éventuellement, d'investir. Dans le cas du programme SRI, on constate que l'itinéraire technique vulgarisé et censé accroitre la résilience face au changement climatique se traduit par un accroissement du risque encouru par les agriculteurs et que cet accroissement est la principale limite à la diffusion de ces pratiques. 
Les politiques volontaristes de promotion de telle ou telle culture et les efforts faits en matière d'amélioration variétale et de diffusion des engrais ont parfois porté leurs fruits, lorsque les financements permettaient de subventionner efficacement ces intrants et que ces derniers étaient disponibles en temps opportuns. Néanmoins, il est clair que ce n'est pas le «paquet technique maïs» ou le «paquet technique arachide » qui, seuls, ont permis d'améliorer durablement la condition des ruraux. La réussite de la diffusion de la révolution verte au Vietnam est indissociable des mesures volontaristes de politique agricole qui l'ont accompagnées : réformes agraires, financement des aménagements hydrauliques, prix garantis du riz, crédit rural et subventions des intrants et des équipements (chapitre 4).

Quoiqu'il en soit, dans les régions étudiées ici, la plupart des programmes de développement, aujourd'hui souvent portés par des ONG et parfois des organisations de producteurs, envisagent encore rarement les exploitations agricoles dans leur complexité. Ces organismes peinent encore à concevoir ces exploitations comme combinaison de productions, qui peuvent être concurrentes dans l'allocation des ressources, mais aussi complémentaires, dans les calendriers de travail, de trésorerie et alimentaire, tout comme dans l'usage de la fumure organique, des fourrages et des résidus de cultures. Ils prennent également rarement en considération la diversité des conditions de production dans lesquelles peuvent être placés les producteurs au sein d'une même région. De nombreux programmes demeurent ainsi centrés sur une unique production : maïs en Tanzanie, riz dans le delta du fleuve Sénégal, niébé qui succède à l'arachide dans le bassin arachidier. Ils offrent, en outre, des conditions inadaptées à de nombreuses familles : surface minimale à intégrer dans le programme qui couvre l'essentiel de leurs terres agricoles, spécialisation trop risquée, disponibilité en capital et niveau d'équipement trop limités.

\section{" Au-delà du changement climatique, une adaptation des agriculteurs aux changements globaux}

\section{L'adaptation des agriculteurs à une combinaison de changements}

Dans chaque région étudiée, la péjoration climatique ou la fréquence accrue de ses aléas a influé sur les pratiques des agriculteurs. Leurs choix productifs respectifs sont aussi directement liés à l'ensemble des changements globaux autres que climatiques qui ont eu lieu en parallèle : croît démographique et réduction tendancielle de la surface par actif, baisse tendancielle et volatilité accrue des prix agricoles, développement des transports intérieurs et intégration croissante aux échanges marchands, réduction des barrières tarifaires et mise en concurrence avec des agricultures motomécanisées à haut niveau de productivité physique du travail, émergence de nouvelles demandes locales en produits vivriers sous l'effet de l'urbanisation croissante..

Face à l'évolution du contexte économique mondial, des règles du commerce international et des prix mondiaux des denrées agricoles et des intrants, les cadres de politiques agricoles nationales ont pu connaître de profonds bouleversements. Ils sont marqués par la faillite des organismes étatiques fournisseurs d'intrants et d'équipements subventionnés, mais aussi celle des organismes qui garantissaient 
l'écoulement de la production à un prix sensiblement supérieur à celui du marché mondial. Le large recul des dispositifs de soutien a conduit les agriculteurs à s'adapter à la baisse des prix intérieurs de certaines productions jusque-là fortement soutenues (arachide au Sénégal à partir du milieu des années 1980, maïs en Zambie et en Tanzanie dès la fin des années 1980) et au fait de ne plus accéder aux engrais de synthèse et aux semences à plus haut potentiel de rendement.

Les principales évolutions identifiées, comme des facteurs d'adaptation à l'évolution des conditions climatiques trouvent donc aussi largement leur origine dans l'adaptation systémique à ce contexte nouveau et aléatoire dans bien des domaines. Lintensification en travail dans la conduite des cultures et des élevages, l'élargissement de la palette des productions et la saturation du calendrier de travail grâce aux cultures de contre-saison, la place croissante des assolements des légumineuses destinées au marché intérieur sont autant de stratégies qui visent aussi à pallier la baisse de la surface disponible par actif, celle du cheptel et l'accès beaucoup plus coûteux à la fertilisation minérale. En jouant sur une plus large palette de productions, les agriculteurs ont aussi plus de chance de réduire leur vulnérabilité face à la variabilité des prix agricoles, qui n'affecte pas toutes les productions avec la même ampleur.

Le développement de productions à plus haute valeur ajoutée s'inscrit dans la même logique. Ces productions souvent périssables (maraîchage) ou recherchées par les urbains pour leur typicité (maïs épi, huile d'arachide, riz local et bissap) offrent aux producteurs familiaux à faible productivité du travail de réels avantages comparatifs, malgré l'abaissement généralisé des barrières tarifaires. La préservation d'un minimum d'autosuffisance alimentaire, dès que les familles en ont les moyens, relève là encore d'une technique anti-risque face aux aléas climatiques, mais aussi face à la forte variabilité des prix des céréales importées, le plus souvent indexés sur ceux du marché mondial, très volatils.

\section{Des stratégies d'élargissement des sources de revenus des ménages agricoles : l'essor des activités de transformation et extra-agricoles}

Outre l'adaptation de leurs pratiques agricoles à ce nouveau contexte climatique et global (accroissement démographique, variation des prix agricoles, conditions d'accès aux intrants et aux équipements, urbanisation et demande sur les marchés intérieurs notamment urbains), nombre de ménages agricoles s'efforcent, selon leurs moyens, de renforcer leurs activités de transformation des produits agricoles (ou de pêche dans les régions qui s'y prêtent). Ils cherchent également à diversifier leurs sources de revenus par des activités extra-agricoles. Il peut s'agir d'envoyer une partie de la famille travailler en ville en période de creux de travail agricole, mais aussi de travailler sur place comme salarié agricole tout au long de l'année lorsque les familles n'ont pas les moyens d'assurer leur survie avec la seule activité agricole.

Dans le nord du bassin arachidier sénégalais (chapitre 1), la profonde sécheresse des années 1970, renforcée par la chute des prix de l'arachide au producteur dès le milieu des années 1980, a amplifié les migrations de travail qui avaient déjà cours dans cette partie du pays. Face à la demande en main-d'œuvre peu qualifiée qui 
émanait alors des pays européens, notamment dans le secteur de la construction, ces migrations ont pris la forme de véritables expatriations lorsque les familles étaient capables de financer le voyage de l'un des leurs. Ces familles disposent aujourd'hui de conséquents revenus extérieurs qui contribuent à sécuriser leur alimentation. Ces revenus expliquent aussi la spécialisation de ces familles dans des productions agricoles destinées à la vente et plus gourmandes en capital.

Sur les berges du Tonlé Sap (Cambodge), certains jeunes actifs peuvent s'expatrier en Thaillande pour occuper des emplois très peu qualifiés : journalier agricole dans les plantations d'hévéa, ouvrier ou employé dans les secteurs d'industrie et des services. Leur statut précaire - politiquement entretenue en Thaillande pour contenir le coût et s'assurer la docilité de cette main-d'œuvre immigrée — rend ces revenus extérieurs particulièrement dépendants de la conjoncture économique thaïlandaise. Les conditions de vie des jeunes femmes rurales migrant dans la capitale cambodgienne Phnom Penh pour travailler dans l'industrie textile ne sont guère plus enviables (chapitre 4).

\section{Une adaptation et une résilience collective, plutôt familiale mais parfois aussi villageoise}

Plusieurs études de cas rassemblées dans cet ouvrage témoignent que les solidarités familiales ont joué et jouent encore un rôle central dans l'adaptation et la réduction de la vulnérabilité des ménages. Lintensité des liens familiaux entre campagnards et citadins, voire avec les expatriés comme dans le nord du bassin arachidier sénégalais, se traduit par des transferts d'argent, de denrées agricoles et des échanges en travail : les activités en ville constituent une source de revenus complémentaires, alors que l'agriculture peut représenter à la fois une activité d'investissement ou une solution de repli. Dans les sociétés wolof et peule du Sénégal où la parenté est fortement hiérarchisée, elles ont plutôt contribué à pérenniser l'autorité des aînés sur les cadets restés au village et dans la gestion des ressources de la famille élargie (stocks alimentaires, allocation de la main-d'œuvre, centralisation et allocation des revenus extérieurs et de l'argent de la migration).

Lintégration croissante aux échanges marchands, la progression de la part des achats dans l'alimentation des familles et le croît démographique semblent avoir contribué à réduire le poids de certains échanges et techniques anti-risques collectives (recul du troc et des greniers villageois). Ces techniques semblent néanmoins se renouveler autour de nouvelles pratiques reposant sur une organisation collective. En l'absence de structure gestionnaire comme la Société d'aménagement et d'exploitation des terres du delta (Saed) réservée aux grands périmètres du delta du fleuve Sénégal, la mise en place de périmètres irrigués villageois opérationnels a reposé — en Zambie, sur les hauts plateaux du Sud-Tanzanie et dans le delta du fleuve Sénégal — sur une gestion sociale de l'eau à l'échelle villageoise suffisamment efficace et sur l'élaboration de règles d'usage. En Zambie, elles portent à la fois sur l'entretien des canaux (corvée annuelle collective de curage soumise à amende en cas de non-participation), ainsi que sur la répartition de l'eau (suivi de la disponibilité en eau en aval, limitation des volumes prélevés en amont au niveau des prises d'eau, prélèvements libres en amont du réseau à l'aide de simples arrosoirs). 


\section{Des politiques agricoles volontaristes pour mieux résister aux aléas?}

Les études de cas présentées dans les chapitres précédents ont montré l'efficacité des politiques agricoles en matière d'adaptation lorsqu'elles se donnent les moyens d'intégrer à la fois :

- l'accès équitable aux moyens de production;

- la diffusion de leviers techniques permettant d'accroître les rendements par hectare pour le plus grand nombre;

- si nécessaire, la prise en charge (maîtrise d'œuvre et financement) d'aménagements (hydraulique par exemple), jusqu'à l'échelle de la parcelle agricole;

- des niveaux de prix agricoles suffisamment stables et rémunérateurs;

- une stratégie de croissance endogène, privilégiant dans un premier temps une souveraineté alimentaire portée par l'agriculture familiale.

La comparaison entre la politique vietnamienne de développement de la riziculture et de celles de la Zambie et de la Tanzanie autour du maïs, ou du Sénégal autour de l'arachide et du riz, est en la matière tout à fait éclairante. Si la politique vietnamienne n'a pas empêché une réelle différenciation sociale au sein de l'agriculture familiale des deltas vietnamiens, la progression fulgurante de la production de riz au Vietnam demeure aujourd'hui portée par une agriculture familiale. Elle doit beaucoup à la très forte intensification en travail fournie par les agriculteurs des deltas (Mékong et fleuve Rouge). Les raisons de cette réussite sont à chercher du côté de la politique volontariste et sécurisante du Vietnam, combinant tout à la fois :

- les réformes agraires pour favoriser l'équité dans l'accès au foncier aménagé;

- le soutien de l'accès aux équipements et aux intrants (facilité par l'absence de taxe à l'import);

- le financement de grands travaux hydrauliques jusqu'à l'échelle de gestion des exploitations (parcelle);

- l'autonomie des agriculteurs;

- la garantie du prix du riz au producteur et fixation du prix du riz à la consommation sur le marché intérieur par un contrôle étroit des échanges aux frontières et par un monopole sur les exportations de riz.

Ce qui frappe aussi, c'est la pérennité de l'ensemble de ce dispositif depuis un demisiècle, malgré les guerres et les changements drastiques de régimes politiques : priorité à l'agriculture familiale (réformes agraires et contrôle de la taille des structures), appui au producteur (intrants et prix); contrôle assez étroit du marché du riz adapté à la position aujourd'hui exportatrice du Vietnam; poursuite des grands travaux d'aménagements dans le souci de développer désormais d'autres productions à plus haute valeur ajoutée et destinées à l'export (chapitre 4).

Les politiques agricoles conduites au sein des autres pays étudiés ici ne présentent que rarement cette complétude et jamais sur un temps aussi long. Les politiques agricoles tanzaniennes et zambiennes déployées dans les années 1950-1980 en faveur de la production du maïs destinés au marché intérieur (prix garantis, accès favorisé aux intrants) et la politique arachidière sénégalaise menée à cette même période (prix garantis, accès facilité aux intrants et aux équipements), mais à des fins d'exportation, ont pris fin avec les plans d'ajustement structurel. En Zambie, un système de soutiens 
publics a été restauré dès le début des années 1990. Il est basé sur un programme de subvention des intrants, de prix garanti pour le maïs et d'écoulement de la production grâce à la Food reserve agency. Malheureusement, il souffre d'un approvisionnement irrégulier et trop tardif en engrais subventionné dans les villages.

La politique de développement de la riziculture irriguée initiée dès les années 1950 dans le delta du fleuve Sénégal s'est rapidement heurtée, quant à elle, à une gestion beaucoup trop centralisatrice de la part de la Société d'aménagement et d'exploitation des terres du delta (Saed) et à des coûts d'investissement et de gestion démesurés au regard des rendements et valeur ajoutée obtenus. L'ensemble de ces aménagements n'a d'ailleurs été permis, avant comme après le désengagement de la Saed à partir des années 1980, que par le concours de bailleurs étrangers. La poursuite de ces aménagements et le maintien de conditions attractives d'accès au crédit et aux équipements pour les producteurs, ainsi que d'un marché du riz local encore légèrement protégé expliquent l'extension globale des périmètres privés depuis les années 1980. Ce nouveau développement a bénéficié de la conjoncture mondiale haussière sur le marché international du riz depuis le milieu des années 2000. Le discours autour d'une autosuffisance rizicole nationale qui serait à portée de main ne s'accompagne plus, comme dans les années 1960-1970, d'une volonté d'assurer l'accroissement de la production grâce à un développement équitable entre producteurs. Il fait craindre un accroissement des inégalités sociales dans le delta du fleuve Sénégal où l'essor de nouvelles formes d'agriculture (patronales et surtout capitalistes), concurrentes directes de l'agriculture familiale, est déjà largement à l'œuvre (chapitre 5).

\section{L'émergence de formes capitalistes de production : une menace pour l'agriculture familiale}

La circulation rapide et massive des capitaux, les récentes crises financières mondiales et les tendances haussières de certains prix agricoles, très fluctuants et incitant à la spéculation, font apparaître de nouveaux risques pour les agricultures familiales. Ces nouveaux risques apparaissent dans les régions où se combinent l'existence au sein du finage villageois de terres considérées comme sous-exploitées par les pouvoirs publics, des règles d'attribution foncière ne protégeant pas suffisamment les familles villageoises et la possibilité de développer des productions extrêmement rémunératrices moyennant des investissements élevés (aménagements et équipements) dans un contexte d'accès à coût réduit au foncier et à la main-d'œuvre.

Dans plusieurs des régions étudiées, les agriculteurs se trouvent confrontés, parfois depuis les années 1980 et de façon semble-t-il accrue depuis une dizaine d'années, au développement de formes d'agriculture de type capitaliste. Leur logique économique (accroissement de la productivité du travail par la culture de vastes surfaces et le recours à des équipements de grande capacité) et leurs très fortes disponibilités en capital les placent dans des conditions productives extrêmement favorables. Elles sont aussi en situation d'exercer une concurrence délétère, au regard des faibles ressources de l'agriculture familiale environnante. Très exigeantes en foncier, ces formes d'agriculture constituent donc aujourd'hui, là où les conditions d'accès à la terre et à l'eau ont permis leur implantation, une menace grave pour les agricultures 
familiales avec lesquelles elles cohabitent. Leur implantation constitue souvent une source supplémentaire d'incertitude et de risque pour les ruraux, les emplois offerts par les investisseurs étant en général peu nombreux et précaires.

Lévolution de l'agriculture du delta du fleuve Sénégal, notamment dans sa partie sud, est emblématique de ces phénomènes. Le développement de l'irrigation, plus tardif que dans le haut delta et plus largement réalisé après le désengagement de la Société d'aménagement et d'exploitation des terres du delta (Saed) du début des années 1980, a davantage reposé sur les financements de bailleurs (réseau d'irrigation primaire et secondaire), sur des aménagements privés (réseau tertiaire) et sur le recours à des motopompes coûteuses seulement accessibles aux investisseurs extérieurs au village. Dans le delta, la maîtrise totale de la crue à partir de la fin des années 1990, l'évolution des modalités d'attribution foncière et le désengagement parallèle de la Saed ont marqué le début d'une course au foncier au rythme des possibilités d'irrigation offertes par les différentes vagues d'aménagements primaires et secondaires (chapitre 5).

Alors que l'agriculture de firme est quasiment absente du delta du Mékong, son expansion est en cours au Cambodge depuis les années 2000. Après un premier projet majeur (un million d'hectares) avorté sur les berges du Tonlé Sap, qui devait impliquer l'État koweitien comme investisseur, ce sont aujourd'hui des entrepreneurs nationaux, principalement de Phnom Penh, qui investissent dans des projets plus limités, donc plus discrets. La productivité de ces grandes exploitations de riziculture irriguée est inférieure par unité de surface à celle des exploitations familiales, tout en privant celles-ci des surfaces aisément irrigables qui leur seraient pourtant très utiles pour sécuriser leur production et leur revenu (chapitre 4).

Dans le district de Mkushi (Zambie centrale), l'extension de périmètres irrigués de grande taille avec canaux de dérivation et irrigation gravitaire, puis pompage direct dans la rivière principale a commencé dès les années 1950. Elle a permis l'essor de la production de tomate (culture à plus haute valeur ajoutée) à destination des marchés urbains et notamment de la capitale. De grandes exploitations à salariés, d'implantation ancienne, occupent toute une rive de la vallée et accaparent ainsi l'essentiel de la ressource en eau grâce à de puissants systèmes de pompage et de pivots d'irrigation. En dégageant de plus faibles valeurs ajoutées par unité de surface (blé, maïs) en comparaison des formes familiales d'agriculture irriguée, elles ne doivent qu'aux très grandes surfaces mobilisées d'offrir de hauts revenus à leur propriétaire (chapitre 2).

De longue date, la basse vallée du fleuve Rufiji a aussi été l'objet d'ambitieux projets d'aménagement, relancés aujourd'hui par l'arrivée récente d'investisseurs étrangers. Ces projets sont maintenant présentés par leurs promoteurs comme une voie à privilégier dans le cadre de l'adaptation au changement climatique. En réduisant fortement l'aléa par une artificialisation poussée du milieu, ces projets seraient en mesure d'accroître substantiellement la production agricole, tout en la sécurisant à long terme. Nous avons vu que le revenu agricole des familles de la basse vallée du Rufiji dépendait étroitement de leur capacité à combiner différents systèmes de culture tirant partie de la diversité des unités agroécologiques. La plaine d'épandage de la crue est, parmi ces différents espaces, la plus recherchée par les agriculteurs en raison de son plus fort potentiel, malgré les risques encourus (chapitre 3). Or, c'est 
précisément cet espace-là qui est aujourd'hui l'objet de grands projets d'aménagement. Il risque d'échapper totalement aux habitants de la région et de se traduire par une éviction massive. De tels projets peuvent donc se traduire par un accroissement de la vulnérabilité et de la précarité des populations : soit en les privant de l'accès à l'un ou l'autre des espaces exploités, soit en diminuant toutes les possibilités de compensation et de gestion de l'hétérogénéité du milieu.

\section{Conclusion}

Ladaptation des agricultures à des conditions climatiques de plus en plus contraignantes et aléatoires, en culture pluviale comme en culture inondée (pluviométrie, durée de la saison des pluies, ampleur de la crue), est ancienne. Dans l'ensemble des régions étudiées, les agriculteurs ont su faire évoluer leurs pratiques et repenser, parfois en profondeur, le fonctionnement de leurs systèmes de production agricoles pour faire face à un bouleversement du climat ou à une plus grande fréquence de ses aléas. Aujourd'hui comme par le passé et dans des contextes géographiques variés, ils se sont appuyés pour cela sur une connaissance fine des écosystèmes qu'ils utilisent, sur des savoir-faire adaptés à leurs conditions pédoclimatiques, à leurs ressources et à leur contexte économique et social. Des leviers communs d'adaptation et d'accroissement de leur résilience se dégagent, qui relèvent souvent d'une démarche d'agroécologie :

- utilisation complémentaire et différenciée de toutes les parties de l'écosystème auxquelles ils ont accès, parfois au prix d'aménagements artisanaux importants (réseaux d'irrigation gravitaires, aménagements de versants);

- renforcement de l'agrobiodiversité (associations de cultures, assolement diversifié, poly-élevages);

- augmentation de la place des légumineuses en agriculture pluviale et renforcement des liens entre cultures et élevage.

Si ces techniques anti-risques relèvent bien, dans les différentes régions étudiées, du champ de l'adaptation à la péjoration ou à l'aléa climatique, elles sont aussi au cour de démarches qui visent aussi à mieux faire face à d'autres types de changements globaux (démographie, volatilité des prix, intégration aux échanges marchands, etc.) Elles reposent souvent sur une intensification en travail qui permet de compenser la baisse tendancielle de la surface exploitée par actif, et sur la diversification des productions, y compris au profit de cultures de vente si ces dernières ne s'avèrent pas trop risquées. Au-delà du changement ou de l'aléa climatique, ces agricultures sont en effet plus directement confrontées, depuis la fin des années 1980 que durant la période postindépendance, à la concurrence des marchés mondiaux. Parallèlement, elles sont moins soutenues par les politiques agricoles nationales dans l'accès aux équipements et aux intrants. Ces agricultures sont aussi plus exposées aux risques d'accaparement foncier et au développement à leur voisinage direct de formes d'agriculture enregistrant des niveaux de productivité du travail incomparablement plus élevés.

Dans les régions étudiées, les classes moyennes et aisées des zones rurales, encore principalement tournées vers les activités agricoles, ont su s'adapter à cette combinaison de changements, souvent en renforçant leurs revenus agricoles par des 
cultures à plus haute valeur ajoutée et des activités de transformation, complétés par des revenus extra-agricoles (commerce, transport, etc.) Les familles les plus pauvres sont en revanche durement touchées par l'évolution défavorable de tous ces facteurs (climatiques, accès au foncier et aux équipements, prix relatifs). Elles se trouvent pour certaines dans des situations de grande pauvreté, contraintes de louer leurs bras une partie de l'année et sans perspective d'emploi suffisamment rémunérateur dans les centres urbains en expansion. Cette réalité invite donc à ne pas céder à la facilité d'un lien directement établi entre changement climatique et pauvreté, trop souvent retenu dans les analyses et les modèles prédictifs proposés. Il s'agit au contraire de considérer l'ensemble des composantes de ces changements globaux pour appréhender et tenter d'apporter des solutions à ces agriculteurs paupérisées et particulièrement vulnérables. 



\title{
Chapitre 8 \\ Quelles politiques pour l'adaptation? Leçons du passé et possibilités à venir
}

\author{
Hubert Cochet, Olivier Ducourtieux \\ ET NADĖGE GARAmbois
}

Les chapitres précédents ont permis de mettre en avant certaines pistes en matière de résilience et d'adaptation. Ils prolongent ou renouvellent les travaux portant sur la vulnérabilité qui mettent en évidence les liens entre pauvreté, vulnérabilité et exposition au risque. Ces chapitres décrivent les processus, les mécanismes et les trajectoires qui expliquent la forte exposition aux aléas de certains groupes d'agriculteurs et de ruraux, ainsi que le maintien ou l'accroissement de cette exposition. Ils permettent d'expliquer les ressorts, à l'échelle des systèmes de production, de cette vulnérabilité en mettant à jour les modalités de leur fonctionnement et leurs résultats, notamment économiques. Ils mettent en évidence ou illustrent le poids des choix passés et actuels en matière de politiques agricole, environnementale et commerciale dans l'aggravation de la vulnérabilité, plus rarement, dans la diminution de celle-ci. Enfin, ces chapitres mettent en lumière ou révèlent les modalités d'ajustement et de transformations passées et actuelles des pratiques d'agriculture et d'élevage allant dans le sens d'une diminution de l'exposition à l'aléa et d'une réduction de la vulnérabilité dans un contexte de forte croissance démographique.

La question est maintenant de savoir quels enseignements peut-on tirer de ces expériences pour orienter et éclairer les choix politiques futurs. Nous regarderons d'abord les principaux documents publics récents qui émanent des institutions nationales ou internationales et qui traitent de l'adaptation. Ce sera l'occasion de 
se demander si les politiques d'adaptation au changement climatique permettront, telles qu'elles sont présentées, de modifier vraiment la donne et de s'écarter des pratiques usuelles. Nous formulerons ensuite quelques propositions allant dans le sens de la réorientation de ces politiques.

\section{$\leadsto$ Organisations internationales, Giec et États : bref état des propositions}

Dans le chapitre intitulé «Ladaptation aux changements climatiques et l'atténuation de leur impact sur l'agriculture» du rapport publié en 2008 par la Banque mondiale, la question de l'adaptation est à peine évoquée et une seule page lui est consacrée. On peut y lire : «La meilleure façon d'aborder l'incertitude accrue qu'entraînent les changements climatiques est la planification de mesures d'urgence» (Banque mondiale, 2008, p. 242). La principale mesure d'adaptation évoquée est alors «la recherche et le développement de cultures adaptées aux nouvelles tendances météorologiques et des techniques visant à réduire la détérioration des terres ».

Depuis, les analyses se sont enrichies et une importante littérature grise a été produite sur l'adaptation des agricultures au changement climatique. Bien qu'une revue exhaustive de ces travaux ne soit pas envisageable ici, il nous a cependant semblé important de présenter les principales approches et propositions émanant de trois types de documents produits par les organisations internationales et les États. Ces documents inspirent largement les réflexions des décideurs et les politiques publiques mises en œuvre. Il s'agit respectivement :

- du dernier rapport du Giec (IPCC, 2014);

- des rapports publiés par la FAO en 2013 concernant la Climate-smart agriculture et en 2016 sur la situation mondiale de l'alimentation et de l'agriculture face au changement climatique;

- des documents nationaux comme les programmes d'action nationaux pour l'adaptation (Pana), les plans nationaux d'adaptation (PNA) ou encore les contributions prévues déterminées au niveau national $(\mathrm{CPDN})$ élaborées dans le cadre de la $21^{\mathrm{e}}$ Conférence des parties (COP 21).

\section{Les apports du Giec}

Dans leur cinquième rapport, publié en 2014, et notamment dans son chapitre Food Security and food production systems, les experts du Giec (2014) insistent sur la complexité des processus d'adaptation en jeu et leur caractère multi-scalaire. S'appuyant sur une large littérature scientifique, ils soulignent aussi la capacité d'adaptation des agriculteurs, notamment dans les pays en développement, et leur expérience passée en matière de prise en compte des changements climatiques :

«Il est de plus en plus évident que les agriculteurs de certaines régions s'adaptent déjà aux changements climatiques observés, en particulier en ce qui concerne les périodes de culture et de semis, les variétés et espèces cultivées, ainsi que les modalités de commercialisation (...). De nombreuses adaptations potentielles des systèmes 
de culture et des systèmes alimentaires ne sont que des améliorations de pratiques déjà existantes de gestion des risques climatiques et qui doivent donc être intégrées dans les systèmes agricoles et les contextes communautaires (Porter et al., p. 514) ${ }^{1}$.» D'une part, ces experts insistent sur la nécessaire prise en compte des savoirs locaux dans la recherche de solutions adaptatives, notamment dans les régions où les agriculteurs n'ont qu'un accès difficile et incertain aux informations scientifiques. Dans le chapitre 22 consacré à l'Afrique par exemple, ils écrivent que :

«La littérature récente a confirmé le rôle positif des connaissances locales et traditionnelles dans le renforcement de la résilience et de la capacité d'adaptation, ainsi que dans l'élaboration des réponses à la variabilité et aux changements climatiques en Afrique» (Niang et al., 2014, p. 1232) 2

D'autre part, l'imbrication entre l'adaptation aux changements climatiques et l'adaptation aux autres changements globaux auxquels les agriculteurs doivent faire face est soulignée à maintes reprises :

«Une grande partie de la littérature traite de l'adaptation incrémentale et réactive. Mais étant donné que les acteurs s'adaptent constamment aux conditions sociales et économiques changeantes, l'adaptation progressive au changement climatique est difficile à distinguer des autres actions. Elle est généralement une réponse à un ensemble de facteurs» (Porter et al., p. 519) $)^{3}$.

Les auteurs soulignent aussi la nécessaire relativisation du rôle à venir que jouera le changement climatique au regard des autres facteurs en jeu :

«Il est probable que les tendances socioéconomiques et technologiques, y compris les changements dans les institutions et les politiques, resteront un facteur de sécurité alimentaire relativement plus fort au cours des prochaines décennies que le changement climatique» (op. cit., p. 513) ${ }^{4}$.

Enfin, les experts soulignent la dimension socioéconomique de la vulnérabilité et le nécessaire dépassement d'approches purement technologiques de l'adaptation au profit d'approches en termes de construction de la résilience (building resilience). Ils écrivent, dans le chapitre 22 consacré à l'Afrique et en s'appuyant sur une large littérature scientifique, que :

«Reconnaissant les dimensions socio-économiques de la vulnérabilité, l'accent mis auparavant sur les solutions technologiques pour traiter directement des impacts spécifiques évolue vers une vision plus large qui souligne l'importance de renforcer la résilience à travers des approches sociales, institutionnelles, politiques, cognitives et informationnelles» (Niang et al., 2014, p. 1226)

Dans le cinquième rapport du Giec, les experts invitent donc les décideurs à une approche qui ne se limite pas à l'énoncé de recommandations «techniques». Lapproche doit intégrer les aspects socio-économiques et politiques, tout en insistant sur la nécessité de valoriser les «savoirs indigènes », et de s'efforcer de renforcer la résilience des groupes les plus vulnérables.

1. Citation traduite par les auteurs.

2. Citation traduite par les auteurs.

3. Citation traduite par les auteurs.

4. Citation traduite par les auteurs.

5. Citation traduite par les auteurs. 
Les publications récentes de la FAO, centrées sur la démarche d'agriculture intelligente face au climat (Climate-smart agriculture) s'éloignent hélas de ces recommandations.

\section{Les propositions de la FAO autour de l'approche de l'agriculture intelligente face au climat (Climate-smart agriculture)}

\section{La notion d'agriculture intelligente face au climat}

La notion d'agriculture intelligente face au climat (Climate-smart agriculture, CSA) a été formalisée sous la forme d'un manuel volumineux (570 p.) publié en 2013 à destination des praticiens et des décideurs (FAO, 2013). Lobjectif affiché est de concilier trois finalités :

- la sécurité alimentaire par le nécessaire accroissement de la production alimentaire;

- l'adaptation au changement climatique;

- l'atténuation du changement climatique par des pratiques moins émettrices de gaz à effet de serre.

Lambition nouvelle, et louable, de cette approche consiste donc à intégrer la question de l'augmentation de la production agricole et celle de la sécurité alimentaire dans les politiques publiques dédiées au climat, plutôt que de traiter ces deux enjeux séparément. Dans le résumé exécutif, les auteurs avertissent que :

«L'agriculture intelligente face au climat ne consiste pas en une technologie ou pratique agricole unique à mettre en œuvre de façon uniforme. C'est une approche qui nécessite une expertise locale spécifique pour identifier les technologies et les pratiques de production agricole appropriées.»

Il s'agit tout à la fois d'accroître l'efficience des systèmes (l'efficience des ressources utilisées) et leur résilience, la diversité des écosystèmes à l'échelle du territoire étant mise en avant, de même que la nécessité de chercher des solutions adaptées à cette échelle-là.

Pourtant, l'approche développée par la FAO s'éloigne des recommandations prudentes et nuancées formulées par les experts du Giec en matière d'adaptation. Le rapport de la FAO est en effet constitué de recommandations exclusivement techniques et sectorielles : water management, soils and their management for climatesmart agriculture, climate-smart crop production system, climate-smart livestock, etc. Et lorsqu'il est question de l'attention à porter aux groupes les plus vulnérables (chapitre 16 du rapport), les propositions se limitent à promouvoir filets de sécurité et protection sociale.

Lensemble du rapport constitue donc un vaste recueil de recommandations techniques embrassant, dans un souci de large consensus, toutes sortes d'approches parfois contradictoires : agriculture de conservation, agriculture raisonnée, agriculture biologique, etc. Bien que l'accroissement de la diversité des productions au champ et à l'échelle du terroir soit souligné dans le chapitre premier comme un pilier de la résilience à promouvoir (FAO, 2013, p. 23), la diversification des systèmes de production est finalement présentée comme une option parmi d'autres. Dans une lecture critique de l'agriculture «climato-intelligente»(ACI), Tissier et Grosclaude (2015, p. 296) 
écrivent à ce propos que «l'agriculture climato-intelligente pourrait davantage s'affirmer en faveur de modes de production agricole cherchant à utiliser intensivement les services écosystémiques». Ils poursuivent que «les concepteurs de l'agriculture «climato-intelligente» ne semblent pas souhaiter produire une critique forte des systèmes de production spécialisés» (p. 297). C'est ainsi que la FAO s'inscrit d'emblée dans le camp du land sparing, au détriment du land sharing ${ }^{6}$. Ainsi, «La justification des modes de production les plus intensifs par l'atténuation du changement climatique qu'ils permettraient au niveau global [...] ne constitue le plus souvent qu'un cachesexe du business as usual» (Tissier et Grosclaude, 2015, p. 296).

Par ailleurs, le libre commerce est considéré d'emblée comme un élément important de la résilience des systèmes, aucune allusion n'étant faite aux conséquences parfois délétères de la libéralisation croissante des échanges et de ses impacts sur les agricultures les moins bien équipées et les moins productives. De la même façon, il n'est aucunement fait référence à la question pourtant cruciale des modèles agricoles à promouvoir et des conséquences, elles aussi très graves, du développement d'exploitations agricoles à grande emprise foncière en lieu et place de l'agriculture familiale. Tissier et Grosclaude (2015, p. 297) écrivent à ce sujet que : «Labsence en particulier de toute référence à l'agriculture familiale - que ne compensent pas les trop nombreuses références aux communautés rurales - devra en toute hypothèse être comblée.»

\section{Le rapport FAO 2016 : la situation mondiale de l'alimentation et de l'agriculture, changement climatique, agriculture et sécurité alimentaire}

Dans son rapport 2016, la FAO insiste sur «l'agriculture intelligente face au climat». Lidée principale développée dans le rapport est qu'il est possible d'améliorer considérablement la sécurité alimentaire et la résilience face au changement climatique en introduisant des pratiques agricoles durables, des pratiques et des techniques intelligentes face au climat. Il convient donc d'identifier et de lever les obstacles à leur adoption par les agriculteurs (FAO, 2016). S'en suit une énumération des pratiques et techniques jugées «intelligentes» et qu'il conviendrait d'introduire dans les systèmes agricoles. Ces techniques sont classées en grandes catégories : intensification durable, agroécologie, gestion efficace de l'eau, gestion du carbone et de l'azote, etc. Le rapport FAO n'est pas dépourvu de contradictions. Tandis que l'agroécologie et l'intensification durable sont considérées comme des solutions, et que toute forme de subvention des intrants est a priori proscrite, on n'en préconise pas moins la promotion d'un paquet technique maïs (semences améliorée et engrais) pour compenser l'impact possible du changement climatique sur les rendements. Par ailleurs, quatre stratégies sont présentées pour renforcer la résilience des moyens d'existence : la diversification, l'appui à la gestion des risques, la réduction des inégalités entre les sexes et la migration (FAO, 2016, p. 64-69).

6. Lapproche land sparing donne la priorité à l'intensification la plus poussée possible sur une surface restreinte de façon à occuper le moins de place possible et à laisser le plus de surfaces possibles dédiées à la protection. Le land sharing se propose au contraire de miser sur les fonctionnalités et les complémentarités de l'écosystème pour limiter l'usage des intrants de synthèse, quitte à considérer l'environnement des agriculteurs comme un tout multifonctionnel, sans séparer espaces productifs et espaces voués à la conservation. 
Essentiellement adressée aux pays en développement, l'agriculture «climato-intelligente» aurait suscité un engouement certain dans ces pays, en particulier en Afrique et en Asie. Elle a conduit à la constitution d'une large alliance pour la promouvoir : Global alliance for climate-smart agriculture (Gacsa), lancée le 23 septembre 2014 lors du sommet mondial pour le climat (Tissier et Grosclaude, 2015).

Concernant le continent africain, l'initiative pour l'Adaptation de l'agriculture africaine (AAA) aux changements climatiques, lancée dans la perspective de la COP 22 de juillet 2016, fournit un exemple de cet «engouement». Sont invoqués pêle-mêle : la gestion intégrée de la fertilité, l'agroforesterie dans sa composante «grande muraille verte», l'agriculture de conservation, le mulch, les rotations et associations culturales, les cultures intercalaires, le compostage, la mise en jachère, le $4 \% o^{7}$, l'agriculture intelligente et la transition agroécologique. En voulant rassembler «l'écosystème d'initiatives existantes», l'initiative AAA dévoile les acteurs qui se pressent pour promouvoir les «pratiques agricoles intelligentes face au climat» : l'initiative pour la fertilité des sols (BM-FAO), la Green revolution in Africa (Agra), la Bill Melinda Gates fondation, l'Africa fertilizer and agro-business partnership (industrie des engrais), etc.

\section{Les propositions des États}

À l'échelle des pays, de nombreux rapports abordant la question de l'adaptation ont été rédigés dans le cadre de la convention cadre des nations unies sur le changement climatique (CCNUCC).

En ce qui concerne les pays les moins avancés, ce furent d'abord les programmes d'action nationaux pour l'adaptation (Pana) rédigés en 2006-2007 et élaborés pour répondre aux besoins urgents de ces pays à une époque où beaucoup d'entre eux étaient soudainement affectés, de manière inédite ou aggravée, par une vulnérabilité accrue aux inondations ou à la sécheresse (Groupe d'experts des pays les moins avancés, 2012). Puis, à partir de 2010, ont été lancés les plans nationaux d'adaptation (PNA), conçus cette fois-ci dans une perspective de plus long terme. Ces plans permettaient d'adopter «une approche plus réfléchie et de viser une transformation évolutive de capacités d'adaptation de ces pays [...] pour réduire la vulnérabilité aux effets nuisibles des changements climatiques » (Groupe d'experts des pays les moins avancés, p. 15; C2A, 2017). Le Burkina a approuvé son PNA en 2015 et le Sénégal en 2016. Beaucoup d'autres plans nationaux d'adaptation sont en cours d'élaboration avec le soutien financier du Pnud.

Le manque de financement a souvent limité la mise en œuvre des programmes Pana, et donc leur impact réel. En ce qui concerne les PNA, il est encore trop tôt pour mesurer l'écho qu'ils auront auprès des bailleurs de fonds et leur degré d'application effective. Néanmoins, leur lecture révèle les priorités affichées en matière de politiques d'adaptation. Lexemple du Burkina Faso, l'un des premiers pays à avoir rédigé son PNA, illustre les mesures d'adaptation proposées (Burkina, ministère de l'Environnement et des Ressources halieutiques, 2015). En ce qui concerne l'agriculture, il s'agit de :

- la mise en culture de variétés précoces ou résistantes à la sécheresse;

7. Le $4 \%$ (quatre pour mille) est une initiative française pour accroître le taux de matière organique des sols de $4 \%$ par an. 
- la mise en œuvre de techniques de conservation des eaux et des sols (cordons pierreux, diguettes, diguettes filtrantes, terrasses, demi-lunes, agroforesterie ou fixation des dunes);

- la promotion de la gestion durable des terres (GDT);

- l'amélioration de l'accès à l'information climatique;

- la mise en place de l'assurance agricole.

Concernant l'élevage, les propositions portent sur :

- la lutte contre les feux de brousse pour éviter la destruction des réserves fourragères de saison sèche;

- la mise en œuvre de bonnes pratiques zootechniques et pastorales (hydraulique pastorale, gestion des ressources pastorales, fauche et conservation du fourrage, cultures fourragères, ensilage, mobilité du bétail et transhumance);

- la prise en compte de la variabilité climatique dans la conception des projets et programmes de développement par les acteurs au moyen d'un renforcement de leurs capacités;

- la préservation de l'élevage des bovins sévèrement menacé par la variabilité climatique;

- l'adoption par les éleveurs de techniques de production animale adaptées au climat chaud.

Quant aux actions à entreprendre, une lecture attentive de ces documents révèle qu'il s'agit le plus souvent de recycler des projets déjà en cours ou déjà programmés, avec différents bailleurs classiques (bilatéraux, multilatéraux et ONG).

Un troisième type de document révèle souvent les priorités énoncées en matière d'adaptation. Il s'agit des «contributions volontaires » des États rédigées en lien avec la COP 21 (Contribution prévue déterminée au niveau national, CPDN-INDC). Des considérations très générales y sont énoncées, comme par exemple : «Promouvoir des activités de conservation/agriculture intelligente conduisant à des bénéfices d'adaptation et améliorant la résilience climatique» (Republic of Zambia, 2015). Mais ce type de documents ne livre aucun détail sur les mesures préconisées.

Ainsi, qu'il s'agisse des Pana, des PNA ou des CPDN, ces documents rédigés par les États ont en commun de privilégier la formulation de recommandations techniques, au demeurant très générales, rarement régionalisées. Les modalités d'adaptation mises en place par les agriculteurs eux-mêmes sont le plus souvent ignorées. Le rôle de la différenciation socio-économique dans la vulnérabilité n'est pas évoqué, pas plus que l'attention à accorder aux agriculteurs les moins bien pourvus.

\section{"Des choix politiques qui reviennent trop souvent au business as usual}

\section{Des choix techniques qui s'inscrivent souvent ans le prolongement de la révolution verte}

Lanalyse des différents documents de politique agricole en matière d'adaptation rédigés par les États et des recommandations faites par les organisations internationales (FAO notamment, Gacsa, Initiative AAA) révèle en réalité une vision partagée 
de l'adaptation. Bien que les vocables tels que «agroécologie», «intensification durable», "gestion conservatoire » et «agroforesterie » y soient abondamment utilisés, force est de constater que, loin de constituer une véritable rupture avec les politiques précédentes, ces documents ne font que remettre au goût du jour les recettes et paquets techniques issus directement de ceux promus pendant la révolution verte : semences améliorées, engrais et pesticides. La principale différence est que ces recommandations ne se limitent pas aux régions irrigables comme ce fut souvent le cas au Mexique, en Inde ou ailleurs à l'époque de la révolution verte. Bien que la mise au point de variétés à cycle plus court, plus résistantes à la chaleur ou à la sécheresse soit bien souvent une nécessité, l'amélioration végétale et les recherches en génétique sont trop souvent corrélées, de facto, au paradigme de la révolution verte; comme la recherche de variétés «à haut rendement» l'était à cette époque.

Le cas de la promotion du maïs en Zambie et en Tanzanie (chapitre 2) fournit un exemple éclairant d'enfermement dans les choix technologiques du passé. À l'occasion d'une conférence donnée dans un grand hôtel de Lusaka en avril 2014, les experts de l'Usaid-Iapri et de l'université du Michigan (Olson et al., 2014) formulaient leurs recommandations en ces termes : bien que la sensibilité du maïs à la sécheresse soit soulignée et que soit affirmée une nécessaire diversification des cultures et des variétés, «l'épandage d'engrais au moment opportun et l'utilisation de variétés à haut rendement resteront le principal déterminant du rendement pour la plus grande partie de la Zambie».

Dans un contexte où la croissance démographique très rapide dans de nombreux pays du Sud, en particulier en Afrique sub-saharienne, rend indispensable un accroissement important de la production agricole, les décideurs se tournent invariablement vers les modèles techniques susceptibles d'accroître au plus vite les rendements, notamment ceux des céréales. L'espoir est de combler l'écart de rendement (yield gap) qui séparerait, dit-on, les rendements obtenus par les agriculteurs de ceux qui seraient permis par l'application sans détours d'un paquet technique plus performant. Bien que le rendement ne soit pas le seul critère de performance à prendre en compte, il s'en faut, notamment lorsque les paquets techniques promus ne font qu'accroître les risques encourus par les agriculteurs (chapitre 7), cette attraction pour des modèles simples, standards et applicables quelles qu'en soient les conditions semble irrésistible.

Cette attraction est d'autant plus forte que de nombreuses études basées sur des méthodes quantitatives de traitement des données et la modélisation incitent les décideurs à aller dans ce sens. La modélisation mathématique impose en effet la simplification : on ne travaille qu'avec une seule culture, conduite en culture pure, souvent dans des conditions «moyennes» et en y appliquant un paquet technique «standard». Plus le modèle a la prétention d'être général, plus il se doit de reposer sur des hypothèses de plus en plus simples; quitte à gommer toute forme d'hétérogénéité, notamment agro-géographique ou socio-économique.

Or, les travaux du Giec fournissent une base de données précieuse pour ce type de modélisations. Combiner les scénarii d'évolution des concentrations de gaz à effet de serre pour le $\mathrm{xx}^{\mathrm{e}}$ siècle (profils représentatifs d'évolution de concentration) ${ }^{8}$ et différents scénarii socio-économiques ou «profils communs d'évolution

8. Les profils représentatifs d'évolution de concentration ou RCP, Representative concentration pathway ont été définis par le Giec. Il y a notamment le RCP 2.6, RCP 4.5, etc. 
socioéconomique » $(\mathrm{SSP})^{9}$ ouvre en effet la voie à l'élaboration de scénarii d'effet du changement climatique sur les rendements, les surfaces cultivées, les productions, les prix et les marchés mondiaux à l'horizon 2050 (modèles IMPACT de l'Ifpri).

Lun de ces modèles a été évoqué dans le chapitre 2 concernant la Tanzanie (Ahmed et al., 2011). En s'appuyant sur les différents modèles climatiques disponibles et sur le modèle économique d'équilibre général, les auteurs tentent de démontrer que : - c'est le changement climatique qui, à travers la baisse des rendements des céréales, explique la pauvreté;

- seules les politiques visant à accroître les rendements du maïs - au travers notamment des paquets techniques dont il a été question - et dans un contexte de libre concurrence, sont susceptibles de permettre une vertueuse «adaptation» au changement climatique (encadré 8.1) ${ }^{10}$.

Dans le rapport 2016 de la FAO déjà cité et largement consacré à l'adaptation, version Climate-smart agriculture, une large place est faite à ce type de démonstration. On peut y lire par exemple que :

«Des simulations fondées sur le modèle IMPACT de l'Ifpri montrent que c'est l'adoption de variétés de cultures résistantes à la chaleur qui permettrait d'obtenir les plus fortes hausses de rendement pour le maïs en 2050, au niveau mondial. Pour le riz, la plus forte augmentation des rendements, au niveau mondial, serait obtenue grâce à des variétés utilisant l'azote plus efficacement. Pour le blé, la meilleure option est le zéro labour» (FAO, 2016, p. 62).

Ou encore :

«D'après Rosegrant et al., (2014) et à partir de simulations fondées sur le modèle IMPACT de l'Ifpri, le nombre de personnes qui risquent de souffrir de sous-alimentation dans les pays en développement serait réduit en 2050 de $12 \%$ (soit près de 124 millions de personnes) si l'on utilisait largement des variétés de cultures utilisant efficacement l'azote, de $9 \%$ (soit 91 millions de personnes) si le zéro labour était plus largement adopté, et de $8 \%$ (soit 80 millions de personnes) si l'on adoptait des variétés de cultures résistantes à la chaleur ou l'agriculture de précision» (FAO, 2016, p. 62-64).

Ce type de travaux utilisant de façon quelque peu abusive les travaux du Giec sont malheureusement légion, bien que les experts du Giec mettent les lecteurs en garde sur les précautions à prendre en la matière ${ }^{11}$. Ces travaux sont en partie à l'origine des

9. Les profils communs d'évolution socioéconomique (SSP 1 à 5) décrivent différentes hypothèses plausibles d'évolution future de la société et des écosystèmes au cours du XXI ${ }^{\mathrm{e}}$ siècle. Ils sont utilisés parallèlement aux RCP pour analyser la rétroaction entre le changement climatique et certains facteurs comme l'accroissement de la population mondiale, le développement économique et le progrès technologique. Ils se fondent sur des scénari décrivant des évolutions possibles qui posent différents problèmes en matière d'adaptation et d'atténuation (FAO, 2016, p. 35).

10. Un autre exemple de ce type de modélisation réalisée par les chercheurs de l'Ifpri est donné par Jalloh et al. (2013) pour l'étude du cas de l'Afrique de l'Ouest. Voir aussi la revue de littérature acritique proposée par Rhodes et al. (2014) et dans laquelle sont citées de nombreuses études de cette nature.

11. Dans le rapport du Giec, les experts insistent, après l'exposé des méthodes et modèles utilisés, sur la prudence à avoir concernant les projections. Ils précisent que dans les 50 dernières années, les études mettant en relation le changement climatique et l'évolution des rendements ne reposent sur aucun scénario contrefactuel (Porter et al., 2014, p 491). Ils soulignent aussi les difficultés qui apparaissent au moment d'extrapoler à la zone intertropicale les résultats expérimentaux obtenus aux États-Unis et en Chine à propos des scenarii FACE (Free air concentration enrichment) (Porter et al., 2014, p. 495). 
prescriptions non contextualisées et aboutissent à des paquets techniques standards provoquant des effets dévastateurs. Dans tous les cas, on attend des agriculteurs qu'ils «adoptent» les «techniques d'adaptation» qui leurs sont proposées. En dépit de ce qui est proclamé — «Il n'existe aucune liste type de pratiques agricoles intelligentes face au climat que l'on pourrait appliquer dans tous les cas» (FAO 2016, p. 64) - les spécificités locales de chaque agrosystème ne sont pas prises en compte, encore moins les inégalités d'accès des agriculteurs et des éleveurs aux ressources, aux moyens de production et au marché. Les savoir-faire locaux et l'expérience des agriculteurs ne sont pas évoqués.

\section{Encadré 8.1. Du modèle mathématique à la promotion des politiques d'adaptation : l'exemple de la Tanzanie (d'après Ahmed et al., 2011)}

L'objectif de l'étude est d'examiner le lien entre le changement climatique, l'évolution du rendement du maïs et la pauvreté par une approche quantitative et modélisatrice, en s'appuyant à la fois sur les tendances passées et les tendances à venir sur un pas de temps de 60 années, 1971-2031.

Le modèle met en évidence :

- des moyennes mensuelles de températures et de précipitations pour la période de croissance du maïs, de janvier à juin*;

- pour faire un lien - via des modèles de régression linéaire multiple — entre le changement climatique et le rendement du maïs basé sur l'exploitation des statistiques tanzaniennes de production pour la période 1992-2005, pour les 17 régions $\mathrm{du}$ pays : "The analysis finds that when considering yields as functions of climate, the temperature coefficients are negative, while the coefficients for precipitation are positive (p. 49). Coefficients on both climate variables are highly significant in all models. [...] An increase in average growing season precipitation by $1 \mathrm{~mm} / \mathrm{month}$ is enough to increase maize and rice yields by 0.005 tonnes per hectare»; les auteurs n'hésitent pas à écrire : "The estimated statistical model, by being based on ex-post data, has the added advantage of endogenizing some adaptive farmer behavior [...]. The historical yields thus reflect some adaptability, as do the estimated parameters in the statistical model » (p. 49);

- pour faire le lien entre l'évolution des rendements du maïs et l'évolution des prix, les auteurs se basent sur un modèle d'équilibre général sous les hypothèses suivantes : (1) à propos de la concurrence libre et parfaite : "Since a review of the literature does not offer strong evidence on the nature of competition in the Tanzanian food sector, we opt for the empirically robust assumptions of constant returns to scale and perfect competition here as well. Clearly, this assumption could be altered as more evidence becomes available on the nature of market structures in the food sector» (p. 50) et (2) à propos du marché des facteurs : "We assume a constant aggregate level of land, labor, and capital employment reflecting the belief that the aggregate supply of factors is unaffected by climate change» (p. 50);

- enfin pour en déduire les conséquences possibles en matière de pauvreté : "We resolve this complication [...] allowing us to attribute poverty changes solely to climate-based agricultural productivity changes, and not any other event that may cause vulnerability to change between climates in two different periods. Since we are interested in the poverty impacts of interannual variability, we adopt a short run factor market closure in which land, capital, and natural resources are immobile across sectors. Thus, we assume that a farmer has already made all production decisions under best available adaptive behavior in that timeframe» (p. 51). 
Les auteurs concluent : «We apply this framework to Tanzania's climate in the $20^{\text {th }}$ Century and $21^{\text {st }}$ Century, and find that changes in climate volatility are likely to render Tanzanians increasingly vulnerable to poverty episodes through its impacts on staple grains production in agriculture » (p. 53).

Ils justifient ensuite les politiques basées sur l'accroissement du rendement (paquet technique sur le maïs) : "These initiatives to increase agricultural productivity will have to account for changes in the climate more generally, such as through updates to crop calendars and improved crop varieties to account for changing rainfall patterns» et sur le libre échange : "In the short run, when resources may not be easily reallocated across economies, open trade regimes have the potential to reduce domestic price volatility» (p. 54).

Cette affirmation est établie après avoir dit que le modèle ne prend pas en compte les accroissements de rendement à l'échelle mondiale et leur influence sur les prix, etc. : "In addition, food prices in Tanzania will be affected to a large degree by changes in crop productivity throughout the world, as these will influence local prices. The current analysis implicitly assumed negligible impacts in other regions, as a way of focusing on the question of how much poverty volatility could be driven by changes in local production» (p. 54).

* En s'appuyant sur les données issues de la Phase 3 of the Coupled Model Intercomparison Project (CMIP3) archive of General Circulation Model (GCM) experiments (Meehl et al., 2005 et 2007), et en considérant le scénario SRES A2 d'émissions, p. 48.

\section{Priorité à la grande hydraulique, un choix toujours justifié?}

Il ne peut être question, dans cet ouvrage, de tirer des conclusions définitives sur des modèles à promouvoir en matière d'aménagements hydrauliques et de développement de l'irrigation. Cette question étant néanmoins posée dans la plupart des régions étudiées, quelques éléments de comparaison peuvent être mis en évidence. Il s'agit notamment de la contribution de ces aménagements à l'adaptation au changement climatique.

On imaginerait mal l'agriculture du delta du Mékong sans les grands aménagements hydrauliques qui en conditionnent aujourd'hui l'usage. Même si les aléas climatiques pèsent toujours davantage sur ces ouvrages (risque de crue exceptionnelle, subsidence du delta et montée du niveau de la mer) et imposent leur renforcement et amélioration continue, nul doute qu'ils ont été un facteur décisif de l'accroissement spectaculaire de la production, de sa sécurisation et de l'accroissement du revenu des producteurs. Cependant, de tels résultats n'auraient pas été atteints si les producteurs du delta n'avaient pas eu un accès partagé et sécurisé à la terre (réformes agraires des années 1960-1970), aux moyens de production et au marché dans des conditions sécurisées, tout en laissant une grande autonomie aux familles dans la conduite de leurs exploitations (chapitre 4).

Dans le delta du fleuve Sénégal, plusieurs phases d'aménagements (publics puis privés) se sont succédé. Ces aménagements ont permis un accroissement continu des surfaces irrigables et des surfaces cultivables à l'abri de la crue, ainsi qu'une amélioration du contrôle de la nappe d'eau dans chaque maille hydraulique. Nul doute que ces aménagements d'assez grande ampleur ont permis, outre l'accroissement spectaculaire de la production rizicole destinée aux marchés urbains, de surmonter les 
difficultés considérables liées à la péjoration climatique des années 1970 et 1980 . Ils ont aussi créé de nombreux emplois, au regard des possibilités offertes par une agriculture pluviale moribonde et la culture de décrue. Pourtant, les extensions récentes du domaine irrigué ont plutôt été confiées à des investisseurs exogènes et l'accroissement des surfaces sous irrigation génère aujourd'hui conflits fonciers, évictions et creusement des inégalités. Dans ces conditions, le développement de l'irrigation pourrait-il encore jouer un rôle pour diminuer la vulnérabilité des ruraux et accroître leur capacité d'adaptation aux changements auxquels ils sont confrontés (chapitre 5)?

Dans le sud de la Tanzanie, les vallées inondables du bas Rufiji et du Kilombero ont été, depuis les débuts de la colonisation, l'objet d'ambitieux projets d'aménagements. Mais contrairement à la vallée du fleuve Sénégal, ces ouvrages en sont restés à l'état de projet. Larrivée récente de nouveaux investisseurs étrangers et les changements législatifs facilitant leur accueil relancent aujourd'hui ces projets. Ils sont désormais présentés par leurs promoteurs comme une voie privilégiée vers l'adaptation au changement climatique. En réduisant fortement l'aléa par une artificialisation poussée du milieu, on en attend un accroissement substantiel de la production agricole et sa sécurisation à long terme. Cependant, le problème se pose ici dans des conditions bien différentes de celles qui caractérisaient la vallée du fleuve Sénégal à l'époque des premiers aménagements. Beaucoup plus densément peuplées aujourd'hui, ces vallées sont désormais mises en valeur par des systèmes de production complexes, intensifs en travail et reposant largement, en l'absence d'aménagement, sur une gestion savante de l'hétérogénéité du milieu (chapitre 3). Attribuer de larges pans de ces vallées à des investisseurs en vue de leur aménagement présente aujourd'hui des risques considérables d'éviction et d'accroissement de la vulnérabilité, alors même que leur capacité à créer une valeur ajoutée par unité de surface plus élevée que les systèmes de production «traditionnels» reste à démontrer dans la durée.

Par ailleurs, en matière de grande irrigation, ce n'est pas l'ampleur des aménagements envisagés qui pose problème en tant que tel - comme le démontre l'exemple du delta du Mékong -, sous réserve que des modalités efficaces de gestion et d'entretien soient au rendez-vous. Souvent les choix technologiques et les paquets techniques associés limitent fortement l'intérêt des agriculteurs potentiellement «bénéficiaires» pour les aménagements. Tel fut le cas par exemple à l'époque où, dans le delta du fleuve Sénégal, la Société d'aménagement et d'exploitation des terres du delta (Saed) imposait aux producteurs bénéficiaires des aménagements publics un itinéraire technique particulièrement rigide. C'est encore vrai aujourd'hui dans le cas du programme mis en place par l'entreprise Kilombero plantations limited (KPL), dans la vallée du Kilombero en Tanzanie, et où l'itinéraire technique vulgarisé - et censé accroître la résilience face au changement climatique - se traduit dans les faits par un accroissement du risque encouru par les agriculteurs (chapitre 3 ).

$\mathrm{Au}$ regard de l'attention et du soutien portés par les pouvoirs publics aux promoteurs de ces grands périmètres irrigués, publics ou privés, force est de constater que le développement de la petite irrigation mise en place à l'initiative des agriculteurs est passé presque inaperçu. Son rôle est pourtant central dans la lutte contre la vulnérabilité et l'accroissement de la résilience. Dans les trois situations que nous avons eu l'occasion d'étudier de près sur les hauts plateaux d'Afrique 
australe, en Zambie et en Tanzanie (chapitre 2), la petite irrigation s'est toujours révélée comme un levier majeur d'accroissement du revenu des agriculteurs et de résilience des systèmes de production. En premier lieu, elle permet de sécuriser le début ou la fin d'un cycle de culture «pluvial» lorsque la pluie est insuffisante ou incertaine. Ensuite, elle autorise la mise en place de cultures de contre-saison, elles-mêmes à l'abri de tout stress hydrique si la ressource en eau est suffisante. Ce faisant, l'accès à la petite irrigation permet aussi d'élargir le champ des possibles, notamment en matière de cultures à plus forte valeur ajoutée. Il permet aussi de diversifier les ressources fourragères accessibles (résidus de culture notamment) au moment de l'étiage fourrager sur les terres pluviales et donc de conforter l'élevage. Il est aussi la voie privilégiée pour occuper la force de travail familiale tout au long de l'année, pour remplir progressivement le calendrier de travail et donc pour accroître de façon significative la productivité du travail et le revenu. Sur les versants escarpés des monts Uluguru (chapitre 6), la petite irrigation a été, avec l'utilisation conjointe d'étages écologiques différents, la colonne vertébrale de l'intensification progressive du système agraire et de sa capacité à supporter de très fortes densités démographiques. Bien que l'accès à cette ressource clef — l'eau d'irrigation — soit très inégal, la construction et l'élargissement progressif de ces systèmes d'irrigation gravitaire par les agriculteurs eux-mêmes, au sein de collectifs de petite dimension, ont permis leur réelle appropriation par les usagers. Le résultat en est une gestion relativement efficace de la ressource. Si elle n'est pas optimale, son utilisation est assez peu conflictuelle et assez économe. Dans les situations étudiées dans le cadre de cet ouvrage, très peu de ces systèmes d'irrigation n'avaient été soutenus de quelque manière que ce soit par les pouvoirs publics ou les «projets », à l'exception cependant des périmètres maraîchers de la vallée du fleuve Sénégal.

\section{Les savoirs locaux et l'expérience accumulée par les agriculteurs sont-ils suffisamment pris en compte?}

Dans le chapitre consacré à la sécurité alimentaire et aux systèmes de production alimentaires du dernier rapport du Giec, (Porter et al., 2014, 514-515), les rédacteurs insistent à juste titre sur les multiples changements opérés par les agriculteurs pour s'adapter aux changements climatiques et l'impact de ces ajustements continus sur la réduction de la vulnérabilité. En s'appuyant sur une revue de la littérature scientifique, ils donnent de multiples exemples de pratiques adaptatives : modifications des dates de semis, changement de variétés, développement de nouvelles cultures, ajustement dans l'organisation du travail, etc. Ces exemples sont largement illustrés, par ailleurs, dans les chapitres précédents de ce rapport. Les rédacteurs qualifient l'ensemble de ces pratiques d'adaptations autonomes (autonomous adaptations) ou d'adaptations progressives (incremental adaptations) ${ }^{12}$. Elles s'opposent aux adaptations planifiées à plus grande échelle (planned adaptations), en général par des acteurs extérieurs au monde rural (pouvoirs, publics, projets et entrepreneurs agricoles) et susceptibles de provoquer, dit-on, un véritable changement de système dans le sens d'une plus grande adaptation.

12. En les définissant comme suit : Autonomous adaptations are incremental changes in the existing system including through the ongoing implementation of extant knowledge and technology in response to the changes in climate experienced. They include coping responses and are reactive in nature (Porter et al., 2014, p. 513). 
On l'aura compris, ce sont les adaptations planifiées qui ont la faveur des décideurs politiques et des bailleurs de fonds, les adaptations mises en place par les agriculteurs eux-mêmes et par ajustements successifs étant jugées — lorsque leur existence est connue - comme largement insuffisantes, voire inopérante. Un exemple de ce genre de jugement est donné par Mulenga Bwalya (2010, p. 17) à propos des agriculteurs zambiens :

«Les communautés locales ont des connaissances et des compétences traditionnelles pour s'adapter au changement climatique et à la variabilité climatique. Mais elles sont assez transitoires et insuffisamment robustes pour être considérées comme des stratégies adéquates pour s'adapter et atténuer les conséquences du changement climatique.»

Dans les programmes nationaux d'adaptation qu'il nous a été donné de consulter (Pana et PNA), peu ou pas d'allusions sont faites aux pratiques d'adaptation «autonomes », les agriculteurs y sont de facto présentés comme un ensemble passif. C'est aussi l'esprit du rapport de la FAO où l'adaptation se limite à l'adoption, par les agriculteurs, de pratiques «intelligentes face au climat». Ce sont les «obstacles à l'adoption» de ces pratiques qui doivent retenir l'attention et faire l'objet de politiques dédiées. Ladaptation est conçue et mesurée comme un taux d'adoption d'innovations exogènes : adoption de nouvelles cultures ou variétés, de nouveaux intrants et de nouvelles techniques de culture. Comme l'adaptation, l'innovation vient d'ailleurs; les schémas d'adoption mis en place dans le sillage de ces recommandations reproduisant à l'identique les vieilles méthodes de vulgarisation de haut en bas, si peu efficaces par le passé. Dès lors que les pratiques qualifiées d'«intelligentes» sont surtout celles qui viennent d'ailleurs et que l'on s'efforce de vulgariser en milieu rural, quelle image donne-t-on ainsi des pratiques paysannes «endogènes»?

\section{Les conditions socio-économiques d'exercice du métier d'agriculteur sont trop peu prises en considération}

Les documents de politique publique dont il a été question au début de ce chapitre, et qui présentent surtout l'éventail des techniques à mettre en œuvre pour s'adapter au changement climatique, ne manquent pas de pointer, dans un deuxième temps, les obstacles qui se dressent à leur «adoption » par les ruraux. C'est ainsi que les «régimes fonciers», la «capacité économique», l' «accès aux technologies», les «conditions d'accès au marché » ou la «gouvernance» sont identifiés comme autant de «barrières à l'adoption des pratiques d'adaptation» (Rhodes et al., 2014, p. 25). Les experts de la FAO, dans leur rapport 2016, proposent de «recenser les entraves à l'adoption de systèmes de production intelligents face au climat» (p. 72). Dans le résumé du rapport, à destination des décideurs, il est affirmé en conclusion que :

«Il est donc crucial de renforcer l'environnement porteur qui permettra des investissements agricoles climato-intelligents, d'intégrer les questions de changement climatique dans les allocations et l'exécution des budgets nationaux et de mobiliser des capitaux privés en faveur d'un développement agricole qui soit également intelligent sur le plan climatique» (FAO, 2016, p. 27).

Cette approche par les «obstacles à l'adoption», qui réduit le développement agricole à un processus d'adoption de technologies exogènes, n'est en rien nouvelle. Comme par le passé, elle fait silence sur les modalités d'accès inégal à la terre, à 
l'eau et aux ressources naturelles, aux moyens de production et aux marchés, et donc aux marges de manœuvre qui permettent aux agriculteurs et aux éleveurs de faire évoluer, ou non, leurs pratiques.

\section{Les modalités d'accès aux ressources (terre, eau d'irrigation et ressources pastorales) et aux moyens de production ne sont pas prises en compte}

Les quelques régions étudiées en détail dans cet ouvrage fournissent autant d'exemples où les agriculteurs sont placés dans des conditions très inégales - selon leurs modalités d'accès aux ressources et aux moyens de production - pour gérer au mieux les aléas auxquels ils sont confrontés, en diminuer l'impact et affronter les défis futurs du changement climatique. Un accès pérenne à une surface agricole utile suffisante, à des écosystèmes variés, aux semences, à un minimum d'intrants, au bétail et à la traction attelée et parfois à du petit matériel d'irrigation (arrosoir, tuyau) peut se révéler crucial et faire toute la différence (chapitre 6). Or ces aspects-là sont presque toujours absents des analyses et propositions formulées en matière d'adaptation. Les difficultés d'accès à la terre que connaissent des centaines de millions de familles pauvres ne sont jamais évoquées comme un «obstacle» à l'adaptation, pas davantage que les difficultés liées à l'accès à l'eau lorsque cette ressource est mobilisable pour réaliser un cycle de contre-saison. Seule «l'insécurité foncière» est parfois mentionnée. Mais l'étude de cette insécurité est limitée aux aspects juridiques propres aux régimes fonciers locaux, tandis que les réformes foncières et les procédures de titrement sont invoquées pour la réduire.

Lorsque les difficultés d'accès aux moyens de production sont soulignées au titre des «obstacles à l'adoption», l'accès aux moyens de production est compris comme «accès aux technologies», sous-entendues «modernes»: la motorisation, les engrais, les semences - y compris les OGM — et les pesticides. Les obstacles institutionnels et les «défaillances de marchés» étant alors jugés responsables, on fait appel au «secteur privé » censé faciliter, dans le cadre de l'agriculture contractuelle, l'accès aux technologies pour tous comme en témoigne, par exemple, le rapport FAO (2016) déjà cité. Les experts y proposent de :

- favoriser des partenariats public-privé pour mobiliser les ressources [...];

- concevoir et expérimenter des structures de placement innovantes susceptibles d'attirer des capitaux supplémentaires en panachant et en gérant les profils rendement/risque de différents investisseurs [...];

- soutenir l'élaboration et l'intégration d'une plus large gamme d'instruments financiers [...], produits d'assurance, reçus d'entrepôt et financement des chaînes de valeur (p. 134)

Cette approche nous paraît pour le moins réductrice. En revanche, soulever le problème de l'accès différencié aux «moyens de production », comme nous le proposons dans cet ouvrage, pose d'emblée la question des inégalités de développement et des moyens à mettre en œuvre pour y faire face.

\section{Les conditions réelles d'accès au marché, pas plus que les conséquences de la dérégulation des marchés de produits agricoles et alimentaires ne sont pas abordées}

Les promoteurs de l'agriculture «climato-intelligente» observent que la trop forte dépendance d'un pays vis-à-vis du marché international de biens alimentaires peut conduire à d'importantes crises alimentaires frappant particulièrement les 
populations les plus déshéritées (Tissier et Grosclaude, 2015, p. 293). Néanmoins, ils considèrent le commerce comme un facteur essentiel de la résilience des systèmes alimentaires. Il n'est pas douteux, en effet, que des échanges fluides de denrées alimentaires puissent contribuer à renforcer la sécurité alimentaire à l'échelle régionale comme l'a démontré Mathilde Douillet (2013) à propos du maïs en Afrique australe et orientale. Cependant, les politiques prônées en matière d'adaptation ne prennent guère de recul par rapport à la doxa du libre-échange alors même que de nombreux travaux scientifiques ont montré l'impact considérable de la mise en concurrence, sans précaution ni protection, d'agricultures inégalement dotées en moyens de production et aux écarts considérables de productivité. Ignorant ces travaux, la profession de foi de la FAO est sans ambiguïté :

«Il faut réduire autant que possible les restrictions au commerce, telles que les obstacles tarifaires et non tarifaires, qui entravent la réaction de la production agricole mondiale face à l'évolution de la demande et de l'offre dans un contexte de changement climatique. [...] Dans la mesure où il est probable que le changement climatique creuse les déséquilibres qui existent déjà entre le monde développé et le monde en développement, [...] il est d'autant plus nécessaire d'aider les pays en développement à faire face aux hausses des prix des denrées alimentaires et de l'énergie, ainsi qu'à l'instabilité des disponibilités alimentaires» (FAO, 2016, p. 116).

Le Nord nourrira le Sud, la messe est dite.

\section{Une agriculture conçue d'emblée comme facteur de dégradation des écosystèmes}

Les documents de politiques d'adaptation font en général de la lutte contre la dégradation des terres - érosion, déforestation, désertification et salinisation - une priorité, et des projets de «restauration des terres dégradées» un axe majeur des actions à entreprendre. Dans la mesure où ces projets visent souvent à rétablir une couverture végétale, ils sont censés contribuer à une captation significative de $\mathrm{CO}_{2}$ et donc aux objectifs d'atténuation. Alors que la mise à disposition de fonds importants a été annoncée à la COP 21 pour financer l'adaptation dans les pays en voie de développement, de nombreux projets, qui pourraient émarger à ces financements, affichent comme objectif la restauration des terres dégradées. Pourtant, cet objectif n'est pas nouveau. Dans les pays du Sud, la période coloniale offre de multiples exemples de politiques de lutte contre l'érosion, les feux de brousse, l'agriculture sur brûlis et le surpâturage. Un retour sur ces expériences s'avère particulièrement utile à l'heure où l'on s'apprête un peu partout à remettre de tels projets au goût du jour au nom de l'adaptation.

À ce titre, l'analyse de la politique de lutte antiérosive mise en place par la tutelle britannique dans les monts Uluguru (chapitre 6) au début des années 1950 (Uluguru land usage scheme) nous a semblé emblématique. Depuis longtemps, l'érosion était présentée comme alarmante, bien qu'aucune démonstration ne soit venue à l'appui et qu'aucun diagnostic des pratiques paysannes ne soit entrepris. Alors, on fit de la construction des terrasses radicales la seule protection jugée efficace contre le ruissellement et le glissement de terrain. Léchec fut retentissant. La technique phare proposée - la terrasse radicale — était inadéquate : difficile à édifier, au 
talus fragile et exposé à l'érosion, mettant à nu des horizons plus profonds et moins fertiles du sol tout en accroissant considérablement les risques de glissements de terrain. Cet échec patent des autorités coloniales n'a pas empêché les versants des monts Uluguru d'être méticuleusement sculptés à la houe et aménagés en billons, escaliers et terrasses par les paysans eux-mêmes. Lagriculture des monts Uluguru offre ainsi un exemple spectaculaire des efforts entrepris par les agriculteurs pour limiter l'érosion, la dégradation des terres et préserver l'avenir, malgré les moyens dérisoires qui étaient à leur portée.

Bien qu'elle obéisse à d'autres desseins, la réorganisation musclée des terroirs, planifiée et exécutée en Afrique du Sud, fut aussi justifiée au nom de la lutte contre l'érosion et le surpâturage. Elle offre un exemple dramatique d'un processus irréversible d'accentuation des phénomènes que l'on prétendait combattre. Dès lors que les populations africaines furent concentrées dans les homelands, sur $13 \%$ du territoire national, les autorités sud-africaines commencèrent à planifier «le développement agricole» réservé aux Noirs par les programmes de Betterment planning où les terres de culture, les pâturages, les lotissements urbains et les boisements devaient être regroupés selon un schéma standard de localisation (Cochet, 2013). Le diagnostic préalable, qui fut porté sur l'agriculture des homelands (native agriculture) par les experts blancs, soulignait les faiblesses de cette agriculture (faible rendement, érosion et surpâturage). Ce diagnostic faisait porter le chapeau aux populations bantu elles-mêmes, alors que ces faiblesses résultaient exclusivement du vaste processus de land grabbing réalisé auparavant. C'est ainsi que la question du surpâturage apparaît massivement dans la littérature sud-africaine. Ce thème sera utilisé à maintes reprises pour expliquer l'érosion et la dégradation des terres des homelands et justifier les mesures de limitation drastique des effectifs de bétail détenu par les familles noires. Cette interprétation passait sous silence le fait que la concentration du bétail résiduel sur un espace particulièrement restreint et l'accroissement excessif de la charge animale qu'il entraînait résultait précisément de l'éviction des populations et de leur confinement dans les réserves. Une «tragédie des communs» créée de toute pièce et qui venait fort à propos pour lutter de façon énergique contre le «démon du surpâturage», une opération supplémentaire de décapitalisation forcée. Cette interprétation négligeait aussi le fait que le bétail sur pied représentait, pour ces populations, l'ultime support possible d'une accumulation de capital, par ailleurs entravée de mille manières. Elle ignorait enfin que, sans aucun accès aux engrais de synthèse, les transferts de fertilité opérés par l'intermédiaire du bétail des espaces pâturés vers les parcelles en culture représentaient le seul mécanisme possible de reproduction de la fertilité des espaces cultivés.

On voudrait croire que ces politiques appartiennent à une époque révolue. Rien n'est moins sûr, hélas. Bien que libérées des idéologies mortifères de l'époque de l'Apartheid, les conséquences des projets et politiques mis en œuvre en matière de lutte contre la dégradation des terres pourraient encore se traduire par des processus d'éviction des populations. En témoigne, le vaste programme du gouvernement éthiopien de mise en défens des terres jugées dégradées en vue de leur restauration (encadré 8.2).

S'il n'est pas douteux que des surfaces considérables sont concernées par ces phénomènes de dégradation, le diagnostic porté sur les causes de ces phénomènes est 
trop souvent hâtif et se solde généralement par la mise à l'index des agricultures «traditionnelles » et leur condamnation plus ou moins explicite. Pourtant, une étude plus fine des pratiques paysannes conduit souvent à des conclusions plus nuancées, voire diamétralement opposées (Cochet, 2001; Ducourtieux, 2009). Ainsi, les agriculteurs, et en général les plus pauvres d'entre eux, se voient souvent accusés d'être les responsables de cette dégradation décrétée en haut lieu. Ils peuvent alors être les principales victimes des politiques d'éviction mise en place pour «enrayer» cette dégradation ou «restaurer» les espaces concernés. À l'heure où une nouvelle génération de projets de lutte contre la dégradation des terres pourrait voir le jour et émarger au guichet de l'adaptation, il semble particulièrement important de ne pas répéter les erreurs du passé.

\section{Conclusion}

Hélas, les principaux axes suivis en matière d'adaptation au changement climatique empruntent les chemins et les impasses du passé. Les leçons de tant d'échecs répétés ne semblent pas avoir été retenues.

En se focalisant encore trop souvent sur un petit nombre de recommandations purement techniques, souvent passe-partout en dépit des déclarations d'intention de «l'agriculture intelligente face au climat», les modalités «d'adaptation» proposées aux agriculteurs, quand elles ne leurs sont pas imposées, se traduisent fréquemment par l'accroissement des risques encourus par les agriculteurs. Alors même qu'il s'agit bien, en réduisant la vulnérabilité des agriculteurs, de limiter les risques inhérents à la péjoration climatique et à l'accroissement des aléas, c'est souvent l'innovation elle-même qui conduit à l'accroissement de la vulnérabilité. Les «paquets techniques » unilatéraux et standards sont destinés au développement d'une seule culture ou variété (maïs et riz) et censés permettre un accroissement significatif des rendements. Mais ils sont inadaptés à la diversité des écosystèmes locaux et à la diversité socio-économique des agriculteurs. Leur cas a été largement évoqué dans les chapitres précédents.

Comme dans le passé, la lutte contre la «dégradation des terres» rime trop souvent avec autoritarisme et mise en défens. Les pratiques agricoles et pastorales étant jugées archaïques et responsables de l'érosion et de la déforestation, il faut en changer au plus vite et imposer un schéma «rationnel» de restauration, de protection et de mise en défens. Pourtant, les évictions et déplacements des populations qui en résultent conduisent d'une part à l'accroissement de la pression exercée sur les écosystèmes limitrophes et d'autre part à l'accroissement de la vulnérabilité des victimes.

Les processus historiques de fragilisation des systèmes agraires ne sont pas étudiés, ni pris en compte. Il en est de même des mécanismes de différenciation qui permettent pourtant d'expliquer les causes réelles de la vulnérabilité de certains groupes sociaux et les ressorts de la résilience plus forte d'autres groupes, et d'entrevoir ainsi les actions à entreprendre pour promouvoir une réelle adaptation. Aveuglement ou rapport de force? Tout se passe comme si les diagnostics établis en matière de vulnérabilité ignoraient à dessein le poids des rapports sociaux et celui des groupes sociaux ayant inspiré les choix politiques passés. En réduisant la portée du diagnostic et les solutions proposées à une énumération de recommandations 


\section{Encadré 8.2. Programme du gouvernement éthiopien de mise en défens de terres jugées dégradées en vue de leur restauration (H. Cochet)}

Le programme de mise en défens des terres dégradées propose l'exclusion ou la limitation des activités humaines et de l'accès au bétail sur les terres concernées. Elle devrait permettre, selon les artisans du projet, la reconstitution de la couverture végétale, y compris le développement d'un recru arboré. Par sa contribution à l'accroissement du stockage de carbone, ce programme est censé participer, d'une part, à l'atténuation du changement climatique dans la perspective des engagements pris par le gouvernement éthiopien (CPDN) et, d'autre part, à l'adaptation. Force est de constater que ce programme repose sur un diagnostic des plus classiques, ancien et non questionné à nouveau. Ainsi, les activités humaines, et en particulier le pâturage et la collecte du bois de feu qui, dans un contexte de forte croissance démographique, seraient seules responsables de la dégradation des terres. Il est alors «logique» de limiter les activités humaines sur les espaces en question, afin de «restaurer l'environnement» et les services environnementaux qui lui sont attribués. De la «tragédie des communs » ${ }^{*}$ à la mise en défens décrétée en haut lieu et aux enclosures, un scénario bien rôdé... depuis des siècles.

Ce diagnostic est pourtant simpliste et ne peut suffire à lui seul de justification au projet de mise en défens des terres dégradées prôné par les pouvoirs publics en Éthiopie. La déforestation d'une grande partie des hauts plateaux du nord de ce pays est très ancienne (plusieurs siècles). En aucun cas, elle ne peut être attribuée aux pratiques récentes des communautés villageoises ou à un quelconque accroissement démographique contemporain. Dans la moitié sud de l'Éthiopie, le phénomène est moins accentué. Il est même établi désormais que certaines régions ont connu au contraire un processus d'afforestation, tandis que d'autres connaissaient l'établissement récent, par les communautés paysannes, de véritables agro-forêts à café en lieu et place des espaces «déforestés» qui prédominaient auparavant. S'il est indéniable que de nombreux espaces éthiopiens ont effectivement connu un processus inquiétant de diminution $\mathrm{du}$ niveau de la biomasse ces dernières décennies, le phénomène est complexe et multifactoriel. Il appelle un diagnostic approfondi au cas par cas.

La politique de mise en défens planifiée par les pouvoirs publics éthiopiens apparaît ainsi comme un remède pire que le mal. En effet, la majorité des espaces en question est utilisée par les villageois pour faire paître bovins, caprins et ovins une grande partie de l'année, les résidus de culture et (parfois) les aliments achetés complétant la ration des animaux, notamment pendant la saison sèche. Il faut rappeler ici que l'élevage des herbivores domestiques est une composante primordiale de la très grande majorité des unités de production agricoles éthiopiennes. Cette activité d'élevage est à la fois pourvoyeuse d'énergie de traction - la traction attelée bovine est généralisée dans tout le pays — et de déjections animales indispensables à la reproduction de la fertilité des terres cultivées quand elles ne sont pas utilisées, comme c'est le cas dans la moitié nord du pays, comme combustible à défaut de bois de feu. La mise en défens de manière unilatérale et «planifiée» de ces espaces par les pouvoirs publics — pour en interdire l'accès aux animaux domestiques - présente donc un risque majeur de fragilisation irréversible de toutes les unités de production agricoles riveraines.

* Garret Hardin, 1968. Tragedy of the commons. Science, december 1968. 
techniques, la question de l'adaptation échappe à tout questionnement politique. Curieusement, alors que les causes du changement climatique sont désormais reconnues par (presque) tous comme étant surtout d'origine anthropiques, «l'aléa » climatique et les risques encourus par les agriculteurs sont encore implicitement présentés comme étant «naturels». Et le «changement climatique» devient ainsi, comme par enchantement, la menace numéro un (voire unique) qui pèserait sur les agriculteurs des régions les plus exposées.

Pourtant, la vulnérabilité est avant tout un construit social, comme nous l'avons montré par l'approche à la fois diachronique et typologique que nous avons développée dans chacune des régions étudiées dans le cadre de ce travail de recherche. C'est pour cela que la définition de politiques de réduction de cette vulnérabilité, dans la perspective d'une meilleure adaptation au changement climatique, suppose que des choix politiques clairs soient faits au bénéfice des groupes les plus vulnérables. Pourtant, les financements accessibles au nom de l'adaptation risquent plutôt de conduire à des mécanismes de capture d'opportunités au bénéfice des mieux placés, comme le suggère Vanderlinden (2015, p. 41-42) :

«Le monde dans lequel ces opportunités vont se déployer n'est pas un monde «plat». C'est un monde où des rapports de force préexistent et où ceux qui sont déjà bien placés seront les mieux placés pour saisir, voire — et c'est le plus inquiétant contribuer à la définition de ces «bénéfices» (les bénéfices attendus des politiques d'atténuation). [...] Si ces mêmes groupes sont appelés à contribuer à la définition des modalités d'adaptation, choisiront-ils de lutter activement contre les inégalités ou encourageront-ils plutôt des solutions techniques distribuées via un marché qui les favorise déjà?»

\section{Un nécessaire renouvellement des approches et des propositions politiques à l'épreuve des faits}

\section{Miser réellement sur les savoir-faire des agriculteurs}

Limportante littérature scientifique produite sur les questions de l'adaptation des agricultures faiblement dotées en ressources et moyens de production a eu le mérite de reconnaître l'efficacité de certaines techniques «traditionnelles» en matière d'adaptation. C'est par exemple le cas du Zaï dans la zone sahélienne, des parcs arborés à Faidherbia albida de la zone sahélo-soudanienne ou même, plus simplement, de l'association agriculture-élevage. Cette reconnaissance — tardive — de l'efficacité de ces pratiques est cependant insuffisante, dans la mesure où elle n'a pas été capable d'infléchir notablement les politiques promues au nom de l'adaptation.

Les quelques situations étudiées dans les chapitres précédents fournissent aussi de nombreux exemples allant dans le même sens :

- gestion du double aléa des précipitations et de la crue dans les basses vallées inondables du Kilombero et du Rufiji (Tanzanie) par la combinaison riz-maïs (chapitre 3);

- choix et associations de plusieurs espèces et variétés cultivées, notamment de niébé, au nord du bassin arachidier sénégalais (chapitre 1); 
- cultures associées et petite irrigation sur les hauts plateaux de Zambie et du SudTanzanie (chapitre 2);

- associations et successions culturales sur les versants étagés des monts Uluguru (chapitre 6);

- combinaison de plusieurs variétés et systèmes rizicoles dans le bassin du Tonlé Sap au Cambodge (chapitre 4).

Par ailleurs, il nous semble primordial de s'appuyer sur l'expérience particulièrement riche des agriculteurs ayant déjà connu des phases de péjoration nette du climat dans le passé. Il s'agit du Sahel notamment, mais aussi de la Tanzanie au moment où était mise en place la politique de villagisation. Les chapitres qui précèdent montrent en quoi les modalités d'adaptation à ces changements anciens du climat (changement de cultures et de variétés, modification des calendriers de cultures, des déplacements des animaux) enrichissent aujourd'hui la recherche de solutions. Ces situations anciennes permettent aussi d'identifier les systèmes de production qui furent les plus résilients et les agriculteurs ayant réussi peu ou prou à s'en sortir ou à moins souffrir que les autres de cette péjoration climatique. $A$ contrario, elles permettent de mettre en lumière les groupes les plus vulnérables, d'en expliquer les raisons et d'en suivre les trajectoires.

S'appuyer sur l'expérience des agriculteurs, en particulier les plus pauvres d'entre eux, est aussi particulièrement riche d'enseignements. En effet, ce sont souvent eux qui ont mis en place des solutions peu gourmandes en intrants et parfois les plus diversifiées parce que tout accès aux moyens de production - engrais de synthèse, pesticides, semences «améliorées» — leur était barré. Aujourd'hui, ces agriculteurs sont les mieux à même de développer des agricultures à la fois adaptées aux conditions du milieu, contribuant très peu aux émissions de gaz à effet de serre et susceptibles de s'adapter. Koohafkan et Altieri (2011) soulignent également le potentiel adaptatif des agricultures «traditionnelles» lié à leur niveau de biodiversité élevé ${ }^{13}$.

Plutôt que de s'enfermer dans la recherche de «techniques intelligentes face au climat» et de tenter de lever les obstacles à leur adoption massive par les agriculteurs, processus de haut en bas (top down) voué à l'échec, les politiques d'adaptation efficaces devraient d'abord chercher à identifier les processus endogènes mis en place par les agriculteurs ou que ces derniers souhaiteraient développer pour diminuer les risques encourus. Ensuite on s'appuierait sur ces processus et tenter d'en accroître l'étendue et l'efficacité par des mesures adaptées.

\section{Promouvoir la diversité}

La diversité cultivée à l'échelle de la parcelle est parfois un gage de dispersion des risques et de plus grande résilience comme il a été vu plus haut (diversité variétale et culture associée). Cependant, c'est à l'échelle de l'exploitation agricole que cette diversité révèle son plus grand potentiel. La spécialisation dans une seule culture

13. À propos du niveau de la biodiversité, le rapport IAASTD (Évaluation internationale des connaissances, des sciences et des technologies agricoles pour le développement, The international Assessment of agricultural science and technology), approuvé en assemblée plénière intergouvernementale en avril 2008, insistait à juste titre sur l'importance du soutien aux agriculteurs les plus modestes, le caractère complexe et multifonctionnel de l'agriculture, ainsi que l'importance de la valorisation des savoir-faire locaux. 
ou une seule variété est toujours extrêmement risquée du point de vue climatique, à moins d'une artificialisation très poussée du milieu (irrigation contrôlée, planage, etc.) Elle est aussi risquée du point de vue économique, sauf dans les situations de plus en plus rares où les agriculteurs sont protégés des fluctuations excessives des prix et sûrs de bénéficier, en vendant leur récolte, d'un revenu suffisant pour faire face à leurs besoins. Au contraire, la mise en place d'une combinaison variée d'espèces et de variétés cultivées est bien la meilleure façon de disperser les risques et de s'assurer que, quelles que soient les circonstances, une récolte minimale sera malgré tout obtenue. Permettre de choisir le milieu le plus adapté à chaque plante et la ou les plantes les mieux adaptées à chaque portion de terrain est souvent aussi la technique la moins coûteuse à mettre en place dans la mesure où le recours accru aux fonctionnalités du milieu permet souvent de limiter les doses d'intrants utilisée. Enfin, une combinaison variée de cultures et d'élevages constitue aussi le meilleur moyen, pour une famille d'agriculteurs, d'occuper la force de travail familiale — dont le coût d'opportunité est souvent très faible faute d'alternatives réelles en matière d'emploi — le plus longtemps possible tout au long de l'année (remplissage du calendrier de travail) et donc d'accroître sa productivité globale.

Il est donc impératif de renoncer aux programmes et projets visant à spécialiser les agriculteurs dans une seule ou un trop petit nombre de productions ou variétés en lieu et place de systèmes plus diversifiés. De même, dans la mesure où un accès à des écosystèmes variés facilite considérablement la mise en œuvre de systèmes de production eux même diversifiés, plus productifs et plus résilients, il semble impératif de mettre un terme aux projets de mise en défens non concertés, fussent-ils au nom de l'adaptation. Ces mises en défens priveraient les agriculteurs de leurs ressources fourragères. Il est également impératif d'arrêter les processus d'éviction résultant des accaparements de terres opérés ici où là et qui amputent le territoire villageois, restreignant de ce fait l'accès des agriculteurs à tel ou tel écosystème.

\section{Raisonner l'adaptation à l'échelle de l'exploitation agricole, pas seulement à celle de la parcelle}

Les principaux documents d'orientation politique consacrés à l'adaptation au changement climatique présentent le plus souvent, in fine, un catalogue de «techniques d'adaptation» à promouvoir, la plupart d'entre elles s'appliquant à la parcelle. Outre les paquets techniques de type révolution verte dont il a été largement question et dont nous avons souligné l'insuffisance, les recommandations plus proches de pratiques agroécologiques (agroforesterie, mulch, agriculture de conservation, application de compost) sont aussi proposées et évaluées à l'échelle de la parcelle. Or, leur véritable efficacité, ou au contraire le danger qu'elles peuvent représenter, ne peuvent être perçus et analysés qu'à l'échelle de l'exploitation agricole dans son ensemble : à l'échelle du système de production.

L'exemple du paillage (mulch) des parcelles caféières au Burundi fournit un exemple éclairant. Le mulch est unanimement reconnu comme une pratique vertueuse, tant du point de vue de l'atténuation (recyclage de la matière organique, substitut aux engrais de synthèse) que de celui de l'adaptation. De surcroît, c'est la clé de voûte de 
l'agriculture «de conservation». Mais au Burundi, le mulch s'est révélé une pratique véritablement destructrice tant pour l'agriculture vivrière de ce pays que pour les recettes d'exportation principalement constituées de café. Le paillage systématique des caféiers a en effet accaparé la quasi-totalité de la biomasse disponible, à un moment où son coût d'opportunité ne cessait de croître. Il a provoqué une baisse accélérée de la fertilité des parcelles pourvoyeuses de biomasse, notamment vivrières, entraînant bon nombre d'exploitations agricoles dans une crise très grave (encadré 8.3).

Elle aussi vulgarisée tout azimut dans de nombreux pays au nom de l'adaptation, la technique du compostage doit être analysée de la même façon. Le compost est bien sûr bénéfique à la parcelle qui en bénéficie. Mais quel bilan peut-on faire à l'échelle de l'exploitation toute entière ou même à l'échelle du système agraire? Le bilan carbone du compostage est largement positif si la biomasse dédiée est brûlée au champ en l'absence de fosse à compost. Mais la compostière est-elle bénéfique à l'ensemble de l'exploitation quand les résidus sont plutôt enfouis au moment du labour ou consommés par les animaux domestiques en période de déficit fourrager ${ }^{14}$ ? C'est ainsi qu'en se penchant sur des exploitations déclarées «climato-intelligentes » parce qu'elles ont «adopté» la technique du compostage, Andrieu et ses collègues (2015) constatent que l'introduction du compostage dans les exploitations se traduit par une augmentation de la durée de la transhumance chez les éleveurs burkinabés, faute de résidus de culture en quantité suffisante.

Basée sur l'absence de labour et le maintien au sol des résidus de culture du cycle précédent, l'agriculture de conservation est aussi présentée comme une des voies possibles pour diminuer la vulnérabilité des systèmes de culture. Néanmoins, elle se heurte aux mêmes défauts de conception. L'enfermement de l'analyse à l'échelle de la parcelle et l'insuffisante prise en compte tant des effets réels de la technique promue à l'échelle de l'exploitation, que de la diversité de situations des agriculteurs, expliquent l'échec relatif de nombreux projets en la matière (Levard et al., 2014; Dugué et al., 2015) $)^{15}$.

Enfin, toutes les techniques promues en matière de gestion conservatoire des eaux et des sols ou de lutte contre la dégradation des terres devraient également être évaluées au cas par cas, en tenant compte des coûts d'opportunité des ressources et du temps de travail qui leurs sont consacrées.

\section{Aménager un accès partagé aux moyens de production}

Les travaux réalisés dans le cadre de ce programme de recherche illustrent largement à quel point l'accès aux moyens de production a été crucial lors des périodes historiques marquées par une péjoration climatique. Cet accès se révèle encore aujourd'hui primordial.

14. Pour être complet, le bilan avec ou sans fosse compostière devrait intégrer le coût d'opportunité du travail nécessaire à la confection et à l'épandage du compost : collecte de matière organique, corvée d'eau, retournement, transport et épandage.

15. Par exemple, d'importants programmes de promotion de l'agriculture de conservation ont été mis en place en Zambie. Leurs succès et limites ont été discutés par Leménager et Ehrenstein (2016). 


\section{Encadré 8.3. Comment une technique jugée pertinente à l'échelle de la parcelle se révèle nuisible à l'échelle de l'exploitation agricole : l'exemple du paillage (mulch) des caféiers au Burundi (Cochet, 2001)}

Depuis les premières plantations dans les années 1930 et au fur et à mesure de l'extension du verger national, le paillage des caféiers (mulch) a toujours fait l'objet d'une vulgarisation intense et d'un encadrement rapproché des producteurs. Ses fonctions agronomiques sont les suivantes :

- ralentissement de la dessiccation du sol pendant la saison sèche;

- enrichissement du sol en humus en se décomposant progressivement;

- empêchement des adventices de se développer;

- protection efficace contre l'érosion pluviale et le ruissellement.

Lefficacité de cette technique est bien connue des agriculteurs parce qu'ils obtiennent de meilleurs rendements lorsque leurs caféiers sont régulièrement et abondamment paillés en temps voulu. Mais son «adoption» a toujours nécessité un «encadrement» particulièrement autoritaire de la part des services agricoles.

La raison principale en est que la matière organique ne tombe pas du ciel. Il s'agit pour l'essentiel de résidus de culture (feuilles et stipes de bananiers, résidus de maïs et de sorgho, fanes de haricots, de patates douces ou d'arachides), d'adventices (y compris les racines de chiendent) et parfois des pâturages résiduels mis en défens puis fauchés. Cette biomasse doit être récoltée et transportée vers la parcelle de café pour y être étalée, la quantité optimale étant de 20 à 25 tonnes de matière sèche par hectare et par an. Or, beaucoup d'agriculteurs n'arrivent pas à rassembler une telle quantité de matière organique chaque année en raison d'une pénurie généralisée de biomasse. Cette pénurie est largement due à : la diminution régulière de la taille moyenne des exploitations (divisions successorales), l'accroissement du rapport entre la surface à pailler et la surface productrice de paillis, la diminution de rendement observée sur les cultures vivrières (la quantité de résidus s'en ressent également) et la diminution ou la quasi disparition des surfaces en herbe à l'intérieur ou à l'extérieur des exploitations.

En provoquant une concentration massive de la matière organique sur la parcelle de café, le paillage enrichit la caféière en humus et en éléments fertilisants. Ce transfert est réalisé au détriment de la fertilité des autres parcelles de l'exploitation, dont la fertilité décroît. Au lieu d'être enfouis lors du labour, les résidus des cultures de céréales et de légumineuses sont utilisés dans les caféières. Au lieu de permettre le paillis de la bananeraie et la restitution au sol d'une partie de la biomasse produite, les feuilles et les stipes de bananiers sont rassemblés en fagots et transférés sur le café. Si l'on paille le café en fauchant les pâturages résiduels, c'est que ces derniers ont été littéralement mis en défens, interdits de pâturage et réservés au paillage du café.

Le paillage des caféiers se traduit ainsi par un transfert massif de fertilité au détriment des parcelles de cultures vivrières, de la bananeraie et des pâturages résiduels. En accentuant la diminution de la fertilité sur ces parcelles, l'obligation de paillage fragilise l'économie de l'exploitation agricole et entraîne une baisse de la productivité du travail. C'est ainsi que la vulgarisation systématique et unilatérale d'une technique adaptée au café — mais pas à l'exploitation agricole toute entière - a conduit à une impasse agronomique, économique et sociale. 
Il ne s'agit pas, nous l'avons vu, d'un simple «accès aux technologies» réduit à sa conception techniciste dominante et qui transiterait par la vulgarisation de tel ou tel paquet technique conçu en station expérimentale. Il s'agit que tous les agriculteurs, y compris les plus pauvres d'entre eux, puissent avoir accès aux moyens de production adaptés à leurs besoins et aux conditions locales de production dans des conditions descentes.

\section{Un matériel végétal diversifié et des intrants adaptés aux besoins locaux}

Les chapitres précédents permettent de se faire une idée assez précise, pour chaque région étudiée, des principaux systèmes de production en présence, ainsi que des niveaux annuels de productivité et de revenus, autoconsommation comprise, qu'ils dégagent. Pour les catégories d'agriculteurs les plus nombreuses, les ordres de grandeurs à retenir sont fréquemment de quelques centaines d'euros par actif. Il résulte parfois de ces très faibles revenus (revenu agricole total, autoconsommation comprise), une grande précarité alimentaire, un pouvoir d'achat et une capacité d'investissement dérisoires. Cet état de fait est autant la cause que le résultat d'un accès trop limité, voire inexistant, aux moyens de production les plus élémentaires. Ce handicap confère une grande vulnérabilité à ces agriculteurs, notamment par rapport à l'aléa climatique. Cette précarité extrême oblige parfois certains paysans à vendre la totalité de leur récolte vivrière pour rembourser leurs dettes et racheter ensuite, au jour le jour et au prix fort, la nourriture nécessaire. Parfois, les familles éprouvent tellement de difficultés à se procurer les semences que les surfaces dédiées à ces cultures s'en ressentent. Ces difficultés empêchent la mise en place de certaines cultures et associations de cultures les mieux adaptées à chaque endroit et à chaque saison. Alors que les semis sont réalisés tant bien que mal en fonction des opportunités tardives d'accès aux semences, le cycle cultural est décalé. Cela entraîne de nouvelles pertes de rendements et un décalage du cycle suivant dans les régions où il est possible de réaliser deux cycles de culture la même année. Lexploitation agricole est alors enfermée dans un cycle de précarité et de crises dont il est parfois impossible de sortir.

Le Malawi et, dans une moindre mesure, la Zambie ont remis en place, contre l'avis des bailleurs de fond, de vigoureuses politiques de subventions aux intrants, notamment les engrais de synthèse. Bien que ces politiques aient contribué à enfermer les agriculteurs dans des paquets techniques trop rigides et exclusivement basés sur la culture pure (chapitre 2), il n'est pas douteux qu'elles ont porté leurs fruits lorsque les intrants étaient mis à disposition en temps et en heure. Ce fut aussi le cas dans le bassin arachidier sénégalais dans les années 1960 et 1970. C'est pourquoi l'on peut s'étonner de voir encore la FAO s'enfermer dans une posture désormais dépassée lorsqu'elle classe, sans autre forme de procès, toute forme de subvention aux intrants dans les «obstacles à l'adoption de pratiques améliorées» (résumé de La situation mondiale de l'alimentation et de l'agriculture : Changement climatique, agriculture et sécurité alimentaire, rapport 2016 de la FAO). Le propos est cependant plus nuancé dans le rapport général :

«Dans les pays en développement, la tendance est à l'utilisation accrue du soutien des prix à la production et des subventions aux intrants. Les défenseurs des subventions aux intrants croient souvent qu'en réduisant le coût, on va accroître les rendements et 
améliorer la sécurité alimentaire [...]. Il convient donc d'apporter tout le soin nécessaire à l'évaluation et à la conception des politiques afin de ne pas créer des mesures d'incitation qui seraient contre-productives pour la réalisation des objectifs relatifs à l'environnement. Une façon d'aligner les objectifs de développement agricole et les objectifs relatifs au climat serait de subordonner les mesures d'appui à l'agriculture à l'adoption de pratiques agricoles qui réduisent les émissions et conservent les ressources naturelles» (FAO, 2016, p. 110).

Faciliter l'accès à un matériel végétal diversifié (semences, boutures, plantules et greffons) et à des intrants adaptés aux besoins des agriculteurs et aux écosystèmes dans lesquels ils travaillent est pourtant crucial. À condition de renoncer aux paquets techniques imposés (ou «proposés») et de faire en sorte que ces moyens de production nouvellement accessibles aux agriculteurs viennent faciliter et accompagner la mise en œuvre de pratiques agroécologiques et n'aillent pas dans le sens de la simplification des rotations, des associations de culture et des itinéraires techniques.

\section{Faciliter l'accès au bétail et à un outillage adapté}

Il en est de même concernant l'outillage et les équipements, ainsi que le capital vif. Dans le chapitre 1, les auteurs ont montré comment la traction animale et un équipement complet (semoir, sarcleur et charrette) avaient permis aux agriculteurs sénégalais qui y eurent accès, de faire face au raccourcissement de la saison de culture dans les années 1970 et à l'impérieuse nécessité de semer plus vite le mil et l'arachide, et de multiplier les sarclages en un temps extrêmement réduit. Le développement de l'usage du tracteur en prestation de service pour le travail du sol va dans le même sens, à condition que son utilisation soit compatible avec le pouvoir d'achat des agriculteurs et ne contribue pas à accroître leur endettement. Au Cambodge, dans le bassin du Tonlé Sap (chapitre 4), l'acquisition d'un motoculteur a permis à certaines familles de gagner un temps précieux en début de cycle. En effet, la rapidité du labour motorisé, alliée à la possibilité d'un travail du sol en sec, permet d'élargir la fenêtre calendaire de travail du sol en s'affranchissant des premières pluies, et en réduisant notoirement les risques encourus. Dans le delta du Mékong (Vietnam), l’introduction planifiée et subventionnée par l'État et la généralisation progressive de l'usage des motoculteurs polyvalents (transport et labours) au cours des années 1980-1990, ainsi que l'introduction des premiers tracteurs permettent de passer à trois cycles annuels de riziculture quand les aménagements hydrauliques, les conditions d'accès au foncier (réformes agraires) et aux intrants le rendent envisageable (chapitre 4).

Sur les hauts plateaux de la Zambie et du Sud-Tanzanie, mais aussi dans les monts Uluguru (Tanzanie), nous avons démontré l'importance cruciale du petit matériel d'irrigation, aussi modeste soit-il — tuyau en caoutchouc, arrosoir et petites pompes à pédale - dans le développement des cultures de contre-saison (chapitres 2 et 6).

On constate donc que faciliter l'accès à l'outillage et au matériel agricole, ainsi qu'aux équipements de stockage et de transformation post-récolte, aux moyens de transport (charrette indispensable à toute forme de transport de biomasse) et bien sûr au bétail, tant il est vrai que les pratiques d'association agriculture-élevage ont fait leur preuve dans bien des contextes, devraient faire partie de toute politique d'accroissement de la résilience et d'aide à l'adaptation au changement climatique. 


\section{Les conditions à réunir}

Nous avons souligné que la vulnérabilité est d'abord un construit social. Il résulte des processus de différenciation socio-économique qui s'inscrivent dans la durée. Toute politique d'adaptation - et donc en premier lieu de réduction de la vulnérabilité - doit s'inscrire nécessairement dans un plan de lutte contre les inégalités de développement et, en tout premier lieu, les inégalités d'accès aux ressources. Nous partageons en cela l'idée que l'adaptation ne peut se penser qu'en termes de réduction des inégalités :

«La corrélation étroite existant entre les inégalités et le tandem vulnérabilité-exposition fait l'objet d'un consensus large, qui date d'avant la question du changement climatique. Mais l'importance mise sur les inégalités d'accès aux ressources résulte de travaux théoriques et empiriques plus récents. L'éducation en est le facteur habilitant pour l'invention et la mise en œuvre de mécanismes d'ajustement. Une inégalité d'accès aux ressources crée un déficit de capacité adaptative pour les groupes les moins favorisés, ce déficit risquant potentiellement de déstabiliser la société dans son ensemble. De ce fait, l'adaptation ne peut se penser, aujourd'hui, qu'en termes de réduction des inégalités, quelle que soit la dimension concernée» (Vanderlinden, 2015, p. 41) ${ }^{16}$.

Contrairement à ce qui est souvent prôné, à savoir la sortie du secteur agricole de tous les ruraux «excédentaires» et l'affectation des facteurs de production ainsi libérés (notamment la terre) aux plus performants, (par exemple dans le rapport Banque Mondiale 2008), il est donc indispensable de promouvoir un développement inclusifs de tous, y compris, donc, de ceux qui se trouvent aujourd'hui dans les situations les plus difficiles et sont également les plus vulnérables au changement climatique. Bien que les revenus envoyés par les migrants jouent parfois un rôle décisif dans la survie des ménages restés au village, parfois même dans la réalisation d'investissements permettant d'accroître la résilience des exploitations, la sortie du secteur agricole - la migration - ne doit donc pas être comprise comme une stratégie d'adaptation au changement climatique, comme on peut le lire parfois sous la plume des mêmes auteurs, mais bien au contraire comme une preuve d'extrême vulnérabilité et de difficultés d'adaptation.

\section{Démocratiser l'accès aux ressources, notamment terres et eaux}

La première ressource dont il convient de garantir un accès équitable est la terre. Dans toutes les régions qu'il nous a été donné d'étudier en détail dans les chapitres précédents, les personnes les plus vulnérables sont toujours celles dont l'accès à la terre est plus limité et plus précaire. Il ne saurait donc y avoir de politique d'adaptation réaliste qui ne s'inscrive dans un contexte de plus grande équité dans l'accès à la terre. Dans de très nombreuses situations, c'est bien l'accès à cette ressource qui représente la plus grande incertitude pour les groupes les plus vulnérables parce qu'ils en ont été exclus dans les périodes précédentes, ou parce qu'ils n'y ont pas

16. Hansen et ses collègues (2007) considèrent aussi que l'amélioration immédiate des conditions de vie des populations rurales à travers des politiques dynamiques de développement en faveur des plus pauvres peut constituer la voie la plus prometteuse pour l'adaptation aux changements climatiques à venir. 
accès aujourd'hui (notamment les jeunes et les femmes). Ainsi, bien que la question foncière dépasse largement le cadre de cet ouvrage, elle ne saurait être ignorée, ni limitée à la question de la «sécurisation» via les procédures de titrement ${ }^{17}$.

Il va de soi qu'une telle politique doit prendre clairement position en faveur de l'agriculture familiale. Elle doit aussi refléter un choix clair en matière de modèle de développement qui permet d'allouer les ressources disponibles à l'agriculture familiale et non aux projets dont les effets exclusifs, y compris en termes d'éviction, sont patents.

\section{Réinventer de nouvelles formes de régulation des marchés}

Enfin, un des principaux aléas auxquels sont confrontés les agriculteurs est celui du niveau des prix agricoles (prix des intrants et des denrées agricoles) et de leurs fluctuations très fortes. La question des politiques commerciales se trouve d'emblée posée et, avec elle, celle des accords de libre-échange dans lesquels se trouvent insérés les pays du Sud. Il paraît difficile de parler de réduction de la vulnérabilité sans réfléchir aux moyens à mettre en œuvre pour réduire les aléas de nature économique et les risques encourus, conjointement aux aléas et risques climatiques. Évoqué dans le chapitre 4 de cet ouvrage, l'exemple de la politique vietnamienne est de ce point de vue riche d'enseignements.

\section{Conclusion}

Pour tenter de diminuer la vulnérabilité des agriculteurs et accroître leur résilience, c'est sur les agriculteurs eux-mêmes qu'il faut compter, c'est-à-dire sur leur connaissance approfondie des écosystèmes qui constituent à la fois leur lieu de vie et leur moyen de travail. Leur capacité d'innovation n'est plus à démontrer, pas plus que leur capacité de discernement entre les innovations qui accroissent la vulnérabilité et celles qui la font reculer. Les priorités nous paraissent donc être de :

- identifier, dans chaque région, les dynamiques en cours et repérer les pratiques et innovations exprimant à la fois une stratégie de limitation du risque et une capacité de résilience accrue, notamment dans le domaine de la gestion et du stockage de la biomasse;

- accompagner ces dynamiques par des programmes facilitant l'accès aux moyens de production dont les agriculteurs ont besoin et en sécurisant leurs conditions d'accès, y compris en intervenant, lorsque cela est indispensable, sur le système des prix relatifs;

- réduire l'aléa dans tous les domaines où cela est possible, notamment lorsque c'est l'action publique elle-même qui est la source de l'aléa, d'incertitude et de vulnérabilité pour les producteurs les plus modestes. C'est le cas du domaine foncier par exemple ou celui de la vulgarisation autoritaire de paquets techniques porteurs de risques et imposés d'en haut.

Dans le débat actuel sur les politiques d'adaptation, il est souvent fait état des adaptations progressives et perceptibles au niveau des pratiques paysannes d'une part,

17. Sur ces questions, nous renvoyons le lecteur aux travaux du Comité technique foncier et développement (Gret-AFD) et à l'abondante littérature qui leurs est consacrée. 
(incremental changes ou incremental adaptation) et des transformations plus radicales et appelant un véritable changement de système (transformation adaptation ou transformative responses) d'autre part. Ces dernières ont souvent la faveur des décideurs au nom de l'urgence et de l'efficacité attendues des politiques. C'est ainsi que Denton et al. (2014, p. 1106) écrivent, dans le chapitre 20 du dernier rapport du Giec intitulé Climate-resilient pathways: adaptation, mitigation, and sustainable development, que :

"Les réponses incrémentales sont souvent considérées comme des approches business as usual, car elles ne remettent pas en cause ou ne perturbent pas les systèmes existants (...) Les réponses transformatrices, en revanche, impliquent des innovations qui contribuent aux changements systémiques en remettant en question certaines des hypothèses qui sous-tendent les approches du business as usual.»

Notre approche de la question de l'adaptation réserve une place de choix, on l'aura compris, aux réponses progressives (incremental responses) mises en place par les agriculteurs eux-mêmes. Pour autant, on aurait évidemment tort d'en déduire, comme le laisse croire ce passage du rapport du Giec qu'il s'agirait là de privilégier une position de «laisser-faire» encore moins de business as usual. Les mesures d'accompagnement et de renforcement de ces «réponses progressives» que nous proposons constituent, au contraire, une rupture majeure au regard des politiques promues dans le passé et de celles aujourd'hui mises en avant sous forme de transformative responses.

\section{》 Références}

AAA - Adaptation de l'agriculture africaine, 2016. Initiative pour l'adaptation de l'agriculture africaine $(A A A)$ aux changements climatiques : faire face aux défis du changement climatique et de l'insécurité alimentaire, livre blanc. $24 \mathrm{p}$.

Ahmed S.A., Noah S., Diffenbaugh N.S., Thomas W., Hertel T.W., David B., Lobell D.B., Ramankutty N., Rios A.R., Rowhani P., 2011. Climate volatility and poverty vulnerability in Tanzania. Global environmental change 21, 46-55.

Andrieu N., Pédelahore P., Howland F., Descheemaeker K., Vall E., Bonilla-Findji O., Corner C., Loboguerero A.M., Chia E., 2015. Exploitations agricoles climato-intelligentes? Études de cas au Burkina Faso et en Colombie. In : Changement climatique et agricultures du monde. Torquebiau E. (ed.). Paris : Quae, 136-146.

Burkina Faso - Ministère de l'Environnement et des Ressources halieutiques, 2015. Plan national d'adaptation aux changements climatiques (PNA) du Burkina Faso. Ouagadougou : volume principal 6/2015, 155 p.

Banque mondiale, 2008. L'adaptation aux changements climatiques et l'atténuation de leur impact sur l'agriculture. Bruxelles : De Boeck Supérieur (1), 241-243.

C2A, 2017. Quelles politiques publiques pour promouvoir l'adaptation des agricultures familiales aux changements climatiques? Rapport de la C2A, octobre 2017. Coordination Sud, Commission agriculture et alimentation (C2A), $82 \mathrm{p}$.

Cochet H., 2001. Crises et révolutions agricoles au Burundi. Paris : Karthala/INAPG, 468 p.

Cochet H., 2009. Lagriculture éthiopienne face à l'accroissement du risque. Dialogues Francoéthiopiens «Éthiopie : une société vulnérable au défi du risque climatique et environnemental», Addis-Abeba : Centre français d'études éthiopiennes, 6 mars 2009.

Cochet H., 2013. La question agraire en Afrique du Sud : échec d'une réforme. Paris : AFD, Focales n¹7, décembre 2013, 158 p. 
Denton F., Wilbanks T.J., Abeysinghe A.C., Burton I., Gao Q., Lemos M.C., Masui T., O’Brien K.L., Warner K., 2014. Climate-resilient pathways : adaptation, mitigation, and sustainable development. In : IPCC, 2014. Climate change 2014: impacts, adaptation, and vulnerability. Part A: global and sectoral aspects. Contribution of Working group II to the Fifth assessment report of the intergovernmental panel on climate change. Cambridge: Cambridge University Press. 1101-1131.

Douillet M., 2013. Maïs en Afrique de l'Est et australe : la sécurité alimentaire régionale liée à l'amélioration du fonctionnement des marchés. Le Déméter, 205-226.

Ducourtieux O., 2009. Du riz et des arbres : l'interdiction de l'agriculture d'abattis-brûlis, une constante politique au Laos. Paris: Karthala-IRD, 371 p.

Dugué P., Djamen Nana P., Faure G., Le Gal P.Y., 2015. Dynamiques d'adoption de l'agriculture de conservation dans les exploitations familiales : de la technique aux processus d'innovation. Cahiers agriculture 24, 60-68.

Groupe d'experts des pays les moins avancés, 2012. Plans nationaux d'adaptation. Directives techniques pour le processus des plans nationaux d'adaptation. Bonn : CCNUCC, $158 \mathrm{p}$.

FAO, 2013. Climate-smart agriculture sourcebook. Roma : FAO, 570 p.

FAO, 2016. La situation mondiale de l'alimentation et de l'agriculture : changement climatique, agriculture et sécurité alimentaire. Rome : FAO, 191 p.

Hansen J.W., Baethgen W., Osgood D., Ceccato P., Ngugi R.K., 2007. Innovations in climate risk management : protecting and building rural livelihoods in a variable and changing climate. Journal of semi-arid tropical agricultural research.

McIntyre B.D., Herren H.R., Wakhungu J., Watson R.T., (eds), IAASTD — International assessment of agricultural science knowledge and technology for development, 2009. Agriculture at a crossroad: global report. Washington DC: Island Press.

Jalloh A., Nelson G.C., Thomas T.S., Zougmoure R., Roy-Macauley H. (eds), 2013. West african agriculture and climate change. Washington DC : Ifpri.

Koohafkan P., Altieri A., 2011. Globally important agricultural heritage systems: a legacy for the future. Roma: GIAHS-FAO, 41 p.

Leménager T., Ehrenstein V., 2016. Des principes agroécologiques à leur mise en pratique. Quels effets environnementaux en Zambie et quels enseignements pour les bailleurs de fonds? Revue Tiers-Monde (226-227), 65-93.

Levard L., Vogel A., Castellanet C., Pillot D., 2014. Agroécologie : évaluation de 15 ans d'actions d'accompagnement de l'AFD. Synthèse du rapport final. Paris : AFD-Gret, (Évaluation de l'AFD, 58), $20 \mathrm{p}$.

Meehl G.A., Washington W.M., Collins W.D., Arblaster J.M., 2005, How much more global warming and sea level rise? Science 307:1769.

Meehl G.A., Stocker T.F., Collins W.D., Friedlingstein P., Gaye A.T., Gregory J.M., Kitoh A. Knutti R., Murphy J.M., Noda A., Raper S.C.B., Watterson I.G., Weaver A.J., Zhao Z.C., 2007. Global climate projections. In: Solomon S., Qin D., Manning M., Chen Z., Marquis M., Averyt K.B., Tignor M., Miller H.L., (eds). Climate change 2007: the physical science basis. Contribution of working group I to the fourth assessment report of the intergovernmental panel on climate change. Cambridge, New York: Cambridge University Press.

Mulenga Bwalya S., 2010. Climate change in Zambia: opportunities for adaptation and mitigation through Africa bio-carbon initiative. Lusaka: Cifor.

Niang I., Ruppel O.C., Abdrabo M.A., Essel A., Lennard C., Padgham J., Urquhart P., 2014. Africa. In : IPCC, 2014. Climate change 2014: impacts, adaptation, and vulnerability. Part B: regional aspects. Contribution of Working group II to the Fifth assessment report of the intergovernmental panel on climate change. Cambridge: Cambridge University Press, 1199-1265.

Olson J., Crawford E., Wineman A., Mulenga B., Chabala L., Kuntashula E., 2014. Climate change impacts on agriculture and household decisions, and implications for adaptation. Usaid/IAPRI/ Michigan State University, Presentation at Chrismar Hotel, 10/04/2014, Lusaka (Zambia). 
Porter J.R., Xie L., Challinor A.J., Cochrane K., Howden S.M., Iqbal M.M., Lobell D.B., Travasso M.I., 2014. Food security and food production systems. In : IPCC, 2014. Climate change 2014: Impacts, Adaptation, and Vulnerability. Part A: Global and sectoral aspects. Contribution of Working group II to the Fifth assessment report of the intergovernmental panel on climate change. Cambridge: Cambridge University Press, 485-533.

Rhodes E.R., Jalloh A., Diouf A., 2014. Revue de la recherche et des politiques en matière d'adaptation au changement climatique dans le secteur de l'agriculture en Afrique de l'Ouest. IDRC-CRDI, Future Agricultures, Document de travail 90, 56 p.

Rosegrant M.W., Jawoo Koo, Cenacchi N., Ringler C., Robertson R., Fisher M., Cox C., Garrett K., Perez N.D., Sabbagh P., 2014. Food security in a world of natural resource scarcity: the role of agricultural technologies. Washington : Ifpri.

Tissier J., Grosclaude J.Y., 2015. Que faut-il penser de l'agriculture climato-intelligente? In : Torquebiau E. (ed.). Changement climatique et agricultures du monde. Paris : Quae, 291-302.

Torquebiau E., Tissier J., Grosclaude J.Y., 2015. Comment le changement climatique modifie la donne agricole. In : Changement climatique et agricultures du monde. Torquebiau E. (ed.). Paris : Quae, 9-24.

Vanderlinden J.P., 2015. Adaptation au changement climatique, vulnérabilité et réduction des inégalités. Revue VRS 402, 41-42.

Republic of Zambia, 2015. Zambia's intended nationally determined contribution (INDC) to the 2015 agreement on climate change, $12 \mathrm{p}$. 



\title{
Conclusion générale
}

\author{
Hubert Cochet, Olivier Ducourtieux \\ ET NADÈGE GARAMBOIS
}

À partir de l'étude détaillée d'un petit nombre de situations très contrastées, nos travaux ont permis de mettre en évidence les processus et les trajectoires expliquant la forte exposition aux aléas de certains groupes d'agriculteurs, ainsi que le maintien ou l'accroissement de cette exposition. Ces travaux permettent d'expliquer, à l'échelle du système agraire et à celle des systèmes de production, les ressorts de cette vulnérabilité en mettant à jour les conditions limitantes d'accès aux ressources et aux moyens de production, ainsi que les modalités de fonctionnement et les résultats des exploitations agricoles. Ils mettent en évidence et illustrent le poids des choix passés et actuels en matière de politiques agricole, environnementale et commerciale dans l'aggravation de la vulnérabilité, parfois aussi, mais plus rarement dans la diminution de celle-ci. Enfin, ils mettent en lumière les modalités d'ajustement et les transformations passées et en cours des pratiques d'agriculture et d'élevage allant dans le sens d'une réduction de l'exposition à l'aléa, d'une atténuation de la vulnérabilité et d'une meilleure adaptation aux changements globaux auxquels sont confrontés les agriculteurs.

Ladaptation des agriculteurs à des conditions climatiques très difficiles ou extrêmement aléatoires, en culture pluviale comme en culture inondée (pluviométrie, durée de la saison des pluies, ampleur de la crue), est déjà ancienne. Dans l'ensemble des régions étudiées, les agriculteurs ont su faire évoluer leurs pratiques et repenser, parfois en profondeur, le fonctionnement de leurs systèmes de production agricole pour faire face à un bouleversement du climat et à une plus grande fréquence de ses aléas. Pour cela, aujourd'hui comme par le passé et dans des contextes géographiques variés, ils se sont appuyés sur une connaissance fine des écosystèmes qu'ils utilisent, 
sur des savoir-faire adaptés aux conditions pédoclimatiques, à leurs ressources et au contexte économique et social. Des leviers communs d'adaptation et d'accroissement de leur résilience se dégagent des expériences analysées dans cet ouvrage. Ils relèvent souvent d'une démarche d'agroécologie :

- utilisation complémentaire et différenciée des différents écosystèmes accessibles aux agriculteurs, parfois au prix d'aménagements artisanaux;

- renforcement de l'agro-biodiversité (diversité variétale, association de cultures, assolement diversifié et poly-élevage), augmentation de la place des légumineuses en agriculture pluviale, renforcement des liens entre cultures et élevages, etc.

Dans les différentes régions étudiées, ces techniques anti-risques relèvent bien du champ de l'adaptation à la péjoration ou à l'aléa climatique. Elles sont aussi au cour des démarches visant à mieux faire face à d'autres changements globaux : accroissement démographique, compétition accrue pour l'accès aux ressources, intégration croissante aux échanges marchands, évolution des prix relatifs et fluctuation de marché, dérégulation et baisse des soutiens publics. Avec un accès extrêmement limité aux équipements et intrants, c'est souvent grâce à une intensification en travail que les agriculteurs les plus pauvres ont réussi à enrayer la baisse de la production et du revenu. D'autres ont réussi à le maintenir ou parfois à l'augmenter, malgré la baisse tendancielle de la surface exploitée par actif. Les productions agricoles ont été diversifiées chaque fois que cela était possible, souvent au profit des cultures de vente pour lesquelles ces agricultures familiales conservent quelques avantages comparatifs (maraichage par exemple), pour peu qu'elles ne soient pas trop risquées.

Au-delà du changement ou de l'aléa climatique, ces agricultures sont plus directement confrontées à la concurrence des marchés mondiaux depuis la fin des années 1980 que durant la période postindépendances. Parallèlement, elles sont beaucoup moins soutenues par les pouvoirs publics, faute de politiques adaptées et de ressources budgétaires. Ces agricultures sont aussi plus exposées aux risques d'accaparement foncier et au développement à leur voisinage de formes d'agriculture directement concurrentes et enregistrant des niveaux de productivité du travail incomparablement plus élevés.

Dans la plupart des situations étudiées, l'accès suffisant à la terre et à l'eau d'irrigation s'est révélé déterminant. Notamment, lorsqu'il autorise une même famille à avoir accès à une palette diversifiée de conditions du milieu permettant de multiplier les espèces et les variétés cultivées, les associations et successions de cultures de façon à valoriser au mieux la force de travail familiale disponible sur place. Laccès aux intrants (semences, engrais de synthèse et parfois pesticides) et aux équipements permet aussi d'accroître la productivité physique au moment des pointes de travail : tracteurs pour le travail du sol, motoculteurs et petites moissonneuses-batteuses, traction attelée et équipement allant de pair pour les semis et sarclages, charrettes, petits équipements d'irrigation, équipements de stockage et de transformation postrécolte. De ce fait, il se révèle souvent déterminant, tout comme l'accès au marché dans des conditions de prix acceptables.

À l'aune de l'accroissement démographique encore très rapide dans la plupart des régions étudiées, ces progrès ne se sont pas toujours révélés suffisants pour faire face à l'augmentation des besoins alimentaires en milieu rural et en ville. Pour autant, compte tenu des conditions extrêmement difficiles dans lesquelles la plupart des 
familles rurales étaient placées, conditions souvent dégradées sous l'effet des changements globaux dont il a été question, les agriculteurs de ces régions ont largement démontré leur «capacité d'adaptation»au changement. Cette capacité contredit l'image d'immobilisme et d'inadaptation qui leur est trop souvent attribuée, notamment par les décideurs.

Hélas, les principaux axes proposés par les États ou des institutions internationales en matière d'adaptation au changement climatique restent figés sur cette image et empruntent les chemins et les impasses du passé, ne tirant pas les enseignements de tant d'échecs répétés. Trop souvent, ils se limitent encore à un petit nombre de recommandations purement techniques et souvent passe-partout, en dépit des déclarations d'intention des promoteurs de «l'agriculture intelligente face au climat». Les modalités «d'adaptation» proposées aux agriculteurs, quand elles ne leur sont pas imposées, sont censées réduire leur vulnérabilité. Mais il est extrêmement fréquent qu'elles se traduisent, au contraire, par l'accroissement des risques encourus par les agriculteurs. Alors même qu'il devrait être question, en réduisant la vulnérabilité des agriculteurs, de limiter les risques inhérents à la péjoration climatique et à l'accroissement des aléas, c'est souvent l'innovation elle-même — le paquet technique — qui conduit à l'accroissement de la vulnérabilité. En outre, les processus historiques de fragilisation des systèmes agraires ne sont ni identifiés, ni pris en compte par ces politiques. Il en est de même pour les mécanismes de différenciation qui permettent pourtant d'expliquer les causes réelles de la vulnérabilité de certains et les ressorts de la résilience plus forte d'autres groupes, ainsi que d'entrevoir les actions spécifiques à entreprendre pour promouvoir une réelle adaptation. Pourtant, la vulnérabilité est avant tout un construit social, comme nous l'avons montré par l'approche à la fois diachronique et typologique développée dans chacune des régions étudiées dans le cadre de cet ouvrage. C'est pour cela qu'il semble que la définition des politiques de réduction de cette vulnérabilité, dans la perspective d'une meilleure adaptation au changement climatique, suppose que des choix politiques clairs soient faits au bénéfice des groupes les plus vulnérables.

Pour tenter de diminuer la vulnérabilité des agriculteurs et d'accroître durablement leur capacité d'adaptation, c'est sur les agriculteurs eux-mêmes qu'il faut compter. Notamment, il faut valoriser leur connaissance approfondie des écosystèmes qui constituent à la fois leur lieu de vie et leur moyen de travail. Leur capacité d'innovation n'est plus à démontrer, comme leur capacité à faire le tri entre les innovations qui accroissent la vulnérabilité et celles qui la font reculer. Dans chaque région, les priorités nous semblent d'abord d'identifier les dynamiques en cours et de repérer les pratiques et innovations exprimant à la fois une stratégie de limitation du risque et une capacité de résilience accrue. Il importe ensuite de les accompagner par des programmes facilitant l'accès aux ressources et aux moyens de production dont les agriculteurs ont besoin. Ces conditions d'accès à ces moyens de production doivent être sécurisées, y compris en intervenant sur le système des prix relatifs, lorsque cela est indispensable. Il convient ensuite de réduire l'aléa dans tous les domaines où cela est possible, notamment lorsque c'est l'action publique elle-même qui est source d'aléa, d'incertitude et de vulnérabilité, et tout particulièrement pour les producteurs les plus modestes, la réduction de l'aléa comme dans le domaine foncier par exemple ou celui de la vulgarisation autoritaire de paquets techniques porteurs de risques et imposés d'en haut. 
Réfléchir aux moyens à rassembler et aux modalités de mise en œuvre de véritables politiques d'adaptation au changement climatique dans un contexte de fort accroissement démographique, de raréfaction de certaines ressources, d'accroissement marqué des inégalités, notamment concernant l'accès aux ressources, et en tenant compte de la nécessaire baisse de la contribution de l'agriculture au changement climatique (atténuation) revient donc à repenser en totalité les politiques de développement agricole et rural. Il ne peut être question de se cantonner à un «volet adaptation» d'une politique climatique aussi ambitieuse soit-elle. Concilier, comme le proposent ceux qui se sont rassemblés autour de l'initiative Climat smart agriculture, adaptation, atténuation et sécurité alimentaire, constitue en soi un objectif louable. Pourtant, relever ce défi ne sera envisageable qu'en s'attaquant résolument aux mécanismes créateurs ou amplificateurs d'inégalités, d'évictions de l'accès aux ressources et aux moyens de production; qu'en réinventant des outils de régulation des marchés permettant aux agriculteurs de vivre décemment de leur activité et d'investir. Il ne sera possible qu'en promouvant des agricultures à la fois riches en emplois, les plus diversifiées possible et ne faisant qu'un usage parcimonieux des intrants de synthèse, bref en tournant la page d'un développement de l'agriculture basé sur un petit nombre de paquets techniques ou de «techniques d'adaptation» conçues en haut lieu et inadaptées à la situation concrète des agriculteurs.

Imaginer que les transformations en cours des pratiques, des exploitations agricoles, des paysages et des territoires pourraient être interprétées comme relevant du seul impact du changement climatique est bien sûr un leurre. Dès lors, la question de l'adaptation au changement climatique reste-t-elle pertinente? Ne constitue-t-elle pas un écran de fumée largement instrumentalisé pour éviter une remise en cause profonde des politiques agricoles en cours et de leurs effets, et pour justifier la poursuite, sous de nouveaux habits, du business as usual? En réduisant la portée du diagnostic et les solutions proposées à une énumération de recommandations techniques, la question de l'adaptation échapperait ainsi à tout questionnement politique. 


\section{Liste des auteurs}

Elsa Champeaux

Chargée d'études économiques

FranceAgriMer

Apt. 13 107, rue de Paris, 93100 Montreuil

elsa.champeaux@gmail.com

\section{Hubert Cochet}

Professeur Agriculture comparée

UFR Agriculture comparée

et développement agricole

AgroParisTech

16, rue Claude Bernard, 75005 Paris

hubert.cochet@agroparistech.fr

\section{Olivier Ducourtieux}

Maître de conférences Agriculture comparée AgroParisTech

16, rue Claude Bernard, 75005 Paris

olivier.ducourtieux@agroparistech.fr

\section{Samir EI Ouaamari}

Agroéconomiste

Chargé d'étude à AGTER

samir.elouaamari@agter.org

\section{Mathilde Fert}

Agroéconomiste

2306, route de Marcerin, 64300 Argagnon

fert.mathilde@gmail.com

\section{Nadège Garambois}

Maître de conférences Agriculture comparée AgroParisTech

16, rue Claude Bernard, 75005 Paris

nadege.garambois@agroparistech.fr

\section{Thérèse Hartog}

ODEADOM

3 bis, villa Jean Godard, 75012 Paris

therese.hartog@odeadom.fr.

\section{Jean-Luc Paul}

Maître de conférences

Institut des Mondes Africains

Université des Antilles

jean-luc.paul@univ-antilles.fr

\section{Philippe Le Clerc}

Chargé de programme Développement rural et sécurité alimentaire

Commission Européenne,

délégation de l'Union européenne

en République islamique de Mauritanie philippe_le_clerc@hotmail.com
Niel Verhoog

Chargé de mission Agriculture biologique

et enseignement technique agricole

CEZ-Bergerie Nationale de Rambouillet

Parc du château

CS 40609, 78514 Rambouillet cedex

niel.verhoog@educagri.fr

\section{Esther Laske}

Doctorante, UMR Art-DEV, CIRAD

TA C-113 - 15, 73, rue Jean-François Breton, 34398 Montpellier Cedex 5

esther.laske@umontpellier.fr

Thibault Labetoulle

Agro-économiste

1, route la Fontaine, 86140 Scorbé Clairvaux

Ulysse Le Goff

Chargé de recherche, FiBL Lausanne

Avenue des Jordils 3, CH-1006 Lausanne

ulysse.legoff@fibl.org

\section{Léa Radzik}

Chargée d'études

Assemblée permanente des Chambres

d'agriculture

8, rue des Iris, 75013 Paris

lea.radzik@gmail.com

\section{Céline Tewa}

cofondatrice du réseau Zéro déchet Les Gamelles celine.tewa@lesgamelles.fr

\section{Lucie Thibaudeau}

Chargée de projet Agriculture

Agence française de développement,

Rabat, Maroc

thibaudeaul@afd.fr

\section{Louis Thomazo}

agroéconomiste

Via di Santa Chiara, 42, 00186 Roma, Italie

louis.thomazo@studiumversailles.fr

\section{Charlotte Verger-Lécuyer}

Secrétaire scientifique Inra

69 bis, rue Philippe de Girard, 5018 Paris

charlotte.verger1@gmail.com

\section{Florie-Anne Wiel}

Conseillère d'entreprises

Chambre d'agriculture de Lozère

9, chemin des Églantiers, 48000 Mende

florieanne.wiel@gmail.com 
Édition : Gaston Boussou

Mise en pages : Hélène Bonnet - Studio 9

Impression : ISIPrint

Dépôt légal : décembre 2018 
À partir de l'étude détaillée et de la comparaison d'une douzaine de situations locales contrastées en Afrique sub-saharienne et en Asie du Sud-Est, les auteurs mettent en évidence les processus et les trajectoires qui expliquent la forte exposition aux aléas des différents groupes d'agriculteurs, ainsi que leur inégale capacité d'adaptation. Ils expliquent les ressorts de cette vulnérabilité et illustrent le poids des choix passés et actuels en matière de politiques agricole, environnementale et commerciale. Enfin, ils présentent les modalités d'ajustement et les transformations passées et en cours des pratiques paysannes allant dans le sens d'une réduction de l'exposition à l'aléa, d'une atténuation de la vulnérabilité, et d'une meilleure adaptation aux changements globaux : dérèglement climatique bien sûr, mais aussi accroissement démographique, compétition accrue pour l'accès aux ressources, évolution des prix relatifs et fluctuations des marchés, dérégulation et baisse des soutiens publics, etc. Ils esquissent en conclusion les chemins possibles en matière d'adaptation et des propositions de mesures politiques pour accompagner les producteurs.

Agro-économiste et géographe, Hubert Cochet est spécialiste des systèmes agraires et de leur évolution, ainsi que de l'étude de l'impact des politiques et des projets de développement sur leur dynamique. Il est professeur à AgroParisTech, responsable de l'UFR Agriculture comparée et développement agricole et membre de l'UMR Prodig Développement et environnement (UMR 8586).

Olivier Ducourtieux est maître de conférences en agriculture comparée à AgroParisTech depuis 2008, dans l'UFR Agriculture comparée et développement agricole et l'UMR Prodig. Ses travaux portent sur les relations entre l'État et les paysans (Asie du Sud-Est, Maghreb), et sur la construction historique des discours et des politiques de développement et environnementales qui sous-tendent ces relations.

Nadège Garambois est maître de conférences à AgroParisTech depuis 2011, au sein de l'UFR Agriculture comparée et développement agricole et de l'UMR Prodig. Ses recherches portent sur l'étude des dynamiques agraires dans différents pays et sur l'évaluation économique des projets de développement agricole. Ses travaux dans les pays du Sud portent notamment sur l'Afrique de l'Ouest et sur les devenirs de son agriculture familiale.

En couverture : Repiquage de rattrapage dans la basse vallée du Rufiji, sud de la Tanzanie (c) Cochet, 2014.

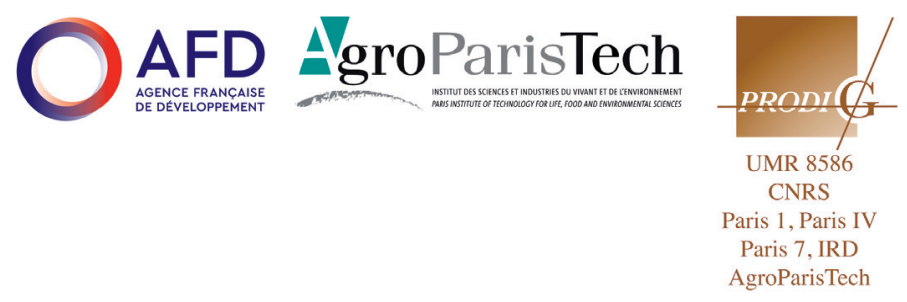

$39 €$

ISBN : 978-2-7592-2919-2

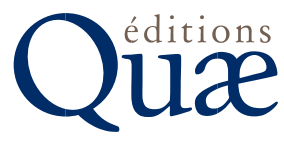

Éditions Cirad, Ifremer, Inra, Irstea www.quae.com 